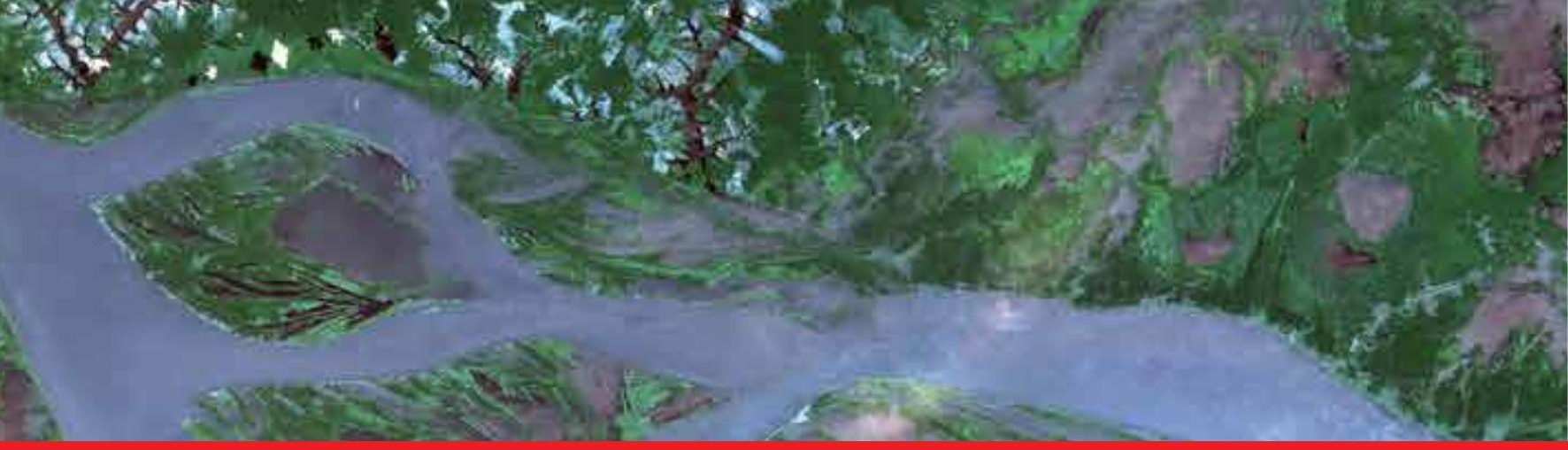

\title{
IntechOpen
}

\section{Environmental Applications of Remote Sensing}

Edited by Maged Marghany
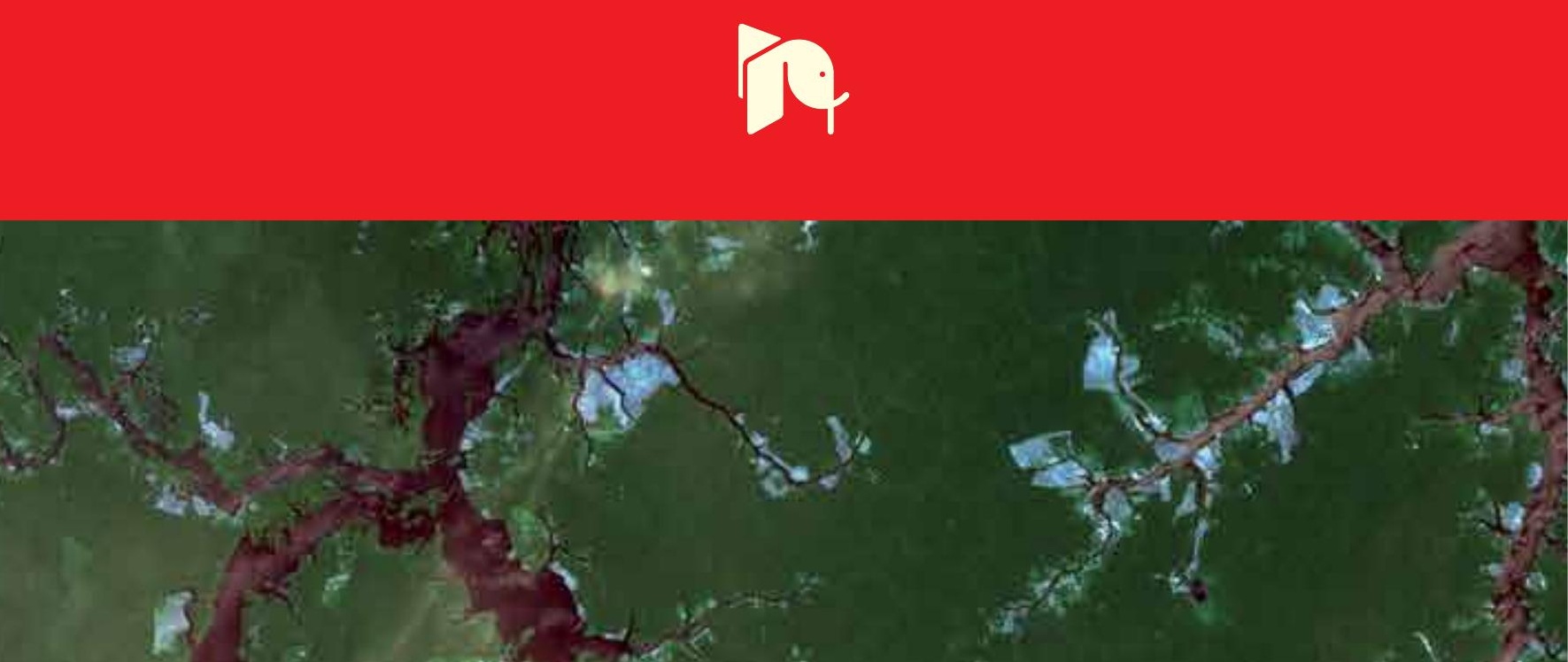



\section{ENVIRONMENTAL APPLICATIONS OF REMOTE SENSING}

Edited by Maged Marghany 


\section{Environmental Applications of Remote Sensing}

http://dx.doi.org/10.5772/60828

Edited by Maged Marghany

\section{Contributors}

Ana Teodoro, Dericks Shukla, Sharad Kumar Gupta, Chandra Dubey, Manoj Thakur, Pasquale Imperatore, Antonio Pepe, Guido Staub, Catherinne Muñoz, Saba Mudaliar, C. P. Vendhan, C. Prabavathi, Maged Marghany, Benoit Vozel, Sergey Abramov, Sergey Krivenko, Vladimir Lukin, Philippe Maillard, Marilia Ferreira Gomes, Arshad Ashraf, Igor Ogashawara, Carlos Araujo, Marcelo Curtarelli, Jose Luiz Stech, Pratima Pandey, Ramanathan Alagappan, Gopalan Venkataraman, Monika GĂhler, Mauricio Galeana, Juan Manuel Nuñez, Nirani Corona Romero, Naftaly Goldshleger, Uri Basson

\section{(c) The Editor(s) and the Author(s) 2016}

The moral rights of the and the author(s) have been asserted. All rights to the book as a whole are reserved by INTECH. The book as a whole (compilation) cannot be reproduced, distributed or used for commercial or non-commercial purposes without INTECH's written permission. Enquiries concerning the use of the book should be directed to INTECH rights and permissions department (permissions@intechopen.com).

Violations are liable to prosecution under the governing Copyright Law.

\section{(cc)BY}

Individual chapters of this publication are distributed under the terms of the Creative Commons Attribution 3.0 Unported License which permits commercial use, distribution and reproduction of the individual chapters, provided the original author(s) and source publication are appropriately acknowledged. If so indicated, certain images may not be included under the Creative Commons license. In such cases users will need to obtain permission from the license holder to reproduce the material. More details and guidelines concerning content reuse and adaptation can be foundat http://www.intechopen.com/copyright-policy.html.

\section{Notice}

Statements and opinions expressed in the chapters are these of the individual contributors and not necessarily those of the editors or publisher. No responsibility is accepted for the accuracy of information contained in the published chapters. The publisher assumes no responsibility for any damage or injury to persons or property arising out of the use of any materials, instructions, methods or ideas contained in the book.

First published in Croatia, 2016 by INTECH d.o.o.

eBook (PDF) Published by IN TECH d.o.o.

Place and year of publication of eBook (PDF): Rijeka, 2019.

IntechOpen is the global imprint of IN TECH d.o.o.

Printed in Croatia

Legal deposit, Croatia: National and University Library in Zagreb

Additional hard and PDF copies can be obtained from orders@intechopen.com

Environmental Applications of Remote Sensing

Edited by Maged Marghany

p. cm.

Print ISBN 978-953-51-2443-6

Online ISBN 978-953-51-2444-3

eBook (PDF) ISBN 978-953-51-5071-8 


\section{We are IntechOpen, the first native scientific \\ publisher of Open Access books}

$3,450+$

Open access books available
$110,000+$

International authors and editors

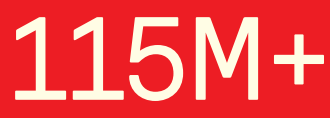

Downloads

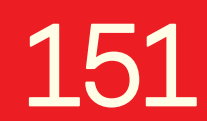

Countries delivered to

Our authors are among the

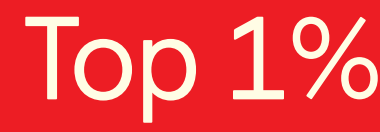

most cited scientists

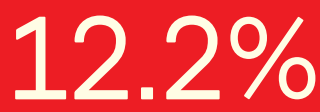

Contributors from top 500 universities

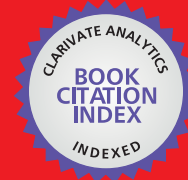

WEB OF SCIENCE ${ }^{\mathrm{TM}}$

Selection of our books indexed in the Book Citation Index in Web of Science ${ }^{\mathrm{TM}}$ Core Collection (BKCI)

Interested in publishing with us?

Contact book.department@intechopen.com

Numbers displayed above are based on latest data collected.

For more information visit www.intechopen.com

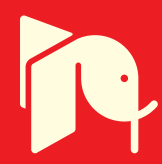





\section{Meet the editor}

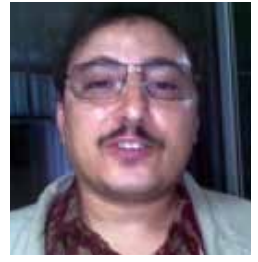

Dr. Maged Marghany received his Ph.D. from the University Putra Malaysia in 2000. He was also awarded the ESA Post-doctoral Fellowship by the International Institute of Aerospace and Earth Observation (ITC) in Enschede, the Netherlands, in 2001. Dr. Maged Marghany is microwave remote sensing expert. Currently, he is associate professor in Geospatial Information Science Research Centre, Faculty of Engineering, University Putra Malaysia. Dr. Maged Marghany has authored more than 200 reviewed papers and book chapters and had served as a reviewer of several international research journals. He was the main leader for several projects related to the application of microwave remote sensing to Malaysian coastal waters, funded by the Ministry of Science and Technology, Malaysia (MOSTE), and Ministry of High Education, Malaysia (MOHE). 



\section{Contents}

Preface XI

Section 1 Remote Sensing for Biomass Estimation 1

Chapter 1 Remote Sensing-Based Biomass Estimation 3

José Mauricio Galeana Pizaña, Juan Manuel Núñez Hernández and Nirani Corona Romero

Chapter 2 Detection of Tree Crowns in Very High Spatial Resolution Images 41

Marilia Ferreira Gomes and Philippe Maillard

Section 2 Remote Sensing Based Glacier Studies 73

Chapter 3 Climate Factors' Effects on Glacier Variations in the Commune of Alto del Carmen, Chile 75

Guido Staub and Catherinne Muñoz

Chapter 4 Remote Sensing of the Glacial Environment Influenced by Climate Change 99

Arshad Ashraf, Manshad Rustam, Shaista ljaz Khan, Muhammad Adnan and Rozina Naz

Chapter 5 Remote Sensing of Mountain Glaciers and Related Hazards 131

Pratima Pandey, Alagappan Ramanathan and Gopalan

Venkataraman

Section 3 Remote Sensing For Coastal and Ocean Applications 163

Chapter 6 Optical Satellite Remote Sensing of the Coastal Zone Environment - An Overview 165

Ana C. Teodoro 
Chapter 7 Remote Sensing of the Ocean Environment Using Finite Element Methods 197

Saba Mudaliar, C.P. Vendhan and C. Prabavathi

Chapter 8 Bio-Optical Modeling in a Tropical Hypersaline Lagoon Environment 235

Igor Ogashawara, Marcelo P. Curtarelli, Carlos A. S. Araujo and José L. Stech

Section 4 Sewage Leaks, and Enviroment Disasters 259

Chapter 9 Utilization of Ground-Penetrating Radar and Frequency Domain Electromagnetic for Investigation of Sewage Leaks 261

Goldshleger Naftaly and Basson Uri

Chapter 10 Geo-spatial Technology for Landslide Hazard Zonation and Prediction 281

Dericks P. Shukla, Sharad Gupta, Chandra S. Dubey and Manoj Thakur

Chapter 11 Remote Sensing for Natural or Man-made Disasters and Environmental Changes 309

Monika Gähler

Section $5 \quad$ Remote Sensing Image Processing 339

Chapter 12 Topological Characterization and Advanced Noise-Filtering Techniques for Phase Unwrapping of Interferometric Data Stacks 341

Pasquale Imperatore and Antonio Pepe

Chapter 13 Processing of Multichannel Remote-Sensing Images with Prediction of Performance Parameters 373

Benoit Vozel, Oleksiy Rubel, Alexander Zemliachenko, Sergey Abramov, Sergey Krivenko, Ruslan Kozhemiakin, Vladimir Lukin and Kacem Chehdi 


\section{Preface}

Nowadays, the innovation in space technologies creates a new trend for the Earth observation from space. Consequently, the rapid innovation of sensor developments allows high resolution of less than $1 \mathrm{~m}$ for optical satellite such as GeoEye-1 satellite, which collects images at nadir with 0.41-meter panchromatic (black and white). Synthetic aperture radar (SAR), as a result, also delivers 1-m high-resolution image, which is assembled by TerraSAR-X spotlight mode. In these contexts, advanced Earth observation from space has commenced novel perceptions for environmental research.

Satellite remote sensing has a plentiful of promise applications in a wide range of environment disciplines. Exploiting satellite data, the status, and temporal growth of the environment over large areas at short-time intervals can be monitored accurately. Integrating this with in situ data and mathematical models tolerates us to monitor and empathize the vital processes at work in huge areas, such as snow cover evolution, vegetation development, or land-slide movements. For instance, British National Antarctic Expedition, which is known as Discovery Expedition, spent 3 years cruising across the world oceans and documenting abundant significant ground information about biology, zoology, geology, meteorology, and magnetism. The expedition discovered the existence of the only snow-free Antarctic valleys. This is because Discovery Expedition's researchers had a healthy environment of research and the great aim of the research novelty.

Successively, the following high-quality book chapters cover wide range of remote sensing uses and address the theories behind each application. Instead, this book is portrayed highquality and compressive work on both microwave and optical remote sensing applications. This book is divided into five sections: (i) remote sensing for biomass estimation; (ii) remote sensing-based glacier studies; (iii) remote sensing for coastal and ocean applications; (iv) sewage leaks and environment disasters; and (v) remote sensing image processing. Accordingly, the first two chapters are devoted for biomass estimation. Chapter 1 involves Lidar (Light Detection and Ranging) application for monitoring biomass spatial variations in Mexico City. Furthermore, the study explores the capability of canopy fraction cover and digital canopy height model (DCHM) for modeling the spatial distribution of the above-ground biomass of two forests, dominated by Abies religiosa and Pinus spp., located in the central of Mexico. Chapter 2 demonstrates new hybrid approach developed by the authors that integrates geometrical-optical modeling (GOM), marked point processes (MPP), and template matching (TM) to individually detect tree crowns in VHR images. Section 2 involves different techniques for remote sensing applications about glacier studies. With this regard, Chapter 3 utilizes the LANDSAT-7 ETM+ satellite data with ground sampling to investigate the climate change effects on glaciers in the Commune Alto del Carmen, Chile. This study covers 21 years, from 1994 to 2015. Such study had tremendous benefits to climate change re- 
search. The interesting part of Chapter 4 is that the authors implemented snow runoff modeling with multisensor remote sensing data. The authors implemented MODIS, Landsat-7 and 8, and SPOT-5 XS, with Google Earth and digital elevation model (DEM) data to investigate the snow/glacier resources and their dynamics in the Karakoram-Himalaya basins. Indeed, this plays important role in climate changes all over the world. Chapter 5, therefore, explores the prospective of remote sensing technology for understanding and surveying glaciers formed at high, inaccessible mountains and glacier-induced hazards.

The third section comprises remote sensing for coastal and ocean applications. In this context, Chapter 6 presents overview of potential of optical remote sensing data for monitoring the coastal environment. Subsequently, Chapter 7 operates a new approach of integration of finite element model with remote sensing data to model coastal dynamic in shallow zone. Furthermore, Chapter 8 overviews the uses of remote sensing to monitor water quality parameters, mainly chlorophyll- $a$ (chl- $a$ ) and turbidity. This chapter synopsizes the main concepts of bio-optical modeling through a case study of the application of the hyperspectral data for monitoring water quality in a tropical hypersaline aquatic environment.

The fourth section is devoted for such precise studies of sewage leaks and environment disasters. With this regard, Chapter 9 operates precise method and model for sewage leak detection using ground-penetrating radar (GPR) and frequency domain electromagnetic (FDEM). This work concluded that advances in active remote sensing technologies, GPR, and FDEM can be used to identify sewage leaks that might cause pollution and to identify minor spills before they cause widespread damage.

Chapter 10 discusses geospatial technology for landslide hazard zonation and prediction. The geospatial technology is demonstrated by soft computing of fuzzy logic, artificial neural network, discriminant analysis, direct mapping, and neuro-fuzzy approach. Moreover, Chapter 11 deliberates precisely the potential of remote sensing applications for nature or man-made disasters. The chapter embraces excellent and wonderful examples of flooding in Germany 2013, earthquake in Nepal 2015, forest fires in Russia 2015, and searching for the Malaysian aircraft 2014.

The last section is assigned for some examples of advanced remote sensing image processing. With this regard, Chapter 12 presents new approach for processing multichannel remote sensing data, especially synthetic aperture radar data (SAR), using new proposed statistical filters. This study is important for feature detection in such coherence data of SAR data. Finally, Chapter 13 addresses the problem of phase unwrapping interferometric data stacks, obtained by multiple SAR acquisitions over the same area on the ground, with a twofold objective. First, a rigorous gradient-based formulation for the multichannel phase unwrapping (MCh-PhU) problem is systematically established, thus capturing the intrinsic topological character of the problem. The presented mathematical formulation is consistent with the theoretical foundation of the discrete calculus. Then within the considered theoretical framework, we formally describe an innovative procedure for the noise filtering of timeredundant multichannel multilook interferograms. The strategy underlying the adopted multichannel noise filtering (MCh-NF) procedure arises from the key observation that multilook interferograms are not fully time consistent due to multilook operations independently applied on each single interferogram. Accordingly, the presented MCh-NF procedure suitably exploits the temporal mutual relationships of the interferograms. 
I wish to convey my appreciation to all authors who have contributed to this book. Without their intense commitment, this book would not have become such a precious piece of knowledge. I am also grateful to the InTech editorial team, especially Ms. Iva Simcic, who has afforded the opportunity to publish this book.

Dr. Maged Marghany

Geospatial Information Science Research Centre Faculty of Engineering, University Putra Malaysia

Selangor, Malaysia 

Section 1

Remote Sensing for Biomass Estimation 



\title{
Chapter 1
}

\section{Remote Sensing-Based Biomass Estimation}

\author{
José Mauricio Galeana Pizaña, Juan Manuel Núñez Hernández and \\ Nirani Corona Romero
}

Additional information is available at the end of the chapter

http://dx.doi.org/10.5772/61813

\begin{abstract}
Over the past two decades, one of the research topics in which many works have been done is spatial modeling of biomass through synergies between remote sensing, forestry, and ecology. In order to identify satellite-derived indices that have correlation with forest structural parameters that are related with carbon storage inventories and forest monitoring, topics that are useful as environmental tools of public policies to focus areas with high environmental value. In this chapter, we present a review of different models of spatial distribution of biomass and resources based on remote sensing that are widely used. We present a case study that explores the capability of canopy fraction cover and digital canopy height model (DCHM) for modeling the spatial distribution of the aboveground biomass of two forests, dominated by Abies Religiosa and Pinus spp., located in Central Mexico. It also presents a comparison of different spatial models and products, in order to know the methods that achieved the highest accuracy through root-mean-square error. Lastly, this chapter provides concluding remarks on the case study and its perspectives in remote sensing-based biomass estimation.
\end{abstract}

Keywords: Aboveground biomass, forest, remote sensing, modeling, resources

\section{Introduction}

Forest ecosystems are about $31 \%$ of the total land cover of the earth [1], being one of the most important ecosystems due to economic goods and environmental services they provide. One of these services is as an environmental regulator, reducing the concentration of carbon dioxide (greenhouse gas) from the atmosphere and transforming it into oxygen and biomass through photosynthesis, thereby playing an important role in the global carbon cycle [2-4]. 
Biomass is defined as the dry weight of both aboveground biomass (AGB) and belowground biomass (BGB) living mass of vegetation, such as wood, bark, branches, twigs, stumps, or roots as well as dead mass of litter associated with the soil [4-6]. According to this, it can be considered as a measure of forest structure and function. Thus, by knowing the spatial distribution of biomass, it is possible to calculate the net flow of terrestrial carbon, nutrient cycling, forest productivity, biomass energy, and carbon storage and sequestration by the forest, reducing the uncertainty of carbon emission and sequestration measures to support climate change modeling studies [5-8].

Since calculating field measures of BGB is difficult, most studies have focused on calculating AGB. The most accurate way to obtain AGB data is by using field measurements and allometric equations for individual trees; however, these techniques are difficult to implement because they are time consuming and labor intensive. Furthermore, forests are a complex and widely distributed ecosystem, which makes these techniques expensive to apply in large areas; therefore, they cannot provide the spatial distribution of biomass $[4,6]$.

An alternative form to map and monitor spatial distribution of AGB is through the use of remote sensing-based techniques, because through them it is possible to obtain a continuous and repetitive collection of digital data from the same area with different spatial resolutions, covering large areas and reducing processing time and costs [5,6]. Due to the increasing availability of satellite imagery, several researches have been developed to prove the effectiveness of both imagery data provided by different sensors and diverse modeling approaches $[4,6,9]$. In order to estimate AGB, two main kinds of models have been used: direct and indirect. The direct models measure biomass throughout the relationship between spectral data response and biomass field measurements. For the indirect models, biomass is estimated from biophysical parameters or forest structural metrics [10].

This chapter reviews the main models used for estimating biomass and key resources used in remote sensing (Sections 1 and 2). The case study integrates some models and resources applied in forests dominated by Abies Religiosa and Pinus spp. located in Central Mexico. In the last section, concluding remarks are provided about the best biomass estimation models as well as their limitations.

\section{Biomass modeling}

Several factors can affect the remote sensing-based AGB estimation, such as insufficient sample data, atmospheric conditions, complex biophysical environments, scale of the study area, availability of software, spatial resolution of remotely sensed data, or mixed pixels, among others $[6,10]$. In order to introduce different approaches that have been developed to reduce the uncertainties produced by these factors on the estimation of the spatial distribution of AGB, the most commonly used models will be described in this section. 


\subsection{Field measurements and allometric equations}

All spatial distribution AGB estimation models need high quality and representative field data to be implemented. Therefore, forest inventories are the most common approach to obtain detailed and periodic data. They are held for monitoring, modeling, and predicting several biophysical processes, such as stocking levels, harvests, diseases, and pests, among others. Therefore, they are generally implemented at several scales to obtain different structural parameters, either through the data aggregated from stand-level management inventories or by plots established through a statistical sampling design $[3,4,6,11]$.

Since the grouping of data from stand-level management inventories tend to underestimate the forested areas and stock volume calculation, presently in most of the countries a statistical sampling design is used. In this procedure, the sampling plots are randomly selected from a population where each one of them has the same positive known probability to be chosen. They can be selected by different methods. One of them is a systematic sampling procedure based on the use of grids of randomly selected points in two dimensions, with a $0.5-20-\mathrm{km}$ separation range. In other cases, plot locations are randomly selected by regular polygons created by a tessellation of large areas, which can be stratified when different sampling intensities are required, for example, when different land uses and covers exist [11].

In order to make a more efficient sampling, a plot generally conforms clusters, commonly of four plots but, in some cases, they can be as large as 18, with a huge variety of shapes and sizes. Circular plots are commonly used in Boreal and Temperate forests, whereas square and rectangular ones are used in rainforests. Plots can be combined with other sampling methods like transect for measuring deadwood or soil pits to assess soil carbon [11].

Commonly, the information gathered about a plot is location, number of trees, species, health, and site description, among others. In addition, individual tree dendrometric variables are considered, such as diameter at breast height (DBH), tree height, crown size, and canopy cover, $\mathrm{DBH}$ and tree height being the most commonly used parameters to derivate AGB through allometric equations $[3,4,10]$.

The allometric biomass equation is the most common and accurate method to translate forest inventory reports of individual tree data to tree and stand biomass. It is a mathematical relation between total tree biomass (stem, branch, and foliage) and its $\mathrm{DBH}$ or both $\mathrm{DBH}$ and height, applying a least-squares regression of logarithmic equation. It can be both species- or site specific (e.g., Pinus montezume or Abies religiosa) or more generic (e.g., pine gender or tropical hardwoods); however, it has been observed that biomass equations at the site-specific level produce better results than generic equations $[3,8,12]$.

The most accurate method to obtain allometric equations is a destructive process in which individual trees from a wide range of $\mathrm{DBH}$, distributed in a local forest, must be felled and separated into boles, branches, and leaves. Then boles are cut into sections and weighted in the field as leaves and branches. After that, a thick disc sample must be cut from the base of each bole section and a subsample is extracted for the other side of the disk, both being dried at $105^{\circ} \mathrm{C}$ until a constant weight is reached to obtain the dry mass, to estimate the moisture 
content and the wood density. The total biomass therefore is the sum of the dry mass of the branches, the leaves, and the various sections of the stem $[3,13]$.

Since it has been observed that growing plants maintain the weight proportion between different parts, it is possible to build a nonlinear mathematical model to relate biomass with $\mathrm{DBH}$ using these parameters [12]. One of the most common models used is the logarithmic equation (1):

$$
\operatorname{Ln}(B)=\operatorname{Ln}(a)+b \operatorname{Ln}(D)
$$

where $B$ is the biomass, $a$ and $b$ are scalar coefficients estimated by least-squares linear regression, and $D$ is the $\mathrm{DBH}$.

Using allometric equations, it is possible to compute the total AGB for a given area using biomass expansion factors or conversion tables; however, these approaches do not provide the spatial distribution of AGB $[3,10]$. Later in this chapter, different models created to obtain spatial distribution of AGB are explained.

\subsection{Regression models}

One of the most common methods to estimate biomass is the regression analysis, which is a statistical technique to investigate and model the relationship between variables. Traditionally, in the remote sensing approach, the regression analysis techniques applied to AGB estimation are based on the quantitative relationship between ground-based data and satellite information, such as spectral reflectance, radar, or light detection and ranging (LiDAR) data [6,14,15]. Models based on regression analysis are considered to be relatively easy to implement and can provide accurate results through their application at all spatial scales [16]. Generally, these methodologies consist of three major steps: biomass estimation based on fieldwork, establishment of regression model between field biomass and satellite information of corresponding pixels, and the use of regression models to generate a biomass image with the spatial prediction.

These remote sensing-based biomass estimation methods assume that the forest information, obtained by the sensors, is highly correlated with AGB. According to this, the keys for biomass estimation are the use of appropriate variables and the development of suitable estimation models for sufficient sample plots, using regression methods that aim for an efficient integration of multisource data, necessary to get better biomass estimation. Spectral data, radar, and LiDAR have their own positive and negative characteristics and proper integration of them can improve biomass estimation accuracy [17].

After data integration, the correct use of regression methods for establishing biomass estimation models is also important. Many models have been developed based on multiple combinations of in situ tree parameters calculated through linear regression (LR) or nonlinear regression (NLR) models [18-20]. Multiple regression analysis may be the most frequently used approach for developing biomass estimation models [21-23]. In both cases, these 
parametric algorithms assume that the relationships between dependent (e.g., biomass) and independent (derived from remote sensing data) variables have explicit model structures that can be specified a priori by parameters [15]. Generally, the independent variables can be spectral bands, vegetation indices, textural images, LiDAR height, and synthetic aperture radar (SAR) backscatter; in some cases, the use of subpixel information offered better estimation results than per-pixel-based spectral signatures [24].

However, the linear regression approach has been known to mislead the prediction of the studied variable at values beyond a saturation point of the canopy reflectance [25]. Since biomass is usually nonlinearly related to remote sensing variables, nonlinear models such as power models [26], logistic regression models [27], and geographically weighted regression models [16] were often used to estimate biomass with more accuracy. Nonetheless, some estimation methods have been established as a nonparametric alternative to the use of regression approaches for biomass modeling: $k$-nearest neighbor $(k-\mathrm{NN})$, artificial neural network (ANN), regression tree, random forest, support vector machine (SVM), and maximum entropy (MaxEnt) [15].

\subsection{Geostatistical models}

Some studies have used geostatistics as the main approach for biomass forest estimation in order to predict variables related to forest structure (e.g., tree height and volume) and aboveground biomass and carbon measurements in unsampled sites based on known values of adjacent spatial data as forest inventory sites $[28,29]$. Other recent works have explored the synergy between geostatistical models with remotely sensed data to improve estimations using remote sensing indices as spatial secondary variables [10, 16, 30-32].

Geostatistics was defined in the 1960s by Georges Matheron, who generalized a set of techniques developed by Krige (1951) in order to exploit the spatial correlation to make predictions in evaluating reserves of gold mines in South Africa. This generalization is detailed in his regionalized variable theory in 1970 [33]. The purpose of geostatistics is the estimation, prediction, and simulation of the values of a variable that is distributed through space [34]. This theory assumes that a variable measured in a spatial domain corresponds to a random variable $z(x)$, assuming that the structure of the phenomenon having spatial correlation is considered a regionalized variable; therefore, a set of spatially distributed random variables will be a random function $Z(x)$. This provides the theoretical basis for establishing the spatial structural characteristics of natural phenomena. Moreover, it can be used as a tool for calculating the value of a variable in a certain position in space, knowing the values of that variable among adjacent positions in space, which is known as interpolation [35].

There are diverse methods of interpolations, which can be classified into two main groups: deterministic and geostatistical. The deterministic techniques are based directly on some properties of similarity of adjacent measured values (e.g., distance), which establish a set of mathematical formulas that determine the smoothness of the resultant surface interpolated. Examples of these are the inverse distance weighting (IDW), nearest neighbors, splines, and triangular irregular network (TIN) [35]. Geostatistical techniques studied spatial autocorrelation of the variables in order to fit a spatial dependence model to a set of random variables. 
This approach produces predictions and also generates an error surface concerning the uncertainty-associated analyzed model [33].

The spatial dependence is the spatial behavior of a phenomenon, derived from spatial patterns in terms of distance and similarity and/or contrast of a spatial unit or relative spatial location to other spatial units [36]. It has its basis in Tobler's first law of geography proposed in 1970 that says, "everything is related to everything else, but near things are more related than distant things" [37].

The kriging algorithms are one such example, which is mostly used in geosciences, ecology, and geomatics [35]. Kriging is a generic name for a family of generalized least-squares regression techniques, where the spatial structural characteristics are accomplished by the semivariogram function as a metric of the spatial autocorrelation [33].

All kriging estimators are variants of the following basic equation (2):

$$
\hat{Z}\left(x_{0}\right)-\mu=\sum_{i=1}^{n} \lambda_{i}\left[Z\left(x_{i}\right)-\mu\left(x_{0}\right)\right]
$$

where $\mu$ is a known stationary mean, assumed to be constant over the whole domain and calculated as the average of the data. The parameter $\lambda$ is the kriging weight; $n$ is the number of sampled data points used to make the estimation, and $\mu\left(x_{0}\right)$ is the mean of the samples within the search window [33].

Different studies have applied univariate and bivariate geostatistical interpolations in order to calculate the forest volume [28], aboveground biomass [10,16,29-31], and carbon in the aboveground biomass [32]. The most commonly used technique for univariate-based modeling is kriging [28], whereas in bivariate-based modeling regression-kriging [10,30-32], cokriging [31], kriging with external drift [29], cokriging regression [31], and geographically weight regression (GWR) are used [16].

\subsection{Nonparametric models}

Similar to regression models, nonparametric algorithms are based on the use of different sensor data, for example, spectral, radar, and LiDAR [21,38], using many of these models in the forest attributes estimation [39-41]. They are a framework for creating complex nonlinear biomass models based on the use of remote sensing variables and as alternatives for the parametric approaches. Common nonparametric algorithms include $k$-nearest neighbor $(k-\mathrm{NN})$, artificial neural network (ANN), random forest, support vector machine (SVM), and maximum entropy (Max Ent).

One of the most applied nonparametric methods is the nearest neighbor approach (NN). In the context of forest attribute estimation, the NN methods have been first introduced in the late 1980s [42]. In the NN methods, the value of the target variable at a certain location is predicted as a weighted average of the values of neighboring observations, with $k$-nearest neighbors spectrally using a weighting method [43]. Several methods have been offered to 
measure the distance from the target unit to the neighbors. In the NN approach, the choice of the $k$ value, type of distance measure including Euclidean and Mahalanobis, along with weighed function are the critical factors influencing the estimation accuracy $[44,45]$.

The ANN provides a more robust solution for complicated and nonlinear problems due to its properties [46]. The network commonly consists of one input layer, one or more hidden layers, and one output layer. Since it does not require the assumption that data have normal distribution and linear relationships between biomass and independent variables, the ANN can deal with different data through approximation, using various complex mathematical functions, with independent variables from different data sources such as remote sensing and ancillary data [15]. A detailed overview of ANN approach is provided in Ref. 47.

Regression tree and random forest are a family of tree-based models; in the first one, data are stratified into homogeneous subsets by decreasing the within-class entropy, whereas in the second one, a large number of regression trees are constructed by selecting random bootstrap samples from the discrete or continuous dataset. In fact, the random forest algorithm is now widely used for biomass estimation [48,49].

SVM is an important method to estimate forest biophysical parameters using remote sensing data $[50,51]$. It is a statistical learning algorithm with the ability to use small training sample data to produce relatively higher estimation accuracy than other approaches like ANN [15]. Ref. 51 provides a detailed overview of the SVM approach used in remote sensing. The Max Ent approach is a general-purpose machine-learning method for predicting or inferring target probability distribution from incomplete information [52]. These kinds of nonparametric algorithms have become popular in biomass modeling when large representative field datasets exist for calibration $[53,54]$.

\section{Remote sensing products for biomass modeling}

\subsection{From optical sources}

Optical sensors are those that detect electromagnetic radiation emitted or reflected from the earth, the main source of light being the sun. Among the passive sensors are photographic and optical-electronic sensors that combine similar photographic optics and electronic detection system (detectors and push scanning) and image spectrometers [55,56]. Optical remote sensing refers to methods and technologies that acquire information from the visible, near-infrared, shortwave infrared, and thermal infrared regions of the electromagnetic spectrum. They are called optical, because energy is directed through optical components such as lenses and mirrors.

\subsection{Spectral indices}

Remotely sensed spectral vegetation indices represent an integrative measure of both vegetation photosynthetic activity and canopy structural variation that are widely used and have benefited numerous disciplines interested in the assessment of biomass estimation $[57,58]$. 
Different kinds of vegetation indices have been in use for a long time in AGB estimation and the number of publications is immense [6].

The key to the development of vegetation indices is the ability of the canopy of green vegetation to interact differently with certain portions of the electromagnetic spectrum. Since this contrast is particularly strong between red and near-infrared regions (NIR), it has been the focus of a large variety of attempts to build up quantitative indices of vegetation condition using remotely sensed imagery [59]. Theoretically, the ideal vegetation indices should be particularly sensitive to different vegetation covers, insensitive to soil brightness and color, and little affected by atmospheric effects [60]. However, in reality, different factors affect the reflectance of vegetation and consequently the vegetation index (e.g., atmospheric correction is essential when biomass is extracted from the vegetation indices as a final product).

According to Ref. 58, vegetation indices can be classified into (1) slope-based, (2) distancebased, and (3) transformation indices. The slope-based indices are simple arithmetic combinations that focus on the contrast between the spectral responses patterns of vegetation in the red and near-infrared portions of the electromagnetic spectrum. The most known of them are the ratio vegetation index (RVI) proposed by Birth and Mc Vey [61], normalized difference vegetation index (NDVI) introduced by Rouse et al. [62], and soil-adjusted vegetation index (SAVI) developed by Huete [63]. The vegetation indices show better sensitivity than individual spectral bands for the detection of biomass [64].

Distance-based indices measure the degree of vegetation from the soil background (known as a soil line) to the pixel with the highest content of vegetation in a perpendicular incremental distance. In this group of indices, the slope and intercept of the soil line have to be defined for each particular image; perpendicular vegetation index (PVI) introduced by Richardson and Weigand [65] cancels the effect of soil brightness in cases where vegetation is sparse and the pixels contain a mixture of green vegetation and soil background. The effect of the background soil is a major limiting factor in certain statistical analyses geared toward the quantitative assessment of AGB [59].

Transformation indices are transformations of the available spectral bands to form a new set of uncorrelated bands within which a vegetation index band can be defined. Tasseled cap (TC) is one of the most widely used indexes of this type and may apply to various remote sensing images with multiple resolutions [66-72].

In the specialized literature, many vegetation indices have been proposed, and depending on the complexity of the forest stand structure, indices vary in their relationships with biomass $[23,60,73]$. For forest sites with complex stand structures, vegetation indices including nearinfrared wavelength have weaker relationships with biomass than those including shortwave infrared wavelength. In contrast, for areas with poor soil conditions and relatively simple forest stand structure, near-infrared vegetation indices had a strong relationship with biomass, and finally the results of transformation indices showed stronger relationships with biomass independent of different biophysical conditions [15]. 


\subsection{Textural indices}

Some studies have used regression analyses between remote sensing textural indices and biomass data from sampling sites [30,32,74-77]. This framework has been applied to different optical and synthetic aperture radar-derived indices in order to use the textural parameters as continuous spatial variables to improve biomass estimations.

In 1973, Haralick proposed a statistical analysis based on a set of parameters according to spatial dependence of gray tones in an image, defined as second-order statistics [78]. Textures are intrinsic properties of surfaces and its importance lies in image-objects segmentation, because they are related to structural arrangements of the land surface and the connections between neighboring spatial objects [79]. The most common mathematical method used to measure texture parameters is the co-occurrence matrix (gray-level co-occurrence matrix) [78]. It describes the frequency of a gray level displayed, in a specific spatial relationship, to another gray value within a neighborhood represented by a mobile window or kernel [79]. Its construction is based on four steps: (1) Window or kernel size definition, (2) band selection input, (3) texture parameters selection, and (4) spatial dependency criteria.

Textures applied parameters are described below:

\begin{tabular}{ll}
\hline Contrast & 1. Dissimilarity \\
$\sum_{i, j=0}^{N-1} P_{i, j}(i-j)^{2}$ & $\sum_{i, j=0}^{N-1} P_{i, j}|i-j|$ \\
\hline 2. Homogeneity & 3. Angular Second Moment \\
$\sum_{\mathrm{i}, \mathrm{j}=0}^{N-1} \frac{\mathrm{P}_{\mathrm{i}, \mathrm{j}}}{1+(\mathrm{i}-\mathrm{j})^{2}}$ & $\sum_{\mathrm{i}, \mathrm{j}=0}^{\mathrm{N}-1} \mathrm{P}_{\mathrm{i},{ }^{2}}$ \\
\hline 4. Maximum Probability & 5. Entropy \\
Largest Pij value found & $\sum_{i, j=0}^{N-1} P_{i, j}\left(-\ln P_{i, j}\right)$ \\
within the window & 7. Correlation \\
\hline 6. Mean & $\sum_{i, j=0}^{N-1} P_{i, j}\left[\frac{\left(i-\mu_{i}\right)\left(j-\mu_{j}\right)}{\sqrt{\left(\sigma_{i}^{2}\right)\left(\sigma_{j}^{2}\right)}}\right]$ \\
$\mu_{i}=\sum_{i, j=0}^{N-1} i\left(P_{i, j}\right)$ & \\
$\mu_{j}=\sum_{i, j=0}^{N-1} j\left(P_{i, j}\right)$ & \\
\hline 8. Variance & \\
$\sigma_{i}^{2}=\sum_{i, j=0}^{N-1} P_{i, j}\left(i-\mu_{j}\right)^{2}$ & \\
$\sigma_{j}^{2}=\sum_{i, j=0}^{N-1} P_{i, j}\left(j-\mu_{j}\right)^{2}$ & \\
\hline
\end{tabular}


$\operatorname{P} i j=\operatorname{Pr}(\mathrm{I} s=i \cap \mathrm{I} t=j)=$ pixel probability of $s$ is $i$ and $t$ is $j$, for separated pixels through one pixel distance in a relative displacement vector between neighboring pixels.

These texture parameters and the indices derived (e.g., ratios) have been applied in different satellite inputs, for example, on high spatial resolution optical-infrared images as SPOT-V images [30,32] and ALOS AVNIR-2 [74], medium spatial resolution resources as Landsat TM [76] and Landsat OLI [76], and SAR images as Jers-1 [76] and ALOS Palsar [32,75].

\subsection{Biophysical variables}

A forest biophysical parameter is a measure that simplifies the aboveground organization of plant materials [4]. In this context, several studies in remote sensing field have focused on determining canopy structural parameters such as leaf area index (LAI), canopy height or canopy fraction [80-86], the second one being the most commonly used for biomass estimation. Because canopy height is most commonly derived from active sensors [87], this part of the chapter is focused on canopy fraction.

The reflectance of forest canopy cover recorded by the instantaneous field of view (IFOV) of the sensor is a spectral mixture obtained from the interaction between electromagnetic radiation and both canopy and forest elements such as nonphotosynthetic vegetation (NPV; such as branches, stem, and litter), photosynthetic vegetation (PV; such as leaves), and others, such as bare soil and shadow. Therefore, image pixels are generally composed of more than one element, making the image interpretation difficult, which can result in a poor relation between AGB and spectral bands [88-91].

One of the most widely used remote sensing approaches to derive and extract fraction covers from mixed pixels is the spectral mixture analysis (SMA) [92]. It decomposes the mixed pixel using a collection of constituent spectra (end members) to obtain their areal proportions or abundances in a pixel, and therefore unmixing a multispectral image into fraction images of end members [88,93]; it can be linear or nonlinear. The linear model assumes a single interaction between each incident photon and the surface object, and therefore the mixed pixel is a linear combination of pure spectral signatures (end members) of the surface materials weighted by their area covered. The nonlinear model is the opposite of linear model, since electromagnetic radiation can intercept more than one element of surface, with mixed pixels resulting from a multiple-scattered signal [94].

As green leaves scatter radiation at NIR spectra, vertical structure of vegetation commonly produces a multiple-scattered signal; however, nonlinear spectral mixture approaches are barely used because they require more specific information, such as scattering properties of end members, the illumination of the sensor, and certain geometrical parameters of the scene [91,93]. For these reasons, linear approaches have been largely implemented [92].

The linear mixture model is expressed in matrix form in the following equation (3):

$$
p=M f+\varepsilon
$$


where $p=[p 1 \ldots p n] T$ is the mixed pixel, $f=[f 1 \ldots f m] T$ is the fractional end-member abundance, $M$ is an $n \times m$ matrix with $n$ end-member spectra as column vectors, and $\varepsilon$ is the residual not explained by the model. If $p$ and $M$ are known, it is possible to estimate it from ordinary leastsquares procedure $[93,95])$, with two common constraints: the full additive condition, which determines that the fraction must sum to one, and the nonnegative condition, which makes all abundances nonnegative, thus making the model physically meaningful [92].

SMA has been successfully applied in vegetation studies to estimate the land cover fractions of PV, NPV, bare soil, and shade [96-98] or mapping the fractional cover of coniferous species [99-101]. In biomass studies, it has been proved that using ASTER fraction images (green vegetation, soil, and shade) in regression models improve the AGB estimation in Mediterranean forests, being better than NDVI or tasseled cap components [88]. Ref. [15] uses the same Landsat Thematic Mapper (TM) fractions and TM spectral signatures to relate with AGB, finding that fractional images perform better for successional forest biomass estimation than TM spectral signatures, but not for primary biomass estimation. SMA has also been applied to remove subpixel atmospheric and soil reflectance contamination in order to improve dry biomass estimations, showing that unmixed vegetation indices are better [102] than those which are not unmixed. Through geometric-optical reflectance models, Peddle et al. also estimated areal fractions of sunlit canopy, sunlit background, and shadow at subpixel scales showing higher accuracy than NDVI [103]. The other case in which sunlit crowns, background, and shadow fractions were compared with seven different vegetation indices (NDVI, SR, MSR, RDVI, WDVI, GEMI, and NLI) and three different soil-adjusted vegetation indices (SAVI, SAVI-1, and SAVI-2) to estimate biomass, LAI, net primary productivity (NPP), DBH, stem density, and basal area was the study conducted by Peddle et al. In this study, the authors concluded that the SMA shadow fraction improves the results by about $20 \%$ compared to vegetation indices [104].

\subsection{From active sources}

Active sensors are those that provide its own energy source in order to control the double operation of signal emission and reception of known characteristics. These sensors have the advantage of an operational capacity to produce information both at night and in the day, in addition to working in a region of the electromagnetic spectrum that makes them less sensitive to atmospheric conditions. Of these, radar and LiDAR systems $[55,56]$ are the most known. In this section, we briefly describe each of them, pointing out the relevant examples of their application in biomass modeling.

\subsection{Radio detection and ranging}

RAdio detection and ranging (RADAR) is the system name of active sensors that work in microwave region of the electromagnetic spectrum. Their mechanism is performed through signal transmission-reception of a portion of energy that interacts with the surface, which is referred as backscattered, being a measure of strength and time delay of the returned signals [105]. 
Such energy is considered consistent or coherent (illumination beam has same wavelength and phase), which makes it possible to use different polarization schemes (orientation of emitted and detected electromagnetic fields) to generate images [106]. The spatial resolution of radar images is strongly dependent on the antenna length (aperture) of the receptor and sensor inclination angle.

Synthetic aperture radar is widely used in forest monitoring through remote sensing, which is able to generate high-resolution imagery by taking advantage of the movement of the aircraft or satellite platform. SAR simulates a long virtual antenna that comprises long coherent successive radar signals, transmitted and received by a small antenna, which simultaneously moves along a given flight path $[105,106]$.

Since microwave energy can penetrate forest canopies, the backscattered energy of SAR systems is modulated or influenced by the structural parameters of trees (e.g., branches, leaves, and stems), which in turn depends on different ecological variables [6,107,108]. Analyses of these data have been used to determine forest state [109], forest types [110], biomass density [32,111], forest canopy height [112], forest fire degradation [49,69], deforestation [113], and forest soil moisture [114].

The sensor sensitivity to forest parameters is a function of the wavelength, for instance, bands $X$ and $C$ with wavelengths 2.4 and $7.5 \mathrm{~cm}$, respectively, are more sensitive to backscatter of leaves, whereas bands $L$ and $P$ with wavelengths 15 and $100 \mathrm{~cm}$, respectively, are associated with backscatter of branches and stems [55,106,115].

Three of the main approaches from SAR systems that are widely used include (1) SAR backscattering coefficient $[108,111,116]$, (2) interferometric SAR data [32,84], and (3) polarimetric SAR data $[49,117]$.

\subsection{SAR backscattering coefficient}

Forest components scatter energy transmitted by the SAR systems in all directions. A portion of energy recorded by radar is translated to a proportional ratio between density of energy scattered and density of energy transmitted from the surface targets per unit area. Backscatter coefficient $\left(\sigma^{\circ}\right)$ or sigma nought is the amount of radar cross section $[106,108]$. Generally, this magnitude is expressed as a logarithm through decibel units as the following linear-form equation (4):

$$
\sigma_{(d b)}^{\circ}=10^{*} \log _{10} \sigma^{\circ}
$$

The backscatter coefficient value is related to two variables of sensor and target parameters. Sensor characteristics are a function of wavelength, polarization, and incidence angle, whereas target characteristics are associated with roughness, geometry, and dielectric properties [106, 108].

Biomass modeling through this approach has been usually applied from simple regression models under the assumption of correlation between backscatter coefficient and aboveground 
biomass/carbon $[32,108,111,116,118]$. The results are different because they rely on saturation of the signal, which is a function of wavelength, polarization, and the characteristics of the vegetation cover as well as of the difficulties caused by the specific properties of the ground as slope and aspect.

Recently, some of them have combined spatial models with remotely sensed data to improve geostatistical estimations using backscatter coefficient as spatial secondary variables [32].

\subsection{Interferometry SAR data}

Interferometric synthetic aperture radar (Figure 1) is a framework containing diverse methods or techniques that use phase information derived by recording phase difference or state of vibration of the wave at the instant that is received by the radar between two SAR images (known as master and slave) acquired from different sensor positions [106], called the interferometric phase ( $\Delta \Phi$ Int). The interferometric phase can be written as equation (5):

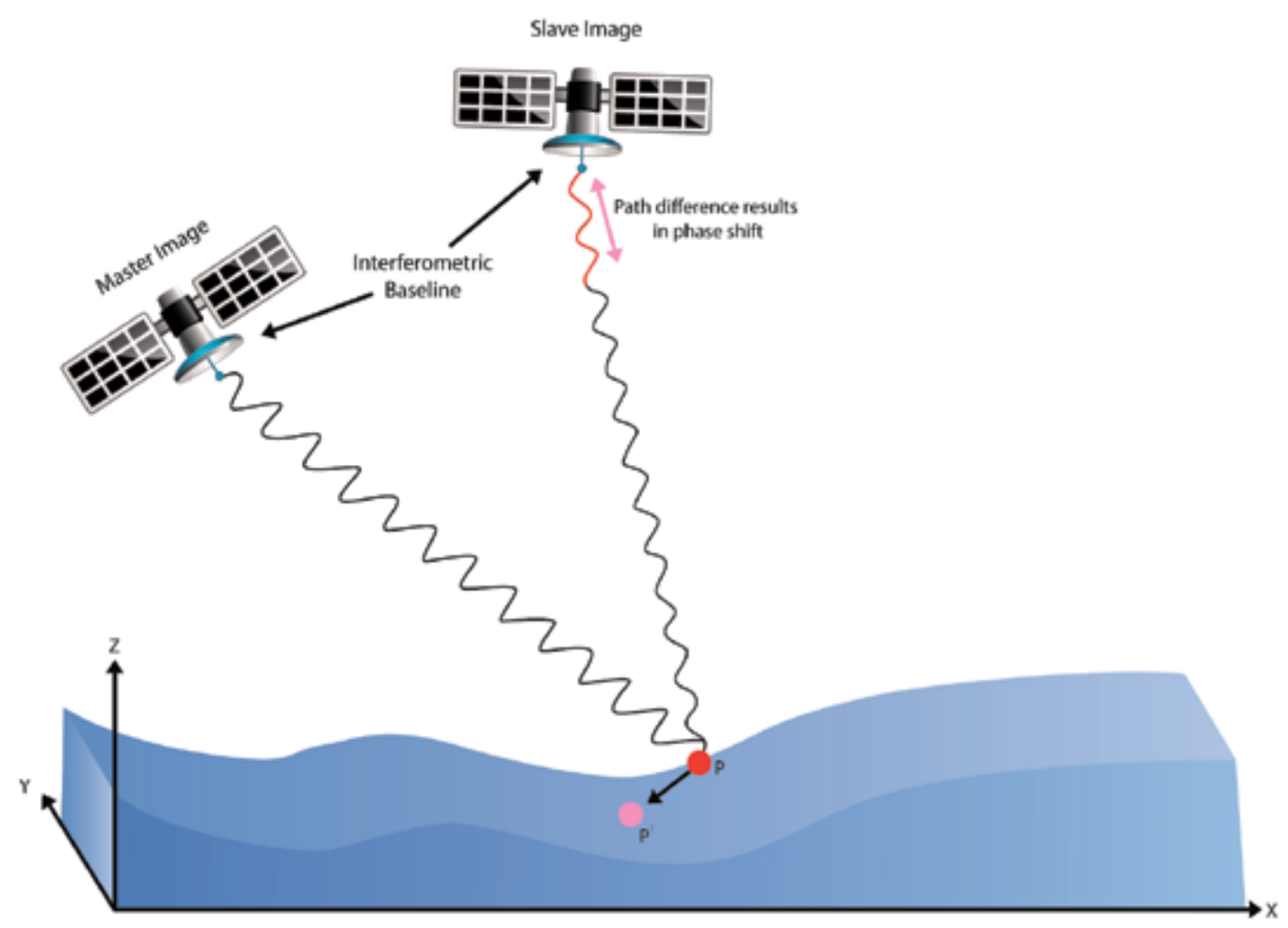

Figure 1. Interferometric synthetic aperture radar.

$$
\Delta \Phi \mathrm{INT}=\Phi S-\Phi M=\Phi T \text { opo }+\Phi \mathrm{Mov}+\Phi \text { Atm }+\Phi \text { Noise }
$$


where $\Phi S$ and $\Phi M$ are the phase observations of slave image and phase observations of master image, respectively, $\Phi$ Topo is the topographic component, $\Phi \mathrm{Mov}$ is the shift component, $\Phi$ Atm is the atmospheric component, and $\Phi$ Noise is the phase noise.

One parameter obtained by this approach is the coherence or correlation image as an indicator of the phase stability [105]. Its mathematical expression is (6)

$$
\gamma=\frac{\left(S_{1} S_{2}^{*}\right)}{\sqrt{\left(S_{1} S_{1}^{*}\right)\left(S_{2} S_{2}^{*}\right)}}
$$

where $\gamma$ is the coherence, the brackets () denote the ensemble average, and * denotes the complex conjugate; $S_{1}$ denotes the complex value of the master single-look complex (SLC) for pixels $x, y$ and $S_{2}^{*}$ indicates the complex conjugate value for pixels $x, y$ in the second image known as slave. Coherence values are included between 0 and 1 and a coherence image quantifies the decorrelation between two SLC images as the loss of coherence [106]. Decorrelation is the combination of impacts in the radar phase: (1) the baseline decorrelation due to changes in the acquisition geometry of the images (which increases as the distance between the satellite orbits at the moment of acquisition increases) and (2) the temporal decorrelation due to variations in reflectivity in the zone, which can be caused by rain, phonological changes, and agricultural factors [105].

The interferometric coherence in biomass modeling is used under the assumption that for forested areas, coherence diminishes with the increment in vegetation density, as the volumetric scattering increases with movement (wind) and forest growth. Biomass modeling through this approach has been typically used from simple regression models under the assumption of correlation between interferometric coherence and aboveground biomass/ carbon $[32,84,116]$, another approach is by combining methods such as regression-kriging [32] and classification algorithms [119]. In this case, results are related to baseline and temporal decorrelations, forest type, polarization, and sensor wavelength.

\subsection{Polarimetric SAR data}

Antennas of radar systems can be configured to transmit and receive electromagnetic radiation polarized either horizontally or vertically. The two most common bases of polarizations are horizontal linear or $\mathrm{H}$, and vertical linear or $\mathrm{V}$. When the energy transmitted is polarized in the same direction as the received, it is called as like-polarized and when the transmitted energy depolarizes in a direction orthogonal to the received system, it is known as crosspolarization [120]. The polarization schemes are $\mathrm{HH}$ (for horizontal transmit and horizontal receive), $\mathrm{VV}$ (for vertical transmit and vertical receive), $\mathrm{HV}$ (for horizontal transmit and vertical receive), and $\mathrm{VH}$ (for vertical transmit and horizontal receive).

A radar system can be configured in different levels of polarization complexity:

- Single polarized - $\mathrm{HH}, \mathrm{VV}, \mathrm{HV}$, or $\mathrm{VH}$ 
- Dual polarized - HH and HV, VV and VH, or HH and VV

- Quad polarized - $\mathrm{HH}, \mathrm{VV}, \mathrm{HV}$, and VH

A quadrature polarization or polarimetric radar uses these four polarizations in order to measure the magnitudes and relative phase difference between the polarization schemes or channels through an ellipse shape [106,120]. These kinds of radar systems promoted a new framework called polarimetry of synthetic aperture radar, which describes the surface through different combinations of polarization under the assumption that the interaction of electromagnetic energy and elements of the land surface can change the polarization of a portion of the wavelength transmitted by the sensor, and therefore receive information of amplitude and relative phase of the same target in four channels of information, which is considered as a basis for description of scattering polarimetric of surface targets [106,120]. It is mathematically simplified in the so-called scattering matrix (equation (7)):

$$
S=\left[\begin{array}{ll}
S_{h h} & S_{h v} \\
S_{v h} & S_{v v}
\end{array}\right]
$$

which describes different forms of the polarized electric fields between incident wave and the scatter wave in order to be the basis for diverse ways to analyze the scattering properties of a target (e.g., the covariance and coherency matrices) and diverse transformations as polarimetric decompositions and through the synergy between polarimetry and interferometry (polarimetric interferometric coherence) [120].

The use of polarimetry in biomass modeling is under the assumption of correlation between forest structural properties and polarimetric behavior. It may be construed through scattering mechanism analysis. This has been addressed mainly by polarimetric decompositions, such as Freeman Durden [49,121], eigenvector-eigenvalue [49], and Cloude and Pottier [31,121]. Biomass modeling through this framework has been usually performed from simple and multiple regression models [31,121] and nonparametric model random forest regression [49]. In this framework, results are related to forest type, spatial resolution, and sensor wavelength. 3.10. Light detection and ranging

Light detection and ranging is an active laser sensor, which emits pulses of polarized light or pulse echo, which can be calibrated within a narrow range of wavelength. The most commonly used wavelength is $1,064 \mathrm{~nm}$ (near-infrared), although it can range from ultraviolet to infrared range of electromagnetic spectrum (500-1500 nm) [122-124].

These laser scanners consist of a range finder, global positioning system (GPS), inertial measuring unit (IMU), and a clock capable of recording travel times to within 0.2 of a nanosecond. The integration of these systems produce accurate measurements of the position and orientation of objects registered. These technologies allow us to measure elapsed time of pulse echo between laser transmitter and objects on the surface. The energy that interacts with surfaces is backscattered over different times exhibiting multiple laser pulse returns associated 
with distinct surface layers toward a laser scanner that can be mounted on an aerial or terrestrial platform $[123,125,126]$.

LiDAR information is essentially a three-dimensional point cloud composed of simple derivative returns and multiple laser pulses, this type of LiDAR data is known as discrete LiDAR returns. In addition to three-dimensional information, most LiDAR systems record the intensity as a fraction of pulse energy reflected at that location [127].

The use of LiDAR in forest areas is mainly to analyze forest vertical structural metrics under the assumption that laser can be sensed from the top of the canopies, elements of different canopies, or even to the ground, which will be reflected in the number of returns. The depth of laser penetration depends on the density of canopies and density of point clouds, which vary from less than one point per square meter to several dozens, with vertical accuracies around $12.5 \mathrm{~cm}[123,127]$.

One of the most widely used products in forest analysis is the result of the processing of threedimensional point cloud, the canopy height model (CHM) (Figure 2). It is derived from the difference or subtraction between digital elevation models and digital terrain models, both datasets generally are a result of different interpolation methods, such as nearest neighbor, splines, inverse distance weighting, and kriging [127]. The first one is associated with first returns and the second one is related to the last returns. Other forest structural measurements are the fractional crown cover, crown area, crown diameter, basal area [38,125], and canopy volume [126], which are of key interest to the managers and represent information that is expensive and time consuming to collect in the field. When small-footprint LiDAR data are acquired at very high enough densities, individual tree crowns can readily be observed in the point clouds, processing algorithm for automated measuring and modeling of vegetation at individual tree crown segmentation (e.g., watershed segmentation) $[95,128,129]$.

Biomass modeling through this approach has been usually used in simple and multiple regression models $[38,125,126,130]$. Other works have explored the use of learning machines [131,132]. Other approach is through combining methods that integrate LiDAR information with other sensors $[22,31,124,133]$.

\section{Case study}

Mexico City is a continuous truss of multiple ecosystems, which is administratively divided into two large areas: urban land (41\%) governed by the Urban Development Programs and Environmental Conservation Zone (ECZ; 61\%) steered by the General Ecological Planning Program (Figure 3). The ECZ provides Mexico City with environmental services such as carbon capture, aquifer recharge, biodiversity, and scenic beauty. The zone is under anthropogenic pressure, including human settlements, land use changes, and extraction of natural resources, and therefore immediate action for conservation and appropriate resource management is necessary. This has led to deforestation, degradation, development of pest infestations, fires, and erosion. Models of the spatial variability of forest density are required in order to obtain 


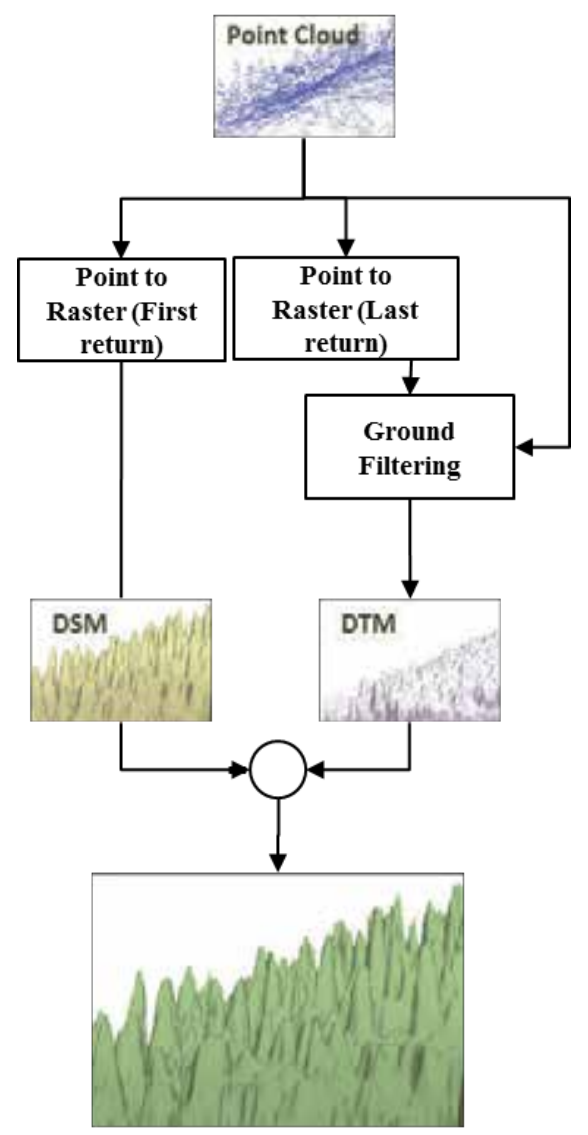

Canopy Height Model

Figure 2. Canopy height model.

an inventory of carbon storage, useful for public policies in areas with high environmental value in order to facilitate decision-making by reducing the complexity involved in integrating and interpreting values at a pixel level.

The study area lies within the ECZ of Mexico City $\left(882 \mathrm{~km}^{2}\right)$ and is covered by sacred fir or oyamel (Abies religiosa) and Mexican mountain pine (Pinus hartwegii) forests. Fir forests generally grow at 2,700-3,500 $\mathrm{m}$ above sea level. They are evergreen forests with heights of 20-40 $\mathrm{m}$ and their understory is densely shaded. This type of forest contains important elements, including alders (Alnusfir mifolia), white cedar (Cupressus lindleyi), oak (Quercus laurina), Mexican Douglas-fir (Pseudotsuga macrolepis), willows (Salix oxylepis), and black cherry (Prunus serotina). Pine forests (Pinus hartwegii) grow above 3,000 $\mathrm{m}$, this species being most tolerant to the extreme environmental conditions of the high mountains. This pine develops along with Festuca and Muhlenbergia grasses [134]. 

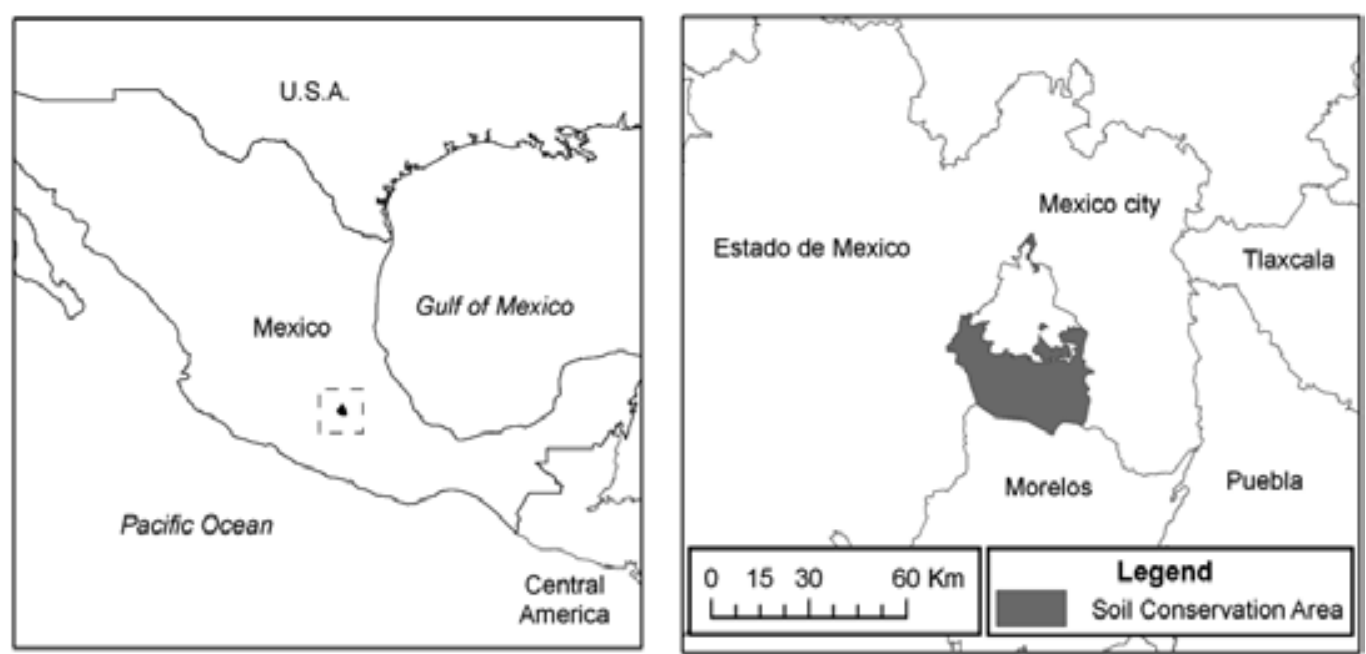

Figure 3. Environmental Conservation Zone.

The present case study is a comparative analysis between regression-cokriging and multiple regression approaches using satellite-derived indices for modeling the aboveground biomass of forests in the Environmental Conservation Zone of Mexico City. The objectives are:

1. to identify satellite-derived indices that are better associated with aboveground biomass, either from LiDAR or fraction cover (SPOT-5) imagery

2. to quantify spatial patterns of the residuals derived from simple regression between satellite indices and carbon values, using spatial autocorrelation

3. to determine whether spatial statistical methods improve the estimates of aboveground biomass carbon pools over nonspatial conventional regression methods

In order to achieve these objectives, a correlation analysis was performed between digital canopy height model (LiDAR data) and vegetation fraction cover (SPOT-5 data) and, on the other hand, ground biomass estimates at forest inventory sites. Then, the spatial autocorrelation was calculated for residuals in order to define the variables to be used in multiple models and regression-cokriging methods. Once models were obtained, the root mean square error (RMSE) was computed for each approach.

\subsection{Methods}

4.1.1. Models of aboveground biomass carbon used three sources of data: Forest inventory data from in situ measurements

Since aboveground carbon is the amount of carbon stored in aboveground biomass, comprising all living plant material above the soil (e.g., trunks, branches, and leaves) [3], the calculation of carbon stock from biomass consists of multiplying the total biomass by a conversion factor 
that represents the average carbon content in biomass. A common assumption is that biomass is around $50 \%$ carbon expressed in tons of dry matter per unit area [135]. Typically, the terms of measurement are density of biomass expressed as mass per unit area (e.g., t/ha). Here, forest inventory data were obtained from Mexico City Environmental and Land Planning Authority (PAOT, because of its name in Spanish) and were derived from sampling 283 plots during 2008-2010. Their sampling is based on the design of the National Forest and Soil Inventory of the National Forest Commission (CONAFOR, because of its name in Spanish). In it, each sampling conglomerate is composed of four circular secondary sampling plots in an inverted " $Y$ " shape, each of which covers an area of $400 \mathrm{~m}^{2}$ and peripheral plots are at $45.15 \mathrm{~m}$ from the center of the conglomerate (Figure 4). Of the 283 plots, 155 were among pines, 86 in fir forest, 30 in mixed forest, 10 in scrub, and 2 in planted forests. Per-tree carbon was estimated from allometric carbon equations developed by Acosta-Mireles et al., Jiménez, and AvendañoHernández et al. for the species of the region [136-138]. Conversion of biomass carbon from conglomerate to hectares [139] used the "ratio of means" as shown in equation (8):

$$
\widehat{R}=\frac{\bar{Y}}{\bar{X}}=\frac{\sum_{i=1}^{n} Y_{i}}{\sum_{i=1}^{n} X_{i}}
$$

where $Y_{i}$ is the total aboveground carbon in all plots of $400 \mathrm{~m}^{2}$ and $X_{i}$ is the total area sampled in $i$ plots.
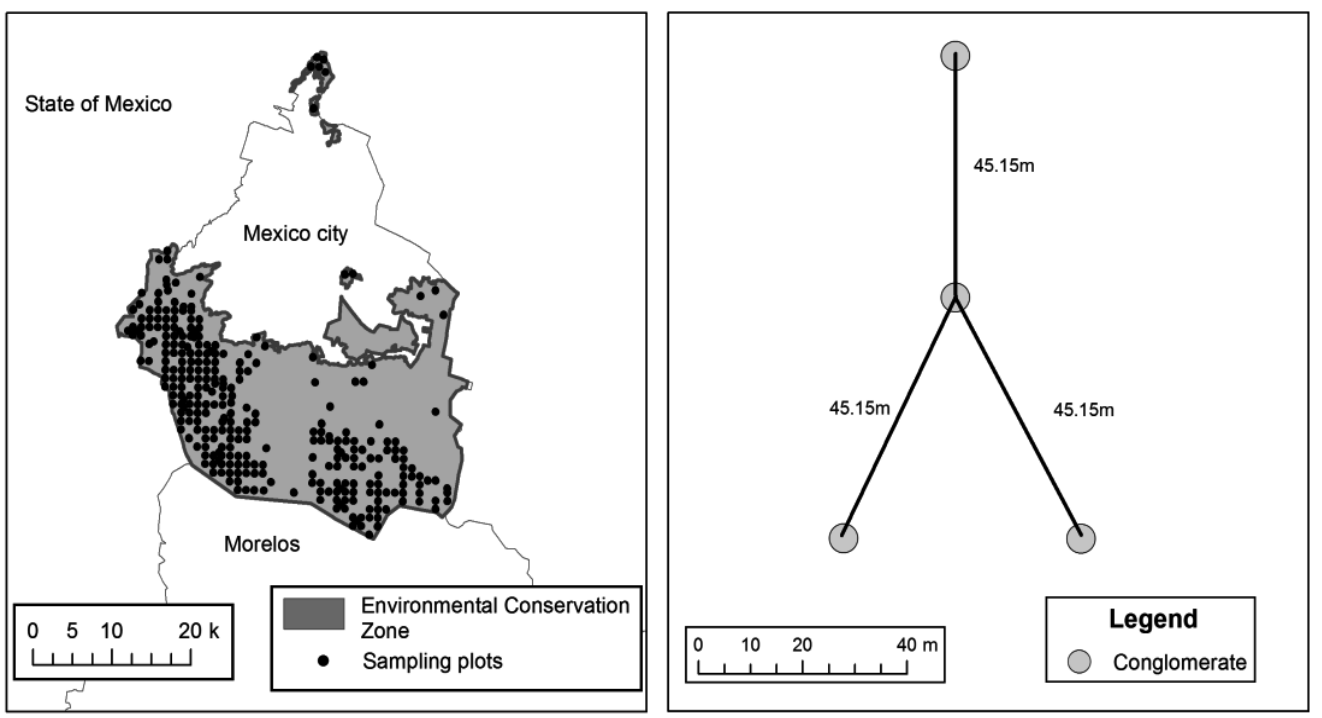

Figure 4. Sampling plots and conglomerate form. 


\subsubsection{SPOT image}

Four multispectral SPOT-5 HRG images were used: two from February 25, 2010 (zenith $51.72^{\circ}$ and $52.03^{\circ}$, azimuth $136.96^{\circ}$ and $136.43^{\circ}$ ) and two from March 28, 2010 (zenith $62.67^{\circ}$ and $62.89^{\circ}$, azimuth $125.66^{\circ}$ and $124.75^{\circ}$ ). These were radiometric and atmospherically corrected with the second simulation of a satellite signal in the solar spectrum (S-6) code through CLASlite software and orthorectified with the polynomial coefficients and geoid information based on Geocover 2000 of Landsat as reference images.

\subsubsection{LiDAR data}

LiDAR data used were acquired from the ALS50-II sensor flown by the National Institute for Statistics and Geography (INEGI, because of its name in Spanish) between November and December of 2007 over the entire Mexico Valley. The data had an average horizontal distance of $2.0 \mathrm{~m}$, minimum point density of 0.433 points $/ \mathrm{m}^{2}$, and vertical root mean square error of 7.3 $\mathrm{cm}$. These points are used as the basis for the generation of digital terrain model (DTM) and digital surface model (DSM) with a resolution of $5 \mathrm{~m}$.

\subsubsection{Photosynthetic vegetation fraction cover}

Photosynthetic vegetation fraction cover was estimated throughout the Automated Monte Carlo Unmixing (AutoMCU) model. This model integrates spectral mixture analysis and spectral end-member libraries resulting from fieldwork (ground spectrometer) and highresolution hyperspectral information of Hyperion Sensor, in order to separate photosynthetic vegetation, non-photosynthetic vegetation, and bare substrate. The photosynthetic vegetation fraction cover was calculated by CLASlite v3.2 software (Figure 5) [140].

\subsubsection{Canopy height model}

The calculation of canopy height model used altitude values of different digital terrain model (DTM) and digital surface model (DSM) in order to extract differences between both models (Figure 6).

\subsubsection{Correlation and autocorrelation coefficients}

Correlation analysis based on multiple regressions explored statistical relationships between aboveground biomass carbon and satellite indices. The sampling points were randomly divided into $50 \%$ for model calibration and $50 \%$ for model verification. Residuals from regressions were retained and their spatial autocorrelation was quantified [141]. Moran's I index was used to identify the type and intensity of spatial pattern, measuring the degree of autocorrelation or dependence of a distribution. Moran's I index can be written as in the equation (9):

$$
I=\frac{n}{\sum_{i} \sum_{j} \varpi_{i j}} * \frac{\sum_{i} \sum_{j} \varpi_{i j}\left(x_{i}-\bar{x}\right)\left(x_{j}-\bar{x}\right)}{\sum_{i}\left(x_{i}-\bar{x}\right)^{2}}
$$




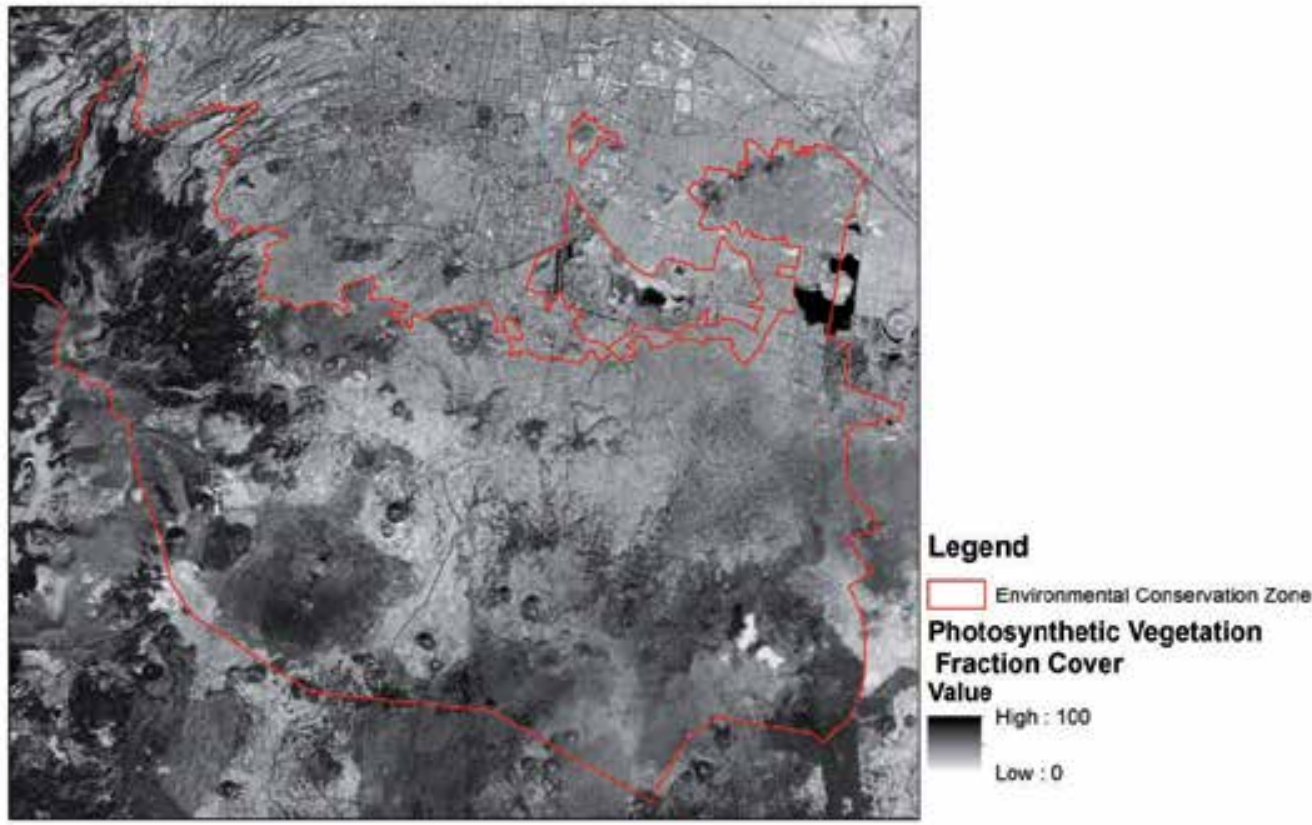

Figure 5. Photosynthetic vegetation fraction cover.

where $n$ is the number of spatial units indexed by $i$ and $j, x$ is the variable of interest, and $\omega_{i j}$ is the spatial weight matrix. Moran's I values near to 1 indicate clustering negative values near to -1 represent spatial dispersion, and a value of zero indicates randomness. Statistical significance was expressed in terms of the $\mathrm{Z}$ descriptor and confidence level 1- $\alpha$. Construction of the spatial weight matrix was distance based, since the spatial representation units are points. This distance or spatial lag includes at least 12 samples as recommended by Isaaks and Srivsatava [33].

\subsubsection{Regression models}

In addition to multiple regression, the present study compared models derived from regression-cokriging. The regression-cokriging was calculated through the estimation of a simple linear regression approach between aboveground carbon and canopy height model (equation (10)) and the addition of interpolated layer via ordinary cokriging integrated by regression residuals and the secondary variable (photosynthetic vegetation fraction cover) [31, 142]. The predictions were carried out separately for drift and residuals, and were added together later as in the following equation (11):

$$
\hat{z} \operatorname{RCoK}\left(S_{0}\right)=\hat{m}\left(S_{0}\right)+\hat{e}\left(S_{0}\right)
$$




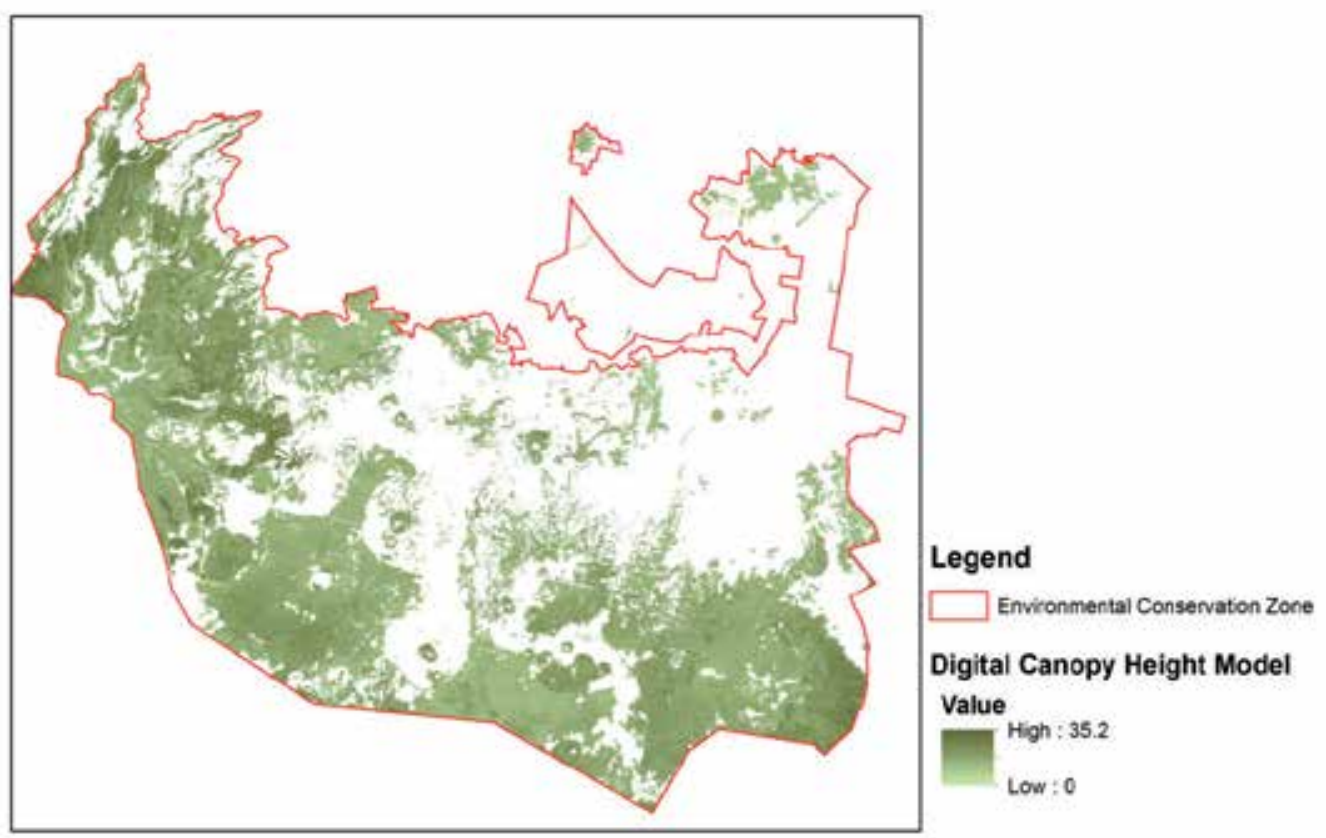

Figure 6. Digital canopy height model.

$$
\hat{z} R \operatorname{CoK}\left(S_{0}\right)=\sum_{k=0}^{p} \hat{\beta}_{k}^{*} q_{k}\left(S_{0}\right)+\left(\sum_{i=1}^{n} \varpi_{i} e(S o)+\sum_{j=1}^{n} \varpi_{2 j} Z_{2}\left(S_{i}\right)\right)
$$

where $\beta k$ are the coefficients of the drift model, $q k$ is the number of auxiliary variables, $\omega i\left(S_{0}\right)$ and $\omega_{2 j}$ are the weights determined by covariogram for regression residuals, and secondary variable and $e$ are the regression residuals [31].

\subsubsection{Model accuracy}

The regression models were validated with data from the field sampling [143]. The RMSE criterion was used to determine which regression models have more precision in the estimation of stored carbon in the area, the RMSE can be written as equation (12):

$$
\operatorname{RMSE}=\sqrt{\sum_{i=1}^{n} \frac{\left(Z_{(s i)}-z_{(s i)}\right)^{2}}{n}}
$$

where $Z(s i)$ is the reference value, $z(s i)$ is the estimated value, and $n$ is the total number of samples. 


\subsection{Results}

\subsubsection{Correlation}

The degree of association between carbon stored and each index derived from remote sensing and multiple associations (Table 2) was the synergy between canopy height model and photosynthetic vegetation fraction cover with an $r$ coefficient of 0.88 . All these correlations were positive, indicating that, as stored carbon increases, vegetation indices increase.

\begin{tabular}{lll}
\hline Satellite indices & $\mathbf{r}$ & Error \\
\hline Canopy Hieght Model & 0.85 & 24.17 \\
\hline Photosynthetic Vegetation Fraction Cover & 0.52 & 39.29 \\
\hline Multiple regression & 0.88 & 22.26 \\
\hline
\end{tabular}

Table 2. Correlation coefficients above-ground carbon and remote sensing indices.

\subsubsection{Moran's I index}

Once the satellite-derived index, that is the most associated with carbon storage, was identified, Moran's I was calculated from regression residuals according to sampling sites in order to identify spatial autocorrelation and, hence, the information could be included as auxiliary information in the regression-cokriging model. A value of $0.31(z=2.96, \alpha=0.01)$ was obtained for the regression residuals between canopy height model and aboveground carbon. In this case, a low-positive spatial autocorrelation was present, with statistical significance, indicating that the neighboring spatial units presented near or close values and a slight trend toward plots.

\subsubsection{Spatial distribution}

To identify the spatial distribution of stored carbon, models were developed with the application of equations resulting from multiple regression and regression-cokriging spatial methods. By obtaining the covariograms for the theoretical fit, no significant variation was found between anisotropic and isotropic covariograms, therefore, the isotropic model was settled.

As the empirical covariogram showed strong spatial dependence, it did not present constant semivariances as a function of distance. In this case, the adjusted theoretical models ranged from 10,000 to $15,000 \mathrm{~m}$, distances at which the observations were independent.

We used the best fit (according to root mean squares in prediction errors) for the ordinary cokriging interpolation to evaluate which is more effective in the predictions throughout the study area. Table 3 shows the parameters obtained. 


\begin{tabular}{lllll}
\hline Remote Sensing indices & model & Sill & Range & Nugget \\
\hline $\begin{array}{l}\text { Photosynthetic Vegetation Fraction Cover and } \\
\text { regression residuals }\end{array}$ & Exponential & 0.89 & 12,007 & 0 \\
\hline
\end{tabular}

Table 3. Covariogram indices

\subsubsection{Model accuracy}

Comparison of the models with the set of verification sites produced the RMSE in $\mathrm{tC} / \mathrm{ha}$ (Table 4). The models based on regression-cokriging presented the least error. Figure 5 shows the spatial distribution obtained by regression-cokriging and multiple regressions for stored carbon. The delineation of forest types (fir and pine) was based on the map of land use and vegetation of PAOT [144].

\begin{tabular}{ll}
\hline Models & RMSE (tC/ha) \\
\hline Multiple regression & 34.1 \\
\hline Regression-Cokriging & 28.6 \\
\hline
\end{tabular}

Table 4. RMSE

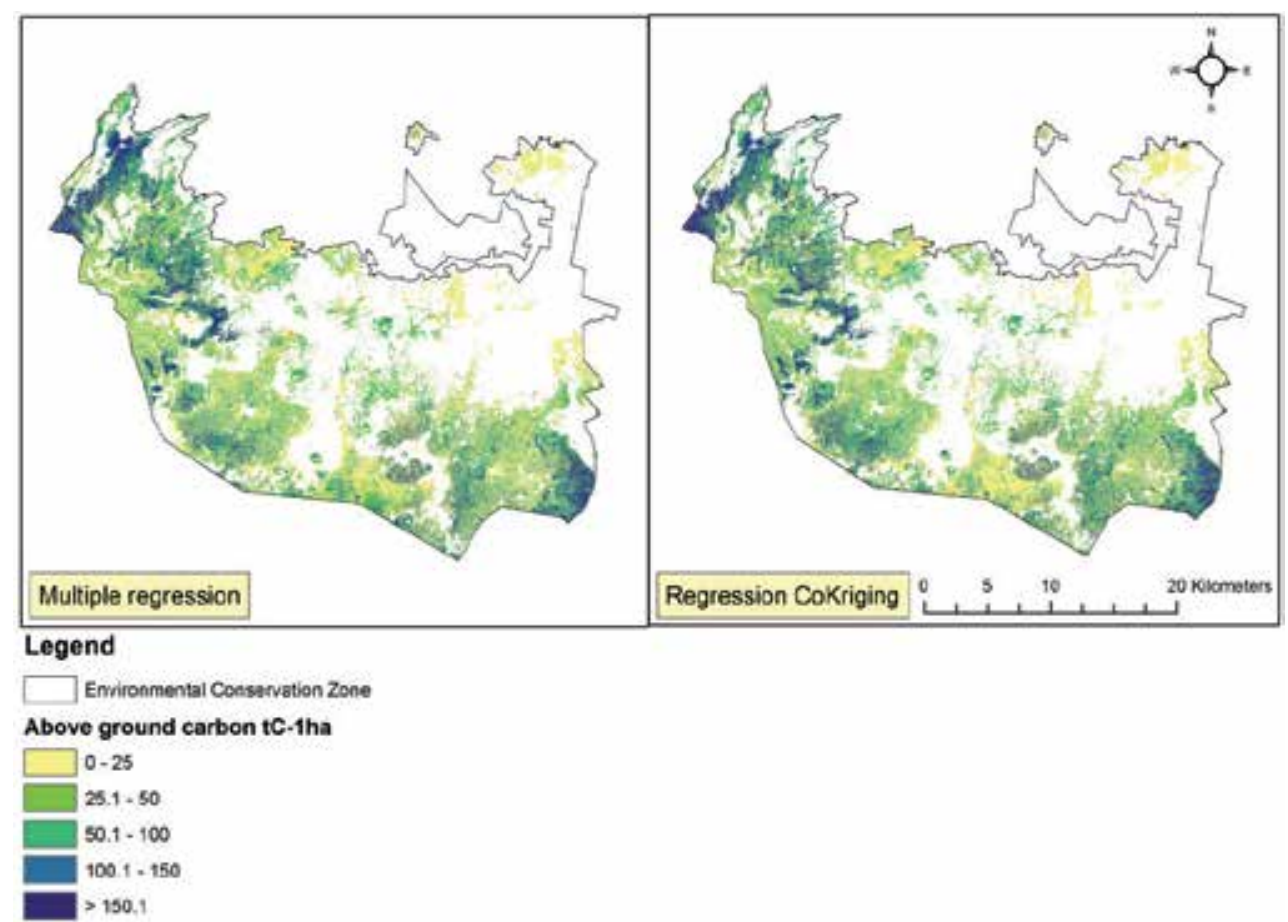

Figure 7. Spatial distribution of the aboveground carbon storage in Environmental Conservation Zone, estimated by two regression models. 
The results of this research indicated that consideration of spatial autocorrelation can improve estimates of carbon content in aboveground biomass, specifically using the regression cokriging method. This could be due to its sensitivity to local variations [142], since it is particularly developed to consider the adjustment of the spatial variance model in order to improve predictions obtained from global models. The present work uses spatial modeling of indices related to carbon for the purpose of exploring the spatial autocorrelation of auxiliary variables, which is useful for representing the way in which a phenomenon radiates through spatial units. Although the primary method used for the estimation of carbon stocks in Mexico is the stratify-and-multiply approach, which assigns a single value or a range of values to each vegetation type and then multiplies these values by the areas covered by the vegetation to estimate total carbon stock values, this investigation has demonstrated a more accurate, spatial-explicit, repeatable alternative.

According to Ref. [145], autocorrelation is "perhaps, after the average and variance, the most important property of any geographic variable and, unlike these, it is explicitly linked with spatial patterns." The present comparative analysis demonstrates the importance of the use of spatial methods to model carbon stored in the aboveground biomass, since these methods consider the spatial pattern of the data. The hypothesis of the homogeneity of the relationships between stored carbon and remote sensing indices sometimes does not consider the spatial heterogeneity of many factors affecting this relationship, such as geographic differences in orientation and climatic and soil conditions [28].

This analysis provided a synoptic mapping of aboveground biomass as a potentially valuable tool for environmental protection policies in the ECZ of Mexico City, one of the most important ecological reserves for the inhabitants of the Mexico Valley in the economic, cultural, and social sense, as well as for the volume and quality of the environmental services it provides.

\section{Conclusion}

Remote sensing-derived indices play a major role in forest monitoring, because traditional methodologies derive their estimates of carbon content in the biomass through forest inventories and, for its implementation, they require much time and money and are generally limited to 10-year intervals. The information resulting from them is designed to present average timber volumes linked to administrative regions, which not represent the spatial variability and therefore it generate a bias in carbon measures..

This has led to great interest to estimate, map, and monitor the carbon stored in forests more precisely, enhancing the recognition of their role in the global carbon cycle, particularly in the mitigation of greenhouse gases. Through the estimation of carbon content, a base line for calculating the dynamics of this gas as a mitigation strategy can be established.

An overview of modeling options and remote sensing resources that have been used for monitoring and researching the forest biomass was presented. Techniques ranging from collecting georeferenced data in the field to the information extraction methods from satellite 
images and synergies between remote sensing and geostatistics were described. A case study was selected to illustrate the application of some of these techniques in the modeling of spatial distribution of aboveground carbon in Mexican coniferous forests.

Based on the study, the following conclusions can be drawn:

1. According to these results, the synergy between remote sensing and geostatistics has the potential to estimate forest biomass to improve estimations using remote sensing indices as spatial secondary variables.

2. Geospatial methods have a better modeling adjustment (e.g., RMSE) than conventional statistical methods as multiple regressions, because geospatial methods considerer local spatial variations.

3. Best Pearson coefficient between the two variables tested in the study is the digital canopy model, which resulted from LiDAR data. This kind of information is very expensive, so integrating multispectral information can be a way to capitalize on multitemporal study of biomass.

\section{Author details}

José Mauricio Galeana Pizaña*, Juan Manuel Núñez Hernández and Nirani Corona Romero

*Address all correspondence to: mgaleana@centrogeo.edu.mx

Centro de Investigación en Geografía y Geomática "Ing. Jorge L. Tamayo", México DF, Mexico

\section{References}

[1] FAO. Global Forest Resources Assessment 2010: Main Report. Roma: Food and Agriculture Organization of the United Nations. 2010. 340 p.

[2] Pavlic G, Chen W, Fernandes R, Cihlar J, Price DT, Latifovic R, Fraser R, Leblanc SG. Canada-wide maps of dominant tree species from remotely sensed and ground data. Geocarto International. 2007;22:185-204. DOI: 10.1080/10106040701201798

[3] Brown S. Measuring carbon in forests: current status and future challenges. Environmental Pollution. 2002;116:363-372. DOI: 10.1016/S0269-7491(01)00212-3

[4] Wulder M. Optical remote-sensing techniques for the assessment of forest inventory and biophysical parameters. Progress in Physical Geography. 1998;22:449-476. DOI: 10.1177/030913339802200402 
[5] Zhu X, Liu D. Improving forest aboveground biomass estimation using seasonal Landsat NDVI time-series. ISPRS Journal of Photogrammetry and Remote Sensing. 2015;102:222-231. DOI: 10.1016/j.isprsjprs.2014.08.014

[6] Lu D. The potential and challenge of remote sensing based biomass estimation. International Journal of Remote Sensing. 2006;27:1297-1328. DOI: $10.1080 / 01431160500486732$

[7] Kim Y, Yang Z, Cohen W, Pflugmacher D, Lauver C, Vankat J. Distinguishing between live and dead standing tree biomass on the North Rim of Grand Canyon National Park, USA using small-footprint lidar data. Remote Sensing of Environment. 2009;113:2499-2510. DOI: 10.1016/j.rse.2009.07.010

[8] Bi H, Turner J, Lambert M. Additive biomass equations for native eucalypt forest trees of temperate Australia. Trees. 2004;18:467-479. DOI: 10.1007/s00468-004-0333-z

[9] Gleason C, Jungho Im. A review of remote sensing of forest biomass and biofuel: options for small-area applications. GIScience \& Remote Sensing. 2011;48:141-170. DOI: 10.2747/1548-1603.48.2.141

[10] Viana H, Aranha J, Lopes D, Cohen W. Estimation of crown biomass of Pinus pinaster stands and shrubland above-ground biomass using forest inventory data, remotely sensed imagery and spatial prediction models. Ecological Modelling. 2012;226:22-35. DOI: 10.1016/j.ecolmodel.2011.11.027

[11] McRoberts R, Tomppo E, Naesset E. Advances and emerging issues on national forest inventories. Scandinavian Journal of Forest Research. 2010;25:368-381. DOI: 10.1080/02827581.2010.496739

[12] Návar-Cháidez J. Biomass allometry for tree species of Northwestern Mexico. Tropical and Subtropical Agroecosystems. 2010;12:507-519.

[13] Vahedi AA, Mataji A, Babayi-Kafaki S, Eshaghi-Rad J, Hodjati SM, Djomo A. Allometric equations for predicting aboveground biomass of beech-hornbeam stands in the Hyrcanian forests of Iran. Journal of Forest Science. 2014;60:236-247.

[14] Sinha S, Jeganathan C, Sharma LK, Nathawat MS. A review of radar remote sensing for biomass estimation. International Journal of Environmental Science and Technology. 2015;12:1779-1792. DOI: 10.1007/s13762-015-0750-0

[15] Lu D, Chen Q, Wang G, Liu L, Li G, Moran E. A survey of remote sensing-based aboveground biomass estimation methods in forest ecosystems. International Journal of Digital Earth. 2014;1-43. DOI: 10.1080/17538947.2014.990526

[16] Propastin P. Modifying geographically weighted regression for estimating aboveground biomass in tropical rainforests by multispectral remote sensing data. International Journal of Applied Earth Observation and Geoinformation. 2012;18:82-90. DOI: 10.1016/j.jag.2011.12.013 
[17] Kellndorfer JM, Walker WS, LaPoint E, Kirsch K, Bishop J, Fiske G. Statistical fusion of Lidar, InSAR, and optical remote sensing data for forest stand height characterization: a regional-scale method based on LVIS, SRTM, Landsat ETM+, and ancillary data sets. Journal of Geophysical Research: Biogeosciences. 2010;115:1-10. DOI: 10.1029/2009JG000997

[18] McRoberts RE, Westfall JA. Effects of uncertainty in model predictions of individual tree volume on large area volume estimates. Forest Science. 2014;60:34-42. DOI: http://dx.doi.org/10.5849/forsci.12-141

[19] Seidel D, Fleck S, Leuschner C, Hammett T. Review of ground-based methods to measure the distribution of biomass in forest canopies. Annals of Forest Science. 2011;68:225-244. DOI: 10.1007/s13595-011-0040-z

[20] Segura M, Kanninen M. Allometric models for tree volume and total aboveground biomass in a tropical humid forest in Costa Rica. Biotropica. 2005;37:2-8. DOI: 10.1111/j.1744-7429.2005.02027.x

[21] Mitchard ETA, Saatchi SS, Lewis SL, Feldpausch TR, Woodhouse IH, Sonké B, Rowland C, Meir P. Measuring biomass changes due to woody encroachment and deforestation/degradation in a forest-savanna boundary region of central Africa using multi-temporal L-band radar backscatter. Remote Sensing of Environment. 2011;115:2861-2873. DOI: 10.1016/j.rse.2010.02.022

[22] Sun G, Ranson KJ, Guo Z, Zhang Z, Montesano P, Kimes D. Forest biomass mapping from lidar and radar synergies. Remote Sensing of Environment. 2011;115:2906-2916. DOI: 10.1016/j.rse.2011.03.021

[23] Lu D. Aboveground biomass estimation using Landsat TM data in the Brazilian Amazon. International Journal of Remote Sensing. 2005;26:2509-2525. DOI: $10.1080 / 01431160500142145$

[24] Lu D, Batistella M, Moran E. Satellite estimation of aboveground biomass and impacts of forest stand structure. Photogrammetric Engineering \& Remote Sensing. 2005;71:967-974. DOI: 10.14358/PERS.71.8.967

[25] Boyd DS, Danson FM. Satellite remote sensing of forest resources: three decades of research development. Progress in Physical Geography. 2005;29:1-26. DOI: 10.1191/0309133305pp432ra

[26] Chen Q, Laurin GV, Battles JJ, Saah D. Integration of airborne lidar and vegetation types derived from aerial photography for mapping aboveground live biomass. Remote Sensing of Environment. 2012;121:108-117. DOI: 10.1016/j.rse.2012.01.021

[27] McRoberts RE, Næsset E, Gobakken T. Inference for lidar-assisted estimation of forest growing stock volume. Remote Sensing of Environment. 2013;128:268-275. DOI: 10.1016/j.rse.2012.10.007 
[28] Maselli F, Chiesi M. Evaluation of statistical methods to estimate forest volume in a Mediterranean Region. IEEE Transaction on Geoscience and Remote Sensing. 2006;44:2239-2250. DOI: 10.1109/TGRS.2006.872074

[29] Sales M, Souza C, Kyriakidis P, Roberts D, Vidal E. Improving spatial distri-bution estimation of forest biomass with geostatistic: a case study for Rondonia, Brazil. Ecological Modelling. 2007;205:221-230. DOI: 10.1016/j.ecolmodel.2007.02.033

[30] Castillo-Santiago M, Ghilardi A, Oyama K, Hernández-Stefanoni J, Torres I, Flamenco-Sandoval A, Fernández A, Mas J. Estimating the spatial distribution of woody biomass suitable for charcoal making from remote sensing and geostatistics in central Mexico. Energy for Sustainable Development. 2013;17:177-188. DOI: 10.1016/j.esd. 2012.10.007

[31] Tsui OW, Coops NC, Wulder MA, Marshall PL. Integrating airborne LiDAR and space-borne radar via multivariate kriging to estimate above-ground biomass. Remote Sensing of Environment. 2013;139:340-352. DOI: 10.1016/j.rse.2013.08.012

[32] Galeana-Pizaña JM, López-Caloca A, López-Quiroz P, Silván-Cárdenas J, Couturier S. Modeling the spatial distribution of above-ground carbon in Mexican coniferous forest using remote sensing and a geostatistical approach. International Journal of Applied Earth Observation and Geoinformation. 2014;30:179-189. DOI: 10.1016/j.jag. 2014.02.005

[33] Isaaks E, Srivastava R. Applied Geostatistics. New York: Oxford University Press; 1989. $561 \mathrm{p}$.

[34] Journel AG, Huijbregts ChJ. Mining Geostatistics. London: Academics Press; 1978. $600 \mathrm{p}$.

[35] Webters R, Oliver M. Geostatistics for Environmental Scientists. 2nd ed. Chichester: John Wiley \& Sons; 2007. 330 p.

[36] Anselin L, Rey S, editors. Perspectives on Spatial Data Analysis. Berlin: Springer; 2010. 290 p. DOI: 10.1007/978-3-642-01976-0_1

[37] Tobler WR. A computer movie simulating urban growth in the Detroit region. Economic Geography. 1970;46:234-240. DOI: 10.2307/143141

[38] García M, Riaño D, Chuvieco E, Danson M. Estimating biomass carbon stocks for a Mediterranean forest in central Spain using LiDAR height and intensity data. Remote Sensing of Environment. 2010;114:816-830. DOI: 10.1016/j.rse.2009.11.021

[39] Mitchard ET, Saatchi SS, Baccini A, Asner GP, Goetz SJ, Harris NL, Brown S. Uncertainty in the spatial distribution of tropical forest biomass: a comparison of pan-tropical maps. Carbon Balance and Management. 2013;8:1-13. DOI: $10.1186 / 1750-0680-8-10$ 
[40] McRoberts RE, GobakkenT, Næsset E. Post-stratified estimation of forest area and growing stock volume using lidar-based stratifications. Remote Sensing of Environment. 2012;125:157-166. DOI: 10.1016/j.rse.2012.07.002

[41] Saatchi S, Malhi Y, Zutta B, Buermann W, Anderson LO, Araujo AM, Phillips OL, Peacock J, ter Steege H, Lopez Gonzalez G, Baker T, Arroyo L, Almeida S, Higuchi N, Killen T, Monteagudo A, Neill D, Pitman N, Prieto A, Salomão R, Silva N, Vásquez Martínez R, Laurence W, Ramírez HA. Mapping landscape scale variations of forest structure, biomass, and productivity in Amazonia. Biogeosciences Discussions. 2009;6:5461-5505. DOI: 10.5194/bgd-6-5461-2009

[42] Kilkki P, Päivinen R. Reference sample plots to combine field measurements and satellite data in forest inventory. Department of Forest Mensuration and Management, University of Helsinki, Research Notes. 1987;19:210-215.

[43] Tomppo EO, Gagliano C, De Natale F, Katila M, McRoberts RE. Predicting categorical forest variables using an improved k-Nearest Neighbour estimator and Landsat imagery. Remote Sensing of Environment. 2009;113:500-517. DOI: 10.1016/j.rse. 2008.05.021.

[44] Latifi H, Nothdurft A, Koch B. Non-parametric prediction and mapping of standing timber volume and biomass in a temperate forest: application of multiple optical/ LiDAR-derived predictors. Forestry. 2010;83:395-407. DOI: 10.1093/forestry/cpq022

[45] Tomppo E, Olsson H, Ståhl G, Nilsson M, Hagner O, Katila M. Combining national forest inventory field plots and remote sensing data for forest databases. Remote Sensing of Environment. 2008;112:1982-1999. DOI: 10.1016/j.rse.2007.03.032

[46] Foody GM, Cutler ME, Mcmorrow J, Pelz D, Tangki H, Boyd DS, Douglas I. Mapping the biomass of Bornean tropical rain forest from remotely sensed data. Global Ecology and Biogeography. 2001;10:379-387.

[47] Mas JF, Flores JJ. The application of artificial neural networks to the analysis of remotely sensed data. International Journal of Remote Sensing. 2008;29:617-663. DOI: 10.1080/01431160701352154

[48] Pflugmacher D, Cohen WB, Kennedy RE, Yang Z. Using Landsat-derived disturbance and recovery history and lidar to map forest biomass dynamics. Remote Sensing of Environment. 2014;151:124-137. DOI: 10.1016/j.rse.2013.05.033

[49] Tanase M, Panciera R, Lowell K, Tian S, Kacker J, Walker J. Airborne multi-temporal L-band polarimetric SAR data for biomass estimation in semi-arid forests. Remote Sensing of Environment. 2014;145:93-104. DOI: 10.1016/j.rse.2014.01.024

[50] Marabel M, Alvarez-Taboada F. Spectroscopic determination of aboveground biomass in grasslands using spectral transformations, support vector machine and partial least squares regression. Sensors. 2013;13:10027-10051. DOI: 10.3390/s130810027 
[51] Mountrakis G, Im J, Ogole C. Support vector machines in remote sensing: a review. ISPRS Journal of Photogrammetry and Remote Sensing. 2011;66:247-259. DOI: 10.1016/j.isprsjprs.2010.11.001

[52] Phillips SJ, Dudík M. Modeling of species distributions with Maxent: new extensions and a comprehensive evaluation. Ecography. 2008;31:161-175. DOI: 10.1111/j. 0906-7590.2008.5203.x

[53] Harris NL, Brown S, Hagen SC, Saatchi SS, Petrova S, Salas W, Hansen MC, Potapov PV, Lotsch A. Baseline map of carbon emissions from deforestation in tropical regions. Science. 2012;336:1573-1576. DOI: 10.1126/science.1217962

[54] Saatchi SS, Harris NL, Brown S, Lefsky M, Mitchard ET, Salas W, Zutta BR, Buermann W, Lewis SL, Hagen S, Petrova S, White L, Silman M, Morel A. Benchmark map of forest carbon stocks in tropical regions across three continents. Proceedings of the National Academy of Sciences of the United States of America. 2011;108:98999904. DOI: 10.1073/pnas.1019576108

[55] Franklin S. Remote sensing for sustainable forest management. USA: CRC Press LLC; 2001. 409 p.

[56] Jensen, J. Remote Sensing of the Environment: An Earth Resource Perspective. 2nd ed. New Jersey: Prentice Hall; 2006. 608 p.

[57] Mundava C, Helmholz P, Schut T, Corner R, McAtee B, Lamb D. Evaluation of vegetation indices for rangeland biomass estimation in the Kimberley area of Western Australia. ISPRS Journal of Photogrammetry and Remote Sensing. 2014;2:47-53. DOI: 10.5194/isprsannals-II-7-47-2014

[58] Jackson RD, Huete AR. Interpreting vegetation indices. Preventive Veterinary Medicine. 1991;11:185-200. DOI: 10.1016/S0167-5877(05)80004-2

[59] Silleos NG, Alexandridis TK, Gitas IZ, Perakis K. Vegetation indices: advances made in biomass estimation and vegetation monitoring in the last 30 years. Geocarto International. 2006;21:21-28. DOI: 10.1080/10106040608542399

[60] Bannari A, Morin D, Bonn F, Huete AR. A review of vegetation indices. Remote Sensing Reviews. 1995;13:95-120. DOI: 10.1080/02757259509532298

[61] Birth GS, McVey GR. Measuring the color of growing turf with a reflectance spectrophotometer. Agronomy Journal. 1986;60:640-643. DOI: 10.2134/ agronj1968.00021962006000060016x

[62] Rouse JW, Haas RH, Deering DW, Harlan JC. Monitoring the vernal advancement and retrogradation (green wave effect) of natural vegetation (Technical report). Texas: A \& M University, Remote Sensing Center. 1974. 8 p.

[63] Huete AR. A soil-adjusted vegetation index (SAVI). Remote Sensing of Environment. 1988;25:295-309. DOI: 10.1016/0034-4257(88)90106-X 
[64] Asrar G, Fuchs M, Kanemasu ET, Hatfield JL. Estimating absorbed photosynthetic radiation and leaf area index from spectral reflectance in wheat. Agronomy Journal. 1984;76:300-306. DOI: 10.2134/agronj1984.00021962007600020029x

[65] Richardson AJ, Weigand CL. Distinguishing vegetation from soil background information. Photogrammetric Engineering and Remote Sensing. 1977;43:1541-1552.

[66] Baig MHA, Zhang L, Shuai T, Tong Q. Derivation of a tasselled cap transformation based on Landsat 8 at-satellite reflectance. Remote Sensing Letters. 2014;5:423-431. DOI: 10.1080/2150704X.2014.915434

[67] Yarbrough LD, Easson G, Kuszmaul JS. Using at-sensor radiance and reflectance tasseled cap transforms applied to change detection for the ASTER sensor. ASTER. 2005;2:141-145.

[68] Horne JH. A tasseled cap transformation for IKONOS images. In: Proceedings of the InASPRS 2003 Annual Conference, May 2003; Anchorage Alaska; 2003. pp. 60-70.

[69] Huang C, Wylie B, Yang L, Homer C, Zylstra G. Derivation of a tasselled cap transformation based on Landsat 7 at-satellite reflectance. International Journal of Remote Sensing. 2002;23:1741-1748. DOI: 10.1080/01431160110106113

[70] Zhang X, Schaaf CB, Friedl M, Strahler AH, Gao F, Hodges JC. MODIS tasseled cap transformation and its utility. In: Proceedings of the Geoscience and Remote Sensing Symposium, IGARSS'02. 2002 IEEE International (Vol. 2); 24-28 June 2002. Canada: IEEE; 2002. pp. 1063-1065.

[71] Crist EP. A TM tasseled cap equivalent transformation for reflectance factor data. Remote Sensing of Environment. 1985;17:301-306. DOI: 10.1016/0034-4257(85)90102-6

[72] Kauth RJ, Thomas GS. The tasseled cap - A graphic description of the spectral-temporal development of agricultural crops as seen by Landsat. In: Proceedings of the Symposium on Machine Processing of Remotely Sensed Data; June 29-July 1 1976; West Lafayette Indiana. 1976. pp. 41-51.

[73] McDonald AJ, Gemmell FM, Lewis PE. Investigation of the utility of spectral vegetation indices for determining information on coniferous forests. Remote Sensing of Environment. 1998;66:250-272. DOI: 10.1016/S0034-4257(98)00057-1

[74] Sarker L, Nichol J. Improved forest biomass estimates using ALOS AVNIR-2 texture indices. Remote Sensing of Environment. 2011;115:968-977. DOI: 10.1016/j.rse. 2010.11.010

[75] Sarker L, Nichol J, Ahmad B, Busu I, Rahman AA. Potential of texture measurements of two-date dual polarization PALSAR data for the improvement of forest biomass estimation. ISPRS Journal of Photogrammetry and Remote Sensing. 2012;69:146-166. DOI: 10.1016/j.isprsjprs.2012.03.002

[76] Cutler MEJ, Boyd DS, Foody GM, Vetrivel A. Estimating tropical forest biomass with a combination of SAR image texture and Landsat TM data: an assessment of predic- 
tions between regions. ISPRS Journal of Photogrammetry and Remote Sensing. 2012;70:66-77. DOI: 10.1016/j.isprsjprs.2012.03.011

[77] Dube T, Mutanga O. Investigating the robustness of the new Landsat-8 Operational Land Imager derived texture metrics in estimating plantation forest aboveground biomass in resource constrained areas. ISPRS Journal of Photogrammetry and Remote Sensing. 2015;108:12-32. DOI: 10.1016/j.isprsjprs.2015.06.002

[78] Haralick R, Shanmugam K, Dinstein I. Textural features for image classification. IEEE Transaction on Systems, Man, and Cybernetics. 1973;6:610-621. DOI: 10.1109/ TSMC.1973.4309314

[79] Richards JA. Remote Sensing Digital Image Analysis (Vol. 3). Berlin: Springer; 1999

[80] Ozdemir I, Donoghue D. Modelling tree size diversity from airborne laser scanning using canopy height model with image textures measures. Forest Ecology and Management. 2013;295:28-37. DOI: 10.1016/j.foreco.2012.12.044

[81] Sharma R, Kajiwara K, Honda Y. Estimation of forest canopy structural parameters using kernel-driven bi-directional reflectance model based multi-angular vegetation indices. ISPRS Journal of Photogrammetry and Remote Sensing. 2013;78:50-57. DOI: 10.1016/j.isprsjprs.2012.12.006

[82] Mura N, Jones D. Characterizing forest ecological structure using pulse types and heights of airborne laser scanning. Remote Sensing of Environment. 2010;114:10691076. DOI: 10.1016/j.rse.2009.12.017

[83] Mandugundu R, Nizalapur V, Jha C. Estimation of LAI and above-ground biomass in deciduous forest: Western Ghats of Karnataka, India. International Journal of Applied Earth Observation and Geoinformation. 2008;10:211-219. DOI: 10.1016/j.jag. 2007.11.004

[84] Solberg S, Astrup R, Gobakken T, Næsset E, Weydahl D. Estimating spruce and pine biomass with interferometric X-band SAR. Remote Sensing of Environment. 2010;114:2353-2360. DOI: 10.1016/j.rse.2010.05.011

[85] Heiskanen J. Estimating aboveground tree biomass and leaf area index in mountain birch forest using ASTER satellite data. International Journal of Remote Sensing. 2006;27:1135-1158. DOI: 10.1080/01431160500353858

[86] White J, Running S, Nemani R, Keane R, Ryan K. Measurement and remote sensing of LAI in Rocky Mountain montane ecosystems. Canadian Journal of Forest Research. 1997;27:1714-1727.

[87] Donoghue D, Watt P, Cox N, Wilson J. Remote sensing of species mixtures in conifer plantations using LIDAR height and intensity data. Remote Sensing of Environment. 2007;110:509-522. DOI: 10.1016/j.rse.2007.02.032

[88] Fernández-Manso O, Fernández-Manso A, Quintano C. Estimation of aboveground biomass in Mediterranean forests by statistical modelling of ASTER fraction images. 
International Journal of Applied Earth Observation and Geoinformation. 2014;31:4556. DOI: 10.1016/j.jag.2014.03.005

[89] Cabacinha CD, de Castro SS. Relationship between floristic diversity and vegetation indices, forest structure and landscape metrics of fragments in Brazilian Cerrado. Forest Ecology and Management. 2009;257:2157-2165. DOI: 10.1016/j.foreco. 2009.02.030

[90] Gilabert MAJ, González-Piqueras J, García-Haro J. Acerca de los índices de vegetación. Revista de Teledetección. 1997;8:1-10.

[91] Roberts DA, Smith MO, Adams JB. Green vegetation, nonphotosynthetic vegetation and soils in AVIRIS data. Remote Sensing of Environment. 1993;44:255-44:255-44:255-44:255-44:255-44:255-269

[92] Quintano C, Fernández-Manso A, Shimabukuro YE, Pereira G. Spectral unmixing. International Journal of Remote Sensing. 2012;33:5307-5340. DOI: 10.1080/01431161.2012.661095

[93] Keshava N, Mustard JF. Spectral unmixing. IEEE. Signal Processing Magazine. 2002; 19:44-57.

[94] Somers B, Asner GP, Tits L, Coppin P. Endmember variability in spectral mixture analysis: a review. Remote Sensing of Environment. 2011;115:1603-1616. DOI: 10.1016/j.rse.2011.03.003

[95] Silván-Cárdenas JL, Wang L. Retrieval of subpixel Tamarix canopy cover from Landsat data along the Forgotten River using linear and nonlinear mixture models. Remote Sensing of Environment. 2010; 114:1777-1790. DOI: 10.1016/j.rse.2010.04.003

[96] Okin GS, Clarke KD, Lewis MM. Comparison of methods for estimation of absolute vegetation and soil fractional cover using MODIS normalized BRDF-adjusted reflectance data. Remote Sensing of Environment. 2013;130:266-279. DOI: 10.1016/j.rse. 2012.11.021

[97] Yang J, Weisberg PJ, Bristow NA. Landsat remote sensing approaches for monitoring long-term tree cover dynamics in semi-arid woodlands: comparison of vegetation indices and spectral mixture analysis. Remote Sensing of Environment. 2012;119:62-71. DOI: 10.1016/j.rse.2011.12.004

[98] Souza Jr. C, Firestone L, Moreira Silva L, Roberts D. Mapping forest degradation in the Eastern Amazon from SPOT 4 through spectral mixture models. Remote Sensing of Environment. 2003;87:494-506. DOI: 10.1016/j.rse.2002.08.002

[99] Olthof I, Fraser RH. Mapping northern land cover fractions using Landsat ETM+. Remote Sensing of Environment. 2007;107:496-509. DOI: 10.1016/j.rse.2006.10.009 
[100] Vikhamar D, Solberg R. Subpixel mapping of snow cover in forests by optical remote sensing. Remote Sensing of Environment. 2002;84:69-82. DOI: 10.1016/ S0034-4257(02)00098-6

[101] Lobell DB, Asner GP, Law BE, Treuhaft RN. View angle effects on canopy reflectance and spectral mixture analysis of coniferous forest using AVIRIS. International Journal of Remote Sensing. 2002;23:2247-2262. DOI: 10.1080/01431160110075613

[102] Huang J, Chen D, Cosh M. Sub-pixel reflectance unmixing in estimating vegetation water content and dry biomass of corn and soybeans cropland using normalized difference water index (NDWI) from satellites. Remote Sensing of Environment. 2009;30:2075-2104. DOI: 10.1080/01431160802549245

[103] Peddle DR, Hall FG, LeDrew EF. Spectral mixture analysis and geometric-optical reflectance modeling of boreal forest biophysical structure. Remote Sensing of Environment. 1999;67:288-297. DOI: 10.1016/S0034-4257(98)00090-X

[104] Peddle DR, Brunke SP, Hall FG. A comparision of spectral mixture analysis and ten vegetation indices for estimating boreal forest biophysical information from airborne data. Canadian Journal of Remote Sensing: Journal canadien de télédétection. 2001;27:627-635. DOI: 10.1080/07038992.2001.10854903

[105] Maître H, editor. Processing of Synthetic Aperture Radar Images. Hoboken: John Wiley \& Sons, Inc; 2008. 384 p.

[106] Massonnet D, Souyris JC. Imaging with Synthetic Aperture Radar. Boca Raton: CRC Press; 2008. 250 p.

[107] Goetz S, Baccini A, Laporte N, Johns T, Walker W, Kellndorfer J, Houghton R, Sun $\mathrm{M}$. Mapping and monitoring carbon stocks with satellite observations: a comparison of methods. Carbon Balance and Management. 2009;4:1-7. DOI: $10.1186 / 1750-0680-4-2$

[108] Collins J, Hutley L, Williams R, Boggs G, Bell D, Bartolo R. Estimating landscapescale vegetation carbon stocks using airborne multi-frequency polarimetric synthetic aperture radar (SAR) in the savannahs of north Australia. International Journal of Remote Sensing. 2009;30:1141-1159. DOI: 10.1080/01431160802448935

[109] Thirion-Leferevre L, Colin-Koeniguer E. Investigating attenuation, scattering phase center and total height using simulated interferometric SAR images of forested areas. IEEE Transaction on Geoscience and Remote Sensing. 2007;45:3172-3179. DOI: 10.1109/TGRS.2007.904921

[110] Laurin G V, Liesenberg V, Chen Q, Guerriero L, Del Frate F, Bartolini A, Valentini R. Optical and SAR sensor synergies for forest and land cover mapping in a tropical site in West Africa. International Journal of Applied Earth Observation and Geoinformation. 2013;21:7-16. DOI: 10.1016/j.jag.2012.08.002 
[111] Cartus O, Santoro M, Kellndorfer J. Mapping forest aboveground biomass in the Northeastern United States with ALOS PALSAR dual-polarization L-band. Remote Sensing of Environment. 2012;124:466-478. DOI: 10.1016/j.rse.2012.05.029

[112] Karjalainen M, Kankare V, Vastaranta M, Holopainen M, Hyyppä J. Prediction of plot-level forest variables using TerraSAR-X stereo SAR data. Remote Sensing of Environment. 2012;117: 338-347. DOI: 10.1016/j.rse.2011.10.008

[113] Schlund M, von Poncet F, Hoekman DH, Kuntz S, Schmullius C. Importance of bistatic SAR features from TanDEM-X for forest mapping and monitoring. Remote Sensing of Environment. 2014;151:16-26. DOI: 10.1016/j.rse.2013.08.024

[114] Bourgeau-Chavez L, Leblon B, Charbonneau F, Buckley J. Evaluation of polarimetric Radarsat-2 SAR data for development of soil moisture retrieval algorithms over a chronosequence of black spruce boreal forest. Remote Sensing of Environment. 2013;132:71-85. DOI: 10.1016/j.rse.2013.01.006

[115] Balzter H. Forest mapping and monitoring with interferometric Synthetic Aperture Radar (InSAR). Progress in Physical Geography. 2001;25:159-177. DOI: $10.1177 / 030913330102500201$

[116] Santoro M, Fransson J, Eriksson L, Magnusson M, Ulander L, Olsson H. Signatures of ALOS PALSAR L-band backscatter in Swedish forest. IEEE Transaction on Geoscience and Remote Sensing. 2009;47:4001-4019. DOI: 10.1109/TGRS.2009.2023906

[117] Le Toan T, Quegan S, Davidson M, Balzter H, Paillou P, Papathanassiou Plummer S, Rocca F, Saatchi S, Shugart H, Ulander L. The BIOMASS mission: mapping global forest biomass to better understand the terrestrial carbon cycle. Remote Sensing of Environment. 2011;115:2850-2860. DOI: 10.1016/j.rse.2011.03.020

[118] Carreiras J, Vasconcelos M, Lucas R. Understanding the relationship between aboveground biomass and ALOS PALSAR data in the forest of Guinea-Bissau (West Africa). Remote Sensing of Environment. 2012;121:426-442. DOI: 10.1016/j.rse.2012.02.012

[119] Tansey KJ, Luckman AJ, Skinner L, Balzter H, Strozzi T, Wagner W. Classification of forest volume resources using ERS tandem coherence and JERS backscatter data. International Journal of Remote Sensing. 2004;25:751-768. DOI: $10.1080 / 0143116031000149970$

[120] Lee JS, Pottier E. Polarimetric radar imaging: from basics to applications. Boca Raton: CRC press; 2009. 391 p. DOI: 10.1201/9781420054989.fmatt

[121] Gonçalves F, Santos J, Treuhaft R. Stem volume of tropical forest from polarimetric radar. International Journal of Remote Sensing. 2011;32:503-522. DOI: 10.1080/01431160903475217

[122] Lefsky MA, Cohen W, Parker G, Harding D. LiDAR remote sensing for ecosystem studies. BioScience. 2002;52:19-30. 
[123] Andersen H, Reutebuch S, McGaughey R. A rigorous assessment of tree height measurements obtained using airborne LiDAR and conventional field methods. Canadian Journal of Remote Sensing. 2006;32:355-366.

[124] Hyde P, Dubayah R, Walker W, Blair JB, Hofton M, Hunsaker C. Mapping forest structure for wildlife habitat analysis using multi-sensor (LiDAR, SAR/InSAR, ETM+, Quickbird) synergy. Remote Sensing of Environment. 2006;102:63-73. DOI: 10.1016/ j.rse.2006.01.021

[125] Chopping M, Nolin A, Moisen G, Martonchik J, Bull M. Forest canopy height from the multiangle imaging spectroradiometer (MISR) assessed with high resolution discrete return lidar. Remote Sensing of Environment. 2009;113:2172-2185. DOI: 10.1016/j.rse.2009.05.017

[126] Vauhkonen J, Næsset E, Gobakken T. Deriving airborne laser scanning based computational canopy volume forest biomass and allometry studies. ISPRS Journal of Photogrammetry and Remote Sensing. 2014;96:57-66. DOI: 10.1016/j.isprsjprs.2014.07.001

[127] Hyyppä J, Hyyppä H, Yu X, Kaartinen H, Kukko A, Holopainen M. Forest inventory using small-footprint airborne LiDAR. Finland. In: Shan J, Toth CK, editors. Topographic Laser Ranging and Scanning: Principles and Processing. CRC Press; 2008. pp. 335-370. DOI: 10.1201/9781420051438.ch12

[128] Chen Q, Baldocchi D, Gong P, Kelly M. Isolating individual trees in a savanna woodland using small footprint lidar data. Photogrammetric Engineering and Remote Sensing. 2006;72:923-932. DOI: 0099-1112/06/7208-0923/\$3.00/0

[129] Hyyppa J, Kelle O, Lehikoinen M, Inkinen M. A segmentation-based method to retrieve stem volume estimates from 3-D tree height models produced by laser scanners. IEEE Transactions on Geoscience and Remote Sensing. 2001;39:969-975. DOI: $10.1109 / 36.921414$

[130] McRoberts R, Næsset E, Gobakken T, Martin O. Indirect and direct estimation of forest biomass change using forest inventory and airborne laser scanning data. Remote Sensing of Environment. 2015;164:36-42. DOI: 10.1016/j.rse.2015.02.018

[131] Gleason C, Jungho Im. Forest biomass estimation from airborne LiDAR data using machine learning approaches. Remote Sensing of Environment. 2012;125:80-91. DOI: 10.1016/j.rse.2012.07.006

[132] García-Gutiérrez J, Martínez-Álvarez F, Troncoso A, Riquelme J. A comparison of machine learning regression techniques for LiDAR-derived estimation of forest variables. Neurocomputing. 2015;167:24-31. DOI: 10.1016/j.neucom.2014.09.091

[133] Clark M, Roberts D, Ewel J, Clark D. Estimation of tropical rain forest aboveground biomass with small-foorprint lidar and hyperspectral sensors. Remote Sensing of Environment. 2011;115:2931-2942. DOI: 10.1016/j.rse.2010.08.029

[134] Rzedowski J. Vegetación de México. Mexico: Limusa; 1978. 432 p. 
[135] Houghton R. Aboveground forest biomass and the global carbon balance. Global Change Biology. 2005;11:945-958. DOI: 10.1111/j.1365-2486.2005.00955.x

[136] Acosta-Mireles M, Vargas-Hernández J, Velásquez-Martínez A, Etchevers-Barra JD. Estimación de la biomasa aérea mediante el uso de relaciones alométricas en seis especies arbóreas en Oaxaca, México. Agrociencia. 2002;36:725-736.

[137] Jiménez M. Ecuaciones alométricas para determinar biomasa y carbono para Pinus hartwegii en el Parque Nacional Izta- Popo [thesis]. Texcoco: Universidad Autónoma Chapingo; 2009.

[138] Avendaño-Hernández DM, Acosta-Mireles M, Carrillo-Anzures F, Etchevers-Barra JD. Estimación de biomasa y carbono en un bosque de Abies religiosa. Fitotecnia Mexicana. 2009;32:233-238.

[139] Šmelko Š, Merganič J. Some methodological aspects of the National Forest Inventory and Monitoring in Slovakia. Journal of Forest Science. 2008;54:476-483.

[140] Asner GP, Heidebrecht KB. Spectral unmixing of vegetation, soil and dry carbon cover in arid regions: comparing multispectral and hyperspectral observations. International Journal of Remote Sensing. 2002;23:3939-3958. DOI: $10.1080 / 01431160110115960$

[141] Anselin L, Rey S, editors. Perspectives on Spatial Data Analysis. New York: Springer; 2010. 290 p. DOI: 10.1007/978-3-642-01976-0

[142] Hengl T, Heuvelink GBM, Stein A, 2003. Comparison of kriging with external drift and regression-kriging. Technical note, ITC, WEB. 3 august 2015. Available online at https://www.itc.nl/library/Papers_2003/misca/hengl_comparison.pdf

[143] Goovaerts P. Geostatistical approaches for incorporating elevation into the spatial interpolation of rainfall. Journal of Hydrology. 2000;228:113-129. DOI: 10.1016/ S0022-1694(00)00144-X

[144] GDF. Atlas geográfico del suelo de conservación del Distrito Federal. Ciudad de México: Gobierno del Distrito Federal, Secretaría del Medio Ambiente, Procuraduría Ambiental y del Ordenamiento Territorial del Distrito Federal; 2012. 96 p.

[145] Celemín JP. Autocorrelación espacial e indicadores locales de asociación espacial: Importancia, estructura y aplicación. Revista Universitaria de Geografía. 2009;18:11-31. 
Chapter 2

\title{
Detection of Tree Crowns in Very High Spatial Resolution Images
}

\author{
Marilia Ferreira Gomes and Philippe Maillard \\ Additional information is available at the end of the chapter \\ http://dx.doi.org/10.5772/62122
}

\begin{abstract}
The requirements for advanced knowledge on forest resources have led researchers to develop efficient methods to provide detailed information about trees. Since 1999, orbital remote sensing has been providing very high resolution (VHR) image data. The new generation of satellite allows individual tree crowns to be visually identifiable. The increase in spatial resolution has also had a profound effect in image processing techniques and has motivated the development of new object-based procedures to extract information. Tree crown detection has become a major area of research in image analysis considering the complex nature of trees in an uncontrolled environment. This chapter is subdivided into two parts. Part I offers an overview of the state of the art in computer detection of individual tree crowns in VHR images. Part II presents a new hybrid approach developed by the authors that integrates geometrical-optical modeling (GOM), marked point processes (MPP), and template matching (TM) to individually detect tree crowns in VHR images. The method is presented for two different applications: isolated tree detection in an urban environment and automatic tree counting in orchards with an average performance rate of $82 \%$ for tree detection and above $90 \%$ for tree counting in orchards.
\end{abstract}

Keywords: Tree crown detection, VHR image, Template matching, Marked point process, Valley-following, Watershed segmentation, Local maxima, Region growing

\section{Introduction}

Inventories on forest communities are performed with the objective of providing support to the management and conservation activities in rural or urban forests or even in tree plantations. The traditional method of obtaining information on forest communities is to use systematic or random sampling or by sampling stands, so that the final parameters for the population are obtained on the basis of statistical extrapolation [1,2]. Usually, the following parameters are 
determined for each tree included in the sampling: location, diameter at breast height (DBH), basal area (BA), height, identification of the species, crown size, and crown closure. Based on these measurements, other parameters such as volume of wood and biomass can be derived for the community stand. This renders the field survey techniques for forest inventories expensive, time consuming, and unsuited for large areas.

Remote sensing with high spatial resolution is a cost-effective and reliable way to obtain information about trees. It may be the only practical manner to assure sustainable management of forests with the necessary information, such as biochemical and biophysical data on the vegetation in a synoptic and repetitive manner for large areas and over long periods of time [3]. The tree crown is the basis of the data required for the inventory, for it allows to determine not only its size but also its position, crown closure, and, in some cases, the species. It also allows the derivation of parameters such as the density of the population, the health condition of the trees, the volume, the biomass, and the carbon sequestration rates [3-6]. This information is crucial to a series of applications such as the inventory and management of forested areas as well as in parks and urban forests. It can also be used for counting and monitoring trees in orchards or under power lines to prevent damage and accidents.

The study of individual trees with remote sensing started with the use of aerial photography with very high spatial resolution (scale greater than 1:10.000), driven mainly by the use of stereoscopy techniques. The task was performed by photointerpreters trained to recognize individual tree species, extract a series of measurements, or evaluate different types of damage [2]. The use of orbital optical remote sensing data for forest studies began in the 1970s, with the development of techniques to separate forested from non-forested areas [7]. The spatial resolution of these satellite images was the main limiting factor for more detailed studies about the forests, and as a result, the studies remained focused on the disturbances affecting forests (such as land clearing, burning, diseases, and pest) or to estimate some biophysical parameters of the vegetation [3,8]. It was only toward the end of the 1990s that orbital remote sensing began to provide very high resolution (VHR) data with a spatial resolution under $1 \mathrm{~m}$, allowing the study of individual trees. Launched in 1999, Ikonos was the first of what is now a series of VHR satellites (Table 1), consolidating the use of orbital data for the study of individual trees. However, the increase in spatial resolution was not always accompanied by an increase in spectral resolution for VHR data which is often restricted to a single panchromatic band.

The increase in spatial resolution changed the focus of many remote sensing studies, which started to analyze not only classes of objects but also each object individually [9]. Branches and irregularities within the crowns became visible, and as a result, the spectral response of a tree is influenced by variations in the shape of the crown (differential illumination) and background effects. This causes an increase in the intra-class variance and often results in a reduced accuracy when using conventional pixel-based classification [10]. This had a significant effect on the image processing techniques for forest studies and generated the development of new forms of information extraction.

Within the study of individual objects, the automatic detection and delineation of tree crowns using remote sensing VHR imagery have attracted much attention from researchers in forestry and computer vision [4,7]. Researchers have developed several automatic and semiautomatic methods for extracting individual trees and their characteristics using digital aerial photos of 
various types and VHR satellite images [11]. The applications range from the identification of tree crowns to their delineation and classification and are often based on image segmentation algorithms and other advanced image processing and analysis techniques [9,12]. Most of these algorithms were specifically developed for the detection and delineation of trees in temperate forests based on the assumption that the trees are cone shaped and round (mostly coniferous) in the images, with the apex of the tree having the highest reflectance of the crown area [4].

\begin{tabular}{lcccc}
\hline \multicolumn{1}{c}{ Satellite } & $\begin{array}{c}\text { Launch } \\
\text { Year }\end{array}$ & Px resolution $(\mathbf{m})$ & Mx resolution ${ }^{(\mathbf{m})}$ & Multispectral bands \\
\hline Ikonos II & 1999 & 0.82 & 3.2 & Blue, Green, Red, Near IR (4) \\
\hline QuickBird & 2001 & 0.65 & 2.62 & Blue, Green, Red, Near IR (4) \\
\hline WorldView-1 & 2007 & 0.46 & - & Blue, Green, Red, Near IR (4) \\
\hline Geoeye-1 & 2008 & 0.46 & 1.84 & Coastal, Blue, Green, Yellow, Red, Red \\
\hline WorldView-2 & 2009 & 0.46 & 1.85 & Edge, Near IR, Near IR2 (8) \\
\hline Pleiades 1A & 2011 & 0.5 & 2.0 & Blue, Green, Red, Near IR (4) \\
\hline Pleiades 1B & 2012 & 0.5 & 2.0 & Blue, Green, Red, Near IR (4) \\
\hline Kompsat-3 & 2012 & 0.7 & 2.8 & Blue, Green, Red, Near IR (4) \\
\hline SkySat-1 & 2013 & 0.9 & 2.0 & Blue, Green, Red, Near IR (4) \\
\hline WorldView-3 & 2014 & 0.31 & 1.24 & Coastal, Blue, Green, Yellow, Red, Red \\
\hline SkySat-2 & 2014 & 0.9 & 2.0 & Edge, Near IR, Near IR2 (8) \\
\hline Kompsat-3A & 2015 & 0.55 & Blue, Green, Red, Near IR (4) \\
\hline WorldView-4 & 2016 & 0.34 & Blue, Green, Red, Near IR (4) \\
\hline
\end{tabular}

${ }^{*}$ Panchromatic (Px) and Multispectral (Mx) resolution at nadir.

Table 1. Very High Resolution satellites (1999-2006), with their spatial resolutions and spectral bands. Note that there is not any available satellite with VHR in multispectral bands.

The analysis of individual trees based on remote sensing images is a complex problem. Images of trees with varied crown size increase the difficulty of the analysis. What is detected as a single object may in fact represent a separate branch or even a group of trees [10]. Other sources of error are caused by the proximity between neighboring trees, trees located under other trees, trees in the shade, or trees that have a low spectral contrast with the background [13]. Consequently, high-level complex algorithms are necessary to exploit this contextual information [1].

This chapter provides an overview of the state of the art in individual tree crown detection based on optical VHR remote sensing data. An original method developed by the authors is also presented as an alternative approach to the problem of tree crown detection. In Part I, we present the main algorithms developed for the detection of individual trees, be it for tree 
identification or delineation. The principle of each approach is presented as well as its potential and limitations. Part II is dedicated to outlining the original MPP-TM approach, a hybrid method that combined two methods used in pattern recognition: marked point process and template matching. The results are shown for tree detection and delineation in an urban environment and for tree counting in orchards.

\section{Part I - Review of tree crown detection methods}

We present six of the main algorithms used in individual tree detection in high spatial resolution images. The algorithms are summarily described individually, but it should be noted that many approaches use hybrid methods for the detection and delineation of tree crowns. For instance, some authors might use one algorithm for detecting the trees and another to delineate them; some may even use one approach as a first approximation and another to fine-tune the results.

\subsection{Local maxima filtering}

Local maxima (LM) filtering is a technique used for identifying tree crowns in high spatial resolution imagery which is based on the recognition of the points with the greatest brightness within a search window that scans the entire image $[4,14]$. The search window, with a fixed size, defines which pixel has the greatest reflectance compared to all the other pixels inside the window. The pixels with the highest digital number are identified as possible tree locations. This method is adequate for trees which have the greatest reflectance at their top, surrounded by lower intensity pixels, and due to its concept, it is widely used for detecting conifers.

When the kernel window passes over the image, it does not take into account the presence of trees with different crown sizes, and the success of the LM tree recognition depends on the careful selection of the size of the search window. If it is too small, errors of commission occur by selecting nonexistent trees or multiple radiance peaks for an individual tree crown; if it is too big, the algorithm is likely to miss some trees (omission errors) [13].

The identification of trees by LM is affected by false bright pixels, which are not part of the brightest part of the crown. An effective method for dealing with the problem is to apply a Gaussian filter to the image. This allows the low-pass filter function to grant more weight to the crown center pixels (surrounded by much lower values) compared to those located toward the crown edge which might belong to other bright objects or noise. Applying a Gaussian filter directly affects the number of local maxima identified and causes the smoothing off of the brightness values on the tree crown edges [15].

In order to minimize the problem of the window size with LM, reference [13] used windows of varying sizes based on the assessment of the spatial structure of the image obtained by analyzing the local semi-variogram with different pixel lags and different window sizes. This results in a personalized window for each pixel, leading to greater accuracy when compared to using a single fixed window size. Reference [16] used LM to identify the centroid of 
eucalyptus trees in Australia. The search for the trees is carried out based on the maxima in four linear kernels pertaining to the four main directions $\left(0^{\circ}, 45^{\circ}, 90^{\circ}\right.$, and $\left.135^{\circ}\right)$ of the image and by summing the individual maxima found in each pass (Figure 1).

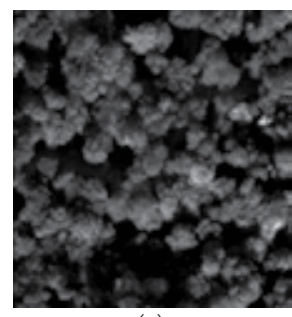

(a)

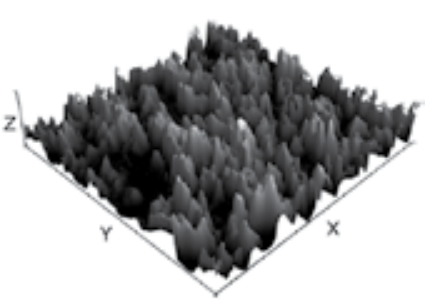

(b)

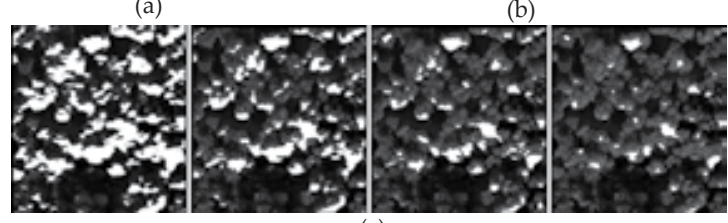

(c)

Figure 1. Examples of the surface produced by applying a LM kernel operator: (a) original image, (b) the local maxima appearing in the third dimension are associated with the presence of trees, (c) application of local maxima filter in four linear cumulative kernels $\left(0^{\circ}, 45^{\circ}, 90^{\circ}\right.$, and $\left.135^{\circ}\right)$.

\subsection{Template matching}

Template matching (TM) is a technique used for object recognition widely cited in the specialized literature which uses quantitative descriptors, such as length, area, and texture to describe recurring patterns in an image $[17,18]$. Based on a synthetic model or a sample extracted from the image, the correlation coefficient between the model and the image is calculated in order to determine the strength of the match between the two matrices. The object is assumed to be located where the measurement of the match reaches a maximum [4].

For tree crown detection, the study of reference [19] was the first to propose an elliptical 3D model for tree crowns based on an ellipsoid of generalized revolution (Equation 1).

$$
\frac{z^{n}}{a^{n}}=\frac{\left(x^{2}+y^{2}\right)^{n / 2}}{b^{n}}=1
$$

where $z$ is the vertical axis of the center of the tree crown in its origin, $a$ is half the height of the ellipsoid, $b$ is half the radius, and $n$ is the parameter of the shape of the tree crown. Subsequently, the model is illuminated using the acquisition parameters of the image (sun elevation and azimuth) and the characteristics of crown absorption and reflection of light in the chosen spectral band. 
Because it is based on a physical model (rather than a complex mathematical concept), TM is considered a user-friendly method. Its limitation is mainly due to the need to use a library of models if many types of trees are present in the image, which may involve a complex phase for generating the models. Figure 2 shows examples of synthetic tree models and an application in a orchard.

References [20 and 21] used this technique to identify tree crowns in aerial images. Other researchers used this technique to recognize individual tree crowns, using templates made from small sub-images of the actual scene to identify the trees [22, 23]. Reference [24] proposed an improved version by generating separate models for trees and their shade in VHR images of unmanned aerial vehicles (UAV). The authors explored the relation between the tree and shade models separately and then joined them to generate a more powerful object detector.

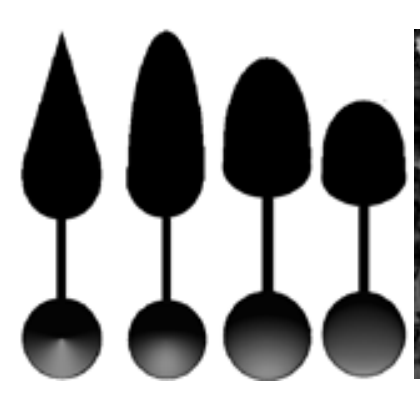

(a)

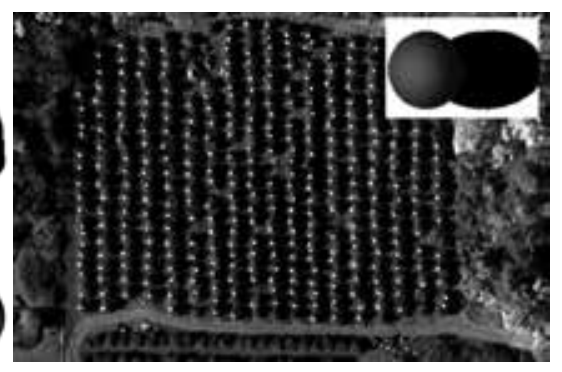

(b)

Figure 2. Left: examples of synthetic tree models to different tree crown shape. Right: identification of trees in an apple orchard showing the model used at the upper right corner.

\subsection{Valley-following}

Valley-following (VF) is a crown delineation method which identifies the shaded areas between the trees. This methodology was initially described in reference [25] and makes an analogy with topographic data, where the shades of gray of the pixels represent local lows in the third dimension. In this analogy, the bright tree crowns would be the hills and the darker zones around the trees the valleys (Figure 3). This darker zone is the one which typically helps human interpreters to separate one tree crown from the other. In this approach the shaded areas are eliminated, making it possible to separate the trees in the image. This was not sufficient to separate all of the trees, so the authors developed an approach based on a series of rules (e.g., no discontinuity, checking directions, context, gap filling, etc.) to accurately describe the boundaries of each tree, one at a time [26].

This approach performed well in images with a combination of low solar elevation angle and conical trees. Conversely, the approach failed to produce good results when the canopy was composed of trees of very different sizes, or when the tree crowns were very large and have internal shadows. The latter case resulted in subdividing the individual tree into two or more parts. Smaller trees, in contrast, tended to be grouped together. Reference [27] found that this 


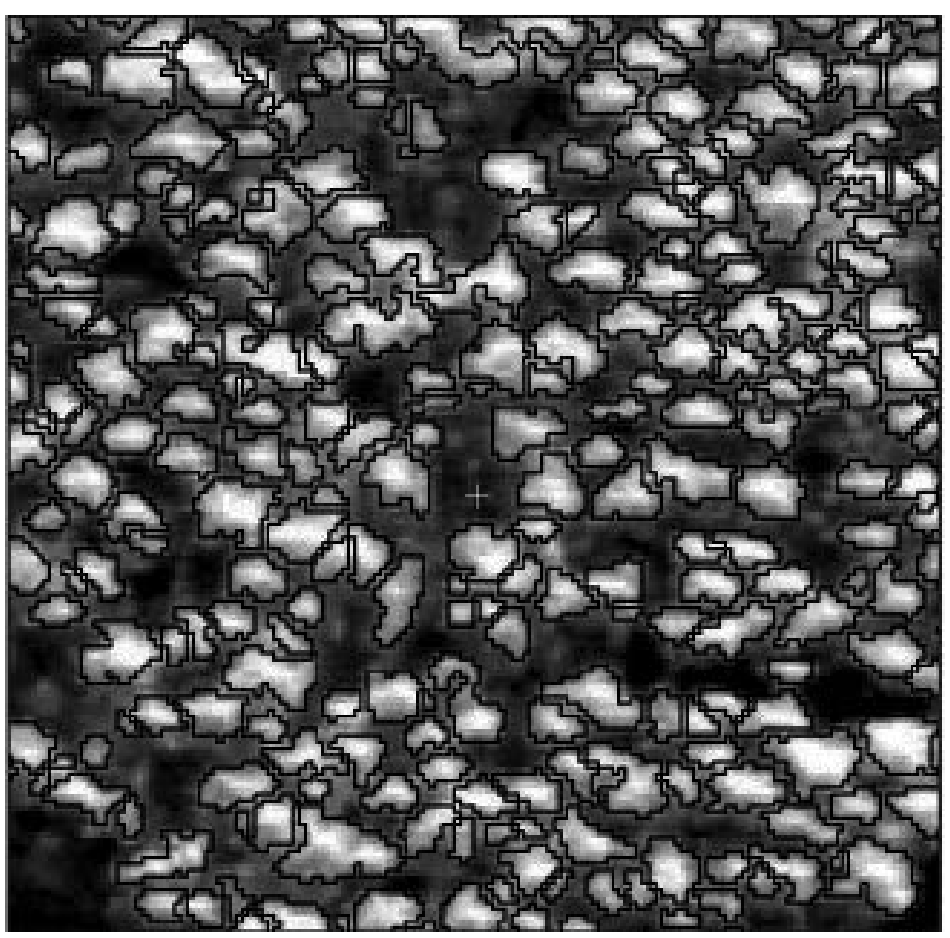

Figure 3. Results of the valley-following applied on a forest image in Canada (source: Gougeon and Leckie, 2003; reproduced with permission from Natural Resources Canada).

approach causes many false positives (FPs) in open areas (clearings). As a solution, they suggested the exclusion of these areas by retaining only the high-value pixels in the normalized difference vegetation index (NDVI).

\subsection{Watershed}

Like VF, the watershed segmentation (WS) is a technique related to thresholding that uses the gray levels in the images as if it were a topographic surface [28]. It is used not only for the delineation of individual tree crowns but also for generic segmentation of images. The watershed concept is based on a 3D image representation, with the third dimension being provided by the intensity of gray. The main objective of the watershed algorithm is to find the "drainage" divide lines. The "relief" in the image is inverted (high gray values become valleys) and progressively filled with a virtual liquid, and when the liquid is almost overflowing from one basin to another, a virtual dam is built, to create the watershed. These lines are considered the limits of each segment. The simplest approach to the construction of the dam is the use of morphological dilation of the minima, without merging the regions [17].

The images are usually preprocessed before the WS is applied. In fact, this segmentation is frequently applied to the gradient of an image, and not to the image itself. This is due to the relative homogeneity of the gray values of objects that do not provide sufficient contrast for 
an effective segmentation. In this formulation, the regional minimum value of the catchment basins usually correlates well with the lower gradient values that match the contours of the objects of interest $[17,28]$. The direct application of the WS algorithm generally leads to oversegmentation due to noise or other local irregularities of the gradient (Figure 4a). One of the approaches used to limit the number of regions is to use markers. The selection of markers can be based on simple procedures, intensity and connectivity between pixels, or even complex descriptors, such as size, format, location, relative distances, texture, and others. The use of markers provides prior knowledge to support the segmentation process [17].

The approaches that use WS for the delineation of the tree crowns normally use markers representing the center of the tree crown, to assist the segmentation process. For instance, reference [29] used WS to detect and delineate tree crowns in a VHR forest image in Canada but divided the approach into two phases, namely using LM to detect the crown and applying WS for the delineation. The LM image with the detected crowns was produced by using a Laplacian of Gaussian edge detection operator. The tree crowns were modeled based on their geometry and radiometry, resulting in an image of markers. This image then served to guide the WS in delineating the crowns. Reference [30] developed a bitemporal procedure for the automatic segmentation and reconciliation of groups of pixels (called blobs) within the forest using WS. By using two dates, they were able to increase the probability of properly defining the tree contours. Many problems were encountered in the segmentation process of the individual trees. For instance, trees with spread branches were sometimes split into two or more segments or contrarily by including several crowns in the same segment when trees were not sufficiently separated.

\subsection{Region growing}

Region growing $(R G)$ is another segmentation technique that groups pixels or groups of pixels based on predefined growth criteria in an attempt to separate and recognize objects in the image [4]. Like WS, RG is used as a generic segmentation method and can be adapted for the delineation of individual tree crowns (Figure 4b). Starting with some seed pixels (which can be random if no other information is provided), the neighboring pixels are examined one by one and added to the growth region if their predefined properties are similar to those of the seeds (such as specific intervals of intensity or color) [17]. When no more pixels can be added or some predefined limit is reached (e.g., number of pixels), these pixels are labeled as belonging to the specific region of the seed pixel. Additional criteria can increase the power of an RG algorithm by introducing a higher concept like size and similarity between candidate pixels and the pixels selected or even the format of the region $[17,31]$.

Reference [16] used RG integrated with LM to identify and delineate tree crowns in Australia. The LM method served to find the center of potential trees, which were then used as seeds for the RG. Reference [6] tested two different types of segmentation by RG, one by Brownian motion and the other by random walk, to detect conifers in a boreal forest. The methods were capable of detecting about $80 \%$ of the illuminated portion of the crowns, with a better performance found in larger crowns (Figure 5). 


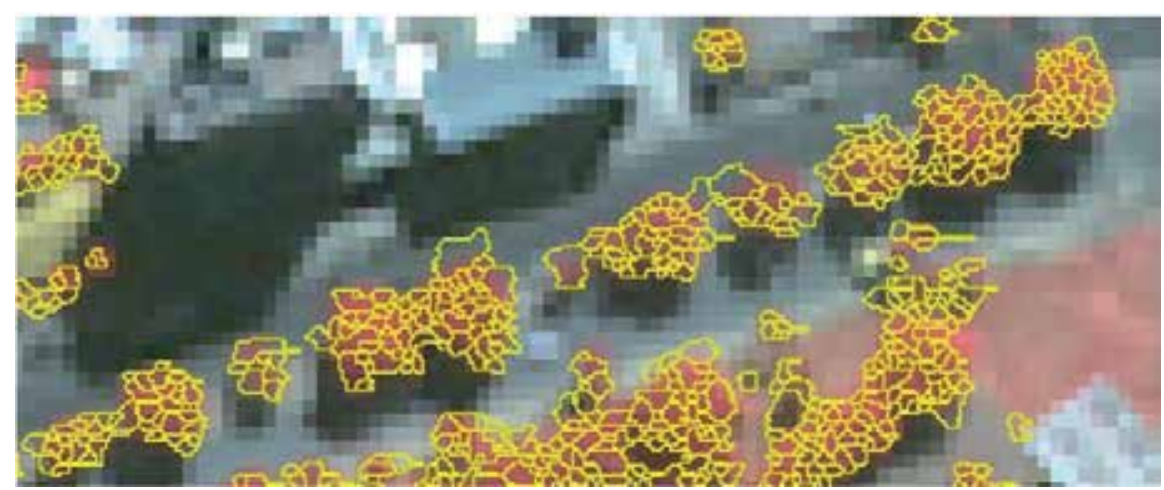

(a)

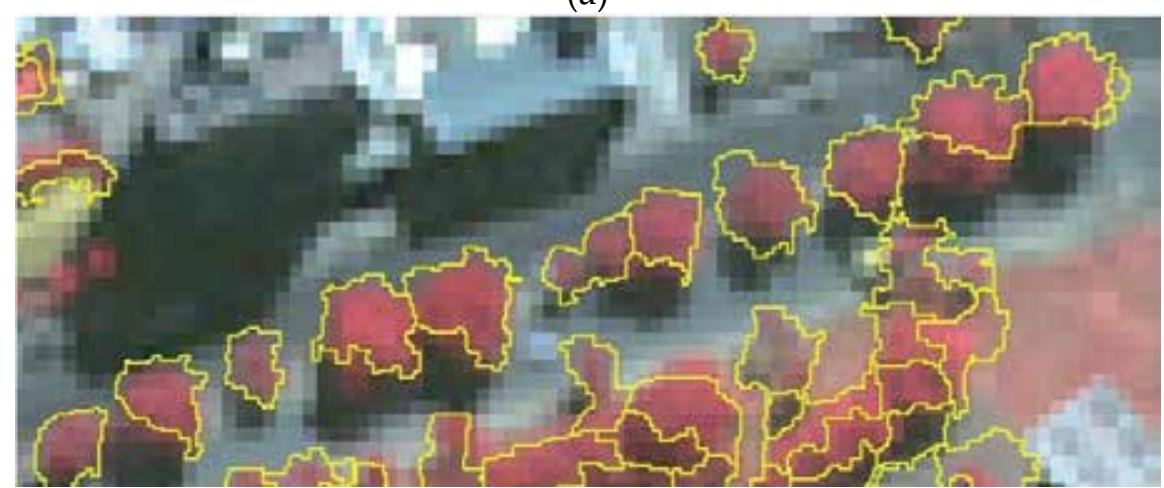

(b)

Figure 4. Comparison between two segmentation algorithms: (a) watershed and (b) region growing on a WorldView-2 image (panchromatic band with a $50 \mathrm{~cm}$ resolution). The WS was applied to the gradient image without using markers and resulted in the over-segmentation of the tree crowns. In (b), the RG segmentation was performed within an objectoriented classification (GEOBIA) approach, where the correct delineation of the tree crowns is noteworthy (source: Gomes and Maillard, 2013).

\subsection{Marked point processes}

The marked point process refers to a probabilistic method which has been used in recent years for the recognition of objects in high spatial resolution imagery [5,11,32-35]. In an MPP, sets of random points in a given space $(x, y)$ are provided with a mark which is complete and separable, allowing the definition of a topology (defined by the mark) and the attribution of a label. An image is considered a random model where the gray tones are the realization of a random point process [34]. This random configuration of gray levels in the images is then modeled based on geometric figures (ellipses, circles, rectangles, and lines), respecting certain geometric (nature of the objects) and radiometric constraints (type of image).

The laws of density and probability distinguish various types of point processes, which can be Poisson, Strauss, Markov, or Gibbs, among others. The Markov or Gibbs point processes have been used for the recognition of tree crowns by a number of authors $[5,32,33]$. These 


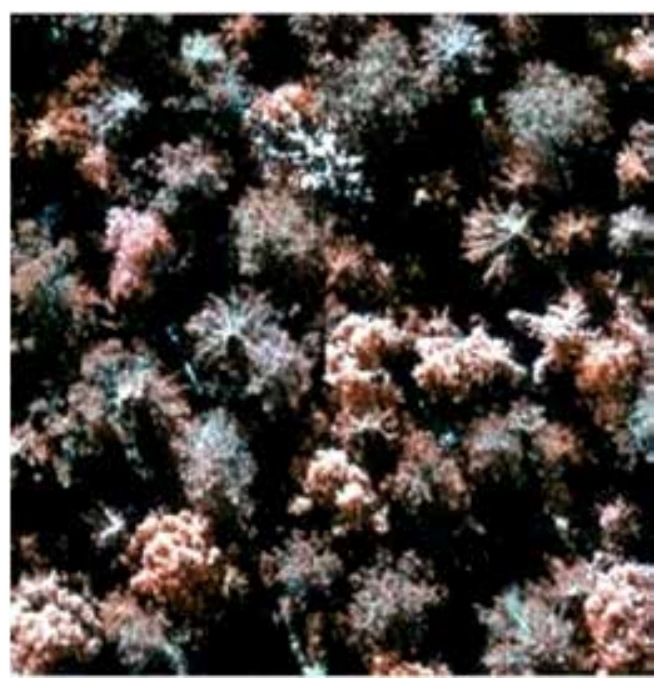

(a)

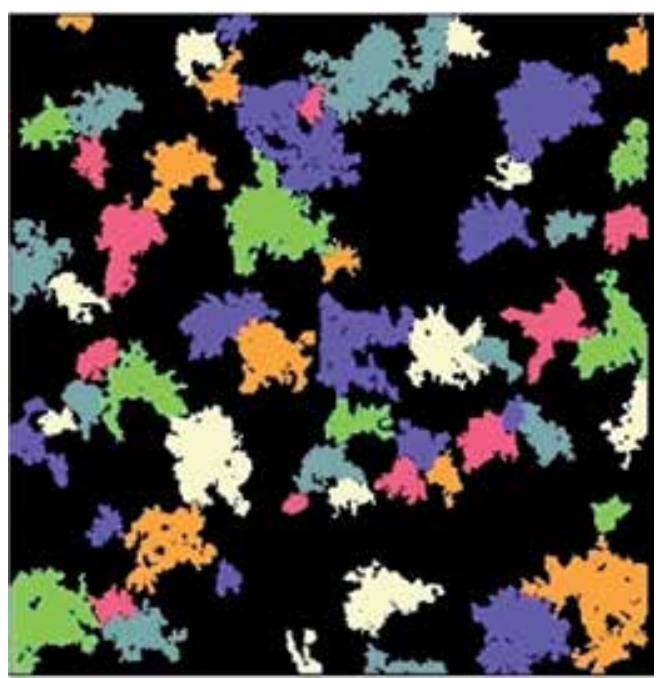

(b)

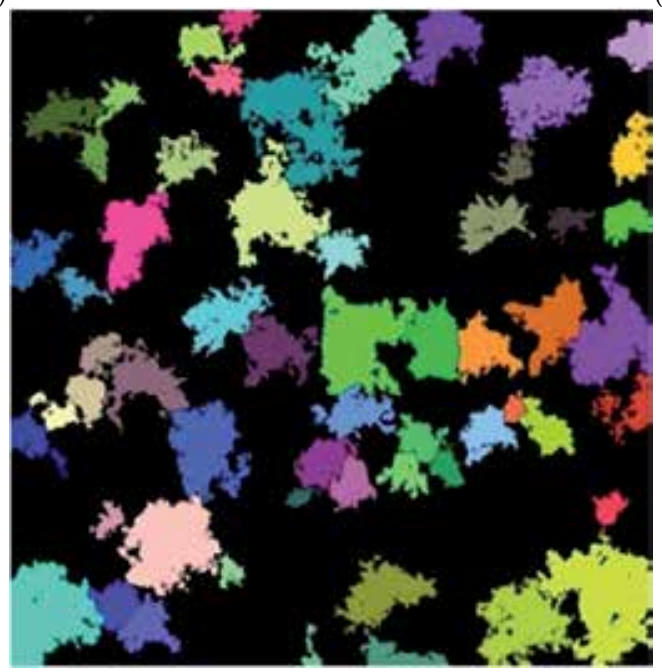

(c)

Figure 5. Example of RG segmentation to delineate tree crowns in a boreal forest. (a) The original image (with a spatial resolution of $3 \mathrm{~cm}$ ), (b) with the results using Brownian motion, (c) and random walk (Source: Erikson, 2004).

processes are defined by a density function using a form of energy expressed as a sum of the a priori energy and the local energy. The process seeks to minimize the global energy of the model, by iterating it with some optimization scheme (Markov random fields, algorithm of multiple births and deaths, and Monte Carlo-Monte Carlo simulations).

Reference [5] proposed two different models to serve as marks in an MPP, one in 2D for detection of trees in densely forested zones (Figure 6) and the other in 3D for scattered or isolated zones, based on aerial photos of high spatial resolution in the infrared band. The MPP was integrated with a reversible jump Markov Chain Monte Carlo in a simulated annealing 


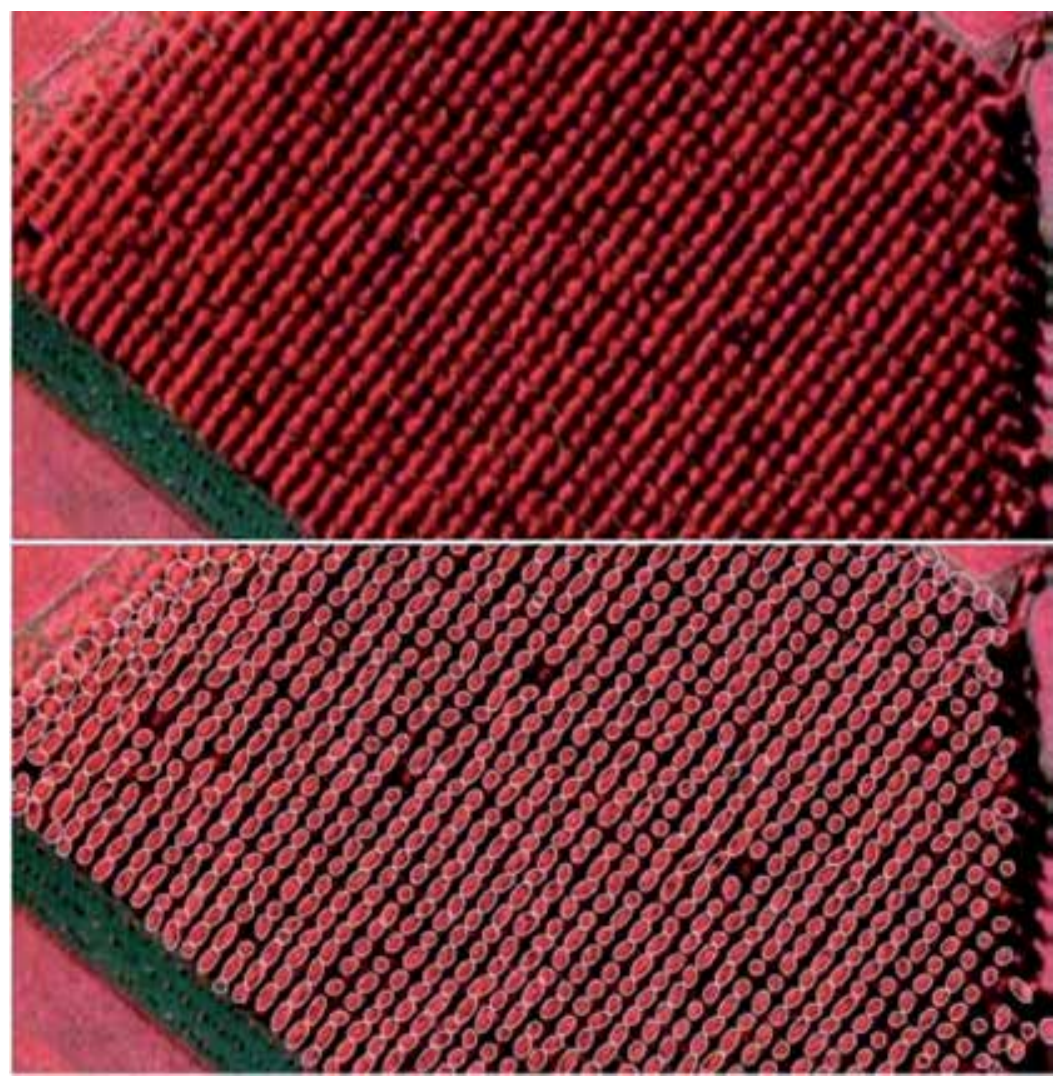

Figure 6. Example of the application of MPP for tree crown recognition on a poplar plantation. The original image is shown at the top and the results at the bottom (Source: Perrin, 2006).

method. Reference [32] used an MPP to automatically detect the tree crowns in high spatial resolution images, based on the modeling of the crowns as 2D circles on high-resolution spatial images. The method was successfully tested on mangrove forests and eucalyptus plantations.

\subsection{Discussion}

In the previous section, we have presented some of the most common algorithms used in the detection of individual trees, be it for their identification, delineation, or both. Table 2 presents a summary of these principles through their main characteristics and limitations.

Trees may differ in shape, size, spectral properties, height, foliage type, and density, and their spatial context varies with illumination, ground type, and inclination. They can also be surrounded by many other objects, especially in an urban setting. As such, the task is not trivial and can become highly complex depending on the number of parameters involved. Conversely, in planted forest and orchards where trees have the same age and species, tree crown extraction can take advantage of their relative uniformity. 


\begin{tabular}{|c|c|c|c|c|}
\hline Algorithm & Usage & Principle & Researches & Characteristics / Limitations \\
\hline $\begin{array}{l}\text { Local } \\
\text { Maxima } \\
\text { (LM) }\end{array}$ & $\begin{array}{l}\text { Identification of } \\
\text { tree crown }\end{array}$ & $\begin{array}{l}\text { Identification of } \\
\text { brightest points } \\
\text { locally as corresponding } \\
\text { to the apex of a } \\
\text { treetop within a } \\
\text { search window. }\end{array}$ & $\begin{array}{l}\text { Wulder et al. } \\
(2000) \\
\text { Culvenor (2002) } \\
\text { Pouliot (2002), } \\
\text { Wang et al. (2004) }\end{array}$ & $\begin{array}{l}\text { Appropriate for conifers, with a conical } \\
\text { shape and high reflectance point at the } \\
\text { top of the tree. } \\
\text { Simple method to use. } \\
\text { Results are affected by the spatial } \\
\text { distribution of trees, variation of tree } \\
\text { crowns size, search window size } \\
\text { (increased omission errors in larger } \\
\text { windows and commission errors in } \\
\text { smaller windows). }\end{array}$ \\
\hline $\begin{array}{l}\text { Template } \\
\text { Matching } \\
\text { (TM) }\end{array}$ & $\begin{array}{l}\text { Pattern } \\
\text { recognition }\end{array}$ & $\begin{array}{l}\text { Quantitative descriptors } \\
\text { used to describe patterns. } \\
\text { Calculate the correlation } \\
\text { between the image and } \\
\text { the model. Model may be } \\
\text { a sample extracted from } \\
\text { the image or not. }\end{array}$ & $\begin{array}{l}\text { Pollock (1996) } \\
\text { Larsen (1997) } \\
\text { Larsen and } \\
\text { Rudemo (1998) } \\
\text { Quackenbush et } \\
\text { al. (2000) } \\
\text { Erikson (2004) } \\
\text { Hung et al. (2012) }\end{array}$ & $\begin{array}{l}\text { Enables analysis of the tree crown from } \\
\text { its spectral, textural and structural } \\
\text { characteristics. } \\
\text { Allows neighborhood analysis of the } \\
\text { tree crown by considering its shadow. } \\
\text { User-friendly method. } \\
\text { Needs a template library, making it } \\
\text { unpractical in complex forests. } \\
\text { Recognition errors increase with } \\
\text { irregularity of the tree crowns. } \\
\text { Easier to detect larger trees than smaller } \\
\text { ones. } \\
\text { Performance reduced in very dense } \\
\text { environments. }\end{array}$ \\
\hline (VF) & $\begin{array}{l}\text { Delineation of } \\
\text { tree crown }\end{array}$ & $\begin{array}{l}\text { Derives from an analogy } \\
\text { with a topographical } \\
\text { surface, programmed to } \\
\text { identify the shaded } \\
\text { portion between the tree } \\
\text { crowns (valleys). }\end{array}$ & $\begin{array}{l}\text { Gougeon (1995, } \\
\text { 1999) } \\
\text { Leckie and } \\
\text { Gougeon (1998) } \\
\text { Gougeon and } \\
\text { Leckie (2003) } \\
\text { Erickson (2004) } \\
\text { Gougeon and } \\
\text { Leckie (2006) }\end{array}$ & $\begin{array}{l}\text { Appropriate for trees with conical shape } \\
\text { that create shadow areas between } \\
\text { individuals. } \\
\text { Most successful to delineate populations } \\
\text { of the same age without intertwined tree } \\
\text { crowns. } \\
\text { Best performance for images in mid-low } \\
\text { solar elevation angle. } \\
\text { Performance reduced when trees are } \\
\text { asymmetrical, of from different species, } \\
\text { with different tree crown sizes or when } \\
\text { shadows of trees protrude over each } \\
\text { other. } \\
\text { Tendency to group smaller trees } \\
\text { together and split larger trees into } \\
\text { multiple segments. }\end{array}$ \\
\hline
\end{tabular}




\begin{tabular}{|c|c|c|c|c|}
\hline Algorithm & Usage & Principle & Researches & Characteristics / Limitations \\
\hline $\begin{array}{l}\text { Watershed } \\
\text { (WS) }\end{array}$ & $\begin{array}{l}\text { Delineation of } \\
\text { tree crown }\end{array}$ & $\begin{array}{l}\text { Performed from the } \\
\text { image gradient. Image is } \\
\text { seen as an inverted } \\
\text { topographic surface } \\
\text { flooded to determine } \\
\text { watershed divides. } \\
\text { Commonly uses markers } \\
\text { to limit the number of } \\
\text { segments. }\end{array}$ & $\begin{array}{l}\text { Wang et al. (2004) } \\
\text { Lamar et al. (2005) }\end{array}$ & $\begin{array}{l}\text { Performs best when applied after } \\
\text { selection of markers to control } \\
\text { segmentation process. More suitable for } \\
\text { conifers, which allow preselection of } \\
\text { treetops by using another approach } \\
\text { (usually LM). } \\
\text { Over-segmentation occurs when applied } \\
\text { directly to the image or without the use } \\
\text { of markers. } \\
\text { Can separate tree crowns in different } \\
\text { segments when the branches are too } \\
\text { spread, or may include several trees in } \\
\text { the same segment when there is no } \\
\text { spatial separation between them. }\end{array}$ \\
\hline $\begin{array}{l}\text { Region } \\
\text { Growing } \\
\text { (RG) }\end{array}$ & $\begin{array}{l}\text { Delineation of } \\
\text { tree crown }\end{array}$ & $\begin{array}{l}\text { Groups pixels or sub- } \\
\text { regions based on } \\
\text { predefined criteria for the } \\
\text { growth of region in order } \\
\text { to separate and recognize } \\
\text { objects in the image. }\end{array}$ & $\begin{array}{l}\text { Culvenor (2002) } \\
\text { Pouliot et al. } \\
\text { (2002) } \\
\text { Erikson (2004) } \\
\text { Bunting and } \\
\text { Lucas (2006) } \\
\text { Pu and Landry } \\
\text { (2012) }\end{array}$ & $\begin{array}{l}\text { More complex shapes of trees are better } \\
\text { delineated. } \\
\text { Method more complex as it requires } \\
\text { different rules for different } \\
\text { environments. } \\
\text { Tends to create more than one segment } \\
\text { when the tree has branches with dark } \\
\text { portions, and tends to group different } \\
\text { trees if they are very similar. }\end{array}$ \\
\hline $\begin{array}{l}\text { Marked Point } \\
\text { Processes } \\
\text { (MPP) }\end{array}$ & $\begin{array}{l}\text { Pattern } \\
\text { recognition }\end{array}$ & $\begin{array}{l}\text { Stochastic process in } \\
\text { which unordered points } \\
\text { in a space are provided } \\
\text { with marks. Marks are } \\
\text { modeled from geometric } \\
\text { and radiometric } \\
\text { characteristics of objects. }\end{array}$ & $\begin{array}{l}\text { Perrin (2006) } \\
\text { Zhou (2012) } \\
\text { Larsen et al. } \\
\text { (2012) }\end{array}$ & $\begin{array}{l}\text { Performs best with plantations of trees } \\
\text { of same species and age and in images } \\
\text { of isolated trees. } \\
\text { It is less effective to detect trees in more } \\
\text { complex environments. }\end{array}$ \\
\hline
\end{tabular}

Table 2. Summary of Local Maxima, Template Matching, Valley Following, Watershed, Region Growing and Marked Point Processes algorithms used to individual tree crown detection. The principles, main researches and main characteristics and limitations are presented.

Reference [11] compared six different algorithms (valley-following, region growing, template matching, scale-space theory, marked point processes, and Markov random fields) in six different aerial images, ranging from a homogeneous plantation and an area with isolated tree crowns to an extremely dense deciduous forest type. The authors found that none of the algorithms can by itself reach a high rate of success in all of the tested images and concluded that there is no single optimum algorithm for all types of images and forests. They also emphasized that for complex types of forests, monoscopic images are insufficient for a consistent detection of tree crowns, even for human interpreters. 


\section{Part II - A hybrid approach integrating marked point process and template matching}

As shown in our brief review, many methods have been developed for trees in temperate forest environments. In an exploratory research [23], three algorithms in urban tropical environments were tested: region growing, watershed, and template matching. Better results were generally obtained by combining region-growing segmentation and geographic object-based image analysis (GEOBIA) for classification. Although highly effective, the approach requires much parameter setting and experience and is not especially dedicated to the problem of tree crown detection.

Studies that use marked point processes have triggered our attention and made us consider that they could benefit from using marks modeled from 3D objects in a different approach than from that developed by reference [5]. We propose to use a geometrical-optical tree model in a manner resembling that of template matching that uses some form of correlation between image and model to identify candidate pixels. An MPP taking advantage of a geometrical optical 3D model and measurements of similarity to seek tree crowns could represent a significant improvement to using simpler marks. Considering such a hypothesis, we developed an algorithm for tree crown detection that combines elements from MPP, TM, and tree crown geometrical-optical modeling for the automatic detection and (simplified) delineation of trees in VHR satellite imagery. We have named our algorithm MPP-TM.

In our approach, the TM did not scan the whole image like it was initially conceived but rather uses an MPP approach to select random locations within the image. Additionally, the 3D marks receive a random diameter between a predetermined range depending on the type of environment. The geometrical-optical model includes both the sunlit and shaded areas of the crown and a portion of the projected shadow to allow a better match between model and image. Some statistical and spectral parameters were also included in the model-matching phase.

MPP-based algorithm for pattern recognition usually alternates between phases of birth and death during which the objects are created (placed) and destroyed when they do not comply with the matching rules. This is also a characteristic of MPP-TM, but we have somewhat deviated from the original concept where the destruction phase also incorporated a random process.

The following subsections are devoted to describe the construction process of the 3D geometrical-optical model and the functioning of the algorithm.

\subsection{Description of MPP-TM approach}

\subsubsection{A geometrical-optical 3D tree crown model}

The parameters that determine the radiance pattern of a tree crown are direct and indirect radiation, shape of tree, branch pattern, leaf reflectance, multiple reflectances within the canopy, etc. [36]. In creating a valid 3D geometrical-optical model, we have chosen a simplified version in which the crown is represented by a dome of varying skewness, a Lambertian 
reflectance model with ambient light, and a projected shadow on the ground (or on another tree). Equations 2 and 3 give the formulation of our model in which each pixel is treated as a singular surface.

$$
\cos \left(\theta_{i}\right)=\left\{\cos \left(\theta_{\mathrm{s}}\right) \cos \left(\theta_{\mathrm{n}}\right)+\sin \left(\theta_{\mathrm{s}}\right) \sin \left(\theta_{\mathrm{n}}\right) \cos \left(\varphi_{\mathrm{s}}-\varphi_{n}\right)\right\}
$$

where $\theta_{i}$ is the local solar incidence angle, $\theta_{\mathrm{s}}$ is the solar zenith angle, $\theta_{\mathrm{n}}$ is the slope of the object surface, $\varphi_{\mathrm{s}}$ is the solar azimuth and $\varphi_{\mathrm{n}}$ is the aspect of the object surface.

$$
\mathrm{L}=L_{M}\left(\frac{\cos \left(\theta_{s}\right)}{\cos \left(\theta_{i}\right)}\right)+\mathrm{amb}
$$

where $L_{M}$ is the maximum reflectance of the model, "amb" represents the diffuse ambient lighting. The geometrical-optical model is adjusted according to the specific illumination parameters of the image, and the size of the trees present on the scene. Figure 7 shows two examples of tree models with similar reflectance but different solar elevations.
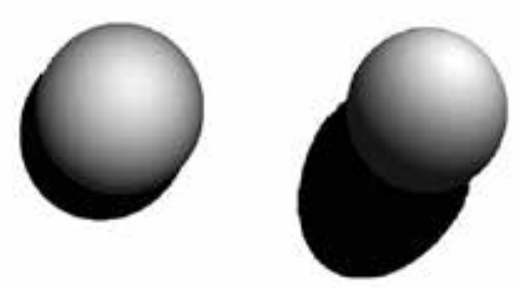

Figure 7. Illustration of the geometrical-optical model of tree crown as seen in the same sun azimuth $\left(32^{\circ}\right)$ but in two different solar elevation angles: (left) $20^{\circ}$ and (right) $45^{\circ}$

A parameter of projected shadow clipping has also been added to account for the fact that it was not beneficial to use the whole shadow in situations where it was projected onto another tree and not on the ground. The height of the tree also affects the size of the shadow so that it did not appear wise to set the height to a fixed value. To illustrate this, Figure 8 shows a comparison between the tree model and an actual tree from the image both with whole and clipped shadows.

\subsubsection{Algorithm description}

According to reference [32], using MPP to extract objects consists in searching for the "best" possible object configuration in a scene, the one that will respect a certain number of properties 


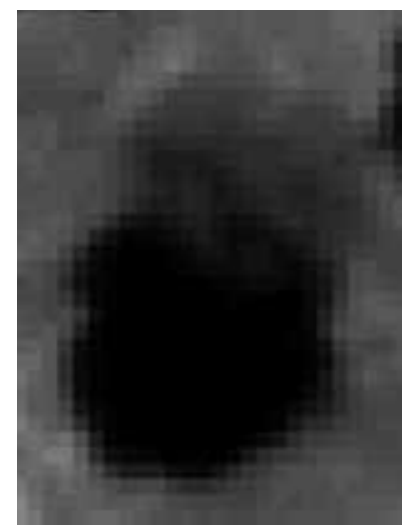

(a)

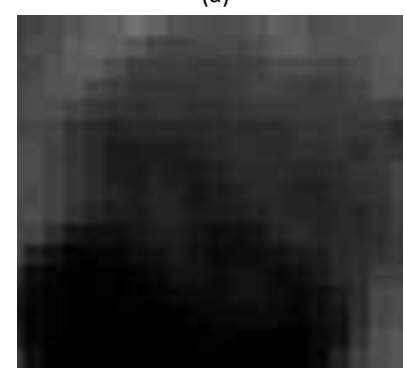

(c)

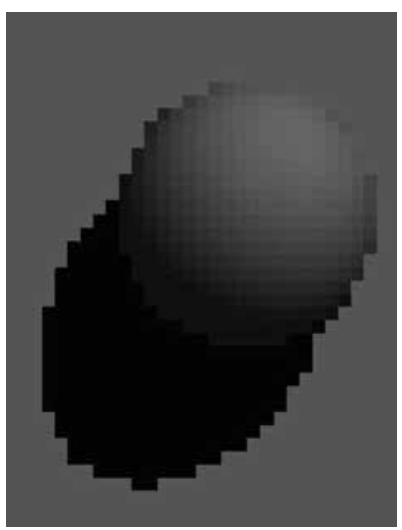

(b)

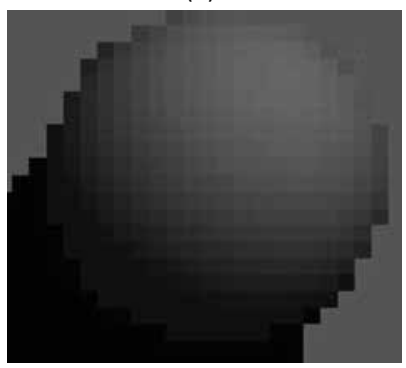

(d)

Figure 8. Comparison between an isolated tree from the (a) WorldView-2 image and (b) the geometrical-optical 3D model. A clipping factor of about $80 \%$ was applied to the same images in (c) and (d) to enable the use of only a portion of the shadow in cases where that shadow is not projected on the ground but on another object.

both of the objects being sought and the radiometric properties of the image. In our algorithm, the "best" configuration be it geometric or radiometric is given by the model.

The process consists in alternating phases of birth and death. The MPP starts with a birth phase during which tree crowns represented by circles of varying size (a randomized interval) are inserted on a matrix of equal size to the image being processed. Tree crowns are only inserted where no other crowns are present. Once all the circles have been inserted (determined by a density parameter $N_{c}$ ), a similarity $(\mathrm{Sm})$ value between the image and a version of the model fitted on each circle is computed and stored in a list along with the parameters of the model. A routine then sorts the list by decreasing values of $S m$. During the death phase, the circles that do not comply with the acceptance restrictions ( $S m$ and minimum and maximum standard deviation threshold) are successively deleted from the matrix and the list. At the end of each death phase, the overall parameters of the pixel distribution of the remaining crowns are updated. The crowns that have been found are definitively kept but are re-thrown in the bundle of crowns of the next iterations. If after an iteration 10 crowns are kept out of 100 , then the next iteration will randomly place 90 more crowns, and the new set of 100 crowns are evaluated and sorted for the next iteration. All tree crowns are considered "found" when one of the three possibilities is encountered: 1) the number of trees found is equal to the number given by the 
density parameter, 2) one of the interruption criteria has been attained, or 3) the maximum number of iteration has been reached.

The $S m$ value is computed as the subtraction of two parameters: cross-correlation and the normalized absolute difference as defined by the following relation (Equation 4 ):

$$
S m=\gamma-\alpha \mathrm{ND}
$$

where $\gamma$ is the cross-correlation between image and model, ND is the normalized sum of absolute differences between them, and $\alpha$ is a constant weight factor (normally approx. 0.5). The cross-correlation and absolute difference are calculated as follows (Equations 5 and 6).

$$
\gamma(x, y)=\frac{\sum_{i} \sum_{j}\left[w_{(i, j)}-\bar{w}\right] \sum_{i} \sum_{j}\left[f_{(i, j)}-\bar{f}\right]}{\left\{\sum_{i} \sum_{j}\left[w_{(i, j)}-\bar{w}\right]^{2} \sum_{i} \sum_{j}\left[f_{(i, j)}-\bar{f}\right]^{2}\right\}^{1 / 2}}
$$

In Equation 5, the cross-correlation is calculated between the model matrix $\left(w_{(i, j)}\right)$ and the portion of the image that corresponds to the circle of the same radius $\left(f_{(i, j)}\right)$. In other words, two matrices of same dimensions are always compared. $\bar{w}$ and $\bar{f}$ are their respective means. The values of gamma range between -1 and 1. The same logic is used in Equation 6 which computes a normalized difference value between the same two matrices.

$$
\mathrm{ND}=\frac{\sum w-\sum f}{\sum w+\sum f}
$$

In the death phase, tree crowns are kept if their similarity is larger or equal to a pre-set threshold. Because we found that such a threshold represented a weak element in our algorithm, we implemented a strategy by which it needs not be predetermined with a fixed value but rather adjusts itself as the number of iterations grows. The threshold is set very high at the beginning but then starts to decay when a certain number of iterations do not find any "new" tree crown (typically 100 iterations). Additionally, if more than a certain amount of iterations (say 1000) still does not add any new tree crown, then the process is stopped. Ultimately, it will be stopped if the maximum number of iterations is reached. A flowchart of our algorithm is presented in Figure 9 and schematically described in Table 3.

Figure 10a shows the state of the crown matrix after a single birth phase with 163 circles of random radius (between 3 and $15 \mathrm{~m}$ ) and randomly located within the image matrix. After the death phase, using a similarity threshold of 0.98 , only one tree crown was kept (Figure 10b). 


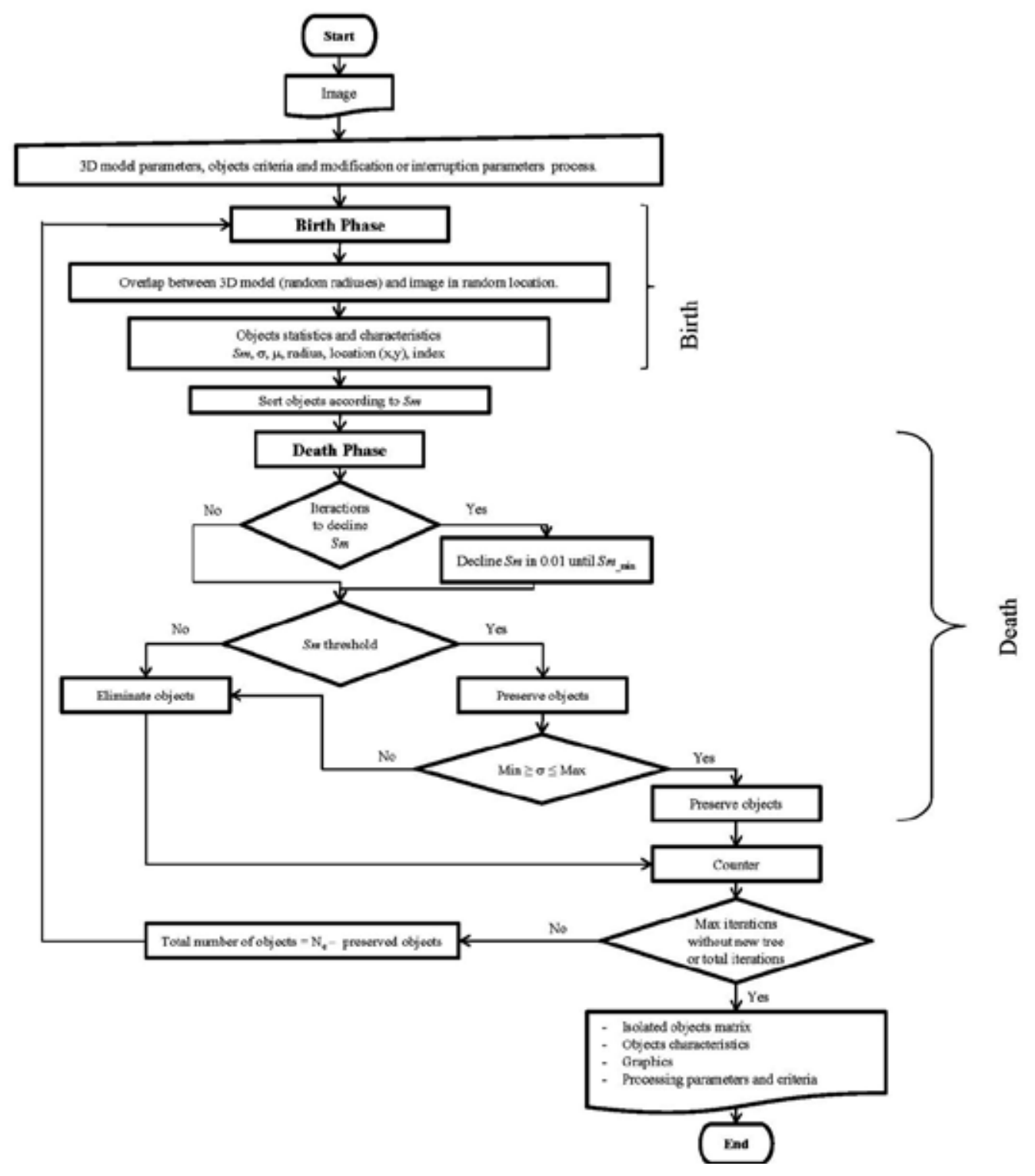

Figure 9. Flowchart of the MPP-TM algorithm.

\subsubsection{A modified approach for orchards}

Because trees in orchards are often individually distinguishable and have similar shape and size, they are perfect candidates for TM with a 3D geometrical-optical model. By using a GOM, the effects of varying illumination (sun elevation and azimuth) become an advantage rather than an obstacle especially when the background is homogeneous. In terms of data, VHR image data such as a large proportion of Google Earth images have sufficient resolution for identi- 
1. Task: Tree crown detection in Very High Resolution images.

2. Set parameters:

a. 3D model: maximum reflectance, ambient light, sun elevation, sun azimuth, tree shape, clip factor.

b. Descriptors of the objects: minimum and maximum radius, minimum and maximum standard deviation ( $\delta$ ) threshold,maximum and minimum similarity $(\mathrm{sm})$ threshold, trees density.

c. Change the process: maximum iterations for decrease similarity

d. Interruption of the process: total iterations, maximum iterations without find new trees.

\begin{tabular}{|c|c|}
\hline \multicolumn{2}{|c|}{ 3. Approach to tree crown detection: } \\
\hline \multicolumn{2}{|c|}{$\begin{array}{l}\text { a. While the number of searched trees is not achieved or some of the interruption process (total iterations } \\
\text { or minimum threshold for similarity). }\end{array}$} \\
\hline \multicolumn{2}{|l|}{ 4. Starts the birth phase: } \\
\hline \multicolumn{2}{|c|}{ a. Randomly pick a radius within model catalogue } \\
\hline \multicolumn{2}{|c|}{ b. Randomly pick $i$ and $j$ coordinates within the image space } \\
\hline \multicolumn{2}{|c|}{ c. Check if crown is already present } \\
\hline \multicolumn{2}{|l|}{ d. If not: } \\
\hline \multicolumn{2}{|r|}{ i. Fill area with circle of radius $r$} \\
\hline \multicolumn{2}{|r|}{ ii. Extract corresponding area in the image matrix } \\
\hline \multicolumn{2}{|r|}{ iii. Compare image and model matrices } \\
\hline \multicolumn{2}{|r|}{ iv. Calculate and store values: $i, j$, average, standard deviation and $S m$} \\
\hline \multicolumn{2}{|l|}{ 5. Starts the death phase: } \\
\hline \multicolumn{2}{|c|}{ a. Input parameters: birth image matrix; crown statistics ( $S m$ sorted); $S m$ threshold; tree models catalogue } \\
\hline \multicolumn{2}{|c|}{ with radius between maximum and minimum radius } \\
\hline \multicolumn{2}{|c|}{ b. While smcrown < smthreshold: } \\
\hline \multicolumn{2}{|r|}{ i. Zero crown pixels in birth image matrix } \\
\hline \multicolumn{2}{|c|}{ c. While $\delta$ crown $<\min \delta$ threshold and $\delta$ crown $>\max \delta$ threshold: } \\
\hline \multicolumn{2}{|r|}{ i. Zero crown pixels in birth image matrix } \\
\hline \multicolumn{2}{|c|}{ 6. Update object and global statistics } \\
\hline \multicolumn{2}{|c|}{ 7. Update number of crowns eliminated for next birth phase } \\
\hline 8. When the process fini & sh: reports, graphs and image with individual tree crowns \\
\hline
\end{tabular}

Table 3. Description of MPP-TM algorithm.

fying orchard trees. In this case, however, illumination parameters are not readily available and must be determined.

The objective of this modified approach is to introduce an adaptation of the algorithm described earlier to detect and count trees in orchards of different types. Because it was aimed at a more regional or even global application, Google Earth images were used in an attempt to simulate a generic operational framework. The modified approach uses a similarity measurement between the GOM and the image to calculate the probability of being the center of tree and then places trees in nonoverlapping positions (unless some overlapping is allowed). The algorithm also incorporates a module to determine the illumination parameters from a sample. 

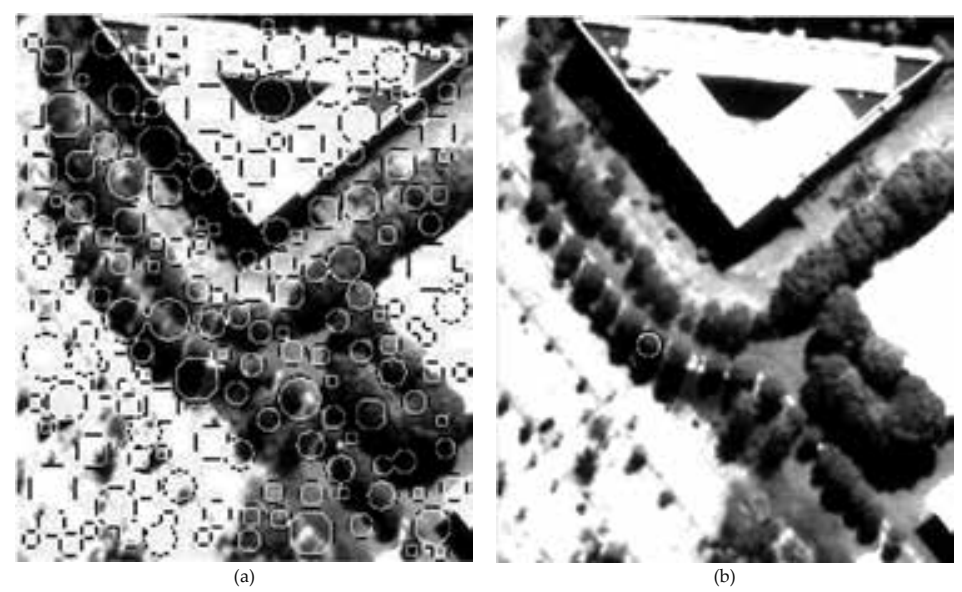

Figure 10. Illustration of the (a) birth and (b) death phases of the MPP-TM algorithm. In this example, of the 163 randomly positioned crowns, only one had a similarity value larger than the threshold of 0.98 .

The algorithm is based on three principles. First, it assumes that the trees have a dome-like shape approximated with a GOM and the right illumination parameters. Second, there is little or no overlapping between trees, and third, the pixel with the highest similarity represents the most likely central position of the tree.

The GOM is a simple dome model for which the height is estimated at 1.5 times the diameter of the crown, and to simplify the problem we have assumed a unique diameter for all trees in the orchard (this can easily be modified to incorporate a range of diameters). The algorithm responsible for the detection of trees are best explained through a list of steps.

Step 1. Get user parameters: percent overlapping allowed minimum similarity value, tree diameter, and coordinate of sample tree. These parameters cannot be estimated automatically and are entered by the user. The illumination parameters can optionally be entered by the user, else they will be estimated by the program using the tree sample.

Step 2. If sun elevation and azimuth are not provided by the user, the parameters are automatically estimated by the program using the coordinates of a single-tree sample. The program then computes the similarity between the sample and all possibilities of illuminations parameters in steps of 10 degrees.

Step 3. Calculate the similarity value for each pixel.

Step 4. Sort pixels by decreasing similarity and store coordinates. If the value is lower than the minimum allowed, the pixel is not stored.

Step 5. Place a temporary tree "stamp" (flat template) at the next pixel location with highest similarity value.

Step 6. Verify if space is already occupied by a tree. If some overlapping is allowed, make sure that the number of nonzero pixel is smaller than the percentage of overlapping allowed. An 
output image is created to receive a permanent "stamp" of the GOM shape with the value of similarity associated.

Step 7. Validate the results. Validation is performed by estimating the overall number of trees using the density of a representative sample and comparing with the number of trees found.

\subsection{Testing the MPP-TM approach}

\subsubsection{Urban trees}

Urban trees play an important role in the welfare and quality of life in cities. They contribute to improving air and water quality, mitigate the carbon dioxide and other pollutants, moderate the microclimate and air temperature, help control soil erosion, reduce the flow of rainwater, and provide biodiversity [37-39]. A good knowledge of the species planted in cities and their health contributes to the inventory and management of these trees. To fulfill their role in the urban environment, trees need to be looked after through maintenance practices such as pruning and monitoring them for pests and diseases.

A WorldView-2 (WV-2) image of the campus of the Universidade Federal de Minas Gerais (UFMG) (and surroundings) in Belo Horizonte, Brazil, was used as our test data (Figure 11). The scene was already orthorectified and radiometrically corrected. Although WV-2 offers nine different spectral bands, only the panchromatic band $(\lambda \approx 450-800 \mathrm{~nm})$ with a ground resolution of $50 \mathrm{~cm}$ was used since all other bands have a ground resolution of $2 \mathrm{~m}$.

Three WV-2 sub-images were selected to test the performance of MPP-TM algorithm (Figure 10). These images were chosen from different contexts with both isolated and grouped trees and with other objects present in the scene. A wide variety of crown radii is also present in these images. The first two images (Figure 12a and $b$ ) are from the university campus of UFMG, and the last is from an urban park (Figure 12c).

To assess the quality of the results produced by MPP-TM, validation was done by comparing our results with a visual interpretation of the trees in the image. For these, only tree counting was used as validation. For the crown counting validation, we considered the following situations: 1) true positives (TP) for found trees, 2) false positives (FP) when a detected object is not a tree, and 3) false negatives (FN) for trees not encountered. The success score was computed as follows (Equation 7):

$$
A=\left(\frac{T D-F P}{N+F N}\right) \times 100
$$

where TD represents the total detected trees and $N$ is the total number of trees.

These results are shown below with their respective overall similarity and standard deviation graphs (Figure 13). The validation results are presented in Table 4. 


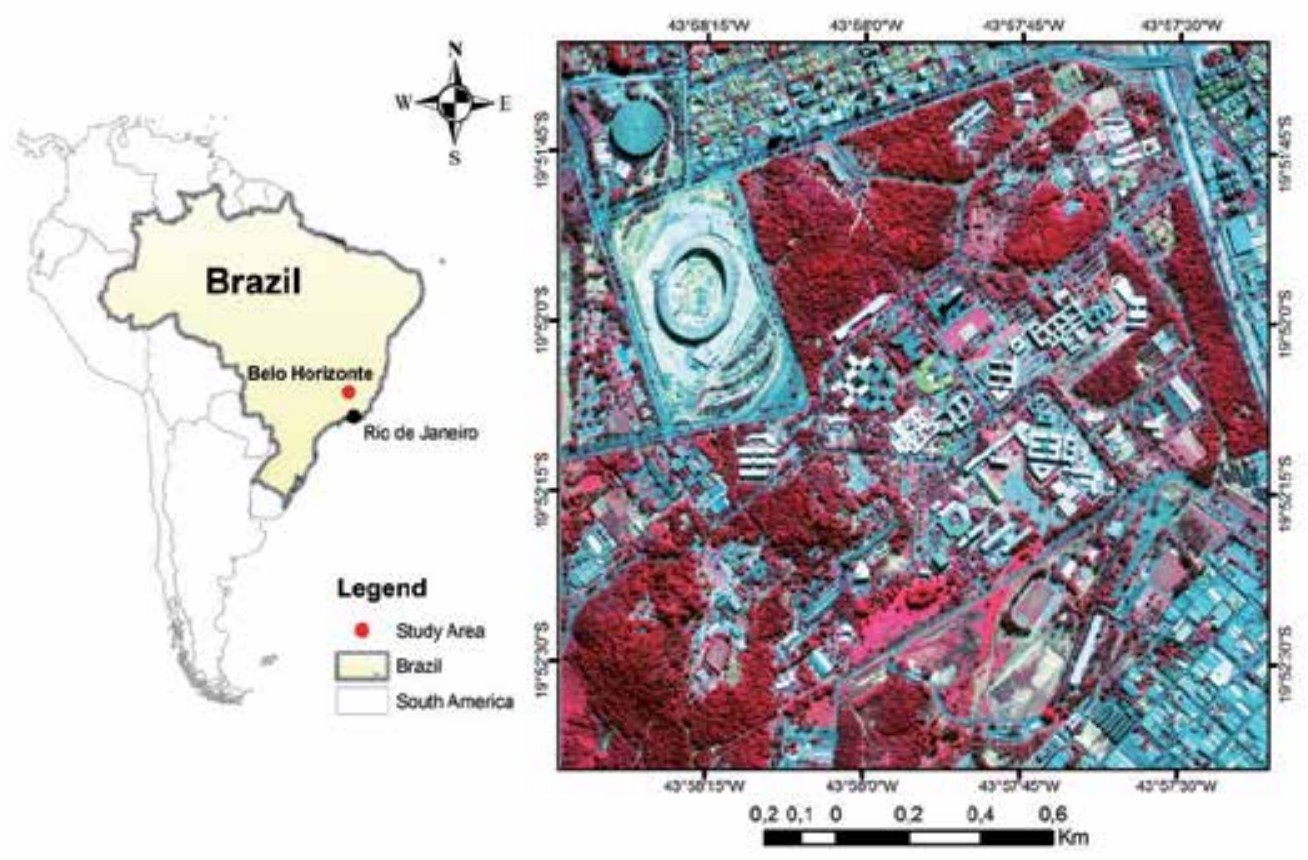

Figure 11. Location of study area. The image on the right is a WorldView-2 false color composite

\begin{tabular}{cccccc}
\hline Image & Number of Trees & Trees Detected & False Positive & False Negative & $\begin{array}{c}\text { Overall Accuracy } \\
(\%)\end{array}$ \\
\hline WV image 1 & 47 & 43 & 3 & 8 & 72.73 \\
\hline WV image 2 & 50 & 59 & 8 & 5 & 92.73 \\
\hline WV image 3 & 175 & 161 & 5 & 20 & 80.00 \\
\hline
\end{tabular}

Table 4. Validation of the MPP-TM results with the three WV-2 images.

In the two images of the campus, the program was able to find $73 \%$ and $93 \%$ of the trees, respectively, with very few errors in isolated trees (Figure 13a and b). The presence of other objects (buildings, streets, and sidewalks) did not hinder the identification of trees and few false positives ( 3 and 8 , respectively) were found. In both images, MPP-TM was able to find most grouped trees, but the crown diameter was often slightly off. It should be noted that some cases are even difficult to correctly identify and delineate visually. Mostly, the errors came from dividing a single crown into two, or including two different crowns as a single object.

The WV-2 image 3 is from a protected urban park area with predominantly isolated trees and relative homogeneous crown size of about $6 \mathrm{~m}$ (Figure 13c). A total of $161 \mathrm{objects}$ were detected with only 5 false positives and 20 false negatives for an overall success of $80 \%$. Although most deciduous trees were selected, the crown size was often incorrect but given the highly irregular 


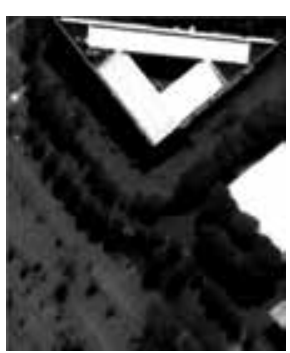

(a)

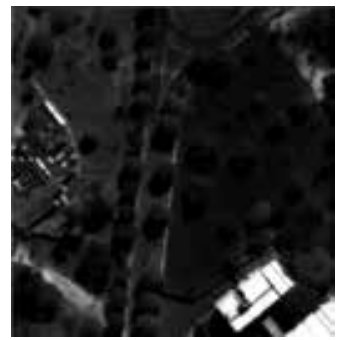

(b)

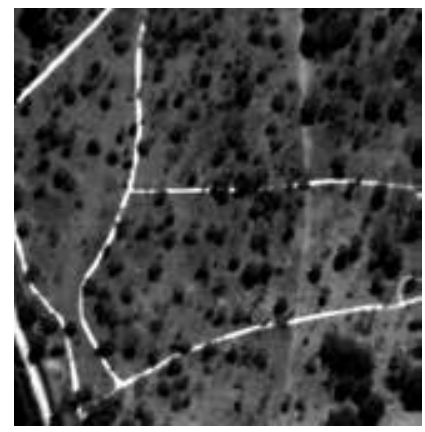

(c)

Figure 12. Sub-images selected from the WV-2 image.

shape of many of these trees, this was somewhat expected, and similar problems have been reported by reference [4].

The behavior of the overall similarity during the iterations tend to increase as the image is progressively occupied by found trees and this is why the overall similarity increases. The standard deviation, however, is very different for each image and is mostly related to the amount of contrast in the original image. Images with highly contrasting objects (e.g., building tops) will tend to show a progressively decreasing standard deviation. Images of low contrast will tend to see it increasing as the trees are progressively added because of the double illumination nature of the trees.

\subsubsection{Orchards}

Orchards are collections of individual trees often arranged regularly for which the MPP-TM algorithm could easily be adapted. Tree counting in orchards can be very useful for inventory and management purposes. For instance, the European Union (EU) Common Agricultural Policy (CAP) regulations (EC 73/2009) provide support for permanent crops such as hazelnuts, almonds, walnuts, and fruits in general [40-42]. Eligible orchards need to have a certain size and tree density depending on the type of crop. It has been estimated that orchard fruit production represents approximately $3-4 \%$ of the total arable land [43], so the task of estimating fruit production needs tools for counting trees in a timely fashion. Furthermore, the task can take advantage of the near-global high-resolution image cover provided by Google (Google Earth and Google Map) and other Internet-based image services. 

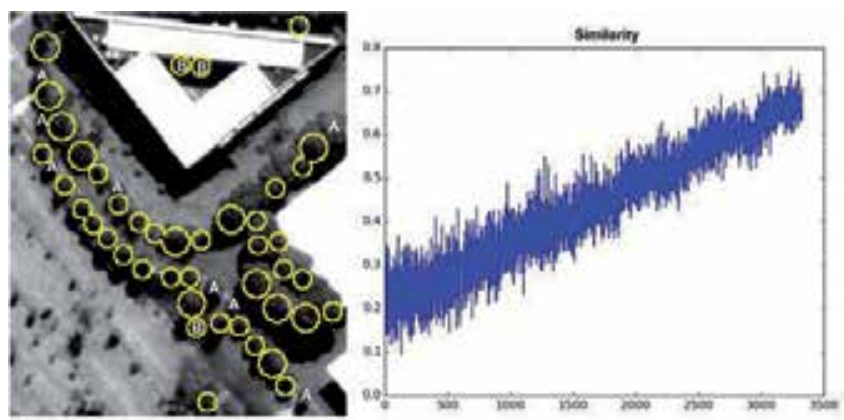

(a)
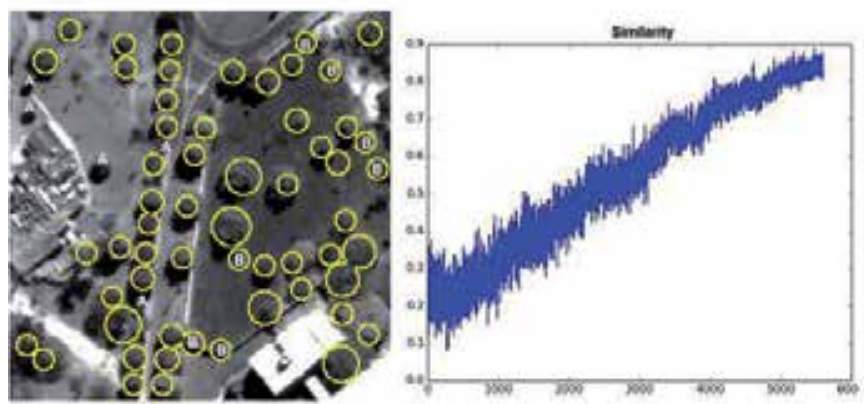

(b)
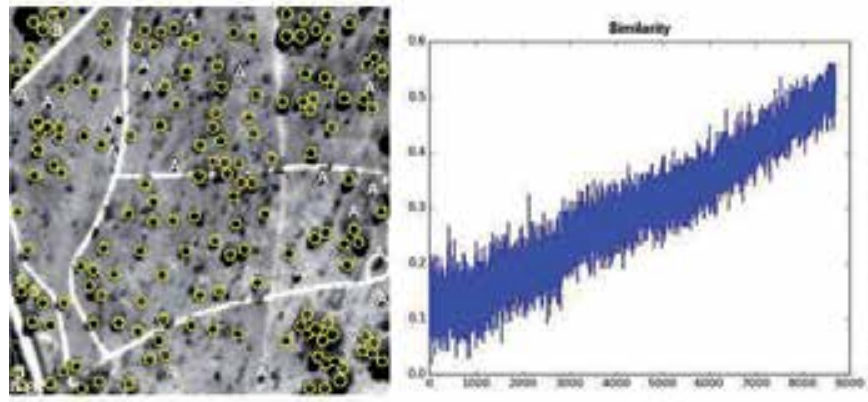

(c)
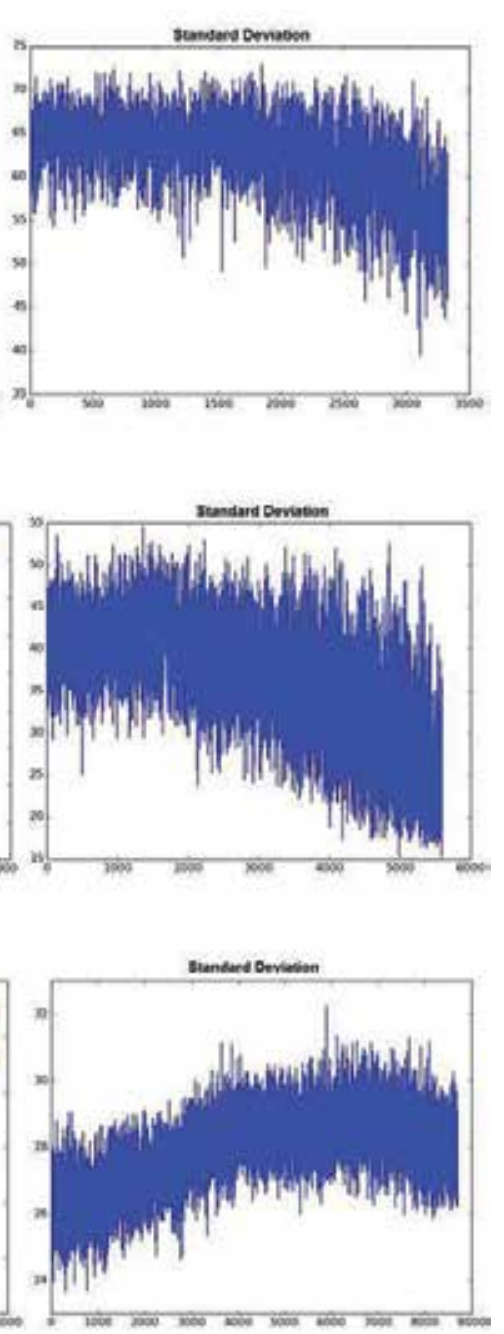

Figure 13. MPP-TM results obtained with the three WV-2 image 1-3 (left) and their graphs of global similarity (center) and standard deviation (right). The yellow circles correspond to correctly identified trees (true positive or TP), the objects marked with a yellow "A" are false negatives (FN) and the objects marked with a yellow "B" are false positives (FP).

Orchards are plantation of trees of the same species and often of the same age. Consequently, trees of orchards usually have similar size and shape and are regularly spaced. Image processing can easily be adapted to such a task providing VHR images are available. To illustrate the adapted MPP-TM algorithm (which no longer is a real MPP), we have tested over three different types of orchards: a mango plantation in Brazil near Juazeiro, a walnut plantation in France near Grenoble, and an olive plantation in Italy near Bracciano. The three images were directly extracted from Google Earth and had a relatively bad quality as they appeared to have been enhanced for sharpness. To validate the results, we have asked three geography students 
to manually interpret and mark the trees belonging to orchards for the three test images, and we have evaluated the results in the following way:

- the total number of trees (NT) was determined by the interpreters;

- matched trees were computed as true positive and are defined by the number of trees found by the algorithm minus the false positives;

- unmatched trees (present on the image but absent from the results) were computed as false negative (FN);

- trees marked by the algorithm but not by the interpreters were marked as false positive;

- the final accuracy was computed as TP / (NT + FN).

To be fair, the interpreters were told not to mark the trees that seem too small or too big for the orchards. In addition, valid trees that were found by the algorithm but did not pertain to an orchard were not computed as false positive. As a further improvement, restricting the search within the boundaries of the orchards would increase the accuracy and enable the similarity parameter to be relaxed. The addition of other spectral bands should also improve the results.

\begin{tabular}{cccccc}
\hline Test Image & Number of trees & True positives & False positives & False negatives & Overall accuracy \\
\hline Grenoble & 2435 & $(2358-69)=2289$ & 69 & 103 & $90.19 \%$ \\
\hline Bracciano & 837 & $(1071-264)=807$ & 264 & 29 & $93.19 \%$ \\
\hline Juazeiro & 2534 & $(2555-114)=2441$ & 114 & 93 & $92.92 \%$ \\
\hline
\end{tabular}

Table 5. Results of the tree counting algorithm for the three regions (France, Italy and Brazil).

Table 5 shows an overview of the results for the three test images, and Figure 14 shows the graphical results. The top row shows the original images, the center row shows the results of the tree identification (as well as false positives and negatives), and the bottom row displays a detailed section of the image on which the results were overlaid. The Grenoble test image (Figure 14 left column) was characterized by densely arranged walnut trees, which have a large round crown so that the model was well correlated with trees on the image, but the fact that the trees are close to one another produced a relatively large number of "miss" (103). This forced to relax the similarity threshold and caused a few false positives (69). In the case of the Bracciano image (Figure 14 center column), the olive trees are more ill- shaped than the walnut trees, and the relaxation of the similarity threshold caused a large number of false positives, especially in the nearby forested areas. Conversely, very few trees were missed. Finally, the last test image from Juazeiro (Figure 14 right column) is populated by mango trees that, like the walnut trees, have large round crowns. Still, the algorithm produced a fair amount of both false positives and false negatives mainly because of the variation of tree crown size and the particular situation of the dirt road at the top of the image that created a pattern of light and shade similar to the trees (approximately one-third of the false positives came from that road). The three very different images still produced similar accuracy results between 90 and 93\%. 


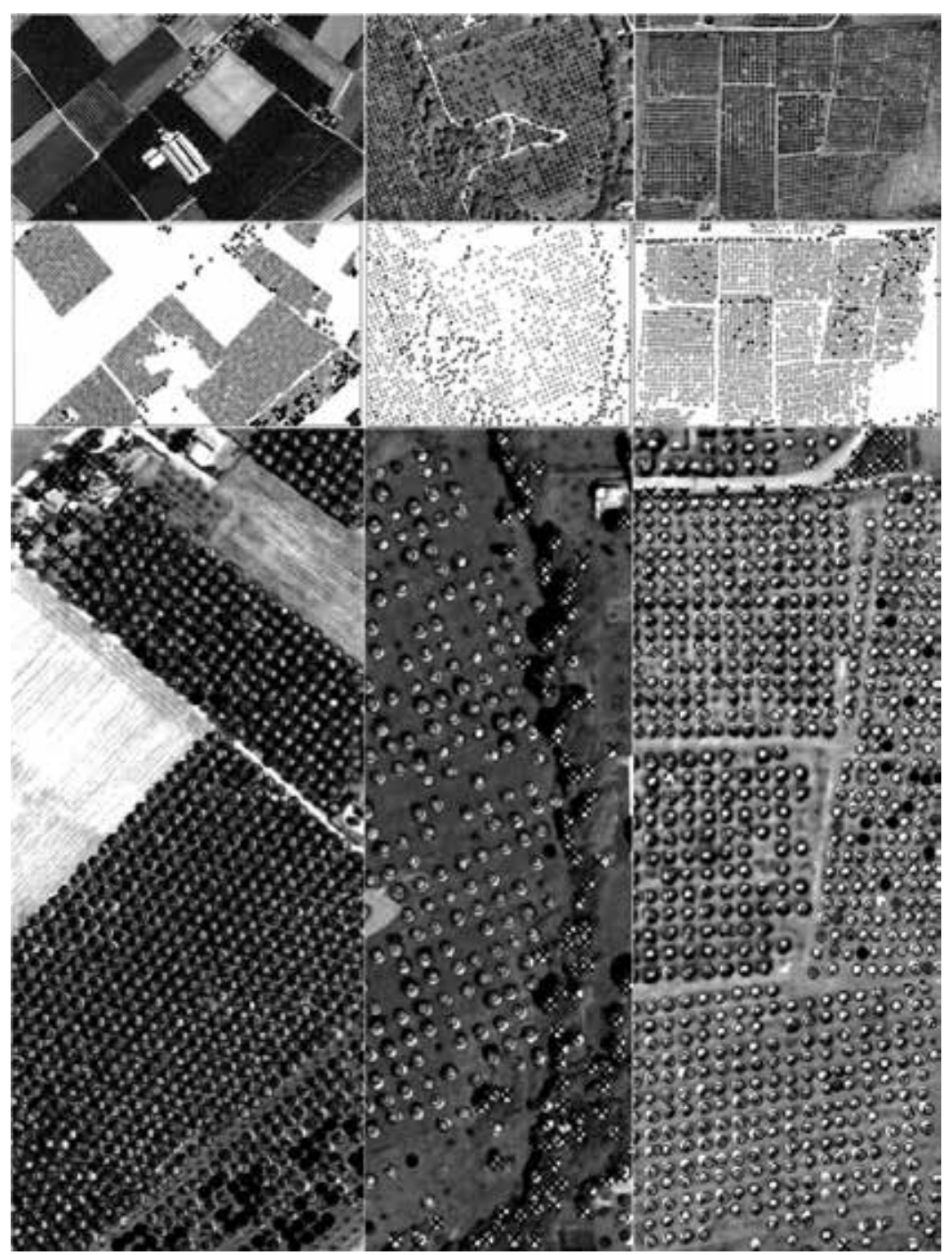

Figure 14. Illustration of the results of the tree counting for the three test images: Grenoble (left column), Briacciano (center column), and Juazeiro (right column). The empty circles represent the trees that were found, " $x$ " represents the false positives and the black circles represent the false negatives.

\section{Final considerations}

The detection of individual tree crown in images of very high resolution is a growing and challenging field of research within the remote sensing community. In addition to the structural complexity of the forest, many other factors such as the characteristics of the scene (topography, illumination, and other environmental variables) and forest type (season and 
biodiversity) make the task difficult. To reference [16], the ability to achieve individual tree crown delineation of all trees in a forest was recognized as an unrealistic expectation.

In an effort to provide the reader with an overview of the current state of the research in tree crown detection, Part I presented a brief review of some of the most common computerized techniques for detecting and delineating trees in optical VHR images. Part II describes the concepts and implementation of a novel approach based on two mathematical/pattern recognition concepts integrated to improve performance. MPP-TM was developed based on concepts from marked point processes and template matching for the former to take advantage of a mark built from a geometrical-optical model.

MPP-TM was highly effective in finding trees in urban environment with images from the WorldView-2 satellite (ground resolution of $50 \mathrm{~cm}$ ). A total of 263 trees out of 272 were found (96\%), and taking false positives into account, a success rate over $90 \%$ was still achieved. The algorithm was also adapted for a tree counting application such as is often needed in large orchards. To count trees in orchards, the approach works very well when the trees are easily distinguishable. Results from three datasets of different crops show an average success better than $90 \%$. Out of 5806 trees, 5537 were found excluding all false positives.

The growing availability of VHR images from commercial satellites or even from web mapping services opens a wide field of applications especially that VHR multispectral images are becoming increasingly common. Multi-temporal studies will further strengthen these applications for monitoring purposes.

Finally, we should mention that Lidar (light detection and ranging) data are also becoming widely available, and its integration with VHR images promises to further improve the results of tree detection algorithm. By adding a third dimension to the images, Lidar reduces the probability of errors by strengthening the evidence around the digital representation of trees.

\section{Acknowledgements}

We are grateful to François Gougeon, Donald Leckie, Guillaume Perrin and Mats Erikson for having kindly provided the rights of reproduction of their figures.

\section{Author details}

Marilia Ferreira Gomes ${ }^{1,2^{*}}$ and Philippe Maillard ${ }^{1}$

*Address all correspondence to: mariliafgomes@yahoo.com

1 Geography Department, Geosciences Institute, Federal University of Minas Gerais, Belo Horizonte, Brazil

2 Cartography Department, National Institute of Land Reform, Belo Horizonte, Brazil 


\section{References}

[1] Pollock RJ. Model-based approach to automatically locating tree crowns in high spatial resolution images. In: Jacky Desachy, editor. Proceedings SPIE 2315: Image and Signal Processing for Remote Sensing; 30 December 1994; Rome. International Society for Optics and Photonics; 1994. p. 526-537. DOI: 10.1117/12.196753

[2] Avery TE, Berlin GL. Fundamentals of remote sensing and airphoto interpretation. 5th ed. New Jersey: Prentice Hall; 1992. 472 p.

[3] Shao G, Reynolds KM, editors. Computer applications in sustainable forest management: Including perspectives on collaboration and integration. 1st ed. Dordrecht: Springer Netherlands; 2006. 277 p. DOI: 10.1007/978-1-4020-4387-1

[4] Ke Y, Quackenbush LJ. A review of methods for automatic individual tree-crown detection and delineation from passive remote sensing. International Journal of Remote Sensing. 2011;32(17):4725-4747. DOI: 10.1080/01431161.2010.494184

[5] Perrin G. Etude du couvert forestier par processus ponctuels marqués [thesis]. Paris: Ecole Centrale Paris; 2006. 170 p. Available from: https://tel.archives-ouvertes.fr/ tel-00109074/ [Accessed: 2015-06-08]

[6] Erikson M. Segmentation and classification of individual tree crowns in high spatial resolution aerial images [thesis]. Uppsala: Swedish University of Agricultural; 2004. 45 p. Available from: http://pub.epsilon.slu.se/676/[Accessed: 2015-04-12]

[7] Gougeon FA, Leckie DG. Forest information extraction from high spatial resolution images using an individual tree crown approach. 1st ed. Victoria: Canadian Forest Service; 2003. 27 p.

[8] Franklin SE. Remote sensing for sustainable forest management. 1st ed. New York: CRC Press; 2001. 424 p.

[9] Blaschke T. Object based image analysis for remote sensing. ISPRS Journal of Photogrammetry and Remote Sensing. 2010;65(1): 2-16. DOI: 10.1016/j.isprsjprs.2009.06.004

[10] Pu R, Landry S. A comparative analysis of high spatial resolution IKONOS and WorldView-2 imagery for mapping urban tree species. Remote Sensing of Environment. 2012;124:516-533. DOI: 10.1016/j.rse.2012.06.011

[11] Larsen M, Eriksson M, Descombes X, Perrin G, Brandtberg T, Gougeon F. Comparison of six individual tree crown detection algorithms evaluated under varying forest conditions. International Journal of Remote Sensing. 2011;32(20):5827-5852. DOI: 10.1080/01431161.2010.507790

[12] Hay GJ, Castilla G. Geographic Object-Based Image Analysis (GEOBIA): A new name for a new discipline?. In: Blaschke T, Lang S, Hay G, editors. Object-Based Im- 
age Analysis - Spatial Concepts for Knowledge-Driven Remote Sensing Applications. 1st ed. Berlin: Springer; 2008. p. 1.4. DOI: 10.1007/978-3-540-77058-9

[13] Wulder M, Niemann KO, Goodenough DG. Local maximum filtering for the extraction of tree locations and basal area from high spatial resolution imagery. Remote Sensing of Environment. 2000;73(1):103-114. DOI: 10.1016/S0034-4257(00)00101-2

[14] Pouliot DA, King DJ, Bell FW, Pitt DG. Automated tree crown detection and delineation in high-resolution digital camera imagery of coniferous forest regeneration. Remote Sensing of Environment. 2002;82(2):322-334. DOI: 10.1016/ S0034-4257(02)00050-0

[15] Brandtberg T, Warner T. High-spatial-resolution remote sensing. In: Shao G, Reynolds KM, editors. Computer Applications in Sustainable Forest Management: Including Perspectives on Collaboration and Integration. 1st ed. Dordrecht: Springer Netherlands; 2006. p. 19-41. DOI: 10.1007/978-1-4020-4387-1

[16] Culvenor DS. TIDA: an algorithm for the delineation of tree crowns in high spatial resolution remotely sensed imagery. Computers \& Geosciences. 2002;28(1):33-44.

[17] Gonzales RC, Woods RE. Digital Image Processing. 3rd ed. New Jersey: Pearson Prentice Hall; 2008. 954 p.

[18] Caves RG, Harley PJ, Quegan S. Matching map features to synthetic aperture radar (SAR) images using Template Matching. IEEE Transactions on Geosciences and Remote Sensing. 1992;30(4):680-685. DOI: 10.1109/36.158861

[19] Pollock RJ. The automatic recognition of individual trees in aerial images of forests based on a synthetic tree crown image model [thesis]. Toronto: The University of British Columbia; 1996. 172 p. Available from: https://circle.ubc.ca/handle/2429/6135

[20] Larsen M. Crown modelling to find tree top positions in aerial photographs. In: In Proceedings of the Third International Airborne Remote Sensing Conference and Exhibition, volume II; 7-10 July 1997; Copenhagen. Ann Arbor: ERIM International; 1997. pp. 428-435.

[21] Larsen M, Rudemo M. Optimizing templates for finding trees in aerial photographs. Pattern Recognition Letters. 1998;19(12):1153-1162. DOI: 10.1016/ S0167-8655(98)00092-0

[22] Quackenbush LJ, Hopkins PF, Kinn GJ. Developing forestry products from high resolution digital aerial imagery. Photogrammetric Engineering and Remote Sensing. 2000;66(11):1337-1346.

[23] Gomes MF, Maillard P. Identification of urban tree crown in a tropical environment using WorldView-2 data: problems and perspectives. In: Michel U, Civco DL, Schulz K, Ehlers M, Nikolakopoulos KG, editors. SPIE 8893, Earth Resources and Environmental Remote Sensing/GIS Applications IV; 23-25 September; Dresden. Washington: SPIE; 2013. p. 88930C-88930C-13. DOI: 10.1117/12.2029073 
[24] Hung C, Bryson M, Sukkarieh S. Multi-class predictive template for tree crown detection. ISPRS Journal of Photogrammetry and Remote Sensing. 2012;68:170-183. DOI: 10.1016/j.isprsjprs.2012.01.009

[25] Gougeon F. A crown-following approach to the automatic delineation of individual tree crowns in high spatial resolution aerial images. Canadian Journal of Remote Sensing. 1995;21(3):274-284.

[26] Leckie DG, Gougeon FA. An assessment of both visual and automated tree counting and species identification with high spatial resolution multispectral imagery. In: Hill DA, Leckie DG, editors. International Forum on Automated Interpretation of High Resolution Digital Imagery for Foresty; 10-12 February 1998; Victoria. Victoria: Canadian Forest Service; 1998. p. 141-154.

[27] Gougeon FA, Leckie DG. The individual tree crown approach applied to Ikonos images of a coniferous plantation area. Photogrammetric Engineering \& Remote Sensing. 2006;72(11):1287-1297. DOI: 10.14358/PERS.72.11.1287

[28] Szeliski R. Computer vision: algorithms and applications. 1st ed. London: SpringerVerlag; 2010. 812 p. DOI: 10.1007/978-1-84882-935-0

[29] Wang L, Gong P, Biging GS. Individual tree-crown delineation and treetop detection in high-spatial-resolution aerial imagery. Photogrammetric Engineering \& Remote Sensing. 2004;70(3):351-357. DOI: 10.14358/PERS.70.3.351

[30] Lamar WR, McGraw JB, Warner TA. Multitemporal censusing of a population of eastern hemlock (Tsuga canadensis L.) from remotely sensed imagery using an automated segmentation and reconciliation procedure. Remote Sensing of Environment. 2005;94(1):133-143. DOI: 10.1016/j.rse.2004.09.003

[31] Bunting P, Lucas RM. The delineation of tree crowns in Australian mixed species forests using hyperspectral Compact Airborne Spectrographic Imager (CASI) data. Remote Sensing of Environment. 2006;101(2):230-248. DOI: 10.1016/j.rse.2005.12.015

[32] Zhou J. Application de l'identification d'objets sur images à l'étude de canopées de peuplements forestiers tropicaux: cas des plantations d'Eucalyptus et des mangroves [thesis]. Montpellier: Université Montpellier II - Sciences et Techniques du Languedoc; 2012. 191 p. Available from: https://tel.archives-ouvertes.fr/tel-00763706/

[33] Descombes X. Méthodes stochastiques en analyse d'image: des champs de Markov aux processus ponctuels marqués [thesis]. Nice: Université de Nice Sophia-Antipolis; 2004. 225 p. Available from: https://tel.archives-ouvertes.fr/tel-00506084/[Accessed: 2015-09-20]

[34] Ortner M. Processus ponctuels marqués pour l'extraction automatique de caricatures de bâtiments à partir de modèles numériques d'élévation [thesis]. Nice: Université de Nice Sophia-Antipolis; 2004. 250 p. Available from: https://tel.archives-ouvertes.fr/ tel-00189803 [Accessed: 2015-09-01] 
[35] Baddeley AJ, Van Lieshout MNM. Stochastic geometry models in high-level vision. Journal of Applied Statistics. 1993;20(5-6):231-256. DOI: 10.1080/02664769300000065

[36] St-Onge B. L'apport de la texture des images numériques de haute resolution a la cartographie forestière automatisée [thesis]. Montréal: Université de Montréal; 1994. $502 \mathrm{p}$.

[37] Östeberg J, Delshammar T,Wiström B, Nielsen AB. Grading of parameters for urban tree inventories by city oficials, arborists, and academics using the Delphi method. Environmental Management. 2013;51(3):694-708. DOI: 10.1007/s00267-012-9973-8

[38] Sander H, Polasky S, Haight RG. The value of urban tree cover: A hedonic property price model in Ramsey and Dakota Counties, Minnesota, USA. Ecological Economics. 2010;69(8):1646-1656. DOI: 10.1016/j.ecolecon.2010.03.011

[39] Almeida, A. L. B. S. S. S. L.. O valor das árvores: árvores e floresta urbana de Lisboa [thesis]. Lisboa: Instituto Superior de Agronomia; 2006. 342 p. Available from: http:// hdl.handle.net/10400.5/469[Accessed: 2015-06-01]

[40] Santoro F, Tarantino E, Figorito B, Gualano S, D'Onghia AM. A tree counting algorithm for precision agriculture tasks. International Journal of Digital Earth. 2013;6(1): 94-102. DOI: 10.1080/17538947.2011.642902

[41] Aksoy S, Yalniz IZ, Tasdemir K. Automatic detection and segmentation of orchards using very high resolution imagery. Geoscience and Remote Sensing. 2012;50(8): 3117-3131. DOI: 10.1109/TGRS.2011.2180912

[42] Tasdemir K. Classification of hazelnut orchards by self-organizing maps," in Pattern Recognition in Remote Sensing (PRRS). In: Aksoy S, Younan NH, Forstner W, editors. IAPR Workshop on Pattern Recognition in Remote Sensing (PRRS); 22-22 August 2010; Istanbul. Institute of Electrical and Electronics Engineers IEEE; 2010. pp. 14. DOI: $10.1109 /$ PRRS.2010.5742803

[43] Food and Agriculture Organziation of the United Nations. Statistical yearbook 2013: World food and agriculture. 1st ed. Rome: FAO; 2012. 289 p. 



\section{Section 2}

Remote Sensing Based Glacier Studies 

Chapter 3

\title{
Climate Factors' Effects on Glacier Variations in the Commune of Alto del Carmen, Chile
}

\author{
Guido Staub and Catherinne Muñoz \\ Additional information is available at the end of the chapter \\ http://dx.doi.org/10.5772/62164
}

\begin{abstract}
Ice bodies in the semi-arid mountainous regions of Chile are of vital importance for the local population. As variations of their extent are often associated with climate change, this study focuses on the glaciers and glacierets situated in the Commune Alto del Carmen and local and regional climate. We combine statistically Landsat satellite imagery, historical and ongoing weather data. The present study covers a time span of 21 years, 1994-2015. Our results indicate that the extent of all ice bodies has continuously diminished as a consequence of long-term climate variability.
\end{abstract}

Keywords: Glaciers, Andes, Climate ENSO

\section{Introduction}

Since the end of the Little Ice Age, from about 1300 to about 1850, many worldwide glaciers have decreased in volume and extent [1]. Therefore, some of them at present are finished and others will disappear in the near future $[2,3]$. It is understood, but still not very well documented, that glacier retreat is closely coupled to global climate change and anthropogenic interventions $[4,5,6,7]$. This is mainly due to the complexity of weather system because of difficult climate history reconstruction. The main causes of receding glaciers, which can be attributed to climate variations, are constantly increasing global and regional temperature and lower stationary precipitation in the affected areas. Glaciologists have found out that the phenomenon of glacier retreat coincides with an increase in greenhouse gas emissions during and after the industrial revolution in the 18th century, see Figure 1. This means that human activities play a major role in this context. Even in a more direct way humans intervene, as exploration and exploitation of nature are activities that can be dated back till the beginning of the new age. It is quite clear that nowadays these interventions are carried out in a different 
way due to the possibility to use highly developed machines, and that the principal purpose has changed as in the past natural resources were exploited by humans as personal necessities had to be covered. At present, more economic reasons are in the foreground $[8,9,10]$.

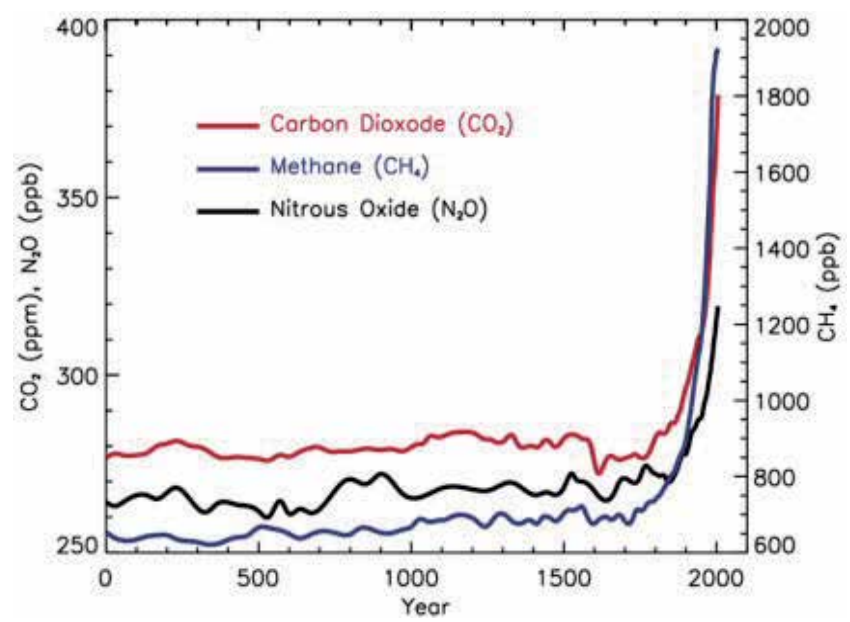

Figure 1. Trend of greenhouse gas emissions over the past 2,000 years (Source: [11])

Nevertheless, by all the interventions that are carried out by humans, ecosystems, our planet in general, suffer continuous alterations. But it would be simple to attribute every trend to humans as there are also natural circumstances, seasonal, periodic and single events, which affect nature. In any case, regardless of what or who have responsibility, the phenomenon of glacier retreat has to be studied as its impact is huge and might affect a whole region or even a country [12].

It has to be mentioned that glacier retreat should not be confused with other cyclical phenomena, like some melt during spring and summer months, which have almost no negative impact on glaciers. Annual thaw starts each spring in the mountains and causes melting of snow and ice accumulated during winter. The melting snow during spring and summer months causes an overall positive impact, since it generates a valuable source of fresh water. During winter months, snow fall results in a recuperation of melted snow. In consequence, an almost neutral mass balance between warm and cold periods is achieved by nature as this process repeats year after year. This is not the case if glaciers melt as there is a negative mass balance during a certain period of time. So the problem arises when the phenomenon is not seasonal, the glacier does not recover its initial volume in the cold months, year after year, so its volume and extend gets diminished and in consequence, natural fresh water source for human consumption and irritation is threatened [13].

In South America, a total surface of about $26,000 \mathrm{~km}^{2}$ is covered by glaciers. Almost $77 \%$ of this area can be found in Chile [14]; considering 1,751 glaciers (16,893 sqkm) already mapped and 5,000 sqkm estimated of not yet registered glaciers. Their distribution from north to south can be grouped as it is shown in Table 1 . 

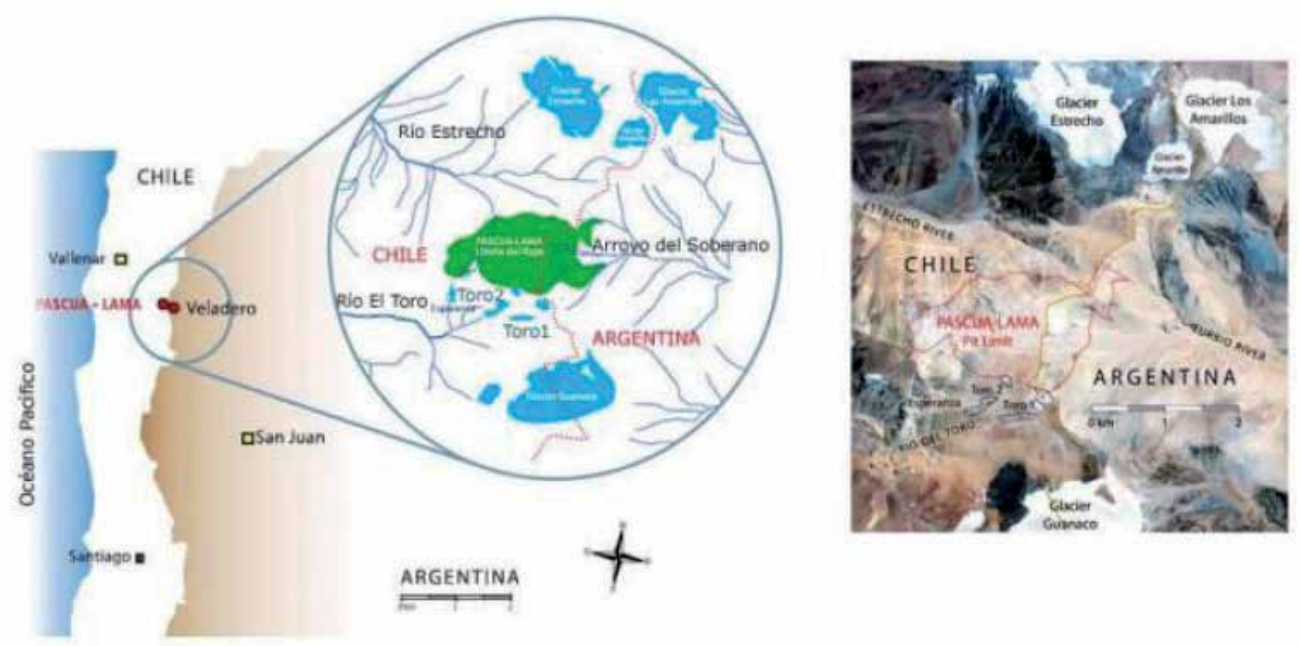

Figure 2. Glaciers and glacierets located in the study area

\begin{tabular}{llll}
\hline Natural Region & Region & Number of Glaciers & Surface [sqkm] \\
\hline Far North & XV, I, II & 28 & 42 \\
\hline Near North & III - IV & 60 & 107 \\
\hline Central & V - VII, RM & 1500 & 1019 \\
\hline South & IX, XIV, X & 87 & 265 \\
\hline Far South & XI - XII & 76 & 15460 \\
\hline
\end{tabular}

Table 1. Geographical distribution of Glaciers in Chile

The current state of Chilean glaciers, according to [14] and [15], indicates that $87 \%$ is in decline, $6 \%$ in advance and $7 \%$ still remains unchanged.

Nowadays and in a near future, the water scarcity is a major concern all over the world. Especially in the arid to semi-arid mountainous regions, the local population hugely depends on alternative water resources such as those stored in glaciers or snow. Glaciological processes at high altitudes in such regions of Chile and Argentina $\left(27^{\circ} \mathrm{S}\right.$ to $\left.33^{\circ} \mathrm{S}\right)$ have previously been studied with special focus on hydrology (e.g. [17]) and climatology (e.g. [17, 18]).

In the rivers that originate in the central Andes, the main water supply is generated from the snowfall that normally covers the upper mountain peaks each winter. Furthermore, besides these melting processes, surface runoff gradually flows into the rivers. During wet years, this runoff can deliver sufficient amount of water throughout the spring and summer period to compensate missing precipitation. In dry years, however, it tends to decrease towards the end of summer. In these drier periods, ice bodies have to provide enough melt water due to its natural resources accumulated in winter. The water contribution of glaciers, glacierets and 
other ice bodies is directly proportional to their area, as it is on the surface where melting caused by solar radiation, ambient heat and other environmental factors happens. As an example, the Chilean General Water Directorate (DGA - Dirección General de Aguas) estimates that the average, annual melting during summer fluctuates between 0.5 liters per second $(1 / \mathrm{s})$ per hectare and $1.8 \mathrm{l} / \mathrm{s}$ per hectare. The total area of the three glacierets located at the southern end of the study area was 16.5 hectares in March 2005, so that the total flow contributing to the basin was estimated to range from $8 \mathrm{l} / \mathrm{s}$ to $30 \mathrm{l} / \mathrm{s}$ during maximum of the melting period. In comparison, the average flow of Huasco River in Algodones, more westerly in an agricultural zone, is greater than $4000 \mathrm{l} / \mathrm{s}$ in summer.

In the Chilean Commune Alto del Carman, in the Atacama region, Figure 2, several glaciers can be found that have shown important variations during the past few decades. These glaciers namely are: Toro 1, Toro 2, Esperanza, Guanaco, Estrecho, Amarillo and Los Amarillos. Several other studies on glacier variations induced by climate have already been carried out in the past at different study sites, but in the vicinity of the mentioned glaciers. Ref. [19] studied the terminus of the Agua Negra Glacier (Argentine); [20] the Tronquitos glacier; [21] Cerro Topado; [22] the Huasco catchment. In 2003, [23] started a glacier and glaceriets (very small glaciers or ice masses of indefinite shapes in hollows and that have little or no movements; [24]) monitoring program in the region where all of the above mentioned glaciers are located.

\subsection{Remote sensing of glaciers}

Nowadays, traditional ground-based glacier monitoring studies can be complemented or even replaced by satellite-based data. Reflected solar radiation by the earth's surface is detected by optical, passive sensors in the visible (400-700 nm), near and short-wave infrared (700 $\mathrm{nm}-7$ $\mu \mathrm{m})$ bands of the electromagnetic spectrum. Radiation emitted by the surface is detected by sensors in the thermal infrared $(7 \mu \mathrm{m}-1 \mathrm{~mm})$ bands. Electromagnetic radiation in the microwave bands $(1 \mathrm{~mm}-1 \mathrm{~m})$ in remote sensing is used mostly by so-called synthetic aperture radar (SAR) active and passive systems [25].

Glacier monitoring can focus on several parameters such as glacier area and length, surface elevation, surface flow fields, accumulation and ablation rates or albedo. For mass balance study, in particular equilibrium line altitude (ELA), accumulation area ratio (AAR) and the mass balance gradient $\delta b / \delta z$ are of importance [26].

All these parameters are relevant to study the influence of glaciers on the environment [27]. Important fields are:

- Glacier Geology: Bedrock material removed by glaciers is redistributed in the landscape. Erosion and deposition caused by glaciers forms U-shaped valleys, cirques, moraines and other glacial landforms. Glacial sediment is redistributed by wind or water, forming new soils and affecting the water quality of rivers, lakes and oceans.

- Glacier Hydrology: Glaciers store water during cool, wet winter periods and release it during warm, dry summer. 
- Glacier Ecology: Glaciers are habitats for flora and fauna. Their meltwater provides aquatic habitat for endangered species.

- Glacier Hazards: Significant hazards are outburst floods, lahars, ice avalanches and spontaneous landslides.

Considering these two principal aspects, sensor types and glacier characteristics, one has to decide what kind of data has to be generated and which method is the most appropriate [28]. For example, digital elevation models are a key element for glacier volume change studies. Several conclusions can be drawn out of it, such as mass balance variability due to climate change. Furthermore, glacier surface flow velocity can be derived from differential InSAR observations and/or feature tracking in optical satellite images.

In scientific literature, a lot of examples can be reviewed that highlight the potential of remote sensing for glaciologic studies carried out all over the world, such as those in Alaska [29], Patagonia [30], the Andes [31], the Alps [32], the Himalaya [33] and Central Asia [34].

Table 2 gives an overview of most common satellites and their application in glacier monitoring.

\begin{tabular}{|c|c|c|c|}
\hline Satellite & Operation dates & Bands & Glaciological application \\
\hline Landsat & Series of satellites since 1972 & VIS, IR & $\begin{array}{l}\text { Glacier variations, spectral } \\
\text { characteristics of snow and } \\
\text { ice }\end{array}$ \\
\hline SPOT & Series of satellites since 1986 & VIS, IR & $\begin{array}{l}\text { Glacier variations, spectral } \\
\text { characteristics of snow and } \\
\text { ice }\end{array}$ \\
\hline SENTINEL & Series of satellites since 2014 & VIS, IR, MW & $\begin{array}{l}\text { Glacier variations, spectral } \\
\text { characteristics of snow and } \\
\text { ice, elevation change } \\
\text { monitoring }\end{array}$ \\
\hline CRYOSAT-2 & Single mission since 2010 & MW & $\begin{array}{l}\text { Glacier variations, surface } \\
\text { velocity estimation, elevation } \\
\text { change monitoring }\end{array}$ \\
\hline TERRA & Single mission since 2000 & VIS, IR, MW & $\begin{array}{c}\text { Glacier variations, elevation } \\
\text { change monitoring }\end{array}$ \\
\hline
\end{tabular}

Table 2. Satellites and their possible application in glacier monitoring

\section{Climate}

Inter-annual global climate variability is mostly caused by the coupled ocean-atmosphere phenomenon ENSO (El Niño Southern Oscillation). It is a naturally, irregularly occurring phenomenon that is characterised by fluctuating ocean temperatures in the equatorial Pacific, 
between Australia and the west coast of South America. El Niño refers to a warming phase whereas La Niña refers to a cooling phase of the Pacific sea surface temperature (SST), the upper layer $(0-10 \mathrm{~cm})$ of the ocean. As ENSO is a coupled ocean-atmosphere phenomenon, air surface pressure in the tropical Western Pacific is higher than normal in case of El Niño and lower in case of La Niña. Both in general last several months or even years and vary in intensity.

ENSO has particular impact on inter-annual climate variability in Latin and South America. In Mexico and parts of the Caribbean, El Niño causes an augmentation in winter precipitation and a diminution in summer precipitation [35]. Severe droughts in Mexico have occurred during summer when El Niño was present [36]. La Niña, however, has an almost opposite effect, precipitation increases during summer months and decreases in winter.

In case of Colombia, El Niño causes reductions in precipitation, whereas La Niña is associated with stronger precipitation, which might result in floods [37]. Furthermore, they indicate that there exists a very high positive correlation between the Southern Oscillation Index (SOI) and river discharge in Colombia. During the December-January period, this relationship is stronger and weaker during April and May. There is also a regional difference. In western Colombia the influence of El Niño is stronger than in the east.

Large positive precipitation anomalies over the eastern part of the Andes (Ecuador and northern Peru) typically are observed during the warm episode [38].

In the Amazon region of Brazil northward to the Caribbean, deficiency in precipitation has been observed during El Niño [39]. In contrast, El Niño effects in southern Brazil are opposite to that in northeast Brazil and northern Amazonia. Positive and extremely large anomalies of rainfall have been observed during El Niño years [40, 41].

Between $30^{\circ} \mathrm{S}$ and $40^{\circ} \mathrm{S}$, northern and central Chile and at high altitudes of the Andes in Argentina, most precipitation is recorded during winter months, with positive anomalies, which can be registered during early stages of El Niño. Due to the area's semi-arid conditions, local and regional economy might strongly be affected [42, 43, 44]. These events stand in contrast to what happens at low altitudes of Chile. Between 1991 and 1993, El Niño years, heavy rainfall triggered debris flows in Santiago de Chile, Antofagasta and surrounding areas [45].

At high altitudes of the Andes, large amounts of snow are consistently recorded. During summer, melting of accumulated snow is the main cause of river runoff. In Chile and centralwestern Argentina, north of $40^{\circ} \mathrm{S}$, during El Niño years, streamflows were normal or above normal $[46,47]$. In contrast, during La Niña years, negative anomalies of rainfall and snowfall can be observed with opposite consequences, which include below-normal summer streamflow. For this region, it is more probable that dry conditions occur during La Niña than wet conditions happen during El Niño years [42].

SST observations and analysis are often used to identify this oscillation and to predict the upcoming climate variability. Nevertheless, it has to be mentioned that it is the sub-surface ocean temperature, which indicates first an upcoming change, a transition from a cold to a 
warm phase or vice versa. It is important to understand that changes in sub-surface ocean temperatures are the first to respond to an oncoming change in the ENSO phase.

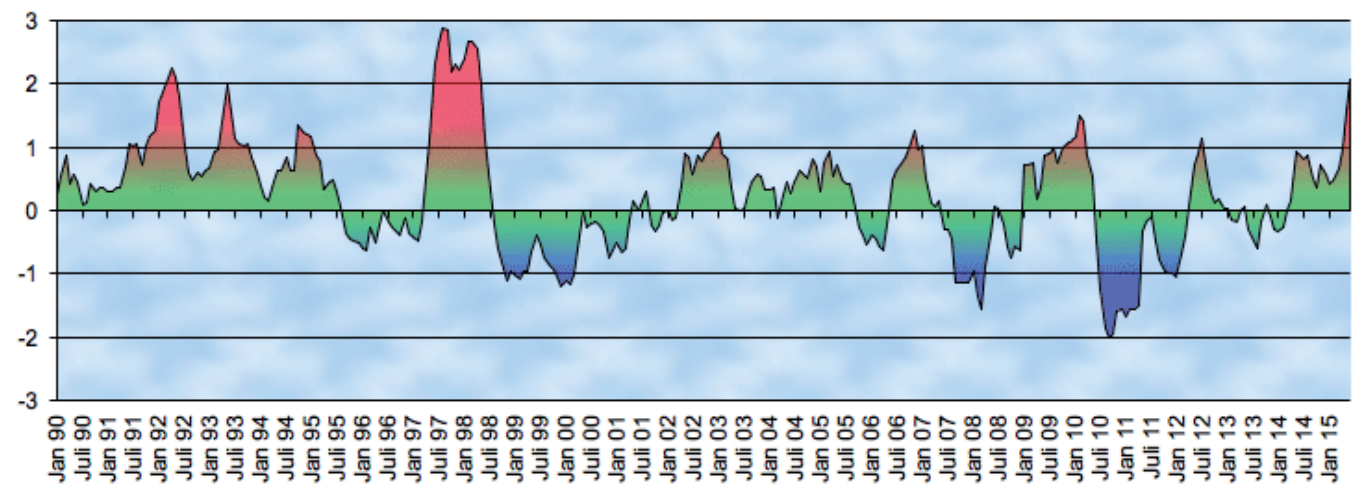

Figure 3. Multivariate ENSO Index (MEI) since 1990 (Source: [48])

Nevertheless, to monitor ENSO in literature the Multivariate ENSO Index (MEI), Figure 3, which is based on the six main observed variables over the tropical Pacific, can be found. These six variables are: sea-level pressure, zonal and meridional components of the surface wind, sea surface temperature, surface air temperature and total cloudiness fraction of the sky. At first, the MEI is computed separately for two consecutive months (Dec/Jan, Jan/Feb,...). Then, spatially filtering of the individual fields into clusters is applied [49]. The MEI is calculated afterwards as the first unrotated principal component (PC) of all six observed fields combined. Finally, the first PC on the co-variance matrix of the combined fields is extracted [50]. In Figure 4 , the results of the past 25 years are illustrated. Positive values (in red) indicate El Niño phases whereas negative values (in blue) represent La Niña phases.

\subsection{Remote sensing of climate}

Since 1959 when the first space-borne observations of solar irradiance and cloud reflectance were made by the Vanguard-2 satellite, remote sensing gradually became a key observation and research method in climate change studies [51]. Satellite data of land, ocean and atmosphere are used to model and simulate the dynamics climate system in the past, present and future $[52,53]$.

Although satellite remote sensing, on a climate history time scale, is a relatively new technique, and therefore has some limitations such as short data spans of satellite records, biases associated with instruments and uncertainties in retrieval algorithms, it has to be considered in a series of particular applications that are listed in Table 3. 


\begin{tabular}{lll}
\hline Application & Observation & Satellites \\
\hline Global warming & $\begin{array}{l}\text { Global temperature trends, particularly NOAA, AQUA, TERRA } \\
\text { at the ocean surface and in the } \\
\text { atmosphere. }\end{array}$ & \\
\hline Snow and ice & $\begin{array}{l}\text { Monitoring the dynamics } \\
\text { of snow extent and ice covers }\end{array}$ & NOAA, SSM/I, ERS \\
\hline Sea level change & Mapping of ocean surface topography & TOPEX/Poseidon, GRACE, Sentinel \\
\hline Solar radiation & $\begin{array}{l}\text { Determination of changes in the sun's } \\
\text { luminosity }\end{array}$ & SORCE, Meteosat, Eumetsat \\
\hline Aerosols & Atmospheric particles concentration & TERRA, AQUA \\
\hline Water vapour and precipitaion & $\begin{array}{l}\text { Precipitable water in the troposphere; } \\
\text { spatial and temporal variability of }\end{array}$ & \\
\hline plouds & TERA, AQUA \\
\hline
\end{tabular}

Table 3. Remote sensing in climate change studies

\section{Objectives and study area}

The main objective of the present work was to determine surface area changes of glaciers in the Commune of Alto del Carmen (Chile) in the near north during the past two decades. And the specific goal of the study was to link these changes to climate variability in the study area.

Our study focuses on the following glaciers and glacierets located in the Commune of Alto del Carmen: Toro 1, Toro 2, Esperanza (all defined as glacierets) Guanaco, Estrecho, Amarillo and Los Amarillos (all defined as glaciers), see Figure 2. Ref. [22] found out that their spatial distribution is highly correlated with natural factors, such as terrain characteristics, solar radiation and shadowing effects. Ref. [54] indicates that only little ice flow exists and that surface areas are smaller than $2 \mathrm{sqkm}$ in 2007. Furthermore, they mention, based on ground penetration radar (GPR) measurements, that ice thickness can reach up to 100 meters. More historical studies of area changes [23] have shown that during the past 50 years, surface area has reduced significantly in almost all glaciers and glacierets.

Furthermore, it is noteworthy that an important mining project of gold, silver, copper and minerals is developed in the nearby vicinity. At first, the responsible mining company (Barrick Gold) proposed to move Toro 1, Toro 2 and Esperanza glacier, as they were considered of little relevance to the basin water, are located in the pit area of the foreseen mine and were in process of disappearance (observed high melt rates). National and Regional Environmental commissions (CONAMA and COREMA, respectively) approved the mining project in general. Nevertheless, they made a couple of observations to the initial proposal and prohibited to move glaciers. As a consequence to the already carried out exploitation activities, such as 
drilling, and installation of infrastructure, e.g. access roads, several negative effects can already be observed.

- Watershed: There are two rivers, which are directly affected by the Pascua Lama mining project, as their source is in that area and are fed by melting snow that infiltrates the ground: On the Argentinian side, it is river Turbio and on the Chilean side, it is El Estrecho river. On its way through rocks and materials that make up the upper river sources, the water comes into contact with the minerals in the soils of the Pascua-Lama deposit. Due to its chemical and mineralogical composition, water becomes acid and can dissolve metals contained in the rocks.

- Glacier: In 2001, COREMA approved the so-called Environmental Impact Assessment of the Pascua Lama Project, which was presented by Barrick Gold. In this study report, several environmental impacts were outlined. Furthermore, several mitigation measures and monitoring programs were proposed to protect the environment. The assessment covered those environmental components, which were considered as most relevant, including: air quality; levels of noise and vibration; flow and quality of surface and groundwater; geomorphology, drainage and soil; vegetation and flora; terrestrial fauna; aquatic flora and fauna; landscape; cultural heritage; road service levels; and socio economy. Nevertheless, glaciers were not considered to be protected. It was proposed to move them to a different location. As this was never realized, the mining company constructed a transportation road right through one of them.

\section{Methodology and data}

Glacier and glacieret surface area were determined from georeferenced satellite images acquired by Landsat 5, 7 and 8 . These satellite images were acquired during summer months from 1994 until present, for two reasons: (1) Cloud cover in the satellite images had to be less than $10 \%$ and (2) glaciers can be detected very easily and with high certainty as seasonal snow cover does not exist anymore. Their ground sampling distance (GSD) is $30 \mathrm{~m}$ in all spectral bands. Landsat 7 satellite images with SLC (Scan Line Correction) off had to be re-processed to fill gaps. This was done by spectral interpolation for every affected satellite image.

\begin{tabular}{llc}
\hline Satellite & Time Span & Total Number of images \\
\hline Landsat 5 & $1994-2003$ & 10 \\
\hline Landsat 7 & $2004-2013$ & 10 \\
\hline Landsat 8 & $2014-2015$ & 2 \\
\hline
\end{tabular}

Table 4. Satellite images used in this study

With all the satellite images acquired, corrected and georeferenced, at first, a visual identification, interpretation and analysis of the glaciers and glacierets were carried out to detect inter- 
annual variations. In a second processing step, image digitalization was applied with the aim to measure glacier extent and to derive surface area variations.

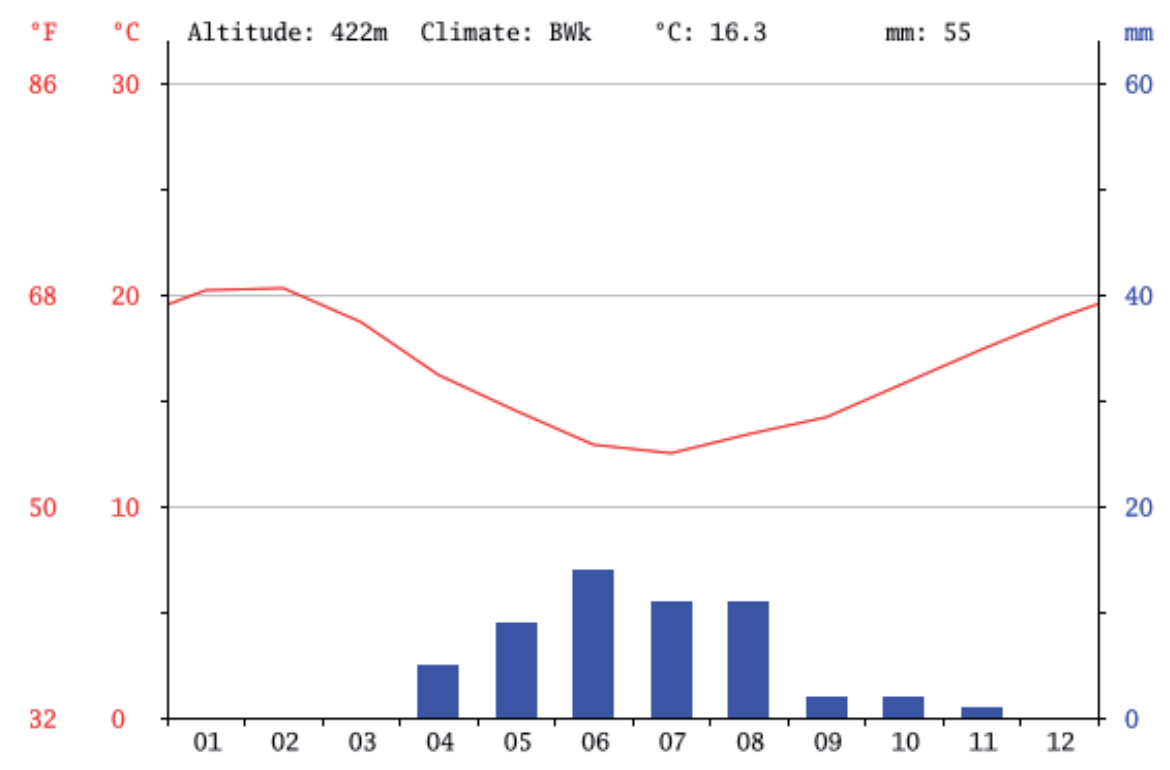

Figure 4. Climate chart for the city of Vallenar

Climate data, which is relevant for this study, is available for free on the internet. There are several weather stations situated in the Atacama region close to the study area. The most complete data set of precipitation and temperature records is available for the city of Vallenar, located at $100 \mathrm{~km}$ to the northwest of the study area. Furthermore, climate data registered for the cities of Conay (60 km to the north) and Chollay (50 km to the northwest) are available, but only from 2008 onwards and with some gaps. Therefore, measurements until 2008 at a fourth station, namely La Olla (80km to the southwest), are taken into account. This data was taken from [23].

In a final step, Pearson product-moment correlation between climate and digitised data is generated. Both are linked together with a special focus on anomalies and unusual events, e.g. high temperature events, heavy and prolonged rainfall. The statistical correlation is determined by the relationship or dependence between the two studied variables: area (sqkm), temperature $\left(\mathrm{T}^{\circ}\right)$, precipitation $(\mathrm{mm})$, in a two-dimensional distribution. In case that there can be found one of these variables influencing another, it can be stated that the variables are correlated or that there exists correlation between them.

The linear correlation coefficient is calculated as follows:

$$
r=r_{x y} / r_{x} r_{\mathrm{y}} ; r \varepsilon[-1,1]
$$




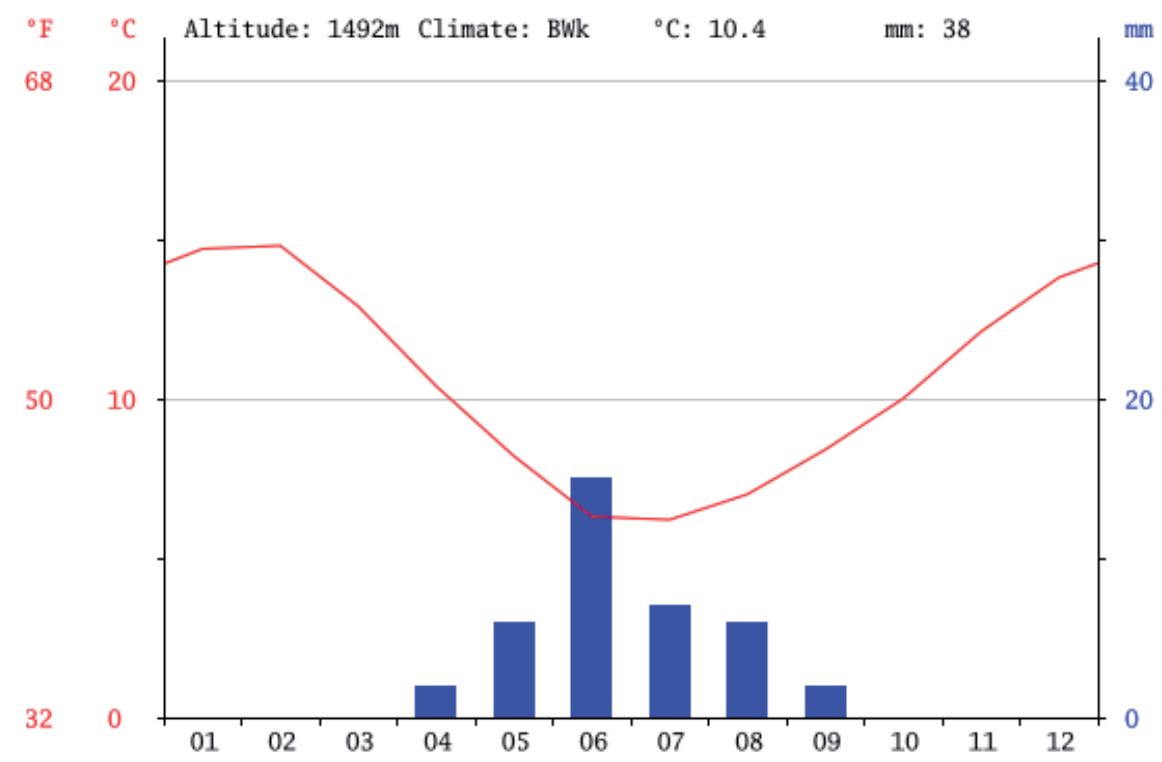

Figure 5. Climate chart for the city of Chollay

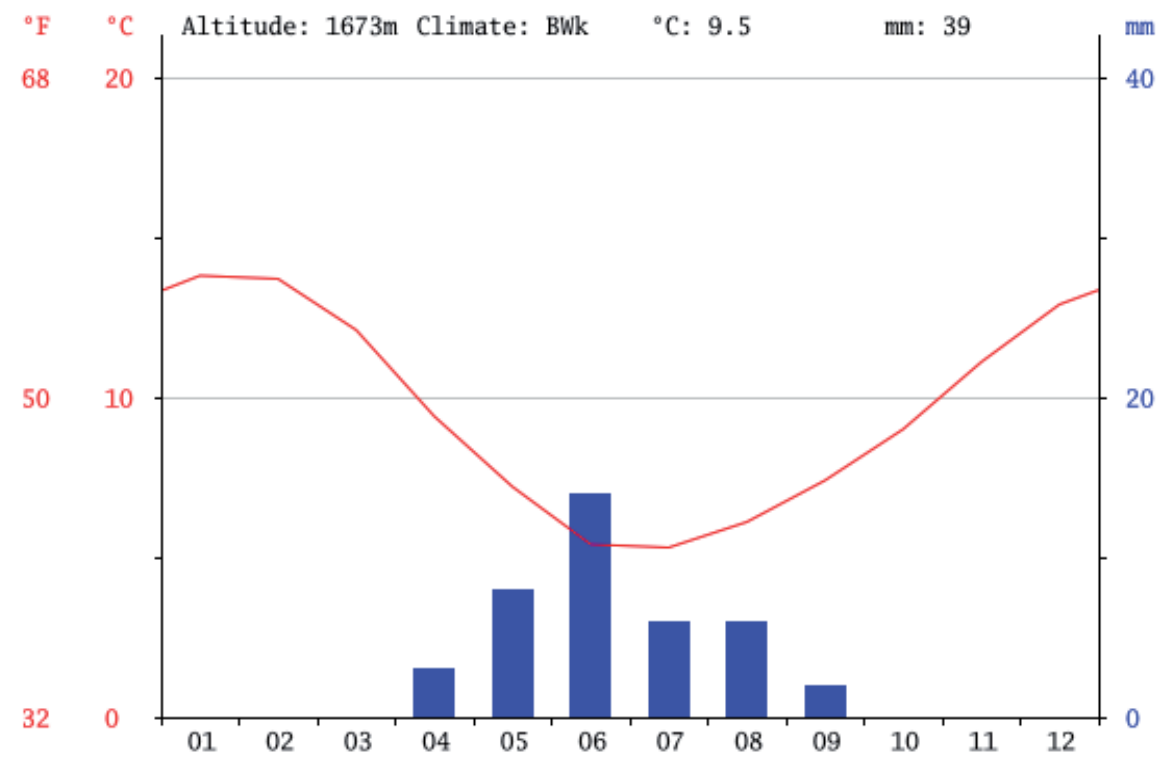

Figure 6. Climate chart for the city of Conay

where $r_{x y}$ is the xy covariance, $r_{x}$ and $r_{y}$ are the standard deviations, respectively.

Q can vary between -1 and 1 . In case that the correlation coefficient is 1 , there is a perfect increasing linear correlation; if it is -1 , a perfect decreasing linear relationship can be found 
between the variables; in all other cases, the value indicates to which degree a linear dependency exists. So, a 0 value means that no correlation exists between two analysed parameters.

For our study, this can be interpreted the following way:

\begin{tabular}{lll}
\hline & $\mathbf{r}_{\text {surface, temperature }}$ & $\mathbf{r}_{\text {surface, precipitation }}$ \\
\hline Positive & Glacier surface area decrease (increase) & Glacier surface area decrease (increase) \\
& due to temperature decrease (increase) & due to precipitation decrease (increase) \\
\hline Zero & No correlation between glacier surface & No correlation between glacier surface \\
& area and temperature variations & area and temperature variations \\
\hline Negative & Glacier surface área decrease (increase) & Glacier surface área decrease (increase) \\
& due to temperature increase (decrease) & due to precipitation increase (decrease) \\
\hline
\end{tabular}

Table 5. Possible results of correlation coefficients statistics and their interpretation regarding surface

\section{Results and discussion}

The Figures 7-13 show how surface area of the studied glaciers and glacierets has reduced during the past 25 years. The blue line indicates the glacier extent in 1994, whereas the green line delimitates the glacier area which was observed in the last suitable satellite image. The surface area which was lost during the past two decades is highlighted by linear hatching in red colour.

In case of Los Amarillos glacier (Figure 7), surface area difference between 1994 and 2015 is $43.53 \%$. More area loss can be identified in the southeastern part of the glacier.

Amarillo glacier (Figure 8), during the past 20 years, has diminished $62.12 \%$. In particular, the southern extend of the glacier has significantly reduced.

Figure 9, which shows the surface area loss at Estrecho glacier, indicates that it has lost surface area almost uniformly; no specific spatial trend can be identified. All margins have uniformly reduced by means of extend. Surface area loss was $43.45 \%$.

For Guanaco glacier (Figure 10), a similar behaviour as for Estrecho glacier can be identified, except the most westerly area, which has completely gone. In 1994, it was already isolated and only connected to the main glacier area by an ice bridge. Total surface area loss during the past 2 decades was $33.84 \%$.

Toro 1 and Toro 2 (Figures 11 and 12) have shown similar spatial behaviours. The eastern part of both glacierets is gone. Only about $4 \%$ of the original surface area remains.

In Esperanza glacier (Figure 13), whose spatial extend was from north to south, surface area loss happened mostly in this spatial direction. Nowadays, the geometry of this glacieret is almost circular. 


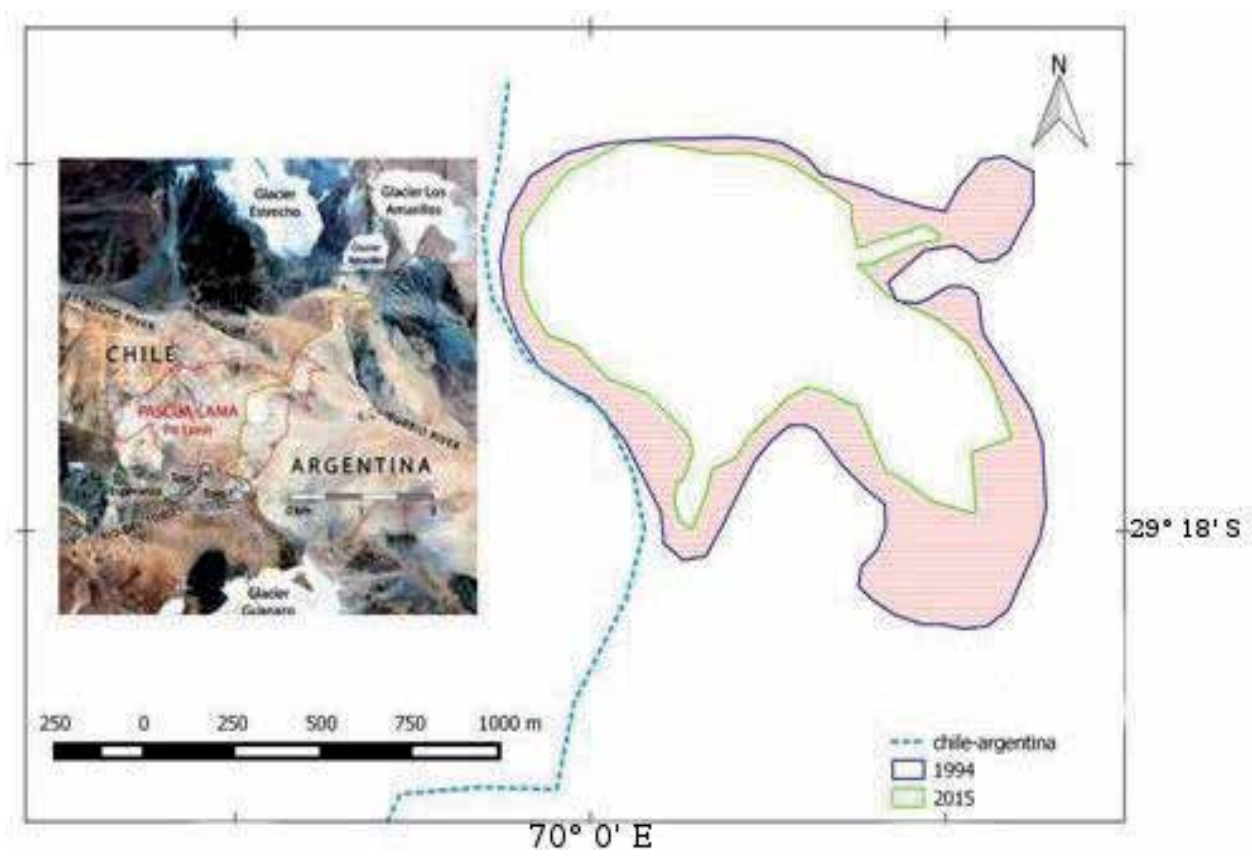

Figure 7. Surface area change of glacier Los Amarillos

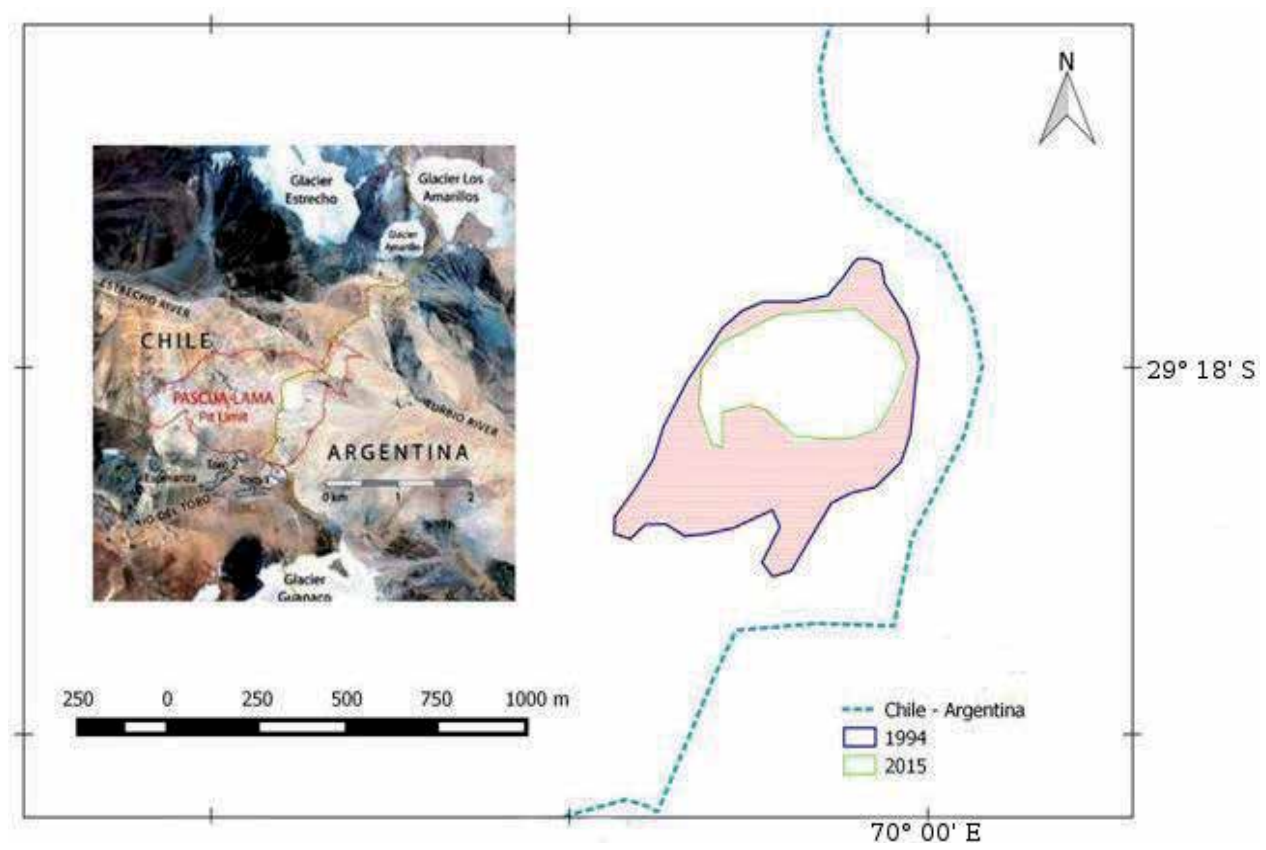

Figure 8. Surface area change of glacier Amarillo 


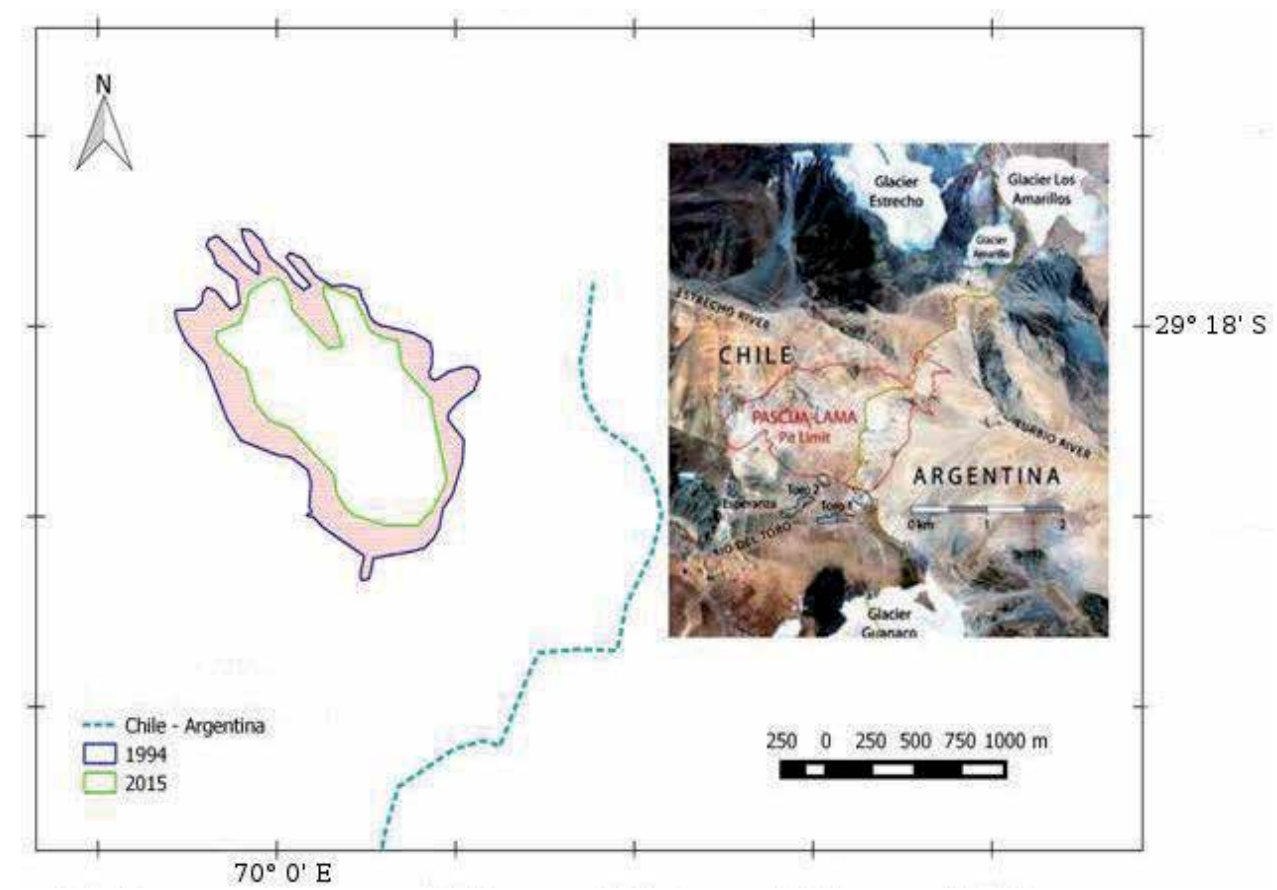

Figure 9. Surface area change of glacier Estrecho

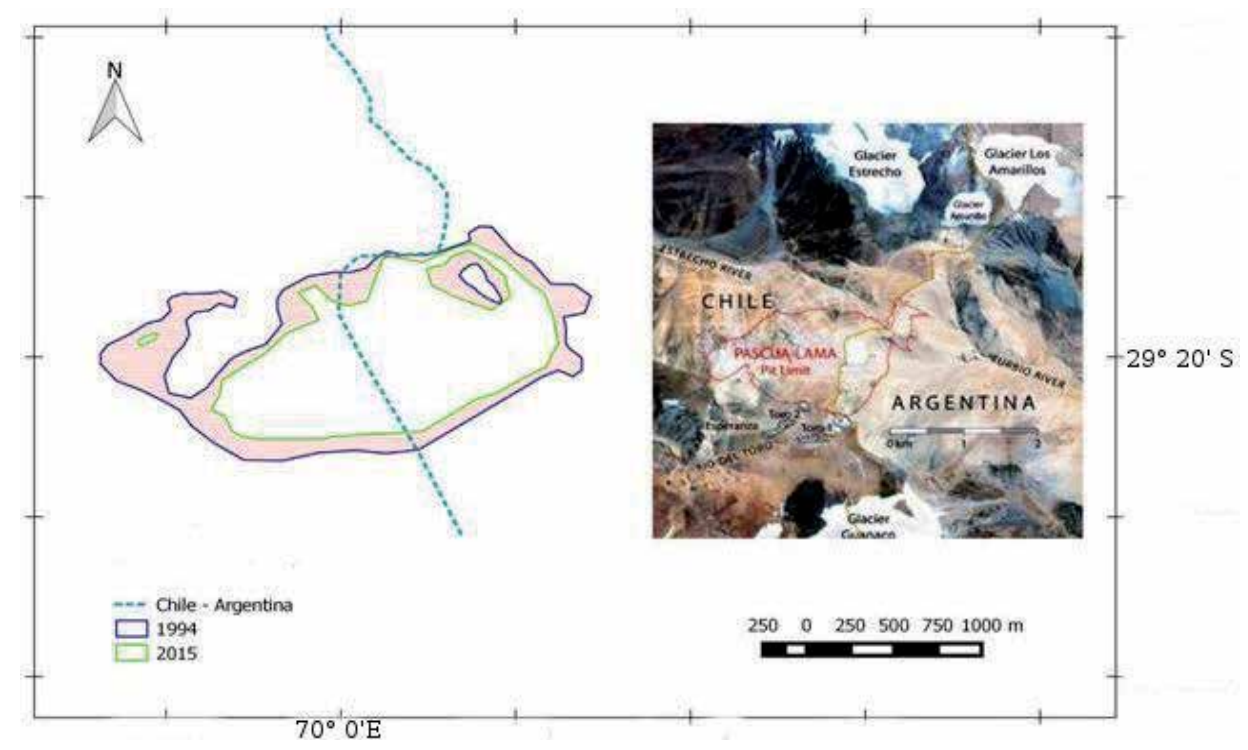

Figure 10. Surface area change of glacier Guanaco 


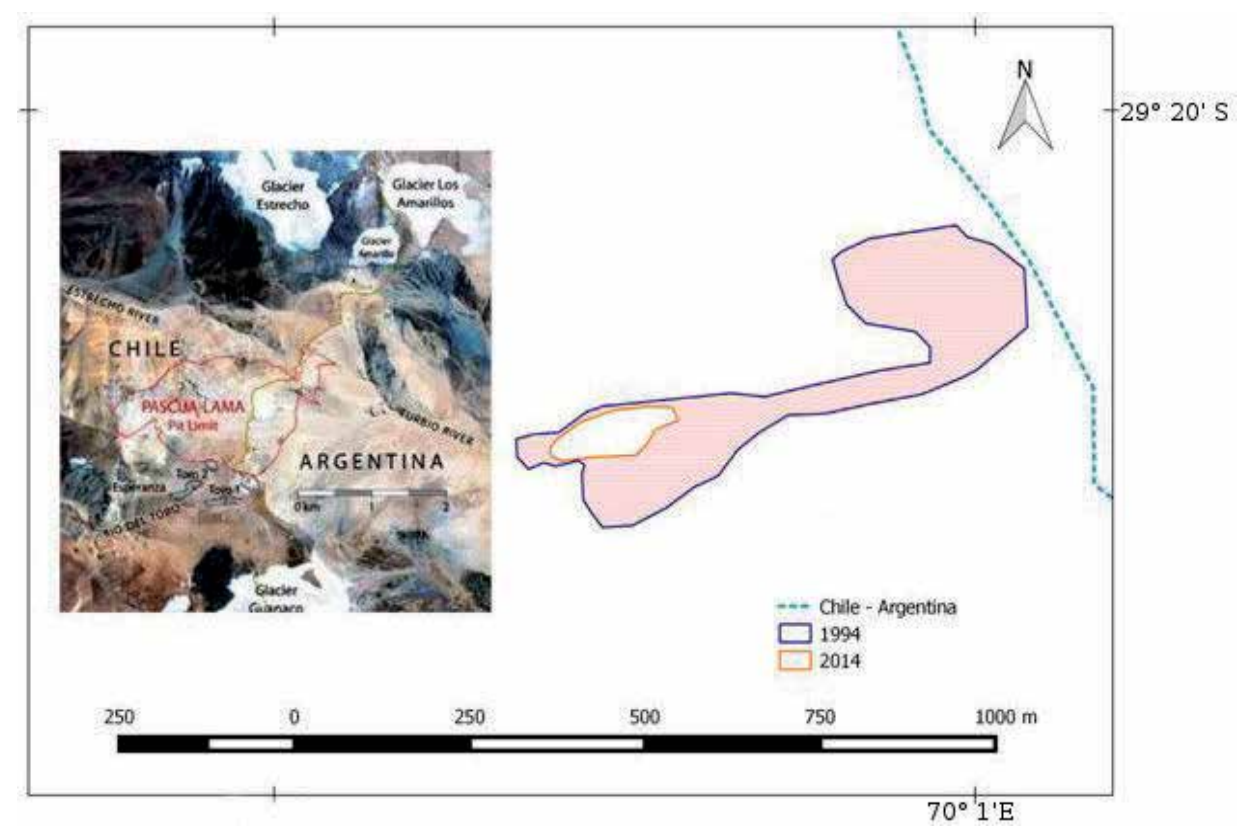

Figure 11. Surface area change of glacieret Toro 1

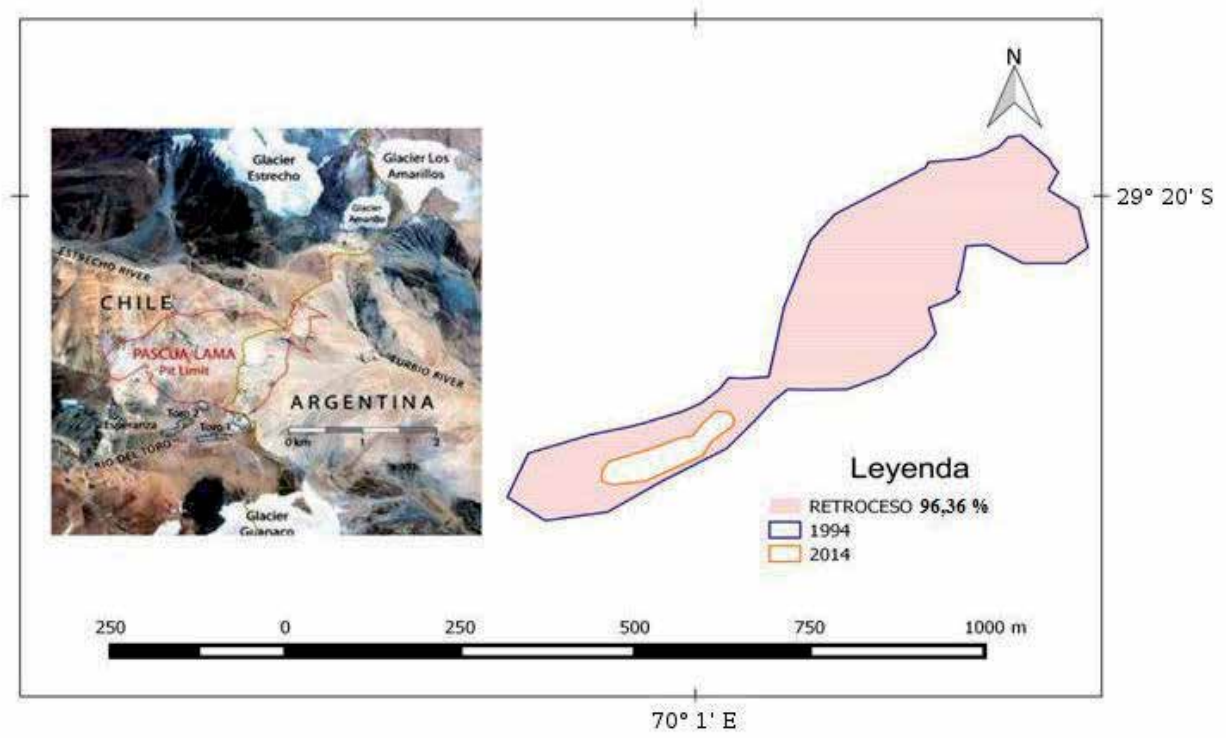

Figure 12. Surface area change of glacieret Toro 2 


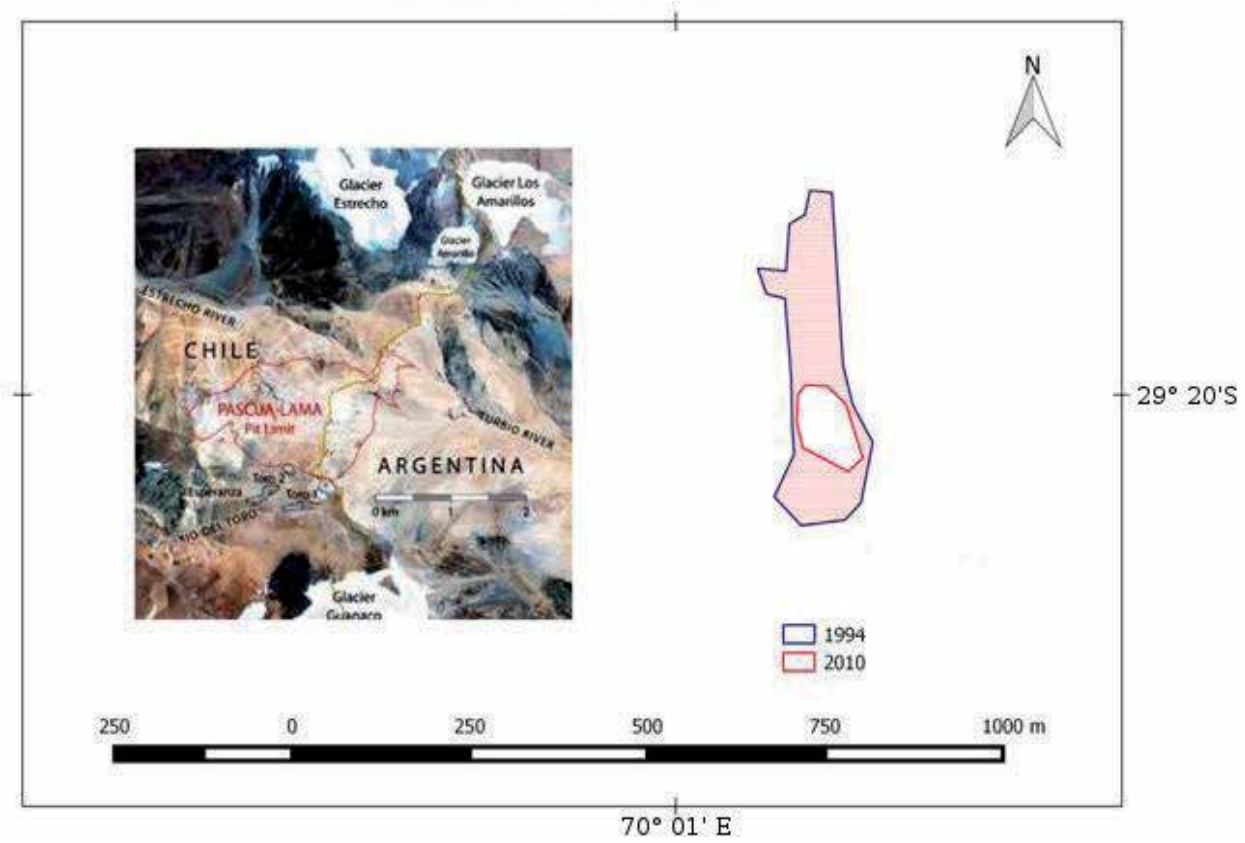

Figure 13. Surface area change of glacieret Esperanza

Table 6 shows the results of the digitalisation carried out to determine surface area variations. Only summer months were considered and satellite images of every second year were taken into account. The generated graphs show that all glaciers and glacierets have suffered surface area loss during the past 21 years. Nevertheless, some of them were able to recover during 2004, 2006 and/or 2008.

\begin{tabular}{lcccccccccccc}
\hline & 1994 & 1996 & 1998 & 2000 & 2002 & 2004 & 2006 & 2008 & 2010 & 2012 & 2014 & 2015 \\
\hline Los & 1,291 & 1,104 & 1,293 & 1,296 & 1,149 & 1,263 & 1,031 & 1,274 & 0,855 & 0,796 & 0,852 & 0,729 \\
Amarillos & & & & & & & & & & & & \\
\hline Amarillo & 0,378 & 0,376 & 0,491 & 0,379 & 0,331 & 0,317 & 0,334 & 0,278 & 0,168 & 0,134 & 0,173 & 0,143 \\
\hline Estrecho & 1,459 & 1,865 & 1,366 & 1,311 & 1,081 & 1,356 & 1,439 & 1,350 & 1,117 & 0,954 & 0,986 & 0,825 \\
\hline Guanaco & 2,077 & 2,254 & 2,181 & 2,038 & 1,999 & 1,942 & 1,720 & 1,893 & 1,668 & 1,479 & 1,482 & 1,374 \\
\hline Toro 1 & 0,163 & 0,137 & 0,233 & 0,101 & 0,059 & 0,063 & 0,090 & 0,084 & 0,019 & 0,000 & 0,008 & 0,000 \\
\hline Toro 2 & 0,199 & 0,124 & 0,364 & 0,044 & 0,022 & 0,060 & 0,089 & 0,113 & 0,000 & 0,000 & 0,007 & 0,000 \\
\hline Esperanza & 0,036 & 0,015 & 0,106 & 0,009 & 0,025 & 0,018 & 0,079 & 0,043 & 0,009 & 0,000 & 0,056 & 0,034 \\
\hline
\end{tabular}

Table 6. Absolute surface area values in sqkm from 1994 till 2015 
Toro 1, Toro 2 and Esperanza have not been gone. Here, zero values indicate that it was not possible to detect them in the satellite images of the corresponding years due to spatial resolution.

Since 1994, surface area of glaciers and glacierets analysed in this study has reduced as shown in Table 7. Toro 1 and Toro 2 have lost almost its entire surface. Esperanza seems to be stable as it was able to recover during the past decade and although it has lost $5 \%$ of its surface between 1994 and 2015. All the other glaciers show a continuous trend of surface area loss during the past 20 years.

\begin{tabular}{lllll}
\hline \multirow{2}{*}{ Glacier } & \multicolumn{3}{c}{ Glacier surface area sqkm } & Loss between 1994 and last year \\
\cline { 2 - 4 } & $\mathbf{1 9 9 4}$ & $\mathbf{2 0 0 4}$ & Last year & \\
\hline Los Amarillos & $\mathbf{1 , 2 9 1}$ & $\mathbf{1 , 0 3 1}$ & 0,729 & $43,53 \%$ \\
\hline Amarillo & 0,378 & 0,317 & 0,143 & $62,12 \%$ \\
\hline Estrecho & 1,459 & 1,356 & 0,825 & $43,45 \%$ \\
\hline Guanaco & 2,077 & 1,942 & 1,374 & $33,84 \%$ \\
\hline Toro 1 & 0,163 & 0,063 & 0,008 & $95,10 \%$ (until 2014) \\
\hline Toro 2 & 0,199 & 0,060 & 0,007 & $96,48 \%$ (until 2014) \\
\hline Esperanza & 0,036 & 0,018 & 0,034 & $5,60 \%$ \\
\hline
\end{tabular}

Table 7. Surface aera loss over the last 2 decades

In order to characterise the temporal behaviour of the glacier surface area lost and to detect its correlations with rainfall and temperature, trends and correlation coefficients as shown in Table 8 were calculated.

\begin{tabular}{lccc}
\hline & Trend (sqkm/a) & $\mathbf{r}_{\text {Surface, Temperature }}$ & $\mathbf{r}_{\text {Surface, } \text { Precipitation }}$ \\
\hline Los Amarillos & $-0,024$ & $-0,4$ & 0,2 \\
\hline Amarillo & $-0,015$ & $-0,4$ & 0,4 \\
\hline Estrecho & $-0,032$ & $-0,4$ & 0,8 \\
\hline Guanaco & $-0,039$ & $-0,5$ & 0,5 \\
\hline Toro 1 & $-0,009$ & $-0,2$ & 0,5 \\
\hline Toro 2 & $-0,010$ & 0,0 & 0,4 \\
\hline Esperanza & $-0,001$ & 0,4 & 0,1 \\
\hline
\end{tabular}

Table 8. Trend in surface area lost and correlation coefficients

Precipitation at the mentioned climate stations Conay, Chollay and Vallenar are shown in Table 9. A couple of peaks can be observed which in general coincide with El Niño years. 
Furthermore, compared to long-term observations as shown in Figures 6, 7 and 8, in 2004, 2006, 2012 and 2015, an absence of precipitation is observable. This also coincides with La Niña events that have been reported. During the past two decades, precipitation only in 1994 (Vallenar) and 2014 (Vallenar, Conay, Chollay) reached normal values.

\begin{tabular}{lllllllllllll}
\hline Station & 1994 & 1996 & 1998 & 2000 & 2002 & 2004 & 2006 & 2008 & 2010 & 2012 & 2014 & 2015 \\
\hline Vallenar & 24,885 & 5,27 & 0,125 & 1,965 & 0,763 & 0,000 & 0,000 & 7,900 & 4.875 & 0,100 & 12.300 & 0,575 \\
\hline Conay & -- & -- & -- & -- & -- & -- & -- & 8,150 & 5,400 & 0,050 & 12,100 & 0,000 \\
\hline Chollay & -- & -- & -- & -- & -- & -- & -- & 8,15 & 5,525 & 0,175 & 11,65 & 0,525 \\
\hline
\end{tabular}

Table 9. Average precipitation in mm during winter months

At all three stations, a positive temperature trend can be observed. Table 10 shows mean temperature during summer from 1994 onwards at Vallenar and from 2010 onwards for Conay and Chollay. In particular, summer of 2013 and 2015 shows huge variations in comparison to long-term climate observation (Figures 6, 7 and 8). Summer (December, January, February) mean temperature observed between 1982 and 2012 (Source: http://en.climate-data.org/) Vallenar station is $19.8^{\circ} \mathrm{C}$; at Conay station $13.5^{\circ} \mathrm{C}$; at Chollay station $14.4^{\circ} \mathrm{C}$.

Our results indicate that all studied ice bodies have reduced in terms of extent over the past few decades and that there is a significant surface area loss in the glaciers and glacierets studied. Some of them show significant changes (Guanaco, Estrecho and Los Amarillos), whereas others seem to be more stable (Esperanza). Smaller ice bodies, glacierets, are more affected than glaciers. In particular, the Guanaco glacier shows major loss of surface area with a trend of $-0.039 \mathrm{sqkm} / \mathrm{a}$. It has already been reported by [55] that Guanaco, in comparison to other glaciers and glacierets in this area, shows major melt rates during summer months. On the other hand, the Esperanza glacier is the one which has almost remained stable. Its surface area loss has a tendency of $-0.001 \mathrm{sqkm} / \mathrm{a}$.

\begin{tabular}{lllllllllllllll}
\hline Station & 1994 & 1996 & 1998 & 2000 & 2002 & 2004 & 2006 & 2008 & 2010 & 2011 & 2012 & 2013 & 2014 & 2015 \\
\hline Vallenar & 19,7 & 19,9 & 21,0 & 19,4 & 19,3 & 17,2 & -- & -- & 18,3 & 19,0 & 21,5 & 22,7 & 22,3 & 23,3 \\
\hline Conay & -- & -- & -- & -- & -- & -- & -- & -- & 19,6 & 18,5 & 20,7 & 22,6 & 20,1 & 24,4 \\
\hline Chollay & -- & -- & -- & -- & -- & -- & -- & -- & 19,5 & 19,6 & 20.5 & 22,7 & 20,6 & 24,3 \\
\hline
\end{tabular}

Table 10. Average temperatura in ${ }^{\circ} \mathrm{C}$ during summer months

In addition, considering climate variables like temperature and precipitation, surface area variation of glaciers and glacierets does weakly correlate with them. Only in case of Guanaco glacier, where the coefficient of correlation between surface temperature and surface-precipitation reaches values around 0.5 , relationship between the variables can be interpreted as more dominant.

ENSO events can clearly be identified using MEI. Although in case of the Chilean Andes region, it is supposed that during El Niño years precipitation increases (as in 1998), this does not mean 
that glaciers and glacierets do not suffer surface area loss. But this does not mean that during La Niña years (e.g. 2010/11), surface area loss does accelerate neither.

A possible negative impact on the glaciers caused by the Pascua-Lama mining project or any other human activity was not considered, and our results do not indicate any correlation either. This coincides with a scientific report, which was recently published by [56]. They also could not find any evidence for surface area loss due to anthropogenic intervention in the study area. They attribute glacier variability to climate change and ENSO events. Nevertheless, due to contentious issues, this subject has to be analysed apart.

\section{Conclusions}

It has to be concluded that the overall climate situation at high latitudes of the Chilean Andes Mountain does have a negative impact on ice bodies. La Niña and El Niño events can be detected and it is possible to correlate them with variations in temperature and precipitation. As temperature during the past 25 years has augmented and precipitation has decreased, glaciers and glacierets have diminished their surface area.

There is evidence that lack of precipitation has a major impact on surface area loss. As an example, Esperanza glacieret was able to recover surface area loss in 2014 when precipitation average at all three stations was almost normal. This coincides with the results reported by [23]. Nevertheless, our results also indicate huge temperature variations and therefore we conclude that nowadays both climate variables have to be considered as responsible for glacier and glacieret surface area loss in the Commune of Alto del Carmen.

Although anthropogenic interventions in the study area are present, such as Pascua-Lama mining project, climate variability does play a major role in glacier changes. Nevertheless, this does not mean that human interference on ecosystems has to be tolerated. Every man-made alteration has to be reviewed critically and in particular in case of exploitation of natural resources, vital for flora and fauna, they have to be carried out complying with several standards protecting our planet. Nowadays, there are lots of technical possibilities, such as GIS and remote sensing that are well known and understood from geosciences, which allow a sustainable management of natural resources.

\section{Author details}

Guido Staub* and Catherinne Muñoz

*Address all correspondence to: gstaub@udec.cl

Universidad de Concepción, Departamento de Ciencias geodésicas y Geomática, Los Ángeles, Chile 


\section{References}

[1] Marshall, S. Glacier retreat crosses a line. Science. 2014;872:345.

[2] Mote, P. and Kaser, G. The Shrinking Glaciers of Kilimanjaro: Can Global Warming Be Blamed?. American Scientist. 2007;95:318.

[3] IPCC. CLIMATE CHANGE 2001: THE SCIENTIFIC BASIS [Internet]. 2001. Available from: http://www.ipcc.ch/ipccreports/tar/wg1/ [Accessed: 01.09.2015]

[4] The Core Writing Team, Pacauri, R. \& Reisinger, A., editors. Climate Change 2007: Synthesis Report - Contribution of Working Groups I, II and III to the Fourth Assessment Report of the Intergovernmental Panel on Climate Change. Geneva, Switzerland: IPCC; 2007. 104 p.

[5] Painter, T., Flanner, M., Kaser, G., Marzeion, B., VanCuren, R. and Abdalati, W. End of the Little Ice Age in the Alps forced by industrial black carbon. Proceedings of the National Academy of Sciences of the United States of America. 2013;110(38):1521615221.

[6] Shakun, J., Clark, P., He, F., Lifton, N., Li, Z., Otto-Bliesner, B. Regional and global forcing of glacier retreat during the last deglaciation. Nature Communications. 2015;6DOI: 10.1038/ncomms9059

[7] López-Morenoa,, J., Fontanedaa, S., Bazob, J., Revueltoa, J., Azorin-Molinaa, C., Valero-Garcésa, B., Morán-Tejedaa, E., Vicente-Serranoa, S., Zubietac, R., Alejo-Cochachínd, J. Recent glacier retreat and climate trends in Cordillera Huaytapallana, Peru. Global and Planetary Change. 2014;112:2014. DOI: 10.1016/j.gloplacha.2013.10.010

[8] van der Ploeg, F. Natural Resources: Curse or Blessing?. Journal of Economic Literature. 2011;49(2):366-420.

[9] O'Neill, D. Measuring progress in the degrowth transition to a steady state economy. Ecological Economics. 2012;84:221-231.

[10] Harris, J., Roach, B. Environmental and Natural Resource Economics: A Contemporary Approach. 3rd ed. Routledge; 2014. 584 p.

[11] American Chemical Society. What are the greenhouse gas changes since the Industrial Revolution? [Internet]. Available from: http://www.acs.org/content/acs/en/climatescience/greenhousegases/industrialrevolution.html [Accessed: 02.09.2015]

[12] Delworth, T. and Knutson, T. Simulation of Early 20th Century Global Warming. Science. 2000;287:2246-2250.

[13] Zhang, R., Delworth, T. Simulated Tropical Response to a Substantial Weakening of the Atlantic. Journal of Climate. 2015;18:1853-1860. 
[14] NSIDC. World Glacier Inventory [Internet]. 1999 [Updated: 2015]. Available from: https://nsidc.org/data/docs/noaa/g01130_glacier_inventory/ [Accessed: 01.10.2015]

[15] Glaciares: Reservas Estratégicas de Agua Dulce [Internet]. 2011. Available from: http://es.slideshare.net/boletinvertientes/glaciares-reservas-estratgicas-de-aguadulce-chile-sustentable [Accessed: 05.09.2015]

[16] Favier, V., Falvey, M., Rabatel, A., Praderio, E., and López, D. Interpreting discrepancies between discharge and precipitation in high-altitude area of Chile's Norte Chico region (26을 $\left.32^{\circ} \mathrm{S}\right)$. Water Resources. 2009;45DOI: 10.1029/2008WR006802

[17] Masiokas, M. H., Villalba, R., Luckman, B. H., Le Quesne, C., and Aravena, J. C. Snowpack variations in the Central Andes of Argentina and Chile, 1951-2005: largescale atmospheric influences and implications for water resources in the region. Journal of Climate. 2006;19:6334-6352.

[18] Vuille, M. and Milana, J. P. High-latitude forcing of regional aridification along the subtropical west coast of South America. Geophysical Research Letters. 2007;34DOI: 10.1029/2007GL031899

[19] Leiva, J. C. Recent fluctuations of the Argentinian glaciers. Global and Planetary Change. 1999;22:169-177. DOI: 10.1016/S0921-8181(99)00034-X

[20] Rivera, A., Acuña, C., Casassa, G., and Bown, F. Use of remote sensing and field data to estimate the contribution of Chilean glaciers to sea level rise. Annals of Glaciology. 2002;34:367-372.

[21] Ginot, P., Kull, C., Schotterer, U., Schwikowski, M., and Gaeggeler, H. W. Glacier mass balance reconstruction by sublimation induced enrichment of chemical species on Cerro Tapado (Chilean Andes). Climate of the past. 2006;2:21-30.

[22] Nicholson. L., Marín, J., Lopez, D., Rabatel, A., Bown, F., and Rivera, A. Glacier inventory of the upper Huasco valley, Norte Chico, Chile: glacier characteristics, glacier change and comparison to central Chile. Annals of Glaciology. 2009;50:111-118.

[23] Rabatel, A., Castebrunet, H., Favier, V., Nicholson, L., and Kinnard, C. Glacier changes in the Pascua Lama region, Chilean Andes (29 $\mathrm{S})$ : recent mass balance and 50yr surface area variations. The Cryosphere. 2011;5:1029-1041.

[24] Kumar, R. Encyclopaedia of snow, ice and glaciers, Encyclopaedia of earth sciences series. 2014. 436 p.

[25] Albertz, J. Einführung in die Fernerkundung. Grundlagen und Interpretation von Luft- und Satellitenbildern. 3rd ed. WBG; 2007. 264 p.

[26] Dyurgerov M. B., Meier M. F. Twentieth century climate change: Evidence from small glaciers. PNAS. 2000;97(4):1406-1411. 
[27] Karpilo, R. Glacier monitoring techniques. In: Young, R., Norby, L, editors. Geological Monitoring: Boulder, Colorado. The Geological Society of America; 2009. p. 141-162.

[28] Sulzer, W., Lieb, G.. Die Gletscher im wandel der Zeit - Gletschermonitoring am Beispiel der Pasterze. Vermessung \& Geoinformation. 2009;3:371-382.

[29] Arendt, A., Echelmeyer K.A., Harrison W.D., Lingle C.S., Valentine V.B. Rapid wastage of Alaska glaciers and their contribution to rising sea level. Science. 2002;297(5580):382-386.

[30] E. Rignot, A. Rivera, G. Casassa. Contribution of the Patagonia Icefields of South America to sea level rise. Science. 2003;302(5644):434-437.

[31] Racoviteanu A., Arnaud Y., Williams M. Decadal changes in glacier parameters in Cordillera Blanca, Peru derived from remote sensing. Journal of Glaciology. 2008;54(186):499-510.

[32] Paul F., Kääb A., Maisch M., Kellenberger T., Haeberli W. Rapid disintegration of Alpine glaciers observed with satellite data. Geophysical Research Letter. 2004;31(21):14.

[33] Kääb A. Combination of SRTM3 and repeat ASTER data for deriving alpine glacier flow velocities in the Bhutan Himalaya.. Remote Sensing of the Environment. 2005;94(4):463-474.

[34] Bolch T. Climate change and glacier retreat in northern Tien Shan (Kazakhstan/ Kyrgyzstan) using remote sensing data. Global Planet Change. 2007;56(1-2):1-12.

[35] Magaña V. and Quintanar, A.. On the use of a general circulation model to study regional climate. In: Cambridge University Press, editor. 2nd. UNAM-CRAY Supercomputing Conference on Earth Sciences; Mexico City. 1997. pp. 39-48.

[36] Magaña, V., Pérez, L. and Conde, C. El fenómeno de El Niño y la Oscilación del sur y sus impactos en México. Revista Ciencias. 1998;51:14-18.

[37] Poveda, G. and Mesa, O. Feedbacks between hydrological processes in tropical South America and large scale oceanic-atmospheric phenomena. Journal of Climate. 1997;10:2690-2702.

[38] Bookhagen, B. and Strecker, M. Modern Andean rainfall variation during ENSO cycles and its impact on the Amazon drainage basin. In: C. Hoorn and F.P. Wesselingh, editors. Amazonia, Landscape and Species Evolution: A Look into the Past. 1st ed. 2010.

[39] Diaz, H. and Kiladis, G. Atmospheric teleconnections associated with the extreme phases of the Southern Oscillation. In: H.F. Diaz and V. Markgraf, editors. Paleoclimatic Aspects of El Niño/Southern Oscillation. Cambridge Press; 1997. 
[40] Grimm, A., Barros, V. and Doyle, M. Climate Variability in Southern South America Associated with El Niño and La Niña Events. Journal of Climate. 2000;13:35-58.

[41] Halpert, M. and Ropelewski, C. Surface Temperature Patterns associated with the Southern Oscillation. Journal of Climate. 1992;5:577-593.

[42] Compagnucci, R. H. and Vargas, W. M. Inter-annual variability of the Cuyo rivers' streamflow in the Argentinean Andean mountains and ENSO events. International Journal of Climatology. 1998;18:1593-1609.

[43] Rutland J. and Fuenzalida, H. Synoptic aspects of the central Chile rainfall variability associated with the Southern Oscillation. International Journal of Climatology. 1991;11:63-76.

[44] Quinn, W. And Neal, V. The historical record of El Niño events. Climate since A.D. 1500. In: S. Bradley and P. D. Jones, editors. Routledge; 1982.

[45] Garreaud, R. and Rutllant, J. Análisis meteorológico de los aluviones de Antofagasta y Santiago de Chile en el periodo 1991-1993. Atmósfera. 1996;9:251-271.

[46] Waylen, P. and Caviedes, C. Annual and seasonal fluctuations of precipitation and streamflow in the Aconcagua river basin, Chile. Journal of Hydrology. 1992;120:79102.

[47] Martinez, C., Fernández, A. and Rubio, P. Flow and climatic variability on a South American Mid-Latitude basin: Río Aconcagua, Central Chile (33ㅇ). Boletín de la Asociación de Geógrafos Española. 2012;58:481-485.

[48] Baldenhofer, K. ENSO Lexikon [Internet]. 1998 [Updated: 2015]. Available from: http://www.enso.info/enso-lexikon/lexikon-m.html [Accessed: 02.09.2015]

[49] Wolter, K. The Southern Oscillation in surface circulation and climate over the tropical Atlantic, Eastern Pacific, and Indian Oceans as captured by cluster analysis. Journal of Applied Meteorology and Climatology. 1987;26:540-558.

[50] Wolter, K., and Timlin, M. Monitoring ENSO in COADS with a seasonally adjusted principal component index. In: Proc. of the 17th Climate Diagnostics Workshop; Norman, OK, USA. 1993. pp. 52-57.

[51] Li, J., Wang, M. H., Ho, Y. S. Trends in research on global climate change: A Science Citation Index Expanded-based analysis. Global Planet Change. 2011;77:13-20.

[52] Ghent, D., Kaduk, J., Remedios, J., Balzter, H. Data assimilation into land surface models: The implications for climate feedbacks. International Journal of Remote Sensing. 2011;32:617-632.

[53] Saha, S., Moorthi, S., Pan, H.-L., Wu, X., Wang, J., Nadiga, S., et al. The NCEP Climate Forecast System Reanalysis. Bull. Amer. Meteor.. 2010;91(8):1015-1057. 
[54] GolderAssociates S.A. Área de Pascua Lama,Tercera Región de Atacama, Recopilación de estudios de línea base actualizada de la criósfera. In: 2009.

[55] MacDonell, S., Mölg, T., Nicholson, L. Kinnard, C. The surface energy balance of the Guanaco and Toro 1 glaciers in the Norte Chico region, Chile. In: EGU General Assembly 2010; 2-7 May, 2010; Vienna, Austria. COPERNICUS; 2012. p. 11042.

[56] Bown, F., Carrión, D., Bravo, C., Hernández, J., Muñoz, C., Correa, J., et al. Greenpeace [Internet]. 2015. Available from: http://www.greenpeace.org/chile/Global/chile/ Fotos/Clima\%20y\%20Energia/2015/10/Informe\%20Excedencia_2015-2.pdf [Accessed: November 2015] 
Chapter 4

\title{
Remote Sensing of the Glacial Environment Influenced by Climate Change
}

\author{
Arshad Ashraf, Manshad Rustam, Shaista ljaz Khan, \\ Muhammad Adnan and Rozina Naz
}

Additional information is available at the end of the chapter

http://dx.doi.org/10.5772/62134

\begin{abstract}
Remote sensing-based observations prove to be critical for the monitoring and assessment of cryosphere in the Himalayan region, where routine data collection in mountainous regions is often hampered by highly inaccessible terrain and harsh climatic conditions. The glacierized region of High Asia is also facing the effects of climate change in the form of rapid melting of glacial ice, creation of new lakes, and expansion of the existing ones, which eventually result in hazardous glacial floods downstream. Multisensor remote sensing (RS) data, e.g., MODIS, Landsat-7 \& 8, and SPOT-5 XS, coupled with Google Earth and digital elevation model (DEM) data were used to investigate the snow/ glacier resources and their dynamics in the Karakoram-Himalaya basins adopting variable image interpretation and modeling techniques. Minimum numbers of large-sized glaciers were identified in the Himalaya range, which points toward higher rates of glacial ice melting in this range. On the contrary, the presence of relatively higher numbers of medium- to large-sized glaciers in the Karakoram range provides an evidence of favorable climate conditions for the glaciers' existence at higher altitudes. A significant gain in snow cover was observed in Hunza basin during the 2001-2011 period, which may feed high-altitude zone resulting in net expansion of the snow cover and ice mass gain in the Karakoram. The integrated use of RS and geographical information systems (GIS) techniques with sparse in situ data is found to be helpful in analyzing the glacial environment in the context of changing climate in the high-altitude Himalayan region.
\end{abstract}

Keywords: Snow cover, Glacial environment, Climate change, Karakoram range

\section{Introduction}

The glacierized region of Hindu Kush-Karakoram-Himalaya $(\mathrm{HKH})$ often referred to as the 'water tower of Asia' stores large volumes of water in the form of ice and snow after the polar 
ice releases freshwater to the Indus, Ganga, and Brahmaputra rivers. Climate change is being predicted by glacial lakes due to their property of acting as sensitive indicators [1], and unstable lakes can pose potential threats to downstream communities and infrastructure [2]. Monitoring of glaciers, glacial lakes, and assessment of glacial lake outburst flood (GLOF) impact downstream can be done quickly and rather reliably through remote sensing data interpretation and analysis. RS technology and GIS have often been used by decision makers as an effective and powerful tool to solve environmental issues [3]. In combination with GIS, RS methods provide useful means to detect potentially hazardous situations and to perform a preliminary assessment of the related hazard potential [4]. Remote sensing data from satellites are very helpful for mapping and monitoring glaciers and their changes over large areas, repeatedly, and by covering large regions with sufficient spatial detail at the same time [5,6]. In combination with digital elevation models, RS data and methods offer the possibility to generate standardized glacier and glacial lake inventories.

When electromagnetic (EM) energy encounters matter, such as solid, liquid, or gas, a number of interactions are possible that may take place at the surface or beneath the surface of a substance. These interactions produce numerous changes in the incident EM radiation primarily in the form of change in magnitude, direction, wavelength, polarization, and phase. The science of RS detects and records these changes, which can be interpreted to identify the characteristics of the matter or land use/land cover, such as various types of vegetation cover, water bodies, soils, farming fields, and exposed rocks. The reflectance characteristics of the features like snow and ice vary according to their surficial/physical characteristics: the reflectance of snow is generally very high in the visible portions of the spectrum, whereas the reflectance of old snow and ice is always lower, i.e., due to compaction and presence of impurities, than that of fresh snow and clean/fresh glacier [7]. Similarly, the reflectance of finegrain snow is comparatively higher than that of coarse-grain snow and glacial ice in the visible portion of the spectrum [8] (Figure 1). Comprehensive reviews of remote sensing systems, data types, techniques, and application to glacier-related hazards have been provided in Refs. [911]. RS technique provides additional opportunities for more complete surveys of glaciers to provide early warning of the potential formation of ice-dammed lakes [12]. The widely used earth observation (EO) sensors in the context of glacier inventory production include the Landsat MSS (Multispectral Scanner), TM (Thematic Mapper), ETM+ (Enhanced Thematic Mapper Plus), OLI (Operational Land Imager), ASTER (Advanced Spaceborne Thermal Emission and Reflection Radiometer) onboard the Terra platform, and the SPOT (Satellite Pour l'Observation de la Terre) satellites. In combination with freely available DEM datasets, remote sensing data offer integrative approaches for observing and assessing the current situation of glaciers, glacier lakes, and associated hazard potential, as well as the means to develop scenarios of potential future evolutions [13]. The snow and ice-melt model like SRM (snowmelt runoff model), which is used to simulate and forecast daily streamflow in snowy and glacierized basins [14], requires accurate data on snow-cover area (SCA), which are provided by Landsat, Terra-MODIS (Moderate Resolution Imaging Spectroradiometer), ERS-SAR (European Remote Sensing-Synthetic Aperture Radar), and NOAA-AVHRR (National Oceanic and Atmospheric Administration-Advanced Very High Resolution Radiometer) satellite sensors 
[15]. For the first time, NOAA began to use remote sensing in 1966 for the detection of SCA to provide weekly estimates of snow cover in the Northern Hemisphere [16].

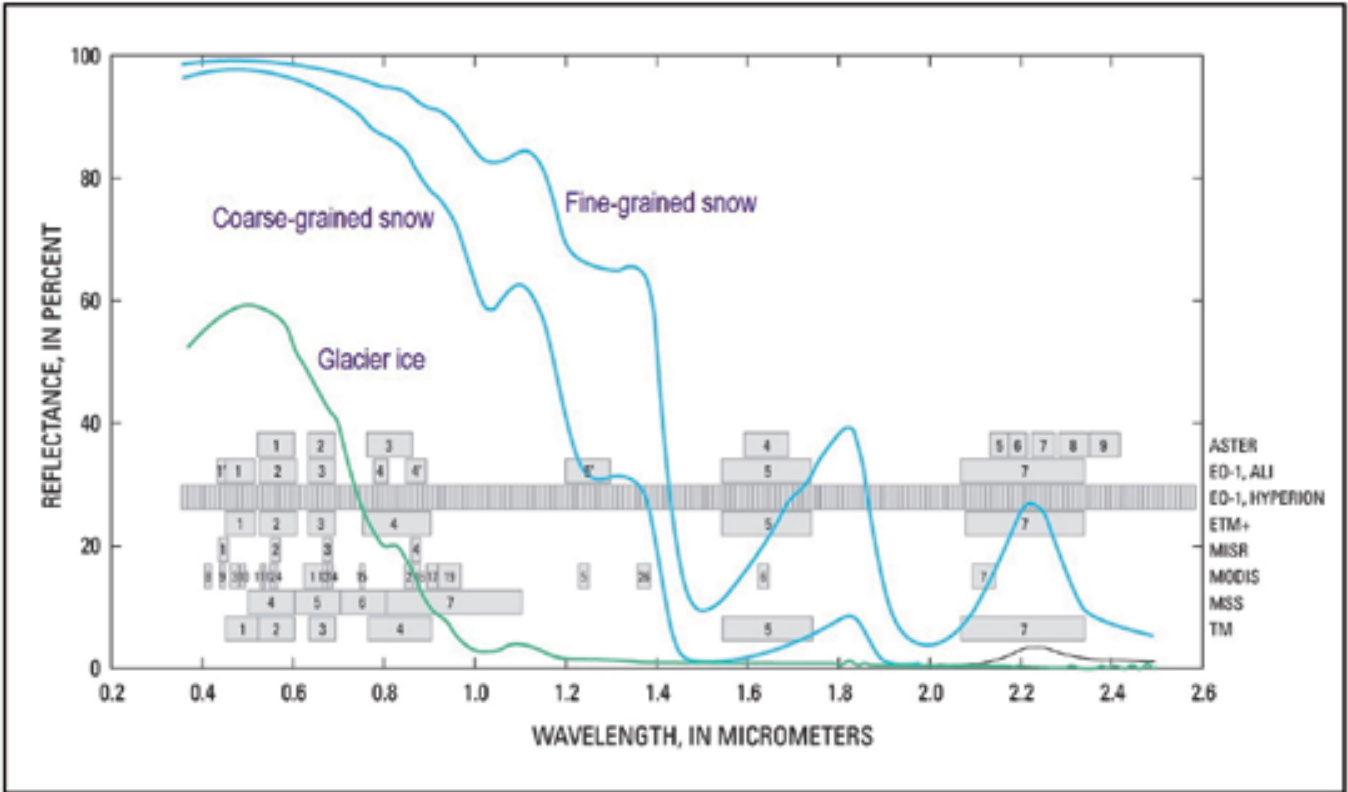

Figure 1. Reflectance response of snow and glacial ice in multisensor remote sensing data [8].

\section{Climate change impacts on glacial environment}

Glaciers are considered as very reliable and easily understandable natural indicators of climate change [17] due to their sensitive response to changes in temperature and precipitation [18]. They have been selected for this reason as an essential climate variable (ECV) by the global climate observing system (GCOS) [19]. According to IPCC [20], the global temperature has risen by $0.85^{\circ} \mathrm{C}$ since 1880 and the surface warming amounting to $3.7^{\circ} \mathrm{C}$ will be likely between 2081 and 2100 if greenhouse gas emissions stay roughly on their current path. The observed and projected changes in global average temperature relative to the 1986-2005 average under four emissions pathways are shown in Figure 2. The increase in air temperature influences the glacier mass balance [21], which is the balance between accumulation and ablation of glaciers [22]. The changes in mass balance cause variations in the volume and thickness of glaciers, which ultimately affect the flow of ice [21], and as a large fraction of the Indus flow is originated from meltwater, both magnitude and timing of the flow are vulnerable to climate change [23]. Furthermore, due to the temperature increase in the region, more precipitation in winter will fall as rainfall than as snowfall compared with the current situation. This rainfall will be added directly to the river system, instead of storing in the form of ice or snow in glaciers [24]. 
The IPCC Report of 2007 estimates a further warming of $3.7^{\circ} \mathrm{C}$ at the end of the 21st century; climate change has been observed through significant warming in the Hindu Kush Himalayas [25]. The climatic change in recent decades has made considerable impact on the glacier life cycle in the Himalayan region. With few exceptions, there has been a global trend toward glacier retreat since the beginning of the 20th century, with this retreat becoming more rapid and more uniform since the 1980s [26]. There will be a decrease of the glacier coverage in the coming decades as a result of global warming. This will lead to a short-term increase in water availability, in the coming decades, due to an increase in meltwater. However, the water availability will decrease in the long term during the second half of the 21st century. This decrease in water availability combined with a projected increase in water demand will cause water shortage for irrigation and thus food insecurity [27].

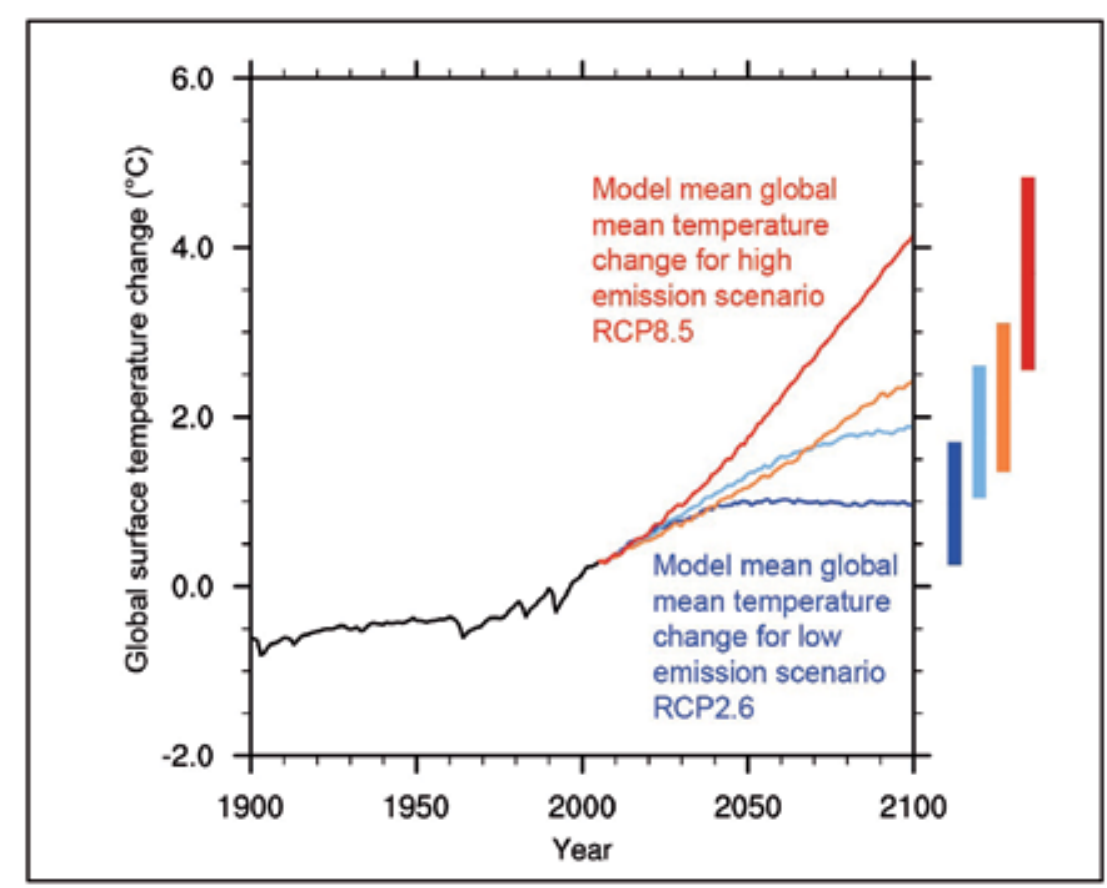

Figure 2. The changes in observed and projected global average temperature relative to the 1986-2005 average. The projections are averaged across a range of climate models. The vertical bars shown at right are likely ranges in temperature by the end of the century [20].

Some of the serious consequences of global warming in the Himalayan region include rapid melting of glaciers, creation of new lakes, and expansion of the existing ones posing high risk of glacial lake outburst flood hazard for downstream communities. The sudden increase in the frequency of floods in recent years, e.g., during 2007, 2008, 2010, 2012, and 2013 [28], demands a better understanding and investigation of the prevailing situation of the glaciers and glacial lakes in this region. The chapter describes a remote sensing-based approach to investigate environmental challenges posed by global warming in the Himalayan region. 


\subsection{Case study}

According to Chaudhry et al. [29], Pakistan experienced $0.76^{\circ} \mathrm{C}$ rise in temperature during the last four decades and the increase was $1.5^{\circ} \mathrm{C}$ in the mountain environment hosting thousands of glaciers. The average annual temperature and annual rainfall at Gilgit meteorological station in the Central Karakoram indicated overall rising trends during the 1960-2013 period (Figure 3). Under varying climate conditions, glaciers in various regions of the Hindu Kush-Karakoram-Himalayan belt behave differently under changeable climate conditions. A general shrinkage of glaciers has been observed in the Himalaya [30,31]; however, this does not imply a synchronous behavior of all glaciers, because there can be local differences and even advancing of existing glaciers [32, 33]. In the present study, snow-cover mapping of Hunza River basin situated in the Karakoram range of Pakistan was carried out using MODIS snow product for assessment of snow-cover dynamics under the changing climate. Multisensor RS data, i.e., MODIS product, LANDSAT-7 ETM+ (Enhanced Thematic Mapper plus), LANDSAT-8, and SPOT-5 XS (Multispectral) coupled with Google Earth and digital elevation model data (ASTER/SRTM) were used to investigate the snow/glacier resources and their dynamics in the selected Karakoram and Himalayan basins adopting variable image interpretation and modeling techniques. The snowmelt runoff model was employed to simulate the daily discharges at Gilgit stream gauging station in Gilgit River basin. World Meteorological Organization (WMO) tested SRM successfully for runoff simulations [34]. The model has been applied widely all over the world to compute snowmelt runoff. With the development of satellite remote sensing (SRS) and GIS, it is possible to apply SRM to a large-sized basin. It uses remote sensing snow-cover data for the estimation of snowmelt runoff. The study would provide base for future monitoring of glaciers and glacial lakes in response to changing climate in this high-altitudinal mountainous region.
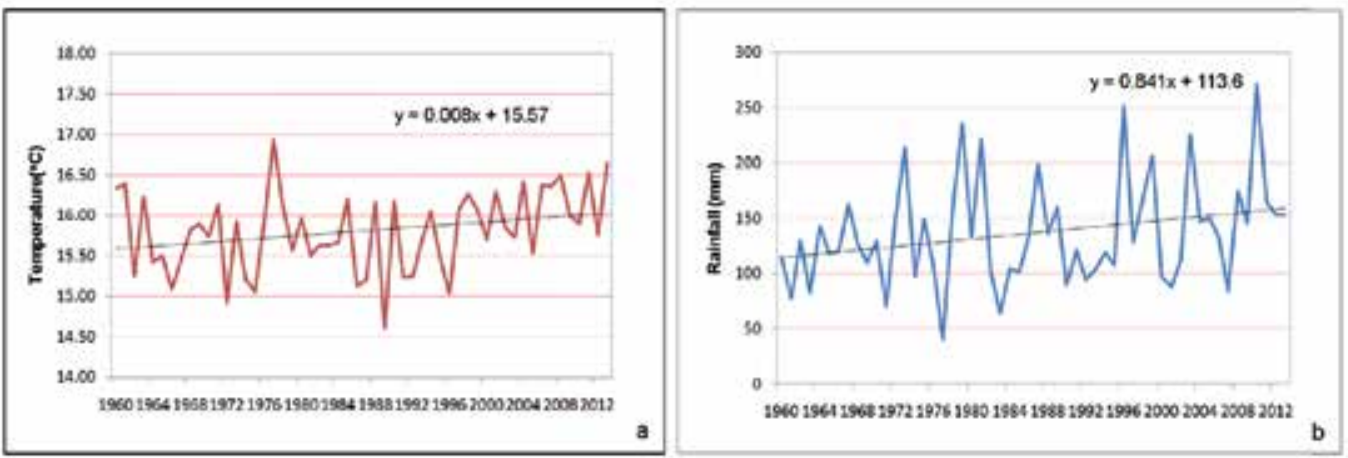

Figure 3. Trends of average annual temperature (a) and annual rainfall at Gilgit (b) during 1960-2013.

\subsection{Description of the study area}

The glacierized region of Pakistan lies within longitudes $70^{\circ} 57^{\prime}-77^{\circ} 52^{\prime} \mathrm{E}$ and latitudes $33^{\circ} 52$ $'-37^{\circ} 09^{\prime} \mathrm{N}$ (Figure 4). The elevation ranges from $366 \mathrm{~m}$ in the south to more than $8,500 \mathrm{~m}$ in 
the northeast. The snow and glacial ice reserves of freshwater nourish the main Indus River system (IRS) of the country. Approximately $11.57 \%$ of the overall area (i.e., $22,000 \mathrm{~km}^{2}$ ) of Upper Indus basin (UIB) is covered by seasonal glacial ice occupied by majority of the largest valley glaciers, the biggest and prevailing snow/ice-covered area outside the polar regions [35]. The high mountain region, i.e., between $35^{\circ}$ and $37^{\circ} \mathrm{N}$, is mostly dominated by winter rains, whereas the submountainous region, i.e., between $33.5^{\circ}$ and $35^{\circ} \mathrm{N}$, is dominated by summer rains. The bulk of the snowfall received from westerlies during the winter half of the year and more local conditions prevail in winter under the existing influence of the Tibetan anticyclone [36]. In addition to the influence of global weather systems, the mountain climates are also influenced on the medium and local scale by elevation, valley orientation, aspect, and slope [37]. The Himalayas have four subregions. The sub-Himalayas or Siwaliks are a range of low hills up to 1,000 $\mathrm{m}$ altitude above the mean sea level. The outer Himalayas go up to about 5,000 $\mathrm{m}$ altitude. The central Himalayas have an average height of about 6,000 m. The transHimalayas including the Karakoram Range are also very high, which include the second highest peak $(8,611 \mathrm{~m})$ in the world. The Hindu Kush and the Western Mountains form the boundary between Pakistan, Afghanistan, and China. The main rivers in these ranges are Swat and Kabul, which eventually run into the river Indus.

Gilgit basin is bounded in the west by Chitral River basin, a small portion in the north by Afghanistan, in the east by Hunza River basin, and in the south by Indus and Swat River basins. The basin occupies an area of about $14,082.4 \mathrm{~km}^{2}$ out of which about $6.9 \%$ is glacierized. The elevation ranges from 1,500 masl to more than 6,500 masl. Hunza basin is located in the upstream part of Upper Indus basin covering an area of about $14,235 \mathrm{~km}^{2}$ in which about $27.6 \%$ area is glacierized. The Hunza River has formed the main subbasin of the Gilgit basin. The tributaries joining the Hunza River are Chapursan, Khunjerab, Ghujerab, Shimshal, and Hispar rivers. Generally, most parts of the ablation areas are debris covered in this region. The Hunza River gauged at Dainyor bridge has a mean annual flow of $323 \mathrm{~m}^{3} \mathrm{~s}^{-1}$ based on 19662008 flow record of the Surface Water Hydrology Project of the Water and Power Development Authority (SWHP-WAPDA). The Astor basin lies in the eastern side of the Nanga Parbat mountain. Astor River drains the snow- and glacier-covered mountains of Ladakh - Deosai and High Himalayas in the northern territory of Pakistan. Shingo basin $\left(4,680 \mathrm{~km}^{2}\right)$ lies in the southeast of Astore basin within the elevation range of 3,800-6,000 m. Generally, the glaciers are few in number and small in size in this basin. The Jhelum basin is bounded in the west by southwestern part of Indus River basin, in the north by Astore basin, and in the east by Shingo basin (Figure 4). The elevation in this basin ranges from 1,200 $\mathrm{m}$ to more than 4,700 $\mathrm{m}$.

\section{Material and methods}

\subsection{Data used}

A dataset of MODIS processed images of MOD10A2 (h23V05, h24V05) and MYD10A2 (h23V05, h24V05) available since 2000-2011 was downloaded from the web link http:// nsidc.org/cgi-bin/snowi/ with a minimum cloud cover of $15 \%$. MODIS is an optical sensor that 


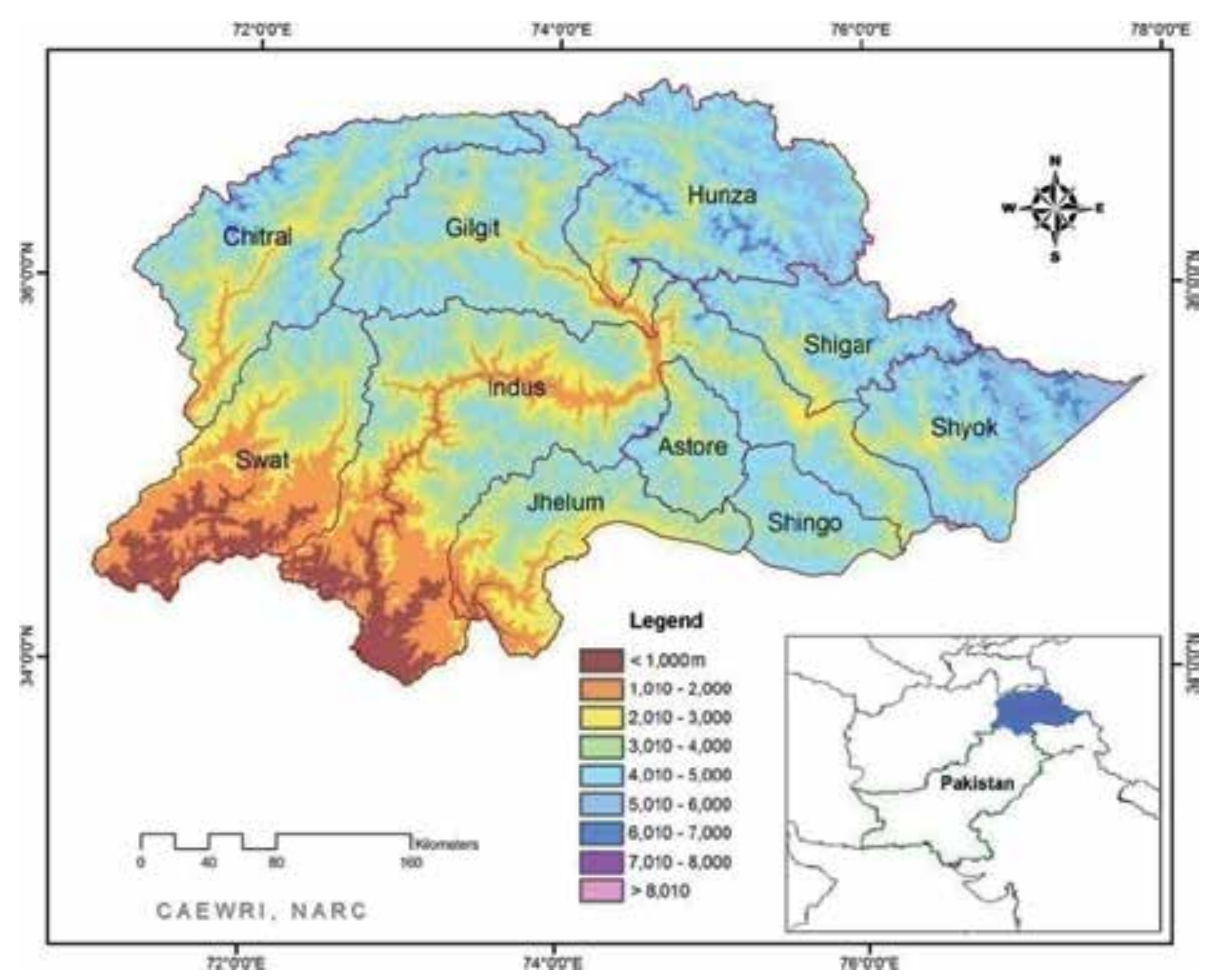

Figure 4. Location map of the glacierized region of Pakistan indicating various river basins and altitudinal ranges.

provides imagery of the earth's surface and clouds in 36 discrete, narrow spectral bands ranging from 0.4 to $14.4 \mu \mathrm{m}$ of the electromagnetic spectrum. MODIS snow-cover images are available globally at a variety of different resolutions and projections. MODIS, aboard terra spacecraft of earth observing systems (EOS), is being very handy for the estimation of normalized differential snow index (NDSI). The MODIS snow-cover product used in this study (MOD10A2 and MYD10A2) contains data fields for maximum snow extent over an 8-day repeated period and has a spatial resolution of $500 \mathrm{~m}$ covering the Hunza River basin completely in two scenes (h23V05 and h24V05).

The glaciers and glacial lakes mapping was based on the Landsat 7 ETM plus and Landsat 8 satellite data of 2001 and 2013, respectively. The later data were downloaded from the web link http://glovis.usgs.gov with minimum cloud and snow cover. The detail of satellite data used in the present study is given in Table 1. The RS analysis for glacial lakes mapping was supplemented by Google Earth imageries and the topographic maps published by Survey of Pakistan. The Landsat 8 satellite images the entire earth every 16 days in an 8-day offset from Landsat 7 ETM plus. The images are terrain-corrected having spatial resolution of $30 \mathrm{~m}$ for multispectral bands 1-7, 9, and $15 \mathrm{~m}$ for panchromatic band 8 and $100 \mathrm{~m}$ for thermal infrared sensor (TIRS) bands 10-11 resampled to $30 \mathrm{~m}$ to match the multispectral bands. The Landsat 8 carries two instruments: the OLI sensor includes refined heritage bands, along with three new bands and thermal infrared sensor provides two thermal bands. The satellite remote 
sensing data of 1993 (Landsat MSS), 2001 (Landsat TM), and 2005 (SPOT XS multispectral) periods acquired from various sources, such as SUPARCO, were used for spatiotemporal analysis of glaciers and lakes in the Astore basin. The location of selected glaciers and lakes in the basin is shown in Figure 5. For historical trend analysis, glacier cover from topographic map of 1:50,000 scale of the year 1964 was acquired from Survey of Pakistan. Digital elevation model data of shuttle radar topography mission (SRTM) $90 \mathrm{~m}$ were used to estimate altitudinal characteristics of the glacial lakes. The DEM is provided with a geographic coordinate system (CGS), and the elevation values refer to datum WGS-84 both horizontally and vertically.

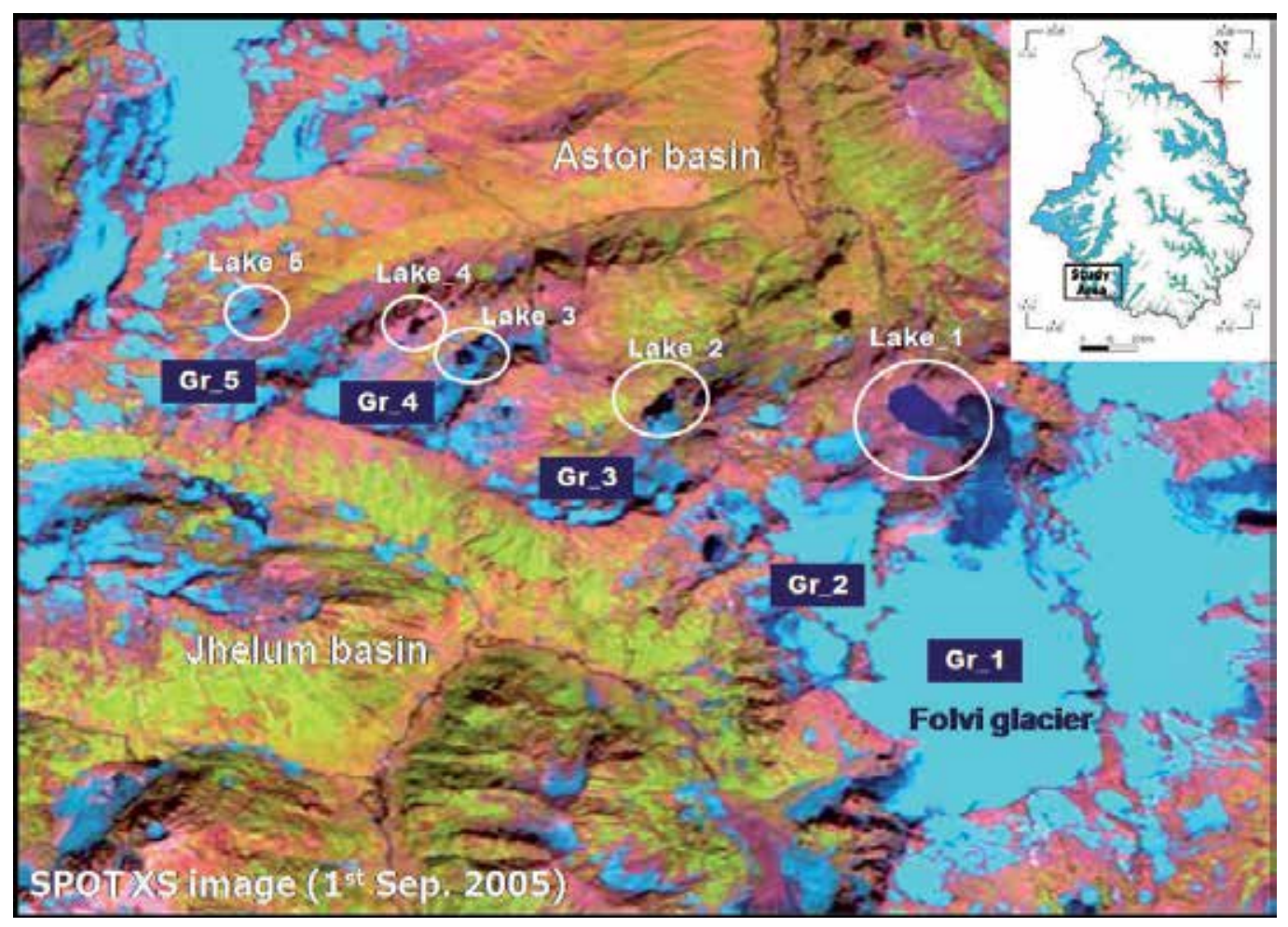

Figure 5. Location of the study site in Astore basin in Himalayas.

The daily flows data of Hunza and Astore rivers were acquired from SWHP-WAPDA for seasonal correlation with climate data and snow-cover dynamics in the catchment since 2000. The Hunza River is gauged at Dainyor Bridge, whereas the Astore River is gauged at Doyean station near Bunji.

\subsection{Image processing and geo-spatial analysis}

Originally downloaded MODIS product was in sinusoidal projection, which was then reprojected into Universal Transverse Mercator (UTM) Zone $43 \mathrm{~N}$ projection with datum WGS-1984 using MODIS Re-projection Tool. MODIS images only for the months of January, 


\begin{tabular}{lcc}
\hline \multicolumn{1}{c}{ SRS data } & Resolution & Period \\
\hline MODIS snow-cover product & $500 \mathrm{~m}$ & $2000-2011$ \\
\hline Landsat 8 OLI/TIRS & $30 \mathrm{~m}$ & 2013 \\
\hline Landsat 7 ETM+ (Enhanced Thematic Mapper Plus) & $15 \mathrm{~m}, 30 \mathrm{~m}$ & 2001 \\
\hline Landsat MSS (Multispectral Scanner) & $80 \mathrm{~m}$ & 1993 \\
\hline SPOT 4 XS (multispectral) & $20 \mathrm{~m}$ & 2005 \\
\hline Google Earth & Variable & Variable \\
\hline
\end{tabular}

Table 1. Satellite remote sensing data used in the present study.

February, and March were mosaicked and used for mapping the maximum SCA to observe snow-cover dynamics in Hunza basin, Karakoram range. The snow cover in these months usually dominates most of the basin area. The month-wise distribution of SCA in the study area during 2011 is shown in Figure 6. The SCA was minimum during August, followed by July, June, and May. It appears to increase from September to March then starts declining. The maximum snow-cover area change (SCAC) was assessed using the MODIS snow-cover product, e.g., MOD10A2 and MYD10A2, available since 2000. Subset of the study area was masked from the MODIS layer. The snow extracts of maximum snowfall period consist of the five classes of the MODIS attribute data from which the snow class (value $=200$ ) was extracted.

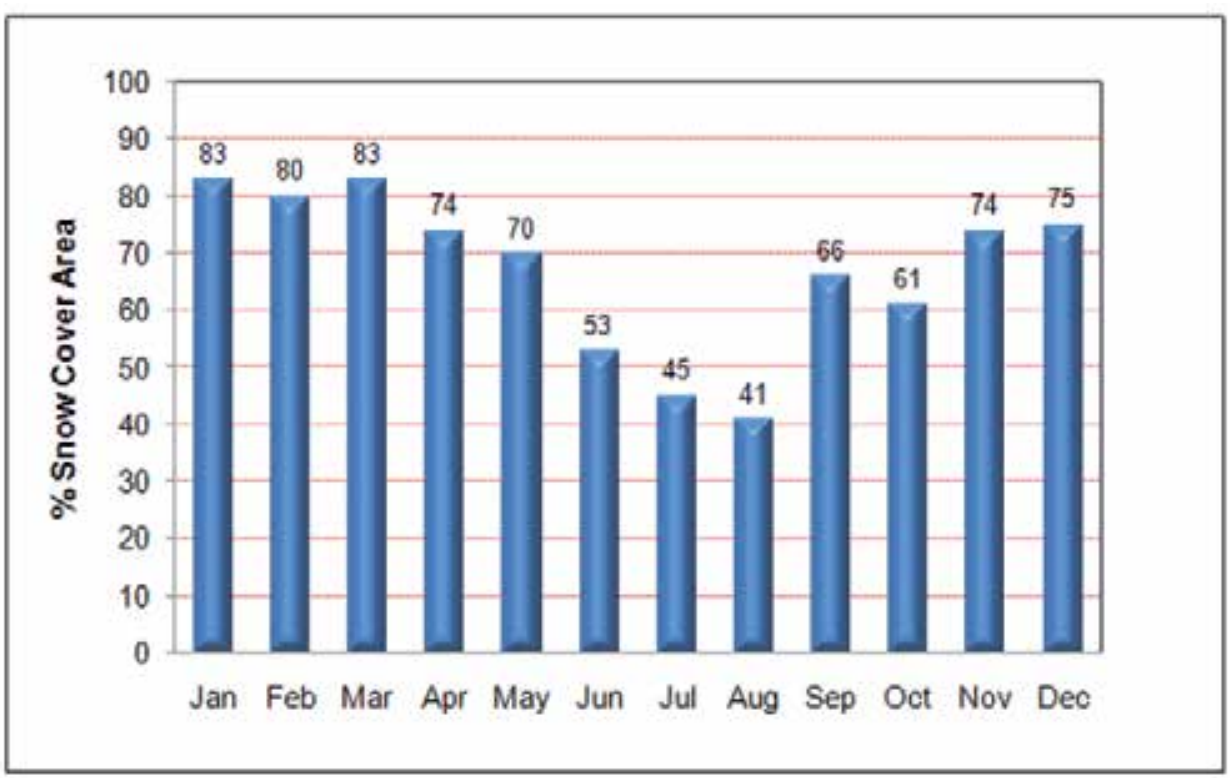

Figure 6. Monthly distribution of maximum SCA during 2011 in Hunza basin. 
The spatiotemporal and altitudinal changes in the lakes were studied to observe the influence of climatic changes occurred during recent decades in this part of the $\mathrm{HKH}$ region. The spatial database of the lakes such as location coordinates, area, and length was systematically developed and analysis was performed for each river basin for 2001 and 2013. For the glacial lakes mapping, the methodology developed by Lanzhou Institute of Glaciology and Geocryology, the Water and Energy Commission Secretariat, and the Nepal Electricity Authority [38] was adopted. The uncertainty analysis for lakes area was performed following the methods provided by researchers, e.g., Refs. $[39,40]$. According to the analysis, the shoreline of the glacial lake passes through the center of pixel giving an uncertainty of 0.5 pixel.

Five glaciers and five associated glacial lakes were selected in Astore basin of the Himalaya range. Spatial data layers of the glaciers and glacial lakes were developed through on-screen digitization in GIS and using different analytical techniques and logical operators. All the polygons representing glaciers and glacial lakes are numbered clockwise sequentially. For geospatial analysis, the attribute data were linked to the spatial data layers of glaciers and glacial lakes in GIS. Time series data of hydrometeorology were used to study the trends in climate data, i.e., summer and winter temperatures (maximum and minimum), precipitation, and river discharge.

\subsection{Remote sensing technique in glaciers and lakes mapping}

The detection of glacial lakes using multispectral imagery involves discriminating between water and other surface types. Delineating surface water can be achieved using the spectral reflectance differences. Water strongly absorbs in the near- and middle-infrared wavelengths $(0.8-2.5 \mu \mathrm{m})$. Vegetation and soil, in contrast, have higher reflectance in the near- and middleinfrared wavelengths; hence, water bodies appear dark compared with their surroundings when using these wavelengths [41]. Methods for semiautomated mapping of glaciers and lakes based on remote sensing data have been well established for several years, and model approaches to assess the hazard potential of glacier lakes have been developed and successfully tested as well. The global elevation datasets of the shuttle radar topography mission and the ASTER global DEM (GDEM) offer the possibility to derive such topographic parameters for glaciers in most regions of the world.

The spatial and radiometric resolution of panchromatic band of Landsat ETM plus images was used for delineation of glacier's boundaries in selected basins. The very low reflectance of ice and snow in the middle-infrared has been widely used for glacier classification, for example, with threshold ratio images from raw data of digital number of TM bands 4 and 5 [42,43]. This technique has proved to be simple, robust, and accurate [44]. It has also been proposed as a method for reducing multiple effects (e.g., the topographic effect of direct light) within multispectral data [45-47]. Visual interpretation is considered to be the most accurate way to delineate snow line in the scale of one outlet glacier, because it is the only method to take topography into account [48]. Because of a pronounced topographic effect, none of the most common band ratios or principal components could offer sufficient contrast to set one threshold value to delineate the ice-cap glaciers. The glaciers were mapped based on methodology developed by the Temporary Technical Secretary (TTS) at the Swiss Federal Institute 
of Technology, Zurich, for the data compilation of World Glacier Inventory [49]. The flowchart of the methodology adopted is shown in Figure 7. After digitization of glaciers' polygons, the numbering of glaciers was started from mouth of the major stream and proceeded clockwise round the basin. If there is a name assigned to the glacier, it was recorded through literature search and information included in the topographic maps. The geographic location of the glacier was recorded from the grid. The area of the glacier was calculated through database of the delineated glacier.

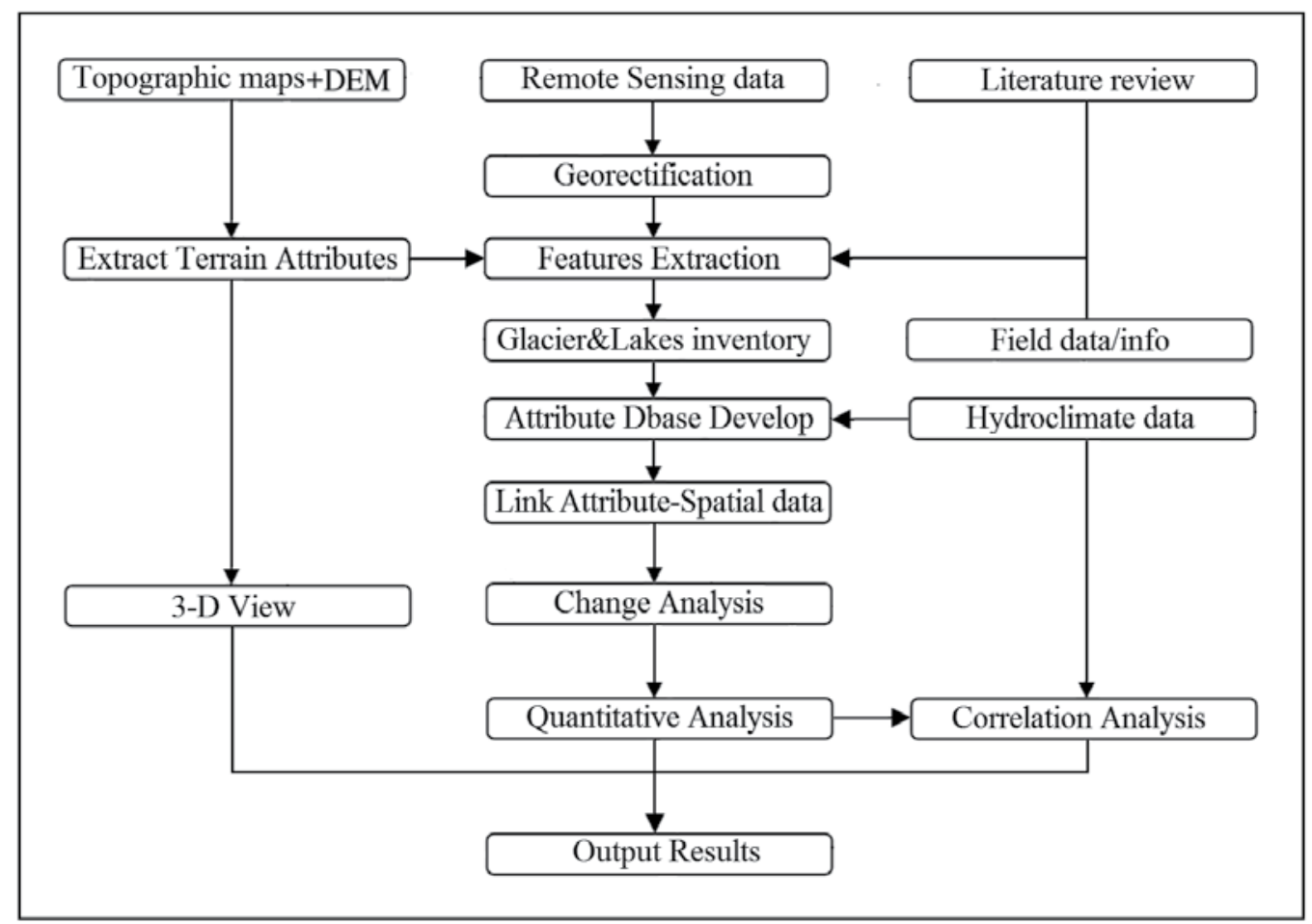

Figure 7. Flowchart of methodology adopted for temporal analysis of glaciers and glacial lakes.

\subsection{Snow Runoff modeling}

Currently, SRM is being used to analyze the effects of changed climate on seasonal river flows in snow and glacierized basins using MODIS satellite data. The daily input data used in the model are precipitation, air temperature, and snow-covered area. The model also requires some basin characteristics such as latitude-longitude, number of zone, zone areas, and means hypsometric elevation of each zone of basin. In the model phenomena, snowmelt and rain are computed every day and then superimposed on the calculated recession flow and transformed into the daily discharge from the catchment. The main equation used in SRM for snowmelt runoff simulation is: 


$$
Q_{n+1}=\left[c_{S n} a_{n}\left(T_{n}+\Delta T_{n}\right) S_{n}+c_{R n} P_{n}\right] \frac{\mathrm{A} \times 10,000}{86,400}\left(1-k_{n+1}\right)+Q_{n} k_{n+1}
$$

where $Q$ is the average daily discharge $\left(\mathrm{m}^{3} / \mathrm{s}\right), C_{\mathrm{sn}}$ and $C_{\mathrm{Rn}}$ are the coefficients of snow and rain, respectively, $a_{n}$ is the degree-day factor $\left(\mathrm{cm}^{\circ} \mathrm{C}^{-1} \mathrm{~d}^{-1}\right), T_{n}$ is the number of degree days in ${ }^{\circ} \mathrm{C} \mathrm{d}$, $S$ is the ratio of the snow-covered area to the total area, $P$ is the precipitation contributing to runoff $(\mathrm{cm}), T_{\text {crit }}\left({ }^{\circ} \mathrm{C}\right)$ is the critical temperature that differentiates between snow and rain, $A$ is the area of the basin or zone in $\mathrm{km}, K$ is the recession coefficients that indicate the decline of discharge in a period without snowmelt or rainfall, and $n$ is the sequence of days during discharge computation period. The degree-day factor is evaluated with regard to snow density, stage of the snowmelt season, and presence of glaciers. The runoff coefficient is an expression of hydrological losses and is estimated by comparing the annual precipitation and runoff, by taking into account the vegetation and current snow coverage, as well as size of the basin. The critical temperature $\left(T_{\text {crit }}\right)$ can be estimated using actual meteorological records, stage of snowmelt season, and visual observations.

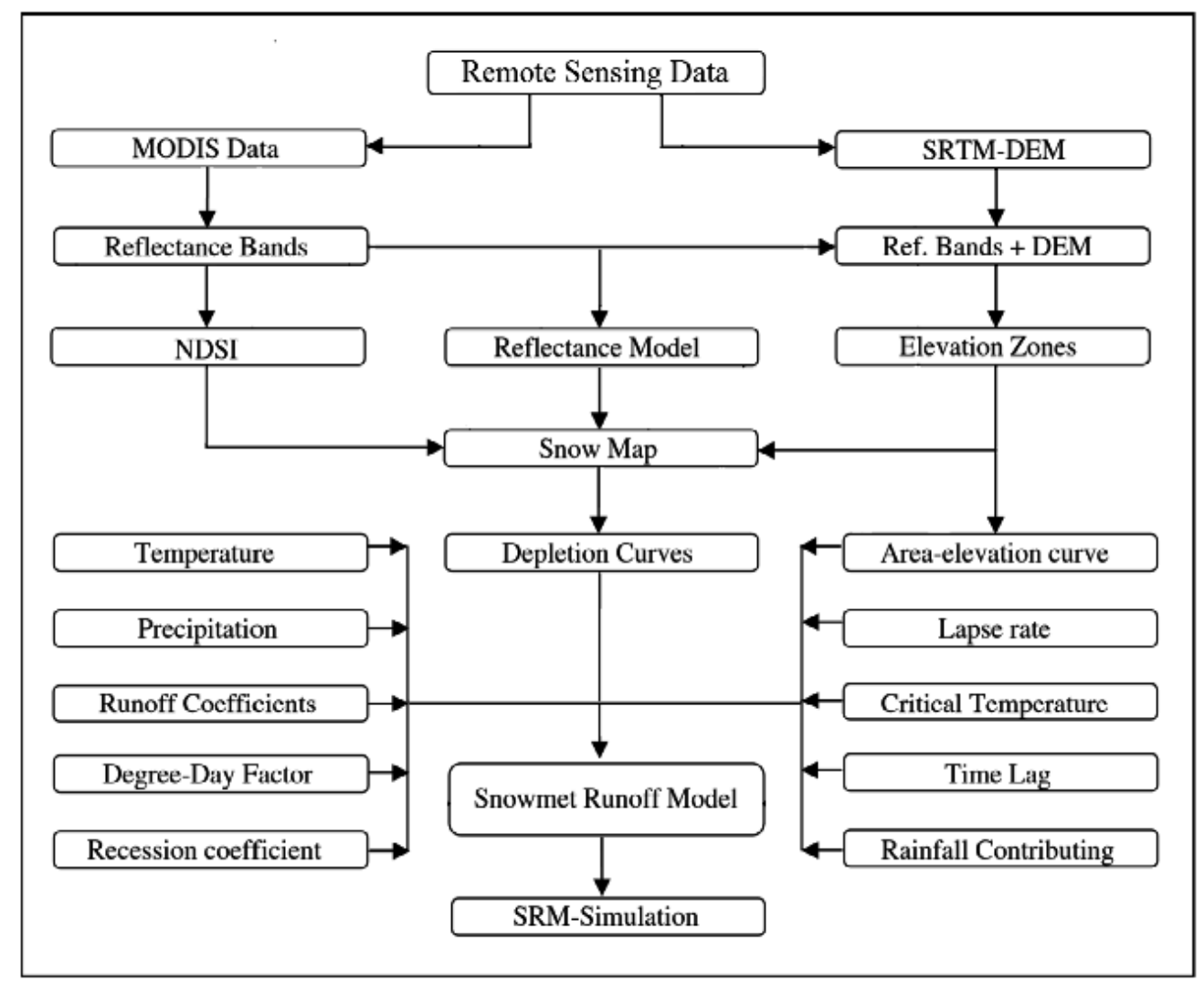

Figure 8. Major steps involved in simulation of snowmelt runoff model (SRM). 
The Gilgit River basin is a snow-covered and glacierized basin, therefore the snowmelt runoff model can be successfully used to simulate and forecast daily stream flows as well as to study the effect of climate change on river flows. The SRM model was calibrated for 4 years from 2001 to 2004 and the model simulations were performed from year 2007 to 2010. The initial values of the parameters used during model calibration such as temperature lapse rate, degree-day factor snow and rain coefficients, and recession coefficients were extracted from past data and from previous studies, e.g., Ref. [50]. The parameters were adjusted during the calibration process until satisfactory results were achieved. The SRM model was calibrated with a coefficient of determination $\left(R^{2}\right)$ value of 0.64 and validated with $R^{2}$ value of 0.78 , indicating a close agreement between the observed and the simulated discharge data. The stepwise methodology followed in the study is shown in Figure 8. Different scenarios were used in SRM to predict future flows of Gilgit River: i. under rise in annual temperature ' $T$ ' and ii. increase in cryosphere area in the basin.

\section{Results and discussion}

\subsection{Analysis of maximum snow-cover area}

The maximum SCA in the Hunza basin, Karakoram range, was evaluated for trend and change analysis using MODIS product of the 2001-2011 period. Figure 9 shows the maximum snow-cover area in the Hunza basin during the 2001-2011 period. Except central valleys consisting of drainage network of the basin, most of the land appears to be snow covered during the period from January to March. From the results, it was observed that percentage SCA is predominantly increasing with time in this high-altitude cryospheric region. From the trend analysis of percentage snow-cover area on annual basis, it was observed that more than $80 \%$ of the basin area was snow covered particularly during the time periods of 2003, 2004, 2005, 2009, and 2011 (Figure 10). The maximum SCA during these years ranged from $80 \%$ to $92 \%$ of the study area. The historical data of precipitation (1961-2000) exhibited a rising trend in the Northern areas [51]. This may give rise to an increasing trend of SCA, which likely feeds the high-altitude zones (usually above 5,000 masl), resulting in net expansion of the snow cover and ice mass gain in the basin.

The maximum snow-cover area change observed during 2001-2011 indicated a significant increase of about $719 \mathrm{~km}^{2}$ in SCA during an 11-year period (Figure 11). From the trend analysis of maximum snow extent on annual basis, it has been observed that the maximum snowfall month has shifted slightly from December to January indicating a spatial shift of winter season, which generally starts from November and continues until the end of March. The possible reasoning for this shift might be attributed to the observed facts that the solid precipitation in winter has been converted into liquid precipitation probably due to increased atmospheric temperatures. 

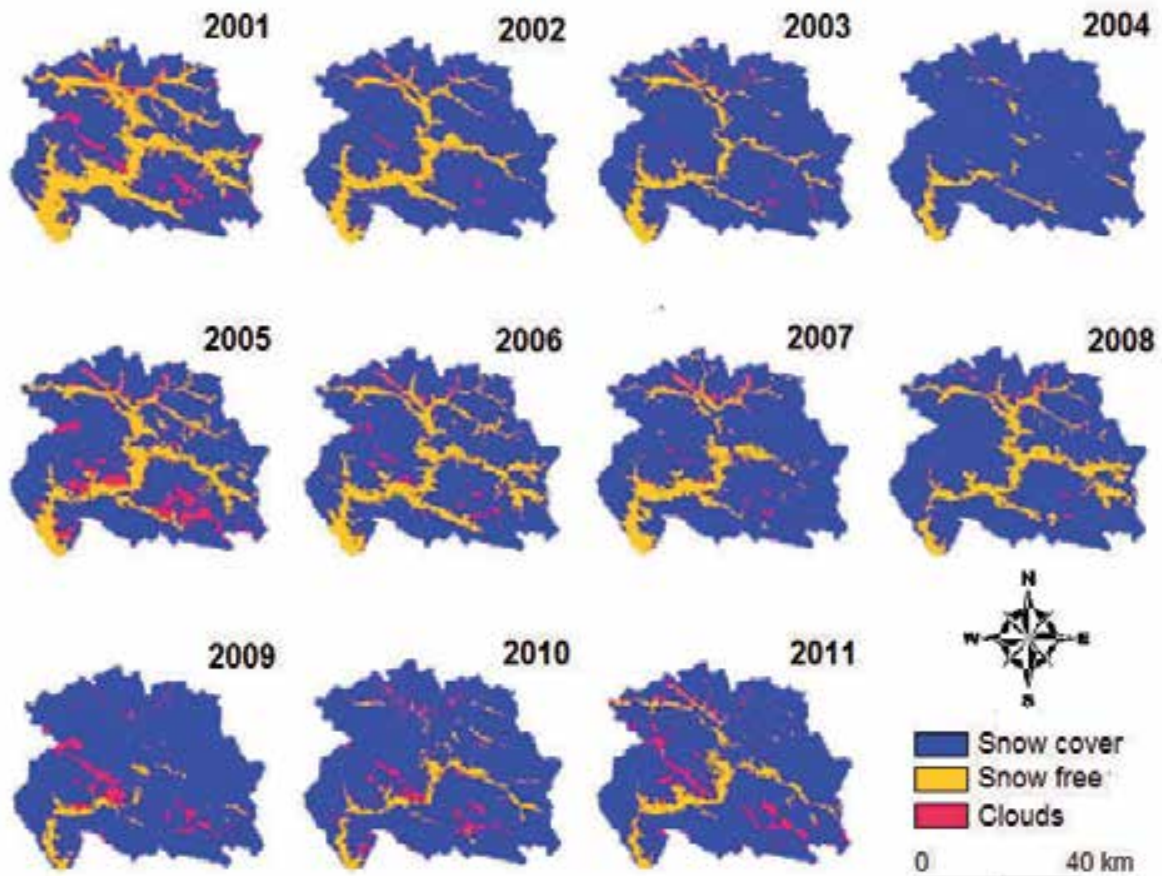

Snow cover

Snow free

Clouds

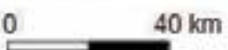

Figure 9. Maximum snow-cover area (SCA) in Hunza basin during the 2001-2011 period.

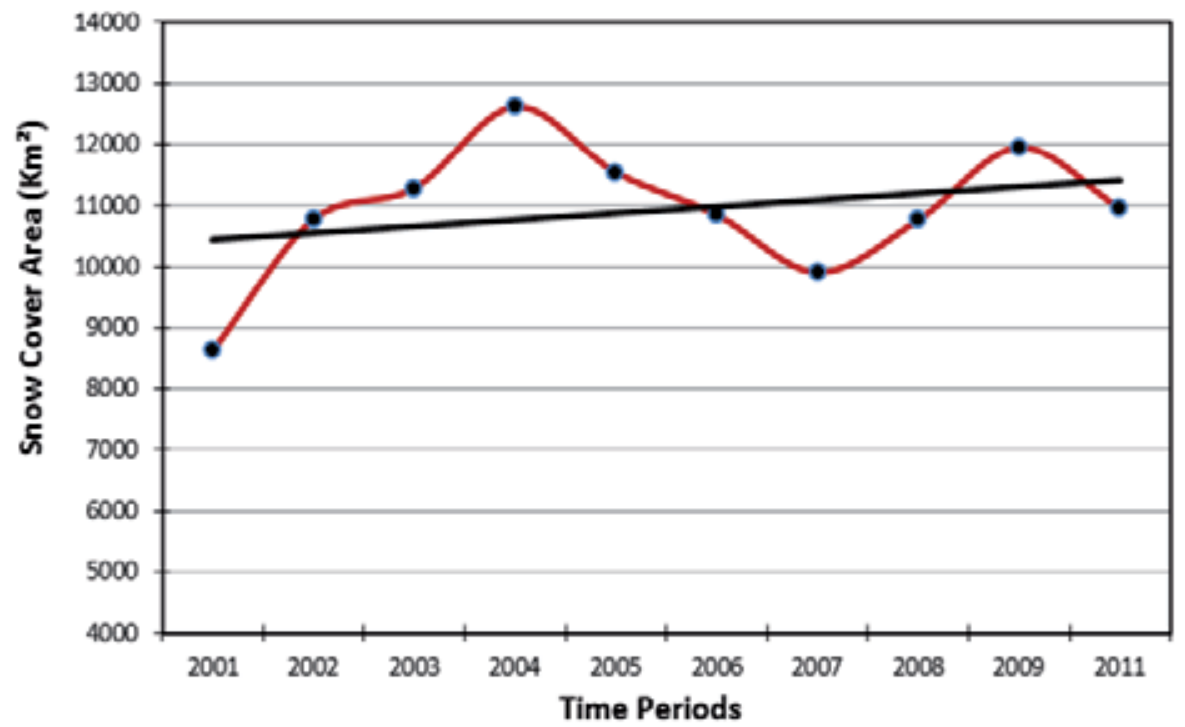

Figure 10. Trend of maximum snow-cover area (SCA) in Hunza basin during the 2001-2011 period. 


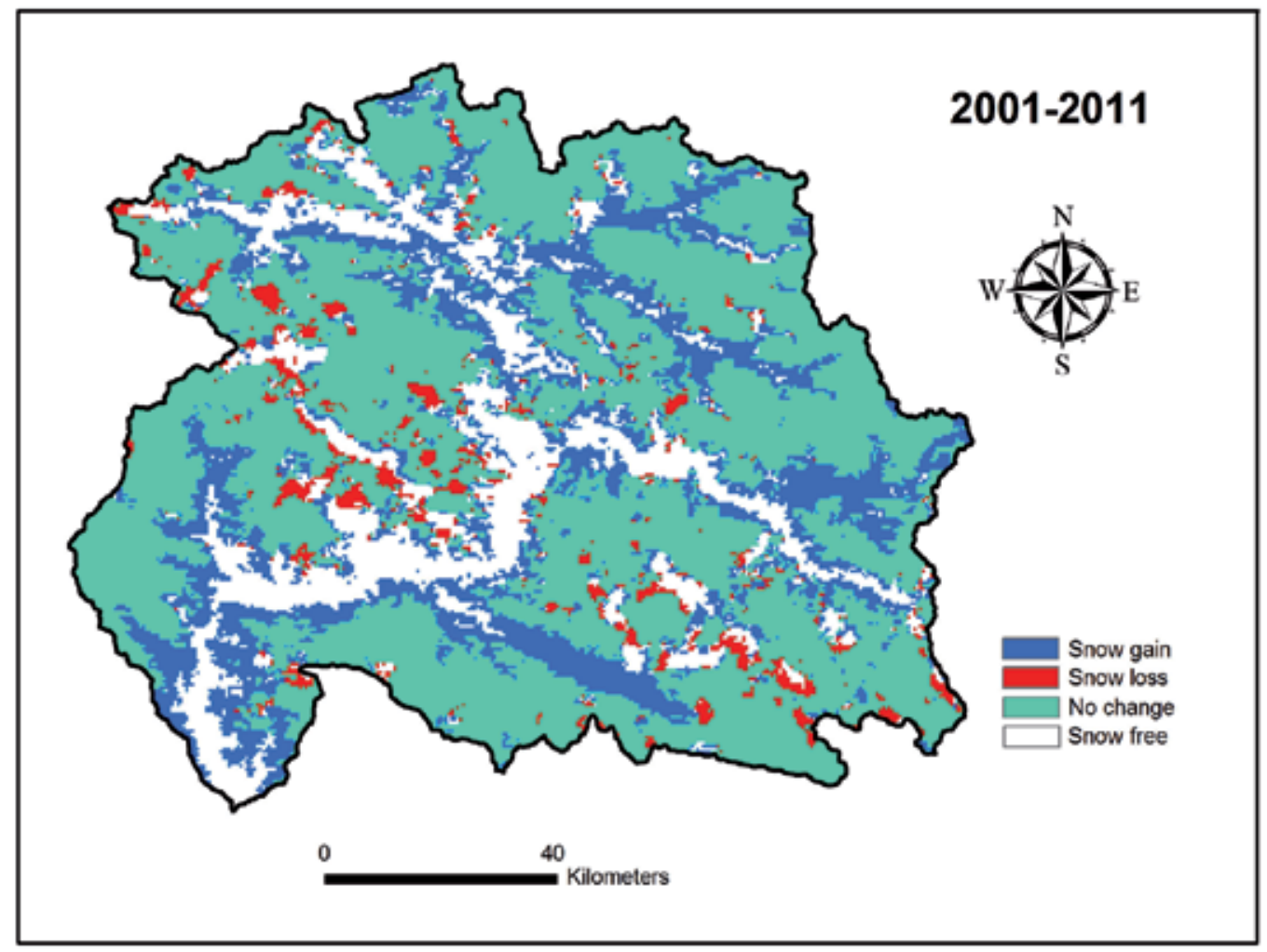

Figure 11. Snow-cover area change (SCAC) during 2001-2011 in Hunza basin.

The snow accumulation has an increasing tendency in the central Karakoram experiencing unique climate signatures, characterized by low temperatures, and enhanced precipitation [52]. The fact also points toward previous observations, e.g., Ref. [53], indicating a regional deviation of the Karakoram glaciers from the usual glacier thinning observed in most glacierized areas of the world and a retreat of some other neighboring Asian glaciers [54]. Since the early 1960s, a rise in winter precipitation in the Karakoram has been observed [55]. From the analysis of interannual variations in the snow-cover area, it has been observed that snow gain is predominantly increasing at the rate of $360 \mathrm{~km}^{2} /$ year in this region perhaps because of high elevation and complex orographic features. During the periods of maximum snow gain, snow was found even at the lowest elevation of 1,400 m. Retention of snow at this low-elevation zone indicates heavy snowfall during this period. Snow gain may be characterized by many factors because the high-altitude region is influenced by complex weather systems. From the analysis of snow loss in terms of elevation (extracted from DEM), it was seen that maximum loss occurred at an elevation ranging from 2,000 to 4,000 m during 2002, 2004, 2005, and 2009 probably because of more liquid precipitation than solid within this elevation range. Most of the snow loss was observed within lower elevations of the valley glaciers, such as Batura, Hispar, and Khinyang. 


\subsection{Analysis of the glacial environment}

The identification of glacial features was performed effectively through variable stretching of the pixel values of Landsat ETM+ panchromatic image data (Figure 12). The land features such as ridgelines and drainage network are highlighted in 0-150 stretch in values of panchromatic image. Similarly, the moraine boundaries are distinct in this stretch range providing good approximation of limits of debris-covered glaciers. Low stretch in values (i.e., 0-100) has proved helpful in extracting glacial ice appearance within the high mountainous shadows. Table 2 indicates stretching values of panchromatic image suitable for identification and delineation of various glacial features. The delineation of snow-/ice-covered ridge and catchment boundaries in panchromatic image is possible using greater than 200-value range. The surface variations and flow pattern of glacial ice become highly distinct using this range in the image.

In the Hunza basin, a total of 1,050 glaciers were identified, which contain 10 glaciers of more than $100 \mathrm{~km}^{2}$ area (Figure 13), Batura, Hispar, and Hasanabad being the renowned ones. These and some other glaciers in this basin penetrate well below 3,000 m, e.g., the 59-km-long Batura glacier, one of the eight largest glaciers of the middle and low latitudes, has its terminus at about 2,400 m. About two-thirds of the middle and lower parts of the glacier is covered with debris (shown in reddish brown color resembling the surrounding rocks in Figure 14) except for a thin strip of white ice (visible in variable shades of cyan color) that extends to within about $4 \mathrm{~km}$ of the terminus. There are seven glaciers that have an area ranging within 50-100 $\mathrm{km}^{2}$, whereas 12 glaciers belong to $20-50 \mathrm{~km}^{2}$ category. The medium-sized glaciers (10-20 $\mathrm{km}^{2}$ ) are 24 in number, whereas the rest belong to small-sized glaciers (less than $10 \mathrm{~km}^{2}$ in size). According to Hewitt [53], the central Karakoram region is one of the exceptional and exclusive cases throughout the world where the expansion of glaciers has been observed. The Karakoram glaciers are the largest store of moisture in Central Asia and the single-most concentrated source of runoff for the whole Upper Indus basin. The glaciers residing on the steep mountains as well as lying in valleys are highly susceptible to global warming, which may create future hazards for downstream communities (Figure 15a). One of the glaciers of surging type in the Upper Hunza valley, e.g., Ghulkin, has burst several times in the past (recently in early 2015) resulting in a loss of infrastructure, property, and valuable lives (Figure 15b). The glaciers prone to surging or that display irregular flow might be expected to be possible candidates for the generation of outburst floods [13].

In the Astore basin, there were 588 glaciers identified, among which about $99 \%$ glaciers belong to $0-10 \mathrm{~km}^{2}$ size category, while only $0.2 \%$ glaciers belong to $50-100 \mathrm{~km}^{2}$ category (Figure 13 ). No glacier of greater than $100 \mathrm{~km}^{2}$ area was found in this basin. The presence of relatively higher numbers of medium- to large-sized glaciers in the Karakoram basin provides an evidence of favorable climate conditions for the glaciers' existence at higher altitudes. The minimum numbers of large-sized glaciers identified in the Himalayan basin point toward higher rates of glacial-ice melting due to increased warming conditions in this range. 

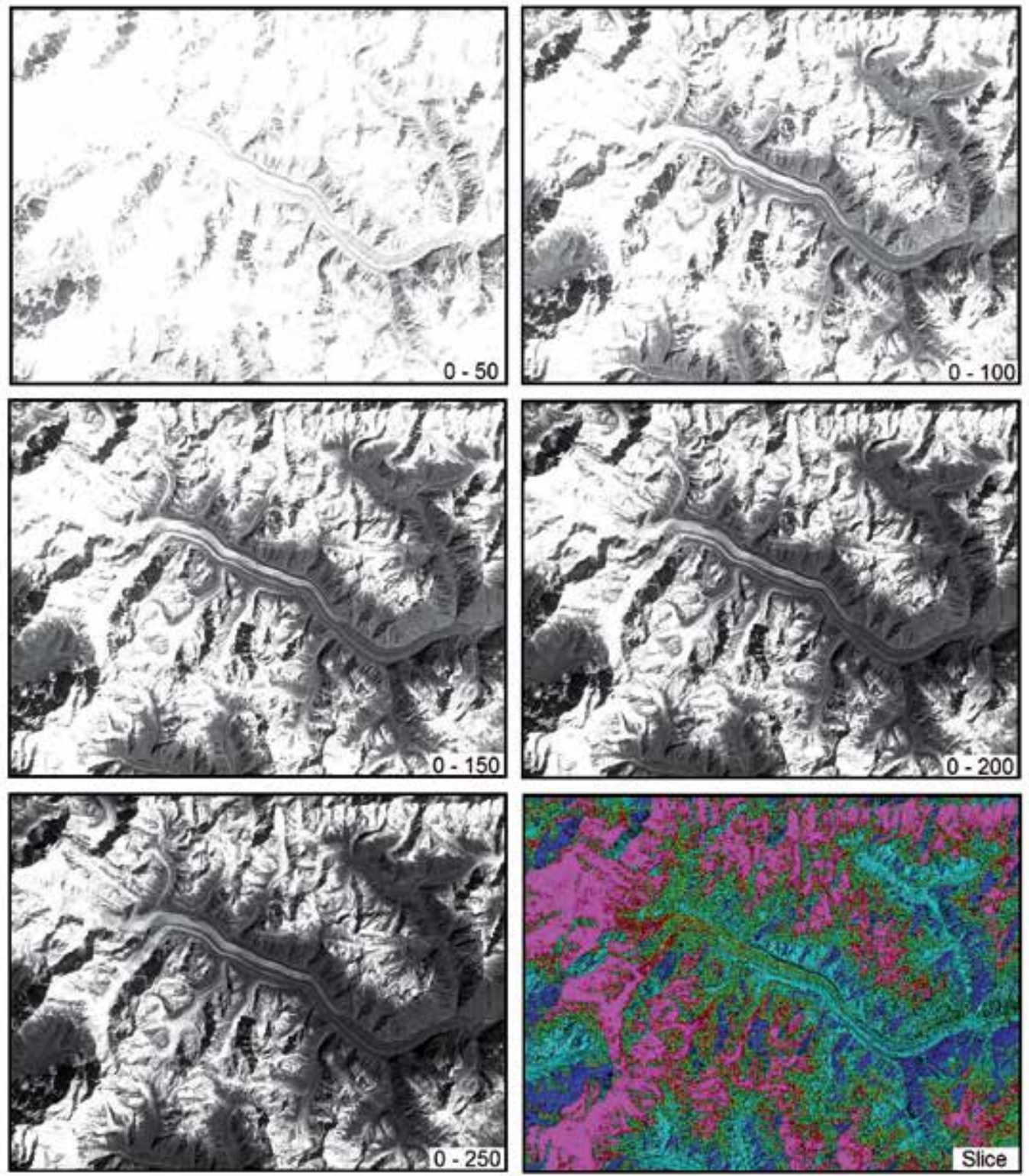

Figure 12. The extraction of glacial features is facilitated by stretching of gray scale values of Landsat ETM+ panchromatic image.

Three basins of the Himalayas, e.g., Shingo, Astore, and Jhelum, were selected to analyze variations in the glacial lakes during 2001 and 2013. Overall, 463 glacial lakes common during the two periods were selected for the analysis. The 204 glacial lakes in Shingo basin indicated an increase in area from 10.35 to $10.84 \mathrm{~km}^{2}$ (Table 3). The 93 lakes in Astore and 166 lakes in Jhelum basin indicated a minor decrease in coverage during the 12-year period. Overall 
changes in the lakes area were positive in the three river basins indicating a net expansion in lakes area in the Himalaya range. Variable changes in the lakes area in the basins during the 2001-2013 period are shown graphically in Figure 16 and geographically in Figures 17a-c. The formation of several new glacial lakes is mainly a result of glacier retreat that is observed in most of the Hindu Kush-Karakoram-Himalayan region [19]. The influence of climate on glacial lakes is rather complex and cannot solely account for lake variations [4].

\begin{tabular}{clcccccc}
\hline S.No. & \multicolumn{1}{c}{ Feature } & $\mathbf{5 0}$ & $\mathbf{1 0 0}$ & $\mathbf{1 5 0}$ & $\mathbf{2 0 0}$ & $\mathbf{2 5 0}$ & Slice \\
\hline 1 & Exposed ridgeline & $\mathrm{L}$ & $\mathrm{M}$ & $\mathrm{H}$ & $\mathrm{M}$ & $\mathrm{L}$ & $\mathrm{L}$ \\
\hline 2 & Ridgeline covered under snow/ice & $\mathrm{N}$ & $\mathrm{P}$ & $\mathrm{L}$ & $\mathrm{M}$ & $\mathrm{H}$ & $\mathrm{N}$ \\
\hline 3 & Snow/ice in shadow cover & $\mathrm{H}$ & $\mathrm{M}$ & $\mathrm{L}$ & $\mathrm{P}$ & $\mathrm{N}$ & $\mathrm{P}$ \\
\hline 4 & Cascading glacier/ice flow pattern & $\mathrm{N}$ & $\mathrm{P}$ & $\mathrm{L}$ & $\mathrm{M}$ & $\mathrm{H}$ & $\mathrm{P}$ \\
\hline 5 & Glacial lake & $\mathrm{H}$ & $\mathrm{M}$ & $\mathrm{L}$ & $\mathrm{P}$ & $\mathrm{P}$ & $\mathrm{L}$ \\
\hline 6 & Drainage network & $\mathrm{P}$ & $\mathrm{M}$ & $\mathrm{H}$ & $\mathrm{M}$ & $\mathrm{L}$ & $\mathrm{P}$ \\
\hline 7 & Moraine boundary & $\mathrm{P}$ & $\mathrm{M}$ & $\mathrm{H}$ & $\mathrm{M}$ & $\mathrm{L}$ & $\mathrm{P}$ \\
\hline 8 & Cloud cover/shadow & $\mathrm{M}$ & $\mathrm{M}$ & $\mathrm{L}$ & $\mathrm{L}$ & $\mathrm{P}$ & $\mathrm{P}$ \\
\hline
\end{tabular}

$\mathrm{H}=$ High; $\mathrm{M}=$ Medium; $\mathrm{L}=$ Low $; \mathrm{P}=$ Poor, $\mathrm{N}=\mathrm{Nil}$

Table 2. Suitability of stretching values of panchromatic image for identification of various glacial features.

Hunza Basin

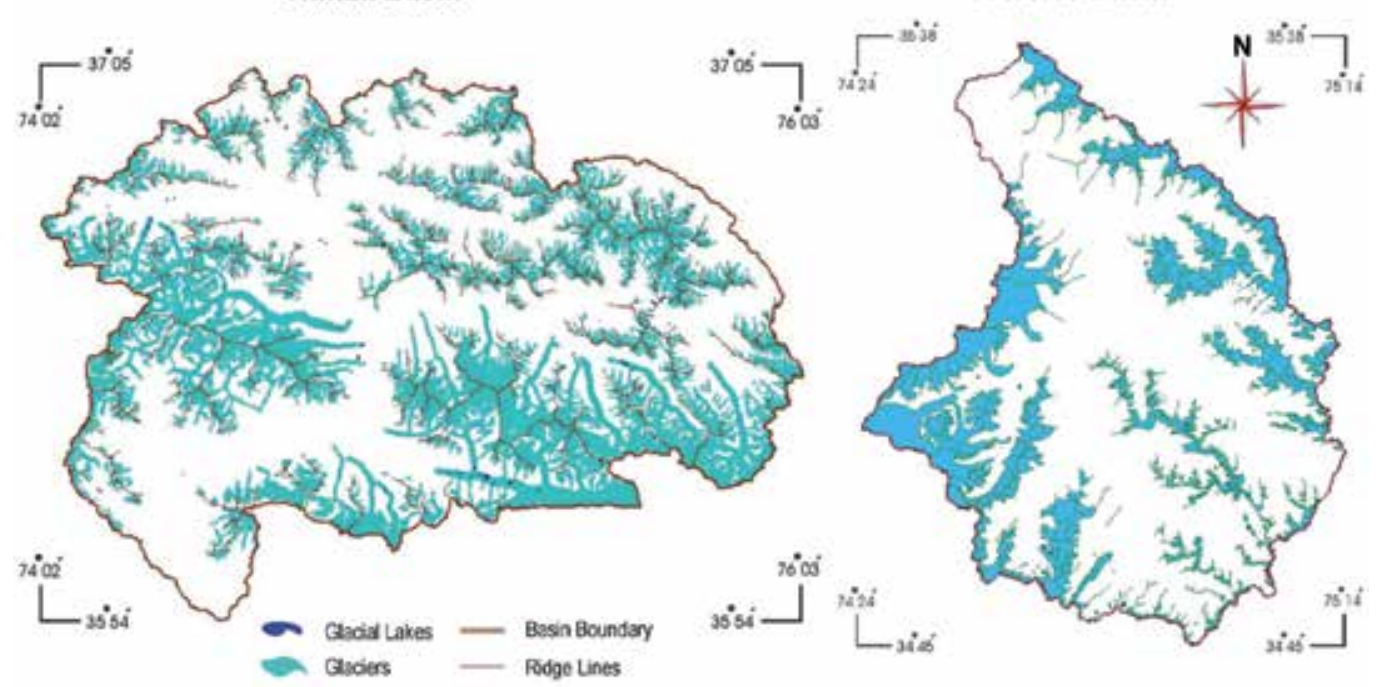

Figure 13. Glaciers and lakes distribution in Hunza and Astore basins. 


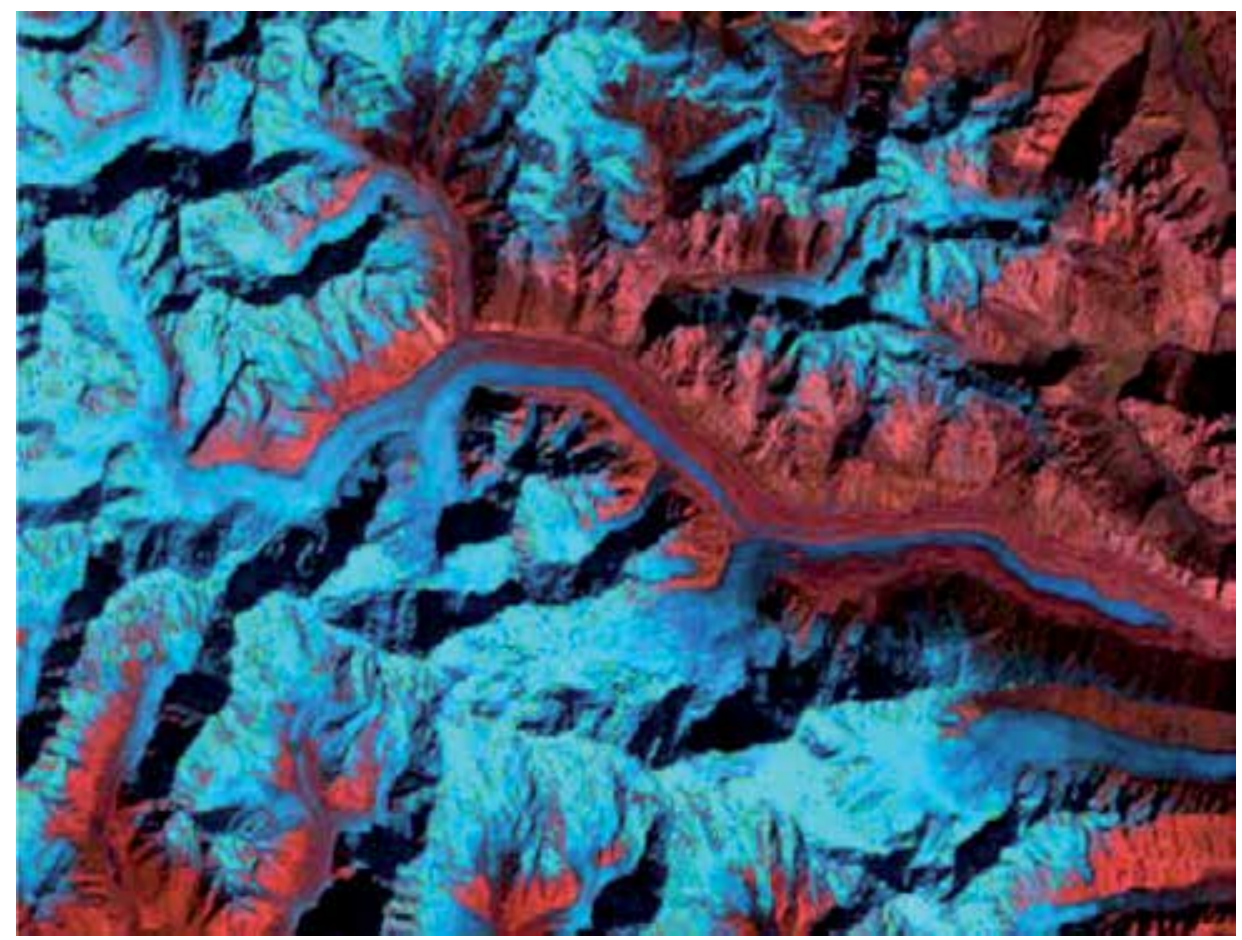

Figure 14. Landsat ETM+ image of a large valley glacier - Batura in upper Hunza valley.

\begin{tabular}{ccccc}
\hline Basin & Number & Area 2001 $\left.\mathbf{( k m}^{\mathbf{2}}\right)$ & Area 2013 $\left.\mathbf{( k m}^{\mathbf{2}}\right)$ & Change $\left.\mathbf{( k m}^{\mathbf{2}}\right)$ \\
\hline Shingo & 204 & 10.35 & 10.84 & 0.49 \\
\hline Astore & 93 & 4.20 & 3.98 & -0.22 \\
\hline Jhelum & 166 & 10.78 & 10.52 & -0.25 \\
\hline Total & 463 & 25.32 & 25.34 & 0.02 \\
\hline
\end{tabular}

Table 3. The glacial lakes status in the Himalayas during 2001 and 2013.

In terms of altitude, the expansion in the lakes area of Shingo basin was positive within the 3,500-5,000 elevation range (Table 4). The expansion in the glacial lakes area within 4,500-5,000 $\mathrm{m}$ points toward changes in the climatic pattern, e.g., increase in warming condition resulting in melting of snow/ice or liquid precipitation that might contribute to growth of lakes area. In Astore basin, the change in glacial lakes area was positive within 3,000-4,000 and 4,500-5,000 $\mathrm{m}$ elevation ranges (Table 4). The maximum number of glacial lakes within 4,000-4,500 m indicated a decline in area due to the effect of glacial hydrodynamics and/or climatic variations at this elevation range. In Jhelum basin, the change in glacial lakes area was positive within 3,000-3,500 m, while it was negative within 3,500-4,500 m elevation range (Table 4). The maximum number of glacial lakes lie within 4,000-4,500 $\mathrm{m}$ in this basin (similar to Astore basin), which also indicated a decline in coverage during the 12-year period. 


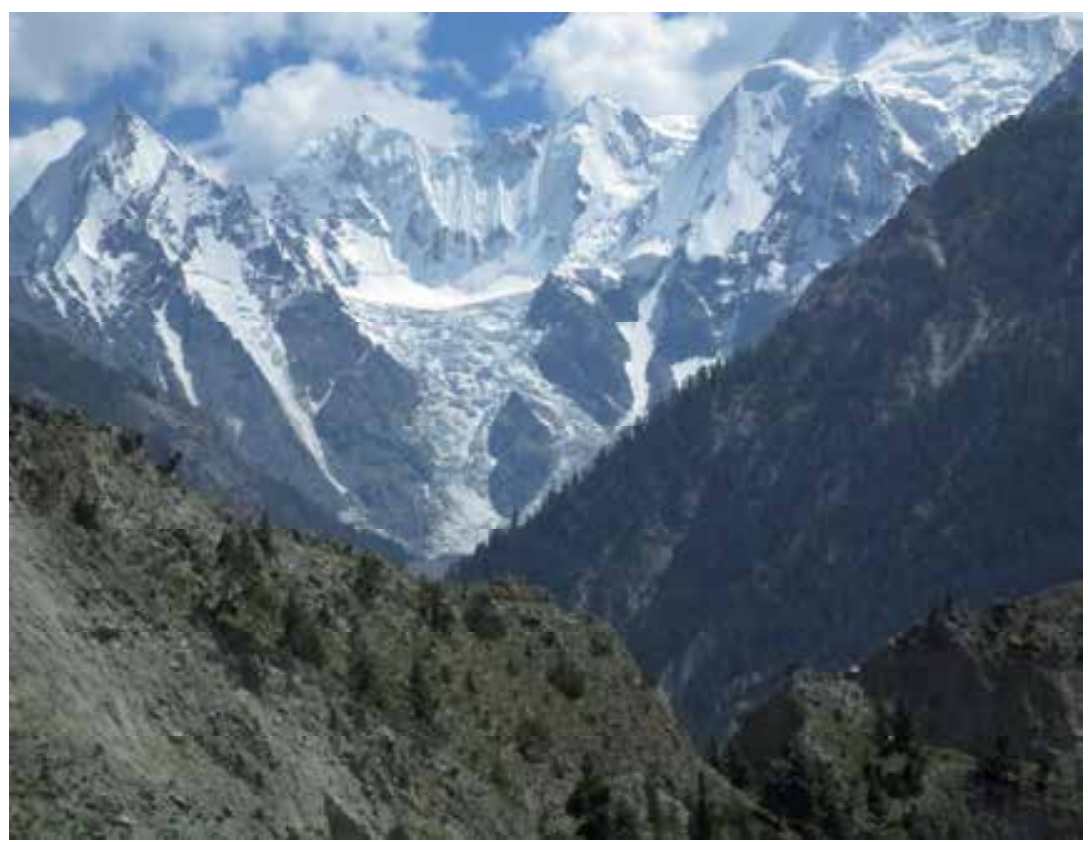

(a)

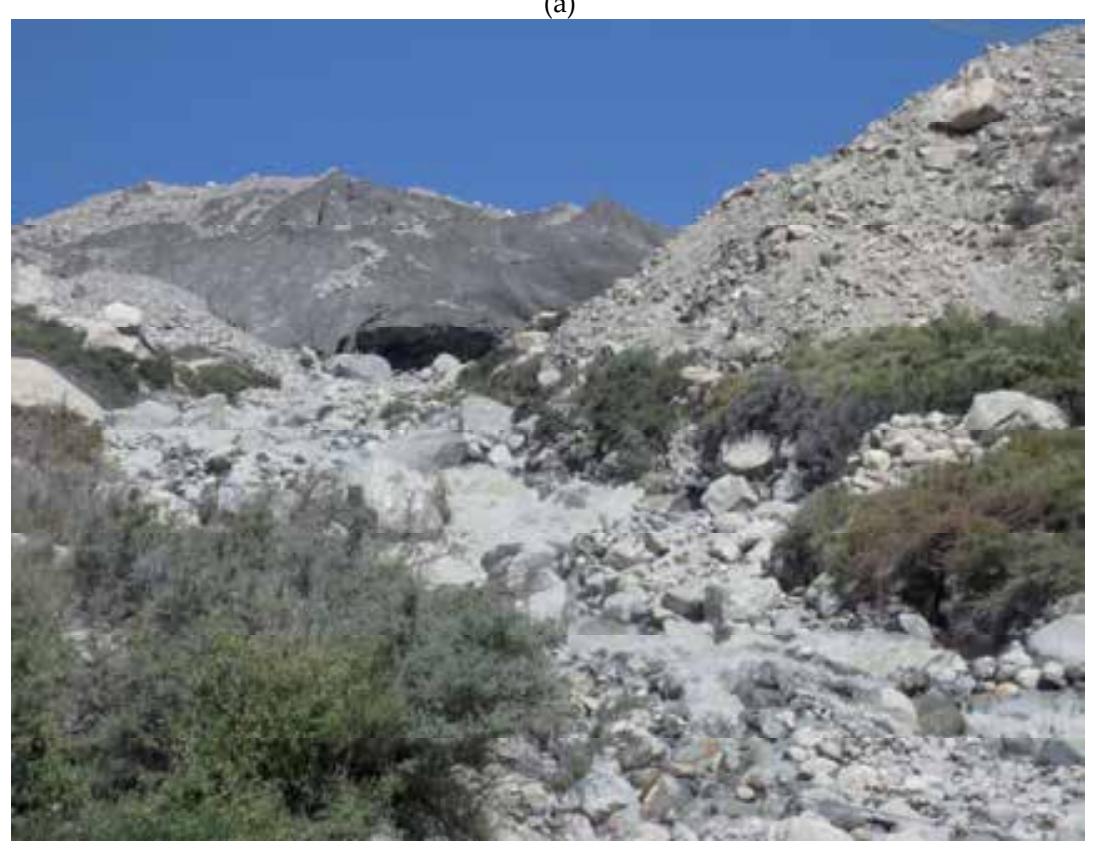

(b)

Figure 15. (a): The glaciers descending from steep gradients of Karakoram mountains are susceptible to global warming. (b): Frequency of glacial floods has been increased in the HKH region. 


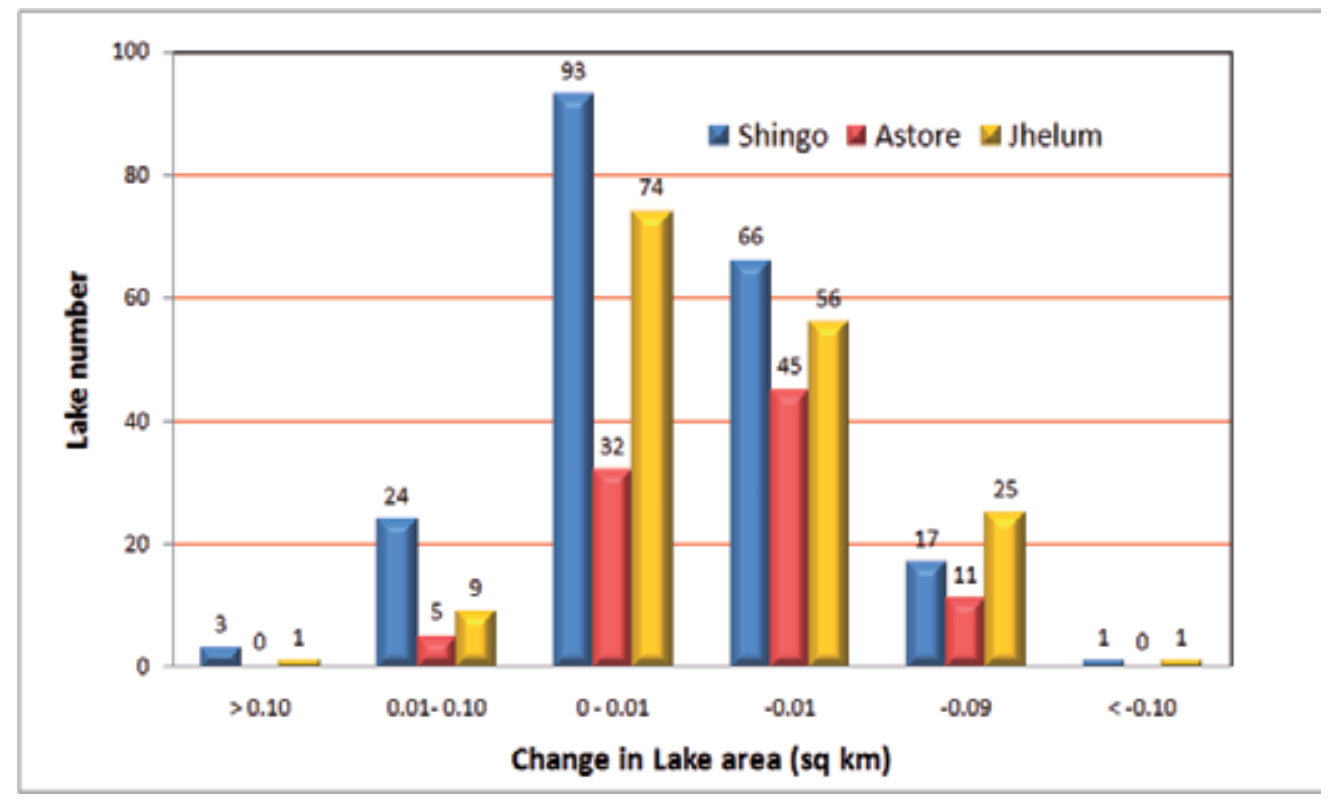

Figure 16. Variable changes in the lakes area in three river basins during the 2001-2013 period.

\begin{tabular}{|c|c|c|c|c|}
\hline Elevation (m) & No. of Lakes & Area_2001 (km²) & Area $2013\left(\mathrm{~km}^{2}\right)$ & Difference \\
\hline \multicolumn{5}{|c|}{ Shingo Basin } \\
\hline $3,500-4,000$ & 1 & 0.01 & 0.23 & 0.22 \\
\hline $4,000-4,500$ & 75 & 4.02 & 4.16 & 0.14 \\
\hline $4,500-5,000$ & 128 & 6.31 & 6.45 & 0.14 \\
\hline Total & 204 & & & \\
\hline \multicolumn{5}{|c|}{ Astore Basin } \\
\hline $3,000-3,500$ & 2 & 0.18 & 0.21 & 0.03 \\
\hline $3,500-4,000$ & 12 & 1.37 & 1.42 & 0.05 \\
\hline $4,000-4,500$ & 62 & 2.24 & 1.93 & -0.31 \\
\hline $4,500-5,000$ & 17 & 0.41 & 0.42 & 0.01 \\
\hline Total & 93 & & & \\
\hline \multicolumn{5}{|c|}{ Jhelum Basin } \\
\hline $3,000-3,500$ & 3 & 1.29 & 1.46 & 0.17 \\
\hline $3,500-4,000$ & 28 & 3.27 & 3.13 & -0.14 \\
\hline $4,000-4,500$ & 135 & 6.21 & 5.93 & -0.28 \\
\hline Total & 166 & & & \\
\hline
\end{tabular}

Table 4. Changes in the lakes area by elevation in three river basins during the 2001-2013 period. 


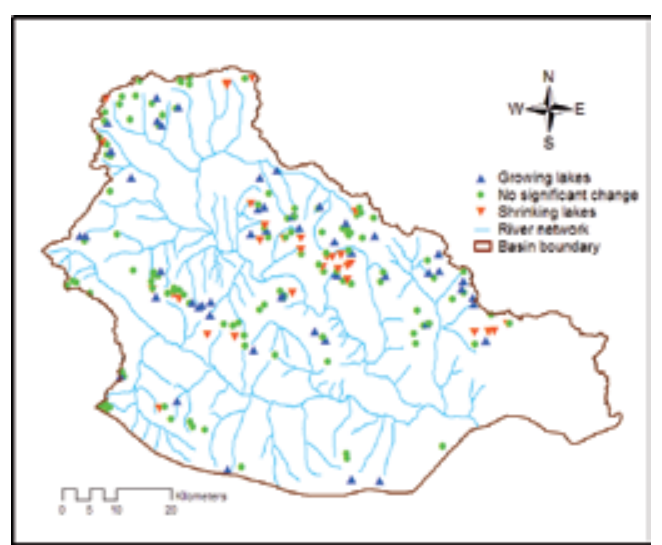

(a)

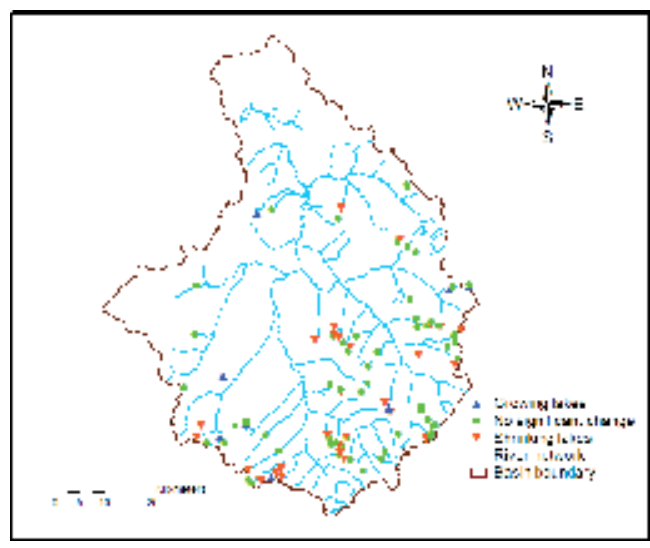

(b)

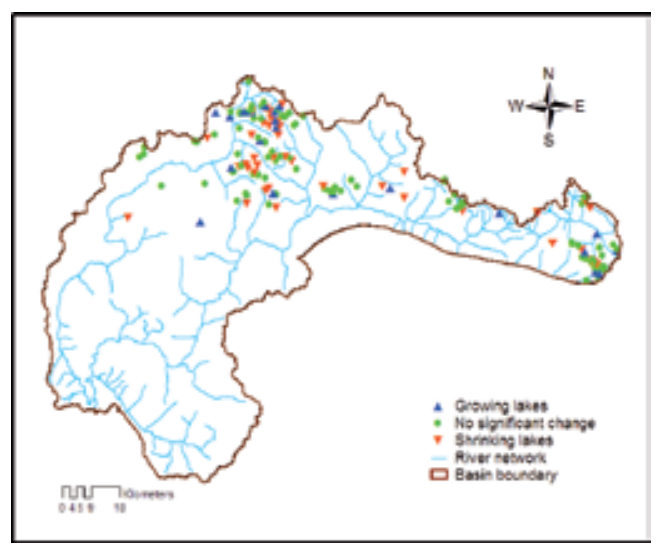

(c)

Figure 17. (a): Changes in the lakes area in Shingo basin during the 2001-2013 period. (b): Changes in the lakes area in Astore basin during the 2001-2013 period. (c): Changes in the lakes area in Jhelum basin during the 2001-2013 period. 
The glacier retreat in the Himalayas has resulted in the formation of new glacial lakes and the enlargement of existing ones due to the accumulation of meltwater behind loosely consolidated end-moraine dams [56]. There was a rising trend observed in Astore River flow during the period 1974-2005. The situation may be attributed to the increase in contribution of snow and ice melts in the river flows. The increase in summer temperatures had affected the overall glacial coverage, thickness, and ice reserves during the period 19642005. There was a gradual decline in the glacial coverage since 1960s (Figure 18). The melting rates of small glaciers appeared higher than those of the large ones. The trend in depletion of the glacial coverage during 1964-2005 is shown in Figure 19. There are previous studies that highlight the receding of glaciers in most of the Himalaya and a general shrinkage on a global scale [30, 31].

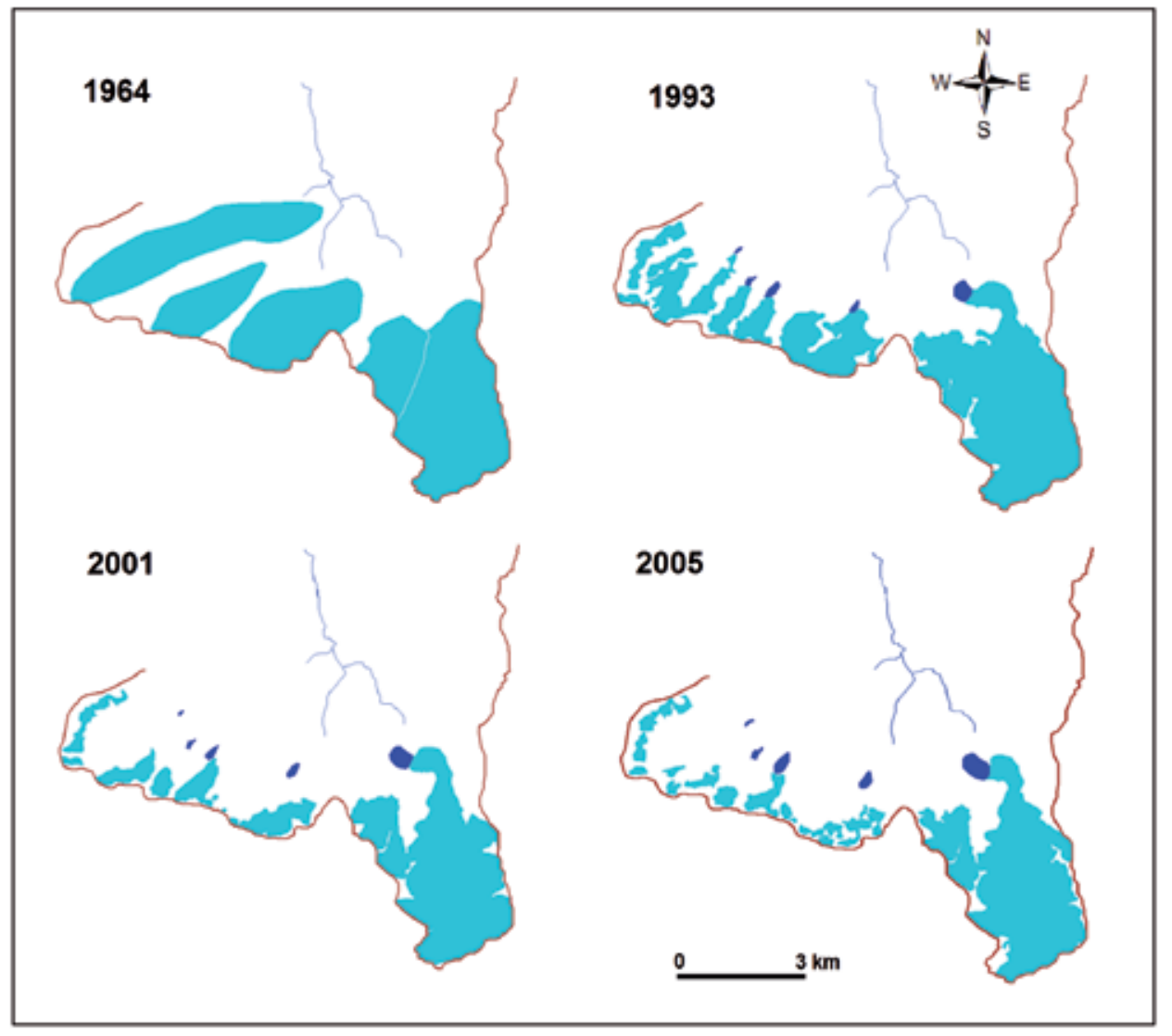

Figure 18. Spatiotemporal analysis of glaciers and glacial lakes in Astore basin.

The melting of glaciers results not only in reduction of surface area and thickness of glaciers but also in expansion of the associated glacial lakes. A large valley glacier Folvi (Gr 1) is expanding at a rate of about $0.013 \mathrm{~km}^{2} \mathrm{y}^{-1}$ [57], while the depletion of this glacier resulted in 
expansion of its associated glacial lake at a rate of about $0.009 \mathrm{~km}^{2} \mathrm{y}^{-1}$ since 1993. Local geomorphic and climatic parameters may influence the retreat of individual glaciers and may not represent the regional changes in climatic condition.

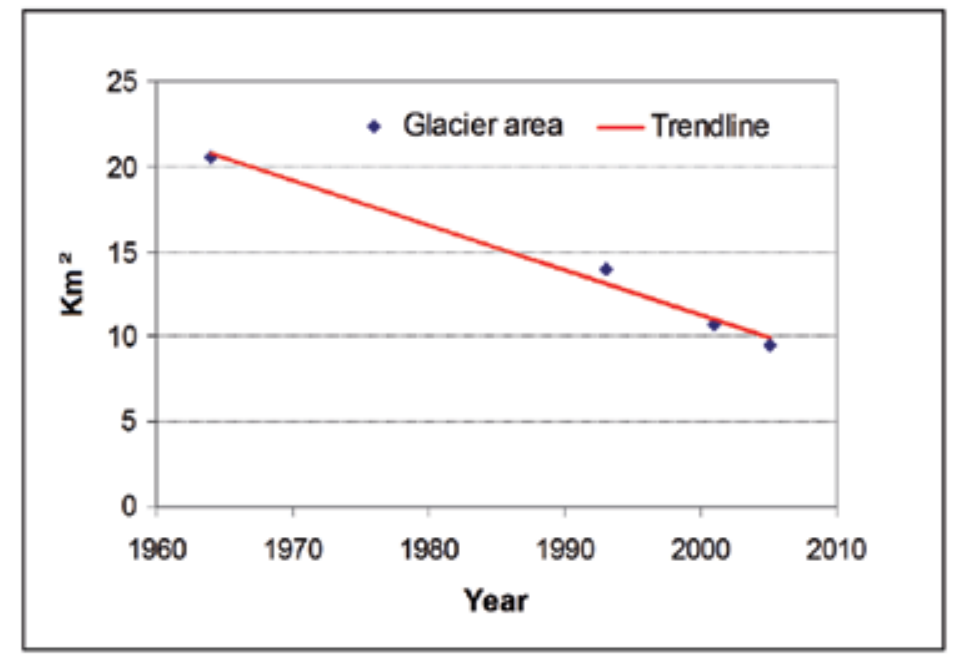

Figure 19. Variation in glacierized area at different time periods in Astore basin.

\subsection{Scenarios of impact of climate change}

The impact of rise in annual temperature ' $T$ ' on river flows was analyzed. It was observed that there was an increasing trend in winter maximum and minimum temperatures of Gilgit from 2011 to 2099. The average values of winter maximum and minimum temperatures were used in snowmelt runoff model to predict future flows of Gilgit River. By increasing the annual maximum and minimum temperatures to $1.24^{\circ} \mathrm{C}$ until 2050, the summer flows will increase by $16 \%$, and when this temperature increases to $2.78^{\circ} \mathrm{C}$ untill 2099 , summer flows will increase by $34 \%$ (Figures $20 \mathrm{a} \& b$ ). Global warming may intensify the summer monsoon, and thereby enhances precipitation especially downstream of the Indus River [25]. The rise in temperature may accelerate the process of seasonal snow and glacier melting resulting in a gradual increase in the river flows.

The results obtained from regional climate model (PRECIS) show that there is an increasing trend of winter precipitation in Gilgit River basin. On this basis, scenarios were developed such that if cryosphere area in Gilgit increases in future due to increase in winter precipitation then what will be its effect on future flows? In previous studies, it was assumed that cryosphere area would increase due to increase in precipitation in Karakorum region as explained in Refs. $[53,58]$. Therefore, on this basis, the scenario of $10 \%$ increase in the cryosphere area until 2050 and 20\% increase in the cryosphere area until 2075 was used in SRM to predict future flows of Gilgit River. According to the modeling results, if cryosphere area increases to $10 \%$ and $20 \%$ in the basin, summer flows will increase to $13 \%$ and $27 \%$, respectively (Figures 20c\&d). 

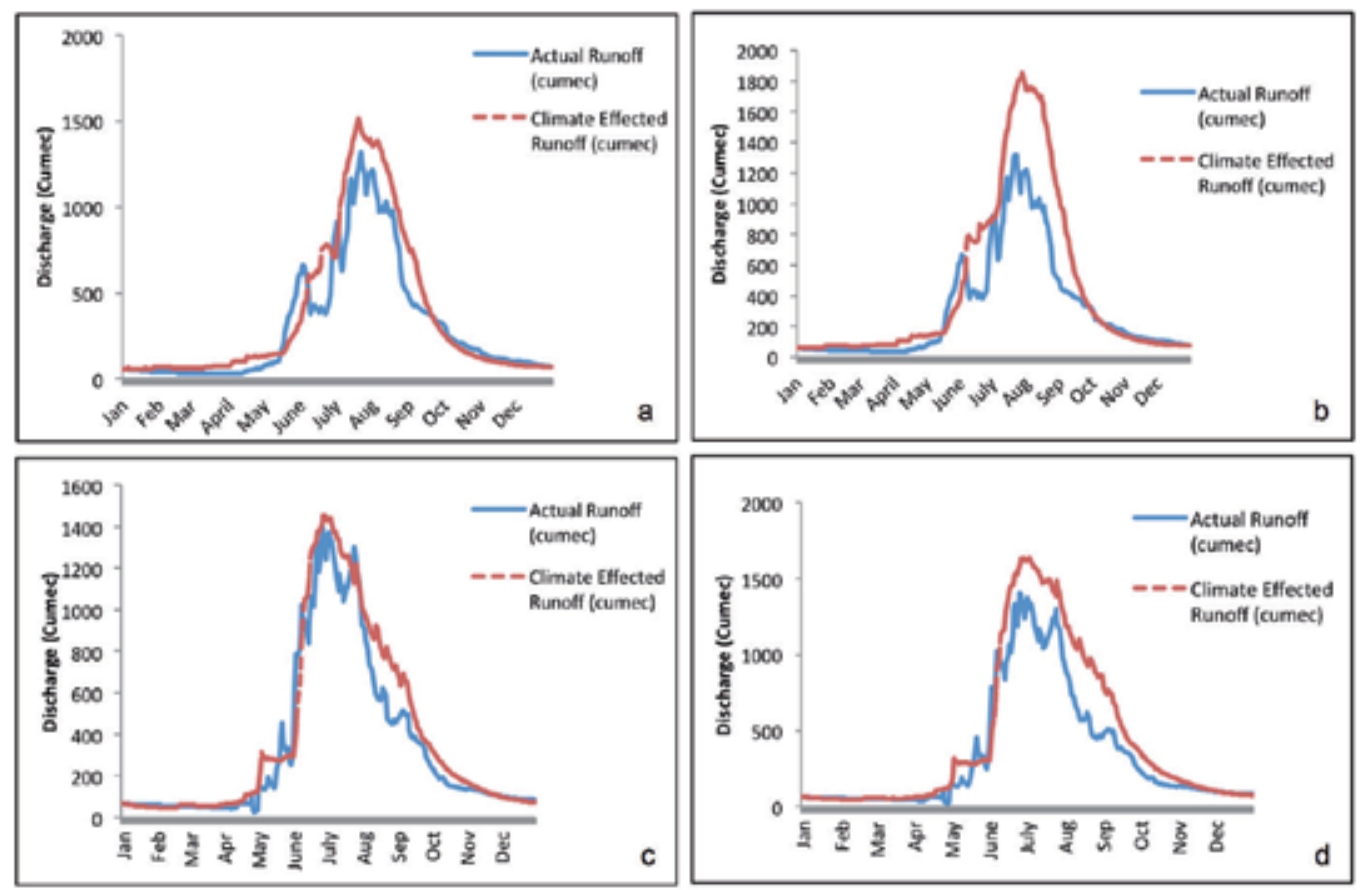

Figure 20. Climate effected runoff due to rise in average annual temperature until 2050 (a); until 2099 (b); increase in cryosphere area by $10 \%$ (c); and by $20 \%$ (d) in Gilgit basin, Central Karakoram.

\subsection{Hazard assessment and early warning using RS technique}

The primary functions of remote sensing approach within the climate risk cycle in glacial environment are to develop understanding of the hazards and monitoring the status of glacial lakes and associated glaciers. Predicting whether a glacier will block a valley and, if so, whether a hazardous lake will develop is difficult and requires monitoring of glaciers through physical approach or remote sensing technique. Current hazard assessment efforts depend on detecting margin fluctuations of those glaciers in physiographical settings favorable to lake development observed through field inspection or derived from optical satellite images. Small supraglacial lakes in majority of cases are not hazardous, but they may generate surprisingly large floods that represent hazards at local scales. They can be particularly difficult to identify and assess using remote sensing because of their frequent small size and short life span. Because of the tendency for repeat events from a single glacier, historical reports of GLOFs and local knowledge are important sources of information.

Early warning systems are helpful in reducing the threat of glacial hazards posed to people in downstream. A complete and effective early warning system mainly comprises interrelated elements: risk knowledge, monitoring and warning service, dissemination and communication, and response capability. The human dimensions of early warnings imply that traditional systems are more likely to factor in attachment to the home environment, assets, belief systems, 
and traditional coping strategies [59]. Although community's involvement in early warning systems is important, remote sensing technology can facilitate in solving the scientific issues related to hazard monitoring, forecasting, and telecommunications.

\section{Conclusions}

The results of the study reveal that glaciers in this part of Himalayan region are being affected by global warming. Increase in the number of glacial lakes in the recent decade provides clue to the changing glacial environment of the Upper Indus basin. The integrated use of RS and GIS techniques with sparse in situ data is found helpful in analyzing the glaciers' behavior of the Himalayan region. Minimum numbers of large-sized glaciers were identified in the Himalaya basin, which points toward higher rates of glacial ice melting in this range. On the contrary, the presence of relatively higher numbers of medium- to large-sized glaciers in the Karakoram basin provides an evidence of favorable climatic conditions for the glaciers' existence at higher altitudes. Similarly. the increase in snow coverage observed in the Hunza basin of Karakoram during the 2001-2011 may result in ice mass gain in the basin. In order to detect potentially critical glacial lakes in advance, adoption of reliable and robust RS-based approaches is required. The rapidly expanding glacial lakes especially near the headwaters and settlements in the glacierized basins needs to be monitored periodically on a long-term basis to mitigate the risk of any future flood hazards in the HKH region. An in-depth study of the impact of global warming on cryosphere of the Himalayan region using high-resolution remote sensing data (IKONOS, QuickBird, aerial photographs) combined with detailed field investigations is required to cope up with situations such as diminishing water resources and flood hazards in the downstream areas in future.

\section{Acknowledgements}

The authors appreciate the support of Pakistan Meteorological Department (PMD), International Center for Integrated Mountain Development (ICIMOD), Nepal, UNDP-Pakistan and Scientists and staff of Climate Change, Alternate Energy and Water Resources Institute for rendering valuable assistance during execution of this study.

\section{Author details}

Arshad Ashraf, Manshad Rustam, Shaista Ijaz Khan, Muhammad Adnan and Rozina Naz

*Address all correspondence to: mashr22@yahoo.com

Climate Change, Alternate Energy and Water Resources Institute (CAEWRI), National Agricultural Research Center, Islamabad, Pakistan 


\section{References}

[1] Gardelle J, Arnaud Y, Berthier E. Contrasted evolution of glacial lakes along the Hindu Kush Himalaya mountain range between 1990 and 2009. Global and Planetary Change. 2011; 75: 47-55. doi:10.1016/j.gloplacha.2010.10.003

[2] Costa JE and Schuster RL. The formation and failure of natural dams. Geological Society of American Bulletin. 1988; 100: 1054-1068.

[3] Ulugtekin N, Balcik FB, Dogru AO, Goksel C, Alaton IA, Orhon D. The use of remote sensing and geographic information systems for the evaluation of river basins: a case study for Turkey, Marmara River Basin and Istanbul. Journal of Environmental Science and Health, Part A. 2009; 44(4): 388-396. doi:10.1080/10934520802659760

[4] Huggel C, Kääb A, Haeberli W, Teysseire P, Paul F. Remote sensing based assessment of hazards from glacier lake outbursts: a case study in the Swiss Alps. Canadian Geotechnical Journal. 2002; 39: 316-330.

[5] Jacobs JD, Simms EL, Simms A. Recession of the southern part of Barnes Ice Cap, Baffin Island, Canada, between 1961 and 1993, determined from digital mapping of Landsat TM. Journal of Glaciology. 1997; 43: 98-102.

[6] Kääb A, Paul F, Maisch M, Hoelzle M, Haeberli W. The new remote-sensing-derived Swiss glacier inventory: II. First results. Annals of Glaciology. 2002; 34: 362-366.

[7] Roohi R, Mool PK, Ashraf A, Bajracharya S, Hussain SA, Naz R, 2005. Inventory of Glaciers, Glacial lakes the Identification of Potential Glacial lake Outburst Floods Affected by Global Warming in the Mountains of Himalayan Region, Pakistan, ICIMOD, Nepal and PARC, Pakistan.

[8] Williams RS Jr. and Ferrigno JG (eds.), State of the Earth's cryosphere at the beginning of the 21st century - glaciers, global snow cover, floating ice, and permafrost and periglacial environments: U.S. Geological Survey Professional Paper 1386-A: 546 p. 2012. http://pubs.usgs.gov/pp/p1386a.

[9] Quincey D, Richardson S, Luckman A, Lucas R, Reynolds J, Hambrey M, Glasser N. Early recognition of glacial lake hazards in the Himalaya using remote sensing datasets. Global and Planetary Change. 2007; 56: 137-152.

[10] Kääb A. Glacier volume changes using ASTER satellite stereo and ICESat GLAS laser altimetry. A test study on Edgeøya, Eastern Svalbard. IEEE Transactions on Geoscience and Remote Sensing. 2008; 46(10): 2823-2830.

[11] Veettil BK. A Remote sensing approach for monitoring debris-covered glaciers in the high altitude Karakoram Himalayas. International Journal of Geomatics and Geosciences. 2012; 2(3): 833-841. 
[12] Richardson SD. Remote sensing approaches for early warning of GLOF hazards in the Hindu Kush-Himalayan region, Final report-ver 1.2, United Nations International Strategy for Disaster Reduction (UN/ISDR). 2010.

[13] Huggel C, Kääb A, Haeberli W, Krummenacher B. Regional-scale GIS-models for assessment of hazards from glacier lake outbursts: evaluation and application in the Swiss Alps. Natural Hazards and Earth System Sciences. 2003; 3: 647-662.

[14] Martinec J. Snowmelt runoff model for stream flow forecasts. Nordic Hydrology. 1975; 6(3): 145-154. doi:10.2166/nh.1975.010

[15] Poon SKM. Hydrological Modeling Using MODIS Data for Snow Covered Area in the Northern Boreal Forest of Manitoba. M.E. Dissertation. Alberta: University of Calgary. 2004.

[16] Klein AG and Barnett AC. Validation of daily MODIS snow cover maps of the Upper Rio Grande River Basin for the 2000-2001 snow year. Remote Sensing of Environment. 2003; 86(2): 162-176. doi:10.1016/ S0034-4257(03)00097-X

[17] Haeberli W. Changing views on changing glaciers. In The Darkening Peaks: Glacial Retreat in Scientific and Social Context (eds.) Orlove B, Wiegandt E and Luckman B, Berkeley: University of California Press, 2005: 23-32.

[18] Haeberli $\mathrm{W}$ and Beniston M. Climate change and its impacts on glaciers and permafrost in the Alps. Ambio. 1998; 27: 258-265.

[19] GCOS: Implementation plan for the Global Observing System for Climate in support of the UNFCCC, GCOS-92, WMO, Geneva. 2004.

[20] IPCC. Fifth Assessment Report of Intergovernmental Panel on Climate Change: Working Group 1. Summary for Policy Makers - Climate Change 2013: The Physical Science Basis. 2013.

[21] UNEP and WGMS. Global glacier changes: facts and figures. 2008.

[22] Jansson P, Hock R, Schneider T. The concept of glacier storage: a review. Journal of Hydrology. 2003; 282(1-4): 116-129.

[23] Sharif M, Archer D, Fowler H, Forsythe N. Trends in timing and magnitude of flow in the Upper Indus Basin. Hydrology and earth system sciences discussions. 2012; 9: 9931-9966.

[24] Bocchiola D, Diolaiuti G, Soncini A, Mihalcea C, Agata CD, Mayer C, Lambrecht A, Rosso R, Smiraglia C. Prediction of future hydrological regimes in poorly gauged high altitude basins: the case study of the upper Indus, Pakistan. Hydrology and Earth System Sciences Discussions. 2011; 8(2): 3743-791.

[25] Panday P, Frey K, Ghimire B. Detection of the timing and duration of snowmelt in the Hindu Kush-Himalaya using QuikSCAT, 2000-2008. Environmental Research Letters. 2011; 8(1): 014020-014033. 
[26] Frey H. Compilation and Applications of Glacier Inventories using Satellite Data and Digital Terrain Information, PhD Dissertation University of Zurich. 2011.

[27] Posma JC. The effects of climate change and associated glacier melting in the HinduKush Himalayas on the water supply and water use of the Indus, Pakistan. BS Thesis, University of Utrecht. 2013.

[28] Ashraf A, Roohi R, Naz R, Mustafa N. Monitoring cryosphere and associated flood hazards in high mountain ranges of Pakistan using remote sensing technique. Natural Hazards. 2014; 73: 933-949. doi:10.1007/s11069-014-1126-3

[29] Chaudhry QZ, Mahmood A, Rasul G, Afzaal M. Climate Indicators of Pakistan. PMD Technical Report 22/2009.

[30] Fujita K and Nuimura T. Spatially heterogeneous wastage of Himalayan glaciers. Proceedings of the National Academy of Sciences of the United States of America. 2011; 108(34): 14011-14014. doi:10.1073/pnas.1106242108

[31] Bolch T, Kulkarni A, Kaab A, Huggel C, Paul F, Cogley JG, Frey H, Kargel JS, Fujita K, Scheel M, Bajracharya S, Stoffel M. The state and fate of Himalayan glaciers. Science. 2012. 336(6079): 310-314.

[32] Kääb A, Berthier E, Nuth C, Gardelle J, Arnaud Y. Contrasting patterns of early twenty-first-century glacier mass change in the Himalayas. Nature. 2012; 488: 495498. doi:10.1038/nature11324

[33] Gardelle J, Berthier E, Arnaud Y, Kääb A. Region-wide glacier mass balances over the Pamir-Karakoram-Himalaya during 1999-2011. The Cryosphere. 2013; 7: 12631286. doi:10.5194/tc-7-1263-2013

[34] WMO. Intercomparison of Models of Snowmelt Runoff, Geneva, Switzerland. 1986.

[35] Hewitt K. Tributary glacier surges: an exceptional concentration at Panmah glacier Karakoram Himalaya. Journal of Glaciology. 2007; 53: 181-188.

[36] Archer DR. The climate and hydrology of northern Pakistan with respect to assessment of flood risks to hydropower schemes. Report by GTZ/WAPDA. 2001.

[37] Awan SA. The climate and flood risk potential of northern Pakistan, special issue of Journal of Science vision. 2002; 47(3,4): 100-109.

[38] LIGG/WECS/NEA. Report on the First Expedition to Glaciers and Glacier Lakes in the Pumqu (Arun) and Poique (Bhote-Sun Kosi) River Basins, Xizang (Tibet), China, Sino-Nepalese Investigation of Glacier Lake Outburst Floods in the Himalaya. Beijing, China: Science Press. 1988.

[39] Wang WC, Yao TD, Yang XX. Variations of glacial lakes and glaciers in the Boshula mountain range, southeast Tibet, from the 1970s to 2009. Annals of Glaciology. 2011; 52: 9-17. doi:10.3189/172756411797252347 
[40] Salerno F, Thakuri S, D’Agata C, Smiraglia C, Manfredi EC, Viviano G, Tartari G. Glacial lake distribution in the Mount Everest region: uncertainty of measurement and conditions of formation. Global and Planetary Change. 2012; (92-93): 30-39. doi: 10.1016/j.gloplacha.2012.04.001

[41] Pietroniro A and Leconte R. A review of Canadian remote sensing applications in hydrology, 1995-1999. Hydrological Processes. 2000; 14: 1641-1666..

[42] Bayr KJ, Hall DK, Kovalick WM. Observations on glaciers in the eastern Austrian Alps using satellite data. International Journal of Remote Sensing. 1994; 15(9): 17331752.

[43] Paul F. Evaluation of different methods for glacier mapping using Landsat TM. EARSeL eProc. 2001; 1: 239-245.

[44] Paul F, Kääb A, Maisch M, Kellenberger T, Haeberli W. The new remote-sensing-derived Swiss glacier inventory. I. Methods. Annals of Glaciology. 2002; 34: 355-361.

[45] Crane RB. Preprocessing techniques to reduce atmospheric and sensor variability in multispectral scanner data. In Proceedings of the 7th International Symposium on Remote Sensing of the Environment, Vol. II, Ann Arbor, MI, USA. 1971: 1345-1355.

[46] Vincent RK. Spectral ratio imaging methods for geological remote sensing from aircraft and satellites. In Anson A ed. Proceedings of the American Society of Photogrammetry, Management and Utilization of Remote Sensing Data Conference, Sioux Falls, South Dakota. Falls Church, VA, American Society of Photogrammetry. 1973: 377-397.

[47] Holben BN. An examination of spectral band rationing to reduce the topographic effect on remotely sensed data. International Journal of Remote Sensing. 1981; 2(2): 115-133.

[48] Meyer P, Radiometric corrections of topographically induced effects on Landsat TM data in an alpine environment. ISPRS Journal of Photogrammetry. 1993; 48(4): 17-28.

[49] Muller F, Caflish T, Muller G. Instruction for Compilation and Assemblage of Data for a World Glacier Inventory. Zurich: Temporary Technical Secretariat for World Glacier Inventory, Swiss Federal Institute of Technology, Zurich. 1977.

[50] Tahir AA, Chevallier P, Arnaud Y, Neppel L, Ahmad B. Modeling Snowmelt-Runoff under climate scenarios in the Hunza River basin, Karakoram Range, Northern Pakistan. Journal of Hydrology. 2011; 409(1-2): 104-117.

[51] Farooqi AB, Khan AH, Mir H. Climate change perspective in Pakistan. Pakistan Journal of Meteorology. 2005; 2(3): 11-21.

[52] Fowler HJ and Archer DR. Conflicting signals of climate change in the upper Indus basin. Journal of Climate. 2005; 9: 4276-4293. 
[53] Hewitt K. The Karakoram anomaly? Glacier expansion and the 'Elevation Effect', Karakoram Himalaya. Mountain Research and Development. 2005; 25: 332-340.

[54] IPCC. Climate Change 2007: Contribution of Working Groups I, II and III to the Fourth Assessment Report of the Intergovernmental Panel on Climate Change. Core Writing Team (eds.) Pachauri RK and Reisinger A, Geneva: IPCC, 2007: pp 104.

[55] Archer DR and Fowler HJ. Spatial and temporal variations in precipitation in the Upper 20 Indus Basin, global teleconnections and hydrological implications, Hydrology and Earth System Sciences. 2004; 8: 47-61.

[56] ICIMOD. Glacial lakes and glacial lake outburst floods in Nepal. Kathmandu: ICIMOD. 2011.

[57] Ashraf A, Roohi R, Ijaz S, Ahmad B, Naz R. Monitoring Global warming Impact on Glacier environment using GIS Application. In proceedings of National Seminar on State and Challenges of GIS/RS Applications in Water sector, by PCRWR, Islamabad 25-26 June, 2008.

[58] Immerzeel WW, Van Beek LPH, Bierkens MFP. Climate change will affect the Asian water towers. Science. 2010; 328(5984): 1382-1385.

[59] ISDR. Living with Risk. A Global Review of Disaster Reduction Initiatives. InterAgency Secretariat of the International Strategy for Disaster Reduction (ISDR). Geneva, 2007: pp 384. 



\title{
Chapter 5
}

\section{Remote Sensing of Mountain Glaciers and Related Hazards}

\author{
Pratima Pandey, Alagappan Ramanathan and Gopalan Venkataraman \\ Additional information is available at the end of the chapter
}

http://dx.doi.org/10.5772/61981

\begin{abstract}
Mountain glaciers are highly sensitive to temperature and precipitation fluctuations and active geomorphic agents in shaping the landforms of glaciated regions which are direct imprints of past glaciations, providing reliable evidence of the evolution of the past Cryosphere and contain important information on climatic variables. But most importantly, glaciers have aroused a lot of concern in terms of glacier area changes, thickness change, mass balance and their consequences on water resources as well as related hazards. The contribution of glacier mass loss to global sea-level rise and increasing number of glacierrelated hazards are the most important and current socioeconomic concerns. Therefore, understanding the dynamics of the changes and constant monitoring of glaciers are essential for studying climate, water resource management and hydropower and also to predict and evade glacier-related hazards. The recent advances in the techniques of earth observations have proved as a boon for investigating glaciers and glacier-related hazards. Remote sensing technology enables extraction of glacier parameters such as albedo/reflectance/scattering, glacier area, glacier zones and facies, equilibrium line, glacier thickness, volume, mass balance, velocity and glacier topography. The present chapter explores the prospective of remote sensing technology for understanding and surveying glaciers formed at high, inaccessible mountains and glacier-induced hazards.
\end{abstract}

Keywords: Mountain glacier, hazard, assessment, remote sensing

\section{Introduction}

Glaciers require standard and accurate technology to be studied. Remote sensing technologies play tremendous role for monitoring glaciers. In fact, a glacier can be considered as a large body of moving ice wherein water penetrates in the form of snow. The snow then transforms into ice by compaction and recrystallization and the ice flows through the system under its own weight and leaves the system by melting and evaporation [1]. The glacier is thus a large 
body of moving ice. Therefore, glaciers store considerable amount of fresh water in frozen form. The water supply from the glaciers located in the upstream mountains is vital for sustaining and maintaining downstream cultures. The melt water from the snowpack and glaciers fulfil manifold requirements of humankind. In the dry season, the water from glaciers is released by delayed response through snow and ice melting and enhances the river runoff, therefore providing water to the downstream when there is no other source of water [2]. For instance, the melt water released from the glaciers in the Alps and Himalayas and other mountain ranges is crucially important and plays a major role in the water supply of large downstream population [3-6]. The ice sheets, ice caps and glaciers constitute $10 \%$ of the earth's land surface contributing to about $3 \%$ of the total water on earth corresponding to about $80 \%$ of the world's freshwater [7]. According to the estimate made by Meier and Bahr [8], the total area of the glaciers and ice sheets are about $680,000 \mathrm{~km}^{2}$ and according to Dyurgerov and Meier [9], the same is about 785,000 $\mathrm{km}^{2}$. The Hindu-Kush Himalayan region alone contains a total of $60,054 \mathrm{~km}^{2}$ glaciated area, which is the largest concentration of glaciers outside the polar caps. The Hindu-Kush Himalayan region is home to about 54,252 glaciers and is aptly called as the "Water Tower of Asia" as it provides 86,000,000 $\mathrm{m}^{3}$ of water annually.

These glaciers feed the world's largest rivers such as the Ganga, Indus, Brahmaputra, Salween, Mekong, Yangtze and Huang Ho and supply water to about one billion people living downstream. The fresh water coming from the glaciers of high mountains in these rivers is an important resource for agriculture, navigation, fishing, generation of hydropower and tourism. Apart from being a boon to society, glaciers also play havoc to life and property of the people residing downstream. The mountain glaciers are a potential source of severe natural hazards [10-12]. Besides playing many roles in hydrological sectors, glaciers are also considered as a key indicator of climate. Any change in the climate is visible through glacier behavior and response. Glaciologists and climatologists carry out research on glacier changes to understand the change in the past and present climate and to predict the future changes. Contribution of glacier melt water to sea level rise under warming climate is the burning topic among the glaciologists and the hydrologists.

Glaciers form under the climatic condition when snowfall is more than snowmelt and this condition in the tropics is fulfilled at very high altitude where the temperature is very less. Therefore, the mountain glaciers are generally located at remote and inaccessible locations. Monitoring of these glaciers through ground survey is costintensive, difficult and sometimes dangerous to life. Remote sensing offers an innovative and valuable tool for gathering information about remotely located glaciers which are otherwise inaccessible and significantly capable of extending the scale of the study both spatially and temporally. In the past few decades, the remote sensing has proved to be a crucial resource for glaciologist. The advent, advancement and increase in the number and quality of earth observing sensors, the development of new technologies, algorithms, high processing capability and new methodologies have brought huge revolution in understanding the Cryospheric processes [13].

Keeping in view the importance of glaciers in society and environment, this chapter will provide information on the remote sensing data available for glaciological studies, the glacier parameters studied by remote sensing and the method of studying those parameters. The chapter will focus on the method of estimating snow and glacier area change, volumetric 
change, mass change, velocity and assessment of glacier-related hazards. The chapter will broadly address two major topics: (a) study of snow and glacier parameters and (b) hazard assessments. This chapter will provide an overview of the importance, impact and the place of mountain glaciers in our social life as well in scientific research.

The objectives of the chapter are very precise and clear, that is, to endow the readers with the scope of studying various glaciological parts and subjects with remote sensing. Our aim is to make the readers familiar with mountain glaciers, their parts and dynamics and the methodology to study the same. Thus, in the chapter we will attempt to discuss about the remote sensing data types and the different glacier parameters which can be studied and derived by them. The emphasis will be given to the methodology of extracting various glaciological parameters from remotely sensed data. Figure 1 is the field photograph of Chhota Shigri glacier taken during September 2014.

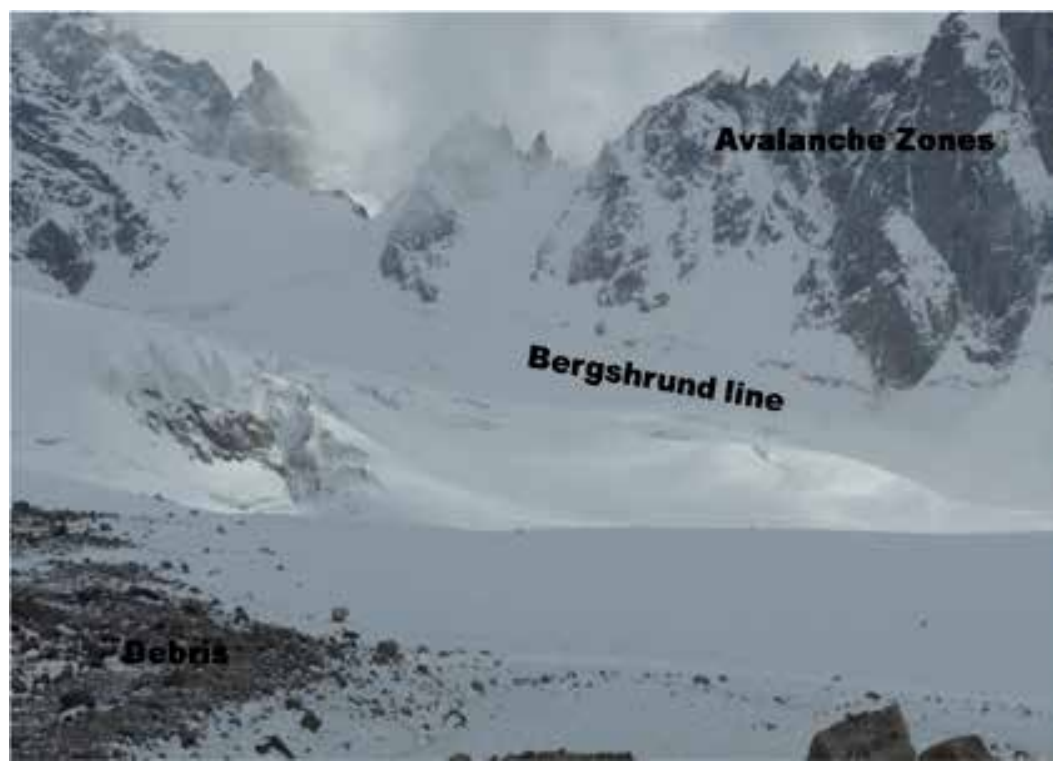

Figure 1. Field photograph of a Himalayan glacier, September 2014 (Chhota Shigri, western Himalaya, India), showing debris on the glacier, the surrounding avalanche prone steep cliffs and the Bergshrund line separating the glacier body from the cliff.

\section{Glacier zones and features}

Glaciers form when in a year fall of snow is more than the wasting of snow and the trend continues for many years. The formation and sustenance of glacier thus are functions of climatic parameters such as precipitation and temperature. The transformation of snow into glacier ice takes place through compaction and recrystallization [14]. Snowfall, snow avalanches and snow drift are some of the accumulation processes through which glaciers gain 
in mass, whereas melting, evaporation and calving are the ablation processes by which glaciers lose mass. Climate and topography play major role in determining the shape, size and type of glacier [15]. Starting from the upper elevation to the terminus, a glacier can be divided into several specific zones. A typical temperate mountain glacier consists of (1) accumulation zone, which is the upper most part of the glacier and where there is net gain of ice, and (2) ablation zone, the lower part of the glacier where there is net loss in the ice through melting, calving and evaporation. The accumulation and ablation zones are separated by equilibrium line where there is neither gain nor loss of glacier ice. The lowest part of the glacier where the glacier ends and the discharge starts is known as snout/terminus/glacier toe. A glacier is a dynamic system which along with snow and ice also transports rocks and debris avalanching on the glacier from the side valley walls. These rocks and debris materials are transported through the glacier system from upper zone to the lower zone. Below the equilibrium line, after melting of ice, these rocks and debris concentrates linearly to the sides of the glacier to form lateral moraine. When a tributary glacier meets the main glaciers, the two adjacent lateral moraines form medial moraine. Terminal and end moraines are the rocks and debris piled near the end of the glacier. When these rocks and debris appear on the surface of the glacier through melting of ice, they are called supra glacier debris. Most of the mountain glaciers are debris-covered glaciers. The debris cover on the glacier changes the interaction of glacier with the climate. Sometimes, a glacier ends with a lake near its snout. This type of lake is known as pro-glacier lake. Many times, these proglacial lakes are dammed with moraines. In the enhanced melting condition of glaciers, these lakes can breach the dam and can cause havoc [16].

\section{Remote sensing of snow and glacier}

The remote sensing is an art and science that can gather information about an object without being in contact with it [13]. The remote sensing system can be airborne or space-borne and uses electromagnetic radiation to collect the information about the object. When the remote sensing system uses naturally occurring radiation, it is called passive remote sensing and when the remote sensing instrument generates its own radiation, it is known as active remote sensing. A glacier surface consists of snow, firn, ice, rock, debris and water, and each component has variable properties in the different electromagnetic spectrum.

\subsection{Optical visible and near infrared}

The optical visible and near infrared (VNIR) regions of electromagnetic spectrum $(0.4-3.0 \mu \mathrm{m})$ are the workhorses of remote sensing [17]. The sensors in the VNIR measure radiance radiated from the object, which is related to the reflectance and albedo of the object. Various glaciers zones such as accumulation, ablation, debris covered and water on the glacier have their own specific reflectance characteristics in the VNIR region, based on which the glacier and its various facies can be mapped (Figure 2). Snow has a very high reflectance in the visible wavelength region and a considerable low reflectance in the near-infrared and middle- and short-wave-infrared regions. The reflectivity of freshly fallen snow is very high in visible and infrared regions. Firn, which is one year old snow, has $25-30 \%$ less reflectance than snow. The 
glacier ice has high reflectance in the blue $(0.4-0.5 \mu \mathrm{m})$ and green $(0.5-0.6 \mu \mathrm{m})$ wavelength band but sharply decreases to near zero in the red $(0.6-0.7 \mu \mathrm{m})$ band [17]. The debris on the surface of the glacier significantly lowers the reflectance. The majority of the space-borne sensors operate in number of bands and known as multispectral. One of the most successful, longest and continuous VNIR program is the Landsat program which is continuously observing earth and gathering data since 1972 (Landsat MSS, TM, ETM+, OLI/TIR). The other optical VNIR operating sensors are ASTER, SPOT, MODIS, IRS LISS III/IV and AWiFS, Quickbird and IKONOS. Table 1 lists the spectral regions of optical bands used in Landsat TM and Table 2 presents some of the important satellite missions with their specifications.

\begin{tabular}{ll}
\hline Bands & Spectral region \\
\hline Visible (VIS) & $0.45-0.52$ (blue) \\
& $0.52-0.60$ (green) \\
& $0.63-0.69$ (red) \\
\hline Near infrared (NIR) & $0.76-0.90$ \\
\hline Short-wave infrared (SWIR) & $1.55-2.35$ \\
\hline Thermal infrared (TIR) & $10.42-12.50$ \\
\hline
\end{tabular}

Table 1. The spectral region in different optical bands

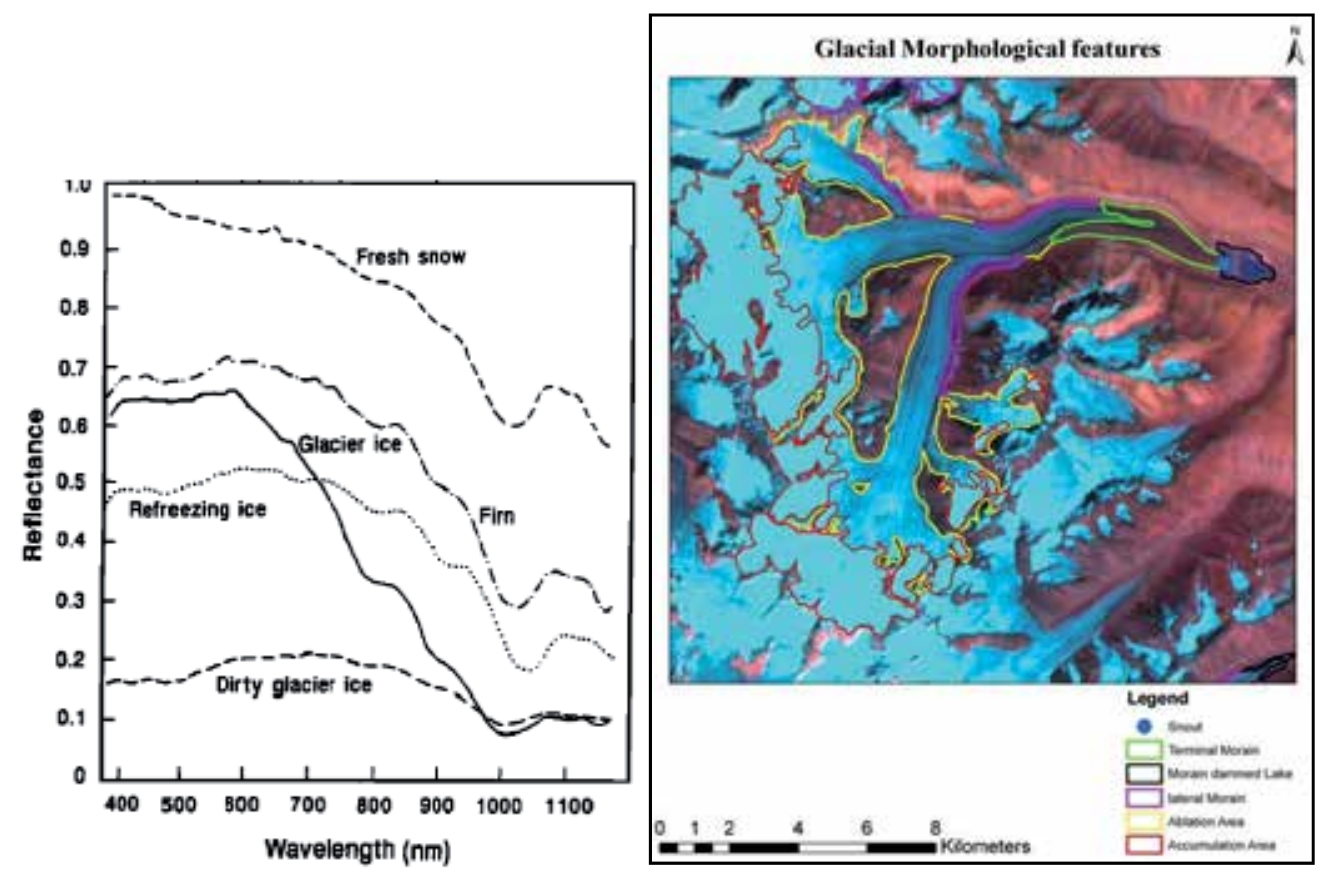

Figure 2. Spectral reflectance curves for snow and ice in different formation stages and satellite image (LISS III, September 11, 2000). 
Figure 2 shows the satellite image of Samudra Tapu glacier showing different features of the glacier based on reflectance. As evident from the spectral response curve, the snow has maximum reflectance followed by firn and ice. The debris cover on the glacier has similar reflectance of surrounding rocks. The same can be confirmed from the satellite image of the Samudra Tapu glacier.

\subsection{Thermal infrared}

The thermal infrared (TIR) $(3-15 \mu \mathrm{m})$ is a powerful remote sensing tool for discriminating surface objects with different temperature or emissivities [18]. Between the thermal band 8-14 $\mu \mathrm{m}$, it is possible to measure the temperature of the earth surface and sea surface as atmosphere works as window for these wavelength regions. The surface temperature of glacier is lower than the surroundings and thus can be differentiated using thermal data. The thermally active layer of a glacier has only $10 \mathrm{~m}$ depth upto which the seasonal variations can be felt [17]. The most commonly used thermal band sensors for the glaciological study are AVHRR, MODIS, Landsat series and ASTER.

\begin{tabular}{lllll}
\hline Platform/sensors & Launch & Number of bands & Spatial resolution & Spectral resolution \\
\hline Landsat MSS & 1972 & & $80 \mathrm{~m}$ & $4 \mathrm{MS}$ \\
Landsat TM & 1984 & & $15,30,60 / 100 \mathrm{~m}$ & PAN, 6MS, 1TIR \\
Landsat ETM+ & $1999-2003$ & & & 2 TIR, PAN,8MS \\
Landsat OLI/TIR & 2013 & & 14 bands & 3 3IS/NIR, 6SWIR, 5TIR \\
\hline ASTER & 1999 & $15,30,90 \mathrm{~m}$ & 3 VIS, 1PAN \\
\hline SPOT & 1984 & $20 \mathrm{~m} / 10 \mathrm{~m}$ & 4 bands & VIS, TIR \\
\hline MODIS & 1999 & $250,500,1000 \mathrm{~m}$ & 36 bands & 3 VIS/NIR, PAN \\
\hline Quick bird & 2001 & $0.6 \mathrm{~m}$ & 4 bands & 3 VIS/NIR, PAN \\
\hline IKONOS & 1999 & $1 \mathrm{~m}$ & 4 bands & VIS/NIR \\
\hline IRS LISS III/IV, AWiFS & $1988-2011$ & $72 \mathrm{~m}$ to 5.8m & 4 bands & \\
\hline
\end{tabular}

Table 2. List of selected optical remote sensing satellite missions

\subsection{Microwave electromagnetic spectra}

Microwave spectrum is the most popular wavelength region for studying snow and glacier properties after optical VNIR. The microwave sensors can be passive (radiometer, 3-6 mm spectral range) and active (radar, $1 \mathrm{~mm}$ to $1 \mathrm{~m}$ spectral range). The atmosphere is transparent in all weather conditions for the whole microwave spectral bands, and therefore, the microwave can be used to study the glacier in all weather conditions and day and night. The major advantage of microwave in monitoring glacier is the ability of microwave signals to penetrate into snow and ice upto various depth and providing information about the internal structure of the glacier. The depth of penetration of the signals depends on the wavelengths. In the dry snow zones, the penetration has been reported to be tens of meters [19]. The L-band radar can 
be significantly used for collecting information about the glaciers' internal stratigraphy. The ability to penetrate in the wet snow conditions is lesser than the dry snow. With the increase in wavelength, the ability of penetration increases. Surface roughness also influences the reflection and backscattering of microwave significantly. With the usage of synthetic aperture radar (SAR) technology, the spatial resolution of the radar remote sensing can be greatly improved. High-quality and high-resolution SAR data can be used to study glacier facies, glacier stratigraphy and other parameters such as glacier thickness and movement. Table 3 and 4 provide the details of microwave bands and satellites.

\begin{tabular}{lll}
\hline Band & Wavelength $\mathbf{( c m )}$ & Instrument \\
\hline $\mathrm{Ka}$ & $0.8-1.1$ & - \\
\hline $\mathrm{K}$ & $1.1-1.7$ & - \\
\hline $\mathrm{Ku}$ & $1.7-2.4$ & - \\
\hline $\mathrm{X}$ & $2.4-3.8$ & TerraSAR-X, TanDEM-X, COSMO-SkyMed \\
\hline $\mathrm{C}$ & $3.8-7.5$ & SIR-C, ERS 1/2, ENVISAT ASAR, RADARSAT 1/2 \\
\hline $\mathrm{S}$ & $7.5-15$ & ALMAZ \\
\hline $\mathrm{L}$ & $15-30$ & JERS-1, SEASAT, ALOS PALSAR \\
\hline $\mathrm{P}$ & $30-100$ & - \\
\hline
\end{tabular}

Table 3. Microwave spectrum bands and sensors

\begin{tabular}{ccccc}
\hline System & Country & Year of launch & Band & Resolution (m) \\
\hline SEASAT & USA & 1978 & L & 25 \\
\hline ERS 1/2 & Europe & $1991 / 1995$ & C & 30 \\
\hline J-ERS & Japan & 1992 & L & 18 \\
\hline SIR-C & USA & 1994 & L & $15-25$ \\
\hline X-SAR & Germany/Italy & 1994 & C/X & $10-100 / 3-100$ \\
\hline Radarsat-1/2 & Canada & $1995 / 2007$ & C & $90 / 30$ \\
\hline SRTM & USA/Germany/Italy & 2000 & C/X & C \\
\hline ENVISAT & Europe & 2002 & L & $7-100,1000$ \\
\hline ALOS & Japan & 2006 & X & $1-16$ \\
\hline TerraSAR-X & Germany & 2007 & X & $1-16$ \\
\hline TanDEM-X & Germany & 2009 & X & $1-100$
\end{tabular}

Table 4. List of some selected SAR missions 


\subsection{Interferometric SAR}

Apart from the amplitude of the returned signal, SAR also exploits the phase of the returning signals to extract information of the target. The interferometric SAR (InSAR) technique is based on the phase difference of at least two complex SAR images acquired from either different orbit positions (single pass) or different times (repeat pass). SAR interferometry uses the phase difference between the two returned signals to measure the slight changes in the earth surface. With the single pass interferometry, where the radar is equipped with two antennas, the same point on the ground can be measured at the same time with slightly different angles and this can produce stereo images. These images can be used to produce highly accurate topographic information of the point and can be used to prepare height maps. The InSAR is highly suitable for computing change in the surface thickness of glaciers over large spatial and temporal scales. SRTM is the best example of single pass interferometry, which has been used to produce highprecision global DEM. Tandem data of ERS 1 and 2 (1996/1997) were the first repeat pass SAR data with interferometric generation capability. TerraSAR-X add-on for Digital Elevation Measurement (TanDEM-X) is the new member of InSAR family along with SRTM, consisting of two satellites TerraSAR-X and TanDEM- $X$ developed by German Aerospace Centre (DLR) and Astrium GmbH. The TanDEM-X (TDX) was launched in June 2010 as an extension of TerraSAR-X in a close formation which enables stereoscopic views. The main aim of this mission was to collect interferometric data over entire global to provide a homogeneous highresolution global DEM with a relative vertical accuracy of better than $2 \mathrm{~m}$ within a horizontal resolution of $12 \mathrm{~m}$ [20]. The advantage of this single pass bistatic mission is generation of highquality accurate DEM against low coherence and limited accuracy of data from repeat pass mission. The generation of DEM from InSAR procedure involves interferometry generation, phase unwrapping, multilooking, reflattening, phase to height conversion and geocoding [21]. From the phase difference of returned signals from the two antennas, an interferogram is generated. The phase in an interferogram is influenced by the geometric effects and the topography of the target assuming no movement of the target [22]. By removing the geometric effects, the elevation of a target can be obtained and a DEM can be created [22]. The DEM created by InSAR method is highly accurate and can be used to derive the elevation change of the glacier along with other topographical parameters. The elevation change can further be used to calculate the mass balance of the glaciers. The phase from repeat pass interferometry is the key source for studying small coherent motions of the target between the imaging times. In repeat pass interferometry, the phase difference from the target acquired by the antenna for a nominal time interval enables the measurement of motion of the target during the small acquisition interval. The velocity of the target is obtained by removing the phase obtained due to topography and retaining only the motion phase. The ERS1/2 tandem mission has been extensively used to derive motion of various objects [23]. Figure 3 demonstrates the acquisition geometry of radar interferometry. SAR1 and SAR2 fly on parallel tracks and view the terrain simultaneously from slightly different directions (single pass interferometry) [24]. The technique of InSAR is based on the phase of returned signals from SAR1 and SAR2. The phase difference resulting from the fractional difference of wavelengths of pulse travel time would provide a parallax due to the topography and the shift in location of the target due to motion [13]. The InSAR technique can be exploited to obtain the topographical information and the motion of the target at high precision. 


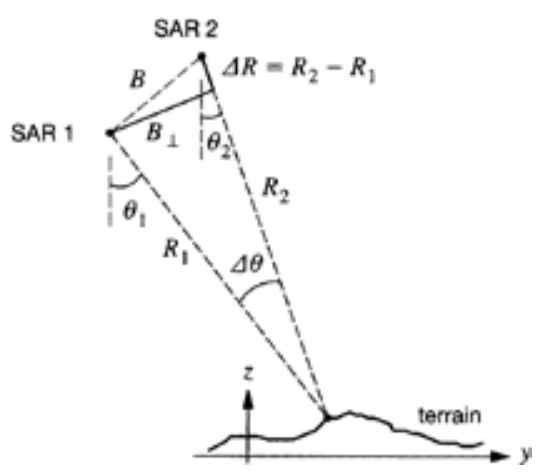

Figure 3. Principal of InSAR acquisition geometry (figure from Balmer and Hartle [24]).

\section{Glacier parameters studied with remote sensing}

\subsection{Snow cover mapping and snowpack properties retrieval}

Snow is the most essential and fundamental constituent of a glacier and a key component of earth's energy balance [25]. The mountain snow and the subsequent snow melt can play a dominant role in modulating the local to regional climate and hydrology [26]. The knowledge of snow coverage and snow properties such as albedo, snow grain size, snow depth, snow density and snow water equivalent (SWE) are crucial to know and predict the snow melt. The unique characteristics of snow like high reflectance relative to other surrounding materials (rocks, water, clouds) in the visible part and low reflectance in the mid-infrared part of the spectrum are the foundation of snow cover mapping from space in optical remote sensing [25]. Dozier and others [26] have developed an automatic algorithm to distinguish snow from soil, rocks and clouds by using ratio of reflectance in the VNIR wavelengths (Landsat TM band 2 and 5)which is known as normalized differential snow index (NDSI). According to Dozier [27], a normalized difference snow index (NDSI) is calculated from reflectance in bands at wavelengths where snow is bright (e.g., TM band 2 or MODIS band 1) and where it is dark (e.g., TM band 5 or MODIS band 6), along with a band used for threshold brightness (e.g., TM band 4 or MODIS band 2):

$$
\text { NDSI }=\frac{\text { TM bands } 2-\text { TM bands } 5}{\text { TM bands } 2+\text { TM bands } 5}
$$

A snow cover area is mapped when NDSI $>0.4$ (Figure 4). Although the snow cover can be mapped with a number of remote sensing devices, multispectral bands in the optical VNIR region of electromagnetic spectrum are most suitable and widely used. In general, the VNIR bands of Landsat MSS, Landsat TM, AVHRR, MODIS, SPOT, ASTER, and IRS have been extensively utilized to map the world's snow cover area. Apart from snow cover mapping, 
optical VNIR remote sensing has little use in retrieving snow pack properties such as snow depth and SWE. SWE is the most essential snowpack properties in the sense that it represents the total amount of water available if the snowpack has to melt instantaneously [28]. However, in comparison with snow mapping, retrieval of SWE and snow depth through remote sensing has limited success till date; only microwave remote sensing offers measurement of snow depth and SWE as there is penetration through the snowpack at these wavelengths [22]. Most of the studies have used empirical relations to retrieve SWE. The passive microwave radiometers have been used to retrieve SWE since 1978 [29]. Chang and others [29] have used the difference in brightness temperature at 19 and $37 \mathrm{GHz}$ in the SWE retrieval algorithm to derive SWE from passive microwave. They have used radiative transfer calculation to derive snow depth from SMMR data. The Advanced Microwave Scanning Radiometer-Earth Observing System (AMSR-E) has been used to provide global SWE product since 2002 [30, 31]. The most recent methods of SWE and snow depth retrieval use active microwave data. Rott and others [32] have used Ku-band and X-band for SWE retrieval.

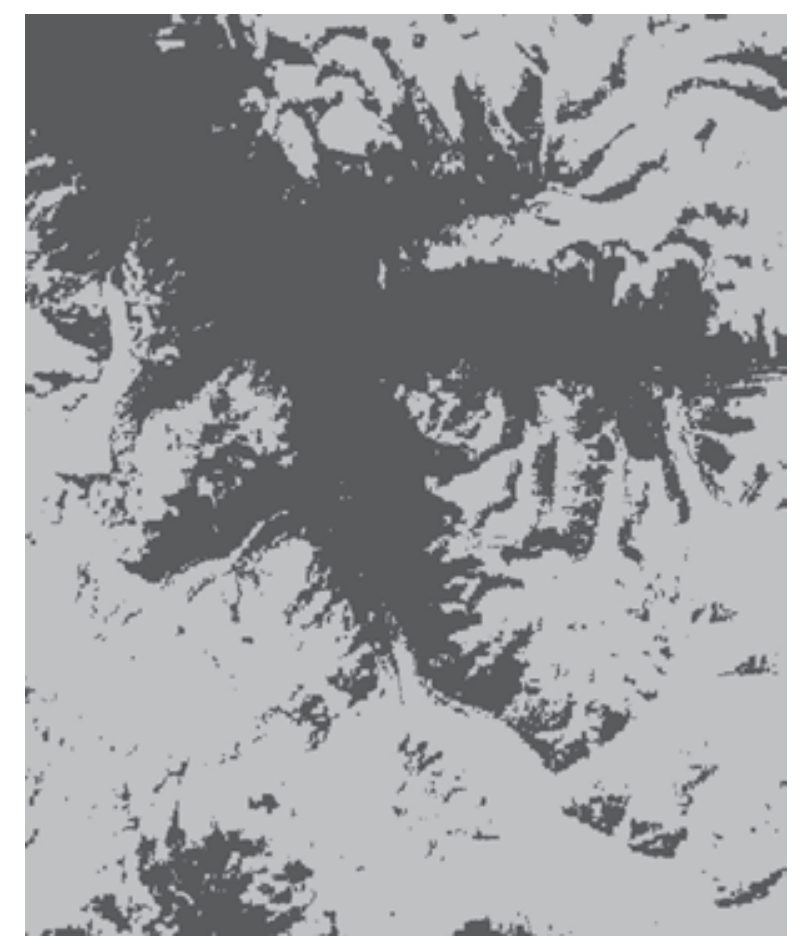

Figure 4. NDSI of Gangotri glacier derived from IRS LISS III image, September 11, 2000, for ablation season. The white part is the snow covered area and the grey is the non snow areas.

\subsection{Glacier surface temperature}

In global warming situation, the glacier surface temperature is the most important parameter to study the effect of climate change. However, use of traditional method of measuring surface 
temperature is difficult in mountain terrains. Thermal bands from satellite data provide an excellent alternative for estimating temperatures. TIR can be used to deduce the temperature of snow, ice, clean glacier and debris-covered glaciers. The most widely used TIR sensors are Landsat ETM+, Landsat OLI/TIR, ASTER and MODIS to extract the surface temperature of glaciated areas. In the longer wavelength region, snow acts as a perfect black body. In the infrared region, the strong absorption by snow allows the estimation of temperature from thermal bands [33]. To estimate the surface temperature, the digital number (DN) is converted into radiance. The radiance is converted into surface radiance by reference channel emissivity (RCE) method [33], which then can be converted into surface temperature. The conversion of top-of-the atmosphere (TOA) radiance to surface radiance can be done by following Ref. [34]. Barsi and others [35] have provided a formula to calculate the surface temperature:

$$
T_{\text {surface }}=\frac{\mathrm{K} 2}{\ln [\mathrm{K} 1+1 / \mathrm{LT}]}
$$

where $T_{\text {surface }}$ is temperature in Kelvin, $\mathrm{K} 1$ and $\mathrm{K} 2$ are the calibration constants and $L_{T}$ is surface radiance calculated as:

$$
L_{T}=L_{\mathrm{TOA}}-L_{\mathrm{v}}-\tau(1-\varepsilon) \times L_{\mathrm{D}} /(\tau \times \varepsilon)
$$

where $L_{\mathrm{TOA}}$ is TOA radiance, $L_{\mathrm{v}}$ is upwelling spectral radiance between surface and sensor, $L_{\mathrm{D}}$ is downwelling spectral radiance from sky, $\tau$ is atmospheric transmittance and $\varepsilon$ is the surface emissivity. With the use of thermal band data, it is possible to map the debris-covered glaciers and also mapping of supra and pro glacial lakes can be done with the thermal data. Figure 5 illustrates the thermal map of glaciated region of Chandra-Bhaga basin, Indian Himalaya, using thermal band of Landsat ETM+ for the year 2000.

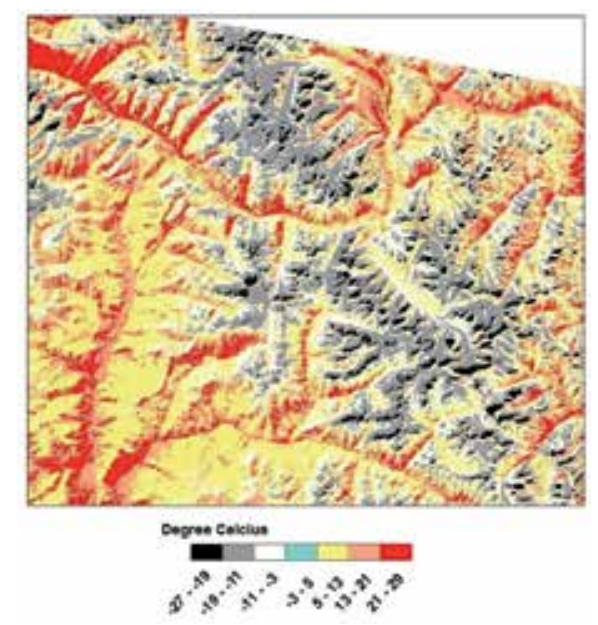

Figure 5. Temperature image of Chandra-Bhaga basin Himachal Himalaya, India, derived from the thermal band of Landsat ETM+ data during ablation season. 


\subsection{Glacier inventory, monitoring and mapping}

Satellite is the backbone of World Glacier Inventory (WGI) and monitoring. Development of new tools and techniques in remote sensing and availability of advanced high-resolution satellite data have brought a revolution in the inventory of world's mountain glaciers. The history of global glacier inventory goes back to 1957-1958, the International Geophysical years, when the inventory of global glaciers was first proposed in the form of national lists of glaciers [35]. This list later known to be WGI under the leadership of Muller and the status was assessed by World Glacier Monitoring Service (WGMS1989), and the digital version of the data was made available by National Snow and Ice Data Center (NSIDC), Boulder, Colorado, USA [35]. A large-scale inventory of global glaciers has been initiated with Global Ice Measurements from Space (GLIMS) in 1995. The GLIMS project was designed to monitor the world's glaciers primarily using data from optical satellite instruments, such as ASTER. GLIMS provide coverage of $58 \%$ of global glacierized area with extensive set of attributes [35]. The most recent global inventory is the Randolph Glacier Inventory (RGI), which provides complete collection of digital outlines of global glacierized area excluding ice sheets. The RGI was developed to meet the needs of the fifth assessment of the IPCC on climate change for estimates of past and future mass balance [35]. Satellite images from Landsat 5 TM, Landsat 7 ETM+, ASTER and SPOT 5 HRS have been used to derive the outline of glaciers for RGI.

There are numerous methods to map and delineate mountain glaciers. One of the best methods is the manual delineation of the glaciers through visual interpretation of satellite images acquired during end of ablation season with no recent snowfall. On a false color composite (FCC) image with enhanced contrast, the visual inspection and hence delineation of glacier and other facies become easier. However, to map and monitor glaciers on regional scale, the manual delineation is very cumbersome and time taking and hence not very useful. From the various methods of glacier delineation and mapping on regional scale, the band rationing is simple, robust, accurate, time effective and most suitable [36-39]. The band ratio method is based on the simple rationing of two bands, that is, TM3 and TM5 (RED/SWIR) or TM4 and TM5 (NIR/SWIR) or combination of two bands (NDSI) with application of a threshold [39] with an additional threshold of TM1. The band ratios strongly enhance a specific surface type as well as reduce the bias in illumination from the terrain at the same time. The band ratios method is based on the contrasting response of glacier in the visible and SWIR regions. When the high reflectance of glacier in the VNIR region is divided by the low reflectance in the SWIR region, a high ratio value results [40]. By applying a threshold value, the glacier can be separated from the surrounding rock, soil and vegetation by setting the value above the threshold to black and all others to white (Figure 6). The ratio of TM3/TM5 (RED/SWIR) has the advantage over TM4/TM5 in the sense that it works better in shadows and with thin debriscovered glacier [33, 36, 38]. However, when TM4/TM5 is used, the threshold of TM1 is not required for the fact that TM4 is not much sensitive to atmospheric scattering as TM3 and also rocks in shadows are not mapped [39]. However, Paul and Hendriks [40] have found the NDSI method to be better than the TM3/TM5 method. Andreassen and others [41] have demonstrated the robustness and simplicity of the band ratio method for mapping of glaciers. 


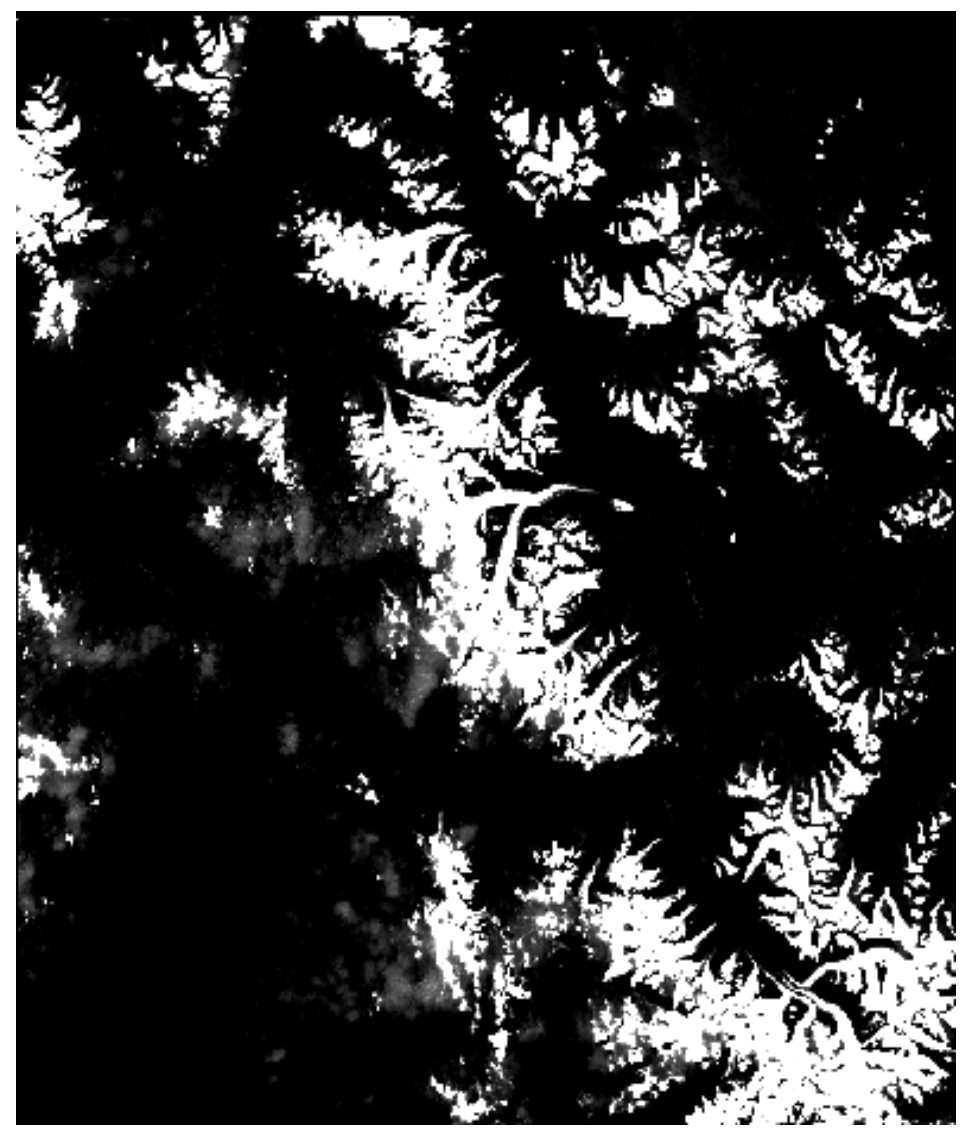

Figure 6. Glacier delineation with NDSI showing glaciated (white) and non-glaciated (black) regions, Chandra-Bhaga basin, Himachal Himalaya, India, obtained from IRS LISS III dated September 11, 2000, data.

\subsection{Glacier facies mapping with SAR}

SAR data can be efficiently used to distinguish the different zones of glacier such as dry snow zone, percolation zone, wet snow zone, firn zone, ablation zone and debris cover. However, the interpretation of SAR data is complicated and difficult than the optical data. The wavelength, polarization, incidence angle, dielectric properties, roughness and grain size are the important glacier parameters that crucially affect the strength of SAR backscatter signals. Based on the contrasting backscatter, the different glacier zones can be mapped with SAR data. Rau and others [42] have identified various radar glacier zones by their backscattering characteristics. These zone are dry snow radar zone, frozen percolation radar zone, wet snow radar zone and bare ice radar zone. Partington [43] has proposed a methodology for facies mapping using multitemporal SAR data. This method involves generation of composite images using winter, early summer and late summer radar backscatter images. Composites are generated by assigning blue to the winter image, green to the late summer image and red to the early summer image. This color combination SAR image is useful to identify different 
glacier zones due to tonal variations (Figure 7). The color composite will be overlaid on a digital elevation model (DEM). This combination helps to obtain the elevation value as well as backscatter coefficient value for any particular pixel to carry out quantitative analysis. Generally, the winter image defines maximum freezing conditions and late summer image defines maximum melt conditions. This methodology is based on the principle that different zones have typical backscatter signatures related to the snow pack characteristics, influenced by the balance of accumulation and melt at different altitudes.

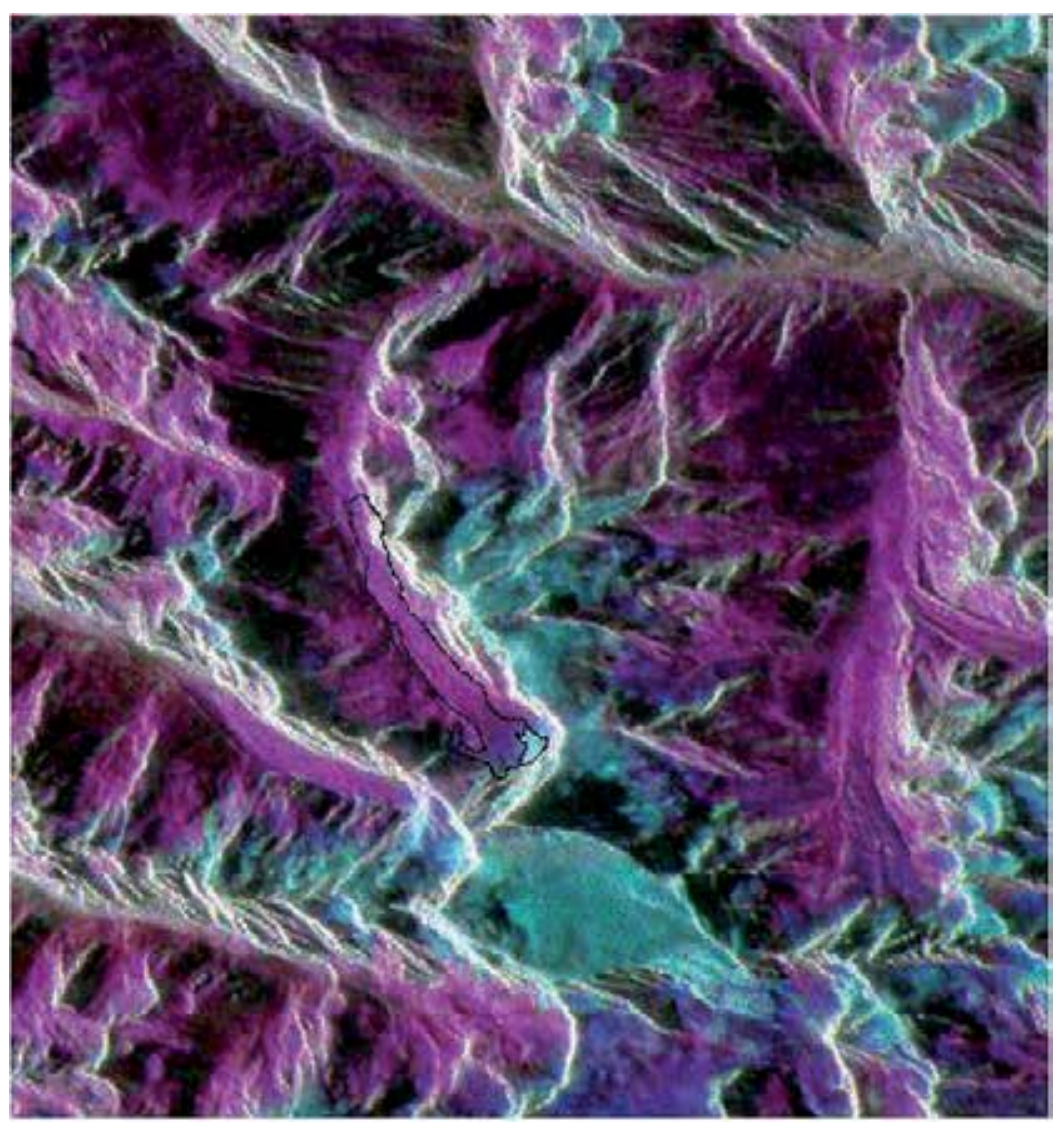

Figure 7. FCC from multitemporal ENVISAT SAR data showing Hamtah glacier region. Three images from winter, early summer and summer have been taken to make the FCC image. In the image, the cyan color indicates fresh snow, blue indicates firn and violet indicates debris cover.

\subsection{Equilibrium line altitude extraction}

The equilibrium line elevation can be extracted by overlaying an optical image on a DEM. The snowline altitude at the end of ablation season is supposed to be coinciding with the equilibrium line altitude. The cloud-free VNIR optical images with no recent snowfall of ablation season are selected for this purpose. To demarcate ELA on glacier and to differentiate snow 
from firn and ice, reflectance images are classified (supervised classification by giving maximum number of training classes for better accuracy). The classified images are then draped over a DEM (SRTM has been proved to be good for the purpose) to get elevation points. Before extracting the elevation points, the DEM and the optical images are brought to a common platform in terms of resolution and datum, and hence they are required to be reprojected, resampled and co-registered properly with each other. The classified images are draped on the DEM, and elevation points are determined along the demarcated line for the glacier. The average of the elevations along the line is considered as the ELA of the glacier (Figure 8).

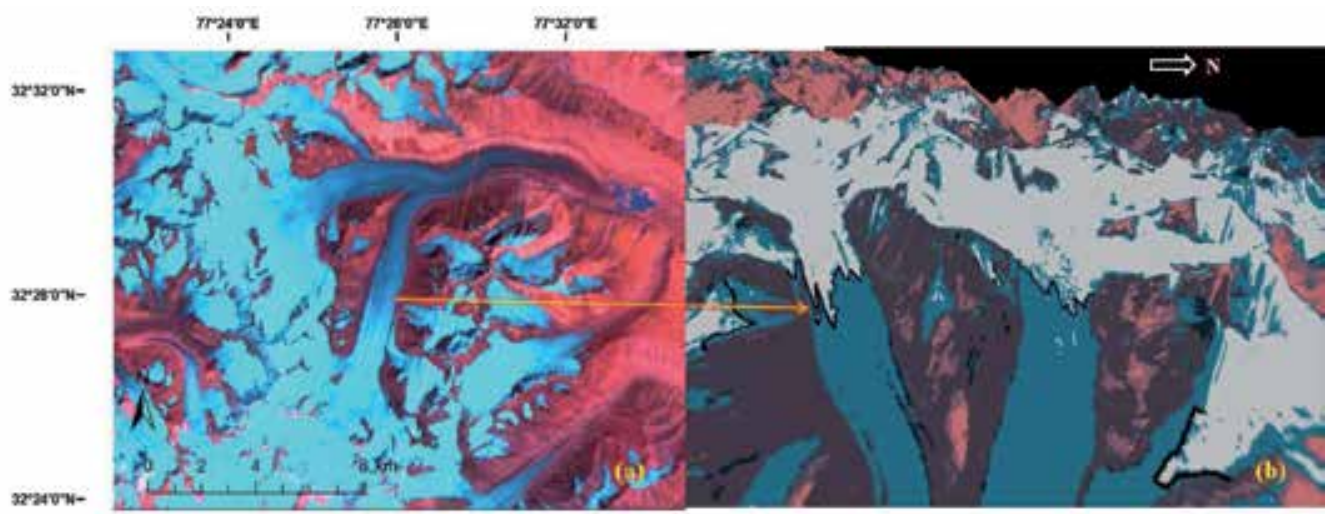

Figure 8. Method of ELA extraction on image: (a) reflectance image from IRS LISS III for Samudra Tapu glacier; $(b)$ the demarcated ELA on the classified LISS III image dated September 11, 2000, draped on SRTM DEM.

\subsection{Glacier topography and morphometry}

If climate is the driving force behind the glacier change, the glacier topographical parameters are the controlling factors that modulate the changes. Glacial topography is an important factor that explains the variability in the recessional rates of glaciers of the same basin [44]. The topographical parameters of a glacier can be listed as maximum, minimum, median and mean elevation of the glacier, the altitude range of the glacier, slope and orientation of the glacier. Derivation of topographical parameters of the glacier requires DEMs. Properly co-registered visible optical image overlaid on a DEM can be used to extract the maximum elevation of the glacier, the elevation of snout and equilibrium line altitude. SRTM and ASTER GDEM are the two freely available global DEM which have been extensively used to derive the topographical parameters of the glaciers along with the used of images from Landsat series, ASTER, SPOT and IRS series. The average slope and mean orientation of the glacier can be extracted from the SRTM or ASTER GDEM in ArcGIS (Figure 9). The compactness ratio, the relative upslope area and the slope of the upslope area are the glacier indices which provide the information about the contribution of the avalanching from the surrounding to the glacier and affect the mass balance of the glacier. The method of calculation of these glacier indices has been discussed in Refs $[45,46]$. The compactness ratio is the measure of glacier morphometry and 
can be derived from the formula (4tarea)/(perimeter) $)^{2}$ following Refs [45, 46]. The relative upslope area is defined as the ratio of the upslope area to glacier surface area and represents the contribution of the surrounding upslope area in the glacier mass balance. The upslope area and the mean slope of the upslope area of glaciers are calculated from the optical data in the visible region along with a DEM in the ArcGIS environment.
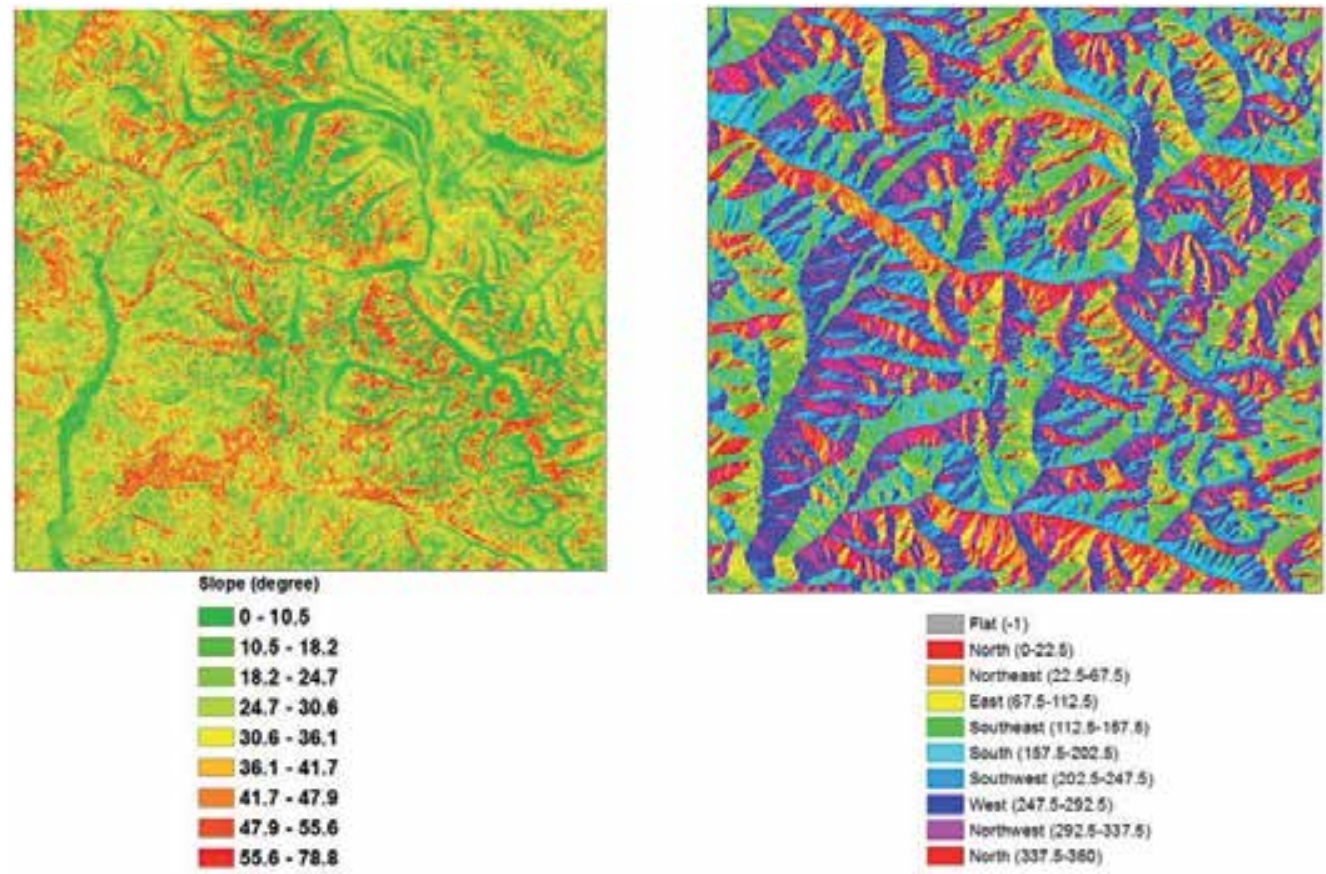

Figure 9. Slope and aspect map derived from SRTM DEM for Chandra-Bhaga basin, Indian Himalaya.

\subsection{Glacier thickness and mass balance}

Glacier mass balance is the most important glacier parameter to be measured and is of interest to glaciologist, climatologist and hydrologists. In a hydrological year, the net gain or loss of the glacier mass is known as glacier mass balance. The glacier mass balance is direct, undelayed and un-filtered response of climate. Mass balance of glaciers reflects the precipitation and temperature conditions surrounding the glacier and hence is studied to infer the condition and/or variability of climate. Due to the remote location, vastness and irrepressible nature of the Himalayan glaciers, remote sensing-based techniques offer effective alternatives to fieldbased measurement of mass balance of glaciers. The direct/glaciological surveys of glaciers for mass balance is not feasible for a large number of glaciers as many glaciers does not fulfill the criteria of benchmark glaciers in terms of size, length, geometry, altitudinal range, accessibility and safety. Geodetic mass balance measurement derived from elevation comparisons method complements glaciological method for large number of glaciers. In this method, the change in surface elevation of glaciers is derived by differencing two DEMs of different times. The brief 
methodology of deriving glacier mass change from DEMs has been illustrated by methodological chart in Figure 10.

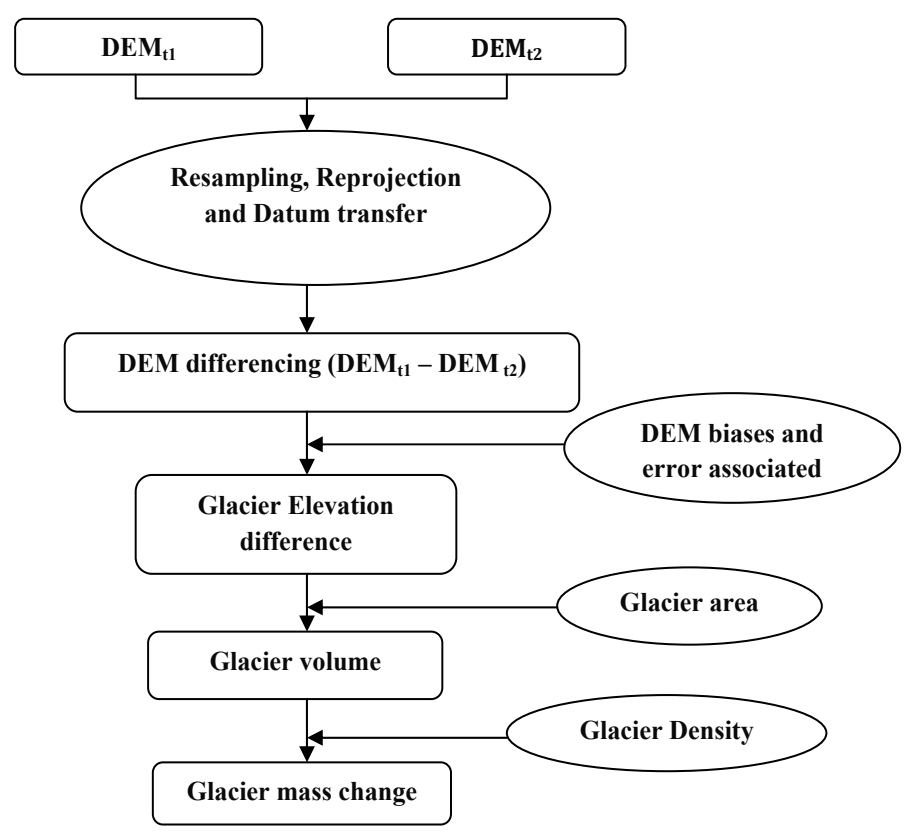

Figure 10. Flow chart showing the methodology of estimating geodetic mass balance of glaciers.

The change in elevation is converted into volume change by multiplying the surface thickness change with the area of the glacier. Now using the density of glacier, the change in volume is converted into mass change.

$$
\begin{aligned}
& d v_{z}=A \sum d h_{z} \\
& \frac{d v}{d t}=A \sum_{1}^{z} \frac{d h}{d t} \\
& \frac{d m}{d t}=\rho \sum_{1}^{z} \frac{d v}{d t}
\end{aligned}
$$

where $d v_{z}$ is volume, $d h_{\mathrm{z}}$ is the elevation change curve, $d m$ is the mass change, $A$ is area and $\rho$ is glacier density. The estimation of mass balance through elevation comparisons method has become frequent with the increasing number of available elevation measurements from satellites data such as ICESat, TanDEM-X, SPOT5 and SRTM and aircrafts [47, 48]. The geodetic 
mass balance has been found to be more accurate for longer periods [49] and has also been used to correct the biases in the in-situ direct measurement [50,51]. Besides, due to the ability of large spatial coverage of satellite data, the method is able to determine mass balance on regional scale $[39,48]$. However, the most vital assumption in converting mass change from elevation change is the density of snow/ice lost or gained $[52,53]$. In geodetic method, glacier surface elevation is converted into volume change and with the knowledge of density of material lost or gained; the volume is converted into mass change [54]. It is assumed that the density profile remains unchanged and only ice is lost or gained from glacier surface [14, 51]. The assumption of glacier density is taken from Sorge's law, which states that "the density of snow at a given depth below the surface does not change with time" given rates of melting near the surface and refreezing at depth are constant and equal. It follows from Sorge's law that a change of glacier thickness can be converted to an equivalent change of mass by multiplying by the density of glacier ice [47]. Figure 11 shows the elevation change map of a glacier in Chandra basin derived by subtracting SRTM of the year 2000 from TanDEM-X DEM of the year 2011.

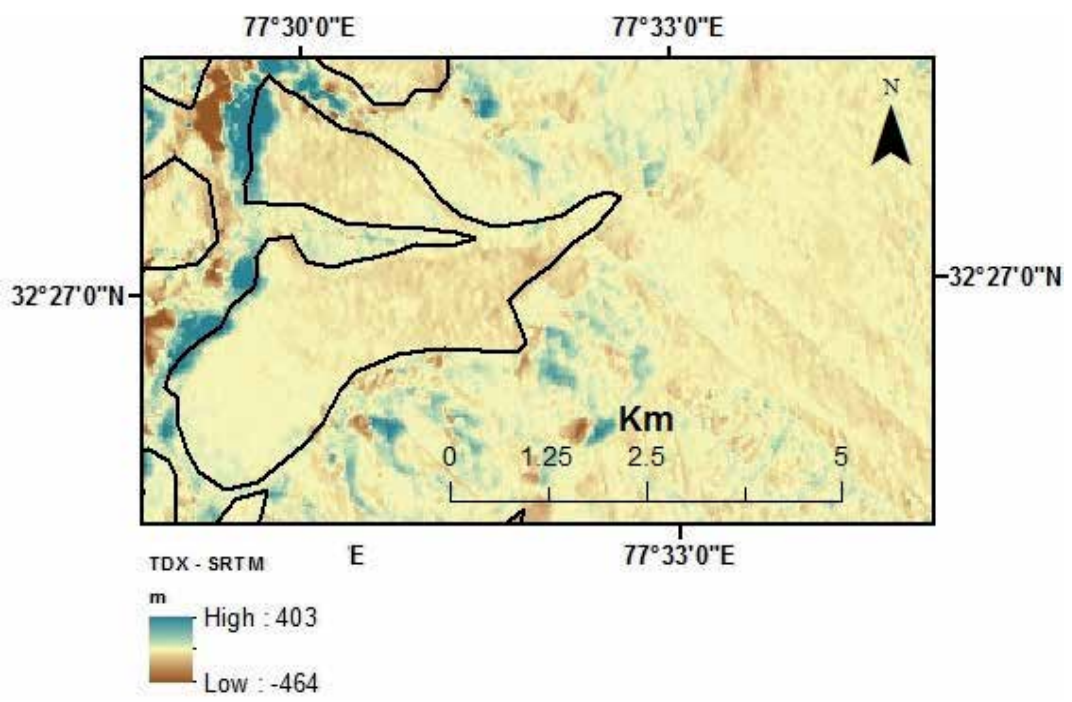

Figure 11. Elevation change map of a glacier of Chandra basin, Himachal Himalaya, India, derived by subtracting SRTM (2000) from TanDEM-X DEM (2011).

\subsection{AAR method of mass balance estimation}

The mass balance of mountain glaciers at regional scale can be inferred from accumulationarea ratio (AAR) and ELA derived from satellite data. The method is discussed elaborately by Kulkarni [55], who has used this to derive the mass balance of Himalayan glaciers using AAR method on basin scale. The method is based on the relation between AAR/ELA and mass balance of glacier. The AAR is the ratio between the accumulation area and the area of an entire glacier [56]. The AAR of a glacier is characteristic of glacier mass balance and also indicates 
the state of health of glacier. AAR of a glacier is closely linked with its mass balance. The variation in the AAR of a glacier from year to year can be used as an indicator of variation in net mass balance [14]. Since it is practically not feasible to monitor large number of glaciers on field, hence even the mass balance data of benchmark glaciers are not available for long time series. AAR method has been used as an alternative to estimate the mass balance of glaciers at many regions [55]. This method involves establishing a relationship between AAR and specific mass balance from long-term field observation. A regression equation is constructed between $\mathrm{AAR}$ and mass balance with AAR on the $x$-axis and specific mass balance on the $y$-axis. The equation obtained is then used to derive mass balance by using AAR values estimated from remote sensing. The mass balance of glaciers can be estimated through this method by using remote sensing data for the periods during which field data are not available. AAR can easily be determined from satellite images. Land sat data, IRS data, ASTER data at medium-resolution scale and SPOT, Quickbird and IKONOS data at higher scale can be utilized to obtain AAR at high precision. To determine the AAR, images at the end of ablation season without cloud cover and recent snowfall are required. The accumulation area can be easily determined by differentiating accumulation zone from ablation zone either manually or by various classification methods. The division of accumulation area from the total glacier area will give the AAR. In Figure 12, an equation has been developed from the linear relation between the specific mass balance and the AAR of Chhota Shigri glacier from the field. From the relation, the following linear equation has been obtained:

$$
y=0.038 x-2.455
$$

In this equation, the $x$ is AAR of the glacier and $y$ is specific mass balance. If we derive AAR from remote sensing data, from the above equation we can compute the specific mass balance of the glacier.

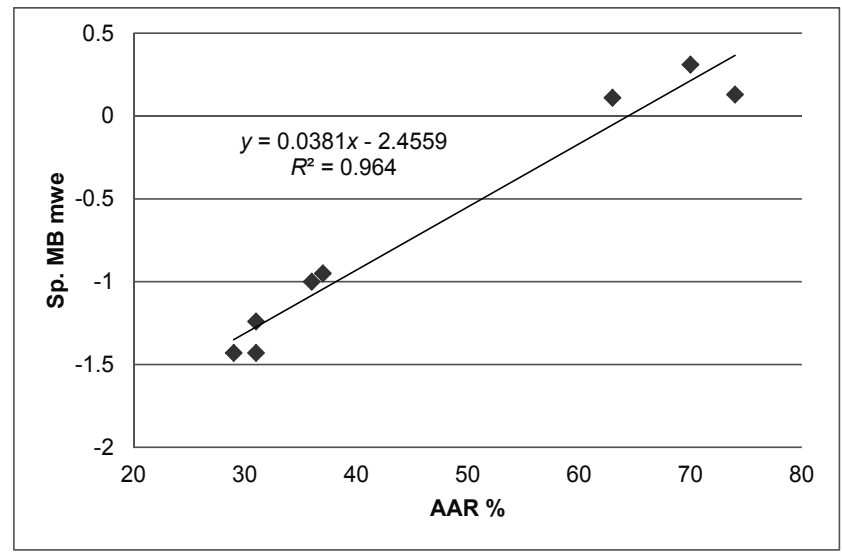

Figure 12. Example of relationship between specific mass balance and AAR, established from field data of Chhota Shigri glacier (data from Ramanathan 2011). 


\subsection{Glacier velocity}

\subsubsection{Glacier velocity with feature tracking}

Study of glacier velocity provides an understanding of various ongoing dynamical processes of the glacier such as ice flow and ice instabilities, ice flux, mass transportation, development of surge and also the formation and growth of glacier lakes and associated hazards [37, 39]. As the global temperature is reported and predicted to be rising, the glaciers on average are experiencing negative mass balance. In response to the negative mass balance, glacier surface velocity is found to be slowing down in mountainous regions [57, 58]. The glacier surface velocity and movement can be tracked by both optical and SAR satellite data on regional scale. With sequential satellite imageries, the glacier velocity can be determined by tracking glacier surface features such as crevasses and big boulders. This method of calculating glacier velocity with repeat optical and SAR satellite data is known as feature tracking method in general, image matching in optical domain and offset tracking in microwave domain [39]. The temporal baseline in the optical domain can range from weeks to years whereas in the microwave domain it is within weeks. The key point of image matching is the precise co-registration and cross-correlation of the two repeat pass images. Also, the temporal baseline of the repeat images should be such that the displacement of the glacier should not be larger than the accuracy of the method and surface changes due to melting, snowfall and deformation should be very small so that the intensity can be matched properly [39].

A correlation matching is commonly used to obtain both azimuth and range-direction offsets based on intensity pattern patches of two repeat-pass SAR image acquisitions. Through oversampling of the correlation surface, the matching peak can be determined to a small fraction of a pixel. The range offset and the azimuth offset are detected from cross-correlation matching. The successful estimation of the local image offsets depends on the presence of nearly identical features in the two SAR images at the scale of the employed patches. If coherence is retained, the speckle pattern of the two images is correlated and tracking with small image patches can be performed to remarkable accuracy.

The most popular and widely used optical repeat pass satellite images to determine glacier velocity are from Landsat TM, Landsat ETM+ pan, ASTER and SPOT [59, 60]. In the microwave realm, the Envisat ASAR, ALOS PALSAR and TerraSAR-X have been used for offset tracking to calculate glacier surface flow.

In the feature matching technique, the repeat images are co-registered by cross-correlation applied on stable nonmoving areas. Glacier features such as crevasses or debris and big rock boulders which are detectable in images are generally preferred for tracking [61]. The glacier velocity can be determined from the temporal separation and the surface displacement. In recent years with the advent sophisticated computer software and tools as well as high precision remote sensing data, many glaciologists have determined the glacier flow velocity successfully with high accuracy. Luckman and others, Quiney and others and Rankl and others [61-63] have shown that the technique of feature/offset tracking is suitable for Himalayan glaciers due to the presence of respective features. 
In the example shown in Figure 13, SAR intensity tracking technique is used for glacier 2-D velocity estimation. The TerraSAR-X high-resolution spotlight mode images acquired on September 27 and October 8, 2012, are used. These images are acquired over the Gangotri glacier, Uttarakhand, India. The estimated surface velocity is varying from 0.1 to $1.1 \mathrm{~cm} /$ day over glaciated area (along the medial axis from the accumulation zone to the snout).

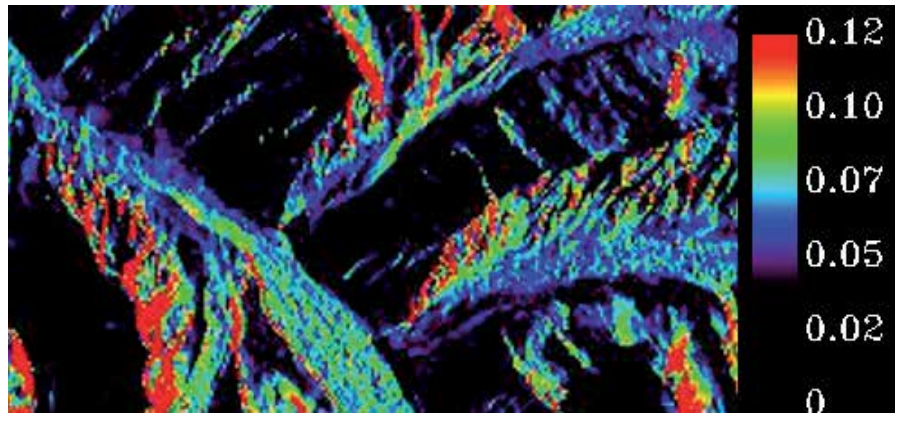

Figure 13. Gangotri glacier velocity estimated using offset tracking method employing TerraSAR-X images. The velocity values are in cm/day (figure and results provided by M. Surendar, CSRE, IIT Powai).

\subsubsection{Glacier velocity using SAR interferometry}

Goldstein and others [64] for the first time have determined the glacier surface velocity from InSAR data. In InSAR technique, the phase information of radar acquisition from two receiving antennas, separated in either time (repeat track) or space (single track), is used. Two SAR images will have a different distance from target when they are taken from an orbit separated by temporally/spatially from each other. An interferogram can be generated by subtracting the phase of the two images, the phases of which contain range difference. When there is no motion of the target, the phase is influenced by topographical and geometrical effects. If the geometrical effect is removed, the topographical information can be extracted from the phases in interferogram. Now, if the target is moving, then having removed the geometrical effect and the topographical effect, the motion of the target can be measured from the interferogram. ERS tandem data and TerraSAR-X data have been used widely to find the surface velocity of mountain glaciers as well as ice sheets by InSAR method.

\section{Comparison between optical, thermal and microwave for Cryospheric studies}

The optical remote sensing is based on the detection of reflected solar radiation from surface of the earth in VNIR regions of electromagnetic spectrum which range from 0.4 to $2.5 \mu \mathrm{m}$. The basis of TIR remote is the emitted radiation in the spectral range between 8 and $14 \mu \mathrm{m}$. Glacier surface has unique spectral properties in the visible-infrared and thermal region, which makes it possible to identify and monitor by optical remote sensing sensors. Optical data at high and 
medium spatial resolutions from SPOT5, IKONOS, Quickbird, Landsat TM, ETM+, IRC-1C and ASTER are highly useful for regular monitoring and mapping of glacier. The optical remote sensing is exceedingly of use for temporal change analysis of spatial extent of snow and glacier area. Aided with a DEM, information about the glacier geometry and topography can be obtained from optical data. The thermal bands from satellite data have the potential to distinguish debris cover on the glacier. However, one of the main drawbacks of working in optical remote sensing is their limitation to cloud-free condition and daylight, which are sometimes not possible in mountain region where there are always possibilities of forming cloud due to orographical effects. The active microwave system has the capability of acquiring data at all weather conditions, during any time of the day. The microwave remote sensing is more effectively used in extracting snow properties such as snow depth, snow wetness and SWE and glacier facies mapping. The emerging technologies of InSAR and DInSAR have great potential in deriving glacier volume change, mass balance, surface elevation change and glacier velocity. Thus, for studying the evolution and dynamics of mountain glaciers, the complemented usage of optical, thermal and microwave remote sensing is needed.

\section{Glacier hazards}

The strong interrelation between climatic changes, glacier recession and increasing number of glacier-related hazards is evident in many mountainous parts of the world including the Alps and the Himalayas $[65,66]$. Fundamental changes are taking place rapidly in the high mountain regions due to continued global warming [65]. In consequence to rising temperature and climate change, it is predicted that the existing glaciated may soon transform into new landscape with vegetation sparse-bare lands, loose debris and abundant lakes [65]. Such newly transformed landscape definitely would not be in equilibrium with the ecosystem and would thus cause many hazards in order to balance with the system. The most dangerous glacierrelated hazards are formation and growth glacier lakes, glacier lake outburst floods (GLOFs), debris and mud flow triggered by flood, snow/ice/rock avalanches and development of crevasses which pose threat to both life and livelihood and brings devastation to mankind and infrastructure including hydropower $[67,68]$. The glacier-related hazards has the potential to cause huge casualties in one single event, the damage amounting to hundreds of million [69]. Thus, the risk of loss of life and the devastation of infrastructure are the main motive for studying glacier-related hazards. Monitoring, assessment and management of glacier-related hazards are highly required for the timely prediction of catastrophes and saving of lives downstream. However, due to remote location, complicated terrain, harsh environment and political restrictions, it is not possible to monitor the mountain glacier-related hazards by field observations. The launching of high-resolution satellites in recent decades, emergence of sensor technologies and development of sophisticated tools have posed remote sensing as effective and efficient alternatives to monitor, assess and manage the mountain glacier-related hazards. The optical spectral region of remote sensing is most suitable for glacier hazards assessment. The nature, characteristics, size and growth of hazards decide the selection of remote sensing data. Fusion of multispectral data with the DEMs is the most promising method of glacier hazards monitoring and assessment. The medium-resolution data from Landsat TM/ 
ETM+/OLI/TIR, ASTER and IRS LISS III can cover regional- to global-scale hazard assessment, whereas high-resolution data such as Quickbird and IKONOS can contribute in providing detailed information [70]. The geometry of the potential dangerous hazardous sites can be obtained from ASTER DEM, SRTM DEM and DEM from other sources. The geometrical assessment of mountain terrain with the help of DEM can provide information about the potential sites of hazards.

\subsection{Glacial lake outburst floods}

In response to warming of climate, the increasing number and volume of glacier lakes are raising wide concern. Regular monitoring of supra and pro glacial lakes are the key parameter to identify the glacier lake hazards [71-73]. Most of the glacier lakes form near the snout of the glacier and are dammed by unstable moraines and are called moraine dammed lakes. The enhanced melting of glaciers due to rising temperature amplifies the storage of water in the lakes. This occasionally may lead to the breaching of the moraine dams, releasing huge amount of lake water, which in its course gathers the surrounding debris along with it and cause destruction in the downstream. This phenomenon of flash flood is known as GLOF and is one of the most severe catastrophes to occur in the Alpine and Himalayan regions. Richardson and Reynolds [66] have suggested three mechanism of glacier outburst: the rupture of an internal water pocket, the progressive enlargement of internal drainage channels and catastrophic glacier buoyancy. The term GLOFs is most commonly used for the glacier flash floods of Himalaya. A large number of GLOFs have been recorded in central and eastern Himalaya [67, 74]. Compared to the central and eastern part, the western Himalayas have seen lesser number of GLOFs. The application of modern remote sensing technology to locate and monitor the formation and growth of potentially dangerous lakes is necessary due to their far reach. The glacier dynamics, probability of formation and future development of lakes can be assessed by time series of multispectral images. DEMs are found to be crucial in the assessment of moraine dam characteristics, dam geometry, surface material and geometry. The visual interpretation of time series data have been extensively exploited in the study if glacier fluctuations and glacier lake outburst [75]. Data from Landsat, ASTER, IRS, SPOT, Quickbird and IKONOS can be used for mapping and classification of glacial lakes. The topographical settings of GLOFs can be obtained from ASTER DEM, freely available ASTER GDEM and SRTM DEM [16] with high accuracy level. Huggel and others [75] have proposed an automatic methodology for mapping of Himalayan glacier lakes employing Landsat TM data. The method is known as normalized difference water index (NDWI) and uses TM1 and TM4 for distinguishing the lakes. NDWI is given as

$$
\mathrm{NDWI}=\frac{\text { TM bands } 4-\mathrm{TM} \text { bands } 1}{\text { TM bands } 4+\mathrm{TM} \text { bands } 1}
$$

In order to calculate the volumetric changes of glaciers, especially the debris-covered type [76], stereo-capable data are useful. The Advanced Land Observing Satellite (ALOS) PRISM is a relatively new remote sensing satellite program (launched in 2006) that has stereo capability 
able to generate digital terrain models (DTMs) and 3D maps and that also offers high spatial resolution stereo-data $(2.5 \mathrm{~m})$. Several studies have investigated volumetric changes in glaciers in the Himalayas using ALOS data [77]. The estimation of area of potentially dangerous supra and proglacier lake area from remote sensing data can be used to find the glacier volume. The lake volume $\left(V: \times 106 \mathrm{~m}^{3}\right)$ and lake area $\left(A: \mathrm{km}^{2}\right)$ have the following relationship [78]:

$$
V=43.24 \times A^{1.5307}
$$

Huggel and others [75] have also represented similar relationships from glacial lakes located in the Swiss Alps, including ice-dammed lakes. The relationship between the maximum depth of lakes $\left(D_{\max }: m\right)$ and lake areas can then be calculated as follows [78]:

$$
D_{\max }=95.665 \times A^{0.489}
$$

The depth, area and volume of glacier lakes, estimated from remote sensing technology, greatly felicitate in the assessment of GLOFs and maintain the early warning system. Figure 14 demonstrates the continuous growing of a moraine dammed lake located at the snout of Samudra Tapu glacier in Himachal Himalaya, India.
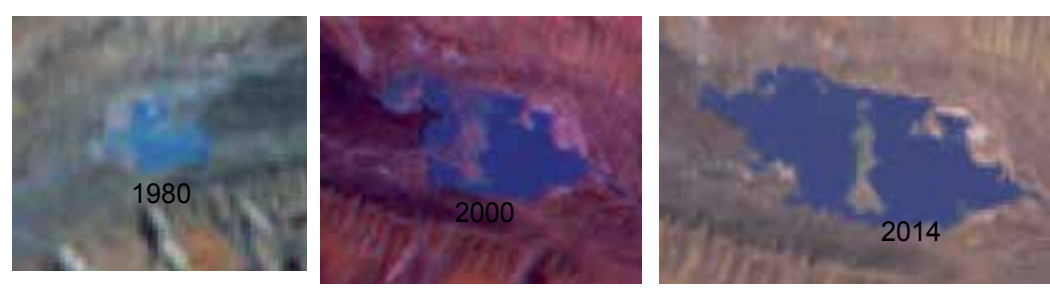

Figure 14. Growth of a moraine dammed lake in western Himalaya as shown using Landsat MSS, IRS LISS III and Landsat OLI/TIRS data of ablation season.

\subsection{Snow, Ice and rock avalanches}

The hazards associated with debris cover and unstable rock in the glacial environment are crucial to study as they are influenced by glacier down-wasting, glacier retreat and permafrost degradation [37] and are connected with ice avalanches and GLOFs [79]. The increasing number of ice avalanches is basically due to the changes in climatic and socioeconomic settings in the mountain region [12]. Typically an ice avalanche occurs from the surrounding steep cliffs in the glacier environment with the breaking of large mass from these cliffs and peaks. The hazards potential of ice avalanches are confined to the high mountain areas only and affect the tourists, trekkers/climbers and glaciologists. Figure 15 illustrates an avalanche prone steep slope present at the backwall of Hamtah glacier, western Himalaya. The monitoring of 
occurrence of ice avalanches and the settings of early warning systems for mitigation require high-quality data and tools for systematic region wide coverage. The combination of GIS tool with the remote sensing data has been found to be useful for hazard mapping in particular to debris flow and snow/ice/rock avalanches. Clague and Evans [80] have demonstrated the use of DEM for comparison of volume of ice avalanched material before and after an event. Salzmann and others [12] have shown that the glacier inventory data can be combined with the slope and aspect maps to locate the potential avalanches zones. The multitemporal data combined with DEMs can be used to identify and monitor the rock avalanches, debris flow and areas to be affected by the debris movement.

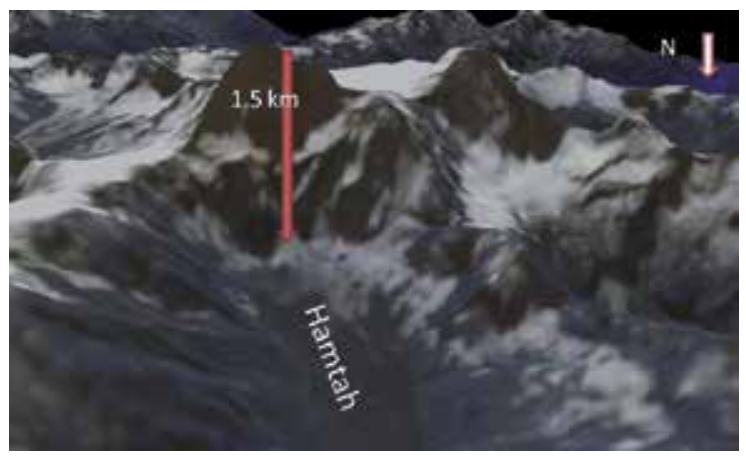

Figure 15. Landsat OLI/TIRS image dated September 28, 2014, overlaid on ASTER GDEM to show the steep back wall and surroundings of Hamtah glacier, which are susceptible to rock and ice avalanches.

\subsection{Glacier surges}

The glacier surges are abnormally rapid movement of large glacier parts with increased velocity due to the temporal instability of the glacier. The velocity of the glacier increases by an order of magnitude or more during the surging and the glaciers advance drastically. The glacier surges itself are not a hazard, but they induce and trigger other hazards such as ice/ rock avalanches, outburst floods, blocking of river, instability of moraines and hence associated hazards. The phenomena of glacier surges are best monitored by high-frequency remote sensing data [81]. A number of glaciers in the Karakoram have been found to be showing the surging phenomena. Bhambri and others [81] have studied the surge type behavior of glaciers in Karakoram by using CORONA, Landsat TM/ETM+ data and SRTM DEM.

\section{Conclusion}

Glaciers are the most visible indicators of climate change, and the study of glacier parameters specifies the prevailing climate. The numbers of glaciological parameters which can be assessed and monitored by remote sensing technology are very long. The optical and radar data are equally valuable and useful for snow cover mapping, glacier area monitoring, glacier feature study, volumetric change, mass balance and velocity measurements. Optical remote 
sensing data is more suitable for snow cover mapping, glacier area and snout monitoring. However, glacier facies mapping, mass balance and glacier velocity can be accurately studied from radar data. DEMs are the essential requirement for studying glacier topographical and geometrical parameters. Although remote sensing methods provide an efficient tool for glacier study, the field method is the most accurate and recommended one, and remote sensing should be applied in conjunction with field work for validation.

\section{Author details}

Pratima Pandey ${ }^{1 *}$, Alagappan Ramanathan ${ }^{2}$ and Gopalan Venkataraman ${ }^{3}$

*Address all correspondence to: pandeypreetu@gmail.com

1 Indian Institute of Remote Sensing, Dehradun, India

2 School of Environmental Science, Jawaharlal Nehru University, New Delhi, India

3 Centre of Studies in Resources Engineering, Indian Institute of Technology, Powai, Mumbai, India

\section{References}

[1] Ben DI and Evans DJA: Glaciers and Glaciation. New York: Wiley, 1998.

[2] Jansson P, Hock R, and Schneider T: The concept of glacier storage: a review. Journal of Hydrology, 2003, 282:116-129, doi:10.1016/S0022-1694(03)00258-0.

[3] Barnett TP, Adam JC, and Lettenmaier DP: Potential impacts of a warming climate on water availability in snow-dominated regions. Nature, 2005, 438(7066):303-309.

[4] Bookhagen B and Burbank DW: Toward a complete Himalayan hydrological budget: spatiotemporal distribution of snowmelt and rainfall and their impact on river discharge. Journal of Geophysical Research, 2010, 115(F3):F03019.

[5] Huss M, Farinotti D, Bauder A, and Funk M: Modelling runoff from highly glacierized alpine drainage basins in a changing climate. Hydrological Processes, 2008, 22(19): 3888-3902.

[6] Huss M: Present and future contribution of glacier storage change to runoff from macroscale drainage basins in Europe. Water Resources Research, 2011, 47(7):W07511.

[7] Reinwarth O and Stäblein G: Die Kryosphäre - das Eis der Erde und seine Untersuchung. Würzburger Geographische Arbeiten, 1972, 36:71 pp. 
[8] Meier MF and Bahr DB: Counting glaciers: use of scaling methods to estimate the number and size distribution of the glaciers on the world. Edited by Hanover, $\mathrm{NH}$, CRREL Spec. Rep., 1996, US Army, 89-95.

[9] Dyurgerov M and Meier MF: Glaciers and the changing earth system: a 2004 snapshot. INSTAAR Occasional Paper, 2005, 58:117 pp.

[10] Kääb A: Photogrammetrische Analyse zur Früherkennung gletscher- und permafrostbedinger Naturgefahren im Hochgebirge. Mitteilungen der Versuchsanstalt für Wasserbau, Hydrologie und Glaziologie (VAW) der ETH Zürich, 1996, 145:182 pp.

[11] Huggel C: Assessment of glacial hazards based on remote sensing and GIS modelling. PhD thesis, Department of Geography, University of Zurich, 2004, 75 pp.

[12] Salzmann ND, Kääb A, Huggel C, Allgöwer B, and Haeberli W: Assessment of the hazard potential of ice avalanches using remote sensing and GIS-modelling. Norwegian Journal of Geography, 2004, 58:74-84.

[13] Barrand N: Notes for Remote Sensing of the Cryosphere. http://glaciers.gi.alaska.edu/sites/default/files/Notes_remotesensing_Barrand2014.pdf

[14] Paterson WSB: The Physics of Glaciers, 3rd edition. Oxford: Pergamon Press, 1994.

[15] Kuhn M: The formation and dynamics of glaciers. Remote Sensing of Glaciers, Editors: Pellikka P and Rees G, CRC Press, Boca Raton, Fla,, 2010, pp. 21-39.

[16] Worni R, Huggel C, and Stoffel M: Glacial lakes in the Indian Himalayas - from an area-wide glacial lake inventory to on-site and modeling based risk assessment of critical glacial lakes. Science of the Total Environment, 2013, 468-469:S71-S84.

[17] Gareth RW and Pellikka P: Principles of remote sensing.. Remote Sensing of Glaciers, Editors: Pellikka P and Rees G, CRC Press, Boca Raton, Fla, 2010, pp. 1-20.

[18] Lepparanta M and Granberg HB: Physics of glacier remote sensing. Remote Sensing of Glaciers, Editors: Pellikka P and Rees G, CRC Press, Boca Raton, Fla,, 2010, 81-98.

[19] Rignot E, Echelmeyer K, Krabill W: Penetration depth of interferometric syntheticaperture radar signals in snow and ice. Geophysical Research Letters, 2001, 28(18):35013504.

[20] Krieger G, Moreira A, Fiedler H, Hajnsek I, Werner M, Younis M, and Zink M: TanDEM-X: a satellite formation for high-resolution SAR interferometry. IEEE Transactions on Geoscience and Remote Sensing, 2007, 45(11), 3317-3341.

[21] Erasmi S, Rosenbauer R, Buchbach R, Busche T, and Rutishauser S: Evaluating the quality and accuracy of TanDEM-X digital elevation models at archaeological sites in the Cilician Plain, Turkey. Remote Sensing, 2014, 6:9475-9493, doi:10.3390/rs6109475.

[22] Konig M: Measuring snow and glacier ice properties from satellite. Reviews of Geophysics, 2001, 39 (1), 1-27. 
[23] Kumar V, Venkataraman G, and Rao YS: SAR interferometry and speckle tracking approach for glacier velocity estimation using ERS-1/2 and TerraSAR-X spotlight high resolution data. Geoscience and Remote Sensing Symposium, 2009 IEEE International, IGARSS 2009 (Volume:5), Cape Town, pp. 332-335.

[24] Balmer R and Hartle P: Synthetic aperture radar interferometry. Inverse Problems, 1998, 14:R1-R54.

[25] Jonathan M, Infant J, Lakhankar T, Khanbilvardi R, Romanov P, Krakauer N, and Powell AL: Synergistic use of remote sensing for snow cover and snow water equivalent estimation. British Journal of Environment \& Climate Change, 2013, 3(4):612-627.

[26] Dozier J, Painter TH, Rittger K, and Frew JE: Time-space continuity of daily maps of fractional snow cover and albedo from MODIS. Advances in Water Resources, 2008, 31(11):1515-1526.

[27] Dozier J: Spectral signature of alpine snow cover from the Landsat Thematic Mapper. Remote Sensing of Environment, 1989, 28(August 1988):9-22.

[28] Nolin AW: Recent advances in remote sensing of seasonal snow. Journal of Glaciology, 2010, 56(200):1141-1150.

[29] Chang ATC, Foster JL, and Hall DK: Nimbus-7 SMMR derived global snow cover parameters. Annals of Glaciology, 1987, 9, 39-44.

[30] Nolin AW: Recent advances in remote sensing of seasonal snow. Journal of Glaciology, 2010, 56(200), 1141-1150.

[31] Tedesco M and Narvekar PS: Assessment of the NASA AMSR-E SWE product. IEEE Journal of Selected Topics in Applied Earth Observations and Remote Sensing, 2010, 3(1): 141-159.

[32] Rott $\mathrm{H}$, et al: Cold regions hydrology high resolution observatory for snow and cold land processes. Proceedings of the IEEE, 2010, 98(5):752-765.

[33] Raj KBG and Fleming K: Surface temperature estimation from Landsat ETM data for a part of the Baspa Basin, NW Himalaya, India. Bulletin of Glaciological Research, 2008, 25:19-26.

[34] Barsi JA, Barker JL, and Schott JR: An atmospheric correction parameter calculator for a single thermal band earth-sensing instrument. IGARSS 03, 21-25 July 2003, Centre de Congres Pierre Baudis, Toulouse, France, p. 3.

[35] PFEFFER WT, et al: The Randolph Glacier Inventory: a globally complete inventory of glaciers. Journal of Glaciology, 2014, 60(221), doi: 10.3189/2014JoG13J176.

[36] Paul F and Kääb A: Perspectives on the production of a glacier inventory from multispectral satellite data in Arctic Canada: Cumberland Peninsula, Baffin Island. Annals of Glaciology, 2005, 42:59-66. 
[37] Kääb A: Combination of SRTM3 and repeat ASTER data for deriving alpine glacier flow velocities in the Bhutan Himalaya. Remote Sensing of Environment, 2005, 94(4): 463-474.

[38] Bolch, T, Menounos B, and Wheate R: Landsat-based inventory of glaciers in western Canada, 1985-2005. Remote Sensing of Environment, 2010, 114:127-137.

[39] Paul F, et al: The glaciers climate change initiative: methods for creating glacier area, elevation change and velocity products. Remote Sensing of Environment, 2013. http:// dx.doi.org/10.1016/j.rse.2013.07.043

[40] Paul F and Hendriks J: Optical remote sensing of glacier extent. In:. Remote Sensing of Glaciers, Editors: Pellikka P and Rees G, CRC Press, Boca Raton, Fla,, 2010, pp. 137152.

[41] Andreassen L, Paul F, Kääb A, and Hausberg J: Landsat-derived glacier inventory for Jotunheimen, Norway, and deduced glacier changes since the 1930s. The Cryosphere, 2008, 2(2):131-145.

[42] Rau F, Braun M, Friedrich M, Weber F, and Gobmann H: Radar glacier zones and their boundaries as indicator of glacier mass balance and climate variability. Proceedings of the EARSeL-SIG-Workshop Land Ice and Snow, Dresden, Germany, 16-17 June, 2000, pp. 317-327.

[43] Partington KC: Discrimination of glacier facies using multi-temporal SAR data. Journal of Glaciology, 1998, 44:42-53.

[44] Davies BJ, Carrivick J, Glasser NF, Hambre MJ, and Smellie JL: A new glacier inventory for 2009 reveals spatial and temporal variability in glacier response to atmospheric warming in the Northern Antarctic Peninsula, 1988-2009. The Cryosphere Discussions, 2011, 5:3541-3595.

[45] Debeer CM and Sharp MJ: Recent changes in glacier area and volume within the southern Canadian Cordillera. Annals of Glaciology, 2007, 46:215-221.

[46] Way RG, Bell T, and Barrand NE: An inventory and topographic analysis of glaciers in the Torngat Mountains, northern Labrador, Canada. Journal of Glaciology, 2014, 60(223), doi: 10.3189/2014JoG13J195.

[47] Arendt A, Echelmeyer KA, and Harrison, WD: Rapid wastage of Alaska glaciers and their contribution to rising sea level. Science, 2002, 297:382-386.

[48] Gardelle J, Berthier E, and Arnaud Y: Slight mass gain of Karakoram glaciers in the early twenty-first century. Nature Geoscience, 2012, 5(5):322-325.

[49] Cox LH and March RS: Comparison of geodetic and glaciological mass-balance techniques, Gulkana Glacier, Alaska, USA. Journal of Glaciology, 2004, 50(170):363-370.

[50] Soruco A, Vincent C, Francou B, Ribstei NP, Berge T, Sicart JE, Wagnon P, Arnaud Y, Favier Y, and Lejeune, Y: Mass balance of Glaciar Zongo, Bolivia, between 1956 and 
2006, using glaciological, hydrological and geodetic methods. Annals of Glaciology, 2009, 50:1-8.

[51] Zemp M, Jansson P, Holmlund P, Gärtner-Roer I, Koblet T, Thee P, and Haeberli, W: Reanalysis of multi-temporal aerial images of Storglaciären, Sweden (1959-1999). Part 2: Comparison of glaciological and volumetric mass balances. The Cryosphere, 2010, 4(3):345-357.

[52] Huss M: Density assumptions for converting geodetic glacier volume change to mass change. The Cryosphere, 2013, 7:877-887.

[53] Kääb A, Berthier E, Nuth C, Gardelle J, and Arnaud, Y: Contrasting patterns of early twenty-first-century glacier mass change in the Himalayas. Nature, 2012, 488(7412): 495-498.

[54] Berthier E, Arnaud Y, Kumar R, Ahmad S, Wagnon P, and Chevallier P: Remote sensing estimates of glacier mass balances in the Himachal Pradesh (Western Himalaya, India). Remote Sensing of Environment, 2007, 108(3):327-338.

[55] Kulkarni AV: Mass balance of Himalayan glaciers using AAR and ELA methods. Journal of Glaciology, 1992, 38:101-104.

[56] Meier MF and Post AS: Recent variations in mass net budgets of glaciers in western North America. International Association of Scientific Hydrology Publication, 1962, 58:6377 (Symposium at Obergurgl 1962 - Variations of Glaciers).

[57] Berthier E and Vincent C: Relative contribution of surface mass balance and ice flux changes to the accelerated thinning of the Mer de Glace (Alps) over 1979-2008. Journal of Glaciology, 2012, 58(209):501-512.

[58] Heid T and Kääb A: Evaluation of existing image matching methods for deriving glacier surface displacements globally from optical satellite imagery. Remote Sensing of Environment, 2012, 118:339-355.

[59] Berthier E, Vadon H, Baratoux D, Arnaud Y, Vincent C, Feigl KL, et al: Surface motion of mountain glaciers derived from satellite optical imagery. Remote Sensing of Environment, 2005, 95:14-28.

[60] Kääb A, Lefauconnier B, and Melvold K: Flow field of Kronebreen, Svalbard, using repeated Landsat 7 and ASTER data. Annals of Glaciology, 2006, 42(1):7-13.

[61] Luckman A, Quincey D, and Bevan S: The potential of satellite radar interferometry and feature tracking for monitoring flow rates of Himalayan glaciers. Remote Sensing of Environment, 2007, 111:172-181.

[62] Quincey DJ, Copland L, Mayer C, Bishop M, Luckman A, and Belò M: Ice velocity and climate variations for Baltoro Glacier, Pakistan. Journal of Glaciology, 2009, 55(194):1061-1071. 
[63] Rankl M, Vijay S, Kienholz C, and Braun M: Glacier changes in the Karakoram region mapped by multi-mission satellite imagery. The Cryosphere, 2013, 7:4065-4099.

[64] Goldstein RM, Engelhart H, Kamb B, and Frolich RM: Satellite radar interferometry for monitoring ice sheet motion: application to an Antarctic ice stream. Science, 1993, 262(5139):1525-1539.

[65] Haeberli $\mathrm{W}$ and Beniston M: Climate change and its impacts on glaciers and permafrost in the Alps. Ambio, 1998, 27:258-265.

[66] Richardson SD and Reynolds JM: An overview of glacial hazards in the Himalayas. Quaternary International, 2000, 65/66:31-47.

[67] Reynolds JM: Managing the risks of glacial flooding at hydro plants. Hydro Review Worldwide, 1998, 6:2-6.

[68] Taylor P and Richardson SD: Glacial risks and high mining. Mining Magazine, 2003, April, 174-176.

[69] Kääb A, Wessels RL, Haeberli W, Huggel C, Kargel JS, and Khalsa SJS: Rapid ASTER imaging facilitates timely assessment of glacier hazards and disasters. EOS, Transactions of the American Geophysical Union, 2003, 84:117-121.

[70] Quincey DJ, Lucas RM, Richardson SD, Glasser NF, Hambrey MJ, and Reynolds JM: Optical remote sensing techniques in high-mountain environments: application to glacial hazards. Progress in Physical Geography, 2005, 29(4):475-505.

[71] Bajracharya B, Shrestha AB, and Rajbhandari L: Glacial lake outburst floods in the Sagarmatha region. Mountain Research and Development, 2007, 27(4):336-344.

[72] Bolch T, Buchroitner M, Peters J, Baessier M, and Bajracharya S: Identification of glacier motion and potentially dangerous glacial lakes in the Mt. Everest region/Nepal using spaceborne imagery. Natural Hazards and Earth System Sciences, 2008, 8:13291340.

[73] Wang X, Shiyin L, Wanqin G, and Junli X: Assessment and simulation of glacier lake outburst floods for Longbasaba and Pida Lakes, China. Mountain Research and Development, 2008, 28(3/4):310-317.

[74] Mool PK: Glacier lake outburst floods in Nepal. Journal of Nepal Geological Society, 1995, 11:273-280.

[75] Huggel C, Kääb A, Haeberli W, Teysseire P, and Paul F: Remote sensing based assessment of hazards from glacier lake outbursts: a case study in the Swiss Alps. Canadian Geotechnical Journal, 2002, 39(2):316-330.

[76] Sawagaki T, Damodar L, Alton CB, and Teiji W: Changes in surface morphology and glacial lake development of Chamlang South Glacier in the eastern Nepal Himalaya since 1964. Global Environmental Research, 2012, 16(2012):83-94. 
[77] Lamsal D, Sawagaki T, and Watanabe: Digital terrain modelling using Corona and ALOS PRISM data to investigate the distal part of Imja Glacier, Khumbu Himal, Nepal. Journal of Mountain Science, 2011, 8:390-402.

[78] Sakai A: Glacial lakes in the Himalayas: a review on formation and expansion processes. Global Environmental Research, 2012, 16(2012):23-30.

[79] Huggel C, Haeberli W, Kääb A, Bieri D, and Richardson S: An assessment procedure for glacial hazards in the Swiss Alps. Canadian Geotechnical Journal, 2004, 41:10681083.

[80] Clague JJ and Evans SG: A review of catastrophic drainage of moraine-dammed lakes in British Columbia. Quaternary Science Reviews, 2000, 19:1763-1783.

[81] Bhambri R, Bolch T, Kawishwar P, Dobhal DP, Srivastava D, and Pratap B: Heterogeneity in glacier response in the upper Shyok valley, northeast Karakoram. The Cryosphere, 2013, 7:1385-1398, doi:10.5194/tc-7-1385-2013. 
Section 3

Remote Sensing For Coastal and Ocean Applications 

Chapter 6

\title{
Optical Satellite Remote Sensing of the Coastal Zone Environment - An Overview
}

\author{
Ana C. Teodoro \\ Additional information is available at the end of the chapter \\ http://dx.doi.org/10.5772/61974
}

\begin{abstract}
Optical remote-sensing data are a powerful source of information for monitoring the coastal environment. Due to the high complexity of coastal environments, where different natural and anthropogenic phenomenon interact, the selection of the most appropriate sensor(s) is related to the applications required, and the different types of resolutions available (spatial, spectral, radiometric, and temporal) need to be considered. The development of specific techniques and tools based on the processing of optical satellite images makes possible the production of information useful for coastal environment management, without any destructive impacts. This chapter will highlight different subjects related to coastal environments: shoreline change detection, ocean color, water quality, river plumes, coral reef, alga bloom, bathymetry, wetland mapping, and coastal hazards/vulnerability. The main objective of this chapter is not an exhaustive description of the image processing methods/algorithms employed in coastal environmental studies, but focus in the range of applications available. Several limitations were identified. The major challenge still is to have remote-sensing techniques adopted as a routine tool in assessment of change in the coastal zone. Continuing research is required into the techniques employed for assessing change in the coastal environment.
\end{abstract}

Keywords: Shoreline Change Detection, Ocean Color, Optical Water Quality, River Plumes, Coral Reef, Alga Bloom, Bathymetry, Wetland Mapping, Hazards, Vulnerability

\section{Introduction}

One of the most useful reviews of remote sensing of the coastal zone was the work published by Cracknell [1], where a review of the current state of the use of remote sensing in estuaries 
and coastal waters at the end of the 20th century was performed. He identified that period (end of the 20th century) as a stage of potential great changes and advances in the use of remote sensing. Since then, the advances in the use of remote sensing for coastal areas have been huge. These advances are related to the availability of new sensors, more adequate for the study of this area, and also the improvements in the classification algorithms. Several useful reviews related to the value of remote sensing in the coastal zone environment have been published since then [2,3]. Malthus and Mumby [2] update the information given by Cracknell [1], and highlight a number of priority areas. Advances were identified in the benefit of high spatial and spectral resolution data and complementary remote-sensing techniques. Further benefits are identified in rapid and more frequent data acquisition, faster and more automated processing and a greater sampling intensity over conventional field-based techniques. All these aspects were fully confirmed. Issues associated with adoption of remotely sensed data for coastal management were also discussed. This issue still is a topic of extreme importance. Although remotely sensed data are currently used for decision-making, their use is not yet an integrated tool for coastal management. Several research priorities were identified in the work of Malthus and Mumby [2]. Areas of value that continue to remain poorly investigated include the improvements to be gained from synergistic use of multiwavelength remote-sensing approaches, change detection techniques, and multitemporal comparisons and knowledgebased approaches to improve classification [2]. The lack of accuracy remains a challenge task. Therefore, the major challenge is to implement the remote-sensing techniques as a routine tool in assessment of coastal zone changes. Unfortunately, this challenge is still unfulfilled, as will be described in this chapter. More recently, Klemas [3] published an overview of remote sensing of emergent and submerged wetlands. Kelmas [3] discusses the impact of climate change on coastal wetland (sea-level rise, increase of temperature, and changes in precipitation), and the impacts due to anthropogenic activities. He has enumerated the recent advances in sensor design (high-resolution multispectral and hyperspectral imagers, light detection and ranging (LiDAR), and radar systems), and image processing techniques that making remotesensing systems more practical and attractive for monitoring coastal ecosystems. The lack of accurate near-shore bathymetric data was identified as a key limitation in the application of geospatial data to coastal environments. He concludes that when remote-sensing systems are used wisely, including complementary combinations of different satellite and airborne sensors, they can provide data that enhance the research and management of coastal ecosystems. According to Klemas [3], the future research priorities should include better understanding and description of the radiative properties of coastal environments. Additional knowledge is required about the spatial and temporal variations of water column optical properties and its constituents. Best approaches for processing hyperspectral data need to be further investigated [3].

The main objectives of this chapter are (i) to provide an overview of the optical satellite remote sensing of the coastal zone environment and (ii) to highlight a number of application fields related to coastal areas where optical remote sensing plays an important role. 


\section{Optical remote sensing for coastal areas: Principles}

Optical imaging sensors are a crucial technology in the field of coastal remote sensing. The main function of electro-optical imaging sensors is to collect incident electromagnetic (EM) radiation and convert it to a stored representation useful for remote-sensing analysis. These sensors operate in the optical region of the EM spectrum defined as radiation with wavelengths between 400 and $15000 \mathrm{~nm}$. This range includes the visible (400-700 nm), the near infrared (NIR, 700-1100 nm), the short infrared (SWIR, 1100-2500 nm), the midwave infrared (MWIR, 2500-7500 nm) and the long-wave infrared (LWIR, 7500-15000 nm) spectral regions [4]. Optical remote sensing involves acquisition and analysis of optical data-EM radiation captured by the sensing modality after reflecting off an area of interest on ground/water. Different materials/ water constituents reflect and absorb differently at different wavelengths. Thus, the targets/ elements can be differentiated by their spectral reflectance signatures in the remotely sensed images. The optically active water constituents, including phytoplankton (chlorophyll a Chla), detritus and minerals, Colored Dissolved Organic Matter (CDOM - also called gelbstoff or yellow substances), and water itself, all have an impact on the optical signature of water in the visible wavelengths. In the visible spectral range of solar radiation, light can penetrate in water bodies and its color can change due to scattering and absorption processes in the water body or at its bottom. This makes it possible to derive from optical remote-sensing data information about the characteristics of the water body and the type/concentration of its components. The water curve (spectral signature) is characterized by a high absorption at NIR wavelengths range and beyond. Because of this absorption property, water bodies as well as features containing water can easily be detected, located, and delineated with remote-sensing data. Turbid water has a higher reflectance in the visible region than clear water. This is also true for waters containing high Chla concentrations. Coastal waters are optically complex and the signal that a remote detector collects is a mixed signal including various water optically active constituents from different sources. Complex interaction among phytoplankton (Chla), Total Suspended Mater (TSM), and CDOM results in poor predictive ability in retrieval of various water quality proprieties in coastal waters.

Optical remote-sensing systems are classified into different types, depending on the number of spectral bands used in the imaging process: 1) Panchromatic imaging system: the sensor is a single-channel detector sensitive to radiation within a broad wavelength range. If the wavelength range coincides with the visible range, then the resulting image resembles a "blackand-white" image. 2) Multispectral imaging system: the sensor is a multichannel detector with a few spectral bands. Each channel is sensitive to radiation within a narrow wavelength band. The resulting image is a multilayer image which contains both the brightness and spectral information of the targets. 3) Hyperspectral Imaging Systems: the sensor acquires images in several (typically hundred or more) contiguous spectral bands. The precise spectral information contained in a hyperspectral image enables better characterization and identification of targets. Hyperspectral images have a great potential in applications regarding coastal management. 


\section{Sensors}

In coastal and inland waters, optically active constituents often vary independently requiring improved spectral and radiometric resolutions, while physical drivers such as tides and geographic boundaries set up different spatial and temporal scales compared to the open ocean [5]. Due to the large number of sensors available, with distinct characteristics, it is a challenge to choose the most appropriate satellite images for monitoring coastal environments. The selection of the sensor is related to the applications required and the different types of resolution (spatial, spectral, radiometric, and temporal) should be considered. Another aspect that could interfere with the selection of the sensor is the data availability. Some images are really expensive and some data can be freely downloaded or granted by national/international organizations for research purposes. A list of the most relevant optical sensors used in the last decade to the assessment of coastal zone environment is shown in Table 1. A number of sensors have been launched since the Coastal Zone Color Scanner (CZCS) in 1978, including the Seaviewing Wide Field-of-viewSensor (SeaWiFS), the MODerate resolution Imaging Spectroradiometer (MODIS), and the MEdium Resolution Imaging Spectrometer (MERIS). These instruments are equipped with sensors optimized for measuring water-leaving radiance or reflectance over most of the world's oceans, but not over many inland or coastal waters. Recently, significant advances have been made in studying coastal and inland waters using global sensors such as MODIS medium resolution data and MERIS full resolution (FR) data [6-8]. The primary mission of MERIS was the measurement of sea color in the oceans and in coastal areas. The applicability of MERIS data to coastal studies is extensive. Unfortunately, the MERIS instrument is no longer available (since May 2012).

Traditionally, the Landsat (TM and ETM+), the French Système Pour l'Observation de la Terre (SPOT), and Terra/ASTER have been reliable data sources for large coastal watersheds' landcover $[9,10]$, water turbidity quantification [11], suspended sediments' concentration estimation [12-15], vegetation cover [16], among others. However, the $30 \mathrm{~m}, 20 \mathrm{~m}$, and $15 \mathrm{~m}$, respectively, spatial resolutions in the visible and Near Infra-Red (NIR) bands were initially designed for land-cover studies. The availability of high spatial and spectral resolution satellite data has significantly improved the capacity for mapping coastal ecosystems. High-resolution imagery obtained from satellites, such as IKONOS-2, Quick Bird-2, GeoEye-1, and Orbview-3 can be used for different purposes regarding coastal applications. WorldView-2 has a spatial resolution of $2 \mathrm{~m}$ for 8 multispectral (MS) bands (4 standard colors: red, blue, green, NIR, and 4 new colors: red edge, coastal, yellow, NIR2, and $0.5 \mathrm{~m}$ spatial resolution for the panchromatic (PAN) band (450-800 nm). The Pleiades 1A/1B satellites were designed with urgent tasking option, and images can be requested less than six hours before they are acquired. This functionality will prove invaluable in situations where the expedited collection of new image data is crucial, such as coastal crisis monitoring. This sensor is comparable to the other highresolution sensors (e.g., GeoEye-1, Orbview-3). The Hyperion provides a high-resolution hyperspectral imager capable of resolving 220 spectral bands with a $30 \mathrm{~m}$ resolution. Through these spectral bands, complex coastal ecosystems can be imaged and accurately classified. 


\begin{tabular}{|c|c|c|c|c|c|}
\hline Sensor & $\begin{array}{c}\text { Spectral } \\
\text { Range (nm) }\end{array}$ & $\begin{array}{c}\text { No. } \\
\text { Bands }\end{array}$ & $\begin{array}{c}\text { Spatial } \\
\text { Resolution }\end{array}$ & $\begin{array}{l}\text { Temporal } \\
\text { Resolution }\end{array}$ & $\begin{array}{l}\text { Swath } \\
\text { width }\end{array}$ \\
\hline Landsat & $450-900$ & 4 VNIR & $30 \mathrm{~m}$ & 16 days & $185 \mathrm{~km}$ \\
\hline \multirow[t]{2}{*}{$\mathrm{TM}$} & $1550-2350$ & 2 SWIR & $30 \mathrm{~m}$ & & \\
\hline & $10410-12500$ & $1 \mathrm{TIR}$ & $120 \mathrm{~m}$ & & \\
\hline Landsat & $450-900$ & 4 VNIR & $30 \mathrm{~m}$ & 16 days & $183 \mathrm{~km}$ \\
\hline \multirow[t]{3}{*}{ ETM+ } & $1550-2350$ & 2 SWIR & $30 \mathrm{~m}$ & & \\
\hline & $10410-12500$ & $1 \mathrm{TIR}$ & $60 \mathrm{~m}$ & & \\
\hline & $520-900$ & 1 PAN & $15 \mathrm{~m}$ & & \\
\hline SPOT 4-5 & $500-890$ & 3 VNIR & $20 \mathrm{~m}$ & 26 days & $60 \mathrm{~km}$ \\
\hline \multirow[t]{2}{*}{ HRVIR } & $1580-1750$ & 1 SWIR & $20 \mathrm{~m}$ & & \\
\hline & $610-680$ & 1 PAN & $10 \mathrm{~m}$ & & \\
\hline SPOT 5 & $500-890$ & 3 VNIR & $10 \mathrm{~m}$ & 26 days & $60 \mathrm{~km}$ \\
\hline \multirow[t]{2}{*}{ HRS } & 1580-1750 & 1 SWIR & $20 \mathrm{~m}$ & & \\
\hline & $510-730$ & 1 PAN & $5 \mathrm{~m}$ & & \\
\hline \multirow[t]{3}{*}{ ASTER } & $520-860$ & 3 VNIR & $15 \mathrm{~m}$ & 16 days & $60 \mathrm{~km}$ \\
\hline & $1600-2430$ & 6 SWIR & $30 \mathrm{~m}$ & & \\
\hline & 8125-11650 & $5 \mathrm{TIR}$ & $90 \mathrm{~m}$ & & \\
\hline \multirow[t]{3}{*}{ MODIS } & 620-14385 & 16 VNIR & $250 \mathrm{~m}-1 \mathrm{~km}$ & 1 day & $2330 \mathrm{~km}$ \\
\hline & & 4 SWIR & & & \\
\hline & & $16 \mathrm{TIR}$ & & & \\
\hline SeaWIFS & $402-885$ & $8 \mathrm{VNIR}$ & $1.1 \mathrm{~km}$ & 1 day & $2800 \mathrm{~km}$ \\
\hline MERIS & 290-1040 & $15 \mathrm{VNIR}$ & $300 \mathrm{~m}$ & $<3$ days & $1150 \mathrm{~km}$ \\
\hline Hyperion EO-1 & $400-2500$ & 220 & $30 \mathrm{~m}$ & 16 days & $8 \mathrm{~km}$ \\
\hline \multirow[t]{2}{*}{ IKONOS-2 } & $455-850$ & 4 VNIR & $4 \mathrm{~m}$ & $1-3$ days & $11 \mathrm{~km}$ \\
\hline & $760-850$ & 1 PAN & $1 \mathrm{~m}$ & & \\
\hline \multirow[t]{2}{*}{ Quick Bird } & $430-918$ & 4 VNIR & $2.44 \mathrm{~m}$ & $<3$ days & $16.5 \mathrm{~km}$ \\
\hline & 405-1053 & 1 PAN & $0.61 \mathrm{~m}$ & & \\
\hline \multirow[t]{2}{*}{ Orbview-3 } & $450-900$ & 4 VNIR & $4 m$ & $<3$ days & $8 \mathrm{~km}$ \\
\hline & $450-900$ & 1 PAN & $1 \mathrm{~m}$ & & \\
\hline \multirow[t]{2}{*}{ GeoEye-1 } & $450-920$ & 4 VNIR & $1.65 \mathrm{~m}$ & 2.1-8.3 days & $15.2 \mathrm{~km}$ \\
\hline & $450-800$ & 1 PAN & $0.41 \mathrm{~m}$ & & \\
\hline \multirow[t]{2}{*}{ WorldView-2 } & 400-1040 & 8 VNIR & $1.85 \mathrm{~m}$ & 1.1-2.7 days & $16.4 \mathrm{~km}$ \\
\hline & $450-800$ & 1 PAN & $0.46 \mathrm{~m}$ & & \\
\hline \multirow[t]{2}{*}{ Pleiades 1A/1B } & $430-950$ & 4 VNIR & $2.0 \mathrm{~m}$ & 1 day & $20 \mathrm{~km}$ \\
\hline & $480-830$ & 1 PAN & $0.5 \mathrm{~m}$ & & \\
\hline Sentinel-2 & $420-2370$ & VNIR-SWIR & $10,20,60 \mathrm{~m}$ & $<3$ days & $290 \mathrm{~km}$ \\
\hline
\end{tabular}

Table 1. Characteristics of some optical systems used in coastal zones applications 
Shortly, the assessment to the Sentinel-2 data will improve coastal environment monitoring programs. The Sentinel-2 was launched in June 2015 within COPERNICUS programme of the European Space Agency (ESA). The design of the Sentinel-2 mission aims at an operational multispectral Earth-observation system that complements the Landsat and SPOT and improves data availability for users. More information about Sentinel-2 can be found in Drusch et al. [17].

The development of specific techniques based on the processing of optical satellite data makes possible the production of information really useful for coastal environments, without any destructive impacts. Different image processing techniques have been applied to the satellite images in order to study the coastal environment. These techniques differ depending on the subject of study. Most of the techniques widely used in land and ocean studies are also applied in coastal research. Some techniques have also been intentionally developed to study specific aspects of this area. The topic of this chapter is not an exhaustive description of the image processing methods/algorithms employed in coastal environmental studies, but focus in the range of applications available. In this chapter will be gathered the most cited/important applications of optical remote sensing regarding the coastal zone environment of the last decade.

\section{Applications}

In this section, several application fields related to coastal environments, where optical remote sensing plays an important role, are addressed.

\subsection{Shoreline change detection}

Shorelines are inherently dynamic features that mark the transition between land and sea and are vulnerable to waves, winds, nearshore currents, and anthropogenic actions [18]. It is estimated that there are around $350000 \mathrm{~km}$ of shoreline in the world and more than $60 \%$ of the world's population lives within $100 \mathrm{~km}$ of the coastal/sea. Therefore, monitoring and managing shorelines evolution are of considerable social, cultural, and economic importance. Furthermore, shoreline erosion and coastal flooding were highlighted among the gravest effects of climate change [19]. Several studies have investigated the potential of optical satellite images to study shoreline change. An idealized definition of shoreline is that it coincides with the physical interface of land and water [20]. Because of the dynamic nature of the idealized shoreline boundary, the use of shoreline indicators has been adopted for coastal studies. A shoreline indicator is a feature that is used as a proxy to represent the "true" shoreline position. Boak and Turner [21] reviewed shoreline definition and detection techniques, and carried out a comprehensive literature study. They categorized shoreline indicators in three groups: (i) visible discernible features; (ii) tidal datum-based indicators; and (iii) indicators based on the processing technique to extract the shoreline. One of the most common technique for shoreline detection was (and still is in some cases) visual interpretation. However, this approach is highly subjective and is not possible to access to any accuracy indicator. The alternative employs 
digital image processing techniques, as supervised and unsupervised classification algorithms. Gen [22] presents a paper that reviews the status of the use of remote sensing for the detection, extraction, and monitoring of coastlines. The review takes the US system as an example. However, the issues researched can be applied to any other part of the world. He concludes that visual interpretation of airborne remote-sensing data is still widely and popularly used for coastal delineation. However, a variety of remote-sensing data and techniques are available to detect, extract, and monitor the coastline.

Guariglia et al. [23] used a multisource approach to coastline mapping, in Basilicata region (Italy). They stated that satellite images are affected by tidal variations depending on their spatial resolution and concluded that the coastline can be extracted from Landsat TM images, without the interference of the tidal factor. Instead,tidal effects must be considered when the coastline is identified from images having higher spatial resolution that are comparable to the errors induced by tide.

Ekercin [24] present a work on the coastline movements at the northeast coasts of the Aegean Sea (Turkey). In this study, the coastline changes were examined using data from Landsat MSS, TM, and ETM collected between 1975 and 2001. In the image processing step, an unsupervised image classification algorithm (ISODATA) was employed and temporal image ratioing techniques were used to carry out coastline change assessment. Significant coastline movements were identified.

Maiti and Bhattacharya [25] used multidate satellite images from Landsat MSS, TM, ETM+, and ASTER to demarcate shoreline positions, from which shoreline change rates have been estimated using linear regression, along the coast of Bay of Bengal (India), between 1973 and 2003. The shorelines have been identified through the NIR bands, and included gray level thresholding and segmentation by edge enhancement technique. The result shows that $39 \%$ of transects have uncertainties in shoreline change rate estimations. On the other hand, 69\% of transects exhibit lower Root Mean Square Error (RMSE) values for the short-term period, indicating better agreement between the estimated and satellite-based shoreline positions.

Kuleli et al. [26] presented a research focused on the shoreline change rate analysis by automatic image analysis techniques through histogram-based segmentation of land and water based on automatic thresholding algorithm, using multitemporal Landsat images (MSS, TM and ETM+) between 1972 and 2009 along the coastal Ramsar wetlands of Turkey. Accretion or erosion processes were observed on multitemporal satellite images along the areas of interest.

Kumar et al. [27] applied and developed the method established by Maiti and Bhattacharya [25] for calculating the rates of shoreline change, shoreline positions, and morphology of spits along the Karnataka coast, western India, for the period from 1910 to 2005 using multidated satellite images and topographic maps. Satellite images (IRS 1C, LISS-III) of IR band were employed. Binary images are used as input layers in unsupervised classification module to a complete separation between land and water classes, and to remove effect of suspended materials, if any. Significant changes in morphology of spits have been recorded. 
Wang et al. [28] presented a class association rule algorithm on the basis of the Apriori algorithm. To test the feasibility of the method, Landsat ETM+ image scene of Jiaozhou Bay near Qingdao city (China) was used to interpret the coastline. First, the association rules of the sea-land separation of the study area were discovered from learning samples by using the class association rule algorithm. Second, the sea and the land of the image were separated with the mined rules. Third, the coastline was interpreted from the separation result. This approach includes not only spectral attributes but also the texture attributes (entropy) and the statistical analysis variables (mean and variance).

Regarding sand spits' behavior, Teodoro and Gonçalves [29] present different approaches in order to extract sand spits from IKONOS-2 data (Figure 1). A semiautomatic approach is proposed in this work, which is based on global thresholding through the Otsu's method, further refined through detected edges (GThE). The performance of GThE is compared with traditional pixel-based and object-based classification algorithms. The dataset is composed by six IKONOS-2 images, acquired between 2001 and 2007, covering a sand spit located in Portugal. The performance of the different methods used in the estimation of the sand spit area was evaluated through two sets of reference values of the sand spit area. The proposed GThE method presented better results than the other traditional methods, with a clear advantage of a considerable faster performance, beyond requiring a minimum operator intervention.

A high-precision geometric method for automated shoreline detection in the Spanish Mediterranean coast, from 45 Landsat TM and ETM+ imagery was presented by Pardo-Pascual et al. [30]. The methodology is based on an algorithm for subpixel shoreline extraction. The algorithm is based on the assumption that the separation between water and land will occur where the infrared intensity gradient around the pixel-level shoreline is maximum. The results confirm that the use of Landsat imagery for detection of instantaneous coastlines yields accuracy comparable to high-resolution techniques.

More recently, García-Rubio et al. [31] developed a method to identify the shoreline from satellite optical images (SPOT), applying an unsupervised classification (ISODATA), using the NIR spectral band to separate the sea and the land in Progreso (Yucatán, México). The shoreline was validated using quasi-simultaneous in situ shoreline measurements, both adjusted to equal water levels. The validation of shoreline obtained by satellite data revealed that the shoreline is located consistently seaward of the in situ shoreline. The success of this method suggests that it should be applicable to other locations, after adapting the confidence bounds to the beach conditions.

In conclusion, several techniques for coastline extraction and change detection from optical satellite imagery have been developed in the recent years. Manual identification, image enhancement, density slice using single or multiple bands, and image classification (supervised and unsupervised) are still the most common techniques employed. In addition, several image processing methods related to segmentation algorithms and statistics approaches have also been used. The data more used still are the traditional Landsat and SPOT images, but some works had also used high spatial resolution data (e.g., IKONOS 2), regarding the availability of an NIR band. In the future, should be considered the recent availability of the new sensors in conjunction with classification/segmentation algorithms more efficient. The 


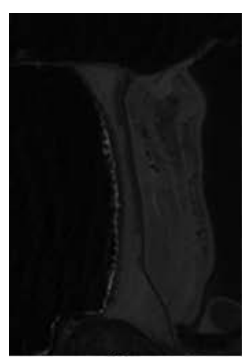

(a)

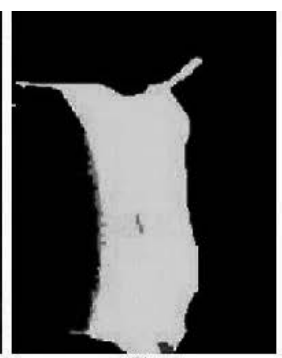

(b)

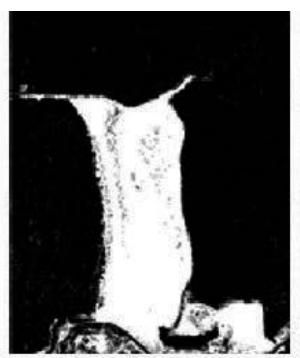

(c)

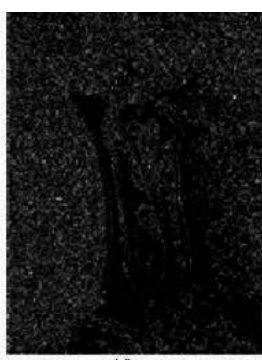

(d)

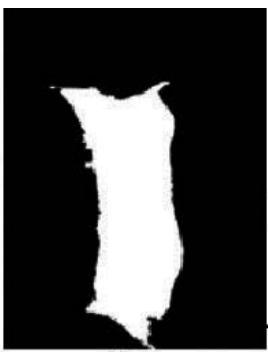

(e)

Figure 1. (a) Panchromatic band of the IKONOS-2 image from Jun. 2005; (b) the sand spit extraction with object-based approach; (c) global thresholding of the image in Fig. 1(a) through the Otsu's method; (d) edges of the image in Fig. 1(a) obtained through the Canny edge detector; (e) final extraction of the sand spit in Fig. 1(a), through the refinement of the global thresholding in (c) through the edges represented in (d) (adapted from [29])

accurate extraction of the shoreline is one of the most important parameter to estimate the erosion rates.

\subsection{Coastal color}

Remote sensing of ocean color has an important role to play as a cost-effective tool for global and frequent observations that can be interpreted in terms of surface concentrations of Chla, TSM, or CDOM. However, this global capability is to some extent questioned by the uneven distribution of field data that are at the basis of empirical algorithms, or are used for the definition of parameters in semianalytical bio-optical algorithms, and frequently these algorithms are not calibrated for coastal waters. The dominant optically active constituent in the open sea (case- 1 waters) is the Chla, whereas in coastal waters (case- 2 waters), TSM and CDOM often dominate the spectral signal of Chla [32].

\section{Chlorophyll-a (Chla)}

Chla is certainly the most commonly derived parameter in water quality mainly because of its use in determining the trophic status of waters. The Chla estimation allows forecasting of the phytoplankton concentration and is therefore an important component in the derivation of secondary products such as primary production. Several techniques/algorithms have been applied in order to estimate the Chla concentration [33]:

i. In high-biomass waters the $700 / 670 \mathrm{~nm}$ ratio reflectance has been widely used. The explanation for the strength of the correlation of Chla with the $700 / 670 \mathrm{~nm}$ is based on the interaction between backscattering from phytoplankton and the strong absorption of water, which both increase toward the IR. The offset to scattering due to absorption by water near $700 \mathrm{~nm}$ causes a sharp peak in highly scattering waters. The height and position of this peak is known to be well-correlated with Chla, with the peak shifting toward greater wavelengths (apx. $715 \mathrm{~nm}$ ) as Chla increases. In contrast, the reflectance near $670 \mathrm{~nm}$ is uncorrelated, with Chla being almost constant owing to the Chla absorption maximum, which offsets backscattering. The positioning of the MERIS bands at 665 and $709 \mathrm{~nm}$ makes MERIS ideally suited for predicting 
Chla using this ratio, and many studies have recently been carried out [34, 35]. Threeband algorithm has also been used to estimates of Chla in turbid and very high biomass hypertrophic waters [36]. A four-band algorithm, including an additional band near $700 \mathrm{~nm}$, was found to be an improvement over the three-band model in highly turbid lake water through better accounting for absorption by water and nonnegligible scattering by TSM in the NIR band [37].

ii. The fluorescence maximum near $685 \mathrm{~nm}$ has been used to estimate Chla [38, 39]. The fluorescence line height (FLH) algorithm measures the height of the fluorescence peak at $685 \mathrm{~nm}$ from a linear baseline drawn between two points on either side of the peak [40]. It is important to consider that the FLH algorithm is only suitable for Chla concentrations generally not exceeding $30 \mathrm{mg} \mathrm{m}^{-3}$ as the backscattering peak near 700 $\mathrm{nm}$ overwhelms the fluorescence peak in high-biomass water.

iii. Sensors such as Landsat [41], SPOT [42], and IKONOS [43] are also frequently used to estimate Chla. However, the lack of narrow bands and low Signal-Noise Ratio (SNR) make very difficult the use of the algorithms already described. Therefore, simple linear regressions of single bands or band ratios are used and with lesssignificant correlations. An alternative could be the use of advanced algorithms, such as Artificial Neural Networks (ANN) and genetic algorithms [44], multivariate regression analysis [45], or spectral decomposition algorithm [46]. The use of these and other complex algorithms generally leads to improved significance of correlations.

\section{Total Suspended Mater (TSM)}

TSM is the total mass of suspended particles as measured per volume of water including inorganic (minerals) and organic (detritus and phytoplankton) components. The study of TSM concentration has a huge ecological importance, because the suspended matter is the main carrier of various inorganic and organic substances and becomes the main substrata for biochemical processes [47]. The TSM concentration affects ocean/coastal productivity, water quality, navigation, and coastal defense. The TSM concentration and distribution in the coastal zone varies with several hydrodynamic factors, such as tidal condition, currents' direction and velocity, river discharges, and wind stress [12]. The discrimination of TSM from water reflectance is based on the relationship between the scattering and absorption properties of water and its constituents. In the visible and NIR region, most of the scattering is caused by suspended sediments, and the absorption is controlled by Chla and CDOM. Therefore, the visible and NIR regions are the most adequate to estimate the TSM concentration. These absorptive in-water components decrease the reflectance in a substantial way. However, these absorptive effects occur generally for wavelengths less than $500 \mathrm{~nm}$ [32]. Several works have demonstrated that optical remotely sensed data can be used to retrieve TSM concentration from turbid coastal waters [14]. Many TSM models based on empirical methods have been used in operational satellite systems. These models were developed on the basis of statistical relationships between TSM concentrations and single-band or multiband reflectance [12, 13]. Although empirical models may be effectively applied to satellite images concurrent with the calibration dataset, their accuracy may be reduced outside the conditions of the calibration 
dataset because of the empirical basis [48]. Therefore, semianalytical models that combine physical methods with statistical methods were proposed for several authors in order to retrieve the TSM concentration [49]. Teodoro et al. [12] present different methodologies to estimate the TSM concentration in a particular area of the Portuguese coast, from remotely sensed multispectral data (ASTER, SPOT HRVIR, and Landsat TM), based on single-band models, multiple regression, and ANNs. The analysis of the RMSE achieved by both the linear and nonlinear models supports the hypothesis that the relationship between the seawater reflectance and TSM concentration is clearly nonlinear. The ANNs have been shown to be useful in estimating the TSM concentration from reflectance of visible and NIR bands of ASTER, HRVIR (Figure 2), and TM sensors, with better results for ASTER and HRVIR sensors.

\section{Colored Dissolved Organic Matter (CDOM)}

CDOM, also called gelbstoff or yellow substances, is primarily composed of humic acids produced from the decomposition of plant litter and organically rich soils within coastal watersheds and upland areas is a significant contributor to water color, because humic substances absorb strongly in the blue region of the spectrum, turning the water brown. The absorption by CDOM (aCDOM - usually referenced at $440 \mathrm{~nm}$ ) takes the form of an exponential function decreasing toward longer wavelengths so that its effects are usually negligible at wavelengths higher than $550 \mathrm{~nm}$. CDOM concentrations increase in coastal waters due to the in situ creation of fulvic acids produced from the seaweed decomposition as a by-product of primary production estimulated by nutrients and the anthropogenic input of industrial or domestic effluents from populated areas. In the coastal environment, the optical properties of CDOM change owing to seawater mixing and photodegradation. Absorption by CDOM is one of the primary additive absorption Inherent Optical Properties (IOPs), along with phytoplankton and water, and is of great interest from a bio-optical perspective. Algorithms using ratios of reflectance in visible range have been found to be well-correlated with aCDOM [50]. In waters with low TSM concentration, Bowers et al. [51] showed theoretically, while making some assumptions about particulate absorption, that there is a linear relationship between aCDOM and the ratio of reflectance in the red and blue bands. Doxaran et al. [52] used a 400/600 nm ratio, whereas D'Sa and Miller [53] used the SeaWiFS band configurations 412/510, 443/510, and $510 / 555 \mathrm{~nm}$, all of which gave good results, although this may reflect the existence of strong covariance between Chla and CDOM. Comparable red/blue ratios produced with the MERIS data also give similarly strong correlations [54]. The low radiometric resolution of some sensors (TM, IKONOS) makes CDOM estimations infeasible [55]. More recently, Loisel et al. [56] proposed a new method to assess aCDOM, based on the theoretical link between the vertical attenuation coefficient and the absorption coefficient. This method, confirmed from radiative transfer simulations and in situ measurements, and tested on an independent in situ data set allows aCDOM to be assessed with higher accuracy.

The optically active water constituents, including Chla, TSM, CDOM, and water itself, all have an impact on the optical signature of water in the visible wavelengths. The water-leaving radiance is modified through the backscattering and absorption of light by these constituents (IOPs). Absorption by Chla, CDOM and detritus, and water itself, are well-defined in the literature and can be used to explain the causal relationships between the observed remote- 
sensing reflectance and the biogeophysical parameters of interest. The backscattering coefficients for water, minerals, Chla, and TSM can be used in the same way. Strong absorption by water at wavelengths $>750 \mathrm{~nm}$ effectively masks out the signals from other constituents except in highly turbid water where scattering by minerals overwhelms absorption by water. Therefore, wavelengths between 400 and $750 \mathrm{~nm}$ generally contain the the most important information on the water constituents, which is detectable by remote-sensing instruments, with the exception of highly turbid water where the signal in the NIR is also useful [33]. Matthews [33] present a review of the empirical procedures of remote sensing in inland and near-coastal transitional waters. A review of empirical algorithms for quantitatively estimating a variety of parameters, including Chla, TSM, turbidity, and aCDOM, were proposed. The theoretical basis of the empirical algorithms was given using fundamental bio-optical theory of the IOPs. More recently, Mouw et al. [7] presented a review that describes the current and desired state of the aquatic satellite remote sensing, namely, mission capability, in situ observations, algorithm development, and operational capacity. They concluded that significant advances have been made in supporting in situ observations, algorithm development, and operational capacity and user engagement, but challenges still exist.

One of the major challenges in coastal and inland waters is the high turbidity and strong absorption. As absorption increases, the effect of self-shading of upwelling radiance increases. For IOPs, the available scattering sensors have the capability to effectively resolve backscattering at very high levels, but standard gain settings for these sensors are typically set to saturate at levels an order of magnitude lower to maximize resolution in the dynamic ranges observed in the ocean.

\subsubsection{Optical Water Quality (OWQ)}

Optical water quality (OWQ) has been defined by Kirk [57] as "the extent to which the suitability of water for its functional role in the biosphere or the human environment is determined by its optical properties." There are four main natural constituents, broadly classified, that attenuate light besides water itself: CDOM, TSM, nonalgal particulate organic matter (POM), and phytoplankton. Assessing OWQ involves quantifying the behavior of light in waters as affected by these light-attenuating constituents. Several publications have described the application of optical remote-sensing systems to measure water-quality conditions in lakes [45], river systems [58], and coastal zones [59, 60]. The interpretation of optical remote-sensing data of estuaries and tidal flat areas is hampered by optical complexity and often extreme turbidity. Extremely high concentrations of TSM, Chla and CDOM, local differences, seasonal and tidal variations, and resuspension are important factors influencing the optical properties in such areas [61].

There are mainly two approaches for deriving water-quality products from remotely sensed data: the model-based and the empirical approach. The model-based (or analytical) approach seeks to model the remote-sensing reflectance in terms of the water IOPs through radiative transfer modeling [62]. The remote-sensing reflectance from the water IOPs is obtained through a bio-optical model and an approximation of the radiative transfer equation [63] or through direct solution of the Radiative Transfer Equation (RTE). The reflectance at the top of 
the atmosphere can then be modeled using radiative transfer calculations for the atmosphere through codes such as 6S [64]. The main concerns with these kinds of algorithms are their sensitivity to errors from atmospheric correction procedures and the existence of nonunique or ambiguous solutions arising from the additive nature of the IOPs and the consequences of using a ratio in the reflectance approximation [65]. The analytical approach is complex and requires measurements of local/regional IOPs to develop a robust forward model. Empirical algorithms are relatively simple to derive and use: simultaneously acquired experimental sets of limnological, atmospheric, and remotely sensed data are used to normally derive site-andtime specific algorithms for a certain parameter using statistical regression techniques. These algorithms generally produce robust results for the areas and data sets from which they are derived. There are many varieties of algorithms that use either single bands, band ratios, band arithmetic, or multiple bands as independent variables in linear, multiple linear, or nonlinear regression analyses [33]. The empirical approach is computationally simpler, and it is employed in the majority of studies in inland waters.

Mélin and Vantrepotte [66] presented a study about the satellite data (SeaWiFS) available for coastal/shelf waters and marginal seas to derive a set of optical water types encompassing the full extent of the optical variability found in these regions. The spatial and temporal sampling considered is well-adapted to capture the optical variability found in coastal waters, whereas a higher level of averaging would tend to smooth out peculiar spectral characteristics. The focus of this work was all the coastal regions and marginal seas of the world. The classification allows the quantification of the optical similarity between regions. The set of 16 classes used in this work covers very turbid waters founded close to river outflow regions to oligotrophic waters. The general variability in optical types at any location has been addressed by quantifying the number of classes selected as dominant during the period and an index of optical diversity that has been linked to indices of marine biodiversity.

The works referred forecast an increasingly important role for OWQ studies driven by increased awareness of the need to protect ecosystems, manage water resources, and advance remote-sensing capabilities.

\subsubsection{River plumes}

River discharge into the coastal waters represents a major link between terrestrial and marine systems. River plumes are a mixture of freshwater and river sediment load, with some dilution caused by currents, and are affected by many factors such as river discharge, coastal wind fields, water stratification, surface layer mixing, tides and current, etc. It is known that plume waters near river mouths can contain high concentrations of nutrients and are excessively turbid [68].

$\mathrm{CDOM}$ is often used as an effective tracer for evaluating relative levels and the spatial distribution of dissolved organic carbon in aquatic environments. In addition, both Chla concentrations and turbidity are typically much higher in river systems, when compared to open sea environments. The river plumes are also distinguished from surround marine waters by their high concentration TSM, which changes the color of the ocean surface. Optical satellite images have been widely employed to study the spatio temporal variations of major river plumes around the world. The river plume observations/quantification included data from 
AVHRR [69], SeaWiFS [70], MODIS [71], MERIS [72], Landsat TM/ETM [74], or combining data from different sensors [73].

Zhu and $\mathrm{Yu}$ [75] present a study that aimed to evaluate the effectiveness of an inversion algorithm for the extraction of riverine and estuarine CDOM properties at global scales through EO-1 Hyperion images applied to ten major rivers from five continents. The river plumes are distinguished from surrounding marine waters by their high concentration of TSM which changes the color of the ocean surface. Since the TSM concentration can be associated with nutrients, pollutants, and other materials, it is of crucial importance to remotely survey their dispersal in order to assess the coastal environmental quality of the regions surrounding river mouths.

Lihan et al. [76] present a study to identify the Tokachi River plume by satellite images (SeaWiFS) and determine its relationship with river discharge and clarify its temporal and spatial dynamics. A supervised (Maximum Likelihood - ML) classifier was used to identify the plume and empirical orthogonal functions were applied to determine the spatial and temporal variability of the plume during 1998-2002.

Gonçalves et al. [4] proposed an automatic procedure for the identification of the Douro river plume (Portugal) based on the thresholding of the 71 of MERIS FR scenes (level 2 data - TSM band) through an automatic search for the optimum value of the threshold parameter. A fully automatic method was considered and a comprehensive characterization of the river plume was performed through a set of attributes, which take into account not only the shape of the river plume, but also the TSM concentration values. Regarding the characterization in terms of shape, the following attributes were considered: size of the plume; corresponding to the number of pixels; perimeter; the major and the minor axis length of the ellipse adjusted to the river plume; and the orientation (Fig. 3).

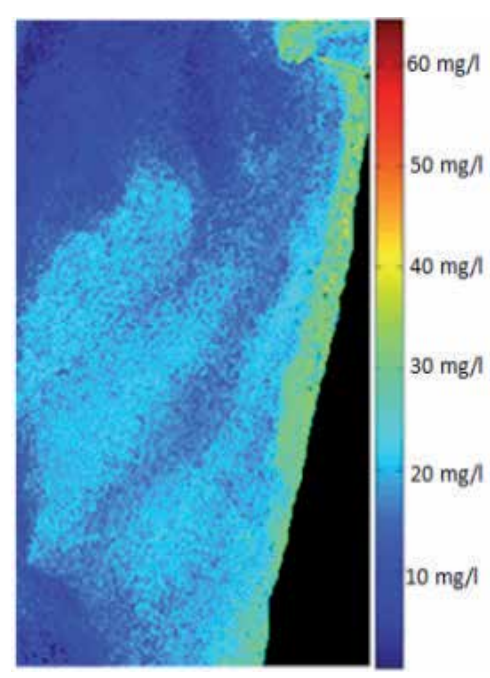

Figure 2. TSM concentration estimated from the HRVIR image through ANN for a region of the Portuguese coast 


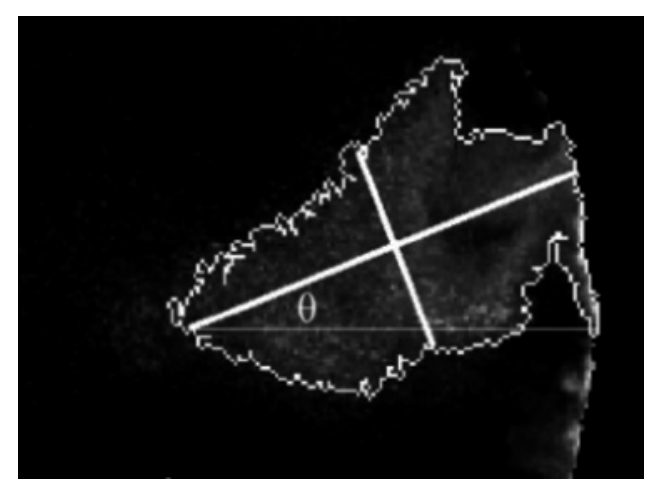

Figure 3. Illustration of the characterization of the river plume (2009-02-26) shape according to the adjusted ellipse (its major and minor axis) and the orientation of the river plume (adapted from [4])

Typically, outflow plumes are tracked in shelf water using density or salinity on account of the notably fresher composition of estuarine water. Unfortunately, there are no satellite-based remote-sensing platforms from which salinity can be directly measured. However, several studies have shown that these outflows carry large amounts of dissolved organic materials and suspended particles, which should allow plume events to be readily identified by remotely sensed optical images [77]. Kim et al. [78] related Chla concentration to salinity in the Changjiang plume area and presented the monthly summer plume area within a limited area during 1998-2007.

Hopkins et al. [79] used four satellite data products to examine the Sea Surface Temperature (SST), Sea Surface Salinity (SSS), Chla, and Mean Sea Level Anomaly (MSLA) fields in an area of the Angola Basin surrounding the Congo River mouth. Although it was not possible to extract a clear plume signature from the SST and MSLA alone, they provide useful supplementary understanding of the regions dynamics. Correlations between the SST, MSLA, Chla, and SSS help identify those areas persistently influenced by river input and those where variability is dominated by other processes.

\subsubsection{Coral reef and Alga bloom}

Coral reefs are one of the most biodiverse marine ecosystems on the planet. Worldwide, coral reef ecosystems are being increasingly threatened by sediment loads from river discharges, which in turn are influenced by changing rainfall patterns due to climate change and by growing human activity in their watersheds. Water turbidity and associated light attenuation are factors widely known to limit coral reef development. Coral reefs are generally limited to shallow and clear water with a mean water temperature of $18^{\circ} \mathrm{C}$ or higher, and are thus largely confined to the tropics [80]. Coral reef can be classified to show different forms of coral reef, dead coral, coral rubble, algal cover, sand, lagoons, different densities of seagrasses, etc. Several environmental variables have been shown to influence the biodiversity of a given habitat. Mapping such habitat variables could indicate the likely spatial distribution of biodiversity at a local scale and suggest priority areas for conservation, at least for the species 
for which habitat-biodiversity relationships have been identified. Remote-sensing technologies have been used to map coral reefs since the early days of Landsat program [81], and research into the use of remote-sensing technology continues with the advent of new sensors and data-processing methods [82]. The mapping of coral reefs and general bottom characteristics from satellites has become more accurate since high-resolution multispectral imagery became available $[83,84]$. The development of hyperspectral instruments has also improved the degree to which accessory pigments can be used to separate detailed classes, and they have therefore enabled mapping of detailed classes while retaining satisfactory mapping accuracy $[85,86]$.

The work of Mumby et al. [85] reviews what can, might, and cannot be mapped using remote sensing, and not only covers aspects of reef structure and health but also discusses the diversity of physical environmental data such as temperature, winds, solar radiation, and water quality. Knudby et al. [87] reviewed coral reef biodiversity, the influence of habitat variables on its local spatial distribution, and the potential for remote sensing to produce maps of these habitat variables. Andréfouët et al. [88] present a review, where a new path is provided by following the diversity of units that have been mapped and characterized using high spatial resolution optical remote-sensing data for the main New Caledonian coral reef complexes and their individual reef-forming units. The combined examination of the different sources of data, and the exhaustive description of remotely sensed reef units, allows to a qualitative synoptic parallel to be drawn between the morphology of modern reefs and the contrasting patterns of reef growth, subsidence, and uplift rates occurring around New Caledonia. Hamel and Andréfouët [89] present a review about the use of very high resolution remote sensing for the management of coral reef fisheries. The rapid degradation of many reefs worldwide calls for more effective monitoring and predictions of the trajectories of coral reef habitats as they cross cycles of disturbance and recovery. Palandro et al. [90] used an 18-year (1984-2002) time series of Landsat 5/TM and 7/ETM+ images to assess changes in eight coral reef sites in the Florida Keys National Marine Sanctuary. A Mahalanobis distance classification was trained for four habitat classes. A detailed pixel-by-pixel examination of the spatial patterns across time suggests that the results range from ecologically plausible to unreliable due to spatial inconsistencies and/or improbable ecological successions.

Harmful Algal Blooms (HABs) phenomena are global and have been increasing in severity and extent, with many devastated implications. They cause eutrophic conditions, depleting oxygen levels needed for organic life, and limiting aquatic plant growth by reducing water transparency. HABs could be defined by an increase in the concentration of a phytoplankton species that has an adverse impact on the environment, with more serious implications when there is toxin production, but also with high biomass accumulation. HABs have been found to occur frequently in optically complex case-2 waters, such as in the Korean South Sea [91], East China Sea [92], Yellow Sea [91], Bohai Sea [93], Gulf of Mexico [94], among others. These blooms are dominated mostly by Cochlodinium polykrikoides (hereafter referred to as $C$. polykrikoides), Alexandrium tamarense, Prorocentrum dentatum, Ceratium furca, and Karenia brevis, causing massive mortalities of aquaculture fish and numerous ecological and health impacts since the last few decades. High concentrations of nutrients exported from agriculture 
or urban sprawl in coastal watersheds are also causing algal blooms in many estuaries and coastal waters [95]. Satellite detection and monitoring of HABs require methods/algorithms that have been developed mostly based on extensive in situ bio-optical observations from optically less complex oceanic waters and optical modeling of water properties. Remotesensing bio-optical algorithms explore the optical properties (absorption, backscattering, and reflectance) of each water component (CDOM, TSM, and Chla) in order to establish equations that can indicate a relationship between the optical characteristics of each component and the total sensor signals. These relationships are generally obtained through empirical, semianalytical, or radiation transfer models, and require in situ data in order to validate the equations/ models. However, this approach is only appropriate for case 1 waters. Several spectral band algorithms have been developed to overcome the limitation of the standard optical algorithms. One of the most common methods for identifying a HAB is to estimate the Chla concentration. More details about the use of remote-sensing techniques for detecting phytoplankton and mapping HABs could be found in Klemas [95]. A range of disciplines including biochemistry, physical oceanography, and geology can be brought together to improve the identification of HABs.

\subsection{Wetland mapping and coastal hazards/vulnerability}

The coastal zone represents a comparatively small but highly productive and extremely diverse system, with a variety of ecosystems. Remote sensing allows to quantitatively retrieving several parameters useful for produce multi-hazard and vulnerability maps [96], wetland mapping [97] and identify infestations of invasive plants [98]. Satellite remote sensors can map coastal ecosystems and their changes cost-effectively at appropriate scales and resolutions, minimizing the need for extensive field and ship measurements. Traditionally, the Landsat TM and ETM and SPOT data have been reliable data sources for wetlands mapping [99]. The current status of methodologies and the most innovative works will be described in the following. The final part of this section will also include a brief reference to beach monitoring/ classification, due to its importance in coastal management.

Wetland health is strongly impacted by runoff from land and its use within the same watershed. To study the impact of land runoff on estuarine and wetland ecosystems, a combination of models is frequently used, including watershed models, hydrodynamic models, and waterquality models [100]. The availability of high spatial and spectral resolution satellite data has significantly improved the capacity for mapping salt marshes and other coastal ecosystems [101]. Major plant species within a complex, heterogeneous tidal marsh have been classified using multitemporal, high-resolution images. Hyperspectral data have also been used for mapping coastal wetlands. The advantages and problems associated with hyperspectral mapping have been clearly demonstrated by Hirano et al. [102]. A number of techniques have been developed for mapping wetlands and even identifying wetland types and plant species $[99,103,104]$. To identify long-term trends and short-term variations, such as the impact of rising sea levels and hurricanes on wetlands, one needs to analyze time-series of remotely sensed imagery $[105,106]$. Submerged aquatic vegetation is an important part of wetland and coastal ecosystems, playing a major role in the ecological functions of these habitats. Alga 
bloom and coral reefs have been discussed in section 3.3. The classification of Land Use and Land Cover (LULC) in delta regions was also the subject of several works. For instance, Fan et al. [107] investigated LULC in the Pear River Delta (China) using Landsat TM and ETM+ images and employed ML classifier. El-Kawy et al. [108] applied a supervised classification (ML) to four Landsat images (TM and ETM+) collected between 1984 and 2009 that provided recent and historical LULC conditions for the western Nile delta. The LULC mapping accuracy of $96 \%$ indicates that the integration of visual interpretation with the supervised classification of remote-sensing imagery is an effective method for the identification of changes in LULC. More recently, Tran et al. [109] presented a study where the main objective was to assess the spatiotemporal dynamics of LULC changes in the lower Mekong Delta (Vietnam) over the last 40 years. LULC change dynamics are derived from Landsat and SPOT satellite imagery between 1973 and 2011.

Vulnerability can be defined as the degree to which a person, community, or a system is likely to experience harm due to exposure to an external stress. Vulnerability also encompasses the idea of response and coping, since it is determined by the potential of a community to react and withstand a disaster [110]. A Multi-Hazard Vulnerability Map (MHVM) incorporates vulnerability in understanding the risk due to a hazard. Mahendra et al. [96] present a study that aims developing a methodology for assessing the multi-hazard vulnerability and gather quantitative estimate on the spatial extent of the inundation caused by composite hazards in Tamil Nadu state in the Bay of Bengal (India). The parameters used in this study were: shoreline change rate, sea level change rate, historical storm surges, and the high-resolution topography. Data from Landsat MSS, TM, and ETM and QuickBird were used to extract some parameters and, afterward, generate the hazard and risk maps. Risk maps and evacuation routes are generated by imbibing land use, transport, and structural information. Scientific study of the natural hazards and coastal processes of the Indian coast has assumed greater significance after the December 2004 tsunami because the country learned lessons on the impact of natural hazards in terms of high damage potential for life, property, and the environment. Several works were published related to this topic. Römer et al. [111] presents a case study that focuses on a local assessment of tsunami hazard and vulnerability, including the socioeconomic and ecological components. High-resolution optical data (IKONOS-2) were employed to create basic geo-data including LULC, to provide input data for the hazard and vulnerability assessment. Results show that the main potential of applying remote-sensing techniques and data derives from a synergistic combination with other types of data. Kumar et al. [27] develop a coastal vulnerability index for the maritime state of Orissa (India), using eight relative risk variables. Ortho-rectified Landsat MSS and TM images covering the Orissa coastline (India) for the years 1970, 1980, and 2000 were used to digitize the shoreline. Indian Remote Sensing Satellite (IRS) P6 Linear Imaging Self-scanning Sensor-IV (LISS-IV) was used to extract the coastal geomorphology. Zones of vulnerability to coastal natural hazards of different magnitude are identified.

Beach morphological classification was mainly based on in situ data (wave, tidal, and sediment parameters). However, parameters such as those are usually unavailable for several coastal areas. Optical remote sensing is a very powerful tool for beach monitoring/classification, since it allows identification and classification of beach morphologies. Teodoro et al. [112] applied 
a pixel-based (supervised or unsupervised) and region-based (object-oriented classification) classification to high-resolution data (aerial photographs and IKONOS-2 image) in order to identify, measure, and classify beach features/patterns and further classify the beach extension considered (Northwest coast of Portugal). Thereafter, in order to implement an automatic beach patterns extraction methodology, Teodoro et al. [113] present a new approach based on Principal Components Analysis and Histogram segmentation (PCAH) aiming to identify and analyze morphological features and hydrodynamic patterns, also applied to aerial photographs and IKONOS-2 image. More recently, Teodoro [114] applied data-mining techniques, particularly ANN and Decision Trees (DT), to the same image in order to identify and classify beach features and their geographic patterns. Teodoro [114] concludes that the use of ANNs and DTs for beach classification from optical remotely sensed data resulted in an increased classification accuracy when compared with traditional classification methods, as shown in Fig. 4. The results of this work should be used as an input in beach classification models, in sediment budget estimation, and also in the identification/characterization of rip currents and bars (location, spacing, persistence, size, and strength).
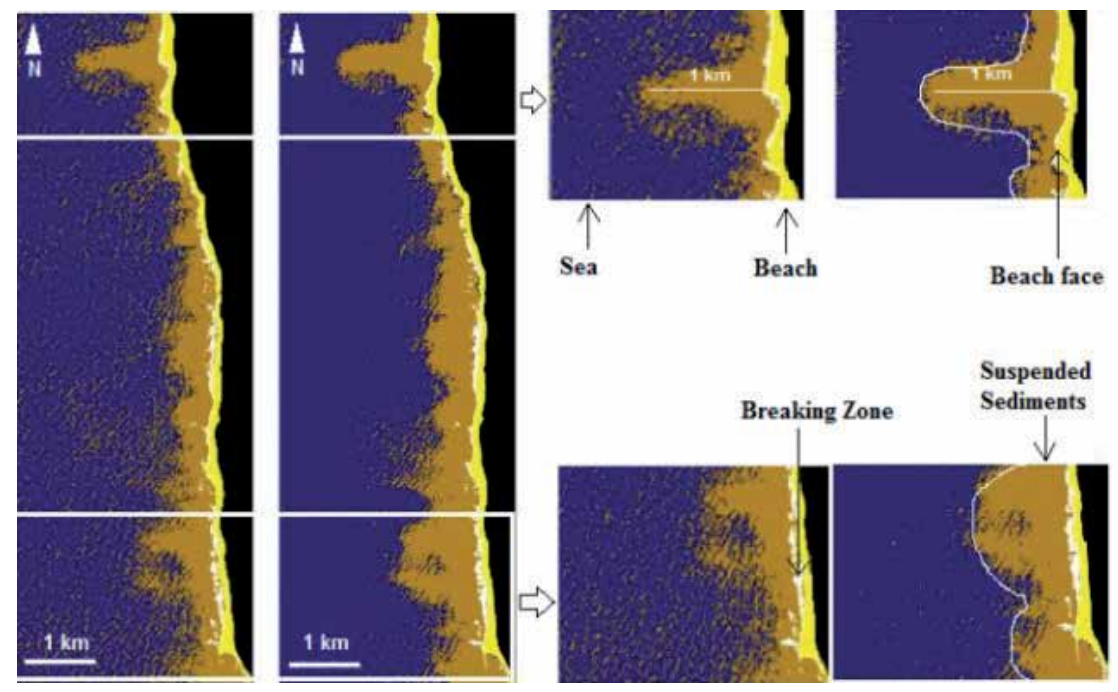

Figure 4. Beach patterns/forms identification and two zoomed areas obtained through (a) DT with pruning and (b) ANN (adapted from Teodoro [114])

Traditionally, the Landsat TM and ETM and SPOT satellite have been reliable data sources for wetlands mapping. However, in recent years the use of high spatial resolution data and hyperspectral data has become quite popular. In the vulnerability and hazards studies, different optical satellite data were commonly used to extract some parameters (e.g., shoreline change rate, land use) essential to hazard and risk maps generation. The use of high spatial resolution data is crucial. All these approaches are the key for a correct and efficient management of coastal environments. 


\subsection{Bathymetry}

Bathymetric information is of crucial importance in coastal areas, such as in estuarine areas, which often exhibit a high population density, and vulnerable natural ecosystems. Optical remote sensing offers a cost-effective alternative to echo sounding and bathymetric LiDAR techniques for deriving bathymetric estimates in shallow coastal and inland waters [115-117]. Images from optical remote sensors possess attractive properties for bathymetric mapping, including synoptic coverage of water surface areas, wide availability for most geographical regions, and relatively low cost [118]. The availability of optical high-resolution satellites, such as IKONOS, QuickBird, and WorldView, has renewed interest in applying optical remotesensing techniques to the retrieval of bathymetric information for shallow coastal and inland waters, due to their high spatial resolution and enhanced water penetration capability. In this context, several inversion algorithms and models have been proposed in the literature for retrieving bottom depth estimates from multispectral remote-sensing imagery [115, 116, 118-120]. The simplest method of retrieving water depth from single-band remote-sensing imagery was first proposed by Lyzenga [121]. Later, Lyzenga [122, 123] derived a log-linear inversion model for inverting multispectral imagery to water depth. This inversion model uses the linear logarithmic-transformed multispectral remote-sensing data as the predictors to estimate water depth.

Minghelli-Roman et al. [124] present a comparison of bathymetric estimation using different satellite images (Quickbird, ETM, Hyperion, MERIS) in coastal seawaters. The aim of this study was to compare, for one bathymetric estimation method and one mesotrophic site, the results of depth estimation with a large panel of satellite and aerial images. For each image, the pair of spectral bands chosen to compute the bathymetry has been optimized. This comparison was discussed, in order to identify the influence of image parameters (spectral bands, SNR, spatial resolution, and quantization) on the bathymetric results and to propose the most adapted image parameters for bathymetric estimation. Regarding the depth RMSE errors obtained, no sensor seems to be the perfect sensor to estimate bathymetry. Regarding the spectral configuration, three spectral bands are required to generate the mask on water: the first in the bluegreen domain; the second in the green domain; and a final band in the near-infrared domain. The atmospheric correction has to be efficient because a strong diffusion operates in the blue domain. A very high resolution such as Quickbird's is not necessary, but a lower resolution than $30 \mathrm{~m}$ induces mixed pixels on the shore and then degrades the estimation in shallow waters.

Teodoro et al. [125] propose a model for the estimation of depth based on Principal Component Analysis (PCA) of an IKONOS-2 image, for the Douro River estuary (Porto, Portugal). Subsequently, Teodoro et al. [117] proposed alternative univariate and bivariate models for the same IKONOS-2 image based on PCA and Independent Component Analysis (ICA). The PCA is the standard method for separating mixed signals. Such analysis provides signals that are linearly uncorrelated. Although the separated signals are uncorrelated they could still be depended, i.e., nonlinear correlation remains. The ICA was developed to investigate such data. The results obtained were compared with the bathymetric estimation through PCA. Best univariate ICA-based model allowed to estimate depth with a mean error that outperforming the best PCA based univariate model results, even with the first PCA component explains $80 \%$ of data variance. With bivariate models the results improved. 
Kanno et al. [116] proposed a method that combines a spatial interpolation method based on nonparametric regression and Lyzenga et al. [115] method on a statistical basis. A multispectral image of QuickBird of a coral reef site along Ishigaki City (Japan) was used in this approach. This method is based on a semiparametric regression model that consists of a parametric imagery-based term and a nonparametric spatial interpolation term that complement one another. An accuracy comparison in a test site showed that this new method is more accurate than either of the existing methods when sufficient training data are available and far more accurate than the spatial interpolation method when the training data are scarce.

Su et al. [118] propose a geographically adaptive inversion model for improving bathymetric retrieval in complex and heterogeneous marine environments for Hawaiian Islands. By using IKONOS-2 and Landsat ETM+ images, they demonstrated that regionally and locally calibrated inversion models can effectively address the problems introduced by spatial heterogeneity in water quality and bottom type, and provide significantly improved bathymetric estimates for more complex coastal waters.

More recently, Eugenio et al. [126] presented an optimal atmospheric correction model, as well as an improved algorithm for sunglint removal based on combined physical and imageprocessing techniques. The spectral capabilities of World View-2 multispectral imagery (for Granadilla in Tenerife Island and Corralejo in Fuerteventura Island) was exploited for bathymetry retrieval. Using the radiative model to compute bathymetry has yielded good results and allowed to improve the outcome of the ratio algorithm as it considers the physical phenomena of water absorption and backscattering and the relationship between the seafloor albedo, its depth, and the water IOPs. The accuracy of the proposed bathymetry retrieval algorithm output for each coastal area image was assessed with a scatter plot of the algorithm output versus acoustic field data.

In the recent years, several methods based in inversion algorithms and radiative models have been proposed in the literature for retrieving bottom depth from optical remote-sensing imagery. Other approaches have also been tested mainly based in statistical methods. The use of high-resolution optical images seems to improve the accuracy of depth estimation. However, several problems related to atmospheric conditions, SNR, and seafloor contributions are yet to be resolved. There is still a long way to go in using this type of data to estimate the depth for coastal environments through optical remote-sensing data.

\section{Conclusions}

Different optical satellite data and different methodologies could be used to monitor the coastal environment. There is not an ideal sensor, or an effective technique/algorithm that can be applied to all the coastal environments components/parameters. Depending on what parameter or element is being studied, the selected sensor should have the best characteristics (spatial, spectral, radiometric, and temporal resolution) for the objective proposed. The optimal spatial resolution for the assessment of coastal ecosystems is not consensual. Despite the high spatial resolution images that provide more detail, for several studies low or moderate spatial resolution is enough. Moreover, the low spatial coverage of the high spatial resolution images 
could be a limiting factor for regional or global studies. The recent developments of hyperspectral sensors that provide very high spectral resolutions introduce a new scenario in this field, allowing, for instance, the development of bio-optical algorithms, more adequate for coastal zones environments. The temporal resolution also depends on the objectives of the research. Various image-processing techniques have been applied to the satellite images in order to study the coastal environment. These techniques differ depending on the subject of study. In the shoreline change detection, beyond visual interpretation, several image segmentation and image classification algorithms are used to identify and detect the evolution of the coastline. Also, several types of algorithms are employed in the quantification of water constituents. A variety of parameters, including Chla, TSM, turbidity, and aCDOM, can be estimated. For instance, in the estimation of Chla, the $700 / 670 \mathrm{~nm}$ ratio reflectance (for highbiomass waters) has been widely used. Alternatively, more complex algorithms, such as ANN, can be employed. Many TSM models are based on empirical methods. However, other algorithms, such as ANN, can also be applied to retrieve the TSM concentration. The identification and monitoring of river plumes can be done considering the water constituents (TSM, salinity, Chla) or applying segmentation and classification algorithms that allow identification of the plume boundaries. The detection and monitoring of HABs require algorithms that have been developed mostly based on extensive in situ bio-optical observations from optically less complex oceanic waters and optical modeling of water properties. Remote-sensing bio-optical algorithms explore the optical properties of each water component. A number of techniques have also been developed for mapping wetlands hazards/vulnerability. When LULC is required, different image classification algorithms can be used. Other algorithms, such PCA, DT, and ANN, can also be used, for instance, in the identification of beach patterns. In the bathymetric estimation, beyond the inversion algorithms and radiative models widely applied, statistical algorithms, such as PCA and ICA can also be used to estimate the depth for estuarine areas. Several advances were discussed related to the recent availability of data from new sensors and hyperspectral data. In short, the assessment of the Sentinel-2 data will improve coastal environment monitoring programs. The elimination of the degree of uncertainty in some procedures should be a priority. There are available at present, a lot of robust, well-tested algorithms that allow quantification and accurate estimation of several parameters. The major challenge still is to have remote-sensing techniques adopted as a routine tool in assessment of change in the coastal zone. Continuing research is required into the techniques employed for assessing change in the coastal environment.

\section{Author details}

Ana C. Teodoro*

Address all correspondence to: amteodor@fc.up.pt

Earth Sciences Institute (ICT) and Department of Geosciences, Environment and Land Planning, Faculty of Sciences, University of Porto, Porto, Portugal 


\section{References}

[1] Cracknell AP: Remote sensing techniques in estuaries and coastal zones - an update. Int J Remote Sens. 1999;20(3):485-496.

[2] Malthus TJ, Mumby PJ: Remote sensing of the coastal zone: an overview and priorities for future research. Int J Remote Sens. 2003;24(13):2805-2815.

[3] Klemas V: Remote sensing of emergent and submerged wetlands: an overview. Int J Remote Sens. 2013;34(18):6286-6320.

[4] Kerekes JP. Optical sensor technology. In: The SAGE Handbook of Remote Sensing. Warner TA, Nelis MD, Foody GM, editors. SAGE Publications; 2009. pp. 95-107.

[5] Mouw CB, Greb S, Aurin D, DiGiacomo P, Lee Z, Twardowski M, Binding C, Hu C, Ma R, Moore T, Moses W, Craig S: Aquatic color radiometry remote sensing of coastal and inland waters: challenges and recommendations for future satellite missions. Remote Sens Environ. 2015;160:15-30.

[6] Gonçalves H, Teodoro AC, Almeida H: Identification, characterization and analysis of the Douro River Plume from MERIS data. IEEE J Select Topics Appl Earth Observ Remote Sens. 2012;5(5):1553-1563.

[7] Feng L, Hu C, Chen X, Tian L, Chen L: Human induced turbidity changes in Poyang Lake between 2000 and 2010: Observations from MODIS. J Geophys Res. 2012;117:C07006.

[8] Palmer SCJ, Kutser T, Hunter PD: Remote sensing of inland waters: Challenges, progress and future directions. Remote Sens Environ. 2015;157:1-8.

[9] Davranche A, Lefebvre G, Poulin B: Wetland monitoring using classification trees and SPOT-5 seasonal time series. Remote Sens Environ. 2010;114(3):552-562.

[10] Santillan J, Makinano M, Paringit E: Integrated Landsat image analysis and hydrologic modeling to detect impacts of 25-Year land-cover change on surface runoff in a Philippine watershed. Remote Sens. 2011;3(6):1067-1087.

[11] Hellweger FL, Schlosser P, Lall U, Weissel JK: Use of satellite imagery for water quality studies in New York Harbor. Estuar Coast Shelf Sci. 2004;61(3):437-448.

[12] Teodoro AC, Marçal ARS, Veloso-Gomes F: Correlation analysis of water wave reflectance and local TSM concentrations in the breaking zone, using remote sensing techniques. J Coast Res. 2007;23(6):1491-1497.

[13] Teodoro AC, Veloso-Gomes F, Goncalves H: Retrieving TSM concentration from multispectral satellite data by multiple regression and artificial neural networks. IEEE Trans Geosci Remote Sens. 2007;45(5):1342-1350. 
[14] Teodoro AC, Veloso-Gomes F: Quantification of the Total Suspended Matter concentration around the sea breaking zone from in situ measurements and TERRA/ASTER data. Mar Geores Geotechnol. 2007;25(2):67-80.

[15] Ouillon S, Douillet P, Petrenko A: Optical algorithms at satellite wavelengths for total suspended matter in tropical coastal waters. Sensors. 2008;8:4165-4185.

[16] Ruelland D, Dezetter A, Puech C, Ardoin-Bardin S: Long-term monitoring of land cover changes based on Landsat imagery to improve hydrological modelling in West Africa. Int J Remote Sens. 2008;29(12):3533-3551.

[17] Drusch M, Del Bello U, Carlier S, Colin O, Fernandez V, Gascon F, Hoersch B, Isola C, Laberinti P, Martimort P, Meygret A, Spoto F, Sy O, Marchese F, Bargellini P: Sentinel-2: ESA's optical high-resolution mission for GMES operational services. Remote Sens Environ. 2012;120:25-36.

[18] Vitousek PM, Mooney HA, Lubchenco J, Melillo JM: Human domination of earth's ecosystems. Science. 1997;277(5325):494-499.

[19] IPCC, 2007: Climate Change 2007: Impacts, Adaptation and Vulnerability. Contribution of Working Group II to the Fourth Assessment Report of the Intergovernmental Panel on Climate Change, M.L. Parry, O.F. Canziani, J.P. Palutikof, P.J. van der Linden and C.E.

[20] Hanson, Eds., Cambridge University Press, Cambridge, UK, 976pp.

[21] Dolan R, Fenster MS, Holme SJ: Temporal analysis of shoreline recession and accretion. J Coastal Res. 1991; 7:723-744.

[22] Boak EH, Turner IL: Shoreline definition and detection: a review. J Coastal Res. 2005; 21:688-703.

[23] Gens R: Remote sensing of coastlines: detection, extraction and monitoring. Int J Remote Sens. 2010;31(7): 1819-1836.

[24] Guariglia A, Buonamassa A, Losurdo A, Saladino R, Trivigno ML, Zaccagnino A, Colangelo A: A multisource approach for coastline mapping and identification of shoreline changes. Ann Geophys. 2006;49:295-304.

[25] Ekercin S: Coastline change assessment at the Aegean Sea Coasts in Turkey using multitemporal Landsat imagery. J Coastal Res. 2007;23(3):691-698.

[26] Maiti S, Bhattacharya AK: Shoreline change analysis and its application to prediction: A remote sensing and statistics based approach. Mar Geol. 2009; 257:11-23.

[27] Kuleli T, Guneroglu A, Karsli F, Dihkan M: Automatic detection of shoreline change on coastal Ramsar wetlands of Turkey. Ocean Engin. 2011;38:1141-1149.

[28] Kumar TS, Mahendra RS, Nayak S, Radhakrishnan K, Sahu KC: Coastal vulnerability assessment for Orissa State, East Coast of India. J Coastal Res. 2010;26(3):523-534. 
[29] Wang CY, Zhang J, Ma Y: Coastline interpretation from multispectral remote sensing images using an association rule algorithm. Int J Remote Sens. 2010;31(24):6409-6423.

[30] Teodoro AC, Gonçalves H: A semi-automatic approach for the extraction of sandy bodies (sand spits) from IKONOS-2 data. IEEE J Select Topics Appl Earth Observ Remote Sens. 2012;5(2):634-642.

[31] Pardo-Pascual JE, Almonacid-Caballer J, Ruiz LA, Palomar-Vázquez J: Automatic extraction of shorelines from Landsat TM and ETM+ multi-temporal images with subpixel precision. Remote Sens Environ. 2012;123:1-11.

[32] García-Rubio G., Huntley D, Russell P: Evaluating shoreline identification using optical satellite images. Mar Geol. 2015;359:96-105.

[33] Myint SW, Walker ND: Quantification of surface suspended sediments along a river dominated coast with NOAA AVHRR and SeaWiFS measurements: Louisiana, USA. Int J Remote Sens. 2002;23(16):3229-3249.

[34] Matthews MW: A current review of empirical procedures of remote sensing in inland and near-coastal transitional waters. Int J Remote Sens. 2011;32(21):6855-6899.

[35] Moses WJ, Gitelson AA, Berdnikov S, Povazhnyy V: Estimation of chlorophyll-a concentration in case II waters using MODIS and MERIS data - successes and challenges. Environ Res Lett. 2009;4:045005.

[36] Kiefer I, Odermatt D, Anneville O, Wuest A, Bouffard D: Application of remote sensing for the optimization of in-situ sampling for monitoring of phytoplankton abundance in a large lake. Sci Total Environ. 2015;527:493-506 2015.

[37] Gitelson AA, Gurli D, Moses WJ, Barrow, T: A bio-optical algorithm for the remote estimation of the chlorophyll-a concentration in case 2 waters. Environ Res Lett. 2009;4:045003.

[38] Le C, Li Y, Zha Y, Sun D, Huang C, Lu H: A four-band semi-analytical model for estimating chlorophyll a in highly turbid lakes: the case of Taihu Lake, China. Remote Sens Environ. 2009;113:1175-1182.

[39] Gitelson A, Mayo M, Yacobi YZ, Parparov A, Berman T: The use of highspectral- resolution radiometer data for detection of low chlorophyll concentrations in Lake Kinneret. J Plankton Res. 1994;16:993-1002.

[40] Ye HB, Chen CQ, Sun ZH, Tang SL, Song XY, Yang CY, Tian LQ, Liu, FF: Estimation of the primary productivity in Pearl River Estuary using MODIS data. Estuaries Coasts. 2015;38(2):506-518.

[41] Giardino C, Candiani G, Zilioli E: Detecting chlorophyll-a in Lake Garda using TOA MERIS radiances. Photogram Engin Remote Sens. 2005;71:1045-1051. 
[42] Duan HT, Zhang YZ, Zhan B, Song KS, Wang ZM: Assessment of chlorophyll-a concentration and trophic state for Lake Chagan using Landsat TM and field spectral data. Environ Monitor Assess. 2007;129(1-3):295-308.

[43] Su YF, et al: A multivariate model for coastal water quality mapping using satellite remote sensing images. Sensors. 2008;8(10):6321-6339.

[44] Ormeci C, Sertel E, Sarikaya O: Determination of chlorophyll-a amount in Golden Horn, Istanbul, Turkey using IKONOS and in situ data. Environ Monitor Assess. 2009;155(1-4):83-90.

[45] Wu M, Zhang W, Wang X, Luo D: Application of MODIS satellite data in monitoring water quality parameters of Chaohu Lake in China. Environ Monitor Assess. 2009;148:255-264.

[46] Tyler AN, Svab E, Preston T, Presing M, Kovacs WA: Remote sensing of the water quality of shallow lakes: A mixture modelling approach to quantifying phytoplankton in water characterized by high-suspended sediment. Int J Remote Sens. 2006;27(8): 1521-1537.

[47] Oyama Y, Matsushita B, Fukushima T, Matsushige K, Imai A: Application of spectral decomposition algorithm for mapping water quality in a turbid lake (Lake Kasumigaura, Japan) from Landsat TM data. ISPRS J Photogram Remote Sens. 2009;64:73-85.

[48] Doeffer R, Fischer J, Stössel M, Brockman C: Analysis of Thematic Mapper data for studying the suspended matter distribution in the coastal area of the German bight (North Sea). Remote Sens Environ. 1989;28:61-73.

[49] Nechad B, Ruddick KG, Park Y: Calibration and validation of a generic multisensor algorithm for mapping of total suspended matter in turbid waters. Remote Sens Environ. 2010;114:854-866.

[50] Kong, JL et al.: A semi-analytical model for remote sensing retrieval of suspended sediment concentration in the Gulf of Bohai, China. Remote Sens. 2015;7(5):5373-5397.

[51] Kutser T, Arst H, Mäekivi S, Kallaste, K: Estimation of the water quality of the Baltic Sea and lakes in Estonia and Finland by passive optical remote sensing measurements on board vessel. Lakes Reserv: Res Manag. 1998;3:53-66.

[52] Bowers D, Harker G, Smith P, Tett, P: Optical properties of a region of freshwater influence (the Clyde Sea). Estuarine Coastal Shelf Sci. 2000;50:717-726.

[53] Doxaran D, Cherukuru R, Lavender S: Use of reflectance band ratios to estimate suspended and dissolved matter concentrations in estuarine waters. Int JRemote Sens. 2005;26:1763-1770.

[54] D'sa EJ, Miller RL: Bio-optical properties in waters influenced by the Mississippi River during low flow conditions. Remote Sens Environ. 2003;84:538-549. 
[55] Koponen S, Attila J, Pulliainen J, Kallio K, Pyhälahti T, Lindfors A, Rasmus K, Hallikainen M: A case study of airborne and satellite remote sensing of a spring bloom event in the Gulf of Finland. Continental Shelf Res. 2007;27:228-244.

[56] Kutser T, Paavel B, Metsamaa L: Mapping coloured dissolved organic matter concentration in coastal waters. Int J Remote Sens. 2009;30:5843-5849.

[57] Loisel H, Vantrepotte V, Dessailly D, Meriaux X: Assessment of the colored dissolved organic matter in coastal waters from ocean color remote sensing. Optics Express. 2014;22(11):13109-13124.

[58] Kirk JTO: Optical water quality: What does it mean and how should we measure it? J Water Poll Contr Fed. 1988;60:194-197.

[59] Sun D, Li Y, Wang Q, Gao J, Lv H, Le C, Huang C: Light scattering properties and their relation to the biogeochemical composition of turbid productive waters: A case study of Lake Taihu. Appl Optics. 2009;48:1979-1989.

[60] Gitelson AA, Dall'Olmo G, Moses W, Rundquist DC, Barrow T, Fisher TR, Gurlin D, Holz J: A simple semi-analytical model for remote estimation of chlorophyll-a in turbid waters: Validation. Remote Sens Environ. 2008;112(9):3582-3593.

[61] Barnes BB, Hu C, Holekamp KL, Blonski S, Spiering BA, Palandro D, et al. Use of Landsat data to track historical water quality changes in Florida Keys marine environments. Remote Sens Environ. 2014;140: 485-496.

[62] Hommersom A, Wernand MR, Peters S, de Boer J: A review on substances and processes relevant for optical remote sensing of extremely turbid marine areas, with a focus on the Wadden Sea. Helgol Mar Res. 2010;64:75-92.

[63] Dekker AG, Vos RJ, Peters SWM: Comparison of remote sensing data, model results and in situ data for total suspended matter (TSM) in the southern Frisian lakes. Sci Total Environ. 2001;268:197-214.

[64] Kaufman, YJ: Solution of the equation of radiative-transfer for remote-sensing over nonuniform surface reflectivity. J Geophys Res - Oceans Atmos. 1982;87(NC6): 4137-4147.

[65] Vermote EF, et al.: Second simulation of the satellite signal in the solar spectrum, 6S: An overview. IEEE Trans Geosci Remote Sens. 1997;35(3):675-686.

[66] Defoin-Platel M, Chami M: How ambiguous is the inverse problem of ocean color in coastal waters? J Geophys Res. 2007;112:C03004.1-C03004.16.

[67] Mélin F, Vantrepotte V: How optically diverse is the coastal ocean? Remote Sens Environ. 2015;160:235-251.

[68] Mertes LAK, Warrick JA: Measuring flood output from 110 coastal watersheds in California with field measurements and SeaWiFS. Geology. 2001;29:659-662. 
[69] Otero P, Ruiz-Villarreal M, Peliz A: River plume fronts off NW Iberia from satellite observations and model data. ICES J Mar Sci: J du Conseil. 2009;66(9):1853-1864.

[70] Son YB, Gardner WD, Richardson MJ, Ishizaka J, Ryu JH, Kim SH, Lee SH:Tracing offshore low-salinity plumes in the Northeastern Gulf of Mexico during the summer season by use of multispectral remote-sensing. J Oceanography. 2012;68(5):743-760.

[71] Fernández-Nóvoa D, Mendes R, deCastro M, Dias JM, Sánchez-Arcilla A, GómezGesteira M: Analysis of the influence of river discharge and wind on the Ebro turbid plume using MODIS-Aqua and MODIS-Terra data. J Mar Sys. 2015;142:40-46.

[72] Teodoro AC, Gonçalves H, Veloso-Gomes F, Gonçalves JA: Modelling of the Douro river plume size, obtained through image segmentation of MERIS data. IEEE Geosci Remote Sens Lett. 2009;6(1):87-91.

[73] Jiang L, Yan XH, Klemas V: Remote sensing for the identification of coastal plumes: case studies of Delaware Bay. Int J Remote Sens. 2009;30(8):2033-2048.

[74] Guneroglu A, Karsli F, Dihkan M: Automatic detection of coastal plumes using Landsat TM/ETM plus images. Int J Remote Sens. 2013;34(13):4702-4714.

[75] Zhu WN, Yu Q: Inversion of chromophoric dissolved organic matter (CDOM) from EO-1 Hyperion imagery for turbid estuarine and coastal waters. IEEE Trans Geosci Remote Sens. 2013;51(6): 3286-3298.

[76] Lihan T, Saitoh S, Lida T, Hirawake T, Lida K: Satellite-measured temporal and spatial variability of the Tokachi River plume. Estuarine Coastal Shelf Sci. 2008;78:237-249.

[77] Dzwonkowski B, Yan X: Tracking of a Chesapeake Bay estuarine outflow plume with satellite-based ocean color data. Continental Shelf Res. 2005;25:1942-1958.

[78] Kim HC, et al.: Distribution of Changiiang diluted water detected by satellite chlorophyll-a and its inter-annual variation during 1998-2007. J Oceanography. 2009;65:129-135.

[79] Hopkins J, Lucas M, Dufau C, Sutton M, Stum J, Lauret O, Channelliere C: Detection and variability of the Congo River plume from satellite derived sea surface temperature, salinity, ocean colour and sea level. Remote Sens Environ. 2015;139:365-385.

[80] Yonge CM. The Biology of Reef Building Corals. London: British Museum, 1940. 353 p.

[81] Smith VE, Rogers RH, Reed LE: Automated mapping and inventory of Great Barrier Reef zonation with Landsat. Oceans. 1975;7:775-780.

[82] Kutser T, Miller I, Jupp D: Mapping coral reef benthic substrates using hyperspectral space-borne images and spectral libraries. Estuarine Coastal Shelf Sci. 2006;70:449-460.

[83] Purkis SJ: A “Reef-Up" approach to classifying coral habitats from IKONOS imagery. IEEE Trans Geosci Remote Sens. 2005;43:1375-1390. 
[84] Mishra D, Narumalani S, Rundquist D, Lawson M: Benthic habitat mapping in tropical marine environments using QuickBird multispectral data. Photogram Engin Remote Sens. 2006;72:1037-1048.

[85] Mumby PJ, Skirving W, Strong AE, Hardy JT, LeDrew EF, Hochberg EJ, Stumpf RP, David LT: Remote sensing of coral reefs and their physical environment. Mar Poll Bull. 2004;48(3-4):219-228.

[86] Kutser T, Dekker AG, Skirving W: Modeling spectral discrimination of Great Barrier Reef benthic communities by remote sensing instruments. Limnol Oceanography. 2003;48:497-510.

[87] Knudby A, LeDrew E, Newman C: Progress in the use of remote sensing for coral reef biodiversity studies. Progr Phys Geography. 2007;31(4):421-434.

[88] Andréfouët S, Cabioch G, Flamand B, Pelletier B: A reappraisal of the diversity of geomorphological and genetic processes of New Caledonian coral reefs: a synthesis from optical remote sensing, coring and acoustic multibeam observations. Coral Reefs. 2009;28(3):691-707.

[89] Hamel MA, Andréfouët S: Using very high resolution remote sensing for the management of coral reef fisheries: Review and perspectives. Mar Poll Bull. 2010;60(9): 1397-1405.

[90] Palandro DA, Andrefouet S, Hu C, Hallock P, Muller-Karger FE, Dustan P, Callahan MK, Kranenburg C, Beaver CR: Quantification of two decades of shallow-water coral reef habitat decline in the Florida Keys National Marine Sanctuary using Landsat data (1984-2002). Remote Sens Environ. 2008;112(8):3388-3399.

[91] Ahn YH, Shanmugam P, Ryu JH, Jeong JC: Satellite detection of harmful algal bloom occurrences in Korean waters. Harmful Algae News. 2006; 213-131.

[92] Gao X, Song J: Phytoplankton distributions and their relationship with the environment in the Changjiang Estuary, China. Mar Poll Bull. 2005;50:327-335.

[93] Tang DL, Kawamura H, Oh IS, Baker J: Satellite evidence of harmful algal blooms and related oceanographic features in the Bohai Sea during autumn 1998. Adv Space Res. 2006;37:681-689.

[94] Tomlinson M., Wynne TT, Stumpf RP: An evaluation of remote sensing techniques for enhanced detection of the toxic dinoflagellate, Karenia brevis. Remote Sens Environ. 2009;113:598-609.

[95] Klemas V: Remote sensing of algal blooms: An overview with case studies. J Coastal Res. 2012;28(1A):34-43.

[96] Mahendra RS, Mohanty PC, Bisoyi H, Srinivas T, Kumar, Nayak, S: Assessment and management of coastal multi-hazard vulnerability along the Cuddalore Villupuram, east coast of India using geospatial techniques. Ocean Coastal Manag. 2011;54: 302-311. 
[97] Gilmore MS, Wilson EH, Barrett N, Civco DL, Prisloe S, Hurd JD, Chadwick C: Integrating multitemporal spectral and structural information to map wetland vegetation in a Lower Connecticut River Tidal Marsh. Remote Sens Environ. 2008;112:4048-4060.

[98] Cavalli RM, Laneve L, Fusilli S, Pignatti F, Santini: Remote sensing water observation for supporting Lake Victoria weed management. J Environ Manag. 2009;90(7): 2199-2211.

[99] Klemas V: Remote sensing of wetlands: Case studies comparing practical techniques. J Coastal Res. 2011;27: 418-427.

[100] Li M, L Zhong WC, Boicourt S, Zhang, Zhang D: Hurricane-induced stratification and destratification in a partially-mixed estuary. J Mar Res. 2007;65:169-192.

[101] Laba M, Downs R, Smith S, Welsh S, Neider C, White S, Richmond M, Philpot W, Baveye P: Mapping invasive wetland plants in the Hudson River National Estuarine Research Reserve using Quickbird satellite imagery. Remote Sens Environ. 2008;112: 286-300.

[102] Hirano A, Madden M, Welch R: Hyperspectral image data for mapping wetland vegetation. Wetlands. 2003;23:436-448.

[103] Yang X. Remote Sensing and Geospatial Technologies for Coastal Ecosystem Assessment and Management. Berlin: Springer-Verlag; 2009.

[104] Heumann BW: Satellite remote sensing of mangrove forests: Recent advances and future opportunities. Progr Phys Geography. 2011;35:87-108.

[105] Baker C, Lawrence RL, Montagne C, Patten D: Change detection of wetland ecosystems using Landsat imagery and change vector analysis. Wetlands. 2007;27:610-619.

[106] Ramsey E, Rangoonwala A. Mapping the onset and progression of marsh dieback. In: Remote Sensing of Coastal Environment, J. Wang, editor. Boca Raton, FL: CRC Press; 2010. pp. 123-150.

[107] Fan F, Wang Y, Wang Z: Temporal and spatial change detecting (1998-2003) and predicting of land use and land cover in Core corridor of Pearl River Delta (China) by using TM and ETM+ images. Environ Monitoring Assess. 2008;137:127-147.

[108] Abd El-Kawy OR, Rød JK, Ismail HA, Suliman AS: Land use and land cover change detection in the western Nile delta of Egypt using remote sensing data. Appl Geography. 2011;31:483-494.

[109] Tran H, Tran T, Kervyn M: Dynamics of land cover/land use changes in the Mekong Delta, 1973-2011: A remote sensing analysis of the Tran Van Thoi District, Ca Mau Province, Vietnam. Remote Sens. 2015;7:2899-2925.

[110] Kumpulainen S. Vulnerability concepts in hazard and risk assessment. Natural and technological hazards and risks affecting the spatial development of European re- 
gions. In: Schmidt-Thomé, Philipp, editors. Geological Survey of Finland, Special Paper 42: 2006. pp. 65-74.

[111] Römer H, Willroth P, Kaiser G, Vafeidis AT, Ludwig R, Sterr H, Revilla Diez J: Potential of remote sensing techniques for tsunami hazard and vulnerability analysis - a case study from Phang-Nga province, Thailand. Natur Haz Earth Sys Sci. 2012;12:2103-2126.

[112] Teodoro AC, Pais-Barbosa J, Veloso-Gomes F, Taveira-Pinto F: Evaluation of beach hydromorphological behaviour and classification using image classification techniques. J Coastal Res. 2009;2(56):1607-1611.

[113] Teodoro AC, Pais-Barbosa J, Gonçalves H, Veloso-Gomes F, Taveira-Pinto F: Identification of beach features/patterns through image classification techniques applied to remotely sensed data. Int J Remote Sens. 2011;32(22):7399-7422.

[114] Teodoro AC: Applicability of data mining algorithms in the identification of beach features/patterns on high-resolution satellite data. J Appl Remote Sens. 2015;9(1): 095095.

[115] Lyzenga DR, Malinas N P, Tanis F J: Multispectral bathymetry using a simple physically based algorithm. IEEE Trans Geosci Remote Sens. 2006;44(8):2251-2259.

[116] Kanno A, Koibuchi Y, Isobe M: Statistical combination of spatial interpolation and multispectral remote sensing for shallow water bathymetry. IEEE Geosci Remote Sens Lett. 2011;8(1)64-67.

[117] Teodoro AC, Almeida R, Gonçalves M: Independent Component Analysis (ICA) performance to bathymetric estimation using high resolution satellite data in an estuarine environment, in Remote Sensing for Agriculture, Ecosystems, and Hydrology XVI, Christopher M. U. Neale; Antonino Maltese, Editors, Proceedings of SPIE Vol. 9239 (SPIE, Bellingham, WA 2014), 923915.

[118] Su H, Liu H, Wang L, Filippi AM, Heyman WD, Beck RA: Geographically adaptive inversion model for improving bathymetric retrieval from satellite multispectral imagery. IEEE Trans Geosci Remote Sens. 2014;52(1): 465-476.

[119] Lesser MP, Mobley CD: Bathymetry, water optical properties, and benthic classification of coral reefs using hyperspectral remote sensing imagery. Coral Reefs. 2007;26(4):819-829.

[120] Su H, Liu H, Heyman W: Automated derivation of bathymetric information from multispectral satellite imagery using a nonlinear inversion model. Mar Geodesy. 2008;31(4):281-298.

[121] Lyzenga DR: Passive remote sensing techniques for mapping water depth and bottom features. Appl Optics. 1978;17:379-383. 
[122] Lyzenga DR: Remote sensing of bottom reflectance and water attenuation parameters in shallow water using aircraft and Landsat data. Int J Remote Sens. 1981;2(1): 71-82.

[123] Lyzenga DR: Shallow-water bathymetry using combined lidar and passive multispectral scanner data. Int J Remote Sens. 1985;6(1):115-125.

[124] Minghelli-Roman A, Goreac A, Mathieu, S, Spigai M, Gouton P: Comparison of bathymetric estimation using different satellite images in coastal sea waters. Int J Remote Sens. 2009;30(21):5737-5750.

[125] Teodoro AC, Gonçalves H, Pais-Barbosa J: Bathymetric estimation through principal components analysis using IKONOS-2 data, in Remote Sensing for Agriculture, Ecosystems, and Hydrology XII, Christopher M. U. Neale; Antonino Maltese, Editors, Proceedings of SPIE Vol. 7824 (SPIE, Bellingham, WA 2010), 782419.

[126] Eugenio F, Marcello J, Javier Martin J: High-resolution maps of bathymetry and benthic habitats in shallow-water environments using multispectral remote sensing imagery. IEEE Trans Geosci Remote Sens. 2015;53(7):3539-3549. 
Chapter 7

\title{
Remote Sensing of the Ocean Environment Using Finite Element Methods
}

\author{
Saba Mudaliar, C.P. Vendhan and C. Prabavathi \\ Additional information is available at the end of the chapter \\ http://dx.doi.org/10.5772/62193
}

\begin{abstract}
Oceans are a vast, complex world where underwater sound is the most efficient tool available to understand its detailed characteristics. However the underwater channel has a very complex geometrical and material structure and hence special techniques are required to model it. Analytical solutions are feasible only when one makes gross assumptions and approximations. Several numerical and semi-numerical techniques have been developed for estimating the sound field in the ocean channel. But no single method is capable of handling all possible environmental conditions, frequency, and ranges of interest in remote sensing problems. We explore in this chapter the scope and feasibility of finite element method in underwater remote sensing. The current study is based on a channel model with cylindrical symmetry and a time-harmonic source signal. A variational formulation is used to derive the finite element model for acoustical radiation, scattering and propagation in the ocean. A Bayliss-type radiation boundary condition is used to model the far field behaviour without the need to deal with a large solution domain. Since the ocean geometry can support several propagating, evanescent, and radiation modes, a penalty function approach is employed to impose the far field radiation condition. A distinct feature of the ocean channel is its depth-dependent sound speed. The eigensolution for this channel is required for imposing the radiation condition at the truncation boundary. We have cast this eigenproblem in a variational form and employed a Rayleigh-Ritz method to obtain an approximate eigensolution. This approach has provided a good approximation of the depth eigenmodes in a compact semi-analytic form. We have employed our finite element algorithm to model several range- and depth-dependent ocean problems. Our numerical study has established that our finite element algorithm gives accurate results with reasonable effort. In particular, our finite element approach is most appropriate for shallow water problems where the interaction of wave modes with irregular ocean bottom is quite complex. The penalty function approach employed to implement the radiation boundary condition has been found to be robust over a wide range of penalty scale factors. We have also extended this work for the case of irregular elastic sea bed. We continue to explore and further develop our finite element approach by applying it
\end{abstract}


to several other ocean acoustic problems encountered in the remote sensing of ocean environment.

Keywords: Wave propagation, scattering, ocean wave guide, irregular boundaries

\section{Introduction}

Oceans are a vast, complex, mostly dark, optically opaque but acoustically transparent world which is only thinly sampled by today's limited science and technology. Underwater sound ${ }^{1}$ is used as the premier tool to determine the detailed characteristics of physical and biological bodies and processes in the ocean. The distributions within the sea of the physical variables affect the transmission of sound. The wide range of acoustic frequencies and wavelengths, together with the diverse oceanographic phenomena that occur over full spectra of space and time scales, thus give rise to a number of interesting effects and opportunities. Because of its great practical importance, especially to naval submarine operations, ocean-acoustics research [1-5] has been driven by applications more than other branches of ocean science.

Acoustic remote sensing in a generic sense refers to sending out acoustic signals and recording the scattered waves, which is hence processed to ascertain the nature of target/obstruction that was encountered by the transmitted signal. This remote sensing in general involves transmission, processing of received signals and some form of inversion. This chapter is exclusively dedicated to accurate modeling of propagation and scattering of acoustic signals in the ocean channel.

The amplitude and phase of sound field generated by an acoustic source in the ocean can be deduced, in principle, by solving either the wave equation or the Helmholtz equation in the case of a harmonic acoustic source [1]. However, this procedure is generally difficult to implement due to the complexity of the ocean-acoustic environment: the sound-speed profile is usually non-uniform in depth and/or range, giving rise to waveguide focusing and shadowing effects; the sea surface is rough and time-dependent; the ocean floor is typically a very complex, rough boundary which may be inclined to the horizontal; and the bottom may be an elastic medium, capable of supporting shear waves along the ocean-bottom boundary. To compound the problem, various ocean processes, including internal waves and small-scale turbulence, introduce small fluctuations in the sound speed, which are responsible for significant acoustic fluctuations over long transmission paths.

Analytical solutions of the governing differential equations in underwater acoustics are not always feasible and can only be obtained if the sound speed of the water column and physical boundaries can be described in simple mathematical terms. This is rarely the case in reality and so it is generally necessary to employ approximate models. A variety of numerical

1 There exists a vast body of literature in remote sensing of ocean using electromagnetic and optical sensors from satellites. Although such methods have definite advantages in several aspects, they have serious limitations for sensing deep underwater channels. 
techniques have been developed for estimating sound fields in the ocean, but no single method is capable of handling all possible environmental conditions, frequencies, and transmission ranges of interest in the applications. Even the existing ocean-acoustic propagation models [6-7] with restricted scope often take several hours to run on a supercomputer.

Several different approaches for the solution of the sound field in the ocean have evolved over the past few decades: ray tracing [8], normal-mode techniques [9] and coupled-mode models [10], the parabolic-equation approximation [11] and fast field programs (FFP) [12]. In this chapter, we will discuss in detail the scope of the finite element method [13-15] in ocean remote sensing applications. In order to motivate our finite element approach and put it in proper context, we briefly summarize the analytical and computational tools that are currently in use in the ocean remote sensing literature especially to point out their main merits and shortcomings.

\section{Background}

Ray-based methods [8-9] involve following the paths of a set of rays as they leave the source and tracking them as they propagate through the medium. They can be used for rangedependent and range-independent problems, but are most commonly used for rangeindependent problems. They are most useful for short-range, high-frequency modeling. Straightforward ray theory suffers from following drawbacks: (i) Need to deal with situations involving caustics and singularities. (ii) At each incidence on surface or bottom, each ray has to be "told" at what angle to go off, and with what percentage of total reflection. (iii) Since problems are almost entirely numerical, each variation is nearly as hard as the first try, e.g., a new source depth or a greater range. The main shortcoming of the ray method is the inherent high-frequency approximation.

A class of propagation models exist which gives the full-wave solution for the field in a horizontally stratified medium. This type of a model is known as "fast field program". This technique is basically a numerical implementation of the integral transform technique for horizontally stratified media $[12,9]$. The field solution is in the form of a wavenumber integral which is evaluated by numerical quadrature. This approach is distinguished by its use of the fast Fourier transform (FFT) to calculate the integral. FFPs determine the field which satisfies the Helmholtz equation or similar equations which include shear wave effects. The Helmholtz equation for the stratified medium is a partial differential equation in two independent variables, range and depth, and hence in principle could be solved by the application of two integral transforms [12]. For certain specific sound-speed profiles having a particular analytical form, this can be achieved, yielding an exact solution for the field. For a general sound-speed profile, however, the transform over depth is intractable and an alternative technique must be sought. Nevertheless, a transform over range can be applied, and this is the starting point of the FFP argument [16]. In contrast to the ray solution, the FFP model yields a result which is essentially exact. Starting from the Helmholtz equation for a stratified medium, the only additional approximation is that of using the asymptotic approximation to the Bessel function. 
This approximation turns out to include negligible errors beyond a wavelength or so from the source.

As an alternative to "exact" numerical propagation models, with their heavy computational overhead, a number of methods have been developed whose starting point is a parabolic equation [11]. Such an equation which is an approximation for the elliptic Helmholtz equation is valid over a small range of angles, usually, but not necessarily, extending about the horizontal. Given their inherently approximate nature, the parabolic-equation (PE) models are distinguished by a lack of precision, the extent of which depends by and large on the problem under consideration. They have acquired popularity amongst the ocean-acoustics community because they give the field over the entire water column with no additional effort and they can handle range-dependent environments. PE methods are often said to be valid within a cone of angles extending $+/-20^{\circ}$ (narrow angle) and $+/-40^{\circ}$ (wide angle) about the horizontal. One of the shortcomings of the PE models is that, when these angles are exceeded, the output continues to look reasonable, showing no obvious indication of error [7]. Apart from the excessive inaccuracy of these results, the lack of consistency among the PE codes highlights the general difficulty of assessing their performance in any given environment. Although the PE is relatively easy to implement, there is a price to be paid: a) it is valid over only a limited range of angles, a consequence of the paraxial approximation, and b) it is a one-way solution, capable of handling only outgoing waves, since incoming radiation, represented by a Hankel function of the second kind of zero order, is neglected in the solution. Little can be done to remedy the backscatter limitation, but considerable effort has gone into extending the angular range of the forward-scatter regime [17]. The advantage of the parabolic equation over the original Helmholtz equation is that the PE can be solved by a straightforward marching in range which requires much less computational effort. From a numerical point of view, this range marching is typically implemented using either standard finite difference techniques or using a fast Fourier transform as in the so-called split-step method. There are other approaches to solve the parabolic wave equation in ocean waveguides. Lee et al. [18] employed the finite difference method whereas Huang [19] used a finite element method to solve the PE.

The sound field in a horizontally stratified ocean can be expressed as an infinite sum of uncoupled normal modes plus one or more branch line integrals [9, 1]. At large ranges from sources, the branch line integral component is negligible and the field is given accurately by the normal-mode sum, but in the vicinity of the source, within the cycle distance of each mode, the integrals are significant and should be taken into account. If the environment shows some range dependence, through either the sound-speed profile or the boundary conditions, the field is no longer separable and strictly (uncoupled) normal-mode theory does not apply. However, provided the range dependence is sufficiently slow, the adiabatic approximation is valid, i.e. there is essentially no transfer of energy between modes as they propagate the channel. If the range dependence is too fast for the adiabatic approximation to hold, mode coupling is significant, which requires the calculation of the coupling coefficients - a time consuming procedure. The normal-mode method is typically accurate for ranges greater than the first 10 water depths or so, a figure which depends on the number of modes that are included in the solution. In the near field, more modes should be computed to closely predict 
the fields accurately. The normal-mode models tend to be thought of as providing solutions to range-independent problems. Range-dependent solutions can be obtained using (a) adiabatic mode theory or (b) coupled-mode theory. The later approach involves more computational cost but can provide more accurate results.

When the range dependence is too strong for mode coupling to be neglected, a different approach than the usual normal-mode theory is required. A complete two-way (i.e. including backscattering) solution to this problem has been formulated in terms of stepwise coupled normal modes [10]. The medium is sub-divided into a large number of thin vertical segments, in each of which the acoustic parameters are held constant in the range direction but are allowed to vary in depth. Across the segment boundaries, the pressure and horizontal particle velocity are required to be continuous. In this method, the field is expressed as a sum of local modes representing both outgoing and incoming cylindrical waves. Again, the modal eigenvalue problem has to be solved, and in this case, the Galerkin method is used, whereby the solution is expanded in a set of basis modes, yielding a tractable eigenvalue matrix problem [20]. This involves rather, complex coupling integrals which have to be evaluated for all modes at all segment boundaries. This method is computationally demanding, but it is essentially exact and forms the basis of the model [10, 21-22]. When the coupling effects are neglected, the full coupled-mode expressions reduce to the adiabatic approximation.

Ray tracing, normal-mode techniques, and coupled-mode models are accurate but computationally intensive; the parabolic equation is an approximation to the wave equation that has been solved using explicit and implicit finite difference schemes; Green's function solutions (fast field programs) are essentially models for which exact solutions are available that cannot account for sound-speed variation. If the variation of sound-speed profile is independent of range, the ocean is said to be horizontally stratified. Several of the numerical ocean-acoustic propagation models assume horizontal stratification. The advantage, from the point of view of the computation, is that the solution field separates into range and depth components, which simplifies the calculation of the field considerably. The speed of sound in the ocean shows only small departures from $1500 \mathrm{~m} / \mathrm{s}$, but nevertheless its effect on sound propagation on the ocean is profound. In the deep ocean, for example, the profile acts as an acoustic waveguide, supporting propagation to long ranges with little attenuation. However, for a general ocean environment, which has a range-dependent sound-speed profile, an ocean bed having irregular geometry, and turbulence in the water column, none of the existing methods described above work satisfactorily.

\section{Finite element method}

For general ocean environments, the finite element method (FEM) [13-15] is a good choice for the numerical modeling of ocean-acoustic wave propagation because it is exact within the limits of numerical accuracy and can accurately account for all the scattering processes. Although the literature on finite element technique on wave scattering and propagation is extensive, the number of available FEM models for ocean remote sensing is fairly small [23-24]. 
Part of the reason for this is the large computational cost involved. However, we feel that for shallow-water applications, the FEM is both feasible and appropriate. The very nature of the waves to radiate into the far field when unbounded requires the domain to be truncated with an artificial boundary, on which an approximate radiation boundary condition should be imposed [25-29]. In the present work, a variational approach is used to derive the finite element approximation for time-harmonic acoustic wave propagation in an axisymmetric, heterogeneous oceanic waveguide, and a BGT-type boundary damper [26] is used to model the effect of the far field. Since a waveguide in general supports multiple propagating/radiation modes in the far field, a penalty function approach has been employed to impose the modal radiation boundary condition in conjunction with the orthogonality property of the depth modes of the waveguide.

In our finite element model for depth- and range-dependent waveguides, the eigensolution of the depth problem is required for the imposition of the radiation condition at the truncation boundary. Unfortunately, the depth eigenproblem could be solved exactly only for a few special profiles. In view of this, several numerical methods have been developed to solve the depth problem [1]. Porter and Reiss [30] employ a finite difference model for the depth equation, and the resulting algebraic eigenproblem has been solved using a combination of iterative techniques and Richardson extrapolation to obtain the radial wavenumbers and modal vectors to a great degree of precision. For our finite element model [31-32], it would be convenient to have the depth modes in a compact analytical form. We have accomplished this by adopting the following procedure: The depth eigenproblem is cast in a variational form by suitably defining a functional. The classical Rayleigh-Ritz (RR) method is employed to find a variational approximation to the eigensolution of the depth problem in ocean-acoustic waveguides. The depth modes thus obtained have a compact semi-analytical form in contrast to methods using finite difference or other finite element methods. An interesting feature of the model is that the trial functions are derived from an isovelocity problem that has an exact solution. It is important to note that such trial functions automatically satisfy even the dynamic interface condition at the seabed, thus contributing to the accuracy of the numerical model. Our procedure has been tested for several different ocean profiles and the results compare well against those obtained using the method of Porter and Reis [33]. The proposed model thus provides an accurate representation of the depth eigenmodes in a compact semi-analytical form.

We have chosen several isovelocity waveguide examples, for which analytical solutions are available, to validate the FE model developed and ascertain its versatility to impose modal radiation boundary condition. We have confirmed the efficacy of the FE model by applying it to several examples of depth- and range-dependent waveguides. This numerical study establishes that our FE model gives accurate results with reasonable computational effort. The penalty function approach employed to implement the radiation boundary condition has been found to be robust over a wide range of penalty scale factors. We have also extended this work for the case of irregular elastic seabed. We continue to explore and further develop our FE model by applying it to several other ocean-acoustic problems encountered in the remote sensing of ocean environment. 


\section{Governing equations and boundary conditions}

The fluid domain $\Omega=\Omega_{I}+\Omega_{O}$ (Fig. 1) of the waveguide problem consists of the inner domain $\Omega_{I}$ truncated by the artificial radiation boundary $S_{R}$, and the outer domain $\Omega_{O}$ (far-field domain). The waveguide is assumed to be axially symmetric about the vertical axis containing a source at depth $z_{s}$, with $r$ denoting the radial coordinate or the range. It is bounded at the top by the $z=0$ plane, which is the air-sea interface $\left(S_{F}\right)$, and at the bottom by a seabed of arbitrary topography $\left(S_{B}\right)$. The waveguide is assumed to have unbounded range. For timeharmonic linear acoustic waves with the pressure field denoted as $\hat{p}(r, z, t)=p(r, z) e^{-i \omega t}$, $\omega$ being the circular frequency of the source, the governing equation is given by

$$
\rho \nabla\left(\frac{1}{\rho} \nabla p\right)+k^{2} p=-\frac{1}{2 \pi r} f_{o} \delta(r) \delta\left(z-z_{s}\right)
$$

where $\nabla$ is the gradient operator, $\rho$ the density of the acoustic fluid, $k$ the acoustic wavenumber, $c$ the local speed of sound, and $f_{o}$ defines the point source at $r=0$ and $z=z_{s}$.

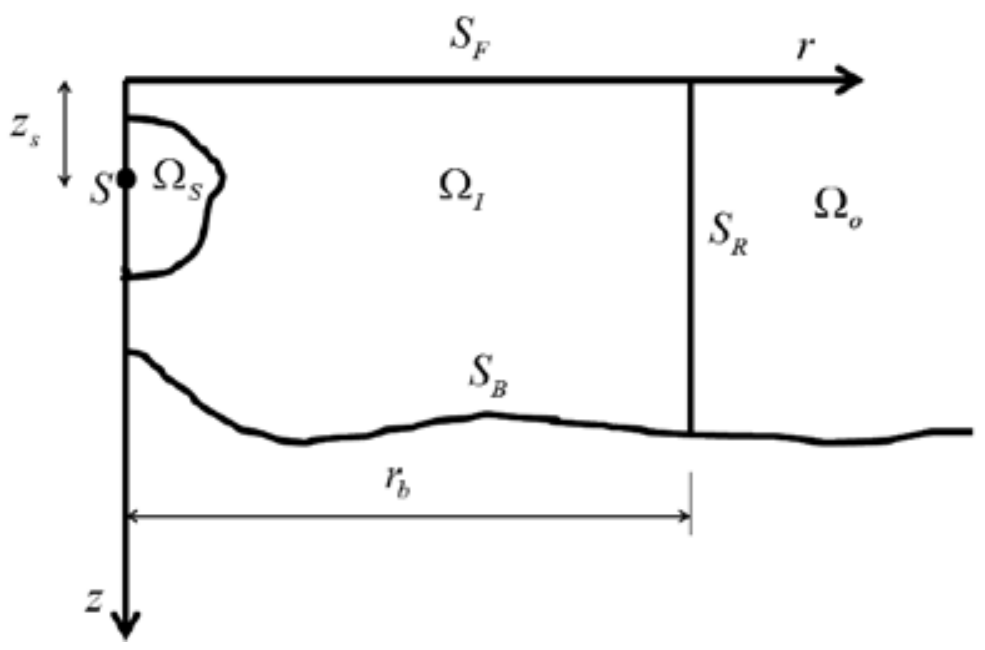

Figure 1. Geometry of the ocean waveguide

Considering the large impedance mismatch between air and water, a pressure release boundary condition may be used at the free surface. Thus,

$$
p=0 \quad \text { on } S_{F}
$$

As the waves encounter the seabed, there is partial reflection and the remaining energy is transmitted into the seabed. A part of the transmitted waves may be coupled back into the 
water column because of refraction through the sediment layers. However, for now, a rigid bottom is assumed, for which the normal derivative of the pressure should vanish at the bottom boundary. In other words,

$$
\frac{\partial p}{\partial n}=0 \quad \text { on } S_{B}
$$

where $S_{\mathrm{B}}$ denotes the sea bottom.

For the purpose of FE modeling, the waveguide, which is unbounded in range, is truncated at $r=r_{b}$, and the truncation boundary is treated as the radiation boundary $S_{R}$, on which a suitable approximate radiation condition should be imposed. Here, the boundary damper approach [26] has been adopted. The first-order cylindrical damper equation may be written as

$$
\frac{\partial p_{m}}{\partial n}+\alpha p_{m}=0, \quad m=1,2, \cdots, M \text { on } S_{R^{\prime}}
$$

where $M$ denotes the number of propagating modes, and the damper coefficient $\alpha_{m}$ associated with the $m$-th mode is given by

$$
\alpha_{m}=\frac{1}{2 r}-i k_{r m}
$$

where $k_{r m}$ denotes a horizontal wavenumber. It may be noted that Eq. (5) is exact for the asymptotic form of a cylindrically symmetric wave. On the truncation boundary $S_{R}$, acoustic pressure may be expressed as a sum of normal pressure modes as

$$
p(z)=\sum_{m=1}^{M} p_{m}(z)
$$

where $p(z), m=1,2, \ldots$, are the normal modes of propagation for the problem in Eq. (1). Following Fix and Marin [31], the radiation boundary condition for the waveguide problem may be written, using Eqs. (4) and (6), as

$$
\frac{\partial p}{\partial r}+\sum_{m=1}^{M} \alpha_{m} p_{m} \quad \text { on } S_{R}
$$

Denoting a normal-mode function at the radiation boundary by $f_{m}(z)$, which is associated with the $m$-th propagating mode eigenvalue, the pressure modes in Eq. (6) may be written as

$$
p_{m}(z)=a_{m} f_{m}(z), \quad m=1,2, \cdots, M
$$


where $a_{m}$ denotes a modal participation factor. Then the radiation boundary condition in Eq. (7) may be rewritten as

$$
p(z)+\sum_{m=1}^{M} a_{m} \alpha_{m} f_{m}(z)=0 \quad \text { on } S_{R}
$$

where the constants $a_{m}$ are determined by using the $(1 / \rho(z))$-orthogonality of the normal modes. It has tacitly been assumed here that the waveguide has constant water depth and range-independent but depth-dependent sound speed in the vicinity of the truncation boundary $S_{\mathrm{R}}$ and beyond, so that the depth eigenproblem corresponding to the problem in Eq. (1) could be solved at least numerically [23].

Note that while the radiation condition in Eq. (4) on an individual mode is local, the radiation condition in Eq. (9) is global, meaning that nodes of an element on the truncation boundary are linked to other elements there in view of the coefficients $a_{m}$.

\section{Constraints}

In view of Eq. (8), Eq. (6) may be written as

$$
[C]\left\{p(z), a_{1}, a_{2}, \ldots, a_{M}\right\}^{T}=0 \text { on } S_{R^{\prime}}
$$

where

$$
[C]=\left[1,-f_{1}(z),-f_{2}(z), \ldots,-f_{M}(z)\right]
$$

and the companion vector in Eq. (10) is unknown. Equation (10) will be treated as a constraint in the following FE model.

\section{Variational formulation}

For the purpose of finite element modeling, it would be convenient to construct a variational formulation [34-35]. In the present study, in order to avoid possible numerical difficulties with handling a point source, a small fluid domain $\Omega_{S}$ surrounding the source has been excluded so that the computational domain is $\bar{\Omega}_{I}=\Omega_{I}-\Omega_{S}$. Consider the following axisymmetric functional $I(p)$ defined in the cylindrical coordinate system $(r, z)$ (see Fig. 1): 


$$
I(p)=\frac{1}{2} \int_{\Omega_{I}} \frac{1}{\rho}\left\{\left(\frac{\partial p}{\partial r}\right)^{2}+\left(\frac{\partial p}{\partial z}\right)^{2}-k^{2} p^{2}\right\} r d r d z+\frac{1}{2} \sum_{m=1}^{M} \int_{S_{\mathrm{R}}} \frac{1}{\rho} \alpha_{m} p_{m}^{2} r d z-\int_{S_{\mathrm{D}}+S_{\mathrm{N}}} \frac{1}{\rho} \frac{\partial p}{\partial n} p d S,
$$

where $S_{\mathrm{D}}$ denotes the surface on which a Dirichlet boundary condition is prescribed and $S_{\mathrm{N}}$ the surface with prescribed Neumann boundary condition, and the other domains of integration are identified in Fig. 1.

It can readily be shown that the variational condition

$$
\delta I=0
$$

leads to the governing differential equation in Eq. (1) and the boundary conditions in Eqs. (2)(4). Thus, Eqs. (12) and (13) can be used to develop an FE model using the Rayleigh-Ritz approximation. However, the resulting solution should also obey the constraints in Eq. (10), which will ensure the imposition of the radiation boundary condition as discussed above. This will be achieved by modifying the discrete approximation to the functional in Eq. (12).

\section{Finite element model}

The finite fluid domain $\bar{\Omega}_{I}$ (which excludes the source) of the axisymmetric waveguide in Fig. 1 may be discretized using eight-noded axisymmetric quadrilateral elements with $C_{o}$ continuity and the well-known isoparametric formulation [15]. The computational domain is discretized into a mesh of finite elements. The finite element approximation for the field variable $p$ may then be written as

$$
p(r, z) \approx \sum_{j=1}^{\tilde{n}} \bar{p}_{e j} N_{j}(\xi, \zeta)=[N]^{T}\left\{\bar{p}_{e}\right\}
$$

where $\tilde{n}$ denotes the number of element nodes (eight in the present study), $\bar{p}_{e j}$ the nodal pressure variable/degrees of freedom (dofs) and $N_{j}(\xi, \zeta)$ the polynomial shape function in the parametric coordinates $(\xi, \zeta)$ in the $(r, z)$ plane [15]. The subscript $e$ is used to indicate the quantity at the element. Substituting Eq. (14) into Eq. (12) yields the following discrete form:

$$
I\left(p_{e}\right) \approx \frac{1}{2}\left\{\bar{p}_{e}\right\}^{T}\left(\left[K_{e}\right]-\left[M_{e}\right]\right)\left\{\bar{p}_{e}\right\}+\frac{1}{2} \sum_{m=1}^{M}\left\{\bar{p}_{e m}\right\}^{T}\left[\bar{R}_{e m}\right]\left\{\bar{p}_{e m}\right\}-\left\{\bar{p}_{e}\right\}^{T}\left\{f_{e}\right\}
$$

where $\left\{\bar{p}_{e m}\right\}$ denotes nodal pressure on the radiation boundary due to the $m$-th mode and the various matrices above will be identified subsequently. The stationary condition of the potential $I\left(p_{e}\right)$ above should be sought subject to the constraint in Eq. (10). There are two ways of implementing this, one the classical Lagrangian multiplier approach and the other the 
penalty function approach; the latter, which is commonly used in the context of finite element analysis $[15,13]$ is adopted in the present work. To achieve this, a modified potential I' may be defined as

$$
I^{\prime}=I+\frac{1}{2}\left\{\bar{p}_{e}^{\prime}\right\}^{T}\left[C_{e}\right]^{T}\left[\beta_{P}\right]\left[C_{e}\right]\left\{\bar{p}_{e}^{\prime}\right\}
$$

where $\left[C_{e}\right]$ denotes the constraint matrix in Eq. (11) specific to an element. The penalty coefficient matrix $\left[\beta_{P}\right]$ above may be chosen to be diagonal for convenience, with $\beta_{P m}$ denoting the penalty parameter associated with the $m$-th mode. Equation (16) may be expanded as

$$
I^{\prime}\left(p_{e}^{\prime}\right)=\frac{1}{2}\left\{\bar{p}_{e}^{\prime}\right\}^{T}\left(\left[K_{e}^{\prime}\right]-\left[M_{e}^{\prime}\right]+\left[R_{e}^{\prime}\right]+\left[C_{e}\right]^{T}\left[\beta_{P}\right]\left[C_{e}\right]\right)\left\{\bar{p}_{e}^{\prime}\right\}-\left\{\bar{p}_{e}^{\prime}\right\}^{T}\left\{f_{e}^{\prime}\right\}
$$

where the enlarged element dof vector is defined as

$$
\left\{\bar{p}_{e}^{\prime}\right\}=\left\{\begin{array}{c}
\left\{\bar{p}_{e}\right\} \\
\{a\}
\end{array}\right\}
$$

The enlarged stiffness, mass and damping matrices, and load vector in expanded Eq. (16), consistent with $\left\{\bar{p}_{e}^{\prime}\right\}$ in Eq. (17), are given by

$$
\left.\left[K_{e}^{\prime}\right]=\left[\begin{array}{cc}
{\left[K_{e}\right]} & 0 \\
0 & 0
\end{array}\right] \quad\left[M_{e}^{\prime}\right]=\left[\begin{array}{cc}
{\left[M_{e}\right]} & 0 \\
0 & 0
\end{array}\right] \quad\left[R_{e}^{\prime}\right]=\left[\begin{array}{cc}
0 & 0 \\
0 & {\left[R_{e}\right.}
\end{array}\right]\right] \quad\left\{f_{e}^{\prime}\right\}=\left\{\begin{array}{c}
\left\{f_{e}\right\} \\
0
\end{array}\right\}
$$

The matrices $\left[K_{e}\right],\left[M_{e}\right]$, and $\left[R_{e}\right]$ in Eq. (18) are traditionally called the element stiffness, mass and radiation damping matrices, and $\left\{f_{e}\right\}$ the load vector, respectively. They are given as follows:

$$
\begin{gathered}
{\left[K_{e}\right]=\int_{\Omega_{e}} \frac{1}{\rho}[\nabla N]^{T}[\nabla N] d \Omega} \\
{\left[M_{e}\right]=\int_{\Omega_{e}} \frac{k^{2}}{\rho}[N]^{T}[N] d \Omega} \\
{\left[R_{e}\right]=\operatorname{diag}\left[R_{e 1}, R_{e 2}, \ldots, R_{e M}\right]} \\
R_{e m}=\left\{f_{z m}\right\}^{T}\left[\bar{R}_{e m}\right]\left\{f_{z m}\right\} \quad\left[\bar{R}_{e m}\right]=\alpha_{m} \int_{S_{R e}} \frac{1}{\rho}[N]^{T}[N] d S \\
\left\{f_{z m}\right\}=\left\langle f_{z m}\left(z_{1}\right), f_{z m}\left(z_{2}\right), \ldots, f_{z m}\left(z_{n}\right)\right\rangle^{T} \\
\left\{f_{e}\right\}=\int_{S_{N e}} \frac{1}{\rho} p_{v}[N]^{T} d S
\end{gathered}
$$


where [N] denotes the shape-function matrix [see Eq. (14)], $p_{v}=\mathrm{\partial} p / \partial n$, and $f_{z m}\left(z_{j}\right)$ denotes the $j$-th nodal value of the $m$-th mode on a finite element in contact with the radiation boundary $S_{R e}$. The steps required to derive Eq. (19c) are outlined in Appendix A. It is of interest to note that the radiation-damping matrix $\left[R_{e}\right]$ in Eq. (19c) implies uncoupled modal participation. However, the constraint term involving the matrix $\left[C_{e}\right]$ in expanded Eq. (16) brings about modal coupling. The various integrals above are defined over relevant finite element domains. The stationary condition of the potential $I^{\prime}$ in expanded Eq. (16) is obtained by setting

$$
\frac{\partial I^{\prime}}{\partial\left\{\bar{p}_{e}^{\prime}\right\}}=0
$$

Equation (20) leads to general element equations of the form

$$
\left(\left[K_{e}^{\prime}\right]-\left[M_{e}^{\prime}\right]+\left[R_{e}^{\prime}\right]+\left[C_{e}\right]^{T}\left[\beta_{P}\right]\left[C_{e}\right]\right)\left\{\bar{p}_{e}^{\prime}\right\}=\left\{f_{e}^{\prime}\right\}
$$

It may be noted that if the penalty matrix $\left[\beta_{P}\right]=0$ in Eq. (21), the constraints are ignored; as the penalty parameter values increase, the error in satisfying the constraint equations decreases, and for very high values of penalty, the numerical solution may break down. Hence, a judicious choice of the penalty parameters is essential. The radiation-damping matrix $\left[R_{e}^{\prime}\right]$ and the constraint matrix $\left[C_{e}\right]$ in Eq. (21) correspond to elements on the radiation boundary. Hence, for this case, the FE equation may be deduced from Eqs. (18) and (21) as

$$
\left(\left[K_{e}\right]-\left[M_{e}\right]\right)\left\{\bar{p}_{e}\right\}=\left\{f_{e}\right\}
$$

The radiation-damping matrix $\left[R_{e}^{\prime}\right]$ in Eq. (19c), which is complex in view of Eq. (5), is defined only for elements that share one or more of their boundaries with the artificial boundary $S_{R}$. Carrying out thus the finite element assemblage operation, yields the following global finite element equations:

$$
\left(\left[K^{\prime}\right]-\left[M^{\prime}\right]+\left[R^{\prime}\right]+\left[C^{\prime}\right]\right)\left\{\bar{p}^{\prime}\right\}=\left\{f^{\prime}\right\}
$$

where the global solution vector $\left\{\bar{p}^{\prime}\right\}$ consists of all the pressure dof in the computational domain as well as the unknown vector $\{a\}$ in Eq. (8).

The global finite element matrices in Eq. (23) may formally be written as

$$
\begin{array}{rr}
{\left[K^{\prime}\right]=\sum_{e}\left[K_{e}^{\prime}\right] \quad\left[M^{\prime}\right]=\sum_{e}\left[M_{e}^{\prime}\right]} & {\left[R^{\prime}\right]=\sum_{e}\left[R_{e}^{\prime}\right]} \\
{\left[C^{\prime}\right]=\sum_{e}\left[C_{e}\right]^{T}\left[\beta_{P}\right]\left[C_{e}\right]} & \left\{f^{\prime}\right\}=\sum_{e}\left\{f_{e}^{\prime}\right\}
\end{array}
$$


where $\Sigma_{e}$ denotes the standard finite element assemblage operation [15].

\section{Modeling of a point source}

When the inhomogeneous Helmholtz equation in Eq. (1) is employed in the FE model, the source term involving the delta function, as the other terms of the differential equation, is satisfied only approximately over the finite elements in contact with the point source. Of course, the error is expected to decrease with mesh refinement. The present FE formulation uses the complex pressure $p$ as the field variable. Hence, a kinematic/Dirichlet boundary condition in terms of $p$ would be satisfied exactly at the finite element nodes. In light of this, it would be interesting to see whether the effect of the source could be modeled as a kinematic boundary condition. To facilitate this, the computational domain employed above (see Eq. (12)) excludes the source. This is achieved by matching each finite element node with the source, and excluding all the finite elements that are in contact with the source node. Then the free field pressure due to the source on the periphery of the excluded domain is imposed as a kinematic boundary condition in the finite element model. The discontinuity of the fields on the periphery of the region enclosing the source is our equivalent source. It may be argued that the pressure distribution on the excluded domain boundary is not the actual one, which would be known only after solving the FE equations. However, the following argument justifies the approach. It is known that for small volume sources, the pressure in the far field is not affected by the individual shape of a source, as long as the source strengths are equal. Thus, this justifies the use of a computational domain that excludes a small FE domain around a point source. In the present study, the size of the excluded domain has been kept at about a tenth of the wavelength. Comparison of the FE results with an analytical solution indicates that such a choice is satisfactory.

\section{Solution of FE equations}

The global FE equation in Eq. (23) may be written for brevity as

$$
[A]\left\{\bar{p}^{\prime}\right\}=\left\{f^{\prime}\right\}
$$

It may be noted that for an acoustic medium with real sound speed, the coefficient matrix $[A]$ above is complex even though $\left[K^{\prime}\right],\left[M^{\prime}\right]$, and $\left[C^{\prime}\right]$ are real. This is because $\left\{f^{\prime}\right\}$ is complex. Also, note that $\left[R^{\prime}\right]$ is complex due to the presence of $\alpha_{m}$ in Eq. (19d). For a lossy medium modeled with complex sound speed, $\left[M^{\prime}\right]$ is also complex. Although $[A]$ is non-self-adjoint, it is a complex symmetric matrix and hence the Gauss solver employed here to obtain the solution to Eq. (25) exploits the attendant computational advantage. Since such solvers for FE equations are coded as block solvers with compact storage scheme, large finite element models can be 
handled even with modest computer storage. Of course, such a solution strategy involves overhead in the form of read/write operations on secondary storage devices. This approach may be contrasted against those of Bayliss et al. [36] and Athanassoulis et al. [37] who have used iterative methods based on the conjugate-gradient technique. Solvers based on the conjugate-gradient method have been found much more efficient than Gauss solvers when the size of the matrix equation is very large, say, several tens of thousands of equations, and hence they hold promise for high frequency FE models.

Since the present FE model adopts a penalty function approach to impose the radiation boundary condition with multiple radiating modes, the choice of suitable penalty parameter $\alpha_{P m}$ is important. This can be resolved through numerical experiments. The penalty parameter was obtained by prescribing a scale factor on the average value of the diagonals of the coefficient matrix $[A]$ in Eq. (25); i.e.,

$$
\beta_{P m}=\frac{\beta_{s}}{n^{\prime}} \sum_{i=1}^{n^{\prime}}\left|A_{i i}\right|
$$

where $n^{\prime}$ denotes the total number of FE equations/dof and $\beta_{s}$ a user-specified penalty scale factor. Computations indicate that the results are stable over a wide range of $\beta_{s}$ values. The results reported here have been obtained using $\beta_{s}=100$.

\section{Normal modes in an ocean waveguide with depth dependence}

The sound speed in an ocean-acoustic waveguide is in general both depth- and rangedependent. Depth dependence is considered very important because it is responsible for many interesting phenomena in waveguide propagation. The two well-known methods that have been developed to study acoustic waves in depth-dependent waveguides are the fast-field technique and the normal-mode expansion $[9,1]$, the latter being the method that we have used. The normal-mode approach consists of first solving the depth eigenproblem for a given sound-speed profile to obtain the radial wavenumbers and the associated depth modes, which respectively are the eigenvalues and eigenfunctions. The depth eigenproblem could be solved exactly only for a few special profiles. In the finite element model for depth- and rangedependent waveguides [31-32], the eigensolution of the depth problem is required for imposition of the radiation condition at the truncation boundary. For such applications, it would be convenient to have the depth modes in a compact analytical form. We have explored this aspect with specific reference to shallow-water waveguides.

The depth eigenproblem can be cast in a variational form by suitably defining a functional. Then, the classical Rayleigh-Ritz method may be employed to find a variational approximation to the eigensolution of the depth problem in ocean-acoustic waveguides. The depth modes obtained would have a more compact analytical form than those derived using finite difference 
or finite element methods. The present work provides an RR model for the depth eigenproblem and demonstrates its utility for shallow-water waveguides.

\section{Mathematical model}

For the cylindrically symmetric waveguide having depth-dependent density $\rho$ and sound speed $c$, the inhomogeneous pseudo Helmholtz equation governing the linear harmonic acoustic pressure field $p(r, z)$ in the waveguide is given in cylindrical coordinates $(r, z)$ as $[9,1]$

$$
\frac{1}{r} \frac{\partial}{\partial r}\left(r \frac{\partial p}{\partial r}\right)+\rho(z) \frac{\partial}{\partial z}\left(\frac{1}{\rho(z)} \frac{\partial p}{\partial z}\right)+\frac{\omega^{2}}{c^{2}(z)} p=-\frac{\delta(r) \delta\left(z-z_{s}\right)}{2 \pi r}
$$

where $r$ denotes the range coordinate and $z$ the depth coordinate as shown in Fig. 2, and the r.h.s. denotes a point source of unit amplitude located at $r=0$ and $z=z_{s}$, with $\delta$ denoting the Dirac delta function. Eq. (27) can also be applied to problems with attenuation by introducing a complex sound speed.

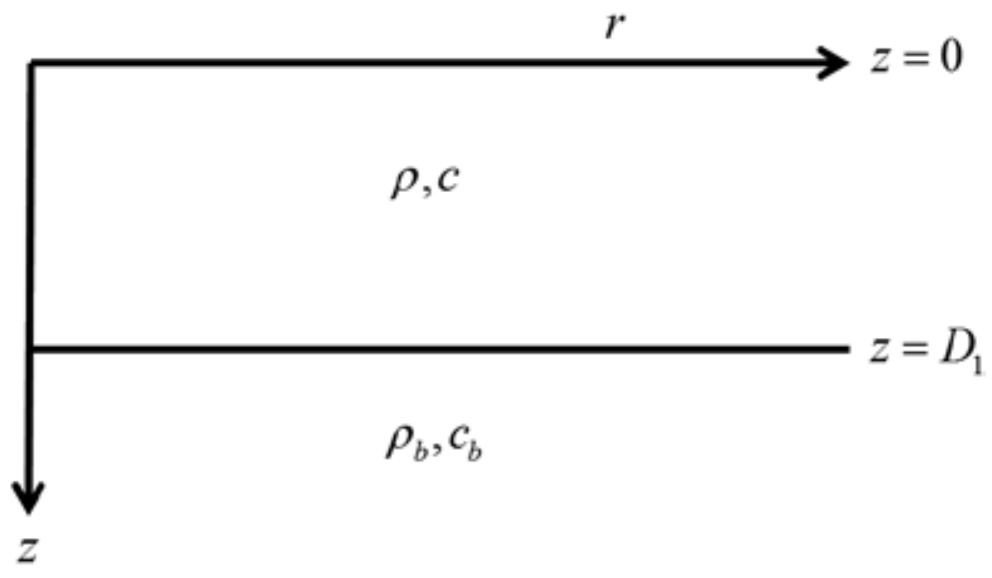

Figure 2. A two-layer cylindrically symmetric waveguide

A variable separable solution for the homogeneous form of Eq. (27) may be written as

$$
p(r, z)=\bar{R}(r) Z(z)
$$

Then, upon using Eq. (28) in the homogeneous form of Eq. (27), the following ordinary differential equations are obtained: 


$$
\begin{gathered}
\frac{1}{r} \frac{d}{d r}\left(r \frac{d \bar{R}(r)}{d r}\right)+k_{r}^{2} \bar{R}(r)=0 \\
\rho(z) \frac{d}{d z}\left(\frac{1}{\rho(z)} \frac{d Z(z)}{d z}\right)+\left(\frac{\omega^{2}}{c^{2}(z)}-k_{r}^{2}\right) Z(z)=0
\end{gathered}
$$

where $\omega$ denotes the circular frequency and $k_{r}^{2}$, the separation constant, which turns out to be the square of the radial/horizontal wavenumber. Eq. (29) evidently pertains to the radial/ horizontal modes $\bar{R}(r)$, and Eq. (30) pertains to the depth modes $Z(z)$. Choosing a pressure release boundary at the top $(z=0)$ and a mixed/Robin boundary condition at the seabed $\left(z=D_{1}\right)$, the boundary conditions of our problem are written as $[1,30,33]$

$$
\begin{gathered}
Z(0)=0 \\
Z\left(D_{1}\right)+\frac{g\left(k_{r}^{2}\right)}{\rho} \frac{d Z\left(D_{1}\right)}{d z}=0
\end{gathered}
$$

where

$$
g\left(k_{r}^{2}\right)=\rho_{b} / \sqrt{\left(k_{r}^{2}-\frac{\omega^{2}}{c^{2}}\right)}
$$

with $\rho_{b}$ denoting the density of the acoustic fluid in the isovelocity half-space underlying the water column. Eq. (32) facilitates replacing the half-space in the Pekeris waveguide [38] by means of an impedance-type boundary condition. It may be noted that Eq. (30) together with the homogeneous boundary conditions in Eqs. (31) and (32) do not constitute a proper SturmLiouville problem because Eq. (32) depends on the unknown eigenvalue $k_{r}^{2}$. Porter and Reiss [30] employed a finite difference model to solve Eq. (30) together with the boundary conditions in Eqs. (31) and (32). As an alternative to the above formulation, the waves in the fluid halfspace below the water column are also considered here [1]. The governing equation for the waves in this fluid half-space is given as,

$$
\rho_{\mathrm{b}}(z) \frac{d}{d z}\left(\frac{1}{\rho_{\mathrm{b}}(z)} \frac{d Z_{\mathrm{b}}(z)}{d z}\right)+\left(\frac{\omega^{2}}{c_{\mathrm{b}}^{2}(z)}-k_{r}^{2}\right) Z_{\mathrm{b}}(z)=0, \quad D_{1} \leq z \leq \infty
$$

where $Z_{b}$ denotes the depth function in the fluid half-space having depth-dependent density $\rho_{\mathrm{b}}$ and sound speed $c_{\mathrm{b}}$. The interface conditions at the seabed are given by the kinematic and dynamic conditions, 


$$
\begin{aligned}
& Z\left(D_{1}\right)=Z_{\mathrm{b}}\left(D_{1}\right) \\
& \frac{1}{\rho} \frac{d Z\left(D_{1}\right)}{d z}=\frac{1}{\rho_{b}} \frac{d Z_{b}\left(D_{1}\right)}{d z}
\end{aligned}
$$

In addition, the depth mode $Z_{\mathrm{b}}$ should remain bounded as $z \rightarrow \infty$. Our primary objective is to consider a variational formulation for Eqs. (30) and (33), together with appropriate boundary conditions, and obtain a RR approximation to the depth-dependent problem.

\section{Variational formulation and Rayleigh-Ritz approximation}

A variational formulation that leads to the boundary value problem in the last section is sought now. The operator being symmetric, there exists a functional, the variation of which leads to Eq. (30) and appropriate boundary conditions, and similarly for the half-space. Consider the functional $\Pi(Z)$ and $\Pi_{b}\left(Z_{b}\right)$ defined respectively in the water column and the half-space as

$$
\begin{gathered}
\Pi(Z)=\frac{1}{2} \int_{0}^{D_{1}}\left[\frac{1}{\rho(z)}\left(\frac{d Z}{d z}\right)^{2}-\frac{\omega^{2}}{\rho(z) c^{2}(z)} Z^{2}+\frac{1}{\rho(z)} k_{r}^{2}(z) Z^{2}\right] d z-\left.\frac{1}{\rho(z)} Z_{v} Z\right|_{0} ^{D_{1}} \\
\prod_{b}\left(Z_{b}\right)= \\
\frac{1}{2} \int_{D_{1}}^{D_{2}}\left[\frac{1}{\rho_{b}(z)}\left(\frac{d Z_{b}}{d z}\right)^{2}-\frac{\omega^{2}}{\rho_{b}(z) c^{2}(z)} Z_{b}^{2}+\frac{1}{\rho_{b}(z)} k_{r}^{2} Z_{b}^{2}\right] d z \\
-\frac{1}{\rho_{b}(z)} Z_{b v}\left(D_{1}\right) Z_{b}\left(D_{1}\right)+\frac{1}{2} \beta \frac{Z_{b}^{2}\left(D_{2}\right)}{\rho_{b}}, \quad D_{2} \rightarrow \infty
\end{gathered}
$$

where suffix $v$ denotes $z$-derivative. At the interface $z=D_{1}$ between the water column and the half-space, the conditions noted in Eq. (30) must be imposed. In view of Eq. (34b), this can be achieved by setting in Eq. (35)

$$
\frac{1}{\rho} Z_{v}\left(D_{1}\right)=\frac{1}{\rho_{b}} \frac{d Z_{b}\left(D_{1}\right)}{d z},
$$

and in Eq. (36),

$$
\frac{1}{\rho_{b}} Z_{b v}\left(D_{1}\right)=\frac{1}{\rho} \frac{d Z\left(D_{1}\right)}{d z}
$$


In addition, Eq. (34a) should be imposed. Then, it can be easily shown that the variational condition $\delta \Pi=0$ leads to Eq. (30) and the boundary conditions in Eq. (31) as well as the interface condition in Eq. (37), where $\delta$ denotes the first variation. Similarly, the variational condition $\delta \Pi_{b}=0$ leads to Eq. (33), and the interface conditions in Eq. (34a) and Eq. (38). In addition, at $z=D_{2}$, we obtain the condition

$$
\frac{d Z_{b}\left(D_{2}\right)}{d z}+\beta Z_{b}\left(D_{2}\right)=0,
$$

where (see Eq. (32)),

$$
\beta=\sqrt{\left(k_{r}^{2}-\frac{\omega^{2}}{c_{b}^{2}}\right)}
$$

Note that there are three cases that can be analyzed using Eq. (36):

Case 1: $D_{2}$ is finite, $\beta \rightarrow 0$

This corresponds to the case when a depth-dependent seabed of finite thickness is terminated by a rigid boundary.

Case 2: $\beta$ is finite, $D_{2} \rightarrow \infty$

This corresponds to a depth-dependent seabed of infinite thickness.

Case 3: $D_{2}$ and $\beta$ are finite

This is a three-layer problem, where the top layer is the water column, the second layer is a layer of seabed with depth varying density and speed, and the bottom layer represents the seabed of infinite extent with uniform sound speed and density.

We now seek an assumed mode solution with $n$ terms to the above variational problem in the form

$$
\begin{array}{cc}
Z(z) \approx \sum_{j=1}^{n_{1}} \bar{\phi}_{j} \psi_{j}(z) & 0 \leq z \leq D_{1} \\
Z_{b}(z) \approx \sum_{j=1}^{n_{2}} \bar{\phi}_{b j} \psi_{b j}(z) & D_{1} \leq z \leq \infty
\end{array}
$$

where $n=n_{1}+n_{2}$, and $\psi_{j}$ and $\psi_{b j}$ denote the known mode function (coordinate function) satisfying the kinematic boundary condition in the water column and $\phi_{j}$ an unknown constant, 
and their counterparts with suffix $b$ correspond to those of the half-space. The two sets of mode functions above are such that they satisfy the relevant boundary conditions as well as the interface conditions in Eq. (34) and the conditions in Eq. (39). Such functions may readily be constructed by solving a two-layer depth problem, which is nothing but the Pekeris waveguide [38], with an appropriate choice of constant velocity and density in the water column and the seabed half-space. This approach has been adopted here. Then, it follows that the continuity of pressure field at the interface $z=D_{1}$ implies that the assumed mode expansion in Eq. (40) reduces as,

$$
Z(z) \approx \sum_{j=1}^{n} \bar{\phi}_{j} \psi_{j}(z) \quad 0 \leq z \leq D_{2}
$$

where we have combined the depth modes of a two-layer isovelocity waveguide as one combined set with redefined coefficients $\phi$. Then, using Eq. (40) in the functionals in Eqs. (35) and (36), and combining them, an algebraic approximation for the functionals is obtained as

$$
\bar{\Pi}=\Pi+\prod_{b}=\frac{1}{2}\{\bar{f}\}^{T}\left[K^{I}\right]\{\bar{f}\}-\frac{1}{2} \omega^{2}\{\bar{f}\}^{T}\left[K^{I I}\right]\{\bar{f}\}+\frac{1}{2} k_{r}^{2}\{\bar{f}\}^{T}\left[K^{I I I}\right]\{\bar{f}\}
$$

where

$$
\begin{aligned}
K_{i j}^{I} & =\int_{0}^{D_{1}} \frac{1}{\rho(z)} \frac{d \psi_{i}}{d z} \frac{d \psi_{j}}{d z} d z+\int_{D_{1}}^{D_{2}} \frac{1}{\rho_{b}(z)} \frac{d \psi_{b i}}{d z} \frac{d \psi_{b j}}{d z} d z \\
K_{i j}^{I I} & =\int_{0}^{D_{1}} \frac{1}{\rho(z) c^{2}(z)} \psi_{i} \psi_{j} d z+\int_{D_{1}}^{D_{2}} \frac{1}{\rho_{b}(z) c_{b}^{2}(z)} \psi_{b i} \psi_{b j} d z \\
K_{i j}^{I I I} & =\int_{0}^{D_{1}} \frac{1}{\rho(z)} \psi_{i} \psi_{j} d z+\int_{D_{1}}^{D_{2}} \frac{1}{\rho_{b}(z)} \psi_{b i} \psi_{b j} d z
\end{aligned}
$$

It has been assumed in the above that the contribution due to the term in Eq. (36) is negligible as $D_{2} \rightarrow \infty$. Further, it may be noted that since the boundary and interface conditions are satisfied by the trial functions chosen above, when the functionals in Eqs. (35) and (36) are combined to obtain Eq. (42), the boundary and interface terms add up to become trivial and hence do not contribute to the discrete approximation in Eq. (42).

The variational condition is now replaced by the condition

$$
\frac{\partial \bar{\Pi}}{\partial \phi_{j}}=0, \quad j=1,2, \ldots, n
$$


Eq. (44) yields a symmetric algebraic eigenproblem given by

$$
\left(\omega^{2}\left[\mathrm{~K}^{\mathrm{II}}\right]-\left[\mathrm{K}^{\mathrm{I}}\right]\right)\{\bar{\phi}\}=k_{r}^{2}\left[\mathrm{~K}^{\mathrm{III}}\right]\{\bar{\phi}\}
$$

The eigensolution of Eq. (45) may be denoted as

$$
\left(k_{r j}^{2},\left\{\phi^{(j)}\right\}\right), \quad j=1,2, . . n
$$

It may be noted here that the eigenproblem in Eq. (45) remains linear unlike the Porter and Reiss model that is based on Eqs. (30)-(32). Having obtained the eigenvalues $k_{r j}^{2}$ and the eigenvectors $\left\{\Phi^{(j)}\right\}$, the eigenfunctions /depth modes may be written, using Eq. (40), as

$$
\mathrm{Z}_{j}(z)=\left\{\bar{\phi}^{(j)}\right\}^{T}\{\psi(z)\}
$$

where

$$
\{\psi(z)\}^{T}=\left\langle\psi_{1}(z), \psi_{2}(z), \cdots, \psi_{n}(z)\right\rangle
$$

Eq. (47) provides a compact semi-analytical form for the depth modes that are convenient to employ in FE models such as those in Fix and Marin [31] and Vendhan et al. [32] for approximating the radiation condition at the truncation boundary. The depth modes obtained can of course be used to set up the normal-mode solution to the forced Helmholtz equation in Eq. (27). Note that for a Pekeris waveguide, the normal-mode solution based on the discrete spectrum has to be augmented with the continuous spectrum contribution [1]. Since the eigenvectors in Eq. (45) are [K $\left.\mathrm{K}^{\mathrm{III}}\right]$-orthogonal, it can easily be shown that the eigenfunctions in Eq. (47) satisfy the following orthogonality condition:

$$
\int_{0}^{D_{1}} \frac{1}{\rho(z)} Z_{i} Z_{j} d z+\int_{D_{1}}^{D_{2}} \frac{1}{\rho_{b}(z)} Z_{i} Z_{j} d z=0, \quad i \neq j
$$

The orthonormal depth functions are obtained as

$$
\bar{Z}_{j}(z)=Z_{j} / \sqrt{\left\{\bar{\phi}^{(j)}\right\}^{T}\left[K^{I I I}\right]\left\{\bar{\phi}^{(j)}\right\}}
$$


In terms of finite element terminology, the RR model for each layer may be looked upon as a super-element with $C_{1}$ continuity at the inter-element boundary and the operation leading to Eq. (42) is equivalent to element-assemblage operation.

\section{Numerical analysis and discussion}

In our Rayleigh-Ritz model, the first task is to compute the symmetric matrices $\left[\mathrm{K}^{\mathrm{I}}\right],\left[\mathrm{K}^{\mathrm{II}}\right]$, and $\left[\mathrm{K}^{\mathrm{III}}\right]$ in Eq. (43). The next task is to find the eigensolution to Eq. (45). For problems with no attenuation, the real eigenvalues have been obtained employing the bisection method. For problems with attenuation, approximations to the complex roots have been obtained using a search procedure [39] and the eigenvalues refined by employing Newton-Raphson iteration. In all cases, the eigenvectors are obtained using inverse iteration.

To validate our algorithm, we applied the Rayleigh-Ritz model first to single-layer isovelocity waveguide examples without attenuation for which exact solutions are available. Different sound-speed profiles have been chosen to evaluate the accuracy of the RR model. Attenuation in the fluid half-space has also been considered. Different sets of RR approximations have been obtained by varying the number of assumed modes $n$ in Eq. (41). The results for $n=2 n_{\mathrm{p}}$, where $n_{\mathrm{p}}$ denotes the number of propagating modes turned out to be of good accuracy.

One should note the following remarks in connection with the performance of the RR model for the depth eigenproblem:

a. The mode shapes of an isovelocity waveguide have been chosen as trial functions, which satisfy appropriate interface conditions and the condition at the free surface. This renders the RR matrix highly diagonally dominant, which also greatly aids in numerical evaluation of the eigensolution.

b. For ocean waveguides, the depth variation of the sound speed is normally only a small percentage of the unperturbed value.

c. When the variation in sound speed is large, the above procedure may not give good results. One has to resort to high-order solutions. Even then, one can expect accurate eigenvalues, but not eigenvectors. This is because the convergence rate for the eigenvectors is slower than that for the eigenvalues.

\section{Numerical examples}

We considered several examples to illustrate the versatility of our FEM approach in remote sensing problems. In all our examples, we employed a Dirichlet boundary condition on the air-sea interface, a Neumann boundary condition on the ocean bottom boundary, and a unit point source at a depth of $36 \mathrm{~m}$ below the air-water interface. Both depth-dependent and uniform sound-speed water columns are considered. 


\subsection{Isovelocity case}

The finite element method for the solution of inhomogeneous ocean-acoustic waveguide problems is validated first with analytical results for isovelocity waveguides. A cylindrically symmetric plane parallel waveguide of depth $100 \mathrm{~m}$ with a point source is shown in Fig. 3. The finite element model consists of a uniform grid of isoparametric quadrilateral elements, with the element length being about a tenth of the source signal wavelength. As discussed previously, a domain of two elements has been excluded to remove the source from the truncated domain (Fig. 1). The FE mesh consists of 1000 elements in range and 60 elements in depth. The computed acoustic pressure along the range at the depth of the source is compared in Fig. 3 with the normal-mode solution with 50 modes, of which only the leading few modes are propagating. In all cases, the FEM results compared well with analytical results. The mesh is chosen appropriately so that the modal error is less than $5 \%$.

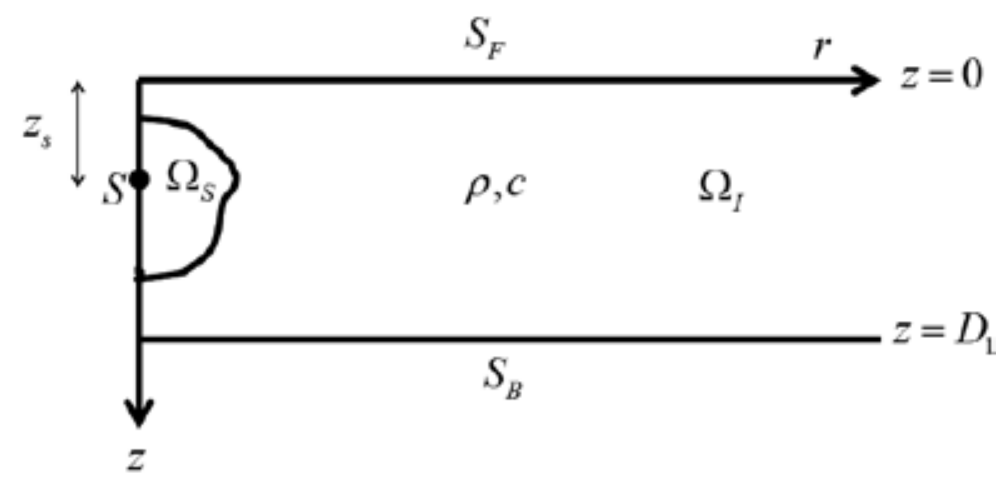

Figure 3. Idealized ocean waveguide

\subsection{Rectangular hump}

Sea mounts are often encountered in under-water ocean problems. In order to understand their impact on wave propagation characteristics in shallow-water environment, we considered a rigid rectangular hump of width $40 \mathrm{~m}$ and height $20 \mathrm{~m}$ on ocean bottom as shown in Fig. 4(a). The contour map of transmission loss (TL) of a $60-\mathrm{Hz}$ point source located on the $z$-axis at a depth of $36 \mathrm{~m}$ from the water surface is shown in Fig. 4. Panel (a) shows the TL in the presence of a rectangular hump on the seabed. Panel (b) shows the TL of the water column without the rectangular hump. Notice that the rectangular hump has a distinct signature in TL pattern especially on the right of the hump.

It is instructive to take a look at the acoustic power distribution in the modes. Figure 5 shows the modal power spectrum of the shallow-water column with the rectangular hump in panel (a) and without the rectangular hump in panel (b). Notice that there is a substantial redistribution of power among the modes due to the presence of the rectangular hump. 


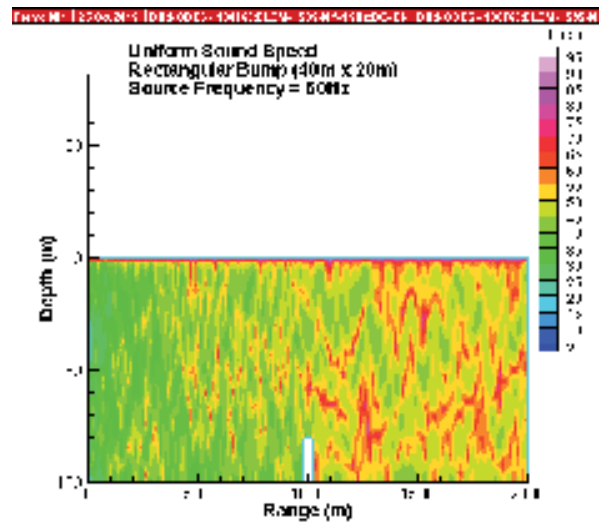

(a)

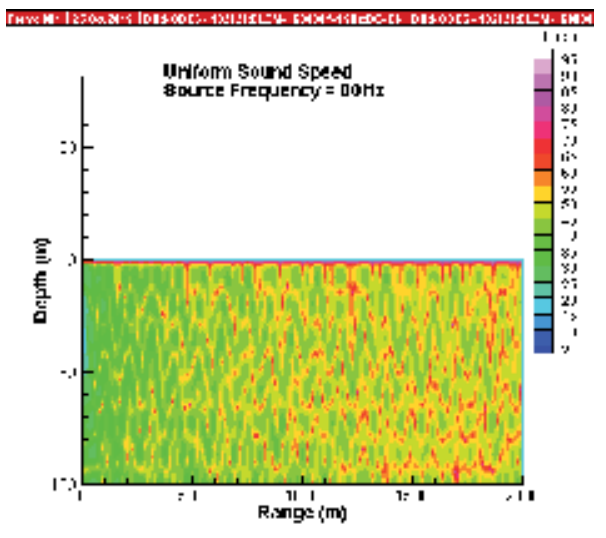

(b)

Figure 4. Transmission loss of a shallow-water column with a (a) rectangular hump on the seabed and (b) flat-bottom surface

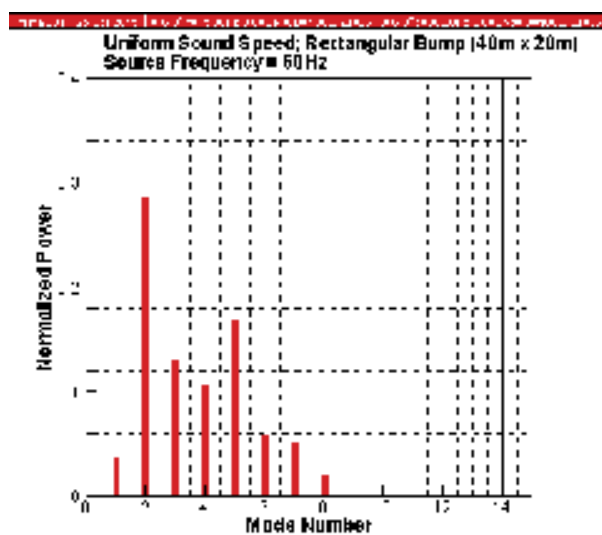

(a)

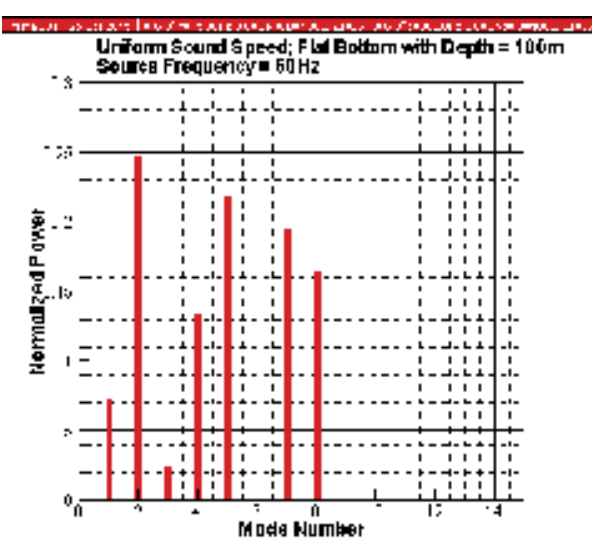

(b)

Figure 5. Spectra of modal efficiencies for (a) seabed with a rectangular bump and (b) a flat seabed

\subsection{Down-sloping bottom}

Shallow-water conditions are encountered in the near-coast context where the ocean bottom has a sloping geometry. There are two situations to consider, up-slope and down-slope, depending on the location of the source with respect to the slope. First we consider the downsloping case where the ocean-bottom slopes down from $100 \mathrm{~m}$ to $230 \mathrm{~m}$ over a distance of 600 m. The details of the geometry are shown in Fig. 6 . 


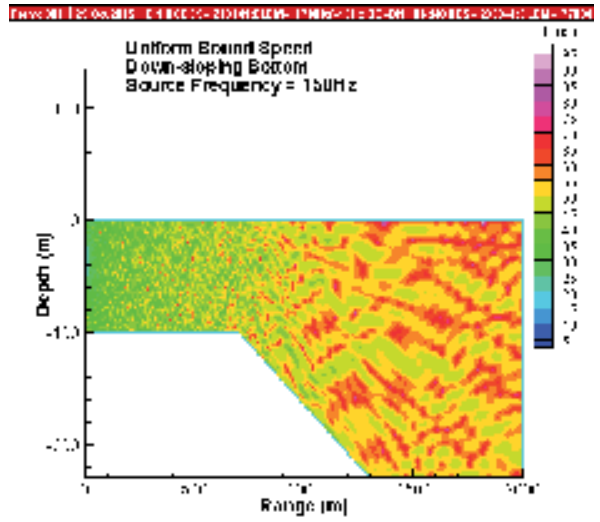

(a)

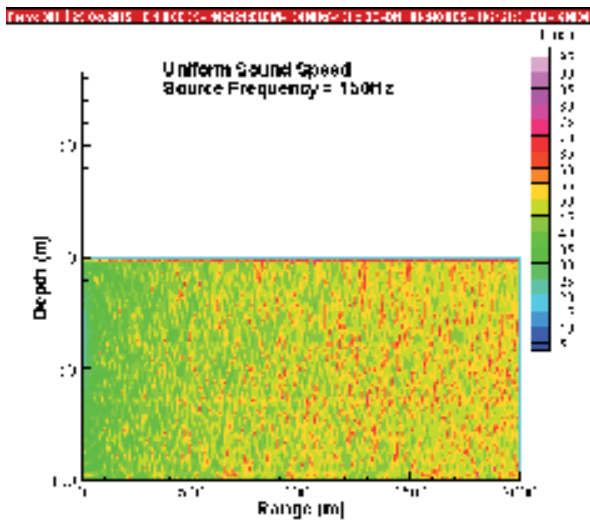

(b)

Figure 6. Transmission loss of a shallow-water column with (a) down-sloping bottom and (b) flat bottom of depth $100 \mathrm{~m}$

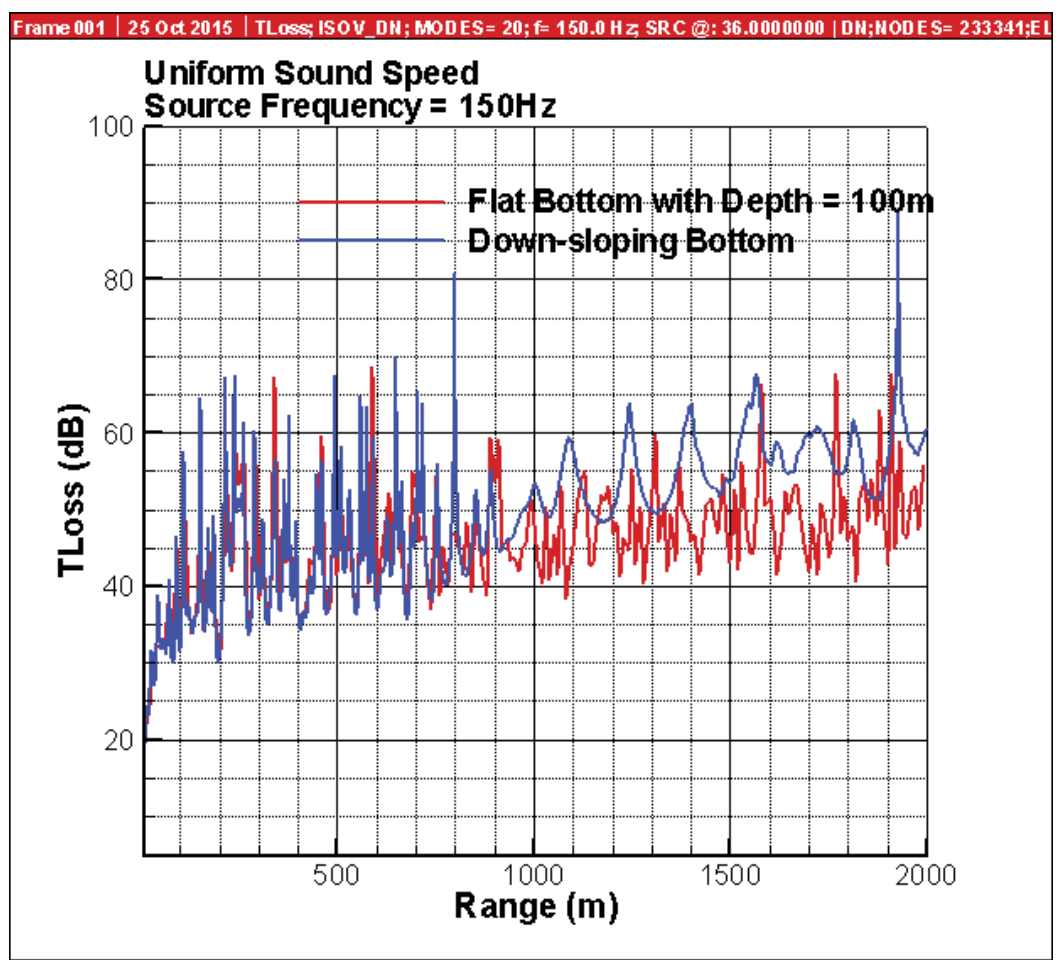

Figure 7. Comparison of TL at $36 \mathrm{~m}$ depth of an ocean with down-sloping bottom and a flat bottom

Panel (a) shows the TL with the down-sloping bottom. Panel (b) shows the TL for a water column with the flat bottom at depth $100 \mathrm{~m}$. Both results are for the source frequency of 150 Hz. Notice the distinct spatial power distribution manifested by the sloping bottom. To 
facilitate a better comparison, we have shown in Fig. 7 the TL at $36 \mathrm{~m}$ depth corresponding to the flat and sloping bottoms. Notice that the TLs for the two cases are similar in the region between the source and the middle of the slope. Beyond that, the TL corresponding to the sloping bottom is significantly larger than that of the flat bottom.

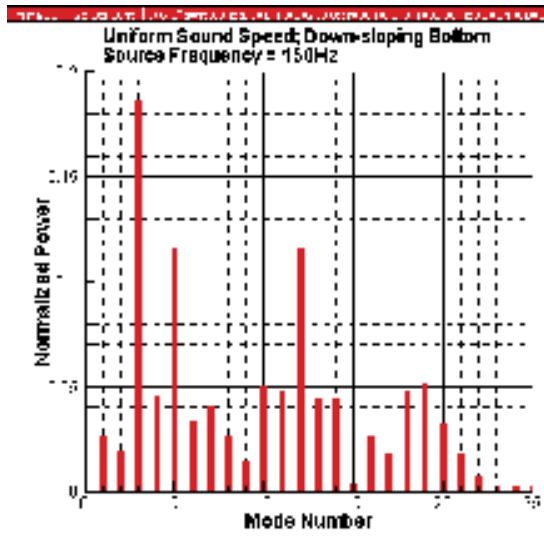

(a)

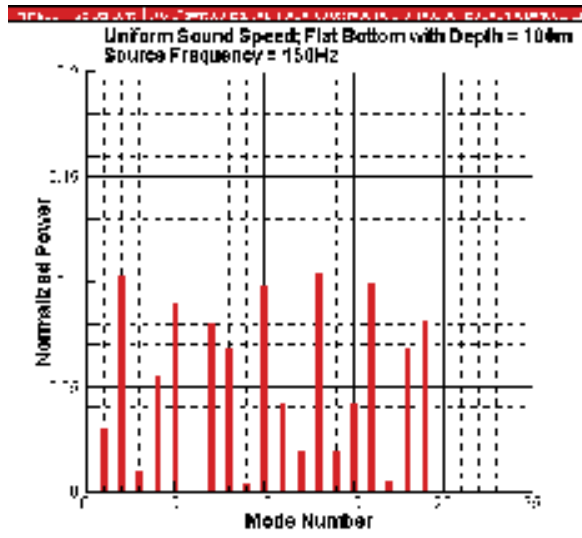

(b)

Figure 8. Modal power spectrum of shallow-water column with (a) down-sloping bottom and (b) flat bottom of depth $100 \mathrm{~m}$

In order to better understand the propagation phenomenology, the modal power spectrum for the shallow-water ocean with (a) down-sloping bottom and (b) flat bottom are shown in Fig. 8. Notice that there is a significant redistribution of energy in the case of sloping bottom although the total power flows in both cases are approximately the same.

\subsection{Up-sloping bottom}

Next we consider the problem of sloping bottom where the ocean bottom slopes up (with respect to location of the source) from $230 \mathrm{~m}$ to $100 \mathrm{~m}$ over a distance of $600 \mathrm{~m}$. The details of the geometry are shown in Fig. 9. The acoustic source is located at $36 \mathrm{~m}$ below the water surface on the left.

Panel (a) shows TL for the case of $105 \mathrm{~Hz}$ and panel (b) shows the case of $150 \mathrm{~Hz}$. We notice that at $105 \mathrm{~Hz}$ there is a substantial reduction in power flow. However, at $150 \mathrm{~Hz}$ the power flow is as good as that of a flat-bottom waveguide. The mode spectral distribution in Fig. 10 shows the details of how the power flows in the two cases. We notice that for the up-slope case, power flow can be good at certain frequencies and not good at others, depending on the impedance matching conditions. In contrast, for the case of down slope the power flow is good for all the frequencies that we studied. 


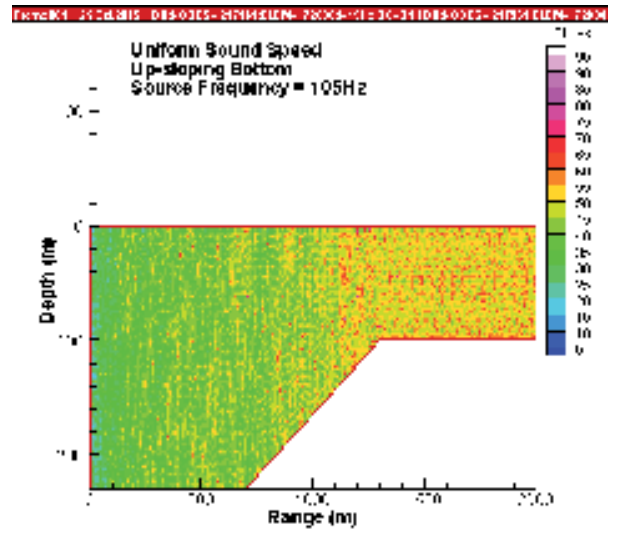

(a)

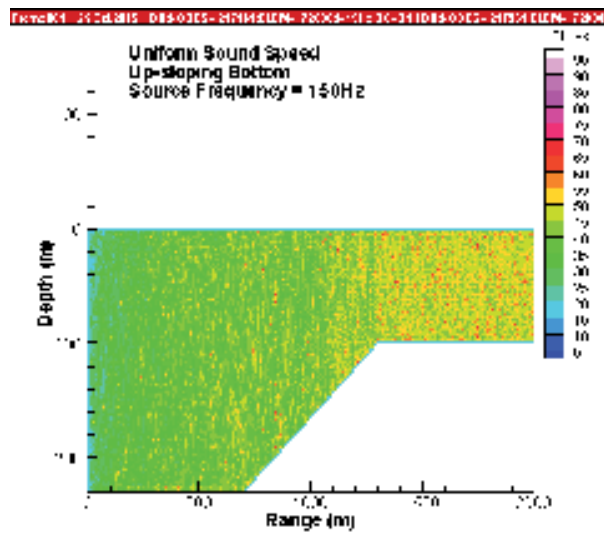

(b)

Figure 9. Transmission loss of shallow-water column with up-slope bottom at $105 \mathrm{~Hz}$ and $150 \mathrm{~Hz}$

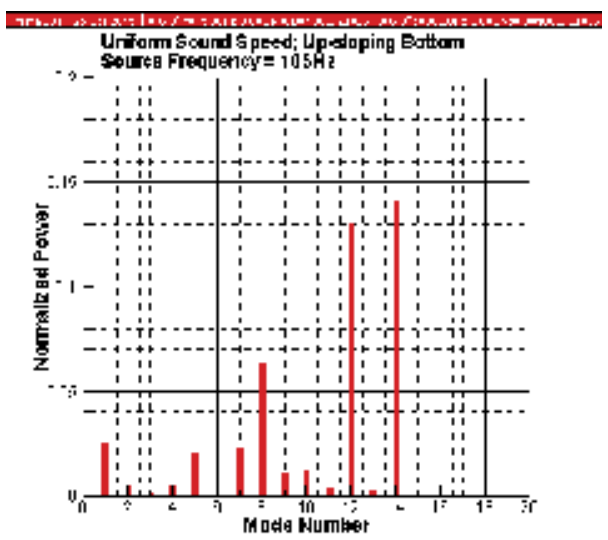

(a)

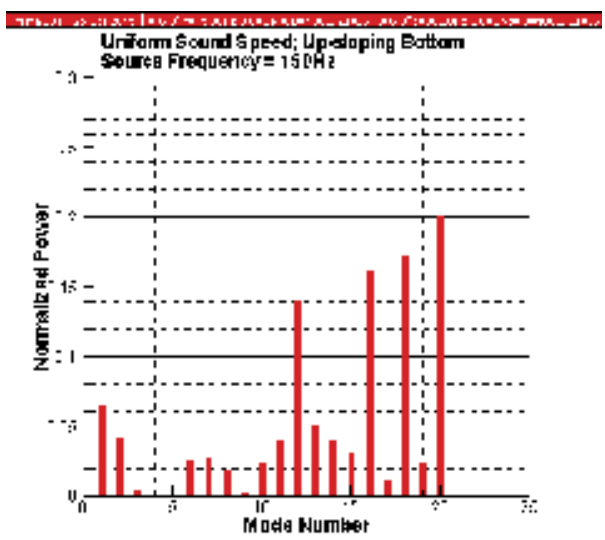

(b)

Figure 10. Modal spectrum of shallow-water column with up-sloping bottom (a) $105 \mathrm{~Hz}$ (b) $150 \mathrm{~Hz}$

\subsection{Object in the water column}

Characterizing the signatures of objects in the ocean is an important remote sensing problem. We consider a cylindrical rigid object of radius $20 \mathrm{~m}$ in the middle of a water column as shown in Fig. 11. Panel (a) shows the TL for the source frequency at $135 \mathrm{~Hz}$. Panel (b) shows the TL for the source frequency at $150 \mathrm{~Hz}$. We notice that the power flow can be substantially influenced by the object, depending on the frequency of operation. This is because of the interference phenomena involving the object and the boundaries of the waveguide. 


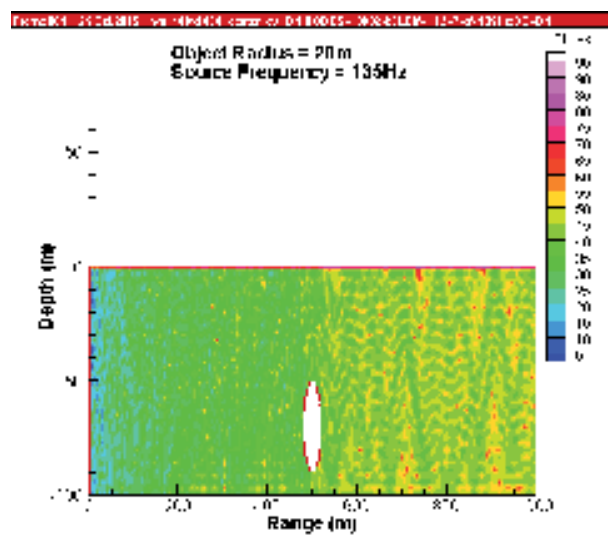

(a)

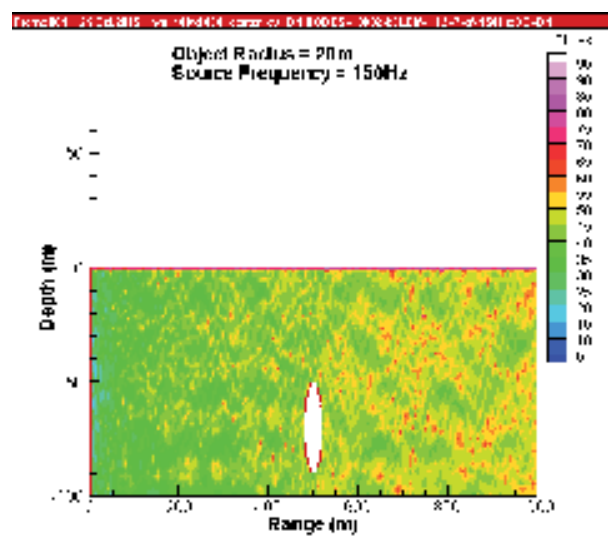

(b)

Figure 11. TL of a shallow-water column with an object (a) $135 \mathrm{~Hz}$ (b) $150 \mathrm{~Hz}$

\subsection{Shallow-water column with rippled top surface}

Ripples on the water surface can be generated by gravity and wind conditions. Such surface undulations can considerably influence the wave propagation in the shallow-water waveguide. To illustrate this phenomenon, we have taken a periodic structure on the air-water interface as shown in Fig. 12. The top surface has a sinusoidal undulation of amplitude $5 \mathrm{~m}$ and period $50 \mathrm{~m}$.

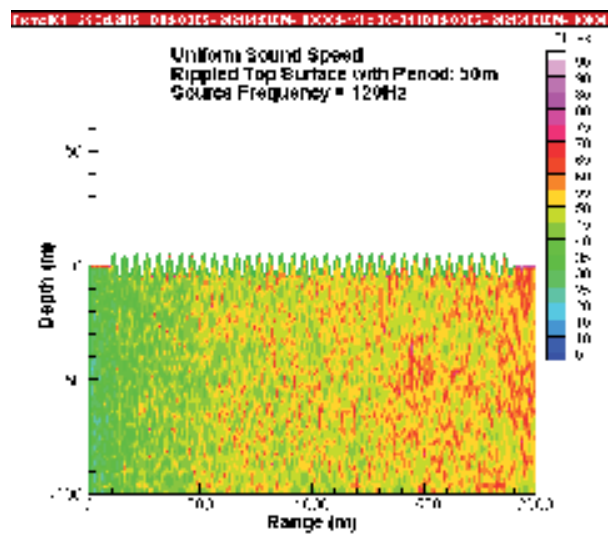

(a)

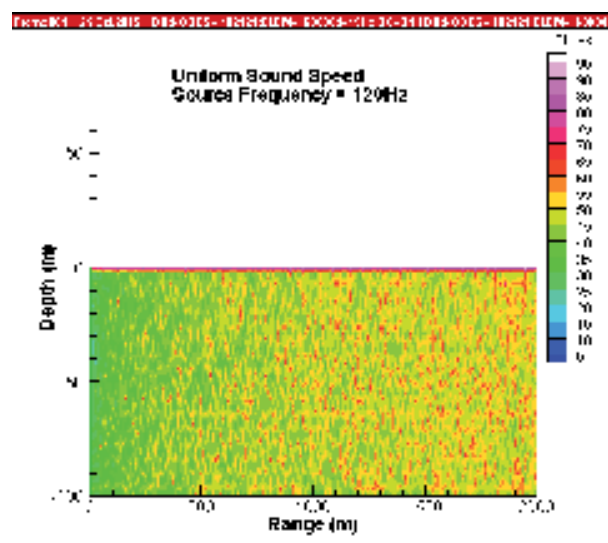

(b)

Figure 12. TL in a shallow-water column with (a) wind-generated rippled air-water interface, and (b) flat water surface 
Our FEM results show that the surface ripples causes substantial transmission loss compared to that of the flat water surface for the case when the source frequency is $120 \mathrm{~Hz}$. However, this pattern is quite sensitive to source frequency. For some frequencies, the TL may be large and for others, TL can be low. Dimensions of the waveguide and ripple geometry in terms of the source signal wavelength are key factors influencing the physics.

\subsection{Shallow-water column with depth-dependent sound speed}

In all the examples considered thus far, we have assumed that the water column has uniform sound speed. This is rarely true in practice even for the shallow-water ocean. The normal modes for the depth-dependent waveguide are required to impose the radiation boundary condition in our finite element procedure. The Rayleigh-Ritz approximation is used for obtaining normal modes for this problem. The sound-speed profile taken for this study is shown in Fig. 13.

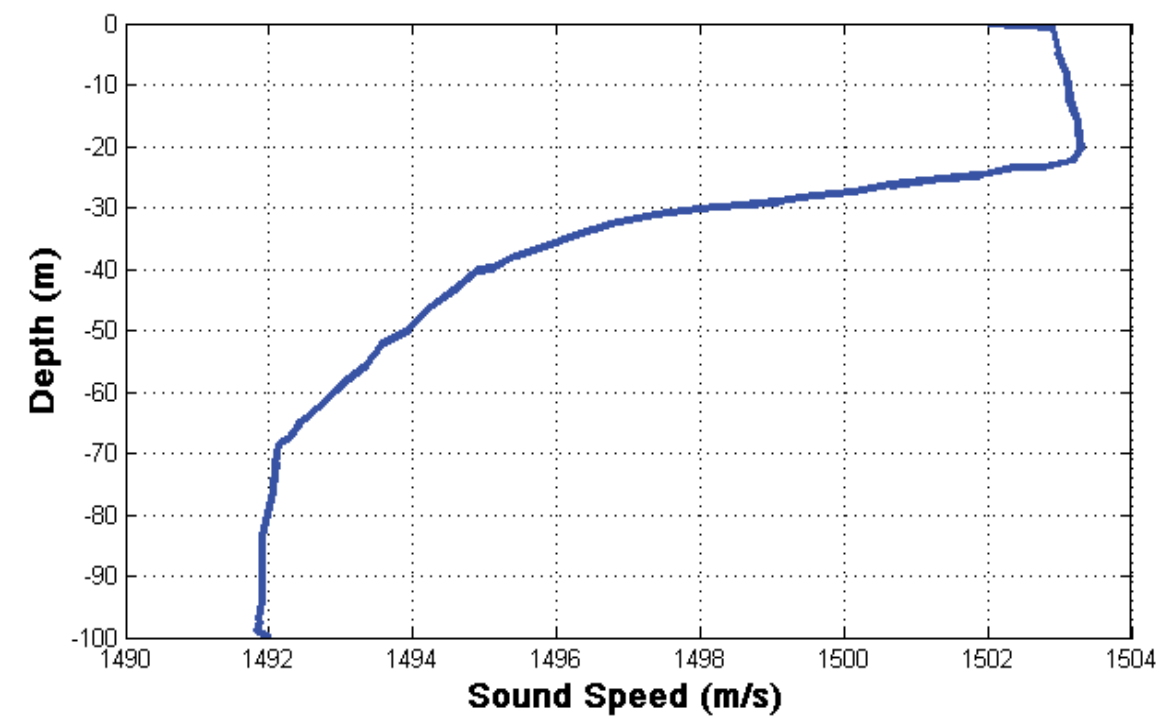

Figure 13. Sound-speed profile (S1) used for our study

The TL for our geometry with the sound-speed profile given in Fig. 13 is shown in Fig. 14. The result for source frequency of $150 \mathrm{~Hz}$ is shown in Panel (a) and that corresponding to isovelocity is shown in Panel (b). Although the sound-speed variation is very small, we notice the impact of depth dependence of sound speed on TL is substantial. However, at lower frequencies, this kind of sound-speed variation does not influence the TL much. 


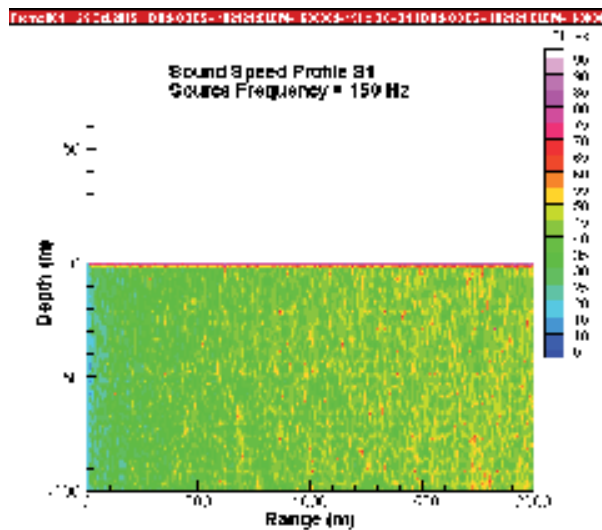

(a)

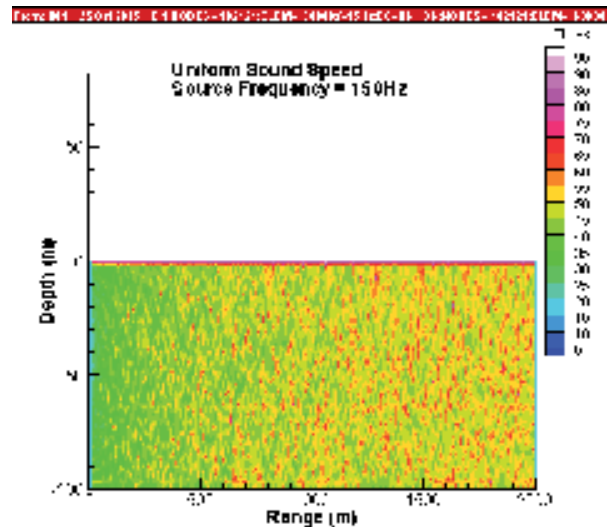

(b)

Figure 14. TL for the shallow-water ocean with (a) depth-dependent sound speed, and (b) uniform sound speed

\subsection{Shallow-water column with depth-dependent sound speed and a rectangular bump on seabed}

Next, we consider the case of shallow-water ocean with depth-dependent sound speed and a rigid rectangular hump on the seabed.

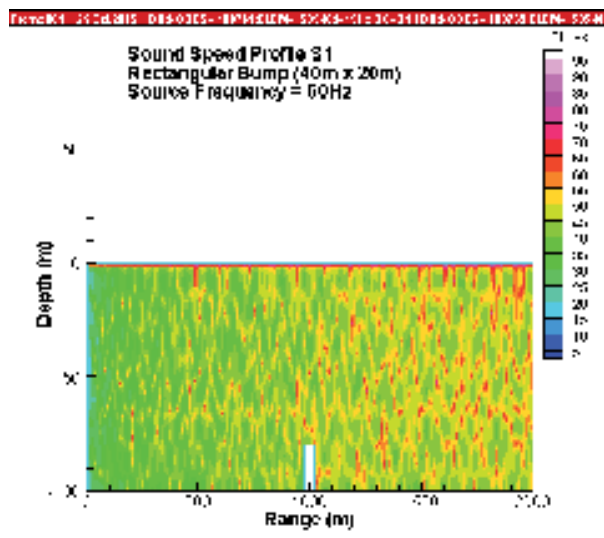

(a)

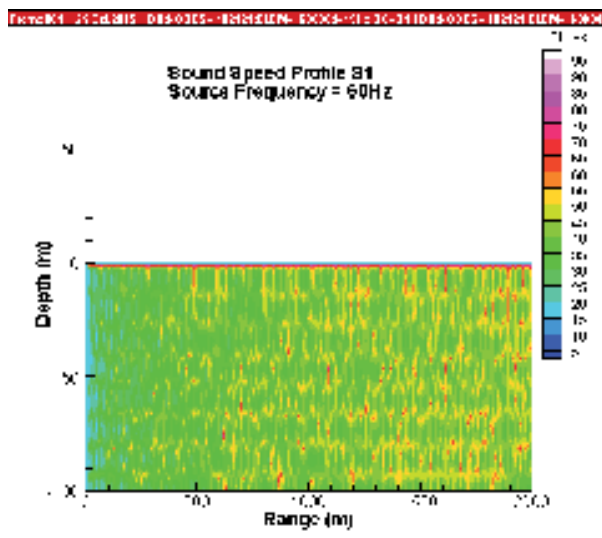

(b)

Figure 15. TL for the shallow-water ocean with (a) depth-dependent sound speed and a rectangular bump on the seabed, and (b) depth-dependent sound speed and flat bottom

We observe that, for the case when the source frequency is $60 \mathrm{~Hz}$, the presence of the small rectangular hump on the seabed has a significant effect on the transmission loss of a depthdependent ocean. 


\subsection{Shallow-water column with depth-dependent sound speed and rippled top surface}

Finally, we consider the case of shallow-water ocean with depth-dependent sound speed (Fig. 13) and a rippled air-water surface. The results are shown in Fig. 16.

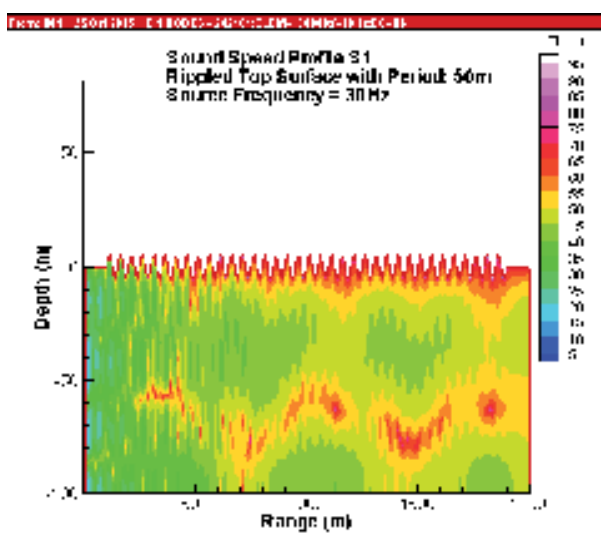

(a)

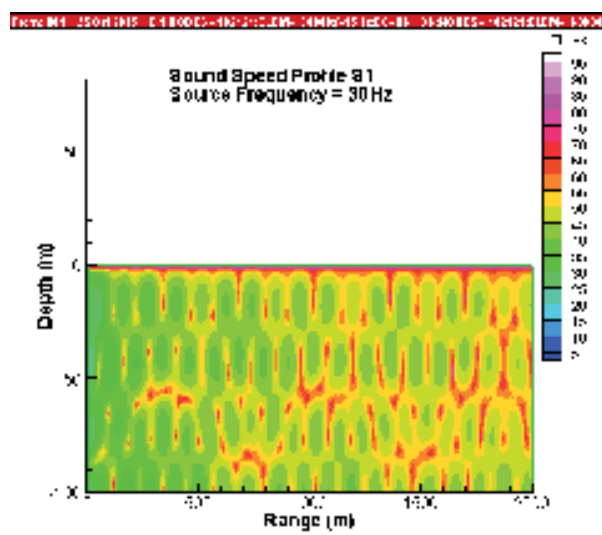

(b)

Figure 16. TL for the shallow-water ocean with (a) depth-dependent sound speed and a rippled air-water interface, and (b) depth-dependent sound speed

Note that for source frequency of $30 \mathrm{~Hz}$, the presence of ripples has reduced the transmission loss in most regions. This is in contrast to the last case (Fig. 15) where there is a rectangular bump on the seabed. However, these characteristics are due to interference phenomenon and hence have strong frequency dependence. The important point is that small features such as ripples can have a significant impact on the underwater propagation characteristics.

\section{Conclusion}

A finite element approach has been presented for remote sensing in shallow-water ocean environment. The three principal elements of remote sensing are: (a) signal propagation and reception, (b) data analysis, and (c) inversion or retrieval. This chapter exclusively deals with part (a) of the trilogy of remote sensing. Although several approaches have been developed for wave propagation studies in underwater ocean, they all have limitations when encountered with complex geometries and environments as in shallow-water ocean. An FE approach is both accurate and feasible for such applications. In order to minimize the problem size, a Bayliss-type damper was imposed to truncate the solution domain. Since several propagating modes can exist in the ocean waveguide, a penalty function approach was used to impose the radiation boundary condition in the variational finite element formulation of the problem. This penalty function approach was found to be robust over a wide range of penalty scale factors. 
For the shallow-water ocean waveguide with depth-dependent sound-speed problem, the eigensolution was obtained using a Rayleigh-Ritz approximation. The trial functions are derived from an isovelocity problem that has exact solution. It is important to note that such trial functions automatically satisfy even the dynamic interface condition at the seabed, thus contributing to the accuracy of the numerical model. The proposed model is accurate and provides a compact semi-analytical form for the depth modes.

We thus have an accurate FE model for the remote sensing in range- and depth-dependent ocean-acoustic waveguides. Numerous examples were considered to illustrate the accuracy and versatility of this model. Admittedly, the computational effort in setting up the matrix in the proposed RR model using numerical quadrature is high compared to setting up the finitedifference-based matrix in the Porter and Reiss approach. However, noting the diagonal dominance of the matrix obtained in the RR model, it would be worthwhile exploring the possibility of approximating it by a narrow banded matrix in order to reduce the volume of computation in setting up the matrix and possibly in obtaining the eigensolution. We have also extended this work for the case of irregular elastic seabed. We continue to explore and further develop our finite element approach by applying it to several other ocean-acoustic problems encountered in the remote sensing of ocean environment.

\section{Appendix A: Derivation of multimode radiation damping matrix}

Consider the functional in Eq. (12). The contribution, $I_{R}\left(p_{e}\right)$, from the radiation boundary of a finite element is represented by the second integral in that equation; i.e.,

$$
I_{R}\left(p_{e}\right)=\frac{1}{2} \sum_{m=1}^{M} \int_{S_{R e}} \frac{1}{\rho} \alpha_{m} p_{m}^{2} r d z
$$

where $M$ denotes the number of propagating modes, $\alpha_{m}$ the damper coefficient associated with the $m$-th mode [see Eq. (5)], $p_{m}(z)$ the pressure associated with the $m$-th normal mode, and $S_{R e}$ the element surface on the radiation boundary (see Fig. 1).

The modal pressure on the radiation boundary is given by Eq. (8):

$$
p_{m}(z)=a_{m} f_{m}(z) \quad m=1,2, \ldots, M,
$$

where $f_{m}(z)$ denotes the normal-mode function and $a_{m}$ the modal coefficient. Using the finite element representation, the modal pressure on the radiation boundary may be written as

$$
p_{m}(z)=\sum_{e}[N]^{T}\left\{\bar{p}_{e m}\right\}
$$


where $[N]$ denotes the shape functions and $\left\{\bar{p}_{e m}\right\}$ the nodal pressure vector on an element edge on the radiation boundary due to the $m$-th mode. The summation symbol is used to indicate that Eq. (53) is a piecewise polynomial representation over the entire depth of the waveguide. Using Eqs. (52) and (53), Eq. (51) may be written in a discrete form for a finite element as [also see Eq. (15)]

$$
I_{R}\left(p_{e}\right)=\frac{1}{2} \sum_{m=1}^{M}\left\{\bar{p}_{e m}\right\}^{T}\left\{\bar{R}_{e m}\right\}\left\{p_{e m}\right\}
$$

where

$$
\left[\bar{R}_{e m}\right]=\alpha_{m} \int_{S_{R e}} \frac{1}{\rho}[N]^{T}[N] d S
$$

In view of Eq. (52), the vector of modal pressure at the nodes of an element in Eq. (53) may be written as

$$
\left\{\bar{p}_{e m}\right\}=a_{m}\left\langle f_{z m}\left(z_{1}\right), f_{z m}\left(z_{2}\right), \ldots, f_{z m}\left(z_{n}\right)\right\rangle^{T}=a_{m}\left\{f_{z m}\right\}
$$

where $f_{z m}\left(z_{j}\right)$ denotes the $j$-th nodal value of the $m$-th eigenmode on a finite element in contact with the radiation boundary. Now, using Eqs. (55) and (56), the functional in Eq. (54) may be written as

$$
I_{R}=\frac{1}{2} \sum_{m=1}^{M} a_{m}^{2} R_{e m}
$$

where

$$
R_{e m}=\left\{f_{z m}\right\}^{T}\left[\bar{R}_{e m}\right]\left\{f_{z m}\right\} .
$$

The foregoing steps form the basis for Eq. (19c).

\section{Appendix B: Normal-mode functions for isovelocity waveguides}

The Rayleigh-Ritz model presented for the depth eigenproblems employs the analytical depth modes for an isovelocity waveguide as the trial functions. The details of the various isovelocity waveguide examples encountered in the ocean context are presented here. It should be kept 
in mind that in our problem, the acoustic source and reception points are both in the water column. Therefore, the wave functions given here have been chosen particularly for this application.

For a single-layer waveguide of depth $D$ with Dirichlet boundary condition on top and Neumann boundary condition on the bottom surface, the trial functions are given by

$$
\psi_{j}=a_{j} \sin \left(k_{z j} z\right)
$$

where

$$
k_{z j}=\frac{(j-0.5) \pi}{D}, j=1,2, \ldots
$$

where $a_{j}$ is chosen to normalize the mode functions.

For a two-layer waveguide shown in Fig. 17, the trial functions are given by

$$
\begin{array}{rlr}
\psi_{j}(z) & =a_{j} \sin k_{z j} z & 0 \leq z \leq D_{1} \\
& =a_{j} \frac{\sin k_{z j} D_{1}}{\cos k_{b z j}\left(D_{2}-D_{1}\right)} \cos k_{b z j}\left(D_{2}-z\right) & D_{1} \leq z \leq D_{2}
\end{array}
$$

where $k_{z j}^{2}=\omega^{2} / c^{2}-k_{r j}^{2}, k_{b z j}^{2}=\omega^{2} / c_{b}^{2}-k_{r j}^{2}$ and $k_{r j}$ is the solution of the transcendental equation

$$
\frac{k_{z j} \rho_{b}}{k_{b z j} \rho}=\tan k_{z j} D_{1} \tan k_{b z j}\left(D_{2}-D_{1}\right)
$$

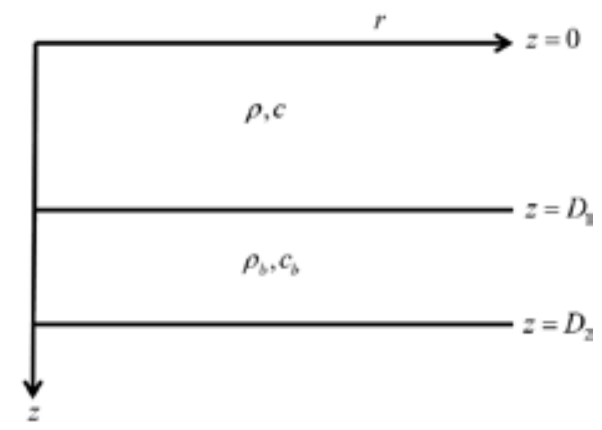

Figure 17. A bounded two-layer waveguide 
In the case of a Pekeris waveguide (for which $D_{2} \rightarrow \infty$ in Fig. 17), the trial functions are given by

$$
\begin{array}{rlrl}
\psi_{j}(z) & =a_{j} \sin k_{z j} z & & \leq z \leq D_{1} \\
& =a_{j} \sin \left(k_{b z j} D_{1}\right) e^{-i k_{b z j}\left(D_{1}-z\right)} & D_{1} \leq z \leq \infty
\end{array}
$$

where $k_{z j}=\sqrt{\omega^{2} / c^{2}-k_{r j}^{2}}, k_{b z j}=i \sqrt{k_{r j}^{2}-\omega^{2} / c_{b}^{2}}$ and $k_{r j}$ is the solution of the transcendental equation

$$
\tan k_{z j} D_{1}=-\frac{i \rho_{b} k_{z j}}{\rho k_{b z j}}
$$

Note that discrete guided modes in the water column exist only for the case when $k_{r j}^{2}>\omega^{2} / c_{b}^{2}$.

There are two cases to consider:

Case 1: $k<k_{b}$

This applies to the situation when the sound-speed velocity in the seabed is smaller than that in the water column. In this case, there are no guided modes. The entire spectrum is continuous and does not have contribution to sound transmission in the water column at long distances.

Case $2: k>k_{b}$

This applies to the situation when the sound speed in the seabed is larger than that in the water column. Here the spectrum consists of (a) discrete guided modes, (b) continuous radiation modes, and (c) surface modes. Among the three, it is the discrete guided modes that carry the sound signal over long distances in the water column.

Since our interest is in long-range sound transmission in the water column, we have restricted attention to discrete guided modes as shown above.

One should observe that our two-layer waveguide problem does not share the above mentioned behavior. Note that the two-layer waveguide is terminated at the bottom by a rigid boundary. Therefore, the underlying physical processes are different.

Case $1: k<k_{b}$

Here the entire spectrum in the waveguide consists of discrete guided modes.

Case $2: k>k_{b}$

In this case, the spectrum consists of discrete guided modes and surface modes. However, for long range propagation, the modes of significance are the discrete guided modes. 


\section{Acknowledgements}

S. Mudaliar thanks the AFOSR for support. C.P. Vendhan thanks AOARD for support during this work period. The authors thank A.D. Chowdhury for his help in eigenvalue computations for depth-dependent water column.

\section{Author details}

Saba Mudaliar ${ }^{1 *}$, C.P. Vendhan ${ }^{2}$ and C. Prabavathi ${ }^{3}$

*Address all correspondence to: saba.mudaliar@us.af.mil

1 Sensors Directorate, Air Force Research Laboratory, WPAFB Ohio, USA

2 Indian Institute of Technology Madras, Chennai, India

3 Independent researcher, Dayton, Ohio, USA

\section{References}

[1] Jensen, F.B., W.A. Kuperman, M.B. Porter, and H. Schmidt (2011) Computational Ocean Acoustics, 2nd ed., Springer, New York.

[2] Lurton, X. (2010) An Introduction to Underwater Acoustics, 2nd ed., Springer, Berlin.

[3] Medwin, H. (2005) Sounds in the Sea, Cambridge University Press, Cambridge.

[4] Urick, R.J. (1983) Principles of Underwater Sound, 3rd ed., McGraw-Hill, New York.

[5] Brekhovskikh, L. and Y. Lysanov (1982) Fundamentals of Ocean Acoustics, SpringerVerlag, Berlin.

[6] Buckingham, M.J. (1992) Ocean-acoustic propagation models, J. Acoustique, Vol. 5, pp. 223-287.

[7] Harrison, C.H. (1989) Ocean acoustic propagation models, App. Acous., Vol. 27, pp. 163-201.

[8] Westwood, E.K. (1990) Ray model solutions to the bench, J. Acous. Soc. Am., Vol. 87, pp. 1539-1545.

[9] Frisk, G.V. (1994) Ocean and Seabed Acoustics: A Theory of Wave Propagation, Prentice Hall, New Jersey. 
[10] Evans, R.B. (1983) A coupled mode solution for acoustic propagation in a waveguide with stepwise depth variations of a penetrable bottom, J. Acous. Soc. Am., Vol.74, pp.188195.

[11] Tappert, F.D (1977) The parabolic approximation method, wave propagation and underwater acoustics, in Wave Propagation and Underwater Acoustics, J.B. Keller and J.S. Papadakis, eds., Springer-Verlag, Berlin, pp. 224-287.

[12] DiNapoli, F.R. and R.L. Deavenport (1980) Theoretical and numerical Green's function field solution in a plane multilayered medium, J. Acous. Soc. Am., Vol. 67, pp. 92-105.

[13] Zienkiewicz, O.C. and R.L. Taylor (1989) The Finite Element Method, Vol. 1-Basic Formulation and Linear Problems, McGraw-Hill, New York.

[14] Bathe, K.J. (1982) Finite Element Procedures in Engineering Analysis, Prentice Hall, Inc., Englewood Cliffs, New Jersey.

[15] CookR.D.,D.S.Malkus, M.E.Plesha, and R.J.Witt(2002)Conceptsand Applications of Finite Element Analysis, 4th ed., John Wiley, New York.

[16] Schmidt, H. and F.B. Jensen (1985) A full wave solution for propagation in multilayered viscoelastic media with application to Gaussian beam reflection and fluid-solid interfaces, J. Acous. Soc. Am., Vol. 77, pp. 813-25.

[17] Thompson, D.J. and N.R. Chapman (1983) A wide-angle split-step algorithm for the parabolic equation, J. Acous. Soc. Am., Vol. 74, pp. 1848-1854.

[18] Lee, D., G. Botseas, and J.S. Papadakis (1981) Finite difference solution to the parabolic wave equation, J. Acous. Soc. Am., Vol. 70, pp. 795-800.

[19] Huang, D. (1988) Finite element solution to the parabolic wave equation, J. Acous. Soc. Am., Vol. 84, pp. 1405-1413.

[20] Evans, R.B. and K.E. Gilbert (1985) Acoustic propagation in a reflecting ocean waveguide with an irregular interface, Comp. Math. Appls. Vol. 11, pp. 795-805.

[21] Dougalis, V.A., N.A.Kampanis, and M.I.Taroudakis(1998)Comparison of finiteelement and coupled mode solutions of the Helmholtz equation in underwater acoustics, Proc. 4th European Conference in Underwater Acoustics, eds. A. Alippi and G.B. Cannelli, CNRIDAC, Rome, Vol. II, pp. 649-654.

[22] Mitsoidis, D.A., N.A. Kampanis, and V.A. Dougalis (2008) Coupled mode and finite element approximations of underwater sound propagation problems in general stratified environments, J. Comput. Acous., Vol. 16, pp. 83-116.

[23] Murphy, J.E. and S.A. Chin-Bing (1988) A finite element model for ocean acoustic propagation, Math. Comput. Modelling, Vol. 11, pp. 70-74.

[24] Murphy, J.E. and S.A. Chin-Bing (1989) A finite-element model for ocean acoustic propagation and scattering, J. Acous. Soc. Am., Vol. 86, pp. 1478-1481. 
[25] Antoine, X., H. Barucq, and A. Bendali (1999) Bayliss-Turkel-like radiation conditions on surfaces of arbitrary shape, J. Math. Anal. Appl., Vol. 229, pp. 184-211.

[26] Bayliss, A., M. Gunzberger, and E. Turkel (1982) Boundary conditions for the numerical solution of elliptic equations in exterior domains, SIAM J. Appl. Math., Vol. 42, pp. 430-451.

[27] Engquist, B. and A. Majda (1977) Absorbing boundary conditions for the numerical simulation of waves, Math. Comput., Vol. 31, pp. 629-651.

[28] Keller, J.B. and D. Givoli (1989) Exact non-reflecting boundary conditions, J. Comput. Phys, Vol. 81, pp. 172-192.

[29] Givoli, D (1999). Recent advances in the DtN FE method, Arch. Comput. Methods Eng., Vol. 6, pp. 71-116.

[30] Porter, M.B. and E.L. Reiss (1984) A numerical method for ocean-acoustic normal modes, J. Acous. Soc. Am., Vol. 76, pp. 244-252.

[31] Fix, G.J. and S.P. Marin (1978) Variational methods for underwater acoustic problems, J. Computat. Phys., Vol. 28, pp. 253-270.

[32] Vendhan C.P., G.C. Diwan, and S.K. Bhattacharyya (2010) Finite-element modeling of depth and range dependent acoustic propagation in ocean waveguides, J. Acoust. Soc. Am., Vol. 127, pp. 3319-3326.

[33] Porter, M.B. and E.L. Reiss (1985) A numerical method for bottom interacting ocean acoustic normal modes, J. Acous. Soc. Am., Vol. 77, pp. 1760-1767.

[34] Ihlenburg, F. (1998) Finite Element Analysis of Acoustic Scattering, Springer, Berlin.

[35] Taroudakis, M.I., G.A. Athanassoulis, and J.P. Ionnidis (1990) A variational principle for underwater acoustic propagation in a three-dimensional ocean environment, $J$. Acoust. Soc. Am., Vol. 88, pp. 1515-1522.

[36] Bayliss, A., C.I. Goldstein, and E. Turkel (1985) The numerical solution of the Helmholtz equation for wave propagation problems in underwater acoustics, Comput. Math. Appl., Vol. 11, pp. 655-665.

[37] Athanassoulis, G.A., K.A. Belibassakis, D.A. Mitsoudis, N.A. Kampanis, and V.A. Dougalis (2008) Coupled mode and finite element approximations of underwater sound propagation problems in general stratified environments, J. Comput. Acoust., Vol. 16, pp. 83-116.

[38] Pekeris, C.L. (1948) Theory of propagation of explosive sound in shallow water, Memoirs of Geological Society of America, Vol. 27, pp. 1-116.

[39] Buckingham, M.J. and E.M. Giddens (2006) On the acoustic field in Pekeris waveguide with attenuation in the bottom half-space, J. Acous. Soc. Am., Vol. 119, pp. 124-142. 

Chapter 8

\title{
Bio-Optical Modeling in a Tropical Hypersaline Lagoon Environment
}

\author{
Igor Ogashawara, Marcelo P. Curtarelli, Carlos A. S. Araujo and José L. Stech
}

Additional information is available at the end of the chapter

http://dx.doi.org/10.5772/61869

\begin{abstract}
In this chapter, we attempted to present an overview of the use of remote sensing to monitor water quality parameters, mainly chlorophyll- $a(\mathrm{chl}-a)$ and turbidity. We summarized the main concepts of bio-optical modeling and presented a case study of the application of the Hyperspectral Imager for the Coastal Ocean (HICO) for the monitoring of water quality in a tropical hypersaline aquatic environment. Using HICO, we evaluated a set of different semi-empirical bio-optical algorithms for chl- $a$ and turbidity estimation developed for inland and oceanic waters in the Araruama Lagoon, RJ, Brazil, which is an extreme environment due to its high salinity values. We also developed an empirical algorithm for both water quality parameters and compared the performances. Results showed that for chl- $a$ estimation all models have a low performance with a normalized root mean square error (NRMSE) varying from 24.13 to 30.46 . For turbidity, the bio-optical algorithms showed a better performance with the NRMSE between 15.49 and 28.04. Overall, these results highlight the importance of including extreme environments, such as the Araruama Lagoon, on the validation of bio-optical algorithms as well as the need for new orbital hyperspectral sensors which will improve the development of the field.
\end{abstract}

Keywords: Water quality, chlorophyll- $a$, turbidity, bio-optical modeling

\section{Introduction}

Earth Observations from space began in August, 1972, with the launch by National Aeronautics and Space Administration (NASA) of the Earth Resources Technology Satellite (ERTS-1) [1]. However, the use of remote sensing techniques to monitor inland water quality parameters such as chlorophyll-a (chl-a), total suspended solids (TSS) and turbidity only started to be extensively used in the past two decades with the development of bio-optical algorithms as 
well as the new hyperspectral and multispectral sensors. The use of optical remote sensing enables spatiotemporally comprehensive assessment of optical properties of the water column.

Water column optical properties are grouped into inherent optical properties (IOPs) and apparent optical properties (AOPs). IOPs are related to those properties that depend only upon the environment, thus, they are independent of the environment light field. The two most essential IOPs are the total absorption coefficient $(a)$ and the total scattering coefficient $(b)$ and the sum of both coefficients is the attenuation coefficient $(k)$. AOPs, on the other hand, are those properties that depend on the environment and also on the directional structure of the environment light field. AOPs are also used as descriptors of a water body due to their regular features and stability. The most common AOPs are the irradiance reflectance $(R)$, the remotesensing reflectance $\left(R_{r s}\right)$ and various diffuse attenuation functions [2]. A list of the most common IOPs and AOPs used in the literature is shown in Table 1.

\begin{tabular}{|c|c|c|}
\hline Quantity & Units (SI) & Simbology \\
\hline \multicolumn{3}{|c|}{ Inherent Optical Properties } \\
\hline Absorption coefficient & $\mathrm{m}^{-1}$ & $a$ \\
\hline Volume scattering function & $\mathrm{m}^{-1} \mathrm{sr}^{-1}$ & $\beta$ \\
\hline Scattering phase function & $\mathrm{m}^{-1}$ & $\beta \sim$ \\
\hline Scattering coefficent & $\mathrm{m}^{-1}$ & $b$ \\
\hline Backscatter coefficient & $\mathrm{m}^{-1}$ & $b_{b}$ \\
\hline Beam attenuation coefficient & $\mathrm{m}^{-1}$ & $c$ \\
\hline Single-scattering albedo & - & $\omega_{0}$ \\
\hline \multicolumn{3}{|c|}{ Apparent Optical Properties } \\
\hline Irradiance reflectance (ratio) & - & $R$ \\
\hline Remote sensing reflectance & $\mathrm{sr}^{-1}$ & $R_{r s}$ \\
\hline Remote sensing reflectance (sub) & $\mathrm{sr}^{-1}$ & $r_{r s}$ \\
\hline \multicolumn{3}{|l|}{ Attenuation coefficients: } \\
\hline of radiance $\mathrm{L}(\mathrm{z}, \theta, \varphi)$ & $\mathrm{m}^{-1}$ & $K(\theta, \varphi)$ \\
\hline of downwelling irradiance $\mathrm{E}_{\mathrm{d}}(\mathrm{z})$ & $\mathrm{m}^{-1}$ & $K_{d}$ \\
\hline of upwelling irradiance $\mathrm{E}_{\mathrm{u}}(\mathrm{z})$ & $\mathrm{m}^{-1}$ & $K_{u}$ \\
\hline $\begin{array}{l}\text { of Photosynthetic Active Radiation } \\
\text { (PAR) }\end{array}$ & $\mathrm{m}^{-1}$ & $K P A R$ \\
\hline
\end{tabular}

Table 1. IOPs and AOPs commonly used in optical hydrology 
Based on the interaction among AOPs and IOPs, absorption, scattering and attenuation properties of the water column are retrieved from proximal, aerial or orbital measurements of the solar spectrum mainly in the visible and near-infrared (NIR) spectral range. These optical properties allow the estimation of different water quality parameters such as: primary production, turbidity, eutrophication, particulate and dissolved carbon contents or the assessment of currents and algal blooms [3]. The relation among all these optical properties as well as the equipment to measure them were developed by oceanographers based on the modeling of downwelling solar and sky radiation spectra with the air-water interface and the subsurface aquatic absorption and scattering centers. Studies such as [4-8], among numerous others, established the main theory of the field before or around the launch of ERTS-1.

The first application of the theories of hydrologic optics was described by [9], which used a Monte Carlo simulation of the radiative transfer equation to relate the AOPs to the IOPs in oceanic waters containing optically active constituents, molecular water and chl- $a$. For inland waters, the first application of the hydrologic optics theories was developed for Lake Ontario, Canada, by a Monte Carlo simulation of the radiative transfer equation and non-linear multivariate optimization analyses [10]. These applications started a relatively new area for remote sensing applications known as bio-optical modeling, which focus on the use of the radiative transfer theory to derive optical properties or biological activity in the water column [2]. In [11], a classification of the bio-optical modeling products (algorithms) was proposed by describing five different types of algorithms: empirical, semi-empirical, semi-analytical, quasianalytical and analytical. In this classification, the first two types (empirical and semiempirical) and the last one (analytical) are usually used to estimate the biological activity from AOPs using more statistical methods, while the other two types (semi-analytical and quasianalytical) are used to estimate IOPs from AOPs using the radiative transfer theory.

The development of bio-optical algorithms usually starts by collecting in situ limnological data as well as hyperspectral $R_{r s}$ using a proximal sensor. The use of a hyperspectral sensor is appropriated to explore absorption peaks, which are very narrow to be identified by a multispectral one, to develop an algorithm. However, the ultimate goal for a bio-optical algorithm is to test its applicability on orbital sensors in order to become an important monitoring tool. Two of the most used satellite sensors to monitor water quality are the medium resolution imaging spectrometer (MERIS) and moderate resolution imaging spectroradiometer (MODIS); both sensors provide the necessary spectral bands; however, their coarse spatial resolution makes them suitable only for very large aquatic systems. Despite the limitation on their spatial resolution, several research focus on the use of these two sensors for the monitoring of water quality parameters in inland water. Ref. [12] evaluated the performance of different chl- $a$ semi-empirical algorithms developed, especially for MERIS on a tropical reservoir in Brazil, and in [13] the authors developed a series of steps to improve the estimation of chl- $a$ and cyanobacteria blooms in inland and near-coastal waters based on the MERIS imagery. For MODIS, empirical [14] and semi-empirical [15-17] algorithms have been developed for the monitoring of different water quality parameters. 
To overpass the problem of the spatial resolution and to keep a good spectral resolution, hyperspectral airborne sensors have been used to monitor the quality of inland waters. One of the most common airborne hyperspectral sensor used to monitor water quality parameters is the airborne imaging spectrometer for application (AISA), which is a push-broom system that collect spectral-radiance data (upwelling radiance and downwelling solar irradiance) in the visible and NIR range of the electromagnetic spectrum (approximately from 392 to $982 \mathrm{~nm}$ with a bandwidth of 7-8 nm). From an altitude of 1,000 $\mathrm{m}$, this sensor has a spatial resolution of $1 \mathrm{~m}$, surpassing the problems caused by medium to low spatial resolutions found in orbital sensors. In [18], AISA imagery was used to estimate chl- $a$ and phycocyanin (PC) concentrations in a mesotrophic reservoir in Central Indiana, USA, based on a series of semi-empirical algorithms. In [19], the authors used the same imagery from the previous study [18] to apply a quasi-analytical algorithm and spatialize the chl- $a$, backscattering $\left(b_{b}\right)$ and $a$. In [20], AISA imagery was used to measure chl- $a$, suspended solids, turbidity and other measures of water clarity from major rivers of Minnesota, USA. Although the use of airborne hyperspectral sensors showed to be an alternative to the development of bio-optical algorithms, because of the expenses of the acquisition and low temporal availability, airborne sensors have not been highly used for water quality monitoring.

An orbital hyperspectral sensor could be the solution for the high costs of flying an airborne sensor, and this was accomplished by the launch of Hyperion, in 2000. However, this sensor was not used in a water quality research because of its signal-to-noise ratio which was very low [21], and also because of its unreliability caused by problems such as radiometric instability. An alternative for the acquisition of hyperspectral images with a medium spatial resolution was the hyperspectral imager for the coastal ocean ( $\mathrm{HICO})$, a hyperspectral sensor with 87 spectral bands covering the visible and NIR range $(400-900 \mathrm{~nm})$ on-board of the International Space Station (ISS). HICO acquired programmed images from September 2009 to September 2014 with a spatial resolution of $90 \mathrm{~m}$, higher than MERIS (300 m) and MODIS (250, 500 and $1000 \mathrm{~m}$ ). Since HICO was a sensor developed for the monitoring of aquatic environments, several researches used it to monitor several parameters such as: seagrass and algae mapping [22], cloud removal [23], red tide detection [24], improved chl- $a$ detection [25] and harmful cyanobacteria bloom detection [26]. These studies showed strong relationships between these aquatic constituents and reflectance data which could be used to monitor water quality. They also highlight the importance of having an orbital hyperspectral sensor with a high signal-to-noise ratio to improve the development of bio-optical algorithms for inland and coastal waters. The bio-optical modeling of water quality parameters can be used as a complement to conventional monitoring programs which are usually based on sampling and analyzing of few spots in the aquatic system. Moreover, traditional monitoring programs are costly and time-consuming [27], while bio-optical modeling can quickly provide a synoptic view of the environment.

\subsection{Hypothesis}

Bio-optical algorithms developed for inland or deep ocean waters are unable to uptake empirical algorithms developed especially for extreme environments. 


\subsection{Objectives}

In this chapter, we attempted to present an overview of the application of bio-optical algorithms to monitor water quality parameters as well as to assess chl- $a$ and turbidity from a hypersaline tropical lake (Araruama Lagoon) in Rio de Janeiro, Brazil, using HICO imagery and different bio-optical algorithms. A secondary goal of this chapter was to evaluate the performance of bio-optical algorithms for the estimation of chl- $a$ and turbidity in an extreme aquatic system such as the Araruama Lagoon.

\section{Study site}

The Araruama Lagoon is a hypersaline coastal lagoon located in the central coast of Rio de Janeiro State, Southeastern Brazil, between latitudes $22^{\circ} 50^{\prime} \mathrm{S}$ and $22^{\circ} 57^{\prime} \mathrm{S}$ and the longitudes $42^{\circ} 00^{\prime} \mathrm{W}$ and $42^{\circ} 44^{\prime} \mathrm{W}$. It is situated in a micro-region called "Região dos Lagos", around 120 $\mathrm{km}$ from Rio de Janeiro City (Figure 1a,b). This region is densely populated showing a population density around 268 habitants per square kilometer [28]. The lagoon area encompasses five municipalities: Araruama, Arraial do Cabo, Cabo Frio, Iguaba Grande, São Pedro da Aldeia and Cabo Frio (see Figure 1c).

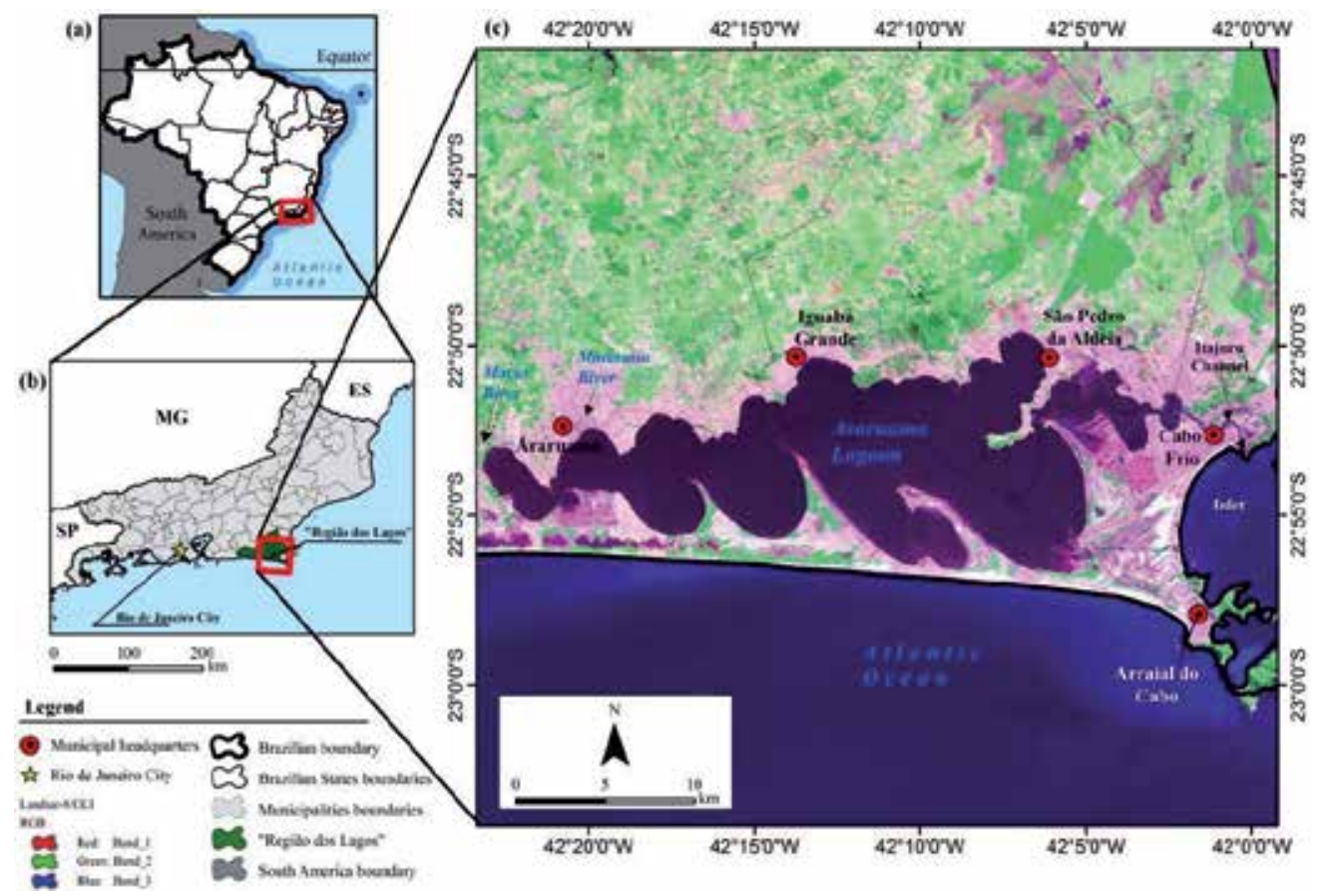

Figure 1. The Araruama Lagoon: (a) Location in Southeastern Brazil, (b) position within the Rio de Janeiro State, and (c) orbital image of the Araruama Lagoon acquired on 1st August 2015 by the Operational Land Imager (OLI) onboard Landsat- 8 satellite. The satellite images are presented in false color composition R4G5B2. 
From the morphological point view, the Araruama Lagoon consists of a series of elongated spits and shallow embayment presenting a longitudinal elongated shape with around $35 \mathrm{~km}$ in length and a mean width of $8 \mathrm{~km}$; the maximum width is around $13 \mathrm{~km}$. The surface area is around $220 \mathrm{~km}^{2}$ and the depth ranges from 1 to $17 \mathrm{~m}$; the mean depth is around $3 \mathrm{~m}$ [29]. The only connection between the Araruama Lagoon and sea, the Itajuru Channel, is located in the Cabo Frio City, Northeastern portion of the lagoon (see Figure 1c). The drainage basin covers around $320 \mathrm{~km}^{2}$, and permanent sources of freshwater come from Moças River and Mataruna River, in the Western portion of the Lagoon (see Figure 1c); the two rivers present a combined discharge of $1 \mathrm{~m}^{3} / \mathrm{s}$ [30].

The salinity of the Araruama Lagoon ranges from 35 to 43 practical salinity unit (psu) in the Itajuru Channel and from 46 to 56 psu in the main body of the Lagoon, being the salinity mainly balanced by the climatology of the area [29]. According to the Köppen-Ginger classification scheme [31], the climate in the region can be classified as Tropical Monsoon (Am) with rainfall ranging between 36 (August) and $101 \mathrm{~mm}$ per month (December) and the air temperature ranging from 21 (August) and $25.4^{\circ} \mathrm{C}$ (February-March) along the year ([32], see Figure 2); the mean annual precipitation is $771 \mathrm{~mm}$ per year and the mean air temperature is around $23^{\circ} \mathrm{C}$.

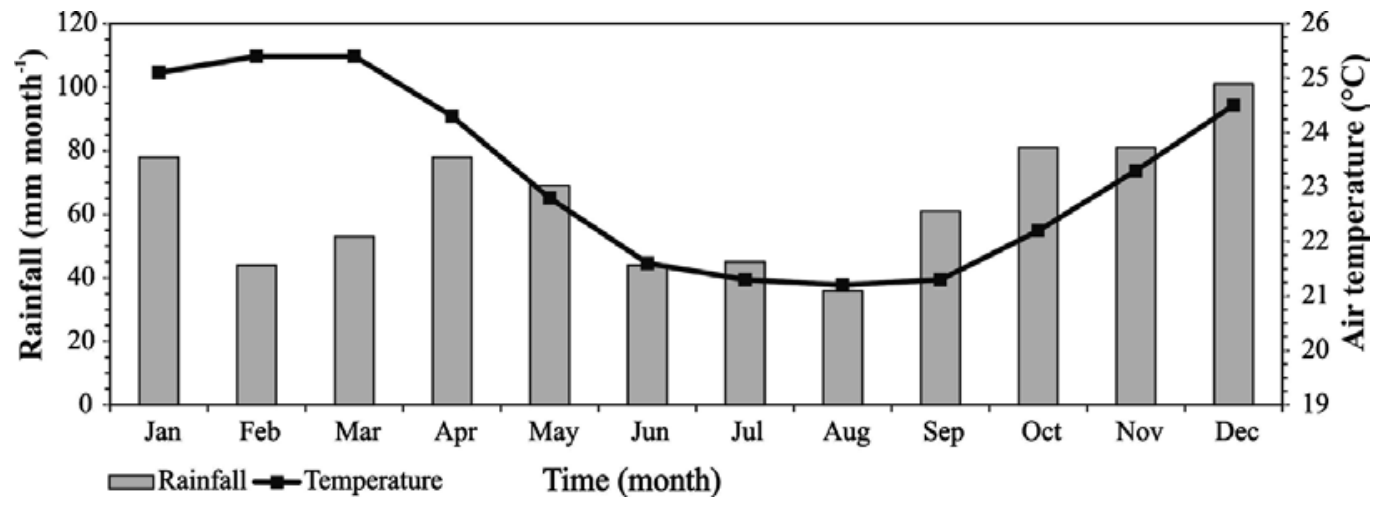

Figure 2. Climatological (1961-1990) monthly rainfall and air temperatures in the Araruama Lagoon region. Data registered on Cabo Frio meteorological station (Lat. -22.98 ${ }^{\circ}$; Long. $42.03^{\circ}$ ). Source [32].

The water quality in the Araruama Lagoon has changed over the time, showing an increasing eutrophication along the past few years as a result of the increasing urban growth in the Região dos Lagos [33]. According to the Trophic State Index (TSI) classification scheme proposed by [34], the Araruama Lagoon can be classified as eutrophic environment, with an average total phosphorous concentration around $0.09 \mathrm{mg} / \mathrm{L}$ and the average chl- $a$ concentration around 11.7 $\mu \mathrm{g} / \mathrm{L}$ [35]. Cyanobacteria (Synechococcus sp, Oscillatoria sp and Synechocystis sp) is the dominant community in the water column along the year (around $84 \%$ of the total cell count), followed by Diatomaceous (around $7 \%$ of the total cell count) and Dinoflagellates (around $5 \%$ of the total cell count) [36]. 


\section{Materials and methods}

\subsection{Remote sensing data}

HICO imageries of Araruama Lagoon were acquired from HICO's website database at Oregon State University (OSU) [37]. The acquisition of the images over Araruama Lagoon occurred from 2011 to 2013, where only images without cloud cover over the lagoon were selected. HICO images are available with a Level $1 \mathrm{~B}$ of processing, which corresponds to the radiance in the top of the atmosphere $\left(\mathrm{L}_{\mathrm{TOA}}\right)$ given in $\mathrm{Wm}^{-2} \mu^{-1} \mathrm{sr}^{-1}$ after the application of a division factor of 50. Table 2 lists the HICO imagery with clear sky over the Araruama Lagoon.

\begin{tabular}{lll}
\hline $\begin{array}{c}\text { Year } \\
\text { dulian }\end{array}$ & \multicolumn{1}{c}{ Image Name } \\
\hline 2011 & 220 & iss.2011220.0808.120519.L1B.GLT_Habitat_Brazil.v04.7594.20110809180058.100m.hico \\
\hline 2012 & 037 & iss.2012037.0206.112051.L1B.GLT_Habitat_Brazil.v04.9365.20120206182247.100m.hico \\
\hline 2012 & 040 & iss.2012040.0209.100728.L1B.GLT_Habitat_Brazil.v04.9394.20120209193848.100m.hico \\
\hline 2012 & 094 & iss.2012094.0403.122511.L1B.GLT_Habitat_Brazil.v04.9907.20120403190851.100m.hico \\
\hline 2012 & 282 & iss.2012282.1008.094232.L1B.GLT_Habitat_Brazil.v04.11631.20121009174522.100m.hico \\
\hline 2013 & 152 & iss.2013152.0601.114032.L1B.GLT_Habitat_Brazil.v04.13707.20130603175752.100m.hico \\
\hline 2013 & 215 & iss.2013215.0803.110724.L1B.GLT_Habitat_Brazil.v04.14303.20130805151206.100m.hico \\
\hline 2013 & 279 & iss.2013279.1006.094546.L1B.GLT_Habitat_Brazil.v04.14826.20131007170614.100m.hico \\
\hline
\end{tabular}

Table 2. List of clear sky HICO images over Araruama Lagoon

All these images were atmospherically corrected by the Second Signal in the Solar Spectrum (6S) implementation of Tafkaa algorithm [38]. Tafkaa is a radiative transfer algorithm developed mainly for applications in the field of oceanic hyperspectral remote sensing, and it is based on an earlier code named ATmospheric REMoval (ATREM) [39]. Tafkaa is available for processing HICO images online via a web tool [37], with prior registration. For the atmospheric correction over the Araruama Lagoon, the aerosol model was set to "maritime" and the atmospheric model was set to "tropical", since these characteristics seem to be the more appropriate for the study site. The final products of this process are delivered in units of $R_{r s}$ $\mathrm{sr}^{-1}$, and the spectra from the 12 sampling points of the Inter-Municipal Consortium Lagos São João [35] were obtained for the bio-optical modeling.

\subsection{Limnological data}

Chl- $a(\mu \mathrm{g} / \mathrm{L})$ and turbidity (NTU) data were acquired from the reports from the Inter-municipal Consortium Lagos São João, which are available at [35]. This consortium collects monthly data from 12 sampling points in the Araruama Lagoon and has the goal to propose and execute actions to recover the environment in the watershed of three different lagoons (Jaconé, 
Saquarema e Araruama) in Rio de Janeiro State, Brazil. Reports matching the HICO imagery (i.e., field campaigns that were carried out on the nearest date as possible as the images acquisition, Table 2) were used to acquire chl- $a$ and turbidity data and a total of 87 useful sampling locations were found. These data were divided into two datasets: calibration (53 sampling points using data from 2011 to 2012) and the validation (34 sampling points using data from 2013). Figure 3 shows box-plots to access the statistical distribution of the chl- $a$ ( $\mu \mathrm{g} /$ L) and turbidity (NTU) values from Araruama Lagoon that were used to calibrate and validate the bio-optical algorithms.

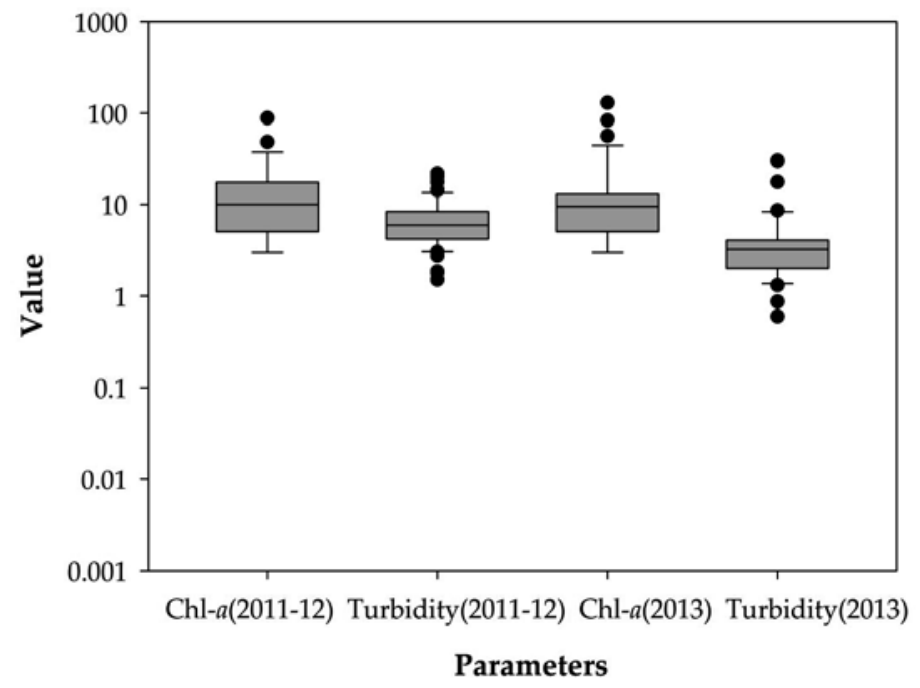

Figure 3. Box-plots of chl- $a(\mu \mathrm{g} / \mathrm{L})$ and turbidity (NTU) values used for calibration (2011-12) and for validation (2013) of the bio-optical algorithms.

\subsection{Bio-optical algorithms}

Several empirical and semi-empirical bio-optical algorithms for chl- $a$ and turbidity have been developed in the past decade. Since HICO is a hyperspectral sensor, it is possible to apply several bio-optical algorithms which use different spectral bands. For the estimation of chl- $a$ spectral features such low reflectance (troughs) at $\sim 430 \mathrm{~nm}$ and $\sim 670 \mathrm{~nm}$ caused by the absorption of chl- $a$ and a phytoplankton scattering peak at $\sim 700 \mathrm{~nm}$ are commonly used in the development of semi-empirical algorithms. The combination of these spectral features makes the ratio of between $R_{r s}$ around 700 and $670 \mathrm{~nm}$ [40] widely used for bio-optical algorithm for estimating chl- $a$ concentration in turbid waters. There are other algorithms that employ slight variations of this ratio, such as the three band algorithm [41] which uses a third band to minimize the effect of scattering which should be a spectral band with minimal absorption (usually around $750 \mathrm{~nm}$ ). Another variation is the four band algorithm [42] which includes a spectral band located near $700 \mathrm{~nm}$ to enhance the minimization of scattering of suspended matter at the NIR and the absorption by water. Recently, a Normalize Difference Chlorophyll 
Index (NDCI) [43] was proposed to estimate chl- $a$ concentrations in turbid waters and also used the relationship between 700 and $670 \mathrm{~nm}$. All these algorithms were proposed to estimate chl- $a$ concentration in turbid waters; however, for deep ocean waters chl- $a$ can also be estimated by algorithms based on band ratios focusing on the chl- $a$ absorption around $430 \mathrm{~nm}$ and the scattering of particulate matter around $560 \mathrm{~nm}$ [44].

\begin{tabular}{|c|c|c|}
\hline Name & Algorithm & Reference \\
\hline \multicolumn{3}{|c|}{ Chl-a Algorithms } \\
\hline $2 \mathrm{BDA}$ & $\frac{R_{r 5}\left(\operatorname{band}_{54}\right)}{R_{r s}\left(\operatorname{band}_{47}\right)}$ & {$[40]$} \\
\hline 3BDA & $\frac{R_{r s}\left(b_{\text {band }}\right)}{\left[R_{r 5}\left(\operatorname{band}_{47}\right)-R_{r 5}\left(\text { band }_{54}\right)\right]}$ & [41] \\
\hline $4 \mathrm{BDA}$ & $\left\{\left[\frac{1}{\left.R_{r s} \text { band }_{46}\right)}\right]-\left[\frac{1}{R_{r s}\left(\text { band }_{51}\right.}\right]\right\} /\left\{\left[\frac{1}{R_{r 5} \text { band }_{60)}}\right]-\left[\frac{1}{R_{r 5} \text { band }_{54}}\right]\right\}$ & [42] \\
\hline NDCI & $\frac{\left[R_{r 5}\left(\operatorname{band}_{54}\right)-R_{r 5}\left(\operatorname{band}_{47}\right)\right]}{\left[R_{r 5}\left(\operatorname{band}_{54}\right)+R_{r 5}\left(\operatorname{band}_{47}\right)\right]}$ & [43] \\
\hline ОС3А & $\frac{R_{r s}\left(\text { band }_{8}\right)}{R_{r s}\left(\text { band }_{27}\right)}$ & [44] \\
\hline ОС $3 \mathrm{~B}$ & $\frac{R_{r b}\left(\operatorname{band}_{16}\right)}{R_{r s}\left(\text { band }_{27}\right)}$ & [44] \\
\hline ОС $3 \mathrm{C}$ & $\frac{R_{r b}\left(\operatorname{band}_{20}\right)}{R_{r s}\left(\operatorname{band}_{27}\right)}$ & [44] \\
\hline \multicolumn{3}{|c|}{ Turbidity Algorithms } \\
\hline $1 \mathrm{BDA}$ & $R_{r s}\left(\right.$ band $\left._{43}\right)$ & [45] \\
\hline $2 \mathrm{BDA}$ & $\frac{R_{r b}\left(\text { band }_{81}\right)}{R_{r s}\left(\text { band }_{43}\right)}$ & [46] \\
\hline LSBA & $R_{r s}\left(b a n d_{15}\right)+R_{r s}\left(b a n d_{28}\right)$ & [47] \\
\hline
\end{tabular}

Table 3. List of bio-optical algorithms for chl- $a$ and turbidity using HICO spectral bands

Turbidity is usually identified by the high reflectance in the red and NIR spectral bands and is usually correlated to the total suspended solids concentration. Therefore, bio-optical algorithms for TSS can be used to estimate turbidity. The simplest algorithm uses the $R_{r s}$ at 645 $\mathrm{nm}$ to estimate turbidity [45]; however, other algorithms were also proposed to estimate turbidity using the relationship between NIR and red spectral bands, such as the band ratio proposed by [46]. Another algorithm to estimate turbidity is based on the sum of $R_{r s}$ in the blue and green spectral bands [47]. However, most of the algorithms were developed for inland, coastal or oceanic waters and have not been applied in extreme environments such as the hypersaline Araruama Lagoon. Table 3 lists the published semi-empirical bio-optical algo- 
rithms for chl- $a$ and turbidity evaluated in this chapter. The algorithms in this list are expressed according to the $87 \mathrm{HICO}^{\prime}$ s spectral bands.

\subsection{Bio-optical algorithm development}

Since the Araruama Lagoon is a hypersaline aquatic system, and the bio-optical algorithms listed in the previous section were develop for fresh or oceanic waters, we developed two empirical algorithms for the estimation of chl- $a$ and turbidity. The development of these empirical algorithms was conducted by calculating the correlation among different band ratios and the concentrations of chl- $a$ and turbidity values. To perform this analysis, we used a web tool named Interactive Correlation Environment (ICE) described by [48] and available at [49]. This web tool builds a two-dimensional correlation plot of the HICO's $R_{r s}$ and its relation to the interested limnological parameter (i.e., chl- $a$ or turbidity). The two-dimensional color correlation plot can cover all possible band ratios, which in the HICOs case is equal to 7,569 possible combinations, making it a useful tool for the analysis of hyperspectral measurements with a large number of spectral bands.

\subsection{Bio-optical algorithms comparison}

As described in Section 3.2, the data were divided in calibration (2011-12, 53 sampling points) and validation (2013, 34 sampling points) datasets. For the calibration dataset, a linear regression analysis was computed by the values of slope and intercept for each of the algorithms listed on Table 3 plus the two empirical algorithms developed by the use of ICE. The determination coefficient $\left(R^{2}\right)$ was also computed and the algorithms that had the highest $R^{2}$ values were used for validation.

The validation process was computed by analysing a scatter plot between the measured and the estimated values of chl- $a$ and turbidity. For chl- $a$, the concentration values were transformed to $\log (\operatorname{chl}-a)$ and for the turbidity, no transformation was needed. We also used errors estimators such as the root mean squared error (RMSE in $\mu \mathrm{g} / \mathrm{L}$ or NTU, equation 1 ) and the normalized root mean squared error (NRMSE, equation 2) to evaluate the performance of the bio-optical algorithms after their calibration.

$$
\begin{aligned}
& \text { RMSE }=\sqrt{\frac{1}{n} \sum_{i=1}^{n}\left(y_{i}-x_{i}\right)^{2}} \\
& N R M S E=\frac{R M S E}{\left(y_{i, \max }-y_{i, \min }\right)}
\end{aligned}
$$

where: $y_{i}$ and $x_{i}$ are the measured and predicted chl-a/turbidity values, respectively. In the $i$ th sample, $y_{i, \max }$ and $y_{i, \min }$ are the maximum and minimum chl-a/turbidity values, respectively. 


\section{Results and discussions}

\subsection{ICE's results}

To compute the two-dimensional color correlation plot, the $R_{r s}$ spectra were extracted from HICO imagery over the sampling locations in the Araruama Lagoon (Figure 4). Figure 4 presents the $R_{r s}$ spectra of the calibration (Figure $4 \mathrm{~A}$ ) and validation (Figure $4 \mathrm{~B}$ ) datasets. Both datasets presented spectral features of an eutrophic water, with a high reflectance peak in the green range around $550 \mathrm{~nm}$, a trough near $620 \mathrm{~nm}$, another trough around $665 \mathrm{~nm}$ and a peak in the NIR around $700 \mathrm{~nm}$. The reflectance peak around $550 \mathrm{~nm}$ represents the minimal absorption of all algal pigments and the scattering of non-organic suspended matter and phytoplankton cell walls [50]. The trough around $620 \mathrm{~nm}$ occurs due to the absorption of phycocyanin, a phycobillin presented in inland water cyanobacteria [51-52]. The trough around $665 \mathrm{~nm}$ is due to the absorption of chl- $a$ in the red range of the spectrum and the peak around $700 \mathrm{~nm}$ is also dependable of the chl- $a$ since it represents the scattering of the suspended matter which includes algal biomass [53]. The two-dimensional color correlation plot was computed using the $R_{r s}$ from the calibration dataset as well as the limnological dataset presented in Section 3.2.
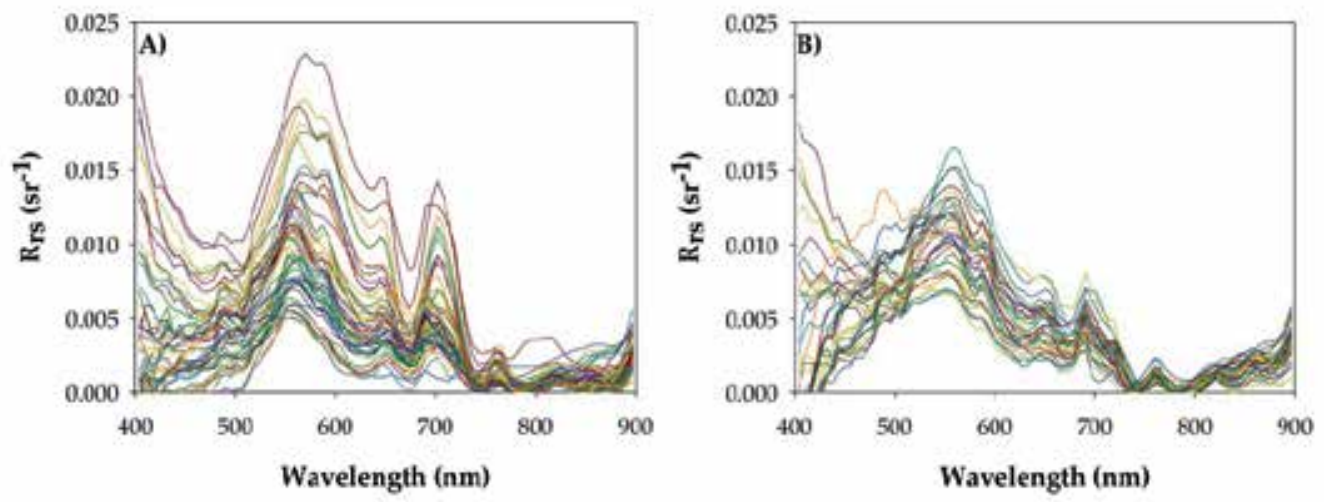

Figure 4. $R_{r s}$ spectra from HICO imagery after atmospheric correction. A) $R_{r s}$ spectra from 2011 and 2012 used for the calibration; B) $R_{r s}$ spectra from 2013 used for the validation.

The use of ICE generates two different two-dimensional color correlation plots, one for chl- $a$ (Figure 5A) and one for turbidity (Figure 5C). Using the filtering tool implemented in ICE, it was possible to select the band ratio that gives the highest $R^{2}$ for each of the parameters. Figure $5 \mathrm{~B}$ shows the filtered plot for chl- $a$ estimation which highlights only the band ratios with high $R^{2}$, Figure 5D shows the same filtered plot for the turbidity. Since the choices of spectral bands are only based on the statistical estimators among all possible band ratios, the algorithms 
derived from this web tool can be classified as empirical, and does not have a biophysical background to support the spectral bands used in each band ratio.
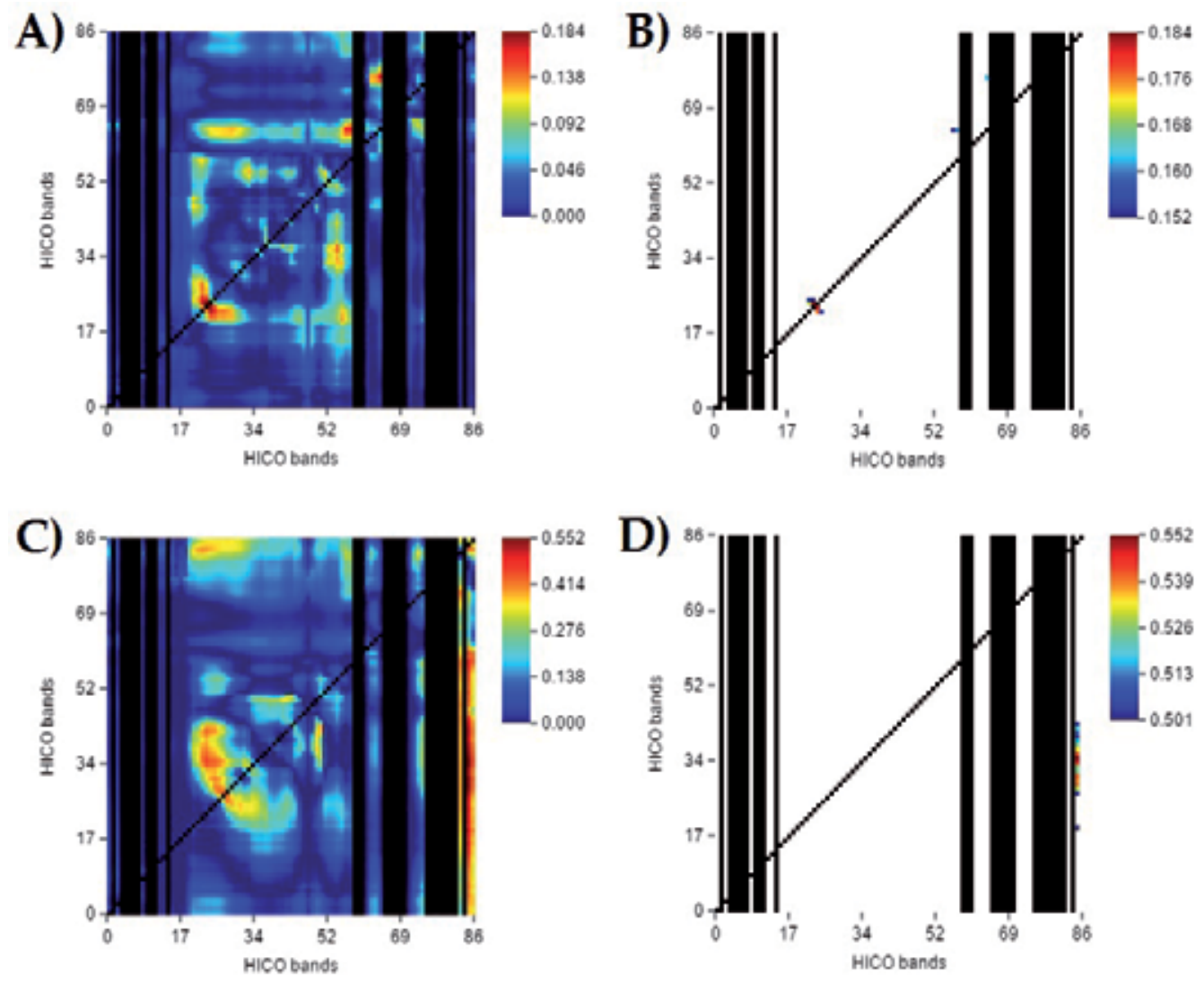

Figure 5. Two-dimensional color correlation plots produced by the web tool. (A) For chl- $a$ estimation; (B) After the filtering the chl- $a$ plot; (C) For turbidity estimation; (D) After the filtering the turbidity plot.

For chl- $a$ the best $R^{2}$ was found in correlation to the ratio between band 26 and band 25 which in wavelengths are around 547 and $541 \mathrm{~nm}$, respectively. This relationship is totally empirical and since both bands are very close to each other, the value from this ratio is probably close to 1 . For the turbidity band ratio, ICE selected the ratio between band 36 and band 87 , which respectively corresponds to 604 and $896 \mathrm{~nm}$. Although it is an empirical model, these two bands can be justified by the fact in both wavelengths the suspended matter will have a high scattering, and if the suspended matter is high, the turbidity will also be high. The formulation and name of these two empirical bio-optical algorithms were described in Table 4. 


\begin{tabular}{lcc}
\hline Name & Parameter & Algorithm \\
\hline EMPC & Chl- $a$ & $\frac{R_{r 5}\left(\text { band }_{26}\right)}{R_{r 5}\left(\text { band }_{25}\right)}$ \\
\hline EMPT & Turbidity & $\frac{R_{r 5}\left(\text { band }_{36}\right)}{\left.R_{r 5} \text { band }_{87}\right)}$ \\
\hline
\end{tabular}

Table 4. Empirical algorithms for chl- $a$ and turbidity developed using ICE

\subsection{Algorithms performances}

\subsubsection{Calibration}

Calibration was conducted using the semi-empirical (Table 3) and empirical (Table 4) biooptical algorithms. Linear regressions were computed between bio-optical algorithms and chl$a$ and TSS values; the $R^{2}$, slope and intercept from each of the regressions were shown in Table 5 . For the calibration of chl- $a$ algorithms, all the algorithms showed a poor performance with the highest $R^{2}$ value of 0.087 found by applying EMPC to the calibration dataset. The other high values of $R^{2}$ were found by using OC3C (0.065), OC3B (0.037) and 4BDA (0.011), which showed that algorithms developed for deep ocean (OC3B and $\mathrm{OC} 3 \mathrm{C}$ ) have better performance than algorithms developed for inland waters (4BDA). If compared to other Brazilian tropical inland water aquatic systems, the performance of 2BDA, 3BDA and NDCI showed $R^{2}$ values higher than 0.9 during the calibration step [12]. However, for the Araruama Lagoon, the $R^{2}$ values from these three algorithms were lower than 0.003 . This difference in the performance could be related to the fact that Araruama Lagoon is a hypersaline environment and the high concentration of salt in the water could be masking the results, although the $R_{r s}$ spectra show the features of a reservoir dominated by cyanobacteria. This poor performance in the calibration of all algorithms highlights the importance of having an extreme environment as a study site in bio-optical modeling studies, since one of the goals of this field is to have an algorithm that can perform well in different aquatic systems.

The poor performance of all algorithms could be associated to the fact that none of these algorithms were developed for hypersaline aquatic systems, which make their calibration difficult in this type of environment. Another source of error could be associated to the temporal window between the image acquisition and field sampling. Since we are using ground truth data that are collected as part of a routine monthly monitoring, we could not find an exact match with temporal windows ranging from 2 to more than 10 days. This can lead to erroneous interpretations since the dynamics of parameters, mainly the biotic ones such as phytoplankton, in the water column can change within days according to the environment dynamics. Adopting a 3-days window, the calibrations showed in Table 5 improved mainly for the chl- $a$ algorithms. Table 6 shows the calibrations using only the images within the 3days window from the field campaign, which shows that EMPC got a $R^{2}$ value of 0.43 , while using the entire dataset the $R^{2}$ value was around 0.08 . For the turbidity estimations, the improvement was not big as for the chl- $a$ estimations varying from an $R^{2}$ of 0.574 for the 1BDA using the entire dataset to an $R^{2}$ of 0.596 using only the 3-days window data. These results 


\begin{tabular}{lccc}
\hline & \multicolumn{2}{c}{ Chl-a algorithms } & \\
\hline Name & $\mathbf{R}^{2}$ & Slope & Intercept \\
\hline 2BDA & $<0.001$ & -0.026 & 14.369 \\
\hline 3BDA & 0.002 & -0.256 & 14.270 \\
\hline 4BDA & 0.011 & 9.806 & 14.097 \\
\hline NDCI & 0.003 & 7.878 & 12.561 \\
\hline OC3A & 0.006 & -4.510 & 15.753 \\
\hline OC3B & 0.037 & -16.635 & 21.911 \\
\hline OC3C & 0.065 & -29.037 & 28.519 \\
\hline EMPC & 0.087 & 101.760 & -98.513 \\
\hline & & Turbidity algorithms & Intercept \\
\hline Name & $\mathbf{R}^{2}$ & Slope & 1.1929 \\
\hline 1BDA & 0.574 & 1145.1 & 8.2162 \\
\hline 2BDA & 0.127 & -3.5418 & 0.3646 \\
\hline LSBA & 0.385 & 453.18 & 3.518 \\
\hline EMPT & 0.450 & 1.2385 & 18 \\
\hline
\end{tabular}

Table 5. $\mathrm{R}^{2}$, slope and intercept of the linear regression from the bio-optical algorithms tested (shaded areas represents the algorithms that were used for validation)

showed that the calibration is most affected by the temporal window when a biotic parameter is being analysed.

Chl-a algorithms

\begin{tabular}{cccc}
\hline Name & $\mathbf{R}^{\mathbf{2}}$ & Slope & Intercept \\
\hline 4BDA & 0.049 & 19.022 & 15.061 \\
\hline OC3A & 0.223 & -33.516 & 29.576 \\
\hline OC3B & 0.186 & -23.12 & 23.798 \\
\hline EMPC & 0.430 & 159.3 & -164.79 \\
\hline Name & Turbidity algorithms & Intercept \\
\hline 1BDA & $\mathbf{R}^{2}$ & Slope & 3.054 \\
\hline 2BDA & 0.596 & 1031.2 & 10.512 \\
\hline LSBA & 0.211 & -3.193 & 2.757 \\
\hline EMPT & 0.509 & 437.33 & 5.550 \\
\hline
\end{tabular}

Table 6. $\mathrm{R}^{2}$, slope and intercept of the linear regression from the bio-optical algorithms tested using a 3 days temporal window 
If compared to the performance of 2BDA and 3BDA for the estimation of chl- $a$ in Taganrog Bay [25] the calibration for Araruama is poor, since the $R^{2}$ values found by [25] were 0.84 and 0.87 for the 2DBA and 3BDA, respectively. However, if compared to another hypersaline environment, such as Mono Lake, CA, USA, the results are equivalent since an $R^{2}$ of 0.49 was found to correlate chl- $a$ and a bio-optical algorithm developed for the airborne visible/infrared imaging spectrometer (AVIRIS) sensor [54]. These results highlight the current need for a global database of bio-optical modeling data for inland waters, as well as the development of more semi- and quasi-analytical algorithms. Although few attempts have been proposed to create a global database of bio-optical modeling data for inland waters [55-56], we still need an organization such as the International Ocean Colour Coordinating Group (IOCCG) to coordinate the protocols, products and database of algorithms and bio-optical modeling data. Thus, the global bio-optical modeling of inland waters will only be achieved when we have algorithms developed and tested for all different types of environments.

\subsubsection{Validation}

The validation of the bio-optical algorithms with the best $R^{2}$ in the calibration was computed using two different methods: validation plots between the measured and the estimated values of chl- $a$ and turbidity and error estimators. Figure 6 showed the validation plots for the four bio-optical algorithms analysed in this chapter: 4BDA (Figure 6A), OC3C (Figure 6B), OC3B (Figure 6C) and EMPC (Figure 6D). The dashed red line represents the 1:1 line where the points of the scatter plot should be over that line. In Figure 6A, we observed that the points are vertically distributed showing that there is no variation in the estimated values of log (chl-a); however, the error estimator showed that 4BDA has the lowest NRMSE of $24.13 \%$ among the tested algorithms. This fact showed that error estimators are only statistical and do not represent well the reality of the distribution of the data. Figure $6 \mathrm{~B}$ and $6 \mathrm{C}$ showed the results for the algorithms proposed for ocean color remote sensing, OC3B and OC3C, the NRMSE for these bio-optical algorithms were $27.37 \%$ and $30.80 \%$, respectively. The validation plots for both bio-optical algorithms showed a better distribution than the 4BDA since they showed a better distribution over the 1:1 line. However, both of the ocean color algorithms showed to underestimate (Figures 6B and 6C) the high values of $\log (\mathrm{chl}-a)$. Figure $6 \mathrm{D}$ showed the scatter plot for the empirical algorithm (EMPC), which showed a NRMSE of $30.46 \%$. This validation plot showed a similar pattern to the previous semi-empirical models and also underestimate the values of $\log (\operatorname{chl}-a)$.

Based on these results for the chl- $a$ bio-optical algorithms, we observed that although the lowest NRMSE was found in the 4BDA, the validation plots showed that the other algorithms showed a better distribution and can explain better the estimation of the log (chl-a). Therefore, OC3B showed the best performance with a NRMSE of $27.37 \%$ and a validation plot that underestimates the high values of chl- $a$. This underestimation was expected since for the ocean color bio-optical modeling the concentration of chl- $a$ is not high and in the case of Araruama Lagoon the concentration can reach $130 \mu \mathrm{g} / \mathrm{L}$ of chl- $a$. As discussed in the calibration results, if compared to another tropical inland water body, the NRMSE are higher. In [12] the NRMSE founded for 2BDA, 3BDA and NDCI were $18.32 \%, 19.68 \%$ and $17.85 \%$, respectively, for bio- 
optical models calculated using proximal hyperspectral sensor. These differences can be related to the atmospheric correction, which is not needed for the proximal hyperspectral sensor [12], but also for the fact that Araruama Lagoon has a very unique biogeochemical cycling, which could lead to different composition of the water column. Overall, more studies should be conducted in Araruama Lagoon to better understand the optical properties in this aquatic system.

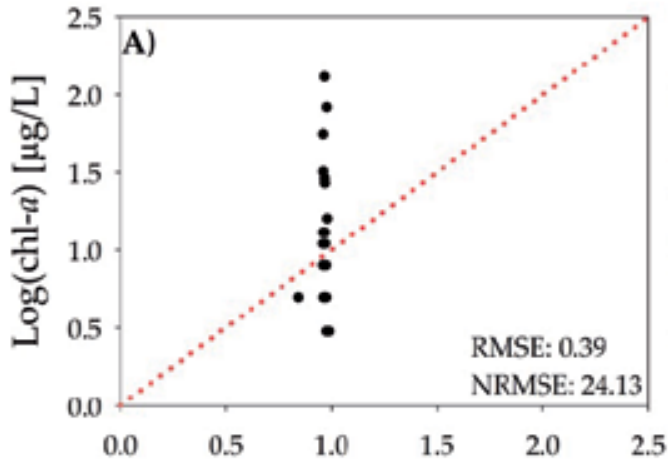

Estimated $\log (\mathrm{chl}-a)[\mu \mathrm{g} / \mathrm{L}]$

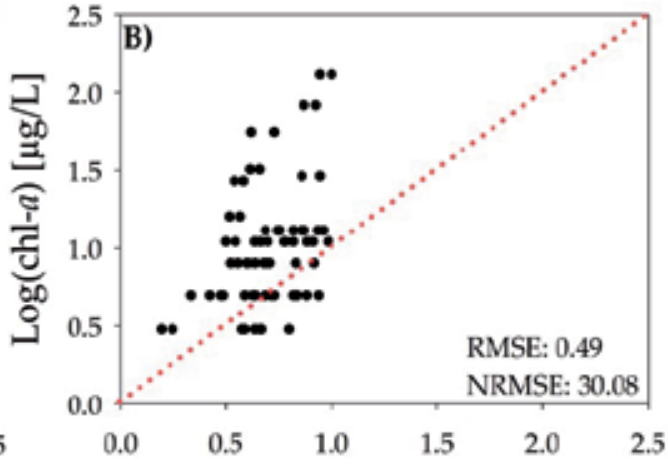

Estimated $\log (\mathrm{chl}-a)[\mu \mathrm{g} / \mathrm{L}]$

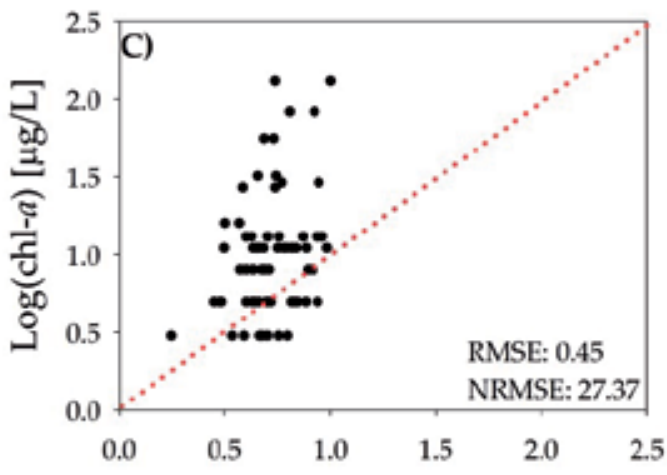

Estimated $\log (\mathrm{chl}-a)[\mu \mathrm{g} / \mathrm{L}]$

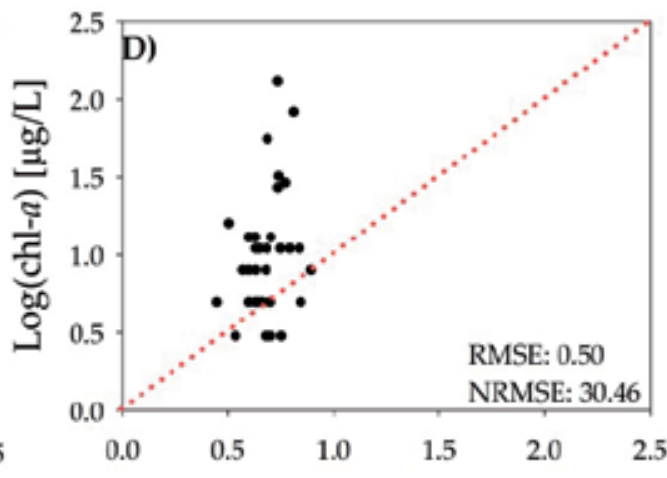

Estimated $\log (\mathrm{chl}-a)[\mu \mathrm{g} / \mathrm{L}]$

Figure 6. Validation plots for the chl- $a$ bio-optical algorithms: (A) 4BDA; (B) OC3C; (C) OC3B; (D) EMPC

The validation for the turbidity bio-optical algorithms showed a better agreement between the validation plots and the error estimators. Figure 7 showed the validation plots for the four biooptical algorithms analysed in this chapter: 1BDA (Figure 7A), 2BDA (Figure 7B), LSBA (Figure 7C) and EMPT (Figure 7D). The lowest NRMSE was $15.49 \%$ and was achieved by applying the $1 \mathrm{BDA}$ to the $R_{\mathrm{rs}}$ data (Figure 7A); the validation plot also showed most of the points close to the 1:1 line, but as well as for the chl- $a$ algorithms for high values of turbidity the algorithms underestimated the values. The empirical algorithm (EMPT) had the second best NRMSE 
(17.87\%) among the turbidity bio-optical algorithms analysed and the validation plot showed to be similar to the previous algorithm. 2BDA and LSBA showed a NRMSE of $22.37 \%$ and $28.04 \%$, respectively, which are higher than the 1BDA and EMPT algorithms. The validation plot for 2BDA and LSBA also showed a worst distribution of the scatter points and also showed an underestimation of the high values of turbidity. Overall, the performance of 1BDA showed the best validation plot and NRMSE value among the four bio-optical algorithms analysed in this chapter.

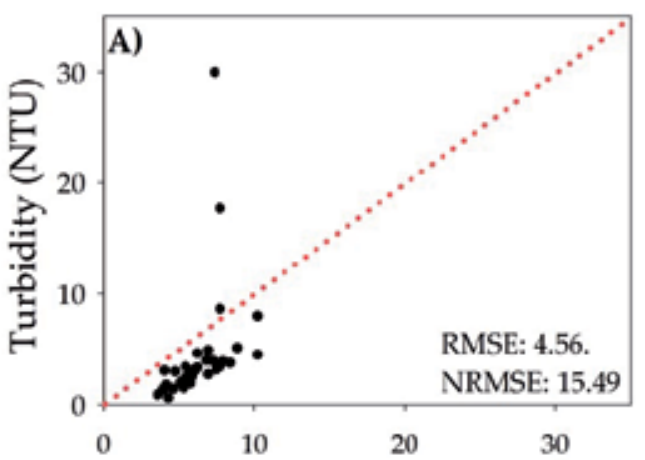

Estimated Tubidity(NTU)

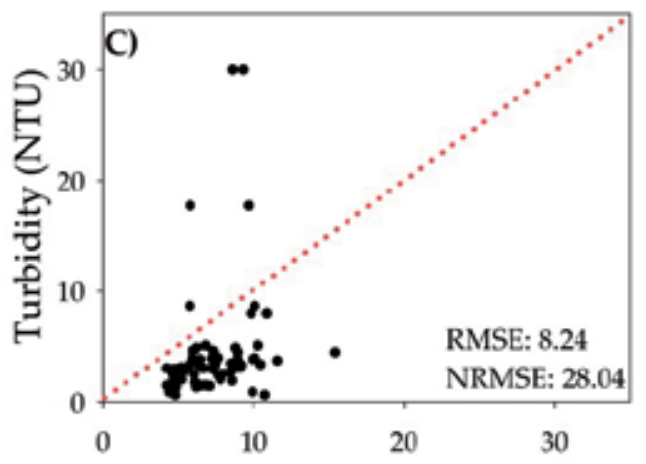

Estimated Tubidity(NTU)

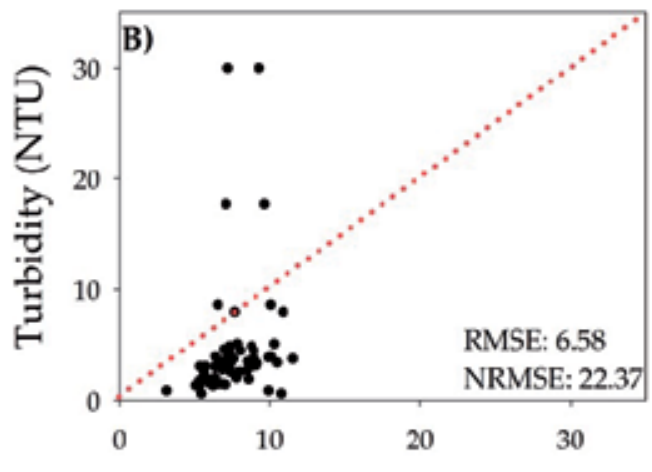

Estimated Tubidity(NTU)

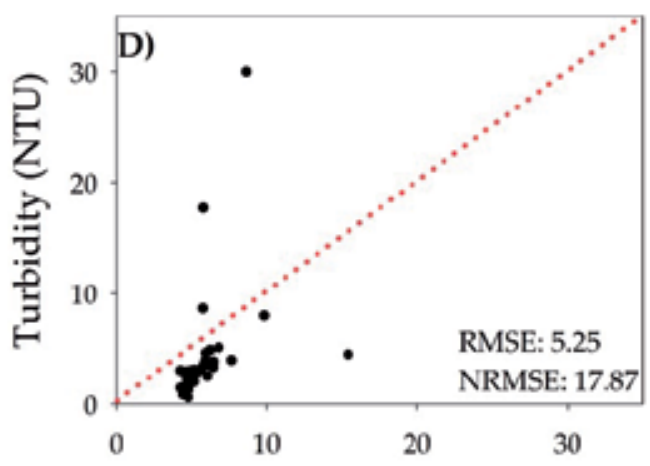

Estimated Tubidity(NTU)

Figure 7. Validation plots for the turbidity bio-optical algorithms: (A) 1BDA; (B) 2BDA; (C) LSBA; (D) EMPT

\subsection{Spatial distribution}

Applications of bio-optical modeling to monitor water quality in inland waters have been increasing in the past decade, and this increase is also noticed in the public and private sector investments on remote sensing technologies to monitor water quality and quantity. The advantages of using remote sensing technologies over traditional methods to monitor water 
quality parameters were already discussed in the introduction of this chapter; however, another advantage of using remote sensing is in the spatial distribution of the data. While using traditional methods of water quality monitoring computes the spatial assessment of the water quality by performing spatial interpolations or by geostatistical methods of few sampling points, remote sensing images can provide different values for each pixel within the aquatic system. The difference is that the few sampling points used to interpolate the data for the aquatic system area is now replaced for several pixels values in the image, where the interpolation is not needed; therefore, it does not have the error caused by data interpolation methods. Figure 8 shows the spatial distribution of chl- $a$ and turbidity in the Araruama Lagoon where we observed that the west part of the lagoon has the highest values of chl- $a$ and for the turbidity regions close to the bays have highest turbidity values. These spatial patterns are related to the hydrodynamic of the aquatic system, and the combination of bio-optical and hydrodynamic modeling [57] is a powerful tool to understand the spatial dynamics of the environment.
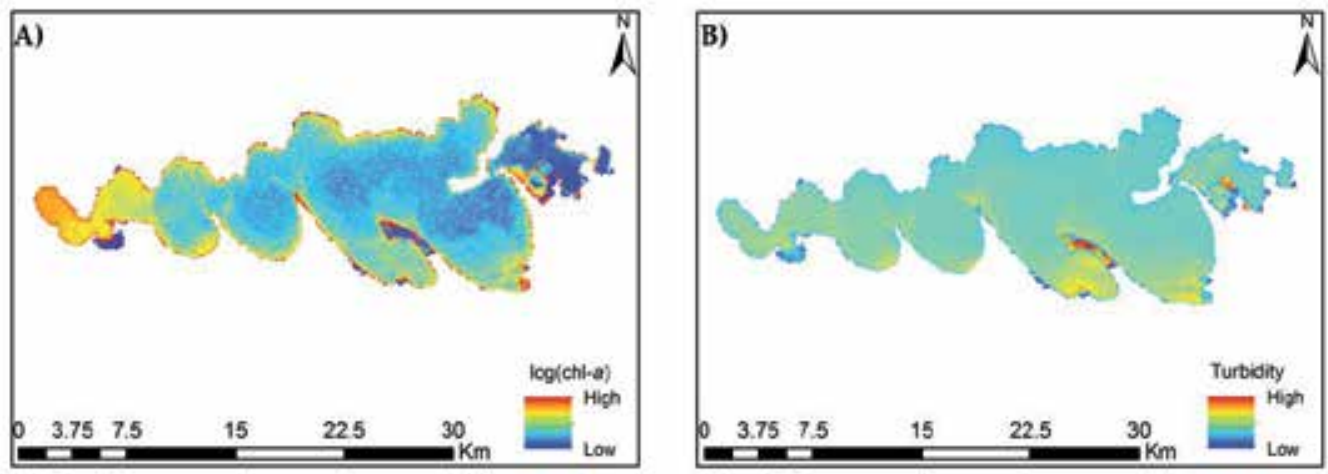

Figure 8. Application of the bio-optical algorithms to the HICO image from Araruama Lagoon acquired on August 3 , 2013. (A) Application of calibrated OC3C; (B) Application of calibrated 1BDA

\section{Final considerations}

Based on the case study of Araruama Lagoon, we observe the need for calibration and validation of bio-optical algorithms in different inland waters since the variability of water column constituents from region to region is big. We also observe that the use of orbital hyperspectral sensors is important for the development of bio-optical modeling due to the number of spectral bands which allow us to study small features, such as the absorption peak of PC around $620 \mathrm{~nm}$. Thus, narrow spectral bands can highlight specific absorption features which can be used in the development and improvement of bio-optical algorithms, mainly the semi- and quasi-analytical algorithms which are based on the radiative transfer theory. Therefore, future hyperspectral missions such as the Hyperspectral Imager SUIte (HISUI), the PRecursore IperSpettrale della Missione Applicativa (PRISMA), and the Environmental 
Mapping and Analysis Program (EnMAP) are important for the development of bio-optical modeling.

Moreover, these new hyperspectral missions will support a global mapping of inland water quality which is only possible through multispectral sensors such as Landsat, MODIS and MERIS. However, not all water quality parameters are possible to be measured only using multispectral sensors, for example, the Landsat series which have a poor spectral resolution that does not detect the spectral features such as peaks and trough of chl- $a$. MODIS, on the other hand, have a narrow band moderate spectral resolution; however, its spatial resolution makes the monitoring of small and medium inland water bodies difficult. Therefore, the development of new global hyperspectral sensors will make the assessment of water quality through remote sensing possible because of the high spectral and spatial resolution.

Finally, our case study showed that even by developing an empirical algorithm, the semiempirical algorithms outperform them. The best performance for chl- $a$ bio-optical algorithms was found by applying OC3B (NRMSE of 27.37\%) and for turbidity, the 1BDA showed the best performance with a NRMSE of $15.49 \%$. Although the lower errors estimators validation plots (Figures 6 and 7) showed that all algorithms underestimated the high values of chl-a and turbidity, highlighting the need of different calibrations for different water types. This chapter showed a very small set of methods used in bio-optical modeling and also highlighted the need for development and improvement of bio-optical algorithms.

\section{Acknowledgements}

We thank the HICO team at Oregon State University (OSU), especially Jasmine Nahorniak for providing access to the database and to all her attention to us. C. A. S. Araújo thanks the Brazilian National Counsel of Technological and Scientific Development (CNPq) for the PCI fellowship (under the grant 300177/2015-1). M. P. Curtarelli also thanks the CNPq for the graduate scholarship (under the grant 161233/2013-9).

\section{Author details}

Igor Ogashawara ${ }^{1 *}$, Marcelo P. Curtarelli ${ }^{2}$, Carlos A. S. Araujo ${ }^{2}$ and José L. Stech ${ }^{2}$

*Address all correspondence to: igoroga@gmail.com

1 Department of Earth Sciences, Indiana University - Purdue University at Indianapolis (IUPUI), Indianapolis, IN, USA

2 Remote Sensing Division, National Institute for Space Research (INPE), São José dos Campos, SP, Brazil 


\section{References}

[1] Jensen JR. Remote Sensing of the Environment: An Earth Resource Perspective. 2nd ed. Upper Saddle River, NJ: Prentice-Hall; 2007. 592 p.

[2] Mobley C. Radiative Transfer in the Ocean. In: Steele JH. (Ed.) Encyclopedia of Ocean Sciences. 1st ed. London: Academic Press; 2001. pp. 2321-2330.

[3] Platt T, Hoepffner N, Stuart V, Brown C. (Eds.) Ocean colour? The societal benefits of ocean-colour technology. Reports of the International Ocean-Colour Coordinating Group, No. 7.. 1st ed. Dartmouth, Canada: IOCCG; 2008.

[4] Cox C, Munk W. Measurement of the roughness of the sea surface from photographs of the sun's glitter. J Optic Soc Am 1954;44(11):838-50.

[5] Petzold TJ. Volume scattering functions for selected ocean waters. Ref. 72-28. San Diego, CA: Scripps Institute of Oceanography, University of California; 1972. 79 p.

[6] Jerlov NG. Optical oceanography. Elsevier Oceanographic Series, v. 5. Amsterdam: Elsevier; 1968. 194 p.

[7] Jerlov NG. Marine optics. Elsevier Oceanographic Series, v. 14. ed. Amsterdam: Elsevier; 1976. 231 p.

[8] Preisendorfer RW. Hydrologic optics. Vol. II: Foundations ed. Washington, DC: U.S. Dept. of Commerce; 1976.

[9] Gordon HR, Brown OB, Jacobs MM. Computed Relationships between the Inherent and Apparent Optical Properties of a Flat Homogeneous Ocean. Appl Optic 1975;14(2):417-27.

[10] Bukata RP, Jerome JH, Bruton JE, Jain SC. Determination of inherent optical properties of Lake Ontario coastal waters. Appl Optic 1979;18(23):3926-32.

[11] Ogashawara I. Terminology and classification of bio-optical algorithms. Remote Sens Lett 2015;6(8):613-7. DOI: 10.1080/2150704X.2015.1066523

[12] Augusto-Silva PB, Ogashawara I, Barbosa CCF, Carvalho LAS, Jorge DSF, Fornari CI, Stech JL. Analysis of MERIS reflectance algorithms for estimating chlorophyll-a concentration in a Brazilian reservoir. Remote Sens 2014;6:11689-707. DOI: 10.3390/ rs61211689

[13] Matthews MW, Odermatt D. Improved algorithm for routine monitoring of cyanobacteria and eutrophication in inland and near-coastal waters. Remote Sens Environ 2015;156:374-82. DOI: 10.1016/j.rse.2014.10.010

[14] Ogashawara I, Alcantara EH, Curtarelli MP, Adami M, Nascimento RFF, Souza, AF, Stech JL, Kampel M. Performance analysis of MODIS 500-m spatial resolution products for estimating chlorophyll-a concentrations in oligo- to meso-trophic waters case 
study: Itumbiara Reservoir, Brazil. Remote Sens 2014;6:1634-53. DOI: 10.3390/ rs6021634

[15] Feng L, Hu C, Chen X, Qingjun S. Influence of the Three Gorges Dam on total suspended matters in the Yangtze Estuary and its adjacent coastal waters: Observations from MODIS. Remote Sens Environ 2014;140:779-88. DOI: 10.1016/j.rse.2013.10.002

[16] El-Alem A, Chokmani K, Laurion I, El-Adlouni SE. Comparative analysis of four models to estimate chlorophyll-a concentration in case-2 waters using MODerate resolution imaging spectroradiometer (MODIS) imagery. Remote Sens 2012;4:2373-400. DOI: $10.3390 / \mathrm{rs} 4082373$

[17] Hu C. A novel ocean color index to detect floating algae in the global oceans. Remote Sens Environ 2009;113:2118-29. DOI: 10.1016/j.rse.2009.05.012

[18] Li L, Sengpiel RE, Pascual DL, Tedesco LP, Wilson JS, Soyeux E. Using hyperspectral remote sensing to estimate chlorophyll-a and phycocyanin in a mesotrophic reservoir. Int J Remote Sens 2010;31(15):4147-62. DOI: 10.1080/01431161003789549

[19] Li L, Li L, Song K, Li Y, Tedesco LP, Shi K, Li Z. An inversion model for deriving inherent optical properties of inland waters: Establishment, validation and application. Remote Sens Environ 2013;135:150-66. DOI: 10.1016/j.rse.2013.03.031

[20] Olmanson LG, Brezonik PL, Bauer ME. Airborne hyperspectral remote sensing to assess spatial distribution of water quality characteristics in large rivers: The Mississippi River and its tributaries in Minnesota. Remote Sens Environ 2013;130:254-65. DOI: 10.1016/j.rse.2012.11.023

[21] Hu C, Feng L, Lee L, Davis CO, Mannino A, McClain CR, Franz BA. Dynamic range and sensitivity requirements of satellite ocean color sensors: Learning from the past. Appl Optic 2012;51(25):6045-62. DOI: 10.1364/AO.51.006045

[22] Cho HJ, Ogashawara I, Mishra D, White J, Kamerosky A, Morris L, Clarker C, Simpson A, Banisakher D. Evaluating Hyperspectral Imager for the Coastal Ocean (HICO) data for seagrass mapping in Indian River Lagoon, FL. GISci Remote Sens 2014;51:120-38. DOI: 10.1080/15481603.2014.895577

[23] Gao BC, Li RR. Removal of think cirrus scattering effects for remote sensing of ocean color from space. IEEE Geosci Remote Sens Lett 2012;9:972-6. DOI: 10.1109/LGRS. 2012.2187876

[24] Ryan JP, Davis CO, Tufllaro NB, Kudela RM, Gao BC. Application of the hyperspectral imager for the coastal ocean to phytoplankton ecology studies in Monterey Bay, CA USA. Remote Sens 2014;6:1007-25. DOI: 10.3390/rs6021007

[25] Moses WJ, Gitelson AA, Berdnikov S, Bowles JH, Povazhnyi V, Sapryngin V, Wagner EJ, Patterson KW. HICO-based NIR-red models for estimating chlorophyll-a concentration in productive coastal waters. IEEE Geosci Remote Sens Lett 2014;11(6):1111-5. DOI: $10.1109 /$ LGRS.2013.2287458 
[26] Kudela RM, Palacios SL, Austerberry DC, Accorsi EK, Guild LS, Torres-Perez JL. Application of hyperspectral remote sensing to cyanobacterial blooms in inland waters. Remote Sens Environ 2015;167:196-205. DOI: 10.1016/j.rse.2015.01.025

[27] Duan H, Ma R, Xu J, Zhang Y, Zhang B. Comparison of different semi-empirical algorithms to estimate chlorophyll-a concentration in inland lake water. Environ Monitor Assess 2010;170:231-44. DOI: 10.1007/s10661-009-1228-7

[28] Instituto Brasileiro de Geografia e Estatística (IBGE). Demographic Census [Internet]. 2010. Available from: http://www.ibge.gov.br/home/estatistica/populacao/censo2010/ [Accessed: 01 Sep 2015]

[29] Kjerfve B, Schettini CAF, Knoppers B, Lessa G, Ferreira HO. Hydrology and salt balance in a large, hypersaline coastal lagoon: Lagoa de Araruama, Brazil. Estuarine, Coastal Shelf Sci 1996;42:701-25.

[30] Braga CZF, Vianna ML, Kjerfve B. Environmental characterization of a hypersaline coastal lagoon from Landsat-5 Thematic Mapper data. Int J Remote Sens 2003;24:3219-34. DOI: 10.1080/0143116031000075099

[31] Peel MC, Finlayson BL, McMahon TA. Updated world map of the Köppen-Geiger climate classification. Hydrol Earth System Sci 2007;11:1633-44. DOI: 10.5194/ hess-11-1633-2007

[32] Empresa Brasileira de Pesquisa Agropecuária (EMBRAPA). Brazilian climatic database [Internet]. 2003. Available from: http://www.bdclima.cnpm.embrapa.br/ [Accessed: 01 Sep 2015]

[33] Mello TBM. Caracterização Biogeoquímica da Lagoa de Araruama, RJ [thesis]. Niterói: Universidade Federal Fluminense - Instituto de Química; 2007. 82 p. [in Portuguese]

[34] Lamparelli MC. Grau de trofia em corpos d'água do estado de São Paulo: avaliação dos métodos de monitoramento [dissertation]. São Paulo: São Paulo University - Department of Ecology; 2004. 235 p. [in Portuguese]

[35] Comitê de Bacias Lagos São João. Phytoplankton monitoring of the Araruama Lake [Internet]. 2012. Available from: http://www.lagossaojoao.org.br/nc-relatorioqualiaguas.htm [Accessed: 25 Aug 2015] [in Portuguese]

[36] Comitê de Bacias Lagos São João. Monthly water quality Report [Internet]. 2014. Available from: http://www.lagossaojoao.org.br/nc-relatorioqualiaguas.htm [Accessed: 25 Aug 2015] [in Portuguese]

[37] Oregon State University. HICO - Hyperspectral Imager for the Coastal Ocean [nternet]. 2015. Available from: http://hico.coas.oregonstate.edu/ [Accessed: 01 Sep 2015] 
[38] Gao BC, Montes MJ, Ahmad Z, Davis CO. Atmospheric correction algorithm for hyperspectral remote sensing of ocean color from space. Appl Optic 2000;39(6):887-96. DOI: $10.1364 / A O .39 .000887$

[39] Gao BC, Goetz AFH. Column atmospheric water vapor and vegetation liquid water retrievals from airborne imaging spectrometer data. J Geophys Res 1990;95(D4):354964. DOI: 10.1029/JD095iD04p03549

[40] Dall'Olmo G, Gitelson AA. Effect of bio-optical parameter variability on the remote estimation of chlorophyll-a concentration in turbid productive waters: Experimental results. Appl Optic 2005;44:412-22. DOI: 10.1364/AO.44.000412

[41] Gitelson AA, Gritz U, Merzlyak MN. Relationships between leaf chlorophyll content and spectral reflectance and algorithms for non-destructive chlorophyll assessment in higher plant leaves. J Plant Physiol 2003;160:271-82. DOI: 10.1078/0176-1617-00887

[42] Le C, Li Y, Zha Y, Sun D, Huang C, Lu H. A four-band semi-analytical model for estimating chlorophyll a in highly turbid lakes: The case of Taihu Lake, China. Remote Sens Environ 2009;113:1175-82. DOI: 10.1016/j.rse.2009.02.005

[43] Mishra S, Mishra DR. Normalized difference chlorophyll index: A novel model for remote estimation of chlorophyll-a concentration in turbid productive waters. Remote Sens Environ 2012;117:394-406. DOI: 10.1016/j.rse.2011.10.016

[44] NASA Ocean Biology Processing Group. Ocean Color Chlorophyll (OC) v6 [Internet]. 18 Mar 2010. Available from: http://oceancolor.gsfc.nasa.gov/REPROCESSING/ R2009/ocv6/ [Accessed: 02 Sep 2015]

[45] Doxaran D, Babin DM, Leymarie E. Near-infrared light scattering by particles in coastal waters. Optics Exp 2007;15:12834-49. DOI: 10.1364/OE.15.012834

[46] Doxaran D, Froidefond JM, Castaing P, Babin M. Dynamics of the turbidity maximum zone in a macrotidal estuary (the Gironde, France): Observations from field and MODIS satellite data. Estuar Coastal Shelf Sci 2009;81(3):321-32. DOI: 10.1016/ j.ecss.2008.11.013

[47] Zhang Y, Lin S, Liu J, Qian X, Ge Y. Time-series MODIS image-based retrieval and distribution analysis of total suspended matter concentrations in Lake Taihu (China). Int J Environ Res Public Health 2010;7(9):3545-60. DOI: 10.3390/ijerph7093545

[48] Ogashawara I, Curtarelli MP, Souza AF, Augusto-Silva PB, Alcântara EH, Stech JL. Interactive correlation environment (ICE) - a statistical web tool for data collinearity analysis. Remote Sens 2014;6:3059-74. DOI: 10.3390/rs6043059

[49] Hidrosfera INPE. ICE - Interactive Correlation Environment [Internet]. 2014. Available from: http://www.dsr.inpe.br/hidrosfera/ice/ [Accessed: 02 Sep 2015] 
[50] Gitelson AA, Yacobi YZ, Schalles JF, Rundquist DC, Han L, Stark R, Etzion D. Remote estimation of phytoplankton density in productive waters. Arch Hydrobiol 2000;55:121-36.

[51] Ogashawara I, Mishra DR, Mishra S, Curtarelli MP, Stech JL. A performance review of reflectance based algorithms for predicting phycocyanin concentrations in inland waters. Remote Sens 2013;5:4774-98. DOI: 10.3390/rs5104774

[52] Dekker AG. Detection of Optical Water Quality Parameters for Eutrophic Waters by High [dissertation]. Amsterdam, the Netherlands: Vrije Universiteit; 1993.

[53] Gitelson AA. The peak near $700 \mathrm{~nm}$ on radiance spectra of algae and water: relationships of its magnitude and position with chlorophyll concentration. Int J Remote Sens 1992;13(17):3367-73. DOI: 10.1080/01431169208904125

[54] Melack JM, Gastil M. Airborne remote sensing of chlorophyll distributions in Mono Lake, California. Hydrobiologia 2001;466:31-8.

[55] GloboLakes. GloboLakes - Global Observatory of Lake Responses to Environmental Change [Internet]. [Updated: 2014]. Available from: http://www.globolakes.ac.uk/ [Accessed: 02 Sep 2015]

[56] GEO. Group on Earth Observations [Internet]. [Updated: 2015]. Available from: https://www.earthobservations.org/index.php [Accessed: 02 Sep 2015]

[57] Curtarelli MP, Ogashawara I, Alcântara EH, Stech JL. Coupling remote sensing biooptical and three-dimensional hydrodynamic modeling to study the phytoplankton dynamics in a tropical hydroelectric reservoir. Remote Sens Environ 2015;157:185-98. DOI: 10.1016/j.rse.2014.06.013 


\section{Section 4}

Sewage Leaks, and Enviroment Disasters 

Chapter 9

\title{
Utilization of Ground-Penetrating Radar and Frequency Domain Electromagnetic for Investigation of Sewage Leaks
}

\author{
Goldshleger Naftaly and Basson Uri \\ Additional information is available at the end of the chapter
}

http://dx.doi.org/10.5772/62156

\begin{abstract}
Fact 1: Underground sewage pipe systems deteriorate over time, developing cracks and joint defects; therefore, leakage is inevitable. Fact 2: The massive worldwide urbanization process, together with rural development, has meaningfully increased the length of sewage pipelines. Result: The concomitant risk of sewage leaks exposes the surrounding land to potential contamination and environmental harm. It is therefore important to locate such leaks in a timely manner, enabling damage control. Advances in active remote-sensing technologies (GPR and FDEM: ground-penetration radar and frequency domain electromagnetic) were used to identify sewage leaks that might cause pollution and to identify minor spills before they cause widespread damage.
\end{abstract}

Keywords: Active remote sensing, FDEM, GPR, Sewage leak, Contamination, Water pollution

\section{Introduction}

Water pollution is the contamination of bodies of water such as aquifers, lakes, ponds, rivers and oceans. This contamination occurs due to direct or indirect discharge of pollutants into the water bodies, without a suitable treatment to remove harmful compounds (pollutants may simply be defined as substances added to the environment that do not belong there). A substantial proportion of water and environmental contaminants are due to leaks from underground sewage pipeline systems in rural, urban and industrial areas, since any sewage pipeline system deteriorates over time, developing cracks and joint defects. Therefore, if sewage pipeline systems are not maintained properly, it is only a matter of time before the sewage leaks out and contaminates the surrounding groundwater and surface water. 
Here, we suggest detecting sewage leaks from pipeline systems using two orthogonal active remote-sensing methods: (I) ground-penetrating radar (GPR) and (II) frequency domain electromagnetic (FDEM). Our hypothesis is that GPR and FDEM screening, which creates subsurface images around and along pipeline systems, will enable the extraction of residual signals and the detection of meaningful leaks. Like most complex near-surface detection missions, detection of sewage leaks in an urban environment requires a professional understanding of the regional setting, from geomorphological, environmental and engineering perspectives.

Advances in remote-sensing technologies now enable their use to identify leakage that is potentially responsible for pollution and to identify minor spills before they can cause widespread damage. The detection of pollutants using GPR [1], was based on the research of Basson [2]. Basson [3] presented a combination of GPR and FDEM methods to detect and monitor saline contaminants in agricultural fields. Goldshleger [4, 5] demonstrated the ability to detect saline-affected soils using remote-sensing methods, toward improved management of these soils. Basson [6] described the detection of subsurface water/sewage/drainage pipe systems and leaks/contamination from such pipes. Ben-Dor [7, 8] reviewed remote-sensingbased methods to assess soil salinity and improve the management of salinity-affected soils. Ly and Chui [9] developed accurate representations of weep holes and leaky sewage pipes, and further showed the systems' long-term and short-term responses to rainfall events. Their simulation results provided a better understanding of local-scale migration of sewage leaks from a sewage pipe to nearby storm water drains. The last few years in Israel have seen increasing use of new methods based on active remote-sensing tools to study subsoil quality. These tools include GPR and underground monitoring systems measuring spatial moisture content, such as FDEM in the subsurface. The use of GPR is based on a method that was originally developed for measuring sand dunes of medium moisture content at an unsaturated resolution of a few percentage points [2]. The GPR helped define the possible reason for emerging high-salinity areas, such as a subsurface regional structure that reduces water infiltration into the deeper groundwater position [5]. The FDEM method provided a very important view of salt contamination in the soil layers (except the root zone layer) and also pinpointed areas with salinity problems. The images obtained from FDEM readings provided a subsurface view that also helped identify the reason for the high salinity in certain areas. In the soil salinity experiment in Israel, a severe defect in the drainage pipelines could be observed, which helped the farmers solve the problem before the subsequent season [5].

The present study focuses on the development of these electromagnetic (EM) methods to replace conventional acoustic methods for the identification of sewage pipe leaks. EM methods provide an additional advantage in that they allow mapping the fluid transport system in the subsurface. Leak-detection systems using GPR and FDEM are not limited to large amounts of water, but can also detect leaks of tens of liters per hour, because they can locate increases in pipes' or tanks' environmental moisture content that amount to only a few percentage points. The importance and uniqueness of this research lies in the development of practical tools to provide a snapshot of the spatial changes in soil moisture content to depths of about 3-4 $\mathrm{m}$ (in areas with asphalt overlay) at relatively low cost, in real time or close to real time. Spatial 
measurements performed using GPR and FDEM systems allow monitoring many tens of thousands of measurement points per hectare, thus providing a picture of the spatial situation along the pipelines. The main purpose of this study was to develop a method for detecting sewage leaks using the above-proposed geophysical methods, as the resultant contaminants can severely affect public health. We focused on identifying, locating and characterizing such leaks in sewage pipes in residential and industrial areas.

\section{Methods}

In recent years, there has been an increase in the use of active remote-sensing tools, such as GPR (Figure 1a) and subsurface FDEM (Figure 1b), for measuring the subsurface's EM velocity and dielectric constant (GPR), and its electrical conductivity profile and magnetic susceptibility (FDEM).

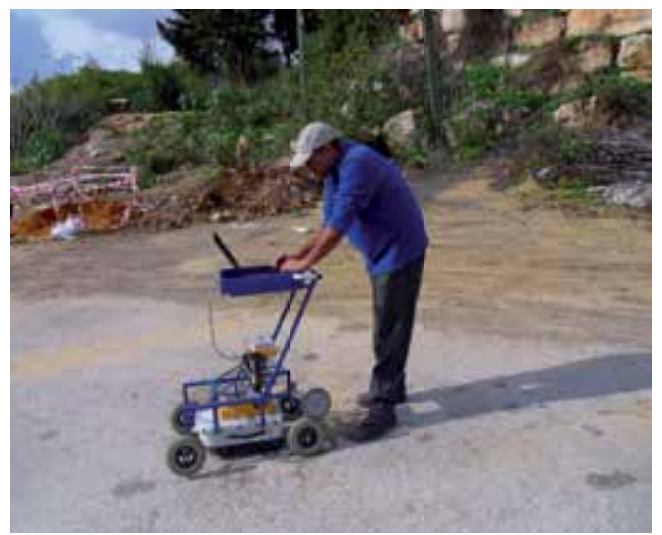

(a)

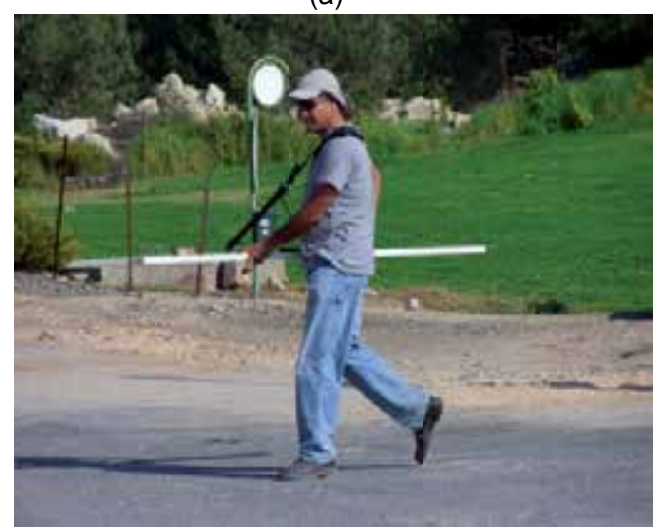

(b)

Figure 1. Taking measurements with the RAMAC GPR (a) and Gem-2 FDEM (b) in the study area. 
Passive remote-sensing spectroscopy of ground surface and cross-sections using an optical fiber termed SPSP (subsurface-penetrating spectral probe), developed [10] and have been conducted as well. This study focuses on remote-sensing tools to replace acoustic methods [11, $12,13]$. EM methods provide the added advantage of being able to map underground liquidcarrying pipelines. Ground leak-detection systems using GPR and FDEM are not limited to large amounts of water: small leaks of tens of liters per hour can be detected in the environment by comparing medium-dry to minimum moisture content in the pipeline and the canal zone.

Our aim was to develop practical tools that would provide a snapshot of changes in spatial soil moisture content to depths of about 3-4 $\mathrm{m}$ in areas covered with asphalt at relatively low cost and in real time. The spatial measurements were performed with FDEM and GPR systems that allow measuring tens of thousands of points per hectare and thus enable monitoring the spatial situation along the pipeline.

\subsection{FDEM}

Traditionally, the electrical method "measures" apparent resistivity using electrodes that require ground contact in a DC electrical survey, while the EM method "measures" apparent conductivity without ground contact. The EM method, known as a "potential method", involves transmitting and receiving EM fields, commonly using a set of coils. The common unit of resistivity is ohm-m and conductivity is its inverse, in Siemen/m. The apparent resistivity $\rho_{a}$ is defined in DC resistivity as:

$$
\rho_{a}=2 \pi G \frac{\Delta V}{I}
$$

where $\Delta V$ is the voltage between a pair of potential electrodes, $I$ is the current that flows through another pair of source electrodes, and $G$ is the geometric factor that depends on the geometry of the electrodes. For a Wenner array that uses four equally spaced electrodes, for instance, $G$ is the electrode spacing itself. Even for this simple array, each electrode spacing generates a different apparent resistivity because the spacing controls the volume of the subsurface sampled by the measurement. It is only when the earth is a homogeneous half space that the apparent resistivity is the same as the true resistivity.

Similarly, apparent conductivity is only same as the true conductivity when the earth is a homogeneous half space. As an example, consider a pair of horizontal coils separated by a distance $r$. A routinely measured quantity is called the mutual coupling ratio which, for a horizontal coplanar (or vertical dipole) coil configuration over a layered earth as derived by $[14,15,16,17]$, among others is written as:

$$
Q=\frac{H \mathrm{~s}}{H \mathrm{p}}=-r^{3} \int_{0}^{\infty} \lambda^{2} R(\lambda) J_{0}(\lambda r) e^{-\lambda h} d \lambda
$$

$H \mathrm{p}$ and $H$ s are the primary and secondary fields at the receiver coil; $J 0$ is the 0th order Bessel function; $r$ is the coil separation and $h$ is the sensor height above the ground. $Q$ represents the 
secondary field normalized against the primary field at the receiver coil. Most frequencydomain sensors measure $Q$ in parts per million (ppm). The kernel $R$ corresponding to a homogeneous half space is:

$$
R(\lambda)=\frac{\lambda-\sqrt{\lambda^{2}+t 2 \pi f \mu \sigma}}{\lambda+\sqrt{\lambda^{2}+t 2 \pi f \mu \sigma}}
$$

where $f$ is the transmitter frequency in $\mathrm{Hz}, \mu$ the magnetic permeability and $\sigma$ the half-space conductivity. Based on $Q$ measured at a particular frequency over a real (heterogeneous) earth, we can invert Equation (2) to obtain the apparent half-space conductivity $\sigma_{a}$. It is obvious from Equation (2) that the resulting $\sigma$ depends on coil separation, sensor height and frequency. In addition, each coil configuration (vertical coplanar, coaxial, etc.) has a different formula for $Q$. Figure 2 shows a coplanar coil pair at height h above layered earth [18], and a damped leastsquares inversion based on singular value decomposition to solve the nonlinear inverse problem.

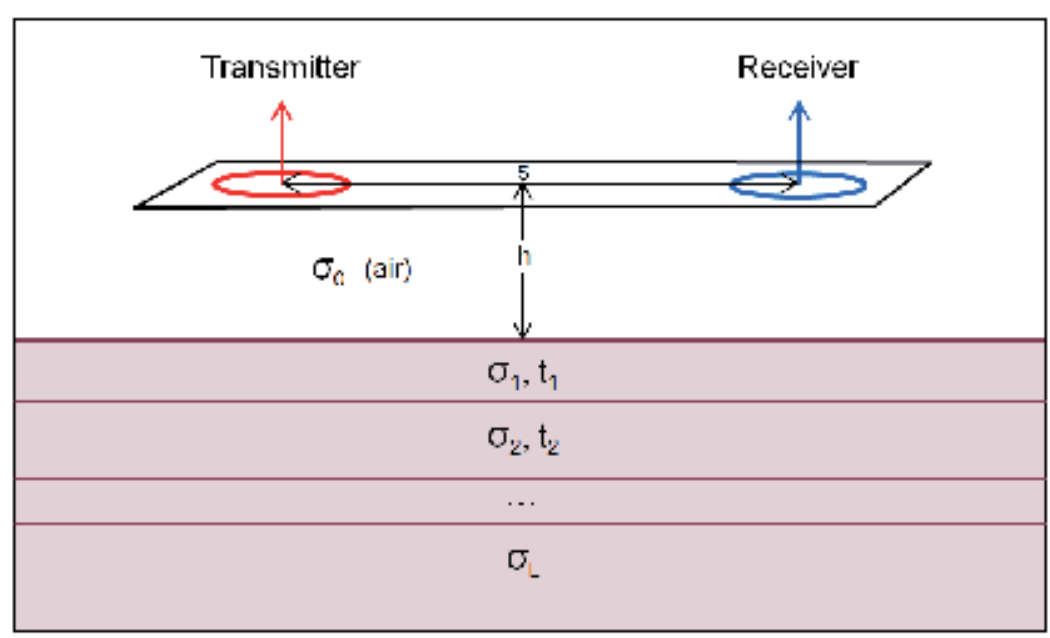

Figure 2. Geometry of the horizontal coplanar electromagnetic sensor over layered earth where $\sigma$ is the conductivity, $t$ is the thickness of each layer, the subscripts stand for the number of layers, $s$ is the coil separation and $h$ is the sensor height [18].

Figure 3 shows the responses of the Gem-2 sensor over a half space as a function of induction number:

$$
\theta=(\sigma \mu \omega / 2)^{1 / 2} s
$$

where $\omega$ is the angular frequency, $\mu$ is the magnetic permeability and $s$ is coil separation. 


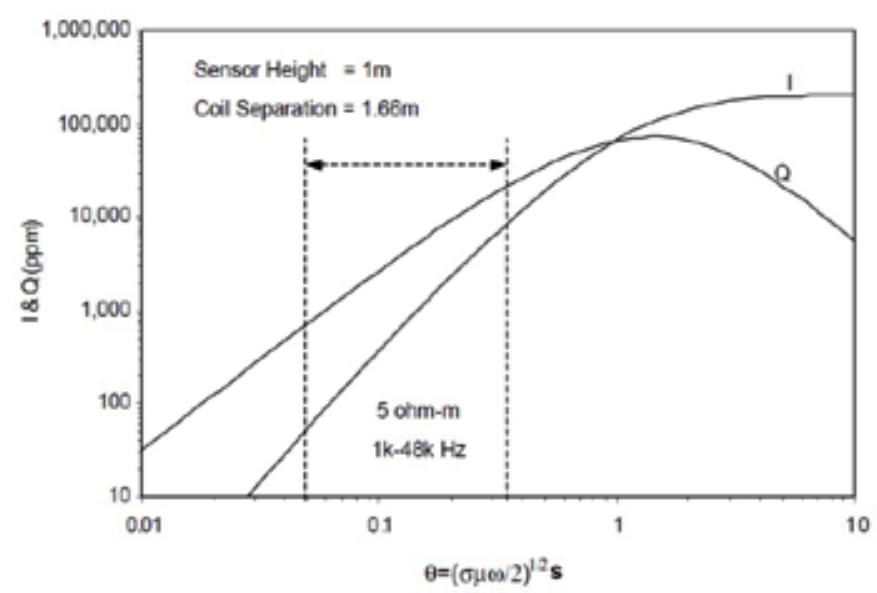

Figure 3. The in-phase and quadrate responses as a function of induction number (from Huang and Won, 2003).

The depth of investigation of an EM system can be estimated using the skin depth $\delta$, which is defined in classical EM theory as the distance in a homogeneous medium over which the amplitude of a plane wave is attenuated by a factor of $1 / e$, or about $37 \%$ of its original amplitude. The skin depth $\delta$ is:

$$
\delta=\sqrt{\frac{2}{\sigma \mu \omega}}
$$

The skin depth and the ability to transmit in several frequencies allows us to perform "frequency sounding" using a multifrequency sensor, thereby resolving different depths of penetration as sketched in Figure 4.

Frequency Sounding

Fixed Geometry-Multiple Frequency

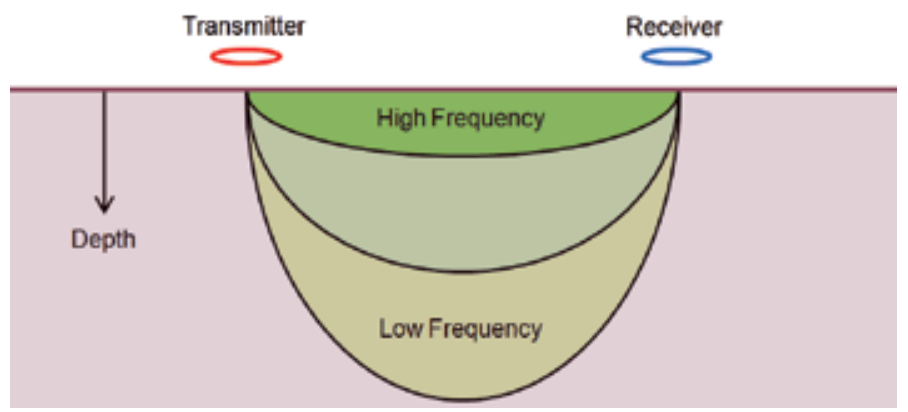

Figure 4. Frequency sounding for various depths using a multifrequency FDEM sensor such as Gem-2. 


\subsection{GPR}

GPR, a reflection-scattering imaging method, is widely used for subsurface imaging in geophysics. GPR uses high frequencies (wavelengths; $\mathrm{MHz}-\mathrm{GHz}$ ). EM waves may form images of the subsurface by transmitting radar pulses into the ground and receiving the deflected waves from the interfaces below. Using wave methods and analysis, GPR images can be analyzed for their derived electrical properties and subsurface characteristics and for spatial mapping of water content $[2,3]$. The range resolution is a function of the subsurface dielectric constants and the wave's frequency. It may vary from several centimeters to several tens of centimeters at the relevant effective frequencies $[19,20]$ For a certain wavelength, the penetration of GPR waves into the subsurface is mainly a function of the host material's conductivity, and therefore GPR waves decay significantly in conductive and saline soils. Using wave methods and analysis, GPR images can be analyzed for their derived electrical properties and subsurface characteristics and for spatial mapping of water content [2,3], as described in the following model.

The connection between the EM velocity and dielectric constant is expressed as:

$$
v=\frac{c}{\sqrt{k}}
$$

where $c$ is the speed of light in a vacuum and $k$ is the dielectric constant.

The dielectric constant of water $\left(k_{\mathrm{w}}\right)$ is about 80 . The dielectric constant of air $\left(k_{\mathrm{a}}\right)$ is 1 . The dielectric constant of common "dry" soil $\left(k_{\text {dry soil }}\right)$ with residual moisture content can range between 6 and 15 (the effective dielectric constant of dry soil is determined according to volumetric mixing ratios between soil, water and air components).

The difference in the effective dielectric constant of "dry" and "wet" soils is mainly a function of the ratio between the air and water volumes, when the volumes are normalized to:

$$
V_{\text {dry soil }}+V_{\mathrm{w}}+V_{\mathrm{a}}=1
$$

then:

$$
k_{\text {eff }}=k_{\text {dry soil }} V_{\text {dry soil }}+k_{\mathrm{w}} V_{\mathrm{w}}+k\left(1-V_{\mathrm{w}}\right)
$$

The maximal soil-water absorbency is a strong function of the effective porosity.

\section{Leak detection in Ariel}

Ariel is a small city (about 20,000 residents) in Israel, located in the central highland region known as the Samarian Hills. It is situated $40 \mathrm{~km}$ ( $25 \mathrm{miles})$ east of Tel Aviv and $40 \mathrm{~km}$ west 
of the Jordan River. It is situated $700 \mathrm{~m}$ (more than 2000 feet) above sea level. The city stretches over $12 \mathrm{~km}$ ( 8 miles) in length and $2 \mathrm{~km}$ in width. The research was performed with Yuvalim, the company that is responsible for maintaining the water and sewage network in the Ariel area and for supplying available water to residents. The mutual research was performed to identify sewage leaks before they pollute and damage the surrounding area. The research was supported by the Israeli Water Authority. The work was performed in several stages.

\subsection{Selecting study sites}

Areas were selected in Ariel for system calibration (Figure 5). Two areas were chosen for the method calibration: the first was an industrial area and the second a residential area, both with well-mapped networks of water and sewage pipes. These areas were selected on the basis of information from computerized data, observations, field visits, use of orthophotos, aerial photography and geological and pedological data.
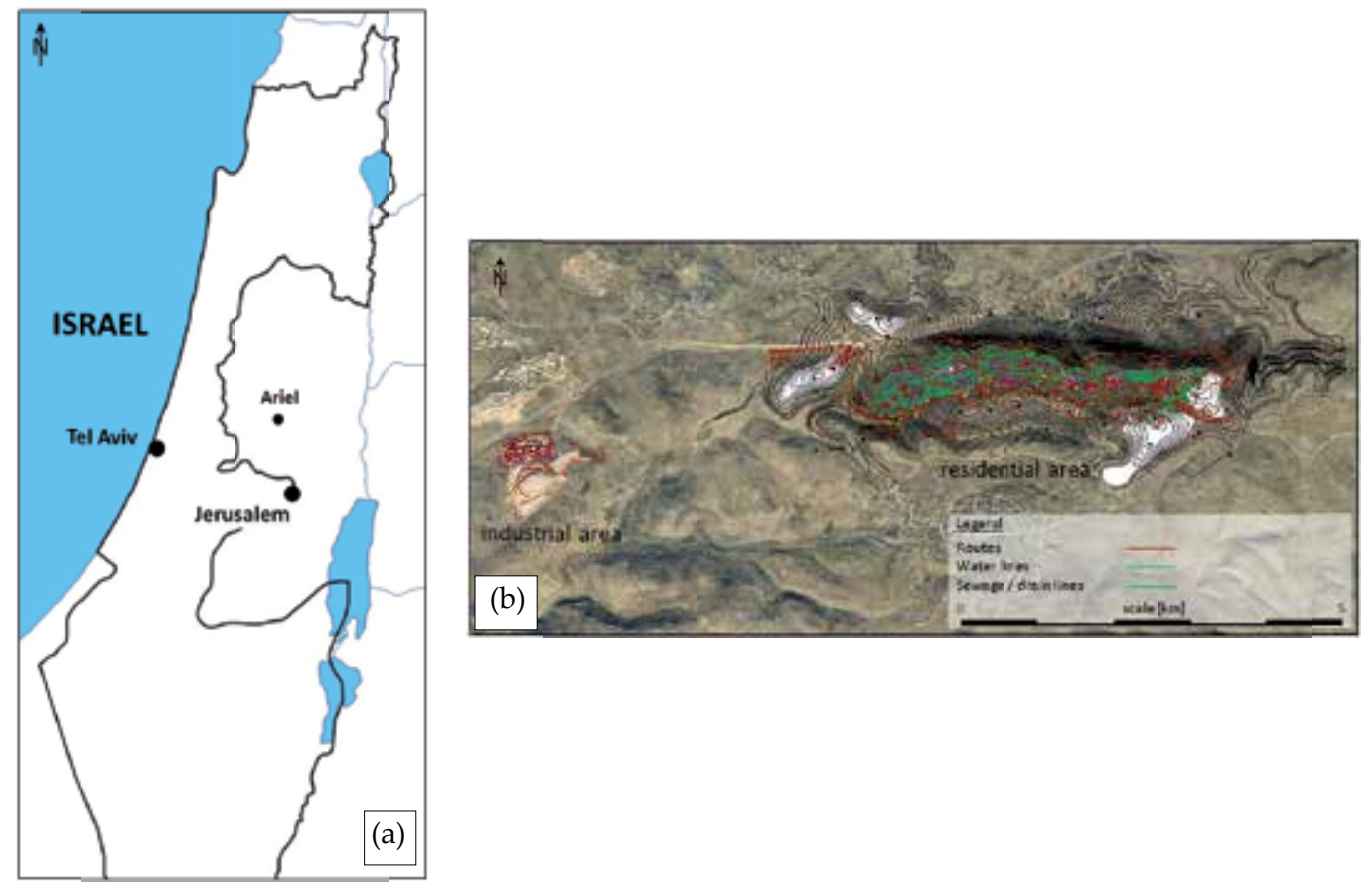

Figure 5. Maps showing Ariel's location (a) and the drainage infrastructure, sewerage and water supply for this city (b).

\subsection{Soil characterization}

To characterize the pedological structure of the subsurface layers, excavations were performed. We sampled grain size, void content and porosity, moisture content, soil density and soil characteristics. We dug a channel in an underground sewage pipe replacement area at the experimental sites. Figure 6 presents the characterization of the sub layer. 


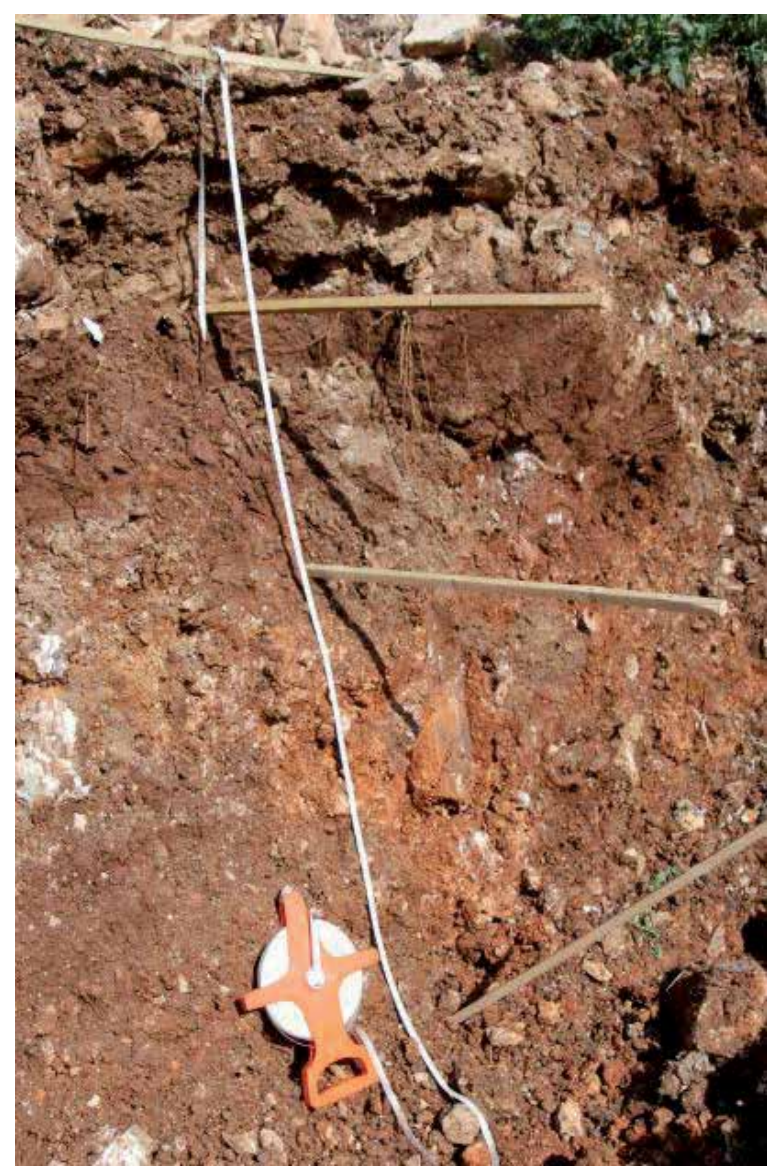

Figure 6. Soil subsurface cross-section at site 1. Wooden pegs mark the changing soil layers.

The soil in the area is red Mediterranean, also known as Terra Rossa [21] and Lithic ruptic Xerochrept [22]. Terra Rossa occurs in areas where heavy rainfall dissolves carbon from the parent calcium carbonate rock and silicates are leached out of the soil, leaving residual deposits that are rich in iron hydroxides, causing the red color. Such areas are usually depressions within limestone. The soil was sampled in a $0.5-\mathrm{m}$-wide ditch at a depth of $2 \mathrm{~m}$. The area has an easterly aspect, with an average elevation of $400 \mathrm{~m}$ above sea level. The local slopes vary between $7 \%$ and $25 \%$. Soil texture was clay loam with an average composition of $45 \%$ sand, $25 \%$ silt and $30 \%$ clay. The sand content increased toward the lower part of the area. The average lime content was $30 \%$. Rock fragments of up to $40 \mathrm{~cm}$ appeared together with the soil.

\subsection{GPR calibration}

Calibration of the GPR system to the subsurface properties of the cross-section in a dry state (without leakage) is shown in Figure 7. The depth to the pipe was measured in a nearby manhole. 


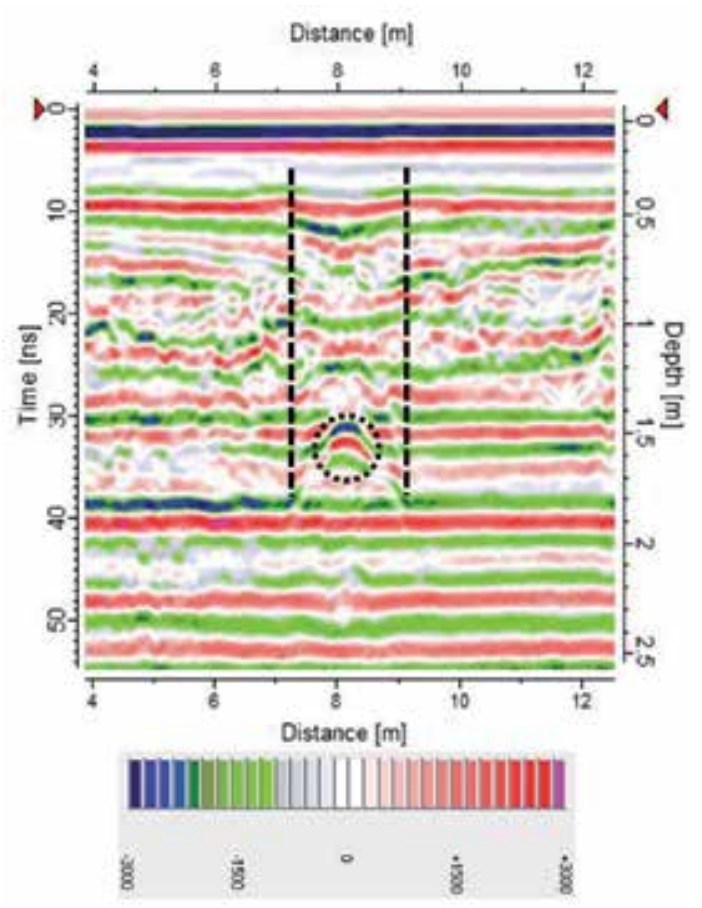

Figure 7. Part of the GPR profile performed for calibration of the GPR system in the Ariel industrial zone, on the road close to a rubber factory. The black circle displays diffraction created by the drain pipe. Above it, the trench is detected as well. The horizontal scale describes the measurement location (in meters) along the profile. The vertical scales describe the time (in nanoseconds) and depth (in meters). The amplitude-intensity scale is shown as well.

Figure 7 shows the results of advanced processing of a cross-section for calibration of the system in the industrial area. On the horizontal scale, simulations are described above the measurement location along the incision in meters; the vertical scales describe the time and depth of the reflections on a timescale of $50 \mathrm{~ns}$ and scale depth of $2.5 \mathrm{~m}$ below the surface (the strength of the reflections is graded according to the color scale in Figure 7, where the diffraction created by the drainage pipe can be deduced from a return time from the pipe of approximately $32 \mathrm{~ns}$ ). The diffraction depth is $2.45 \mathrm{~m}$, and the data from the system matches the data measured on the ground. This adaptation makes it possible to determine the velocity of the EM wave. The average measured subsurface speed of the EM wave $(v)$ was $0.093 \pm 0.001 \mathrm{~m} / \mathrm{ns}$ at the Ariel industrial site. It is important to note that the speed of the wave depends on the directly calculated form and location of the anomaly and thus data processing is critical to the research results.

\subsection{The experimental site}

The experimental site for sewage pipeline and manhole leaks was located near Ariel's old stadium, not far from HaAtsmaut Street (Figure 8, blue rectangle), where a project for the replacement of old sewer pipes has been initiated. 


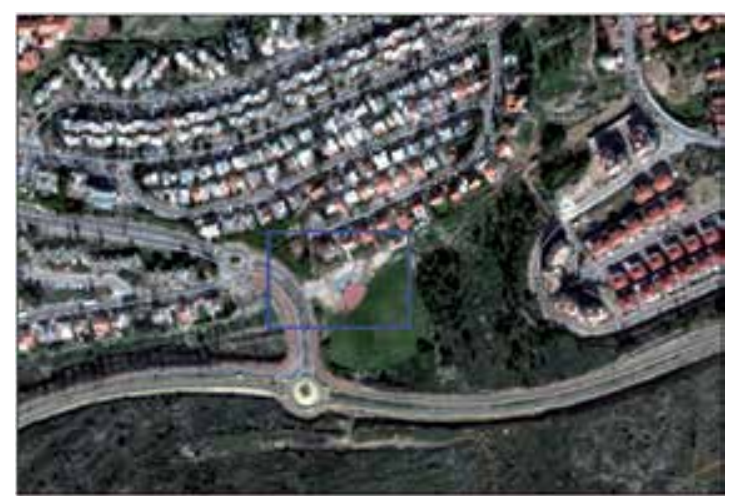

Figure 8. The experimental site is located at the western end of the sewage line adjacent to HaAtsmaut Street (blue rectangle). It includes 12-in. diameter iron pipes carrying on the order of 1000-1200 $\mathrm{m}^{3}$ sewage water per day, and an average $100 \mathrm{~m}^{3} / \mathrm{h}$ during peak flow.

Leakage was initiated in two places at the western site by cracking the sewer pipes close to their bottom side. One crack was made about $6 \mathrm{~m}$ from the sewage pit in the northern iron pipe using an electrical disk that created a wedge-shaped hole $15-20 \mathrm{~cm}$ in diameter; the second crack was also a circle of $15-20 \mathrm{~cm}$ diameter in the lower part of the pipe (Figure 9). The experimental site was monitored daily by radar and FDEM before the start of and during the controlled leakage.
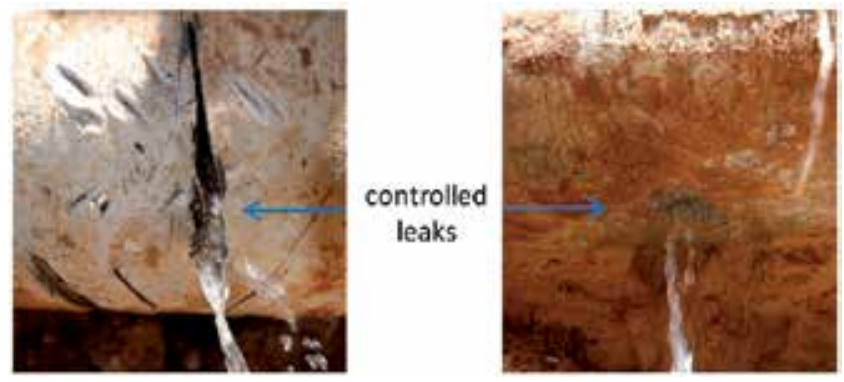

Figure 9. Pictures of the two cracks made in the sewer pipes for the controlled leakage experiment.

\section{Results}

Daily monitoring with the FDEM method included five cross-sections: four were parallel to the sewer pipeline and the fifth was above it, running on each side of the pipeline at a distance of $0.5 \mathrm{~m}$. During the experiment, FDEM scanning was performed to qualify the effect of moisture on the soil cross-section. Figure 10 shows the status of the subsurface before the start of the controlled leak; it was in a relatively dry state characteristic of the month of May at this site. 


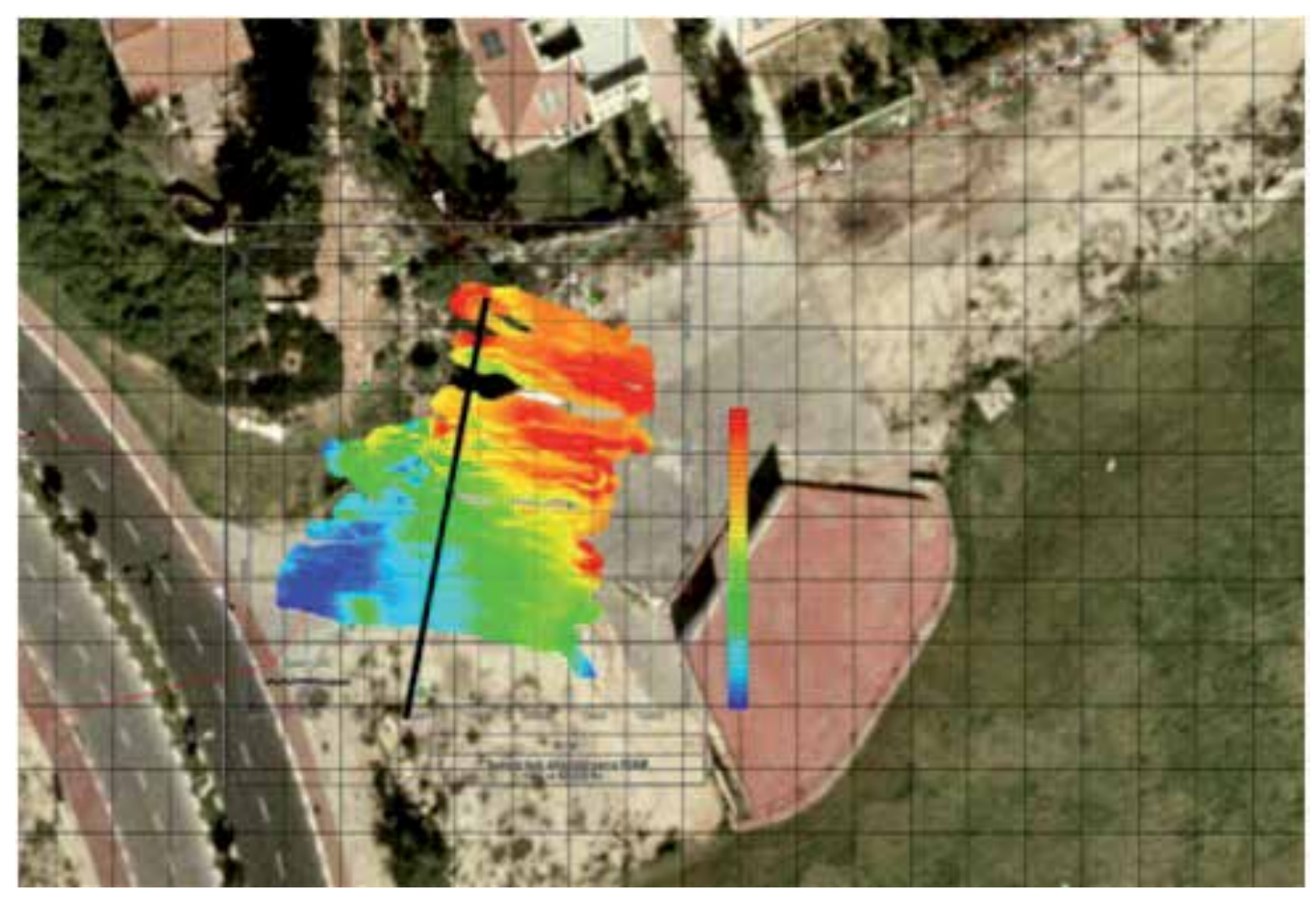

Figure 10. Map of the integrated electrical conductivity at $60,025 \mathrm{~Hz}$ before the start of the controlled leak at the western site (locations of the measurements are shown by the blue rectangle in Figure 8). The map is based on measurements performed with a GEM-2 FDEM sensor. The location of the sewer pipe is marked with a black line. Data were collected prior to the leak with dimensional scanning of approximately $30 \mathrm{~m} \times 25 \mathrm{~m}$. Lower conductivity $(\sigma)$ values $(11$ $\mathrm{mS} / \mathrm{m}$ ) appear in blue-green in the southwestern corner of the area, while the highest conductivity appears in red-purple $(55 \mathrm{mS} / \mathrm{m})$ in the northeastern part of the map. These conductivity changes suggest anomalous subsurface moisture from the water pipe near the old stadium, as well as the accumulation of water from the slope, where there is a garden.

Figure 11 shows a pronounced increase in electrical conductivity of about $40 \mathrm{mS} / \mathrm{m}$ after 4 days of controlled leakage. The area has high conductivity because of changes in wetness due to a significant increase in liquid as a result of the sewage flow.

The results of the FDEM measurements conducted 10 days after the beginning of the controlled leak are presented in Figure 12. This picture may look similar to Figure 11 in terms of colors, but their intensity has increased due to an increase in the conductivity values to about $152 \mathrm{mS} / \mathrm{m}$.

On the map in Figure 12, low visibility, reflecting low electrical conductivity, is shown in bluegreen shades, high visibility in red-colored shades. Purple indicates sewer leakage on the background of the driest area, highlighting the differences in moisture. A wide area can be seen west of the pipe (black line in Figure 12) with relatively low electrical conductivity compared to the rest of the region. Northeast of the pipe, there is high electrical conductivity resulting from the spillover of sewage water. 


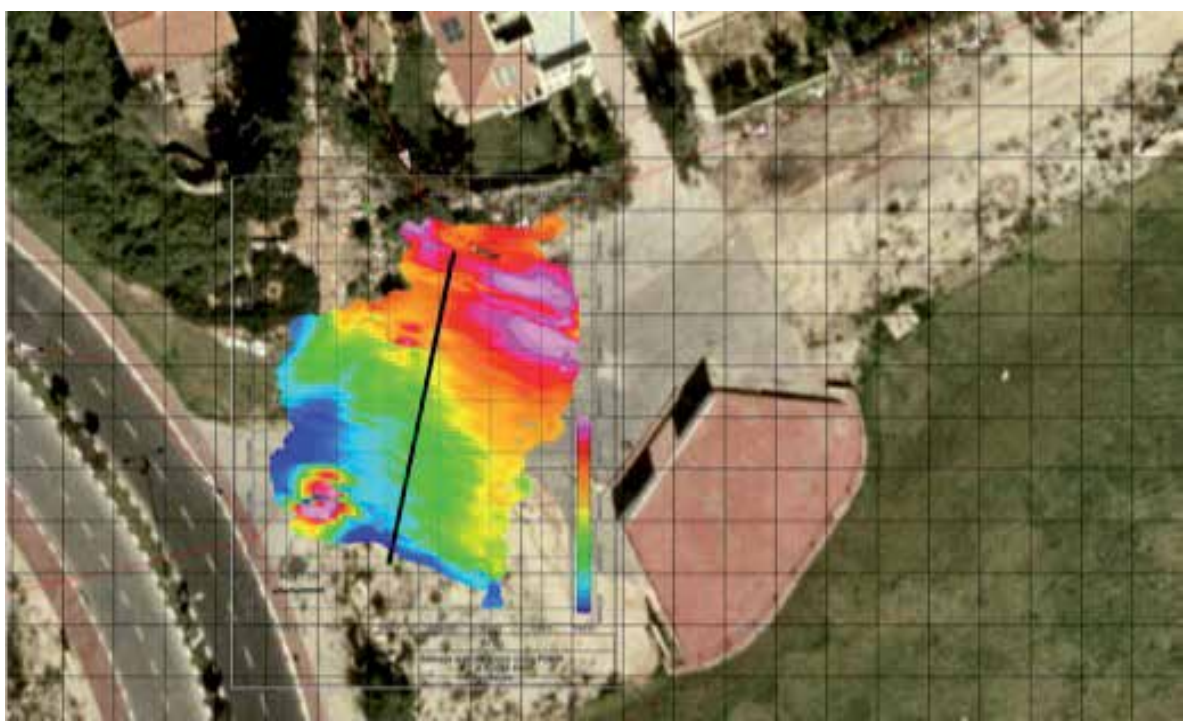

Figure 11. Map of the electrical conductivity at $60,025 \mathrm{~Hz}$ after about 4 days of leakage. Measurements were collected during the sewage leak, under wet conditions, with the GEM-2 sensor (locations of the measurements are shown by the blue rectangle in Figure 8). The location of the sewer pipe is marked with a black line. The highest conductivity value was about $95 \mathrm{mS} / \mathrm{m}$. The significant increase in electrical conductivity is a result of the sewer liquids that were spilled during the 4 days of the controlled leak, in both the southwestern and northeastern sides of the area, probably due to a subsurface topography gradient.

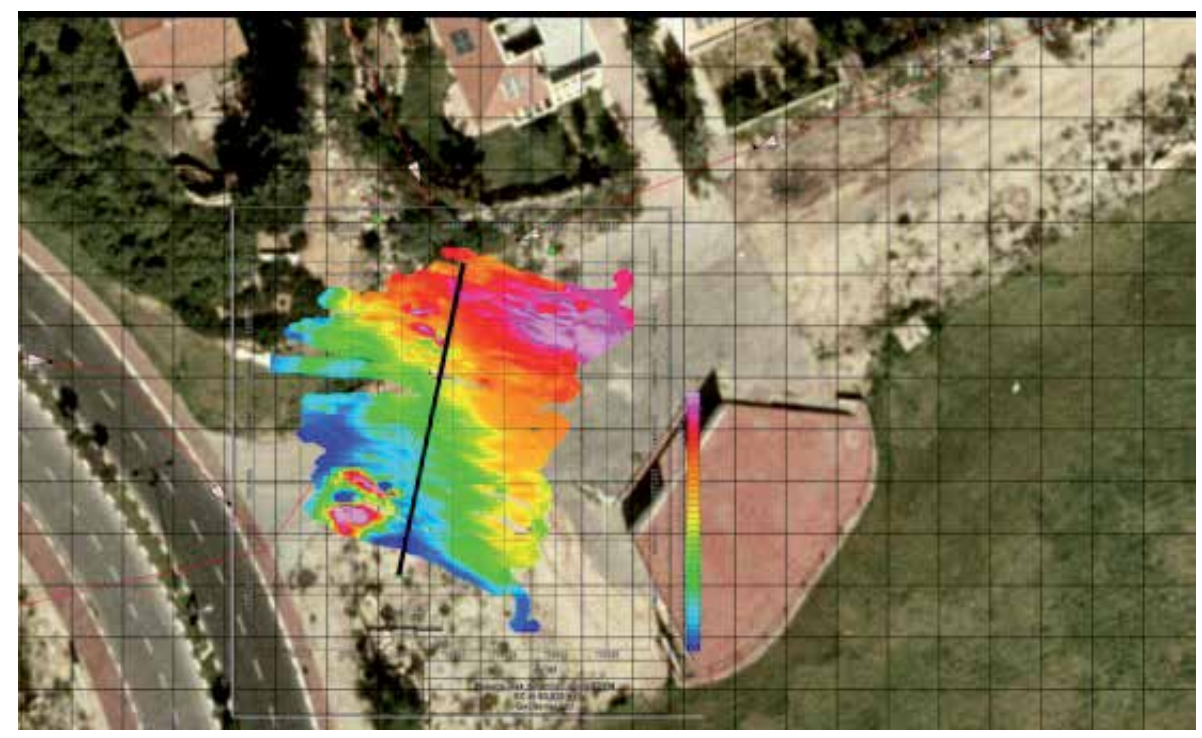

Figure 12. Map of integrated electrical conductivity at 60,025 Hz. Measurements were collected with the FDEM system, under wet conditions, after 10 days of controlled leakage (locations of the measurements are shown by the blue rectangle in Figure 8). Electrical conductivity ranged from 0 to $152 \mathrm{mS} / \mathrm{m}$. Low conductivity is expressed in blue-green shades, high conductivity in purple-red colors. 
Figure 13 shows maps made by FDEM monitoring of electrical conductivity at various frequencies in the first tested area. The maps are arranged, from left to right, at increasing frequencies and depth: the frequencies were $2,025 \mathrm{~Hz}, 4,725 \mathrm{~Hz}, 11,025 \mathrm{~Hz}, 25,725 \mathrm{~Hz}$ and $60,025 \mathrm{~Hz}$, each frequency representing a $30 \mathrm{~cm}$ increase in depth. The low-visibility electrical conductivity is represented by blue-green hues, and the high-visibility electrical conductivity by red-purple hues. There were a few quantitative differences in the map scales.
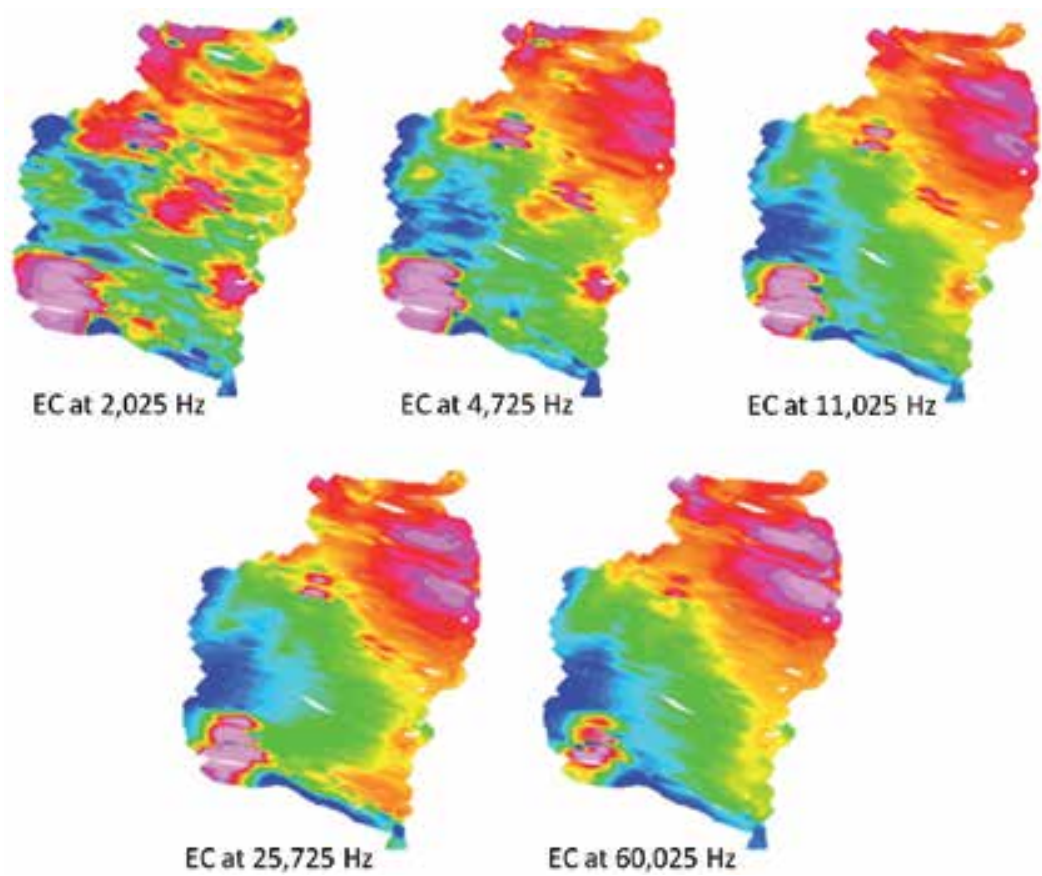

Figure 13. Maps made by FDEM monitoring of electrical conductivity at 2,025 Hz, 4,725 Hz, 11,025 Hz, 25,725 Hz and $60,025 \mathrm{~Hz}$. The lower EC values are represented by blue-green hues, and the higher EC values by red-purple hues. There were a few quantitative differences between the maps' scales.

Four sections, two on each side of the sewer, were monitored by GPR and are shown in Figure 14. The distance between the main radar cross-sectional cuts was approximately $0.5 \mathrm{~m}$. The radar sections shown in Figure 14 were collected with an antenna at a nominal frequency of $250 \mathrm{MHz}$ over the location of the underground sewage pipe at the first (western) test site. The first cross-section was obtained before the leak started and reflects the typical dry state of the ground in May. An incision was made a few days after the initiation of the leak and shows a relatively wet subsoil. The right cross-section shows an incision made at a lower depth, 10 days after leak initiation, indicating a further increase in wetness. Similar data processing was carried out for the three cross-sections to highlight their differences. 
Dry section

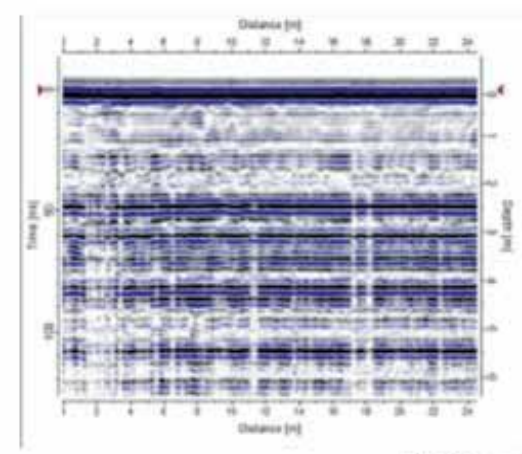

Wet section

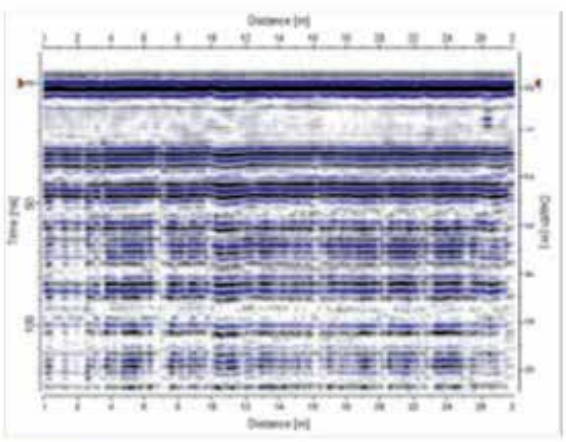

|IIIIIII

Max. Wet section

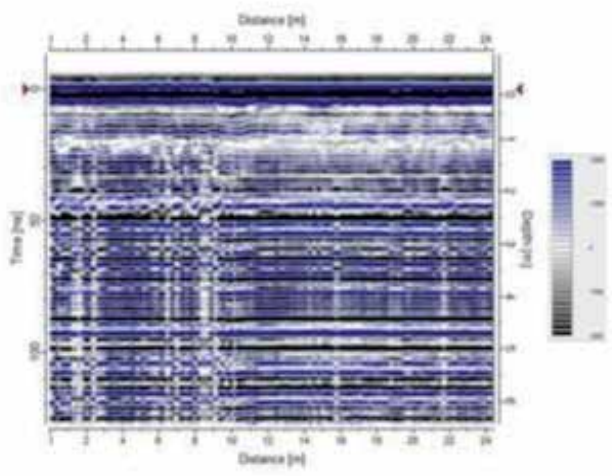

Figure 14. Soil moisture reflected by GPR cross-section (locations of the measurements are shown by the blue rectangle in Figure 8).

\section{Modeling subsurface moisture content}

Moisture content was computed on the basis of subsurface GPR and FDEM measurements and its spatial spread was obtained for calibration and wetness testing with water- and sewagecarrying pipelines. In these experiments, radar velocities were measured and dielectric constants were computed. Their correlations were used to measure the moisture content from data collected in the residential and industrial neighborhoods.

The computation of moisture content using GPR was based on the method developed by Basson [2] From the calibration measurements conducted at the end of May 2012, the average 
subsurface EM wave velocity was $0.093 \pm 0.001 \mathrm{~m} / \mathrm{ns}$. The calculated dielectric constant during this period was about 10.4. This value is low but not minimal, as minimal moisture content is typically found in the mid-to-late summer months (according to data from the Israel Meteorological Service, the rain that accumulated in the area in the months before the GPR measurements amounted to about $161 \mathrm{~mm}$ ).

The velocity of EM waves in a substance is mainly a function of that substance's bulk dielectric properties and moisture content. When a substance is composed of a mixture of materials, the velocity is a function of their mixing ratios. In the case of a subsurface environment, we can treat the substance as a bulk property composed of soil, rock, minerals and organic materials mixed with air and water. When the rate of air increases, the velocity increases as well. However, when the moisture content increases, the average dielectric constant decreases as well and fro equation (6) it can be seen that the EM velocity (v) decreases as well.

The difference in the effective dielectric constant of "dry" and "wet" soils is mainly a function of the ratio between the air and water volumes, when the volumes are normalized according to equations (7) and (8). The maximal soil-water absorbency is a strong function of the effective porosity. For soils in the Ariel region, the effective porosity can vary from $40 \%$ to $60 \%$. We used an average effective porosity of $50 \%$ in our computations. Therefore, the possible mixing ratios relative to the normalized volume are:

$$
\begin{gathered}
V_{\text {dry soil }}=0.5 V_{\text {tot }} \\
V_{\mathrm{w}}+V_{\mathrm{a}}=0.5 V_{\text {tot }}
\end{gathered}
$$

Since $k_{\text {dry soil }}$ is the effective dielectric constant measured using GPR imaging for a soil with residual moisture content and since $k_{\mathrm{a}}=1$ :

$$
k_{\text {top soil }}=0.5 k_{\text {dry soil }}+80 V_{\mathrm{w}}+0.5-V_{\mathrm{w}}
$$

The radar wave velocity for "dry" soil at the surface will be measured and is expected to vary with the GPR and its value, $v_{\text {top soil }} \sim 0.07-0.14 \mathrm{~m} / \mathrm{ns}$. From Equation (1), this velocity range can reflect dielectric constant values of $\sim 4.6-18.4$ for $k_{\text {top soil }}$. For example, for maximal dielectric constant values of 5-14 for delicate quartz-based soils and for the presented computations, the moisture content in the surface can vary as $V_{\text {w top soil }} \sim 0.4 \%-2.1 \%$. In the same way, we can investigate deeper soils where the moisture content is expected to be greater. The average radar wave velocity ( $\left.v_{\text {humid soil }}\right)$ measured by the GPR at the calibration site in Ariel at the end of May is $0.093 \mathrm{~m} / \mathrm{ns}$. Using Equation (1), this velocity reflects a dielectric constant value $\left(k_{\text {humid soil }}\right)$ of 10.406. The additional volume of water needed to increase the dielectric constant from 4.6 to 10.41 can be computed as:

$$
\Delta k=5.81
$$




$$
\begin{gathered}
\Delta k=80 \Delta V_{\mathrm{w}} \\
\Delta V_{w}=7.26
\end{gathered}
$$

We develop a moisture content model using relative values of the moisture content (based on Equations (6-14)) causing an increase in electrical conductivity as measured by the FDEM. We had to consider the overall subsurface features, such as texture, density and effective porosity, as well as the content of salts in soils irrigated with brackish effluent water. The model results are presented in the graph in Figure 15.

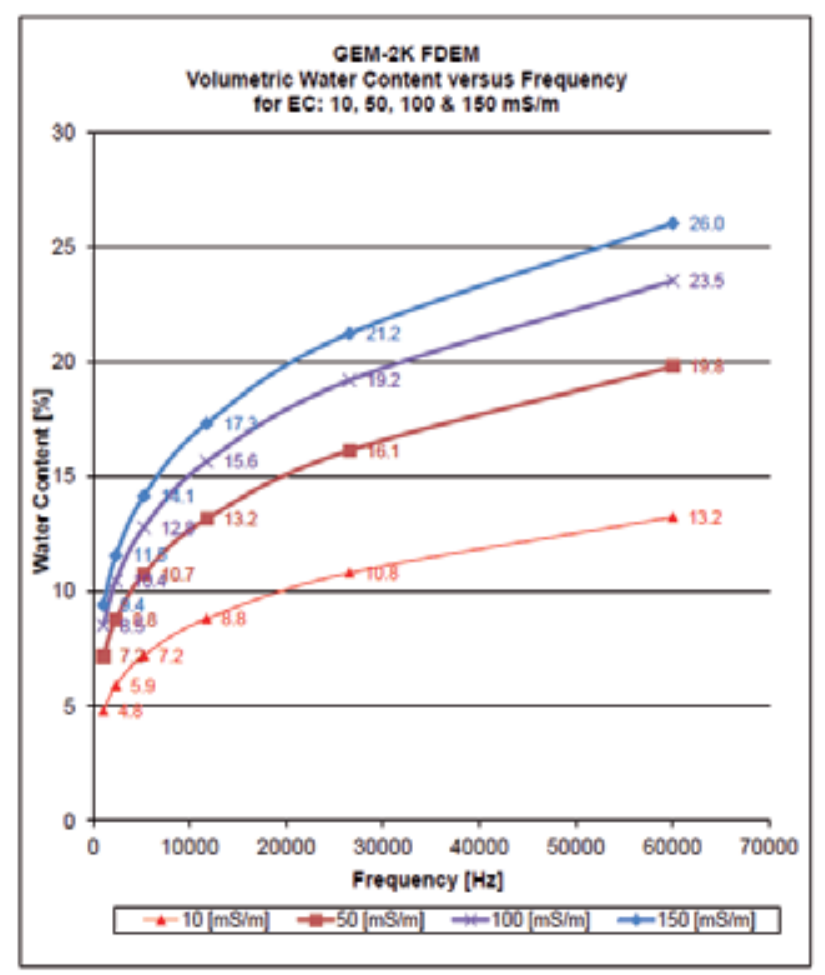

Figure 15. Volumetric moisture content calculated from measurements and from the FDEM model in the experimental zones in Ariel (accuracy $\pm 10 \%$ of the measured value).

\section{Discussion and conclusions}

We introduced a combination of GPR and FDEM orthogonal methods to detect subsurface leaks from a sewage pipeline system. The rationale for this combination is to increase the 
probability of detection, especially in complex urban environments and when the soil-rock setting can vary from relatively resistive to relatively conductive. The results of our study indicate that even minor leaks, such as the minor controlled leaks created in the experiment, and changes in the subsurface moisture content can be accurately detected. We could detect sewage leakage, as well as its progress. The combination of the two methods enabled not only the detection of the leak but also a qualitative assessment of its size. Factors affecting the ability to detect leaks were limited by the soil-rock conductivity, as well as the density of the terrain and subterrain systems and structures. The geophysical methods may detect sewage effluent flow paths as well as the contaminant in the soil.

The limestone and dolomite bedrock in the Ariel area is suitable for GPR mapping. The clarity of the GPR profile enabled analysis and interpretation of the physical data with good accuracy. We could detect sewage leakage, as well as its progress. The anomalous moisture of the leakage accumulating around the sewage pit in the southwest research area validated the efficiency of the methods.

\section{Acknowledgements}

The research was supported by the Israel water authority and by the Water Cooperation of Yuvalim. We would like to thank Mr. Omer Shamir from GeoSense for assistance with the data collection.

\section{Author details}

Goldshleger Naftaly ${ }^{1,2^{*}}$ and Basson Uri ${ }^{3}$

*Address all correspondence to: Goldshleger1@gmail.com

1 Civil Engineering Ariel University, Israel

2 Israel Ministry of Agriculture, Beit Dagan, Israel

3 Geosense Ltd., Even Yehuda, Israel

\section{References}

[1] Basson, U., and Ben-Avraham, Z., 1994. Subsurface spatial mapping of pollutants concentrations using ground penetrating radar. Proceedings of the $25^{\text {th }}$ Annual Meeting of the IsraelSociety for Ecology and Environmental Quality Sciences, Tel-Aviv, Israel, 3-4 May 1994, p. 29. 
[2] Basson, U., 1992. Mapping of Moisture Content and Structure of Unsaturated Sand Layers with Ground Penetrating Radar. M.Sc. thesis.Tel-Aviv University, Tel-Aviv, Israel.

[3] Basson, U., 2000. Imaging of Active Fault Zone in the Dead Sea Rift: Evrona Fault Zone as a Case Study. Ph.D. thesis. Tel-Aviv University, Tel-Aviv, Israel.

[4] Goldshleger, N., Mirlas, V., Ben-Dor, E., Eshel, M., and Basson, U., 2007. Using Remote Sensing Methods for Improving the Management of Saline Affected Soils ERSA, Conference Paris, France.

[5] Goldshleger, N., Livene, I., Chudnovsky, A., and Ben-Dor, E., 2012. Integrating passive and active remote sensing methods to assess soil salinity: a case study from Jezre'el Valley, Israel, Soil science 177(6), 392-401.

[6] Basson, U., 2007. Imaging and mapping subsurface infrastructures and buildings using GPR and FDEM electromagnetic methods. Journal of Nondestructive News, Vol. 10, pp. 29-30.

[7] Ben-Dor, E., Goldshleger, N., Eshel, M., Mirablis, V., and Basson, U., 2008.Combined active and passive remote sensing methods for assessing soil salinity. In: Remote Sensing of Soil Salinization. Impact and Land Managemen (G. Metternicht and A. Zinck, eds.), pp. 235-255. CRC Press, USA.

[8] Ben-Dor, E., Metternicht, G., Goldshleger, N., Eshel, M., Mirablis, V., and Basson, U., 2008. Review of remote sensing based methods to assess soil salinity. In: Remote Sensing of Soil Salinization. Impact and Land Management (G. Metternich and A. Zinck, eds.), pp. 39-60. CRC Press, USA.

[9] Ly, D.K., and Chui, T.F., 2012. Modeling sewage leakage to surrounding groundwater and storm water drains. Water Science Technology 66(12), 2659-2665.

[10] Ben-Dor, E., Heller, D. and A. Chudnovsky, 2008. 10. A novel method of classifying soil A A novel method of classifying soil profiles in the field using optical means Soil Science Society of American Journal, 72:1-13.

[11] Klein, W.R., 1993. Acoustic leak detection. American Society of Mechanical Engineers, Petroleum Division 55, 57-61.

[12] Hough, J.E., 1988, Leak testing of pipelines uses pressure and acoustic velocity. Oil and Gas Journal 86, 35-41.

[13] Hunaidi, O., and Wang, A., 2004. Acoustic methods for locating leaks in municipal water pipe networks. International Water Demand Management Conference, Dead Sea, Jordan, 30 May-3 Jun 2004.

[14] Frischknecht, F.C., 1967. Fields about an oscillating magnetic dipole over a two-layer earth and application to ground and airborne electromagnetic surveys. Quarterly of the Colorado School of Mines 62, 326. 
[15] Ward, S.H., 1967. Electromagnetic theory for geophysical applications. In: Mining Geophysics (S.H. Ward, ed.), pp. 13-196. Society of Exploration Geophysicists, Theory, USGS.

[16] Ward, S.H., and Hohmann, G.W., 1988. Electromagnetic theory for geophysical applications. In: Electromagnetic Methods in Applied Geophysics (M.N. Nabighian, ed.), pp. 130-311. Society of Exploration Geophysics, Theory, Tulsa, Oklahoma.

[17] Won, I.J., and Huang, H., 2004. Magnetometers and electro magnetometers. The Leading Edge 23(5), 448-451.

[18] Huang, H., and Won, I.J., 2003. Real-time resistivity sounding using hand-held electromagnetic sensor. Geophysics 68(4), 1224-1231.

[19] Davis, J.L., and Annan A.P., 1986. High resolution sounding using ground probing radar. Geoscience Canada 3: 205-208.

[20] Davis, J.L., and Annan, A.P., 1989. Ground penetrating radar for high resolution mapping of soil and rock stratigraphy. Geophysical Prospecting 37: 531-551.

[21] Dan, Y., and Raz, Z., 1970. Soil Association Map of Israel. Volcani Institute for Agriculture Research, Israel (in Hebrew).

[22] Soil Survey Staff, 1975. Soil Taxonomy: A Basic System of Soil Classification for Making and Interpreting Soil Surveys. US Department of Agriculture, Handbook 436, pp. 754. 


\title{
Geo-spatial Technology for Landslide Hazard Zonation and Prediction
}

\author{
Dericks P. Shukla, Sharad Gupta, Chandra S. Dubey and Manoj Thakur \\ Additional information is available at the end of the chapter
}

http://dx.doi.org/10.5772/62667

\begin{abstract}
Similar to other geo hazards, landslides cannot be avoided in mountainous terrain. It is the most common natural hazard in the mountain regions and can result in enormous damage to both property and life every year. Better understanding of the hazard will help people to live in harmony with the pristine nature. Since India has $15 \%$ of its land area prone to landslides, preparation of landslide susceptibility zonation (LSZ) maps for these areas is of utmost importance. These susceptibility zonation maps will give the areas that are prone to landslides and the safe areas, which in-turn help the administrators for safer planning and future development activities. There are various methods for the preparation of LSZ maps such as based on Fuzzy logic, Artificial Neural Network, Discriminant Analysis, Direct Mapping, Regression Analysis, Neuro-Fuzzy approach and other techniques. These different approaches apply different rating system and the weights, which are area and factors dependent. Therefore, these weights and ratings play a vital role in the preparation of susceptibility maps using any of the approach. However, one technique that gives very high accuracy in certain might not be applicable to other parts of the world due to change in various factors, weights and ratings. Hence, only one method cannot be suggested to be applied in any other terrain. Therefore, an understanding of these approaches, factors and weights needs to be enhanced so that their execution in Geographic Information System (GIS) environment could give better results and yield actual ground like scenarios for landslide susceptibility mapping. Hence, the available and applicable approaches are discussed in this chapter along with detailed account of the literature survey in the areas of LSZ mapping. Also a case study of Garhwal area where Support Vector Machine (SVM) technique is used for preparing LSZ is also given. These LSZ maps will also be an important input for preparing the risk assessment of LSZ.
\end{abstract}

Keywords: Landslide, LSZ, Remote Sensing and Geographic Information System, Modeling, SVM, Garhwal Himalaya 


\section{Introduction}

According to the information on the International Red Cross, there are roughly 200 major natural disasters that occur each year in the world. These natural disasters cause an annual average loss of nearly 130,000 persons, and more than 140 million normal lives are affected. The frequency of occurrences of these natural disasters has increased many times in the recent past, and its effects are becoming more severe in the coming years. The major attribute is being the population growth, urbanization/industrialization leading to climate change. In general, most of the "natural risks" are accentuated by humans themselves by direct or indirect interference with the nature. Understanding a natural disaster is very difficult as it is a very complex system that involves various controlling and contributing factors. This means that no easy, one-sided solutions can be found, but applying the holistic approach to tackle such problems could yield some beneficial results. Currently, many researches are being carried out to understand the phenomenon acting behind these natural disasters such as floods, tsunamis, cyclones, earthquakes, landslides, etc. So to combat these natural risks, the holistic concepts should be developed and applied, particularly to tackle landslide risk as landslides are one of the major environmental problems in our society.

The adverse impacts of climate change on developing countries have been highly consequential. High-magnitude flash floods and increased rains has been one of the pertinent causes of extensive landslides, which accounts for around $4.89 \%$ of the globally occurring natural disasters during the last two decades. The unplanned urbanization and development coupled with continued deforestation may be attributed to this rise in figure. Landslides are quite frequent along the tectonically active Himalayan region. In the year 1984, Varnes defined the term hazard as "the probability of occurrence of a potentially damaging phenomenon within a specified period of time and within a given area". When such spatial distributions of hazards are represented on maps into various classes, it gives zonation maps. Thus, landslide hazard zonation refers to the division of area into various classes, which is categorised on the basis of degrees of actual/potential hazard caused by landslides. Hence, hazard zonation forms a critical factor for effective landslide management and is used as a tool for planning mitigation measures. The preparation of the landslide hazard map requires the analysis of most determining factors that leads to soil failure. The preparation of landslide hazard zonation requires detailed landslide inventory, processes involved in slope instability, triggering factors and many other associated studies. Landslides may occur due to a variety of conditional and triggering factors such as change in slope angle, slope aspect, faults, lithology, deforestation, improper drainage system, rainfall, and earthquakes. Thus, this zonation can be carried out at various scales from national (1:1 million) to local (1:5000). Depending on the scale of map, the parameters/factors and their accuracy varies.

With the advent of satellite data and various sensors, the scope of remote sensing has increased widely. The bird's eye view of the area at moderate to fine resolution gives fast and quick information about the terrain. Clubbed with the spectral and temporal characteristics of the satellite, the ability to identify and recognise landslides for the preparation of inventory map has been improved a lot. Both visual as well as automatic processes are well developed for 
recognition of landslide features. This preparation of inventory map has been made more effective with recent developments of resolution merging where data from different sensors could be merged to obtain better, sharp and good resolution images. Not only in the identification of landslides but also in the preparation of other contributing and controlling factors, remote sensing plays a crucial role. The elevation data from DEM (Digital Elevation Model) are used for the preparation of slope, aspect, relief, curvature, etc., parameter that controls the behaviour of landslide as well as the slope stability/instability. Not only the optical and multispectral data but the Radar and SAR data are being used for the analysis of landslides. The interferometric SAR technique is capable of distinguishing very minute changes in elevation and slope; hence, it is used for the identification of higher-resolution and correspondingly smaller area. Data from various sensors, i.e. optical, multispectral, thermal and microwave/radar, are being used for landslide studies.

There are various methods for the preparation of Landslide Susceptibility Zonation (LSZ) such as based on Fuzzy logic, Artificial Neural Network, Discriminant Analysis, Direct Mapping, Regression Analysis, Neuro-Fuzzy approach and other techniques. These different approaches apply different rating system and the weights, which are area and factors dependent. Therefore, these weights and ratings play a vital role in the preparation of susceptibility maps using any of the approach. However, one technique that gives very high accuracy in certain might not be applicable to other parts of the world due to change in various factors, weights and ratings. Hence, only one method cannot be suggested to be applied in any other terrain. This chapter discusses the methods being used in the field of LSZ, what are the input parameters being used, what the accuracy is and how best the method map the LSZ. However, it should be kept in mind that most of these methods/analysis are based on landslide inventory of any area, so the first and foremost step for working towards LSZ should be preparation of landslide inventory. Finally, this chapter discusses a case study of application of geo-spatial technology for preparation of LSZ in Garhwal Himalayan region, which is tectonically very active and prone to landsliding.

\section{Various Approaches for LSZ Mapping}

\subsection{Regression Analysis}

People are normally interested in finding the relationship between different variables. For example, whether smoking causes lung cancer? Regression analysis is the statistical method of finding relationship between dependent/predicted variable (denoted as $y$ ) and independent/ predictor variables (denoted as $x_{1}, x_{2}, \ldots, x_{n}$ ), where $n$ denotes the number of predictor variables [1]. The true relationship between $y$ and $x_{1}, x_{2}, \ldots, x_{n}$ can be approximated by the regression model as indicated in equation 1

$$
y=f\left(x_{1}, x_{2}, \ldots, x_{n}\right)+\varepsilon
$$


where $\varepsilon$ is assumed to be a random error representing the discrepancy in the approximation. It accounts for the failure of the model to fit the data exactly [2]. Typically, regression analysis is used for one of these three purposes [3] viz. (i) Modelling the relationship between $x$ and y, (ii) Prediction of target variable, and (iii) Testing of hypotheses.

There are three types of regression models:

Simple linear regression: It models the linear relationship between two variables; out of which one is dependent variable $y$, and other is independent variable $x$. In this model, regression equation is given as below in equation 2

$$
y=a x+b+\varepsilon
$$

where $a=$ slope of regression line, $b=$ intercept and $\varepsilon=$ random error. Simple linear regression is shown in Figure.1.

Multiple linear regression: There are many situations when result depends on one or more predictor variables. In such situations, simple linear regression is not sufficient to model the output, hence it requires a regression equation as given in eq 3, which models the linear relationship between one dependent variable $y$ and more than one independent variables $x_{1}, x_{2}, \ldots, x_{n}$. In this model, regression equation is given as below

$$
y=a_{1} x_{1}+a_{2} x_{2}+\ldots+a_{n} x_{n}+a_{0}+\varepsilon
$$

where $a_{1}, a_{2}, \ldots, a_{n}$ are regression coefficients, $a_{0}=$ intercept and $\varepsilon=$ random error

After the determination of regression model, its parameters are estimated based on the collected data. This is called as parameter estimation and model fitting. Most commonly used method of estimation is called the least square method [1, 2, 3].

Nonlinear regression: When the relationship between dependent and independent variable cannot be modelled using straight line, nonlinear regression is used. For example, nonlinear regression model for growth of a particular organism (y) as a function of time $(\mathrm{t})$ can be written as

$$
y=\frac{\alpha}{1+e^{\beta t}}+\varepsilon
$$

where $\alpha$ and $\beta$ are model parameters and $\varepsilon=$ random error. All nonlinear functions that can be transformed into linear functions are called linearizable functions $[2,3]$. 


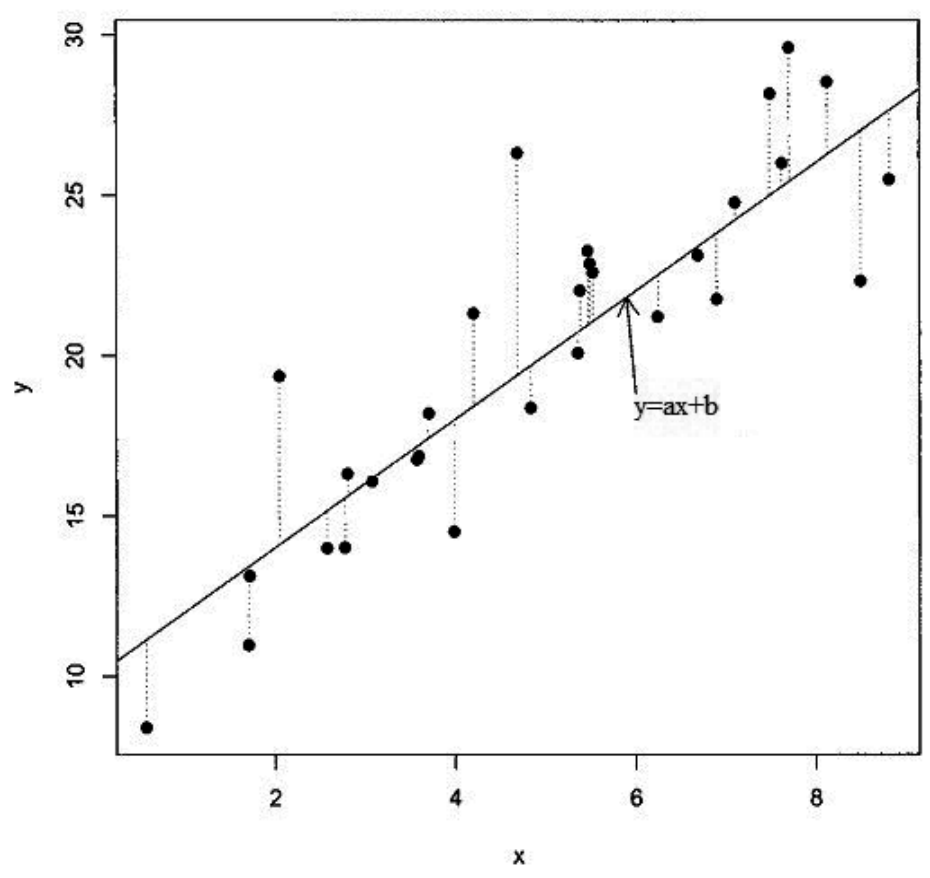

Figure 1. Simple linear regression model, solid line corresponds to true regression line and the dotted line corresponds to random error $\varepsilon$ [3].

\subsubsection{Estimation Using Least Square}

The least square method for linear regression finds regression coefficients $a_{0}, a_{1}, a_{2}, \ldots, a_{n}$ such that sum of squared distance from actual value $y_{i}$ and fitted value $\hat{y}_{i}$ reaches minimum for all possible choices of regression coefficients $a_{0}, a_{1}, a_{2}, \ldots, a_{n^{\prime}}[1,4]$ using the given eq 5 .

$$
\sum_{i=1}^{n}\left[y_{i}-\left(a_{0}+a_{1} x_{1}+a_{2} x_{2}+\ldots+a_{i} x_{i}\right)\right]^{2}
$$

For any choice of observed coefficients $\hat{a}$, the estimated/fitted value given for the observed values is

$$
\widehat{y_{i}}=\widehat{a_{0}}+\widehat{a_{1}} x_{1}+\widehat{a_{2}} x_{2}+\ldots+\widehat{a_{i}} x_{i}
$$

The difference between observed value $y_{i}$ and fitted value $\hat{y}_{i}$ is called residual. 
When dealing with regression analysis, if there is only one response variable, regression analysis is called univariate regression, and in case of two or more response variables, the regression is called multivariate regression. The difference between simple and multiple regressions is determined by the number of predictor variables (i.e. simple means one predictor variable and multiple means two or more predictor variables), whereas the difference between univariate and multivariate regressions is determined by the number of response variables. A brief summary of various classifications is given in Table-1. Out of all these regression types, logistic regression method is used a lot since most variables in hazard zonation mapping tends to be qualitative rather than quantitative.

\begin{tabular}{|c|c|}
\hline Types of Regression & Conditions \\
\hline Univariate & Only one quantitative response variable \\
\hline Multivariate & Two or more quantitative response variables \\
\hline Simple & Only one predictor variable \\
\hline Multiple & Two or more predictor variables \\
\hline Linear & $\begin{array}{l}\text { All parameters enter the equation linearly, possibly after transformation of the } \\
\text { data }\end{array}$ \\
\hline Nonlinear & $\begin{array}{l}\text { The relationship between the response and some of the predictors is nonlinear or } \\
\text { some of the parameters appear nonlinearly, but no transformation is possible to } \\
\text { make the parameters appear linearly }\end{array}$ \\
\hline Analysis of Variance & All predictors are qualitative variables \\
\hline Analysis of Covariance & Some predictors are quantitative variables and others are qualitative variables \\
\hline Logistic & The response variable is qualitative \\
\hline
\end{tabular}

Table 1. Various Classifications of Regression Analysis [2].

\subsubsection{Logistic Regression}

Logistic regression model is a general linear model, which models the data with binary responses [1], i.e. it predicts the presence or absence of an outcome based on the values of a set of predictor variables [5]. The dependent variable in logistic regression is binary (i.e. 0 or 1 , true or false), whereas the independent variable can be categorical, dichotomous or interval [6]. For landslide study, dependent variable is binary, showing either the presence or the absence of landslide.

Example: For determining risk factor for cancer, health data of several people were collected on several variables such as age, sex, smoking, diet, and the family's medical history. The response variable " $\mathrm{y}$ " is the person having cancer $(y=1)$ or not having cancer $(y=0)[2]$.

Coefficients of logistic regression can be used to calculate ratios for each independent variable in the model. Logistic regression model can be represented in simplest form as shown in equation 7 


$$
p=\frac{1}{1+e^{-y}}
$$

where $p$ is the probability of occurrence of an event (varies between 0 and 1 on S-shaped curve), and $y$ is dependent variable and calculated using the logistic regression equation 8

$$
y=a_{0}+a_{1} x_{1}+a_{2} x_{2}+\ldots+a_{n} x_{n}
$$

where $a_{1}, a_{2}, \ldots, a_{n}$ are logistic regression coefficients and $a_{0}=$ intercept, $x_{1}, x_{2}, \ldots, x_{n}$ are independent variables [7].

\subsubsection{Applications $[2,4]$}

i. $\quad$ Agricultural sciences (e.g. analysis of data of milk production).

ii. Management, industrial and labour relations (e.g. Do chief executive officers (CEOs) and their top managers always agree on the goals of the company?).

iii. Environmental sciences (e.g. exploration of relationship between water quality and land use).

iv. Psychology (e.g. What are the factors that impact the likelihood of a moonlighting worker becoming aggressive toward his or her supervisor?).

v. Geography (Can the population of an urban area be estimated without taking a census?).

\subsubsection{Landslide Hazard Zonation using Regression Analysis}

Regression analysis is one of the most widely used statistical tool as it provides simple methods for establishing a functional relationship among variables. Logistic regression has been used widely for preparation of landslide hazard zonation maps [5, 6, 8, 9]. Slope, aspect, curvature, distance from drainage, lithology, distance from lineaments, land cover, vegetation index, and precipitation are considered as landslide-causing factors in many literatures. In logistic regression model, LHI is calculated by solving the regression equation. Correlation between landslide event and landslide affecting factors is estimated, and then, equation predicting the landslide is obtained.

\subsection{Analytic Hierarchy Process}

AHP, developed by Thomas L. Saaty in 1975, is an effective tool for decision making. It helps the decision makers in setting priorities and making best decision on complex decisive problems. It distributes the problems in hierarchy of criteria and options (alternatives), i.e. it reduces complex decisions to pairwise comparisons and then synthesizes the result. The AHP considers both the rational and the intuitive to select the best from a number of alternatives 
evaluated with respect to several criteria. It checks for consistencies in decision maker's evaluation and also allows limited inconsistencies in judgements.

\subsubsection{Working of $A H P$}

The AHP uses a set of evaluation criteria and a set of alternative options among which the best decision is to be made. It generates a weight for each evaluation criteria according to pairwise comparisons of criteria. The criteria with higher weight are selected since it is most important of all the criteria. Further, for fixed criteria, it assigns a score to each alternative option according to pairwise comparisons of options based on those criteria. Higher the score for an option, better the performance of that option w.r.t. considered criteria. Information is then arranged in a hierarchical tree. Finally, the AHP generates global score for each option using the combinations of the criteria weights and options scores and determines relative ranking of alternatives. A simple hierarchy with three levels is shown in Figure.2.

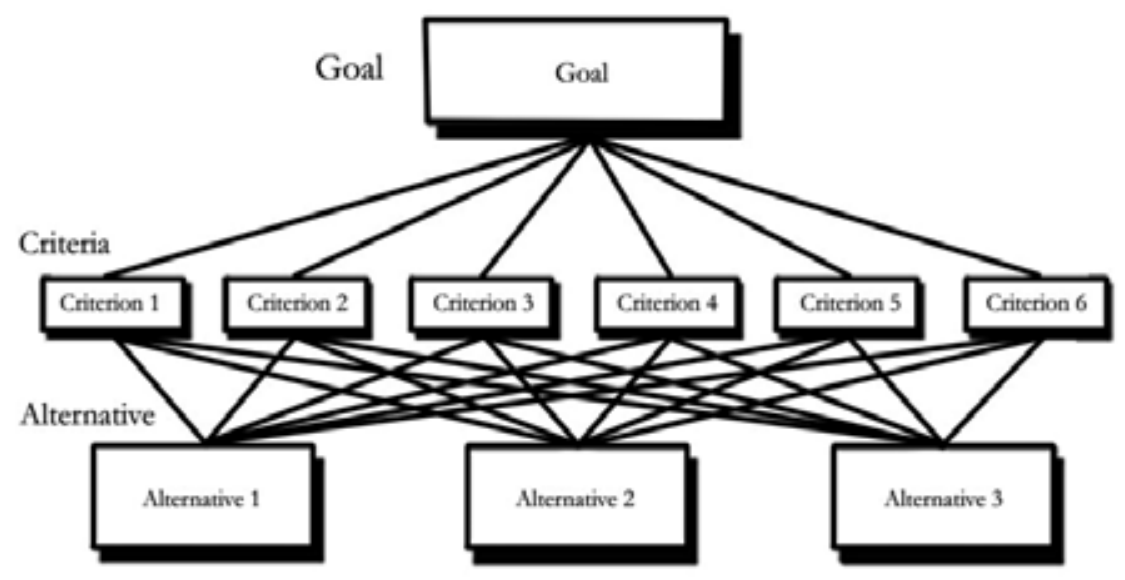

Figure 2. A three level hierarchy [10].

\section{Implementation of AHP}

AHP can be implemented in three simple steps

i. Computation of weight vector for all criteria

ii. Computation of score matrix for all options

iii. Ranking of options based on final score

Once the goal has been set, then for all the alternatives, different ranks are given based on the criterion fixed to reach that goal. In this way, the priorities are set, and these factors are compared pairwise. For example, in case of landslide zonation, the goal could be to identify the areas that are prone to landsliding and the factors/parameters, such as slope, elevation, soil type, rock type, distance to drainage, etc., controlling it would become the alternatives. And 
to select the areas prone to landsliding, the criteria could be fixed such as slope should be more than $45^{\circ}$, soil type should be clayey, rock type should be other than granite/gneiss (hard rock), etc. Hence, the area fulfilling these criteria will be selected. This way of preparing the landslide susceptibility map is area specific, and the criteria applicable to one location may not be true for other location. Hence, a different approach is needed where the system adjust itself with the given conditions and scenarios.

\subsubsection{The Fundamental Scale}

The AHP is a general theory of measurement and is used to derive relative priorities of different criteria on absolute scales. Pairwise comparison judgments in the AHP are applied to pairs of homogeneous elements. The fundamental scale represents the intensities of judgments. In many cases, the elements to be compared are almost equal in measurements. In this situation, comparison must be made not on what fraction it is larger than the other [10]. Pairwise comparisons of criteria and/or options are performed based on the scale given in Table-2.

\begin{tabular}{lll}
\hline $\begin{array}{l}\text { Intensity of } \\
\text { Importance }\end{array}$ & Definition & Explanation \\
\hline 1 & Equal importance & Two activities contribute equally to the objective \\
\hline 3 & Weak & \\
\hline 4 & Moderate importance & $\begin{array}{l}\text { Experience and judgment slightly favour one activity over } \\
\text { another }\end{array}$ \\
\hline 5 & Moderate plus & $\begin{array}{l}\text { Experience and judgment strongly favours one activity over } \\
\text { another }\end{array}$ \\
\hline 6 & Strong importance & $\begin{array}{l}\text { An activity is favoured very strongly over another; its } \\
\text { dominance is demonstrated in practice }\end{array}$ \\
\hline 7 & Strong plus & $\begin{array}{l}\text { The evidence favouring one activity over another is of the } \\
\text { highest possible order of affirmation }\end{array}$ \\
\hline 9 & importance &
\end{tabular}

Table 2. The fundamental scale by T. L. Saaty $[10,11]$.

\subsubsection{Applications of AHP [10, 12, 13].}

i. Evaluation of cities for livelihood and planning

ii. Ranking of countries

iii. Customers adoption of mobile devices and mobile services

iv. Human organ transplants

v. Prediction of winners in chess matches

vi. Natural resource management 


\subsubsection{Landslide Hazard Zonation using AHP}

Various authors $[14,15,16,17,18,19]$ have used AHP for giving weights to various factors of landslide occurrence. The effect of each factor and factor classes, on landslide occurrence, is determined using pairwise comparison, and an equation is modelled for landside susceptible index (LSI), as given below in equation 9

$$
\operatorname{LSI}_{A H P}=\sum_{i=1}^{n} \text { Factor }_{i} * W_{A H P_{i}}
$$

where Factor $_{i}=$ landslide conditioning factor such as slope, aspect, lithology, etc. $W_{A H P_{i}}=$ Weightage for each causative factor. Pixel (LSI) values derived from above equation are classified into various susceptibility classes (low, moderate, high, and very high) based on natural break.

\subsection{Artificial Neural Network}

Artificial neural network attempts to model the information processing capabilities of the brain. The operation of the brain is based on simple basic elements called as neurons. Neurons are connected to each other with transmission lines called as axons and receptive lines called as dendrites. Information is stored at synapses. Each neuron has an activation level that ranges between some minimum and maximum value [20,21]. A neural network is a massively parallel distributed processor made from simple processing units, which can store knowledge gained from experiments and can utilize it later. It replicates the processing of the brain in two respects [22].

i. Knowledge is acquired by the network from its environment through a learning process.

ii. Synaptic weights are used to store the acquired knowledge.

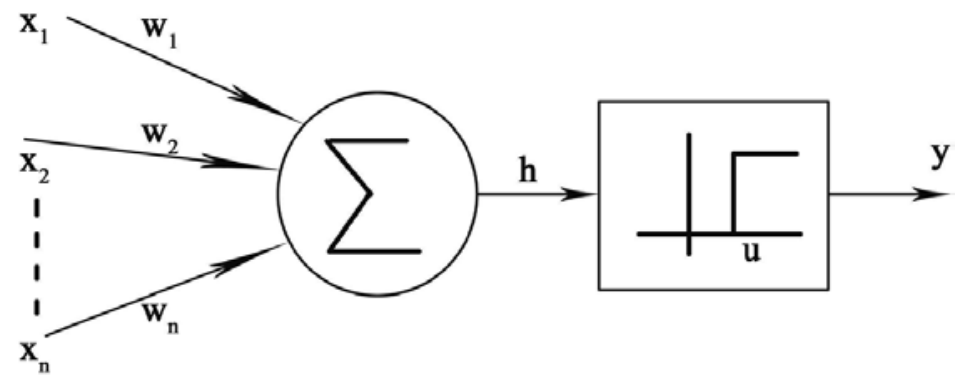

Figure 3. McCulloch and Pitts model of artificial neuron [20].

In 1943, McCulloch and Pitts proposed a computational model for artificial neuron, based on binary threshold [23]. This neuron calculates a weighted sum of ' $n$ ' input signals, $x_{j}$ where $j=$ 
$1,2,3 \ldots . . . n$, and generates an output of 1 if this sum is above a certain threshold ' $u$ ', else output 0 . The model [24] is shown in Figure. 3 and given by equation 10.

$$
\begin{array}{r}
y=1, \text { if } \sum_{j=1}^{n} w_{j} x_{j}>u, \\
y=0, \text { otherwise }
\end{array}
$$

ANN is a weighted directed graph, in which artificial neurons are nodes and directed edges with weights are connections between neuron outputs and neuron inputs. ANN can be grouped in two categories [20, 22].

i. Feed-forward network, where graph has no loops, as shown in Figure. 4. Here, all the nodes in each layers are connected to every other node in forward layer, hence it is called fully connected network. If some of the links are missing, then it is called partially connected network. Example: single-layer perceptron, multilayer perceptron, radial basis function, etc.

ii. Recurrent or feedback network, where graph has loops because of feedback connections, as shown in Figure. 5. Here, output from all the neurons is applied to input using feedback connection. Example: self-organizing map, adaptive resonance theory model, Hopfield network, etc.

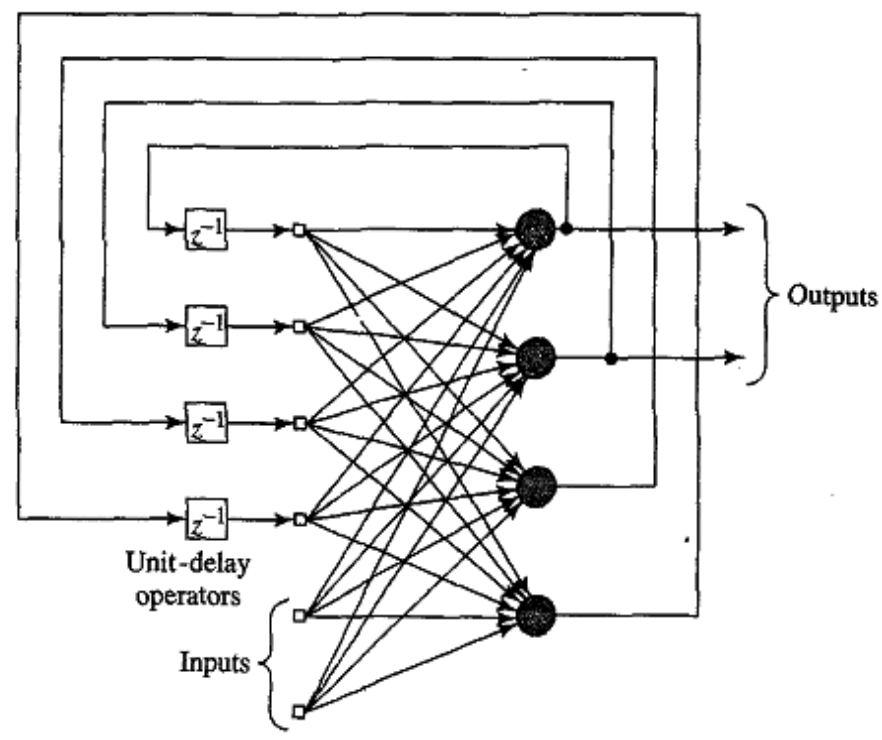

Figure 4. Example of feed forward network with one hidden layer \& one output Layer 


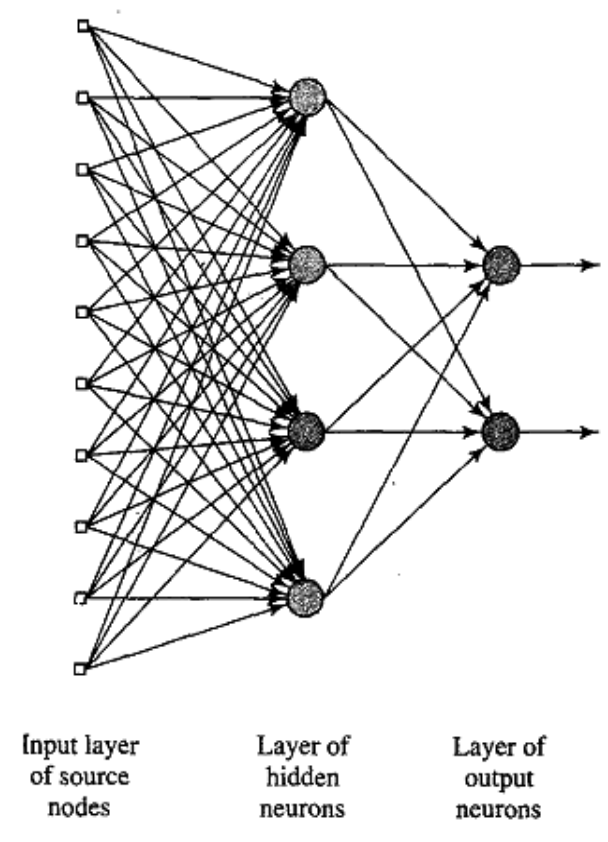

Figure 5. Example of recurrent network with hidden layer

\subsubsection{Learning Algorithms}

To be able to learn is the fundamental trait of intelligence. Although it is difficult to formulate a precise definition of learning, the process of learning in the context of ANN can be defined as the problem of updating network architecture and connection weights so that a network can efficiently perform a specific task [20]. Artificial neural network tries to learn input-output relationships from the given collection of representative examples, instead of following a set of rules specified by human experts. This is one of the major advantages of neural networks over traditional expert systems. A learning algorithm refers to a procedure in which learning rules are used for adjusting the weights. Some examples of learning algorithms are (i) Error correction learning, (ii) Memory-based learning, (iii) Hebbian learning, (iv) Competitive learning, (v) Boltzmann learning, etc. [23, 25].

\subsubsection{Feed-Forward Back-Propagation Network (Based on error correction learning)}

It is basically a feed-forward multilayer perceptron with back-propagation as learning/training algorithm. In order to train a neural network to perform desired task, the weight of each input has to be adjusted, such that the error between the desired and actual output is minimal (Figure. 6 after [21]) i.e.

$$
\text { Error Signal }(\mathrm{e})=\text { Desired Response }(\mathrm{d})-\operatorname{Actual} \text { Output }(\mathrm{y})
$$




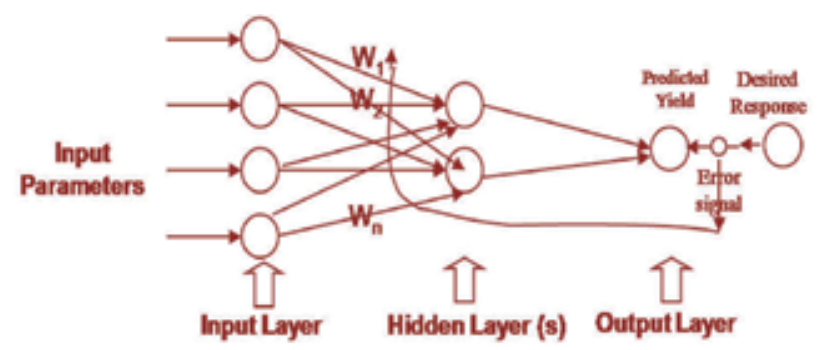

Figure 6. Back-Propagation Neural Network [21].

\subsubsection{Applications of ANN}

1. Image processing, classification of satellite data, compression of large images, etc.

2. Medical signal processing and developing medical decision support system [26, 27].

3. Paper making industry for prediction of curl in paper reel [28].

4. Calculation of nonlinear interpolation algorithm [29].

5. Detection and classification of vehicles in traffic management [30].

6. Optical and handwritten character recognition [31].

7. Operations research [32].

8. Application in Mineral Potential Mapping [33].

9. Landslide Susceptibility Mapping [34-37].

\subsubsection{Application of ANN in Landslide Hazard Zonation}

ANN has been used widely in the preparation of LHZ maps [34-37]. People have used variations of ANN with one input layer, two hidden layers, and one output layer for various factors controlling landslide occurrence. ANN connection weights are used to provide weights or rankings to the input data source (landslide-causative factors). Weights of factors and rankings of categories are integrated to provide LSZ map.

\subsection{Support Vector Machine}

Support Vector Machine is a data classification technique, developed by Vapnik in 1990. Classification process involves separating data into training and testing sets. Each element in the training set contains a corresponding target value (i.e. the class labels) and several attribute (i.e. the features of elements). The ultimate goal of SVM is to predict the target value for the test data, with only attributes of the test data given [38, 39]. Support vector machines are based on the concept of decision planes that define decision boundaries [40]. SVM finds the best hyperplane (n-dimensional plane) that separates all data points of one class from those of other 
class. It uses kernel method to project linearly non-separable data to a higher dimension. The kernel can separate classes even if mean values are near to each other. A simple illustration of the method is shown in Figure.7. The data points shown are linearly separable. The maximum margin hyper plane is shown in red, and the margin between the support vectors is shown by the parallel light blue lines. The two classes do not overlap. The support vectors (patterns that are on the margin) are shown [41] as yellow circles for class 1 and triangles for class 2.

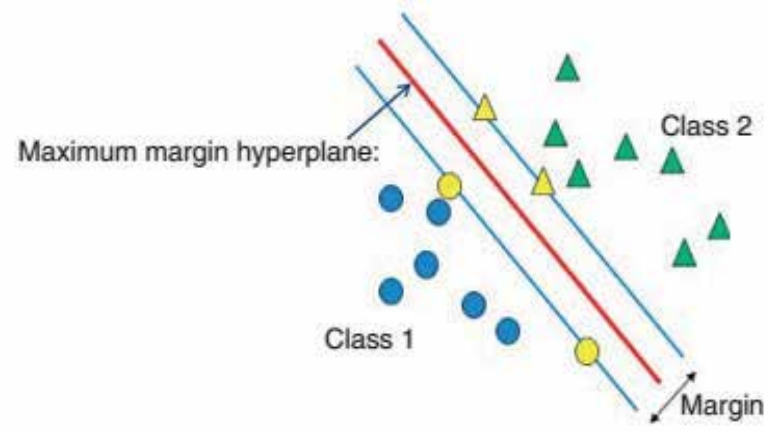

Figure 7. Illustration of the support vector [41].

Let $\mathrm{m}$-dimensional training inputs $\mathrm{x}_{\mathrm{i}}(\mathrm{i}=1, \ldots, \mathrm{M})$ belong to Class 1 or 2 and the associated labels be $y_{i}=1$ for Class 1 and -1 for Class 2 . If these data are linearly separable, we can determine the decision function, which is represented by equation 11 [42]

$$
D(x)=w^{T} x+b
$$

where $\mathbf{w}$ and $\mathrm{b}$ are weight and bias, respectively, to map the input into a higher dimensional space. The optimal separating hyper plane (i.e., $w^{T} x+b=0$ ) is located where the margin between the two classes is maximized, and the misclassification is minimized. The optimal hyper plane satisfies the following constrained minimization as given by equations 12-13

$$
\begin{gathered}
\text { Min: } \frac{1}{2} w^{T} w \\
w^{T} x_{i}+b\left\{\begin{array}{c}
>0 \text { for } y_{i}=1, \\
<0 \text { for } y_{i}=-1
\end{array}\right\}
\end{gathered}
$$

They can be obtained by solving the following constrained optimization problem by the method of Lagrange multipliers and maximizing the equation 14 as given below 


$$
L(w, b)=\frac{1}{2}(w \cdot w)-\sum_{i=1}^{m} \alpha_{i}\left(y_{i}\left(w \cdot x_{i}+b\right)-1\right)
$$

where $\alpha_{i}=$ Lagrange's multiplier and $\alpha_{i} \geq 0$. SVM can perform only binary classification; however, classifying data in more than two classes can be performed using pairwise classification $[42,43]$.

\subsubsection{Applications of Support Vector Machine}

i. Image processing for classification of satellite images [44].

ii. Modelling of Seismic Liquefaction Potential [45].

iii. $\quad$ Financial Literacy Modelling [46].

iv. Text charactization [47].

v. Face detection [48].

vi. Texture classification [49].

\section{Advantages and Disadvantages}

All these methods mentioned above have certain advantages as well as disadvantage over the other, hence a detailed comparative Table 3 showing their advantages and disadvantages are given below.

\begin{tabular}{|c|c|c|}
\hline Method & Advantages & Disadvantages \\
\hline \multirow{4}{*}{ Regression Analysis } & Model developer has full knowledge of variables. & It requires the data to be independent. \\
\hline & It is most strongly predictive of an outcome. & It is sensitive to outliers. \\
\hline & $\begin{array}{l}\text { It runs faster than neural network/support vector } \\
\text { machine-based models. }\end{array}$ & \\
\hline & It is not "black box" as ANN. & \\
\hline \multirow{4}{*}{$\begin{array}{l}\text { Analytic Hierarchy } \\
\text { Process (AHP) }\end{array}$} & It is simple, flexible and powerful. & It requires a large number of comparisons. \\
\hline & $\begin{array}{l}\text { All the calculations are driven by decision maker's } \\
\text { experience. }\end{array}$ & $\begin{array}{l}\text { Limitation of the use of } 9 \text { point T. L. Saaty's } \\
\text { scale. }\end{array}$ \\
\hline & $\begin{array}{l}\text { It does not require an expert system with the } \\
\text { decision maker's knowledge embedded in it. }\end{array}$ & $\begin{array}{l}\text { It adds extra burden on decision maker for } \\
\text { complex problem. }\end{array}$ \\
\hline & & Rank reversal \\
\hline
\end{tabular}




\begin{tabular}{|c|c|c|}
\hline Method & Advantages & Disadvantages \\
\hline \multirow{5}{*}{$\begin{array}{l}\text { Artificial Neural } \\
\text { Network (ANN) }\end{array}$} & $\begin{array}{l}\text { It requires less formal statistical training to } \\
\text { develop the network. }\end{array}$ & Neural network are "black box". \\
\hline & $\begin{array}{l}\text { It can implicitly detect complex nonlinear } \\
\text { relationships. }\end{array}$ & $\begin{array}{l}\text { Single-layer perceptron work only on } \\
\text { linearly separable classification problems. }\end{array}$ \\
\hline & Availability of multiple training algorithms. & It requires greater computational resources. \\
\hline & & It is prone to over fitting. \\
\hline & & Can trap in local minima. \\
\hline \multirow{5}{*}{$\begin{array}{l}\text { Support Vector } \\
\text { Machine (SVM) }\end{array}$} & $\begin{array}{l}\text { It has high prediction accuracy and good } \\
\text { mathematical foundation. }\end{array}$ & $\begin{array}{l}\text { The biggest limitation of the support vector } \\
\text { approach is the choice of the kernel. }\end{array}$ \\
\hline & Overfitting does not occur. & It requires long training time. \\
\hline & $\begin{array}{l}\text { It does not trap in local minima, i.e. it finds the } \\
\text { global solution. }\end{array}$ & $\begin{array}{l}\text { Problem has to be formulated as two-class } \\
\text { problem. }\end{array}$ \\
\hline & $\begin{array}{l}\text { It works well with fewer training samples (i.e. } \\
\text { number of support vectors do not matter much). }\end{array}$ & \\
\hline & It requires fewer parameters (kernel, error cost). & \\
\hline
\end{tabular}

Table 3. Advantages and Disadvantages of these methods [10, 12, 13, 50, 51]

\section{Literature Survey}

The literature survey of some of the available research works carried out for Landslide Susceptibility Zonation is shown in Table 4 below:

\begin{tabular}{llll}
\hline S. No. & Techniques used & Accuracy (\%) & References \\
\hline 1. & Discriminant Analysis & 83.8 & Carrara et al [52] \\
\hline 2. & Regression Analysis & 70 & Jade \& Sarkar [53] \\
\hline 3. & Logistic Regression & 74.8 & Guzzetti et al. [54] \\
\hline 4. & Multilayer Perceptron & 73 & Ermini et al. [55] \\
\hline 5. & Neuro-Fuzzy approach & 97 & Pradhan et al. [36] \\
\hline 6. & Combined Neural Network and Fuzzy & 74.5 & Kanungo et al. [56] \\
\hline
\end{tabular}

Table 4. A comparative table for various techniques uesd with their accuracy.

The results obtained showed that the Artificial Neuro Fuzzy (ANF) modeling is a very useful and powerful tool for the regional landslide susceptibility risk assessments. Various membership functions should be selected and a number of training sets should be carefully and 
optimally selected to prevent over learning of the model. Therefore, the results that are to be obtained from the ANF modeling should be assessed carefully because the over learning may cause misleading results [35]. As a final recommendation, the results obtained from various papers showed that the methods followed in the study based on Neuro-Fuzzy approach exhibits a high performance. However, it is not forgotten that the performance of such type maps depends not only on the methodology followed but also on the quality of the available data and the factors considered for preparing LSZ. These input factors can be natural factors (like rainfall, lithology, slope, etc.) and anthropogenic factors (like road construction, mining, etc.). For this reason, if the quality of the data increases, the performance of the maps produced by these methods could increase. The detailed literature survey where various different models have been used for landslide hazard zonation is given below:

Lee and Pradhan[5] used frequency ratio and logistic regression model for mapping the landslide susceptible areas by considering slope, aspect, curvature, distance from drainage, lithology, distance from lineaments, land cover, vegetation index, and precipitation as landslide stimulating factors. They calculated the Landslide Hazard Index (LHI) by summation of frequency ratios for all the factors and solving the regression equation, respectively, for both methods and concluded that the frequency ratio model has 2.7\% (93.04-90.34\%) better predication accuracy than the logistic regression model.

Pradhan et al [57] combined frequency ratio and fuzzy algorithm for generating landslide hazard maps. Fuzzy membership values were calculated using frequency ratio and detected landslides. Fuzzy algebraic operators (such as fuzzy and, or, product, sum) and fuzzy gamma operators were applied on fuzzy membership values for landslide hazard mapping. Value of fuzzy gamma operator was set to $0.025,0.05,0.1,0.2,0.3,0.4,0.5,0.6,0.7,0.8,0.9,0.95$, and 0.975 for detecting its effect on landslide hazard maps. After verification, they found that out of 17 cases tested, the gamma operator with value 0.8 performed best (prediction accuracy $80.26 \%$ ), while 'Fuzzy algebraic sum' and 'fuzzy or' showed worst accuracy of $64.77 \%$ and $56.86 \%$, respectively.

Pourghasemi et al[14] showed the applicability of fuzzy logic and analytic hierarchy process in the mapping and zonation of landslide susceptible areas. A total of 12 data layers, which correspond to 12 landslide conditioning factors, were exploited to detect the most susceptible areas. Fuzzy membership values to all pixels were assigned based on the frequency ratio model. Landslide susceptibility was then identified using fuzzy if then else rules. Using the AHP model, weightage of each contributing factor was identified using pairwise comparisons and an equation was modelled for landside susceptible index. Validation of the maps created using both the methods was performed using ROC curve. They concluded that the model with fuzzy logic has the highest area under the curve (AUC) value 0.9194, whereas AHP has 0.8887.

Devkota et al[6] compared certainty factor, index of entropy and logistic regression methods for landslide susceptibility mapping. Slope gradient, slope aspect, altitude, plan curvature, lithology, land use, distance from faults, rivers and roads, topographic wetness index, stream power index and sediment transport index were considered as prominent factors for landslide susceptibility study. The value of the certainty factor ranges between -1 and +1 . A positive value means an increasing certainty in landslide occurrence, while a negative value corre- 
sponds to a decreasing certainty in landslide occurrence. CF values of the landslide conditioning factors were combined pairwise to generate landslide susceptibility index. Natural breaks were used to classify LSI value to Landslide Hazard Zones. The performance of landslide susceptibility models was assessed using ROC curves. They found that the hazard map prepared using the index of the entropy model has the highest prediction accuracy $(90.16 \%)$, followed by the logistic regression model $(86.29 \%)$ and the certainty factor model $(83.57 \%)$.

Nourani et al[8] prepared landslide hazard zonation maps using genetic programming and compared it with frequency ratio, logistic regression, artificial neural network. Seven factors, i.e. lithology, slope, aspect, elevation, land cover, distance to stream, and distance to road, were considered prominent for landslide hazard zonation study. In the frequency ratio model, landslide hazard index was calculated by summation of frequency ratios for all the factors. In the logistic regression model, LHI was calculated by solving the regression equation. Correlation between landslide event and landslide affecting factors was estimated, and then, equation predicting the landslide was obtained. Three layered feed-forward neural network with back-propagation as training algorithm was used for calculation of LHI. Two different criteria were used to measure the efficiency of the ANN method, i.e. the root mean square error (RMSE) and the determination coefficient (DC). For producing the best landslide susceptibility maps, sensitivity analysis was also implemented in ANN. For verification of LSM, produced by FR, LR, ANN, and GP methods, landslide testing data were compared with these maps. The assessment of AUCs showed that the prediction accuracy of FR, LR, ANN, and GP methods were $89.42 \%, 87.57 \%, 92.37 \%$, and $93.27 \%$, respectively.

Bui et al[37] compared the accuracy of landslide prediction, using support vector machine, multilayer perceptron neural network, radial basis function neural network, kernel logistic regression and logistic model tree. Slope, aspect, altitude, relief amplitude, topographic wetness index, stream power index, sediment transport index, lithology, fault density, land use, and rainfall were studied as landslide conditioning factors. For choosing the best subset of conditioning factors, predictive ability of the factors was assessed using the information gain ratio with 10-fold cross-validation technique. The analysis of landslide inventory map showed that landslides mainly occurred during and after the heavy rainfall. The performance of landslide susceptibility models was assessed using receiver operating characteristics (ROC) curves, and reliability was assessed using kappa index. They found that the MLP neural net model has the highest prediction capability of $90.2 \%$, followed by the SVM model $88.7 \%$, the KLR model $87.9 \%$, the RBF neural net model $87.1 \%$, and the LMT model $86.1 \%$.

Youssef et al[9] combined logistic regression and frequency ratio for removing their weaknesses and producing landslide susceptibility maps with better accuracy. Altitude, curvature, distance from wadis, distance from road, distance from fault, stream power index, topographic wetness index, soil type, geology, slope, and aspect were used as contributing factors in landslide occurrences. Frequency ratio was calculated by analyzing the relationship between 11 conditioning factors and landslide occurrence. Landslide hazard index was calculated by summation of frequency ratios for all the factors and solving the regression equation, respectively, for the frequency ratio and logistic regression methods. After this, the probability index 
for ensemble of FR and LR was calculated and normalized to be between 0 and 1. For calculating the landslide susceptibility map from ensemble method, the probability index value was classified in five categories using quantile classifier. Probability index value represents the predicted probability of landslide for each pixel in the presence of given set of conditioning factor. Validation of all three models was performed using ROC curves, and they observed that the prediction accuracy of ensemble of FR and LR was higher $(82 \%)$ than that of FR (58\%) and LR (77\%) separately.

\section{Case Study}

The landslide susceptibility mapping is carried out in the Mandakini River basin of Uttarakhand, which covers an area of about 2439 sq. $\mathrm{km}$ and is situated between $30^{\circ} 19^{\prime} 00^{\prime \prime} \mathrm{N}$ to $30^{\circ} 49^{\prime} 00^{\prime \prime} \mathrm{N}$ latitude and $78^{\circ} 49^{\prime} 00^{\prime \prime} \mathrm{E}$ to $79^{\circ} 20^{\prime} 00^{\prime \prime} \mathrm{E}$ longitude (Figure. 8a) falling in Survey of India toposheet Nos. 53J and 53N.

\subsection{Geological setting of the Study Area}

The lithological mapping of the area (Figure. $8 \mathrm{~b}$ ) shows the presence of Vaikrita formation in the north, forming most of the Greater/Higher Himalaya in Garhwal. South of this formation, the Munsiyari formation is present in the Lesser Himalaya. South of the Munsiyari formation, the Ramgarh group is present. The southernmost area of the basin is comprised of Berinag Formation. Vaikrita, Munsiyari, Ramgarh, and Berinag formations are, respectively, separated by Main Central Thrust (MCT-I), which is equivalent to Vaikrita Thrust; Main Central Thrust (MCT-II), which is equivalent to Munsiyari/Jutogh Thrust and Main Central Thrust (MCT-III), which is equivalent to Ramgarh/Chail Thrust [58,59] (Figure. 8b). The presence of MCT Thrust zone causes high shearing and fractures in this area, which makes the rocks weak and highly prone to landslides and other natural hazards.

The high susceptibility to landslides in the Mandakini River basin is mainly due to complex geological settings, varying slopes and relief, heavy rainfall, along with ever-increasing human interference in the ecosystem. Extreme climatic events increase the instability of the terrain, which results in landslides, example includes the Kedarnath disaster [60]. Some of the major landslides occurred in the past are near Okhimath in 1997, 1998, 2010, 2012, 2013; in Phata Byung area in 2001, 2005, 2013; in Madhyamaheshwar area in 1998, 2005, 2013, etc., which are dependent on various factors such as geology, structure, land use, old slides, slope, slope aspect, and drainage in the area $[61,62,63]$.

\subsection{Data Used}

The Survey of India (SOI) toposheet Nos. 53N and 53J were used to create the base map of the study area. Landsat satellite image of October 2008 with 30-m spatial resolution was taken to finalize the tectonic and geologic map of the study area (after) [59]. Elevation data were taken from ASTER-GDEM (Advance Spaceborne Thermal Emission and Reflection Radiometer, Global Digital Elevation Model) having spatial resolution of $30 \mathrm{~m}$ with an accuracy of $\pm 10 \mathrm{~m}$. 
These data sets were analyzed, preprocessed and then categorized using Arc GIS 9.3, ERDAS Imagine 9.1 software to generate various thematic layers such as elevation, slope, aspect, drainages, geology/lithology, soil, buffer of thrusts/faults, and buffer of streams in the study area (Figure 8 a-h).
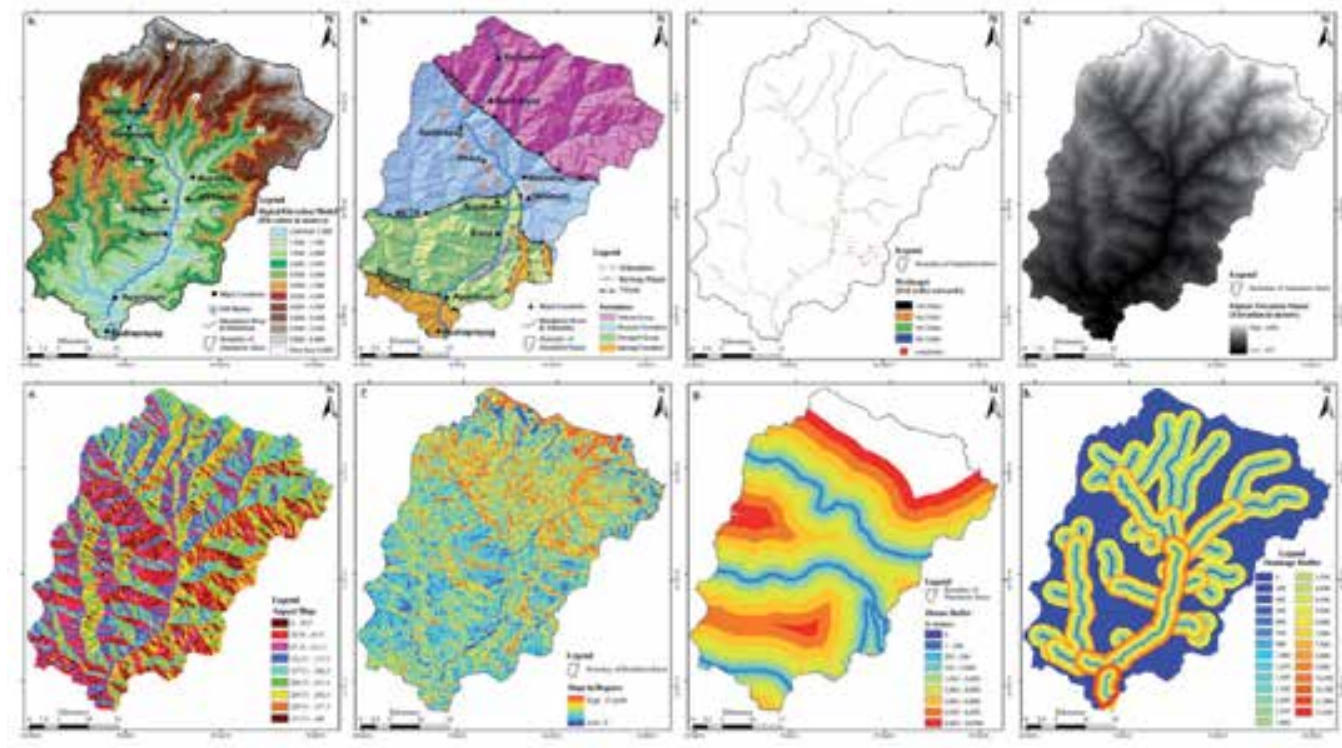

Figure 8. Various thematic layers used in landslide susceptibility prediction using PSVM model. a) Classified elevation map of the study area prepared from ASTER-GDEM showing major locations of Mandakini River basin. b) Geological map showing various formations and structures mainly MCT-I, MCT-II and Ramgarh Thrust (after Shukla et al. [59]). c) Drainage map derived from DEM showing third-order onwards and the presence of landslides in the study area. d) DEM map. e) Aspect map showing variation in the hill facets. f) Slope map showing comparatively higher slopes in northern sides as compared to southern side because of the presence of glacial features. g) Buffer map of the thrusts present in the study area created at specified intervals and reclassified in nine classes. h) Buffer map of the drainages third-order onwards. For the simplicity of the model, first- and second-order streams were not taken.

\subsection{Model Selection and Results}

All the data sets were generated in Geographic Information System (GIS) environment at $30 \times$ $30 \mathrm{~m}$ pixel resolution, the vector layers were converted to raster format with other raster data sets. These raster data sets were converted to ASCII format to be read in MATLAB for using Support Vector Machine (SVM) for prediction of Landslide susceptibility. The landslide data for Okhimath River basin, procured from Geological Survey of India (GSI), were considered to test the SVM model and generate the predictive susceptibility map. The study area contains $1,805,548$ pixels, while 2207 pixels are present as landslides. Thus, the pixels representing the landslides are mere $0.125 \%$ of the whole study area. The purpose of this study is to predict the landslide, so 1 denotes that pixel involved in landslide and -1 represents pixels that are not involved in landslide. In the whole study area, 2207 pixels were mapped as landslide based on the past data from GSI and other published reports. The whole set of data were divided into $60 \%$ as training data and $40 \%$ as testing data. 


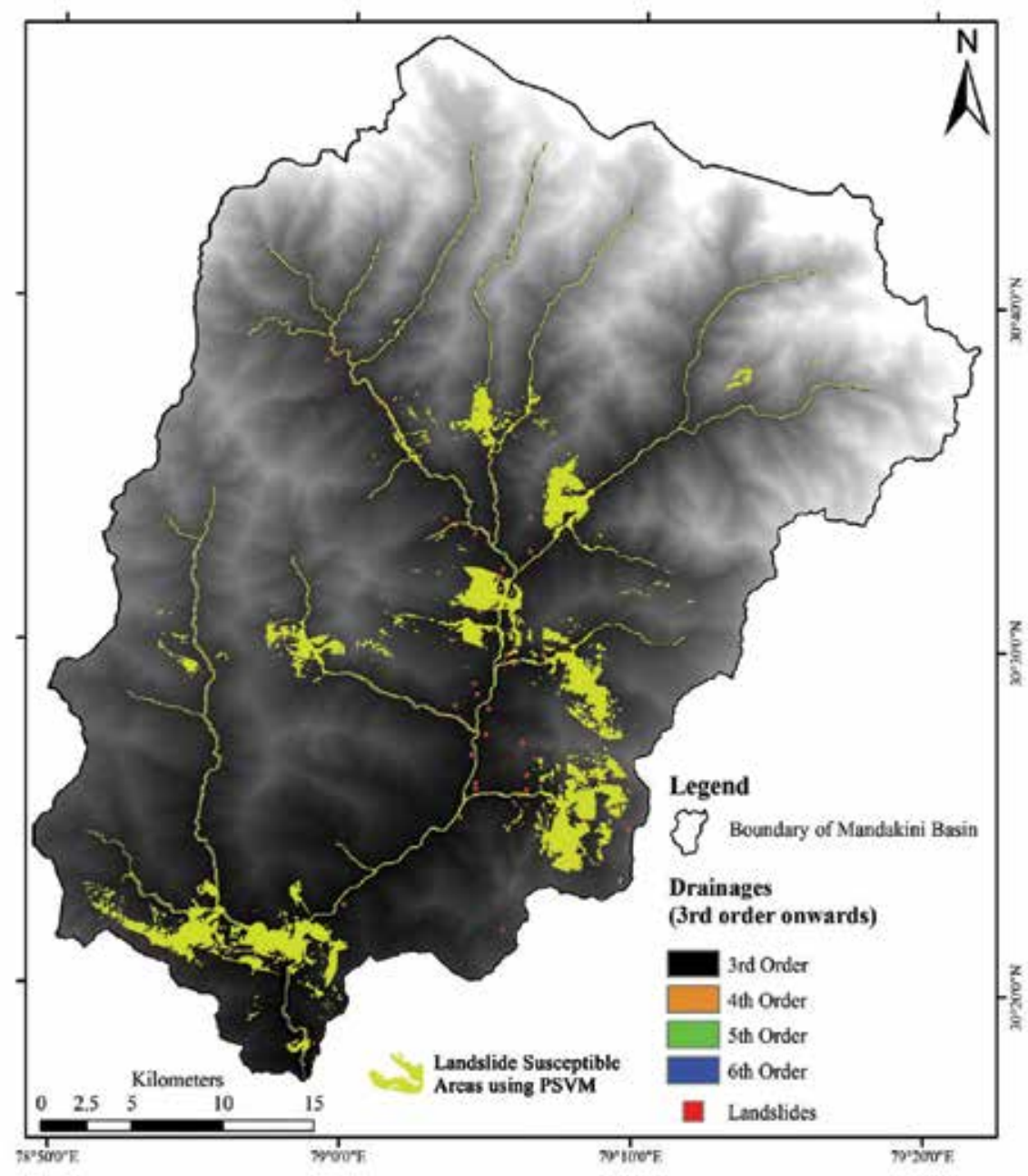

Figure 9. Landslide Susceptibility Map prepared using PSVM model shows areas susceptible to landslides on the DEM and drainage map of the study area with the actual past landslides.

Hence, the landslide susceptibility map for Mandakini River basin was prepared using the Proximal Support Vector Machine (PSVM) model (Figure. 9). It is evident from this figure that the PSVM model classified more areas in landslide susceptible zone as compared to certain landslides have been missed. Hence, various performance metrics such as average prediction accuracy (AA), true positive rate (TPR), true negative rate (TNR) and relative operating characteristic curve (ROC) were computed on testing data to validate the performance of prediction models $[64,65,66]$. The validation results in terms of AUC, and their corresponding testing accuracy showed that the PSVM model has higher AUC values when rainfall data from TRMM were considered with respect to when not considered as shown in Figure 10. The PSVM model with TRMM and without TRMM has an AA of $82.85 \%$ and $84.20 \%$, TPR of $79.43 \%$ and $72.46 \%$, TNR of $82.85 \%$ and $84.22 \%$ and an AUC value of $81.15 \%$ and $78.34 \%$, respectively 
(Table 5). The high value of TNR (82.85\% and $84.22 \%$ ) achieved by the PSVM model in this case is due to the large number of pixels for the study area as compared to pixels forming the landslides. Hence, this model predicted/demarcated the safe areas with $84.22 \%$ accuracy when TRMM data were taken into consideration, while it predicted the areas prone to landslide with $79.43 \%$ accuracy when TRMM data were taken in consideration because of less number of landslide pixels. Though the AUC values $(78.34 \%$ and $81.15 \%)$ are good, the average accuracy for the PSVM model is quite high between $82.85 \%$ and $84.20 \%$. Similar results were also obtained by Pradhan [67] where SVM yielded $81.46 \%$ AUC when applied on altitude, slope angle, plan curvature, distance from drainage, distance from road, soil type and NDVI as the input parameters considered for landslide susceptibility mapping for Penang Island in Malaysia.

\begin{tabular}{lccccc}
\hline Model & AA\% & TPR $\%$ & TNR\% & AUC $\%$ & C \\
\hline PSVM (with TRMM) & 82.85 & $\mathbf{7 9 . 4 3}$ & 82.85 & 81.15 & 100 \\
\hline PSVM (without TRMM) & 84.2 & 72.46 & $\mathbf{8 4 . 2 2}$ & 78.34 & 128 \\
\hline
\end{tabular}

Table 5. Prediction performance for PSVM model.

Best results are shown in bold. $\mathrm{AA}(\%)$ is the average accuracy, $\mathrm{TPR}(\%)$ is the true predictive rate, $\operatorname{TNR}(\%)$ is the true negative rate and $\mathrm{AUC}(\%)$ is the area under the curve.

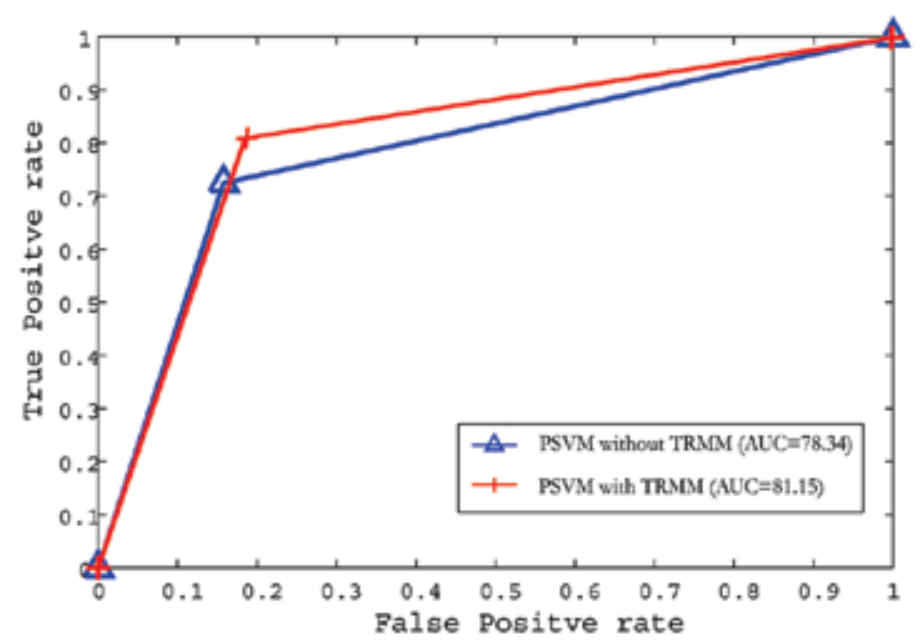

Figure 10. Best Prediction rate and area under the curves (AUC) produced by PSVM model with and without TRMM data consideration.

\subsection{Conclusion}

In Garhwal Himalaya, Mandakini River basin is highly vulnerable to landslides, especially the town of Okhimath and its nearby villages. In the vicinity of the study area, Mandakini 
River crosses various Himalayan thrusts, and due to the presence of these tectonically active MCT zones, the rocks shows high shearing and fracturing and becomes more susceptible for landsliding. The susceptibility to landslide is mainly controlled by valley slopes, attitude of discontinuity of surfaces, soil type, presence of drainage, nature of rocks exposed, and structural and tectonic features present, besides human interaction in the terrain.

Hence, recently developed Support Vector Machine (SVM) learning technique was applied on this area to demarcate the landslide prone and safe areas. The PSVM method has been applied for landslide susceptibility mapping of the study area. The PSVM model showed higher average accuracy (AA) of $82.82 \%-84.20 \%$ for this study area, and the ROC curve indicates that the PSVM model has the prediction accuracy of $81.15 \%$. Nevertheless, this model can be effectively used for landslide susceptibility mapping in this area or similar terrain with these sets of input parameters.

\section{Acknowledgements}

Authors would like to thank Dr. R. P. Singh, Ms. A. S. Ningreichon and Ms. Yogita Garbyal of Department of Geology, University of Delhi for carrying out the geological field mapping and figure preparations of this study area. The field work for this work was supported by DST project Landslide Dham (MANU Project), Project No. NRDMS/11/3010/013 (G) from NRDMS sanctioned to CSD.

\section{Author details}

Dericks P. Shukla ${ }^{1 *}$, Sharad Gupta ${ }^{1}$, Chandra S. Dubey ${ }^{2}$ and Manoj Thakur ${ }^{3}$

*Address all correspondence to: dericks.82@gmail.com

1 School of Engineering, Indian Institute of Technology, Mandi (HP), India

2 Department of Geology, University of Delhi, Delhi, India

3 School of Basic Sciences, Indian Institute of Technology, Mandi (HP), India

\section{References}

[1] Yan, X. \& Su, X.G., 2009. Linear Regression Analysis: Theory and Computing, World Scientific, pp. 1-4. 
[2] Chatterjee, S. \& Hadi, A.S., 2006. Regression Analysis by Example. $4^{\text {th }}$ ed., Wiley InterScience, New Jersey, pp. 12-15.

[3] Chatterjee, S. \& Simonoff, J.S., 2013. Handbook of Regression Analysis. Wiley InterScience, New Jersey, pp. 3-16.

[4] Mendenhall, W. \& Sincich, T., 2012. A Second Course in Statistics Regression Analysis. $7^{\text {th }}$ ed., Prentice Hall.

[5] Lee, S. \& Pradhan, B., 2007. Landslide hazard mapping at Selangor, Malaysia using frequency ratio and logistic regression models. Landslides, 4(1), pp. 33-41.

[6] Devkota, K.C., Regmi, A.D., Pourghasemi, H.R., Yoshida, K. et al., 2013. Landslide susceptibility mapping using certainty factor, index of entropy and logistic regression models in GIS and their comparison at Mugling-Narayanghat road section in Nepal Himalaya. Natural Hazards, 65(1), pp.135-165.

[7] Kleinbaum, D.G. \& Klein, M., 2010. Logistic Regression: A Self-Learning Text, $3^{\text {rd }}$ ed., Springer, pp. 4-10.

[8] Nourani, V., Pradhan, B., Ghaffari, H., \& Sharifi, S.S., 2014. Landslide susceptibility mapping at Zonouz Plain, Iran using genetic programming and comparison with frequency ratio, logistic regression, artificial neural network models. Natural hazards, 71(1), pp. 523-547.

[9] Youssef, A.M., Pradhan, B., Jebur, M.N., \& El-Harbi, H.M., 2014. Landslide susceptibility mapping using ensemble bivariate and multivariate statistical models in Fayfa area, Saudi Arabia. Environmental Earth Sciences, 73(7), pp. 3745-3761.

[10] Saaty, T.L. \& Vargas, L.G., 2012. Models, Methods, Concepts \& Applications of the Analytic Hierarchy Process. Springer Science \& Business Media, New York, pp. 1-7.

[11] Saaty, T.L. \& Kearns, K.P., 1985. Analytical Planning: The Organization of Systems. Pergamon Press, pp. 19-40.

[12] Saaty, T.L. \& Vargas, L.G., 1982. The Logic of Priorities-Applications in Business, Energy, Health, and transportation. Springer Science $\mathcal{E}$ Business Media, New York.

[13] Brunelli, M., 2015. Introduction to the Analytic Hierarchy Process. Springer Briefs in Operations Research, pp. 1-15.

[14] Pourghasemi, H.R., Pradhan, B. \& Gokceoglu, C., 2012. Application of fuzzy logic and analytical hierarchy process (AHP) to landslide susceptibility mapping at Haraz watershed, Iran. Natural Hazards, 63(2), pp. 965-996.

[15] Bhatt, P.B., Awasthi, K.D., Heyojoo, B.P., Silwal, T., \& Kafle, G., 2013. Using geographic information system and analytical hierarchy process in landslide hazard zonation. Applied Ecology and Environmental Sciences, 1(2), pp. 14-22. 
[16] Reza, M. \& Daneshvar, M., 2014. Landslide susceptibility zonation using analytical hierarchy process and GIS for the Bojnurd region, northeast of Iran. Landslides, 11, pp. 1079-1091.

[17] Tazik, E., Jahantab, Z., Bakhtiari, M., Rezaei, A. \& Alavipanah, S.K., 2014. Landslide susceptibility mapping by combining the three methods Fuzzy Logic, Frequency Ratio and Analytical Hierarchy Process in Dozain basin. In ISPRS-International Archives of the Photogrammetry, Remote Sensing and Spatial Information Sciences, pp. 267272.

[18] Boroumandi, M., Khamehchiyan, M. \& Nikoudel, M.R., 2015. Using of Analytic Hierarchy Process for Landslide Hazard Zonation in Zanjan Province, Iran. Engineering Geology for Society and Territory, 2, pp. 951-955.

[19] Arora, M.K., Das Gupta, A.S. \& Gupta, R.P., 2004. An artificial neural network approach for landslide hazard zonation in the Bhagirathi (Ganga) Valley, Himalayas. International Journal of Remote Sensing, 25(3), pp. 559-572.

[20] Jain, A.K., Mao, J. \& Mohiuddin, K.M., 1996. Artificial neural network: a tutorial. Computer, 29(3), pp. 31-44.

[21] Konar, A., 1999. Artificial Intelligence and Soft Computing, Behavioral and Cognitive Modelling of the Human Brain. CRC Press.

[22] Haykin, S., 2005. Neural Network: A Comprehensive Foundation. $2^{\text {nd }}$ ed., Prentice Hall.

[23] Zurada, J.M., 1992. Introduction to Artificial Neural System. West Publishing Company.

[24] Demuth, H.B. \& Beale, M., 2002. Neural Network Toolbox. The MathWorks, ver. 4.

[25] Alawala, C.R., 2007. Fuzzy Logic and Neural Networks: Basic Concepts and Applications. New Age International Publisher, pp. 121-143.

[26] Graupe, D., Liu, R.W. \& Moschytz, G.S., 1988. Applications of neural networks to medical signal processing. In Proceedings of the $27^{\text {th }}$ IEEE Conference on Decision and Control Austin, Texas, pp. 343-347.

[27] Gorzalczany, M.B., 1996. An idea of the application of fuzzy neural networks to medical decision support systems. In Proceedings of the IEEE International Symposium on Industrial Electronics, 1, pp. 398-403.

[28] Edwards, P.J., Murray, A.F., Papadopoulos, G., Wallace, A.R., et al., 1999. The application of neural networks to the papermaking industry. IEEE Transactions on Neural Networks, 10(6), pp. 1456-1464.

[29] Sun, Z., 2009. Application of neural network in calculation of nonlinear interpolation algorithm. In IEEE International Conference on Information Science and Engineering, pp. 3981-3984. 
[30] Daigavane, P.M., Bajaj, P.R. \& Daigavane, M.B., 2011. Vehicle Detection and Neural Network Application for Vehicle Classification. In International Conference on Computational Intelligence and Communication Systems.

[31] Mani, N. \& Srinivasan, B., 1997. Application of artificial neural network model for optical character recognition. In IEEE International Conference on Systems, Man, and Cybernetics. Computational Cybernetics and Simulation. pp. 7-10.

[32] Smith, K.A. \& Gupta, J.N.D., 2000. Neural networks in business: techniques and applications for the operations researcher. Computers $\mathcal{E}$ Operations Research, 27, pp. 1023-1044.

[33] *Lee, S. \& Oh, H.J., 2011. Application of Artificial Neural Network for Mineral Potential Mapping, Artificial Neural Networks - Application, Dr. Chi Leung Patrick Hui (Ed.). ISBN: 978-953-307-188-6, InTech, DOI: 10.5772/16187.

[34] Kanungo, D.P., Arora, M.K., Sarkar, S., \& Gupta, R.P., 2006. A comparative study of conventional, ANN black box, fuzzy and combined neural and fuzzy weighting procedures for landslide susceptibility zonation in Darjeeling Himalayas. Engineering Geology, 85(3-4), pp.347-366.

[35] Pradhan, B., Sezer, E. A., Gokceoglu, C., \& Buchroithner, M. F. (2010). Landslide susceptibility mapping by neuro-fuzzy approach in a landslide-prone area (Cameron Highlands, Malaysia). Geoscience and Remote Sensing, IEEE Transactions on, 48(12), 4164-4177.

[36] Pradhan, B., Mansor, S. \& Pirasteh, S., 2011. Landslide Susceptibility Mapping: an Assessment of the Use of an Advanced Neural Network Model with Five Different Training Strategies, Artificial Neural Networks - Application, Dr. Chi Leung Patrick Hui (Ed.), ISBN: 978-953-307-188-6, InTech, DOI: 10.5772/15738.

[37] Bui, D. T., Tuan, T. A., Klempe, H., Pradhan, B., \& Revhaug, I. (2015). Spatial prediction models for shallow landslide hazards: a comparative assessment of the efficacy of support vector machines, artificial neural networks, kernel logistic regression, and logistic model tree. Landslides, 1-18.

[38] Hsu, C.W., Chang, C.C., \& Lin, C.J., 2003. A Practical Guide to Support Vector Classification.

[39] Chang, C. C., \& Lin, C. J. (2011). LIBSVM: A library for support vector machines. ACM Transactions on Intelligent Systems and Technology (TIST),2(3), 27.

[40] Support Vector Machines (SVM) Introductory Overview, http://www.statsoft.com/ Textbook/Support-Vector-Machines

[41] Mather, P.M. \& Koch, M., 2011. Computer Processing of Remotely-Sensed Images: An Introduction. $4^{\text {th }}$ ed., Wiley Blackwell, pp. 267-268. 
[42] Abe, S., 2010. Support Vector Machines for Pattern Classification, $2^{\text {nd }}$ ed., SpringerVerlag London, pp. 20-24.

[43] Campbell, C. \& Ying, Y., 2011. Learning with Support Vector Machines. Morgan Claypool Publishers, pp. 1-5.

[44] Watanachaturaporn, P., Arora, M.K., \& Varshney, P.K., 2008. Multisource Classification Using Support Vector Machines: An Empirical Comparison with Decision Tree and Neural Network Classifiers. Photogrammetric Engineering \& Remote Sensing, 74(2), pp. 239-246.

[45] Samui, P., 2014. Vector machine techniques for modeling of seismic liquefaction data. Ain Shams Engineering Journal, 5, pp.355-360.

[46] Huang, R., Samy, M., Tawfik, H., \& Nagar, A.K., 2008. Application of Support Vector Machines in Financial Literacy Modelling. in Second UKSIM European Symposium on Computer Modeling and Simulation, 2008, pp. 311-316.

[47] Moguerza, J.M. \& Munoz, A., 2006. Support Vector Machines with Applications. Statistical Science, 21(3), pp.322-336.

[48] Osuna, E., Freund, R. \& Girosi, F., 1997. Training Support Vector Machines: an Application to Face Detection. In IEEE Conference on Computer Vision and Pattern Recognition, pp. 130-136.

[49] Kim, K.I., Jung, K., Park, S.H., Kim, H.J., 2002. Support Vector Machines for Texture Classification. IEEE Trans on Pattern Analysis and Machine Intelligence, 24(11), pp.15421550.

[50] Tu, J. V, 1996. Advantages and disadvantages of using artificial neural networks versus logistic regression for predicting medical outcomes. Journal of clinical epidemiology, 49(11), pp.1225-1231.

[51] Igelnik, B., 2011. Computational Modeling and Simulation of Intellect: Current State and Future Perspectives. Information Science Refer, Chocolate Avenue Hershey PA, pp.226.

[52] Carrara, A., Cardinali, M., Detti, R., Guzzetti, F., Pasqui, V., \& Reichenbach, P. (1991). GIS techniques and statistical models in evaluating landslide hazard.Earth surface processes and landforms, 16(5), 427-445.

[53] Jade, S., \& Sarkar, S. (1993). Statistical models for slope instability classification. Engineering Geology, 36(1), 91-98.

[54] Guzzetti, F., Carrara, A., Cardinali, M., \& Reichenbach, P. (1999). Landslide hazard evaluation: a review of current techniques and their application in a multi-scale study, Central Italy. Geomorphology, 31(1), 181-216.

[55] Ermini, L., Catani, F., \& Casagli, N. (2005). Artificial neural networks applied to landslide susceptibility assessment. Geomorphology, 66(1), 327-343. 
[56] Kanungo, D. P., Sarkar, S., \& Sharma, S. (2011). Combining neural network with fuz$\mathrm{zy}$, certainty factor and likelihood ratio concepts for spatial prediction of landslides. Natural hazards, 59(3), 1491-1512.

[57] Pradhan, B., Lee, S., \& Buchroithner, M. F. (2009). Use of geospatial data and fuzzy algebraic operators to landslide-hazard mapping. Applied Geomatics, 1(1-2), 3-15.

[58] Ray, Y., Srivastava, P.: Widespread aggradation in the mountainous catchment of the Alaknanda-Ganga river system: timescales and implications to hinterland-foreland relationships. Quaternary Science Reviews 29(17), 2238-2260 (2010)

[59] Shukla, D., Dubey, C., Ningreichon, A., Singh, R., Mishra, B., Singh, S.: GIS-based morphotectonic studies of Alaknanda river basin: a precursor for hazard zonation. Natural hazards 71(3), 1433-1452 (2014)

[60] Dubey, C., Shukla, D., Ningreichon, A., Usham, A.: Orographic control of the Kedarnath disaster. Current Science 105(11), 1474-1476 (2013)

[61] Rautela, P., Thakur, V.: Landslide hazard zonation in Kaliganga and Madhyamaheshwar valleys of Garhwal Himalaya: a GIS based approach. Himalayan Geol 20:2, 31-44 (1999)

[62] Sati, S., Naithani, A., Rawat, G.: Landslides in the Garhwal Lesser Himalaya, UP, India. Environmentalist 18(3), 149-155 (1998)

[63] Chaudhary, S., Gupta, V., Sundriyal, Y.: Surface and sub-surface characterization of Byung landslide in Mandakini valley, Garhwal Himalaya. Himalayan Geology 31:2, 125-132 (2010)

[64] Bradley, A.P.: The use of the area under the roc curve in the evaluation of machine learning algorithms. Pattern recognition 30(7), 1145-1159 (1997)

[65] Brenning, A.: Spatial prediction models for landslide hazards: review, comparison and evaluation. Natural Hazards and Earth System Science 5(6), 853-862 (2005)

[66] Webb, A.R.: Statistical pattern recognition. John Wiley \& Sons (2003)

[67] Pradhan, B.: A comparative study on the predictive ability of the decision tree, support vector machine and neuro-fuzzy models in landslide susceptibility mapping using GIS. Computers \& Geosciences 51, 350-365 (2013) 
Chapter 11

\title{
Remote Sensing for Natural or Man-made Disasters and Environmental Changes
}

\author{
Monika Gähler \\ Additional information is available at the end of the chapter \\ http://dx.doi.org/10.5772/62183
}

\begin{abstract}
Disasters can cause drastic environmental changes. A large amount of spatial data is required for managing the disasters and to assess their environmental impacts. Earth observation data offers independent coverage of wide areas for a broad spectrum of crisis situations. It provides information over large areas in near-real-time interval and supplementary at short-time and long-time intervals. Therefore, remote sensing can support disaster management in various applications. In order to demonstrate not only the efficiency but also the limitations of remote sensing technologies for disaster management, a number of case studies are presented, including applications for flooding in Germany 2013, earthquake in Nepal 2015, forest fires in Russia 2015, and searching for the Malaysian aircraft 2014. The discussed aspects comprise data access, information extraction and analysis, management of data and its integration with other data sources, product design, and organisational aspects.
\end{abstract}

Keywords: Satellite Based Crisis Information, Environmental Changes, Natural Disaster, Man-made Disaster

\section{Introduction}

The impact of disasters on the environment has become more severe over the last decades. Moreover, the reported number of disasters has dramatically increased, as well as the costs to the global economy and the number of people affected (see Figure 1 for natural disasters) [1,2]. The reasons for these disasters are manifold, and the impact can be found in the increasing vulnerability of societies, infrastructure, and population. Furthermore, extreme weather events have become more common and severe [3].

The increasing occurrences of natural and man-made disasters lead to a growing demand for up-to-date geographic information, especially timely material on rapidly evolving events. This 
includes comprehensive, near-real-time Earth observation data, which offer independent coverage of wide areas for a broad spectrum of civilian crisis situations [4]. Satellite imagery can serve as a source of information in disaster situation. Accordingly, remote sensing can provide information on various domains of the disaster management, from risk modelling and vulnerability analysis to early warning and damage assessment [5].

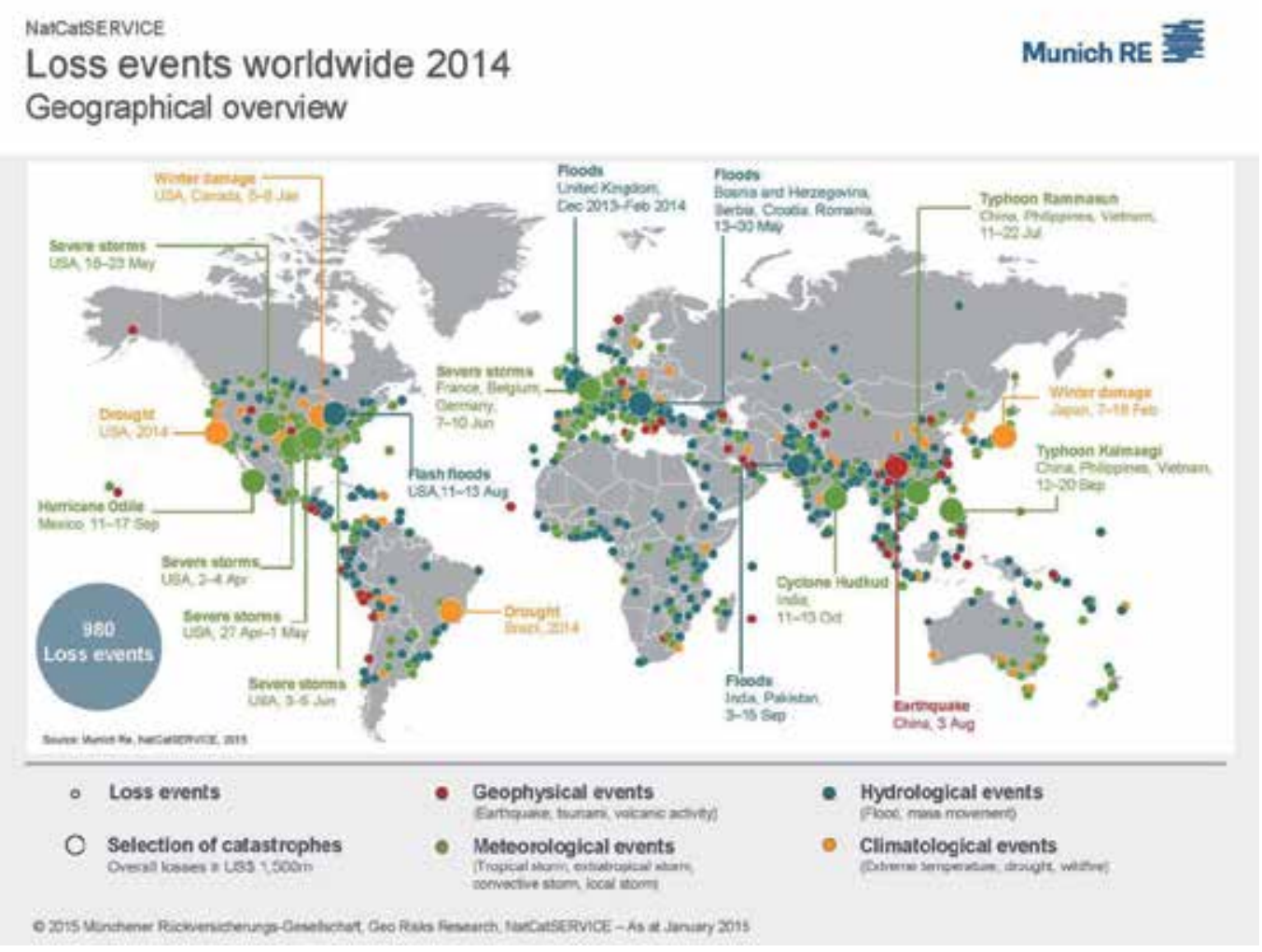

Figure 1. World Map of Natural Disasters 2014 [2]

\section{Disaster management and remote sensing}

\subsection{Disaster types and their environmental impact: A brief overview}

There are several ways to classify disaster types [1,6]. One common classification is natural and man-made disasters. Severe geo-physical or climatic events, such as volcanic eruptions, floods, cyclones and fires that threaten people or property, are termed as natural disasters. Man-made disasters are events which are caused by human activities (e.g. industrial chemical accidents and oil spills). Sometimes, natural disasters that are accelerated by human influence are termed human-induced disasters [6]. In addition, the Centre for Research on the Epidemi- 
ology of Disasters [7] divides the natural disaster category into six sub-groups, which in turn include 17 disaster types, and 33 sub-types (see Table 1). The technological disaster category is segregated into three sub-groups which in turn include 15 disaster types (see Table 2). Besides, disasters can be categorised as acute (e.g. earthquake) or slow (e.g. drought) based on their onset.

\begin{tabular}{|c|c|c|c|c|c|}
\hline \multicolumn{6}{|c|}{ Natural disaster sub-group } \\
\hline \begin{tabular}{|c|} 
Cimatological \\
\end{tabular} & Geophysical & Hydrological & \begin{tabular}{|l|l|l} 
Mieterological \\
\end{tabular} & Eiological' & riall' \\
\hline \multicolumn{6}{|c|}{ Natural disaster types and sub-types } \\
\hline Drought & Earthquake & Flood & Storm & Animal accident & Impact \\
\hline Glacial Lake Outburst & Ground Shaking & Coastal food & Extra-tropical cyclone & Insect infestation & Airburst \\
\hline Wildfire & Tsunami & Riverine flood & Tropical cyclone & Grasshoper & Space Weather \\
\hline Forest fire & Mass movement & Fash flood & Convective Storm & Locust & Energetic particles \\
\hline \multirow[t]{6}{*}{ Land fire } & Volcanic activity & Ice jam flood & Extreme temperature & Epidemic & Geomagnetic storm \\
\hline & Ash fall & Landslide & Cold wave & Viral disease & Shockwave \\
\hline & Lahar & $\begin{array}{l}\text { Avalanche (snow, debris, } \\
\text { mudflow, rockfall) }\end{array}$ & Heat wave & Bacterial disease & \\
\hline & Pyroclastic flow & Wave action & $\begin{array}{l}\text { Severe winter } \\
\text { conditions }\end{array}$ & Parasitic disease & \\
\hline & Lawa flow & Rogue wave & Fog & Fungal disease & \\
\hline & & Seiche & & Prion disease & \\
\hline
\end{tabular}

Table 1. Natural disasters categorisation after [7]; *not being considered below

\begin{tabular}{|l|l|l|}
\hline \multicolumn{3}{|c|}{ Man-made disaster sub-group } \\
\hline \multicolumn{3}{|c|}{ Man-made disaster types } \\
\hline Chemical spill & Air & Collapse \\
\hline Collapse & Road & Explosion \\
\hline Explosion & Rail & Fire \\
\hline Fire & Water & Other \\
\hline Gasleak & & \\
\hline Poisoning & & \\
\hline Radiation & & \\
\hline Other & & \\
\hline
\end{tabular}

Table 2. Man-made disasters categorisation after [7]

There are many effects that result from disasters, whether natural or man-made. For instance, the impacts of disasters have a human and an environmental dimension. UNEP concludes that 'environmental conditions may exasperate the impact of a disaster, and vice versa, disasters tend to have an impact on the environment' [8, p.1]. Reference [9] discusses down the environmental impacts for different types of disasters in detail. They raise the interesting point that while most environmental impacts are negative, some are positive. For example, 'floods can help rejuvenate floodplain vegetation and are important drivers of many ecological processes 
in floodplains' [9, p. 55]. In Table 3, a selection of environmental impacts for different types of disasters is listed.

\begin{tabular}{|c|c|c|c|}
\hline \multirow{12}{*}{ 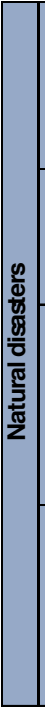 } & \multirow{6}{*}{ 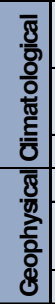 } & Drought: & $\begin{array}{l}\text { Droughts generally damage ecological systems: depletion of water resources, loss of plant and } \\
\text { animal life, deterioration of soil, fire }\end{array}$ \\
\hline & & \begin{tabular}{|l|l|l} 
Gacial lake \\
outburst
\end{tabular} & Fooding, destruction of plant life, landslide, erosion \\
\hline & & \begin{tabular}{|l} 
Wildfire \\
\end{tabular} & Loss of plant and animal life, erosion, flooding, mud slides, long-term smog \\
\hline & & Earthquake & The dominant losses from earthquakes and mass movements are to structures and potentially to \\
\hline & & Mass movement & $\begin{array}{l}\text { humans. Nevertheless, both disasters can also result in adverse environmental consequences: flora } \\
\text { and fauna damaged by the shocks, shifts in land surfaces, alterations in local hydrologic systems. }\end{array}$ \\
\hline & & Volcanic activity & Loss of plant and animal life, deterioration of soil, air and water pollution, long-term smog \\
\hline & .ृ. & Food & $\begin{array}{l}\text { Major floods have varied effects on river-floodplain ecosystems: e.g. negative impact on trees if } \\
\text { they are too long submerged; polluted water infiltrate floodplains and contaminate ground water } \\
\text { aquifers; positiv impact like rejuvenate floodplain vegetation }\end{array}$ \\
\hline & 음 & Landslide & Destruction/loss of plants, erosion, depletion of water resources \\
\hline & 음 & Wave action & $\begin{array}{l}\text { Modifies the dynamics of coastal marine communities e.g. the influence the structure of biological } \\
\text { communities on rocky shores }\end{array}$ \\
\hline & ब & Storm & $\begin{array}{l}\text { The dominant losses from storms are to structures and potentially to humans. The environmental } \\
\text { effects are: e.g. destruction of plants, forest fire, flash flood. }\end{array}$ \\
\hline & $\frac{8}{6}$ & \begin{tabular}{|l|l|l} 
Extreme \\
temperature
\end{tabular} & Avalanche, snow melt, loss of plants and animals, flash floods, flooding, drougth, erosion, fire \\
\hline & $\stackrel{\bar{d}}{\Sigma}$ & Fog & $\begin{array}{l}\text { Loss of plant and animal life, decreasing the UV radiation, damages to health for humans, animals } \\
\text { and vegetation }\end{array}$ \\
\hline 高 & $\frac{\sqrt{8}}{\frac{8}{2}}$ & $\begin{array}{l}\text { Chemical spill } \\
\text { Collapse } \\
\text { Explosion } \\
\text { Fire } \\
\text { Gasleak } \\
\text { Poisoning } \\
\end{array}$ & $\begin{array}{l}\text { There are several effects on the environment depending on the detailed subtype and dimension of } \\
\text { the disaster. Some general impacts are for example: } \\
\text { Negative health outcomesfrom accidental releases of toxins, } \\
\text { Loss of plants and animals, } \\
\text { Water/soil/air pollution, } \\
\text { Damages to health for humans, animals and vegetation, }\end{array}$ \\
\hline 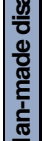 & 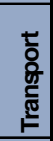 & \begin{tabular}{|l|} 
Air \\
Road \\
Rail \\
Water \\
\end{tabular} & $\begin{array}{l}\text { Destruction of plants, } \\
\text { Erosion, } \\
\text { Fooding, } \\
\text { Fog, }\end{array}$ \\
\hline$\Sigma$ & 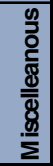 & $\begin{array}{l}\text { Collapse } \\
\text { Explosion } \\
\text { Fire }\end{array}$ & etc. \\
\hline
\end{tabular}

Table 3. Disasters and their environmental impacts [modified after 9]

The impact of disasters can be reduced through a proper disaster management [10]. The process of disaster management is often interpreted as a cycle consisting of four main phases: mitigation, preparedness, response and recovery (see Figure 2 and for more information [10]).

\subsection{Earth observation for disaster management: potential and limitations}

The Earth is being imaged each day by a constellation of remote sensing satellites. Two complementary types of Earth observation satellites are particularly relevant to disaster management. 'Geostationary Earth observation satellites' are placed at an altitude of approximately 35,800 kilometres. At this altitude, one orbit takes 24 hours, the same length of time as 


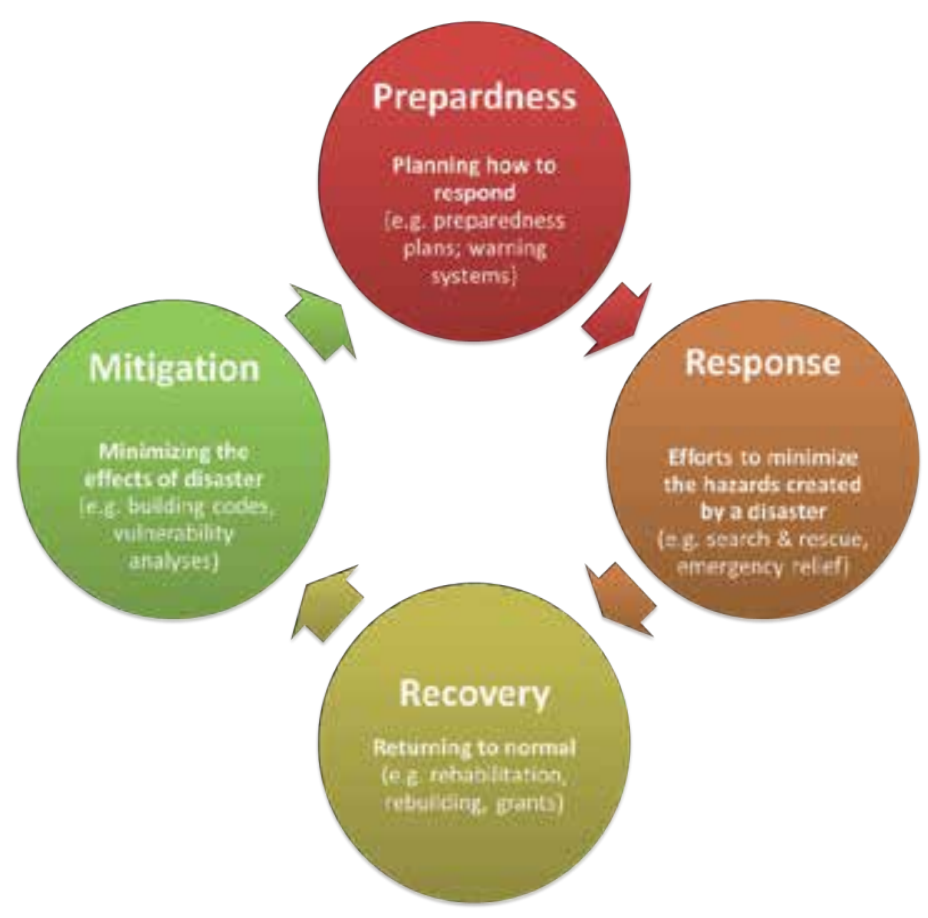

Figure 2. Disaster management cycle

the Earth requires to rotate once on its axis [11,12]. In effect, it means that satellites in this orbit remain stationary above the ground and view the whole Earth disk below. Their spatial data resolution is very low but is collected at the same point every 15 minutes. With these kinds of data, the evolution of atmospheric phenomena can be observed, ensuring real-time coverage of meteorological events such as severe local storms and tropical cyclones [13]. The importance of this capability has been exemplified during several hurricane events.

The great advantage of 'polar-orbiting satellites' is the provision of relatively high spatial resolution data (up to 0.3 meter for optical imagery and 1 meter for radar imagery) [11], which is very important for mapping disaster damages in detail, such as affected infrastructure or buildings after an earthquake [13]. Most of the Earth observation satellites are in a low and 'near-polar' orbit with an orbital period of approximately 90-100 minutes and an orbit inclination near 90 degrees. This allows the satellite to see virtually every part of the Earth as the Earth rotates underneath it. However, no spot on the Earth's surface can be sensed continuously or at any point of time from a satellite in a polar orbit. The time elapsed between observations of the same point on the Earth (revisit time) is limited to once every few days with the same sensor parameters or maximum once a day for steerable satellite. Moreover, most satellites do not continuously collect data due to limitations in power and memory. Some offer regular and reliable data acquisition while others may be more ad hoc, collecting only 5 
or 10 minutes' worth of data in a 90-minute orbit. Data are stored on board the satellite until it is in sight of a ground station to downlink the data. The time between an image being taken and being available to download can range between a month to a few minutes and is getting faster all the time. Thus, the collection of high-resolution data has some limitations regarding acquisition time, data provision and image extent.

The Earth observation satellites have their own special systems of imaging sensors which make use of the visible, infrared, microwave and other parts of the electromagnetic spectrum [11]. The characteristics of some sensors that are commonly used to support disaster management are listed in Table 4.

\begin{tabular}{|c|c|c|c|c|c|}
\hline Data type & Sensor & $\begin{array}{l}\text { Nadir spatial } \\
\text { resolution }(\mathrm{m})\end{array}$ & Bands & $\begin{array}{l}\text { Swath } \\
(\mathbf{k m})\end{array}$ & Revisit Frequency \\
\hline \multirow{4}{*}{$\begin{array}{c}\text { Optical } \\
\text { (multispectral) }\end{array}$} & Worldview-3 & $\begin{array}{c}0.31 \\
1.24 \\
3.7 \\
30\end{array}$ & $\begin{array}{c}\text { Panchromatic } \\
8 \text { Multispectral } \\
\text { 8 SNIR } \\
12 \text { CAVS (Corrects for Couds, } \\
\text { Aerosols, Vapors, Ice \& Snow) }\end{array}$ & 13.1 & $\begin{array}{l}1.1 \text { days at } 1 \mathrm{~m} \mathrm{GSD} \text { or less } \\
4.5 \text { days at } 20^{\circ} \text { off-nadir or less }\end{array}$ \\
\hline & Worldview-2 & $\begin{array}{l}0.46 \\
1.84 \\
\end{array}$ & $\begin{array}{l}\text { Panchromatic } \\
8 \text { Multispectral } \\
\end{array}$ & 16.4 & $\begin{array}{c}1.1 \text { days at } 1 \mathrm{~m} \text { GSD or less } \\
3.7 \text { days at } 20^{\circ} \text { off-nadir or less }\end{array}$ \\
\hline & Peiades-1A/ 1-B & $\begin{array}{l}0.70 \\
2.00 \\
\end{array}$ & $\begin{array}{l}\text { Panchromatic } \\
\text { 4 Multispectral }\end{array}$ & 20 & Daily \\
\hline & SPOT-6/ -7 & $\begin{array}{l}1.50 \\
6.00\end{array}$ & $\begin{array}{l}\text { Panchromatic } \\
4 \text { Multispectral }\end{array}$ & 60 & Daily \\
\hline \multirow[b]{2}{*}{ Thermal } & $\begin{array}{l}\text { RapidEye } \\
\text { ASTER }\end{array}$ & $\begin{array}{l}6.5 \\
15 \\
30 \\
90 \\
\end{array}$ & $\begin{array}{c}5 \text { Multispectral } \\
4 \text { Multispectral } \\
6 \text { SWIR } \\
5 \pi R \\
\end{array}$ & $\begin{array}{l}77 \\
60\end{array}$ & $\begin{array}{l}\text { Daily } \\
\text { 4-16 days }\end{array}$ \\
\hline & MODIS & $\begin{array}{c}250 \\
500 \\
1,000 \\
\end{array}$ & $\begin{array}{c}6 \text { bands } \\
\text { (VIS NIR, SWIR/MWIR, LWIR) }\end{array}$ & 2,330 & Daily \\
\hline \multirow{4}{*}{$\begin{array}{c}\text { Synthetic } \\
\text { Aperture Padar } \\
\text { (SAR) }\end{array}$} & TerraSAR X/ TanDEM-X & $\begin{array}{c}1 \\
3 \\
18 \\
\end{array}$ & $\begin{array}{l}\text { Spotlight } \\
\text { Stripmap } \\
\text { ScanSAR }\end{array}$ & $\begin{array}{c}10 \\
30 \\
100 \\
\end{array}$ & 11 days \\
\hline & Cosmo-SkyMed & $\begin{array}{c}<1 \\
3-15 \\
30-100 \\
\end{array}$ & $\begin{array}{l}\text { Spotlight } \\
\text { Sripmap } \\
\text { ScanSAR }\end{array}$ & $\begin{array}{c}10 \\
40 \\
100-200 \\
\end{array}$ & 1.5 days \\
\hline & Radarsat -2 & $\begin{array}{c}3 \\
25 \\
8 \\
8 \\
25 \\
25 \\
50 \\
100 \\
\end{array}$ & $\begin{array}{l}\text { Ultra-fine } \\
\text { Fine } \\
\text { Quad-pol fine } \\
\text { Standard } \\
\text { Quad-pol standard } \\
\text { ScanSARnarrow } \\
\text { ScanSARwide } \\
\text { Extended high } \\
\end{array}$ & 20 & Every few days \\
\hline & ALOS & $\begin{array}{c}10 \\
100 \\
\end{array}$ & $\begin{array}{c}\text { PALSAR (Fine) } \\
\text { PALSAR (ScanSAR) }\end{array}$ & $\begin{array}{c}40-70 \\
250-350 \\
\end{array}$ & $\begin{array}{c}\text { Several times per year as per } \\
\text { JAXA acquisition plan }\end{array}$ \\
\hline
\end{tabular}

Table 4. Examples of sensors and their characteristics to support disaster management [modified after 16]

'Optical data' are of great importance for disaster management support, because they can be used nearly for all disaster types and for all phases of disaster management. For example, they are used for planning the logistics of relief actions in the field immediately after an earthquake or tsunami [13-14]. Optical images are easy to understand and interpret even for nonspecialists, particularly when it consists of the three visual primary colour bands (red, green 
and blue) and the bands are combined to produce a 'true colour' image. However, the interpretation of false colour composite images is not intuitive and requires expert knowledge; likewise, all advanced analysis techniques need comprehensive know-how. To select the most appropriate data type for the needs of the individual disaster situation, the characteristics of the sensor are of great importance [15]. Particularly, temporal and spatial resolutions are key factors. For example, for mapping an earthquake in an urban area optical data with a spatial resolution of $<0.5$ meters are most valuable. The most crucial point for the use of optical images is their availability. Due to cloud coverage, haze and other atmospheric conditions useful optical images could not obtained by every satellite overpass. Aggravating this situation, there are some disasters such as wildfire or severe storms which are characterised by clouds and smoke.

The 'thermal imagery' offers excellent possibilities for automated extraction of anomalous high temperature or hot spots caused by wild fires or information about volcanic eruptions. However, due to the fact that energy decreases with increasing wavelength, thermal wavelength have relatively low energy levels and consequently thermal image data have a lower spatial resolution than optical data. [16]. Techniques for automatic fire detection from the space are operational and are accepted by the users (e.g. European Forest Fire Information System) [17].

'Microwave sensors' are of great value for the fast response mapping and analysis tasks, as they allow imaging at wavelengths almost unaffected by atmospheric disturbances such as rain or cloud. Most modern synthetic aperture radar (SAR) sensors are designed to acquire data from various ground resolution elements (see Table 4). In most applications, only the relative variability of backscatter intensity within the image is used. Nonetheless, backscatter intensity and the phase of SAR images can be utilised. Phase information of a single SAR data set has no value, but the comparison of phases between two SAR images acquired at distinct times are utilised in SAR interferometry or INSAR. Moreover, with modern satellites (e.g. TerraSAR-X and Radarsat-2) it is possible to acquire simultaneous data with more than one polarisation [16]. SAR systems can be used to map flooding or to measure earth deformations before and during earthquakes or volcanic eruptions, particularly when post-event imagery can be jointly analysed with archived reference imagery for change detection or interferometric coherence or displacement measurements $[15,13]$.

Table 5 summarises the remotely sensed data types and image processing techniques for information extraction about natural disasters.

In general, the availability of appropriate data with respect to acquisition time, image extent, spatial as well as temporal and spectral resolution is an important consideration for most applications in the disaster context [18]. Particularly, there are numerous examples for the importance of the necessity of fast availability of remote sensing data like damage assessment maps for earthquakes, landslides or flooding. However, for monitoring the spread of an oil spill or the extent of flooding the revisit time is relevant too [13].

Remote sensing has proven to be useful for a range of applications. Especially high spatial resolution data and remote sensing techniques are being deployed in the context of the disaster 


\begin{tabular}{|c|c|c|c|}
\hline Data type & Sensor examples & Technique & Application \\
\hline \multirow{7}{*}{$\begin{array}{l}\text { Optical } \\
\text { (multispectral) }\end{array}$} & \multirow{7}{*}{$\begin{array}{l}\text { Worldview, } \\
\text { Pleiades, } \\
\text { Quickbird, Ikonos, } \\
\text { RapidEye, SPOT, } \\
\text { ASTER, Landsat, } \\
\text { ALOS }\end{array}$} & Manual interpretation & $\begin{array}{l}\text { Infrastructure and property damage due to flooding, } \\
\text { earthquakes, landslides, etc. }\end{array}$ \\
\hline & & Spectral classification & $\begin{array}{l}\text { Location and extent of flooding, landslides, volcanic } \\
\text { debris, fire scars }\end{array}$ \\
\hline & & $\begin{array}{l}\text { Semivariogram analysis and } \\
\text { other textural classifiers }\end{array}$ & Damage due to earthquakes; location of landslides \\
\hline & & \begin{tabular}{|l|} 
Image thresholding \\
(including band ratios)
\end{tabular} & $\begin{array}{l}\text { Location and extent of flooding, landslides, volcanic } \\
\text { debris, fire scars }\end{array}$ \\
\hline & & Image differencing & $\begin{array}{l}\text { Location and extent of flooding, landslides, volcanic } \\
\text { debris, fire scars }\end{array}$ \\
\hline & & $\begin{array}{l}\text { Postclassification change } \\
\text { detection }\end{array}$ & $\begin{array}{l}\text { Location and extent of flooding, landslides, volcanic } \\
\text { debris, fire scars }\end{array}$ \\
\hline & & DEM generation & $\begin{array}{l}\text { DEM is used as a supplementary information in variety } \\
\text { of studies }\end{array}$ \\
\hline \multirow{2}{*}{ Thermal } & \multirow{2}{*}{$\begin{array}{l}\text { ASTER, MODIS, } \\
\text { AVHRR }\end{array}$} & Solit window & $\begin{array}{l}\text { Orater lake temperatures, lava flow, precursor to } \\
\text { earthquake activity, temperature and size of fire } \\
\text { hotspots }\end{array}$ \\
\hline & & Dual band & $\begin{array}{l}\text { Orater lake temperatures, lava flow, precursor to } \\
\text { earthquake activity, temperature and size of fire } \\
\text { hotspots }\end{array}$ \\
\hline \multirow{5}{*}{$\begin{array}{l}\text { Synthetic } \\
\text { Aperture } \\
\text { Radar (SAR) }\end{array}$} & \multirow{5}{*}{$\begin{array}{l}\text { TerraSARX, } \\
\text { TANDEM-X, } \\
\text { Cosmo-SkyMed, } \\
\text { Radarsat-1/2, } \\
\text { JERS1, ERS-1/2, } \\
\text { ENVISAT, ALOS }\end{array}$} & Coherence & $\begin{array}{l}\text { Coherence Change detection due to landslide, flooding, } \\
\text { fire, etc. }\end{array}$ \\
\hline & & Backscatter intensity & $\begin{array}{l}\text { Coherence Change detection due to landslide, flooding, } \\
\text { fire, etc. }\end{array}$ \\
\hline & & \begin{tabular}{|l|} 
Interferometry/DEM \\
generation
\end{tabular} & Change detection due to landslide, flooding, fire, etc. \\
\hline & & Differential interferometry & $\begin{array}{l}\text { Surface deformation due to volcanic or tectonic } \\
\text { activity; velocity and extent of slow moving landslides }\end{array}$ \\
\hline & & Polarimetry & Landcover classification and change detection \\
\hline
\end{tabular}

Table 5. Remotely sensed data types and image processing techniques for information extraction about natural disasters [modified after 13]

management domain, from risk modelling and vulnerability analysis to early warning and damage assessment (see Table 6). A broad assessment of several remote sensing sensors (optical, thermal, SAR, etc.) and their utility for providing information about natural disasters is given in Ref. [13, p. 200-201].

Reference [19, p. 2-3] concludes that 'the most evident parts are preparedness (warning for storms, cyclones, floods, etc.,) and response (mapping of all types of crisis impact and situations), while applications of satellite information during the phases of recovery and mitigation prevention are being still further developed'. Additionally, the authors give the following main reasons for a drastically increased demand for rapid satellite data analysis for all kinds of disaster and phases over the past years:

- accessibility of very high resolution optical (up to 0.3 meter) as well as radar imagery (up to 1 meter) from space has risen significantly over the past years even for the civilian domain

- relief agencies rapidly gain a better understanding on what these new geoinformation technologies can bring to their work in the fields of mission planning, logistics, situation awareness and even mission security 


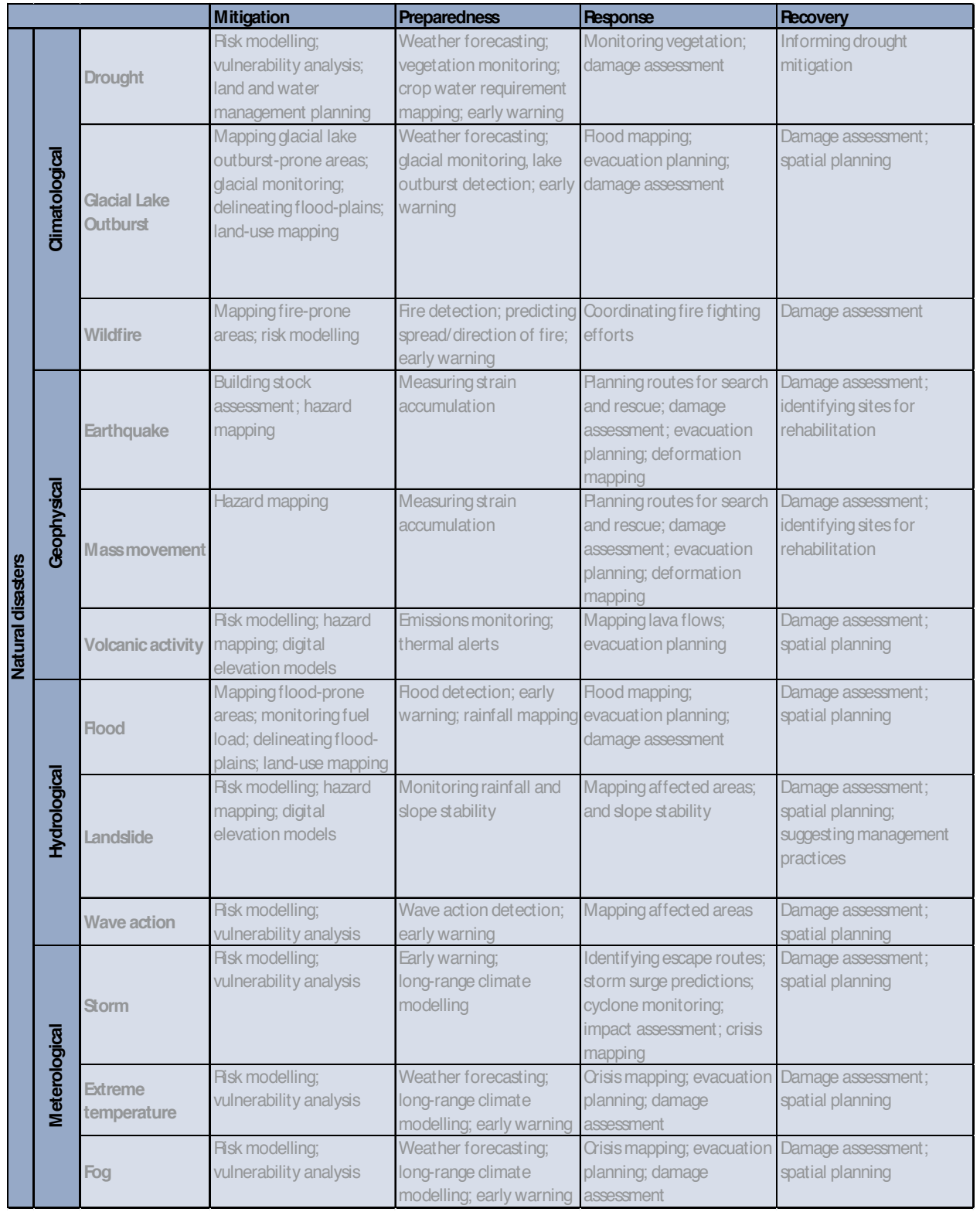

Table 6. Remote sensing applications for disaster management [complemented after 12]

- media and the public raise the demand for up-to-date easy-to-understand visual information on disaster areas and ongoing relief work

The following sections focus primarily on the contribution of remote sensing to the response phase, in particular, giving a brief overview of the workflow from an emergency call or request for assistance, through satellite tasking, data acquisition, analysis, map provision and further- 
more explaining some existing operational services, and finally a number of case studies are presented.

\subsection{Rapid mapping workflow}

No decision maker or relief worker can work with raw satellite imagery. To generate the required situation maps, reports or statistics, which can be read and understood by nonsatellite expert users, experts in remote sensing and cartography are necessary. In 2004, German Aerospace Center (DLR) was one of the first institutions, which has set up a dedicated interface called Center for Satellite Based Crisis Information (ZKI) to facilitate the use of its Earth observation capacities in the services of national and international response to disaster situations [18]. ZKI's function is particularly 'rapid mapping' - the rapid acquisition, processing and analysis of satellite data and the provision of satellite-based information products. Analyses are tailored to meet the specific requirements of national and international political bodies or humanitarian relief organisations. In order to provide up-to-date and relevant satellite-based cartographic information and situation analysis, it is necessary to establish efficient and operational data flow lines between satellite operators, receiving stations and distribution networks on the one hand and the decision makers and relief workers on the other hand. Service lines and feedback loops have been created to allow best possible data and information provision, as well as optimised decision support [20]. In order to meet with users' demands and service requirements in crisis situations, ZKI set up a rapid mapping workflow (Figure 3) ensuring a fast access to available, reliable and affordable crisis information worldwide.

Schedules for the full cycle from the emergency call (mobilisation phase), satellite tasking (data acquisition), pre-processing, analysis and interpretation, map production and data provision to the end-user are tight (as fast as possible). Hence, rapid mapping is still a complex task [15].

After the mandatory decision process, whether satellite analysis is appropriate for the respective crisis or not, the area of interest has to be defined and cross-checked to avoid false geolocation. Following this iterative process, it has to be assured that all applicable satellites are programmed for data acquisition. Furthermore, an enquiry for corresponding archive imagery has to be set up for documentation of the pre-disaster situation and change detection analysis. Besides the procurement of satellite data, it is necessary to check and prepare supplementary geodata such as population and infrastructure data, road network, contour lines and administrative boundaries. Experience of several activations and user feedback shows that additional geoinformation increases the satellite data analysis significantly. This includes place names, critical infrastructure, transportation network or further detailed specifications. Availability and access to accurate and up-to-date spatial data, particularly in remote regions, are the most crucial problems [18].

After receiving the archived and recently recorded satellite imagery, essential pre-processing has to be done. This includes geo- and ortho-rectification as well as radiometric corrections and data format conversions. Data re-projection is necessary due to varying demands and standards. In the majority of activations, a Universal Transverse Mercator (UTM) projection 
is used due to global applicability and following international standards. Depending on user's needs, crisis type and extent, different analysis process chains have to be applied [18].

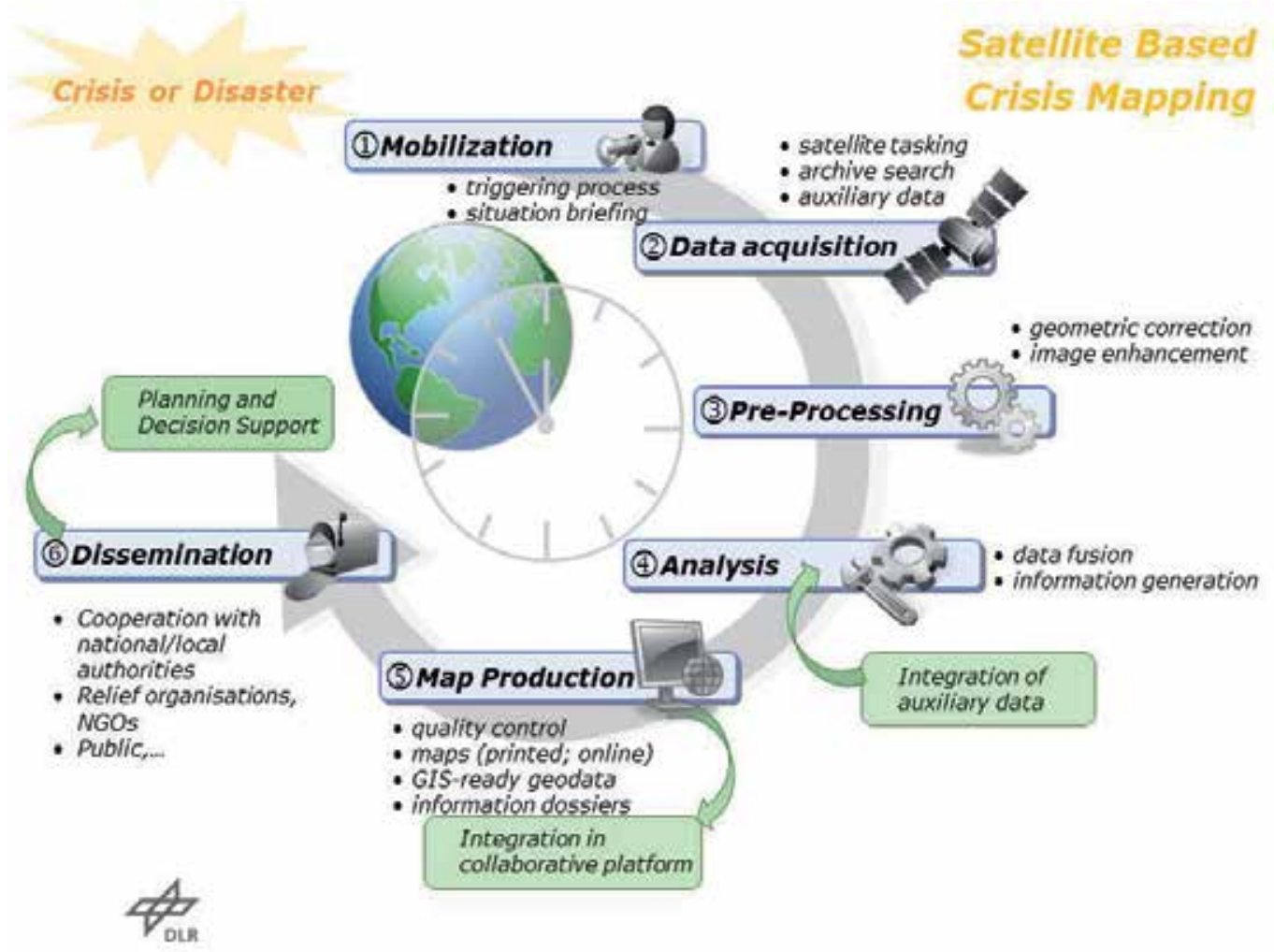

Figure 3. Rapid mapping workflow

Derivation of water surfaces or general damage assessment is dependent on input data type, scale and possible availability of archived satellite imagery. Before and after image comparison allows the quantification of affected areas. This change detection method can either be applied for optical or radar imagery in order to detect areas where significant change can be identified. Furthermore, general image classification and differencing methods allows quantification of flooded areas, fire scars or damaged areas [19].

Situation and damage maps are generated in order to translate complex satellite information in readable and coherent crisis information. Following this map compilation, an adapted map generation process is applied. A settled quality control process takes place after each single product generation step as well as before publishing. Delivery is accomplished via Internet, intranet, ftp, e-mail or satellite communication. Furthermore, printed and laminated maps will be sent via express delivery on request. User feedback from field units has proved to be an important source for optimisation. Maps are updated when new and improved data are 
available or knowledgeable feedback is received even though the maps are published and delivered [18].

In order to fulfil its tasks, DLR-ZKI is involved in international, European and national mechanisms providing space-based information supporting the disaster relief (e.g. International Charter Space and Major Disaster). The understanding of the organisational frameworks of these mechanisms, their activation procedures and workflows are a prerequisite to take advantage of the products provided by these mechanisms.

\subsection{Mechanisms of providing satellite-based crisis information}

\subsubsection{International Charter 'Space and Major Disasters'}

For providing fast and reliable image access on archive or new post-event imagery effectively, there is a need for more than a single research-oriented or commercial system. Thus, 'effective and well-balanced coordination among the different observing systems is required in order to allow best service to the civil-protection and humanitarian relief community' [18, p. 1527].

With the installation of International Charter Space and Major Disasters in 1999, from now onwards referred to as 'Charter', a globally functioning mechanism was established to provide a unified system of rapid space data acquisition and delivery in case of natural or man-made disasters [21]. The Charter is a consortium of space agencies and satellite data providers. Each member agency of the Charter has committed resources to support relief organisations as well as civil protection and defence organisations with free of charge satellite (raw) data in order to help mitigating effects of disasters on man life and environment. Its members, conscious of the need to improve its access globally, have adopted the principle of 'Universal Access': any national disaster management authority will be able to submit requests to the Charter for emergency responses [21]. Proper procedures have to be followed, but the affected country does not have to be its member as it was before. A registration process is available for national authorities to express interest in participating in the Charter. Universal Access implementation started in September 2012 and is being implemented gradually [21].

Since its inception in 2000, the Charter has been activated for more than 470 disasters (as end of September 2015), in more than 110 countries. In 2014, the Charter was activated 41 times for disasters in 30 countries. In the same year, more than $75 \%$ of Charter activations were based on weather-related disasters such as flooding, ocean storms and landslides, while solid Earthrelated hazards (e.g. earthquakes, volcanic eruptions) represented $10 \%$ of Charter activations; activations for man-made disasters (e.g. oil spills) are marginal ( $<5 \%$; see Figure 4$)$ [21].

Comparing Charter activations with occurrence of disasters of hazard types reported by emergency events database (EM-DAT), proportions of both fit together to some extent (see Figure 5). One obvious difference can be recognised in category "Others" which incorporates particularly all man-made disasters. Nevertheless, the Charter covered 7 of the 10 most severe disasters by fatalities 2014 as reported by EM-DAT (Table 7). 


\begin{tabular}{|c|c|c|c|c|c|}
\hline \multicolumn{6}{|c|}{ Top 10 Disasters - Number Killed - 2014} \\
\hline Country & Disaster type & Date & \#killed & \#Affected people & $\begin{array}{c}\text { Total Damage } \\
\qquad\left(000^{\prime} \$\right)\end{array}$ \\
\hline China P Rep & Earthquake & $3 / 8 / 2014$ & 731 & $1,120,513$ & $5,000,000$ \\
\hline Nepal & Landslide & $2 / 8 / 2014$ & 450 & 184,894 & - \\
\hline Afghanistan & Flood & $24 / 4 / 2014$ & 431 & 140,100 & - \\
\hline Pakistan & Flood & $1 / 9 / 2014$ & 367 & $2,470,673$ & $2,000,000$ \\
\hline India & Flood & $8-9 / 2014$ & 298 & 275,000 & $16,000,000$ \\
\hline Nepal & Flood & $12 / 8 / 2014$ & 217 & 28,279 & - \\
\hline India & Landslide & $30 / 7 / 2014$ & 209 & - & - \\
\hline Sri Lanka & Landslide & 29/10/2014 & 196 & - & - \\
\hline China P Rep & Storm & $7 / 4 / 2014$ & 128 & - & - \\
\hline Philippines & Storm & $15 / 7 / 2014$ & 111 & $4,654,966$ & 820576 \\
\hline
\end{tabular}

Table 7. Ten most severe natural disasters by number of fatalities in 2014 based on EM-DAT statistics [7] and events covered by Charter activations (indicated in bold and italics) [source 21; p.49]

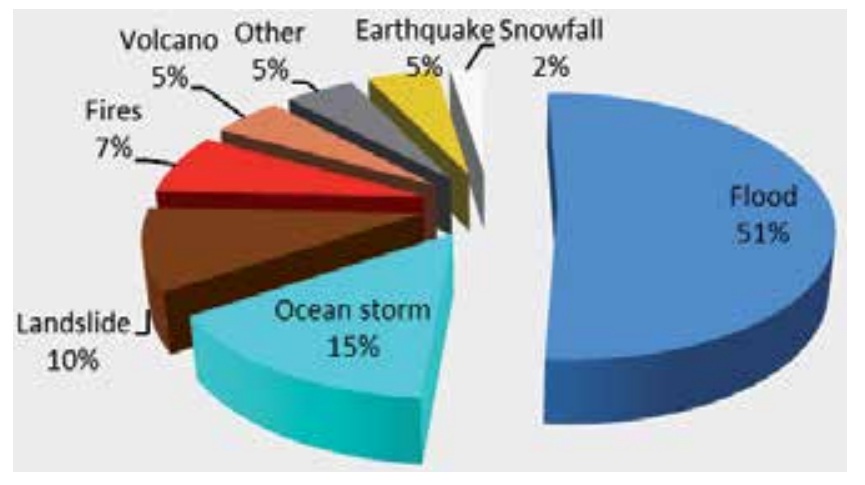

Figure 4. Percentage of hazard-type Charter activations in 2014 [21, p.24]

Due to user feedbacks and meaningful statistics, it can be concluded that a meaningful satellite observation information capacity was established for a variety of non-expert users.

However, it should be mentioned, that the Charter does not concern the whole disaster management cycle (see Figure 2) and not for long humanitarian crisis as well. Moreover, the rapid mapping value-adding activities (see the following section) are not primary in the mandate of the Charter. The analysis of the satellite (raw) data and map production are often entrusted to associated value-adders. Today there is no other operational capacity playing such 


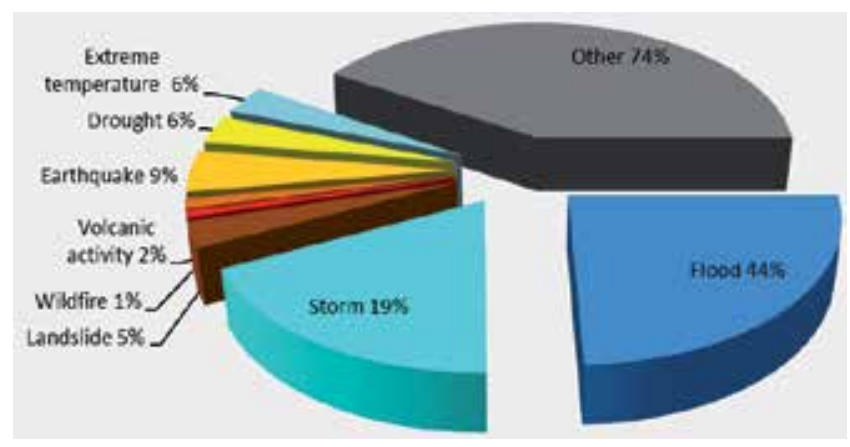

Figure 5. Occurrence of disasters in 2014 in percentage, by hazard type [data source 7]

an important role on a worldwide basis. However, other space-based initiatives are available providing new capacities to other users.

\subsubsection{Sentinel Asia}

Another collaboration between space agencies is the so-called Sentinel Asia initiative. It has a regional focus and was established in 2005, as a collaboration between regional space agencies and disaster management agencies, applying remote sensing and Web-GIS technologies to assist in disaster management in the Asia-Pacific region. Until today multiple national agencies of about 25 countries in the region have joined and benefited from the disaster support services provided by Sentinel Asia. It intends to expand efforts like the Charter and make relevant data available to all countries and many more people in the region [22].

Sentinel Asia also cooperates with the Charter: since its inception Sentinel Asia provides a regional enhancement to the Charter, as it allows any country in the region to join their network and request disaster-relevant information, regardless of their membership of the Charter (even before the Universal Access was implemented). Moreover, Sentinel Asia built up an expert team with different knowledge base, such as disaster management agencies, space agencies, as well as relevant regional and international entities. They created a network with so-called data provider nodes (DPNs), where several regional space agencies and related institutes providing satellite data from their national satellite systems to the so-called data analysis nodes (DANs) [23]. These DANs analyse raw image data together with their own geospatial data. Moreover, they implemented specific technical working groups, which aim to accelerate and optimise information analysis process (e.g. expand utilisation of satellite-derived products for tsunamis or wildfires). In parallel with the activities above, capacity building for technical and emergency-response agencies users of the Sentinel Asia system is realised [22-23].

In summary, Sentinal Asia is a direct and active collaboration with regional disaster management agencies, and great regional network of data providers, data analysis nodes and users. With regard to the fact that Asia comprises 39\% of the worldwide total disasters, Sentinel Asia is a very valuable initiative [22]. 


\subsubsection{Copernicus Emergency Management Service}

Yet another service which collaborates with the Charter is the Copernicus Emergency Management Service (EMS). Copernicus EMS is intended as an operational service offered to authorised users active in the field of crisis management in the EU member states, the European civil protection mechanism, the Commission's Directorates-General (DGs) and the participating executive agencies and international humanitarian aid [24]. The service started its operations in April 2012 and is implemented by the European Commission DG Joint Research Centre (JRC). The scope of the service is the provision of timely and accurate geospatial information derived from the satellite remote sensing and completed by the available in situ or open data sources. Copernicus EMS is provided free of charge for the users, during all phases of the disaster management cycle, and in two temporal modes [25].

EMS service and all other Copernicus services such as land monitoring or atmosphere monitoring are based on the provision of satellite imagery from contributing missions that are made available through the Copernicus Space Component Data Access (CSCDA) system operated by European Space Agency (ESA) since 2008. In future, the service will also be supported by all the Sentinels; for Sentinel 1-A first maps were already produced [26].

Analysis products are standardised and depend on the set of parameters chosen by users when placing the service request. For rapid mapping, the following product categories are offered: reference maps, delineation maps (providing an assessment of the geographic extent of the event) and grading maps (providing an assessment of the damage grade and its spatial distribution) [25].

Unlike the Charter analysis and map, production is explicitly within the mandate of Copernicus EMS. Therefore, an agreement has been set up to exploit the advanced crisis mapping capability of the EMS to support Charter requests pertinent to European policy sectors. Another important advantage of Copernicus EMS is the opportunity to request geospatial information in support of disaster management activities not related to immediate response. This is of particular importance for activities dealing with prevention, preparedness, disaster risk reduction and recovery phases [25]. For this purpose, there are three categories of maps offered: reference maps, pre-disaster situation maps and post-disaster situation maps.

In summary, Copernicus EMS is a fully operational service with a predefined and standardised product portfolio, covering the whole disaster cycle, which is free of charge for authorised users. In contrast, satellite data providers as well as value adders have paid service contracts with the European Commission, which leads often to a faster and guaranteed product delivery, but not necessarily to better products. Some restrictions are given for the service: only largescale disasters and crises are within the scope of the service and the request should not be related to an existing on-going conflict or crisis with EU military operations or in politically sensitive areas [25].

\subsubsection{UNITAR Operational Satellite Applications Programme (UNOSAT)}

UNOSAT is the United Nations Institute for Training and Research (UNITAR) Operational Satellite Applications Programme which was created in 2000 [27]. UNOSAT provides maps, 
reports as well as geographic information system (GIS) compatible data layers for natural hazards, complex emergency situations or conflict crises - at no cost to the user. The users are entities of the United Nations systems such as OCHA, UNHCR, UNICEF, WFP, UNDP, WHO, IFRC, ICRC; International and national NGOs and the governments of affected countries. UNOSAT is covering the response and recovery phase and is working worldwide. UNOSAT collaborates with several partners (e.g. other services, satellite data providers, UN entities, companies like Google and ESRI) [28].

\subsubsection{SERVIR}

SERVIR mechanism is a joint venture between NASA and the United States Agency for International Development (USAID) [29]. It integrates satellite observations, ground-based data and forecast models to help developing nations in Central America, East Africa and the Himalaya region to assess environmental threats and to respond to and assess damage from disasters of natural origin. SERVIR is a multi-agency and multi-government mechanism with over 30 partners and collaborators and is endorsed by governments in Central America, Africa and the Hindu-Kush Himalaya region of Asia. The coordination office is located in United States and is supported by three regional centres: The Regional Centre for Mapping of Resources for Development (RCMRD) in Kenya, the International Centre for Integrated Mountain Development (ICIMOD) in Nepal and the Water Centre for the Humid Tropics of Latin America and the Caribbean in Panama [28].

Program supports not only national governments, but also universities, non-governmental organisations, and the private sectors. Users of SERVIR are government officials, disaster managers, scientists/researcher, students and the general public [29]. SERVIR serves as a source for satellite imagery and information provider during extreme events. The SERVIR mechanism is intended to respond to needs for satellite-based geoinformation in Mesoamerica, Africa or the Himalaya [28].

\subsubsection{ZKI service for federal agencies}

One of the first national operational services providing rapid space data acquisition and delivery in case of natural or man-made disasters is the so-called ZKI Service for Federal Agencies (ZKI-DE). ZKI-DE was established in January 2013, based on a framework contract between German Federal Ministry of the Interior (BMI) and the German Aerospace Center (DLR), coping all phases of the disaster management cycle. It enables German national authorities and other authorised users to order products of DLRs Center for Satellite Based Crisis Information (ZKI), even for requests at regional scale and for users like national security authorities (with the option of arrangements of confidentiality). Moreover, aiming at a better and more customised use of the products by public authorities, the service includes not only the provision of maps and dossiers in case of a disaster but also user trainings, a consulting service and continuous further developments based on user requirements and new technical capabilities [30]. This cooperation is not limited to BMI and its special agency (e.g. like 'Federal Office of Civil Protection and Disaster Assistance' or 'Federal Criminal Police Office'). As a first institution, the German Red Cross also uses ZKI-DE products for their emergency 
operations worldwide [30]. As a matter of fact, due to licence and safety regulations products could often not be published.

\subsubsection{Other initiatives}

There are more and more actors gathering/providing further space-based disaster information such as private companies (e.g. Digital Globe, Google, ESRI). Other interesting and upcoming actors are volunteer organisations like Map Action and crowdsourcing crisis mapper (e.g. Open Street Map initiative-OSM, Tomnod owned by Digital Globe). In this context, data acquisition and reliability are often critical aspects. Depending on the expertise of volunteer's equipment and raw data quality, analysis can vary considerably. Nevertheless, changing data policies in case of (major) disasters and new techniques in image analysis can facilitate the access to satellite data, as well as the dissemination of rapid-mapping products.

\section{Examples for applying satellite-based information in disaster management: Case studies}

In this section, a number of examples of satellite imagery application for disaster relief intend to highlight swift and synergistic use of state-of-the-art processing techniques and rapid data access. These rapid-mapping results could be achieved by building on existing scientific results, long-term engineering experience in the domain of satellite data processing and last but not least operational data access mechanisms. It is not indented to report major generic methodological research results or method comparison here.

\subsection{Flooding in Germany 2013}

Extreme flooding in Germany and other parts of the Central Europe began after several days of heavy rain in the late May and early June 2013 [31]. Flooding and damages primarily affected southern and eastern German states as well as Czech Republic and Austria. Switzerland, Slovakia, Belarus, Poland, Hungary and Serbia were affected to a lesser extent [31].

German Joint Information and Situation Centre (GMLZ) tasked Charter, Copernicus GIO EMS (Precursor of Copernicus EMS) and national Service ZKI-DE with the provision of satellite data and the creation of satellite and aerial image-based situation information covering the regions most affected by the current floods in Thuringia, Saxony, Bavaria and Baden-Wuerttemberg [32-34]. GMLZ is a facility of the German Federal Office of Civil Protection and Disaster Assistance (BBK). Charter and Copernicus EMS provided fast and cost-free access to satellite images covering a disaster area; moreover, Copernicus EMS delivered 38 maps (reference and disaster). National ZKI-DE service complemented the response products with up-to-date airborne data and more than 50 products such as supplementing monitoring maps or web services (see Figure 6). 


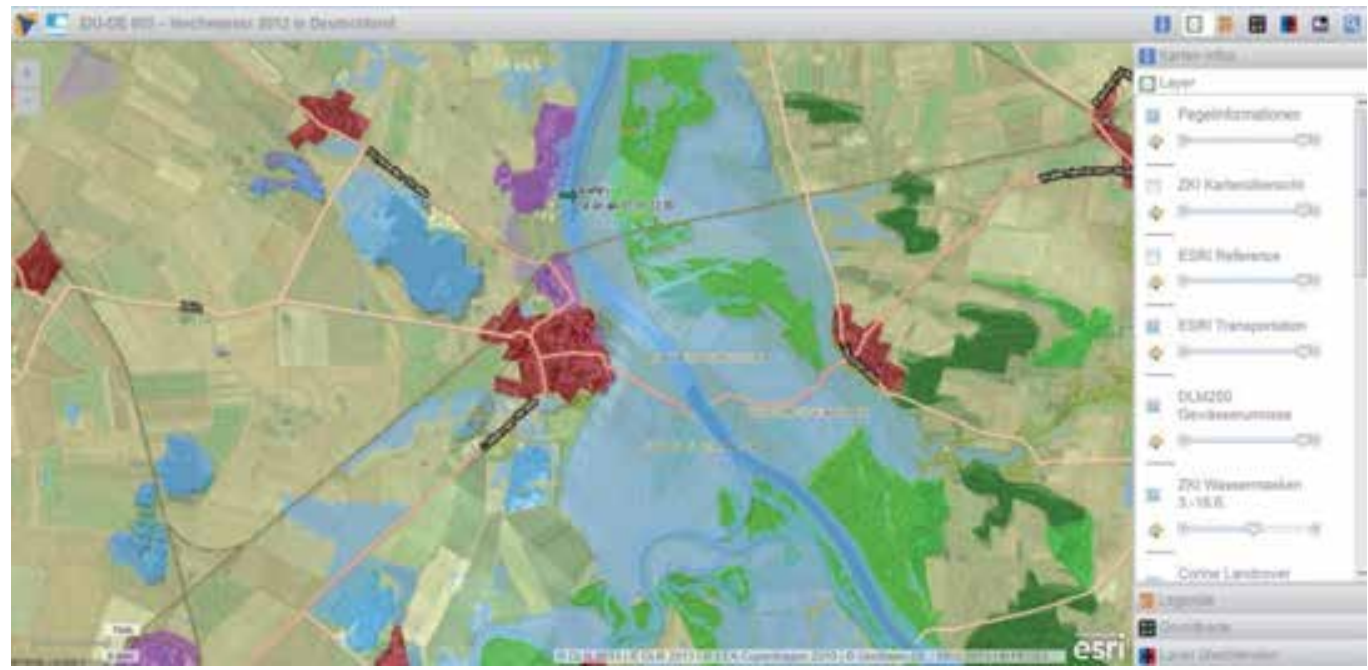

Figure 6. Flooding in Germany 2013 - ZKI-DE Web service [32]

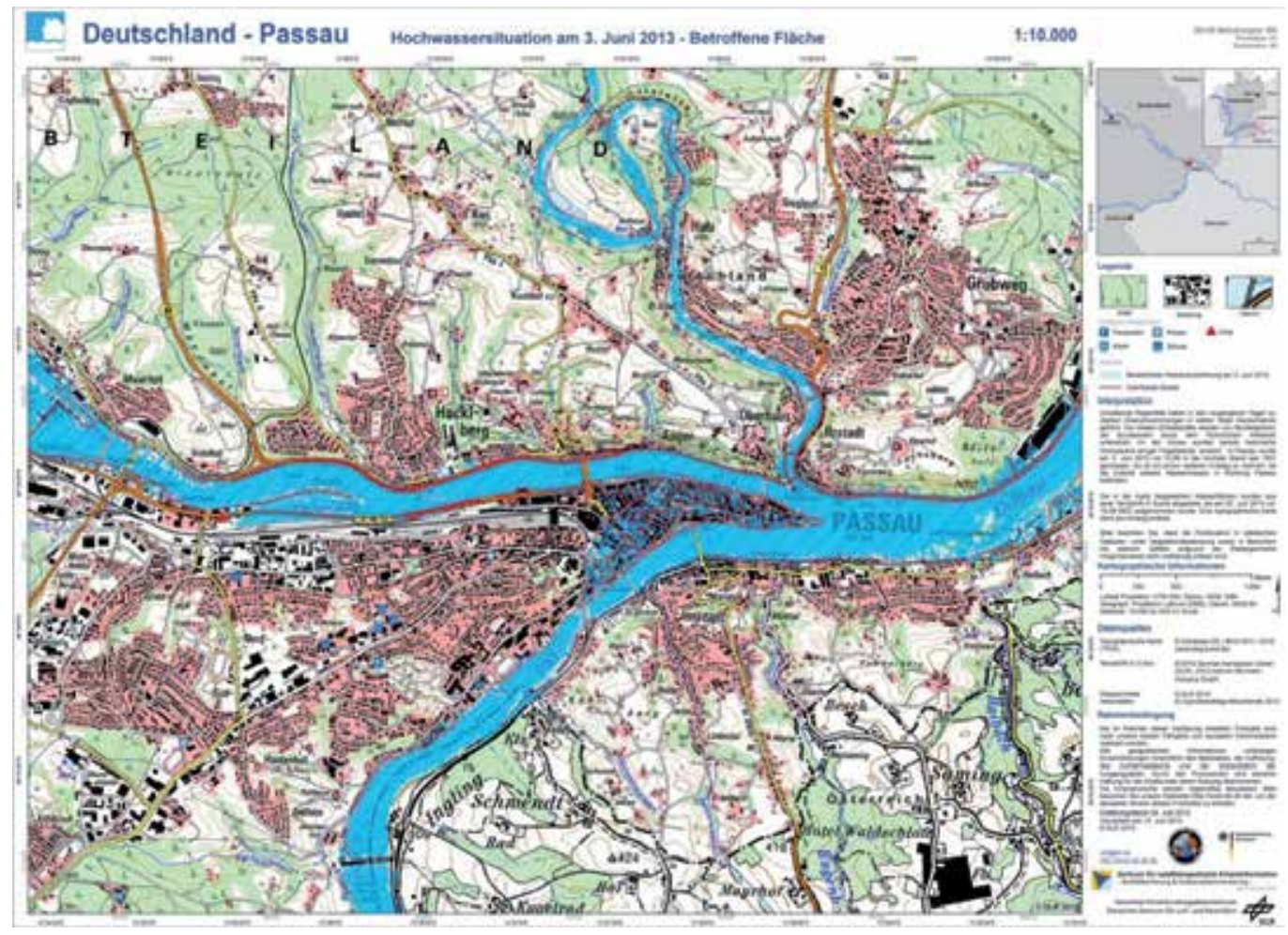

Figure 7. Flooding in Germany 2013, Passau - first situation map $10 \mathrm{~h}$ after acquisition [34] 
ZKI-DE was able to present the first situation map products to the users. The products based on the German radar-satellite TerraSAR-X and were delivered 10 hours after acquisition. The maps show the flood extent derived from the radar data, as backdrop serves as a topographic map (see Figure 7). Derivation of flood extent from TerraSAR-X data and map production/ dissemination just took 4 hours ( 6 hours for data downlink and pre-processing, respectively). These fast rapid-mapping results could be achieved by building on existing operational organisational structures (24/7) with trained staff, (semi-) automated image analysis procedures, and several templates as well as models/macros for the map products and their dissemination.

Nearly all the products were published for everyone on websites and were used in the disaster response phase by several users in Germany - from decision makers in the situation centres as well as local or top-ranking politician. Moreover weeks and months after the disaster, vector data sets of the disaster extent were requested several times by environmental and research institutes. These entities work in different phases of the disaster management cycle. Following up the experiences of the flooding 2013, several actions were implemented to reduce the impact of such heavy weather conditions [35].

In general, optical as well as radar satellite remote sensing have proven to provide essential large-scale information on flood situations. For optical input data, the standard semi-automatic method is (unsupervised) classified [36]. If the spectral resolution of the sensor and/or the cloud coverage does not allow clear semi-automatic classification, the flood information can be extracted via visual interpretation. Change detection analysis is used if pre- and postdisaster satellite data are available [34]. Even though, optical data provide positive result information on inundation, radar data are a preferred input for flood detection. Fortunately, the number of automatic image processing algorithms to derive flooding from high-resolution SAR data (TerraSAR-X, Radarsat-2, Cosmo-SkyMed) has increased in the last years. One thing in common in these algorithms is that they make use of automatic thresholding algorithms for the initialisation of the classification process [36-39].

\subsection{Earthquake and Landslide in Nepal 2015}

On 25th April 2015, a 7.8 magnitude earthquake hit the Himalayan region. The epicentre was located near Kathmandu, the capital of Nepal. In addition to Nepal, India, China and Bangladesh were affected. The event and several aftershocks caused wide-ranging destruction. The earthquake triggered several landslides, an avalanche on Mount Everest. More than eight million people were affected by the earthquake [40]. Several actors were involved in producing useful information as a response to the disaster. Copernicus EMS was activated by European Commission's Humanitarian aid and Civil 40 products were published at the EMS webpage [41].

The International Charter on Space and Major Disasters was activated by several organisations (e.g. Indian Space Research Organisation - ISRO), and a plenty of maps were made available on webpage of the Charter in the aftermath of the earthquake [42]. Moreover, Sentinel Asia, ZKI-DE and several other actors [43] delivered a number of standard maps (see Figure 8) and innovative products such as a 3D-Animation flight over Kathmandu before the earthquake, based on $10 \mathrm{~cm}$ airborne data (see Figure 9) [42,44]. Even the National Geospatial-Intelligence 


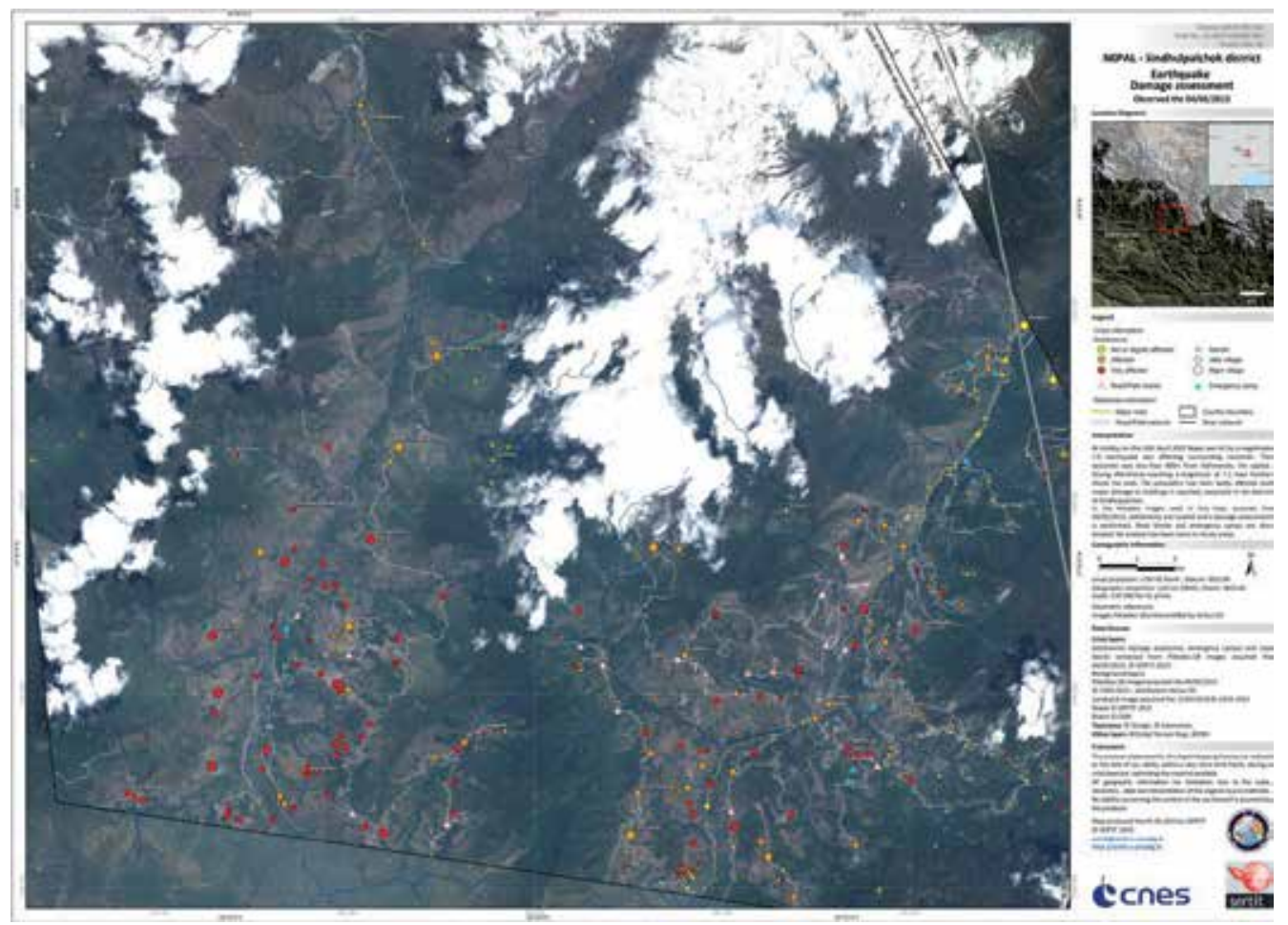

Figure 8. Earthquake in Nepal-Damage assessment map based on Pléiades data and visual interpretation [42]

Agency released unclassified geospatial intelligence data, products and services [42]. Within the crowdsource community also several initiatives were working on the Nepal earthquake such as Tomnod and Open Street Map (see Figure 10), Map Action, Micromappers [45].

Various methodologies have been proposed for earthquake damage assessment using optical and radar Earth observation data. For estimating infrastructural damages based on SAR, methods exploiting changes in backscattering intensity and the related image correlation coefficient [47] or a combination of backscatter intensity, phase changes and/or ancillary data are often used [48]. Reference [15] stated that 'most SAR-based change detection approaches suffer from a lack of archive data with the same acquisition parameters as the post crisisimagery'. Consequently, only very few of the SAR or optical-based approaches have been targeted for the use in an operational rapid mapping environment. For analysing optical satellite data several analysis methods were used to detect damages. Several authors applied either semi- or fully automatic change detection methods for earthquake damage assessment [49,47]. However, for various reasons, such methods have rarely been applied during rapid mapping activities [15]. For instance, automatic change detection approaches will potentially detect changes that are not related to earthquake damages (e.g. vegetation changes, different illumination, etc.). Moreover, in case of cloud coverage, haze or radiometric and spectral problems just manual extraction methods like visual interpretation and grid interpretation can be performed. The 


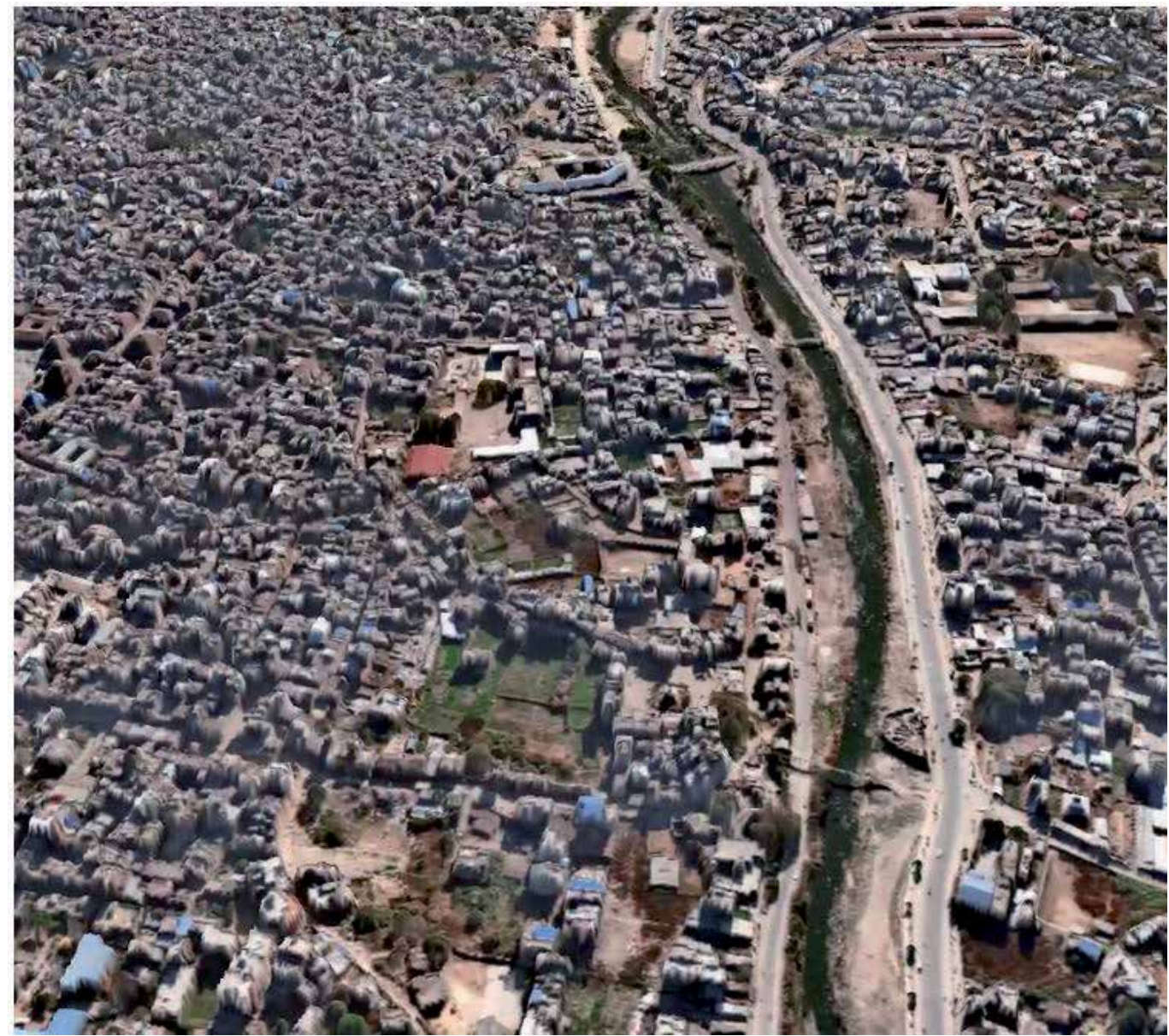

Figure 9. Earthquake in Nepal-Screenshot of a 3D-Animation flight over Kathmandu before the earthquake based on $10 \mathrm{~cm}$ airborne data (sensorDLR MACS) [44]

selection of the method depends on the requested information. For instance, if single (smallscale and heterogeneous) objects (e.g. houses, streets, ships and other relevant objects) have to be identified only visual interpretation is possible. Otherwise, the grid analysis allows the interpretation in specified areas (grid cells) and takes the relation of the neighbourhood into account by spatial aggregation of the thematic information content to be provided [18].

In summary, a fast activation of several mechanisms has taken place and resulted in large amounts of satellite imagery and airborne data. Nearly all results are based on optical data and visual interpretation. Many useful maps and visualisations facilitated a general understanding of the situation as well as the assessment of detailed aspects of the disaster and the relief work, including damage overview, road and infrastructure accessibility, gathering areas, strategic holding areas etc. According to several users' feedback, the maps and layers (streets, damage etc.) provided vital information with respect to evacuation planning, general 


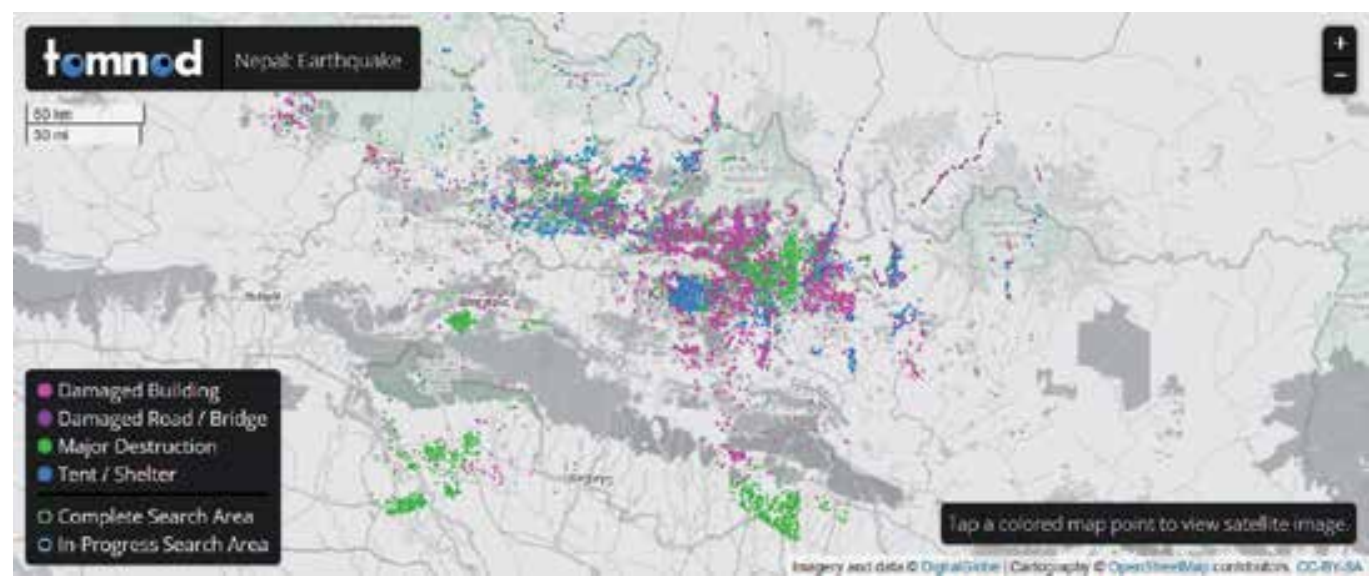

Figure 10. Earthquake in Nepal-Online damage map created by tomnod/OSM based on WorldView-1,-2,-3 and GeoEye [46]

pathfinding to get a better overview and understanding of problems on site. In addition, these maps proved to be very useful for making decisions on logistics and joint operations among relief organisations. Nevertheless, a multitude of websites and platforms hosted the maps, which resulted for some users in an overflow of mapping and imagery. During such extreme events, the authors of source [15] recommended a better coordination and harmonisation of global mapping efforts. As a consequence, an International Working Group on Satellite based Emergency Mapping (IWG-SEM) was initiated in 2012 resulting from the experiences of the Haiti earthquake in 2011. The IWG-SEM is a voluntary group of organisations involved in satellite-based emergency mapping which supports disaster response by improving international cooperation in such mapping activities. The group was founded to improve cooperation, communication and professional standards among the global network of satellite-based emergency mapping providers.

\subsection{Forest fire in Russia}

In July 2015, a heat wave in Russia's Siberian district started with over one hundred forest fires in the Buryatia and Irkustkaya Republics. Fires spread to an area of approximately 100,000 hectares [50].

After a request from the Russian Federal Space Agency (ROSCOSMOS) together with the Agency for Support and Coordination of Russian Participation in International Humanitarian Operations(EMERCOM), the Charter was triggered [Charter]. Burned area was mapped using the Russian satellite Resurs-P and its multispectral sensor with 12 meter resolution data (see Figure 10) and furthermore with SPOT-7 and GAOFEN-1 for another area [50]. In addition, fire hot spots were detected using RapidEye, GAOFEN and SPOT 7 [e.g. see Figure 11]. Burnt area analysis and fire hot spot detection was obtained by visual interpretation. 

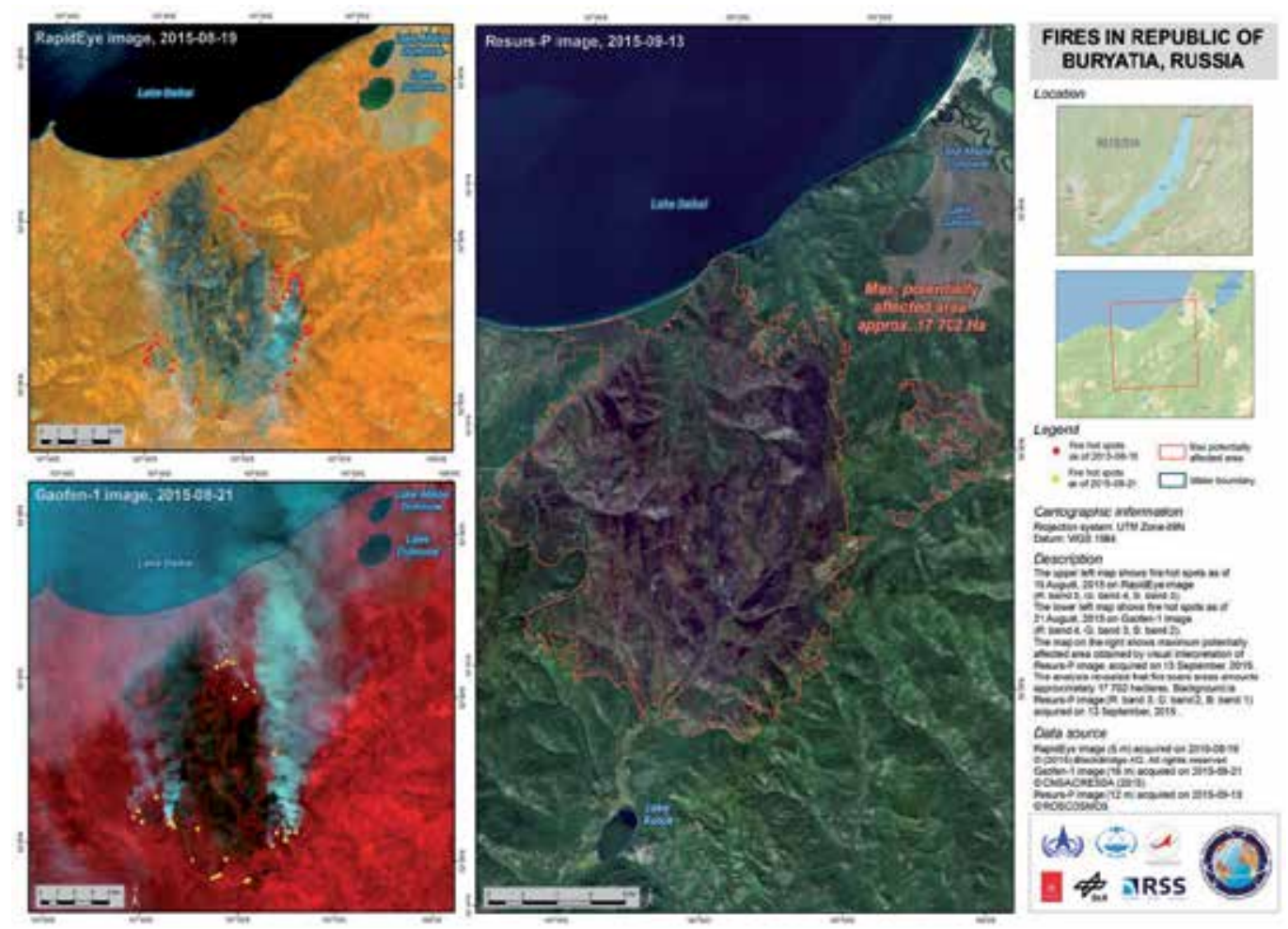

Figure 11. Forest Fires in Russia 2015 - Mapping hot spots and burned areas created by Research Center for Earth Operative Monitoring (NTs OMZ) [48]

In general, to identify fires and/or burnt areas optical data are the best choice and either semiautomated methods or visual interpretations can be applied [51]. In case of cloud coverage or direct fire effects such as smoke plumes or haze, visual interpretation usually gives better results. If the area is completely covered with clouds, radar data is an option. First positive results were gathered using SAR data for burnt area detection, applying backscatter coefficient analysis [52-53]. Nevertheless, optical satellites are commonly the main data source used for burnt area mapping in a rush-mode. In addition, fire hot spots can be detected automatically with optical data and appropriate methods. For instance, based on data of the NASA-owned MODIS sensors on board of the Terra-1 and Aqua-1 satellites, active fires can be detected [54].

\subsection{Search for Malaysia Airlines Flight 370}

On 11th March 2014, China Meteorological Administration requested the Charter for supporting search for Malaysia Airlines Flight 370 (MH370) [55]. The aircraft disappeared from radar on March 7th 2014 with 239 people on board. Soon an international search began in the South China Sea, the last known location of the aircraft. A few days later the search area has been expanded several times (e.g. to Indian Ocean). Satellite imagery was used to search for any evidence of the aircraft. Satellite images have revealed suspected debris or oil spill of 
missing aircraft in a number of locations (see example in Figure 12), but despite efforts to search an area of the southern Indian Ocean no trace of the plane has been found [55].

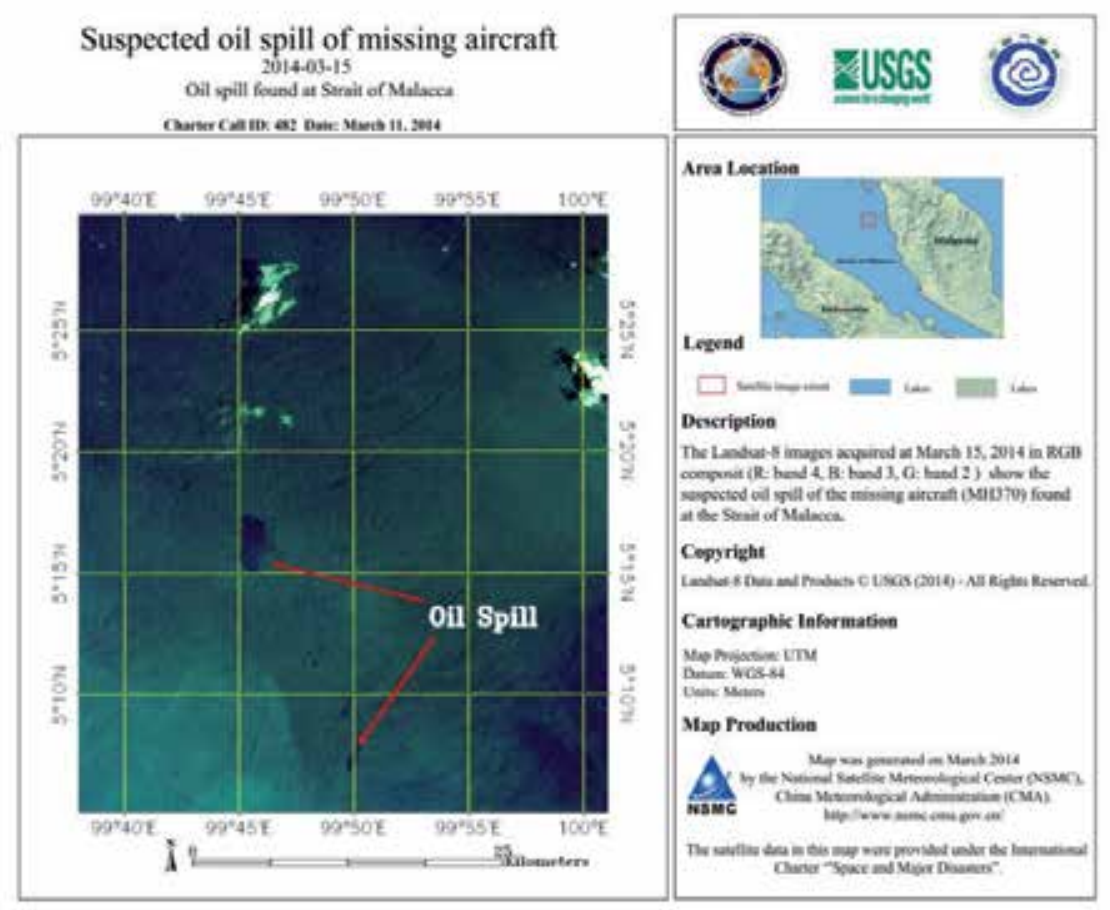

Figure 12. Searching for Malaysia Flight 370-Suspected oil spill of missing aircraft; created by National Satellite Meteorological Center (NSMC), China Meteorological Administration (CMA) [55]

Tomnod, a company owned by the satellite provider DigitalGlobe, started a crowdsourcing campaign in which over two million volunteers have studied WorldView-2 images of the area. The search area was sliced up in many small images which every user was able to see and tag with four types: Wreckage, Oil slick, Life raft and Other. Like other microtasking platforms, Tomnod uses triangulation to calculate areas of greatest consensus by the crowd [56]. The results are illustrated in Google Earth (see Figure 13).

Even though crowdsourced satellite information gave some reliable results or even misjudgements for this disaster, this way of data provision and processing information has been useful in man-made disasters before [56-57] and is a powerful new approach of producing crisis information based on satellite data. Nevertheless, Tomnod has to improve their infrastructure such as adding server capacity. Due to the huge volume of traffic (an estimated 100,000 views per minute), the site was down for several hours on March 11th and 12th.

However, the information provided by the Charter was also wrong. It is very difficult to search small items even if the imagery has a spatial resolution of 0.5 meters in an unspecific area with the current Earth observation technology. However, still there are a lot of data (e.g. SAR or other complex information) and several applications in disaster management which need 
advanced image analysis procedures. Therefore, remote sensing experts and specific tools are mandatory.

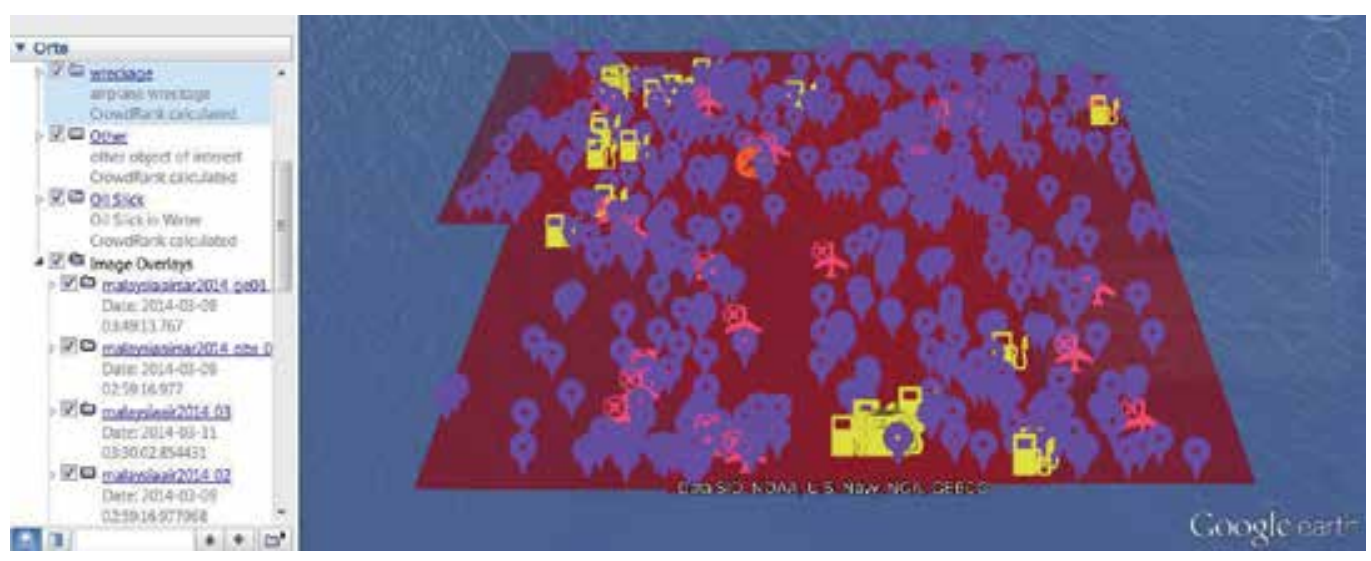

Figure 13. Searching for Malaysia Flight 370 - Online damage map created by tomnod based in Worldview-2 data and illustrated in Google Earth [56-57, visualisation in GoogleEarth]

\section{Conclusion and outlook}

The increasing occurrence of natural disasters and humanitarian emergency situations cause a growing demand for timely and up-to-date geoinformation for an effective disaster management. Within the last 10-15 years, a promising and considerable development has taken place to improve and accelerate the provision of Earth observation-based disaster information. Accordingly, remote sensing technology plays an important role in disaster management, especially during the preparedness and response phase.

Examples could be shown of how operational mechanisms (e.g. Charter, Copernicus EMS, ZKI-DE, etc.) serve rapid mapping based on Earth Observation data. In addition, a number of potential remote sensing data sources (TerraSAR-X, SPOT, RapidEye, WorldView and airborne data) and new (semi-automated) algorithms as well as visual interpretation results could be showcased for different disaster types.

Nevertheless, there are still some limitations with respect to the rapid availability of imagery and the reliability of the rapid image analysis in case of a disaster. Even if the imagery has a spatial resolution of 0.5 meters, geometric resolution is often still too coarse to assess damage or other important disaster information. Moreover, compromise must be found between the time spent on an analysis and the mapping accuracy that needs to be achieved. These aspects also have to be evaluated against user requirements during an emergency.

Further effort and scientific work is needed to derive even better, faster and more standardised crisis information from space-based imagery. In addition, in case of extreme disasters, a more structured and coordinated way of collaboration is needed to achieve most powerful results [15]. The International Working Group on Satellite based Emergency Mapping provides an important framework in this context. 
Within the next years, new data sources (better geometric, spectral and temporal resolution), new tools, modified data policies (open access or strictly regulated) and new actors/collaborations (crowdsourcing crisis mapper, national services, inter-organisational cooperation) will influence the potential of remote sensing for natural or man-made disasters.

\title{
Author details
}

\author{
Monika Gähler*
}

Address all correspondence to: monika.gaehler@dlr.de

German Aerospace Center (DLR), Center for Satellite Based Crisis Information (ZKI) of the German Remote Sensing Data Center (DFD), Oberpfaffenhofen / Wessling, Germany

\section{References}

[1] Guha-Sapir D., Hargitt D., Hoyois P. Thirty Years of Natural Disasters 1974-2003: The Numbers. Louvain: Univ. Louvain Presses. 2004. 76 p.

[2] Munich Re NatCatSERVICE. World Map of Natural Disasters 2014, Annual Statistics [Internet]. 2015. Available from: http://www.munichre.com/en/reinsurance/business/ non-life/natcatservice/annual-statistics/index.html [Accessed: 2015-11-24]

[3] Cavallo E. A., Noy I. The Economics of Natural Disasters: A Survey. IDB Working Paper no. 35 [Internet]. 2009. Available from: http://ideas.repec.org/p/idb/wpaper/ 4649.html [Accessed: 2015-11-24]

[4] Schneiderhan T., Gähler M., Kranz O., Voigt S. Insights into the Emergency Mapping Service within the GMES project SAFER - Highlights, main achievements and challenges. In: Proceedings of the ESA Living Planet Symposium, June 28-July 2, 2010, Bergen Norway. 2010. pp. 1-5

[5] Bello O. M., Aina Y. A. Satellite remote sensing as a tool in disaster management and sustainable development: Towards a synergistic approach. Procedia-Social and Behavioral Sciences. 2014. 120: 365-373. DOI:10.1016/j.sbspro.2014.02.114

[6] Van Westen C. Remote sensing for natural disaster management. International Archives of Photogrammetry and Remote Sensing. 2000. XXXIII: 1612-1617

[7] Centre for Research on the Epidemiology of Disasters (CRED): The OFDA/CRED International Disaster Database-Emergency Events Database (EM-DAT) [Internet]. 2015. Available from: http://www.emdat.be [Accessed: 2015-11-24] 
[8] UNEP. IETC and Disaster Management: Looking at the Entire Cycle of Disaster Management [Internet]. 2009. Available from: http://www.unep.or.jp/ietc/kms/data/ 2585.pdf [Accessed: 2015-11-24]

[9] Committee on Assessing the Costs of Natural Disasters, National Research Council, Division on Earth and Life Studies, Commission on Geosciences, Environment and Resources. The Impacts of Natural Disasters: A Framework for Loss Estimation. National Academies Press. Washington. 1999. 80p.

[10] Coppola D. Introduction to International Disaster Management. 3rd Edition. Butterworth-Heinemann. Oxford. 2015. 760p.

[11] Campbell J. B. and Wynne R. H. Introduction to Remote Sensing, 5th Edition. The Guilford Press. New York. 2011. 662 p.

[12] Lewis S. Remote Sensing for Natural Disasters: Facts and Figures, Science and Development Network [Internet]. 2009. Available from: http://www.scidev.net/global/ earth-science/feature/remote-sensing-for-natural-disasters-facts-and-figures.html

[Accessed: 2015-11-24]

[13] Joyce K. E., Belliss S. E., Samsonov S. V., McNeill S. J., Glassey P. J. A review of the status of satellite remote sensing and image processing techniques for mapping natural hazards and disasters. Progress in Physical Geography. 2009. 33(2): 183-207. DOI: $10.1177 / 0309133309339563$

[14] Van Westen C. J. Remote sensing and GIS for natural hazards assessment and disaster risk management. In: Treatise on Geomorphology. Schroder J. F., Bishop M. P., editors. San Diego: Academic Press, Elsevier, 2013 (Remote Sensing and GIScience in Geomorphology, vol. 3). pp. 259-298.

[15] Voigt S., Schneiderhan T., Twele A., Gähler M., Stein E., Mehl H. Rapid damage assessment and situation mapping: Learning from the 2010 Haiti Earthquake. Photogrammetric Engineering \& Remote Sensing. 2011. 77(9): 923-931.

[16] Joyce K. E., Wright K. C., Samonsov S. V., Ambrosia V. G. Remote sensing and the disaster management cycle. Geoscience and Remote Sensing. Vienna: In-Tech Publishing 2011: 317-346. DOI: 10.5772/8341

[17] European Commission, Joint Research Centre: European Forest Fire Information System [Internet]. 2015. Available from: http://forest.jrc.ec.europa.eu/effis/about-effis [Accessed: 2015-11-24]

[18] Voigt S., Kemper T., Riedlinger T., Kiefl R., Scholte K., Mehl H. Satellite image analysis for disaster and crisis-management support. IEEE Transactions on Geoscience and Remote Sensing. 2007. 45(6): 1520-1528.

[19] Voigt S., Kranz O. Satellite-based crisis management and geoinformation systems. Safety \& Security International. 2008. 4: 2-4 
[20] Gähler M., ZKI Team. Support Disaster Management with Remote Sensing. In: Schiewe J., Michel U. (eds): Geoinformatics Paves the Highway to Digital Earth, Osnabrück. 2008. pp. 24-29

[21] European Space Agency (ESA). International Charter Space and Major Disasters. 14th Annual Report [Internet]. 2015. Available from: https://www.disasterscharter.org/documents/10180/66908/14thAnnualReport [Accessed: 2015-11-24]

[22] Kaku K., Held H. Sentinel Asia: A space-based disaster management support system in the Asia-Pacific region. International Journal of Disaster Risk Reduction. 2013. 6: 1-17. DOI: 10.1016/j.ijdrr.2013.08.004

[23] Sentinel Asia. [Internet]. 2015. Available from: https://sentinel.tksc.jaxa.jp/sentinel2/ topControl.jsp [Accessed: 2015-11-24]

[24] European Commission: Copernicus Programme [Internet]. 2015. Available from: http://www.copernicus.eu [Accessed: 2015-11-24]

[25] European Commission: Copernicus Emergency Management Service [Internet]. 2015. Available from: http://emergency.copernicus.eu [Accessed: 2015-11-24]

[26] European Space Agency (ESA). Copernicus - Observing the Earth [Internet]. 2015. Available from: http://www.esa.int/Our_Activities/Observing_the_Earth/Copernicus/Overview3 [Accessed: 2015-11-24]

[27] Unitar's Operational Satellite Applications Programme - UNOSAT [Internet]. 2015. Available from: http://www.unitar.org/unosat/ [Accessed: 2015-11-24]

[28] UN-SPIDER Knowledge Portal - Emergencies Mechanisms [Internet]. 2015. Available from: http://www.un-spider.org/space-application/emergency-mechanisms [Accessed: 2015-11-24]

[29] NASA-SERVIR Global [Internet]. 2015. Available from: https://www.servirglobal.net [Accessed: 2015-11-24]

[30] DLR - ZKI-DE Service [Internet]. 2015. Available from: http://www.zki.dlr.de/services/zki-de [Accessed: 2015-11-24]

[31] Munich Re - Floods Dominate Natural Catastrophe Statistics in First Half of 2013 [Internet]. 2013. Available from: http://www.munichre.com/en/media-relations/publications/press-releases/2013/2013-07-09-press-release/index.html [Accessed: 2015-11-24]

[32] European Space Agency (ESA). International Charter Space and Major Disasters. Flooding in Germany [Internet]. 2013. Available from: https://www.disasterscharter.org/web/guest/-/floods-in-germany [Accessed: 2015-11-24]

[33] European Commission: Copernicus Emergency Management Service. Flooding in Germany [Internet]. 2013. Available from: http://emergency.copernicus.eu/mapping/ list-of-components/EMSR044 and EMSR047 [Accessed: 2015-11-24] 
[34] DLR - ZKI-DE. Flooding in Germany [Internet]. 2013. Available from: http:// www.zki.dlr.de/article/2373 [Accessed: 2015-11-24]

[35] LAWA, Bund/Länder-Arbeitsgemeinschaft Wasser. Zusammenfassende Analyse der Ergebnisse der vom Hochwasser 2013 betroffenen Flussgebietsgemeinschaften [Internet]. 2014. Available from: http://www.lawa.de/documents/LAWA_Analysebericht_Hochwasser_Juni_2013_dae.pdf [Accessed: 2015-11-24]

[36] Martinis S., Kersten J., Twele A. A fully automated Terra SAR-X based flood service. ISPRS Journal of Photogrammetry and Remote Sensing. 2015. 104: 203-212. DOI: 10.1016/j.isprsjprs.2014.07.014

[37] Martinis S, Twele A, Strobl C, Kersten J, Stein E. A multi-scale flood monitoring system based on fully automatic MODIS and TerraSAR-X processing chains. Remote Sensing. 2013. 5: 5598-5619. DOI: 10.3390/rs5115598

[38] Martinis S., Künzer C, Wendleder A, Huth J, Twele A, Roth A, Dech S. Comparing four operational SAR-based water and flood detection approaches. International Journal of Remote Sensing. 2015. 36(13): 3519-3543. DOI: 10.1080/01431161.2015.1060647.

[39] Pulvirenti L., Pierdicca N., Chini M., Guerriero L. An algorithm for operational flood mapping from Synthetic Aperture Radar (SAR) data using fuzzy logic. Natural Hazards Earth System Sciences 2011. 11: 529-540. DOI:10.5194/nhess-11-529-2011

[40] European Commission: ECHO Fact Sheet - Nepal [Internet]. 2015. Available from: http://ec.europa.eu/echo/files/aid/countries/factsheets/nepal_en.pdf [Accessed: 2015-11-24]

[41] European Commission: Copernicus Emergency Management Service. Earthquake in Nepal [Internet]. 2015. Available from: http://emergency.copernicus.eu/mapping/listof-components/EMSR125 [Accessed: 2015-11-24]

[42] European Space Agency (ESA). International Charter Space and Major Disasters. Earthquake in Nepal [Internet]. 2015. Available from: https://www.disasterscharter.org/web/guest/-/landslide-in-nep-2 [Accessed: 2015-11-24]

[43] UN-SPIEDER Knowledge Portal - Earthquake in Nepal, India, Bangladesh, China [Internet]. 2015. Available from: http://www.un-spider.org/advisory-support/emergency-support/9911/earthquake-nepal-india-bangladesh-china

[Accessed: 2015-11-24]

[44] DLR - ZKI-DE. Earthquake in Nepal [Internet]. 2015. Available from: http:// www.zki.dlr.de/article/2748 [Accessed: 2015-11-24]

[45] iRevolutions. A Force for Good: How Digital Jedis are Responding to the Nepal Earthquake [Internet]. 2015. Available from: http://irevolution.net/2015/04/27/digitaljedis-nepal-earthquake [Accessed: 2015-11-24] 
[46] Tomnod. Nepal Earthquake Data Portal [Internet]. 2015. Available from: http:// blog.tomnod.com/Nepal-Earthquake-Data-Portal/ [Accessed: 2015-11-24]

[47] Stramondo S., Bignami C., Chini M., Pierdicca N., Tertulliani A. The radar and optical remote sensing for damage detection: Results from different case studies. International Journal of Remote Sensing. 2006. 27: 4433-4447

[48] Gamba P., Dell'Acqua F., Trianni G. Rapid damage detection in Bam area using multi-temporal SAR and exploiting ancillary data. IEEE Transactions on Geoscience and Remote Sensing. 2007, 45(6): 1582-1589

[49] Chini M., Pierdicca N., Emery W. J. Exploiting SAR and VHR optical images to quantify damage caused by the 2003 Bam earthquake. IEEE Transaction on Geosciences and Remote Sensing. 2009. 47(1): 145-152

[50] European Space Agency (ESA). International Charter Space and Major Disasters. Fire Russia [Internet]. 2015. Available from: https://www.disasterscharter.org/web/ guest/-/fire-in-russian-federation [Accessed: 2015-11-24]

[51] Liew S. C., Kwoh L. K., Lim O. K., Lim H. Remote sensing of fire and haze. In: Eaton P., Radojevic M., editors. Forest Fires and Regional Haze in Southeast Asia. New York: Nova Science Publishers, 2001. pp. 67-89

[52] Tanase M. A., Santoro M., Wegmüller U., de la Riva J., Pérez-Cabello F. Properties of X-, C-and L-band repeat-pass interferometric SAR coherence in Mediterranean pine forests affected by fires. Remote Sensing of Environment. 2010. 114(10): 2182-2194. DOI: 10.1016/j.rse.2010.04.021

[53] Bernhard E. M., Twele A., Martinis S. The effect of vegetation type and density on Xband SAR backscatter after forest fires. Photogrammetrie, Fernerkundung, Geoinformation. 2014. 4: 275-285. DOI: 10.1127/1432-8364/2014/0222

[54] Giglio L., Descloitresa J., Justicec C. O., Kaufman Y. J. An enhanced contextual fire detection algorithm for MODIS. Remote Sensing of Environment. 2003. 87(2/3): 273282.

[55] European Space Agency (ESA). International Charter Space and Major Disasters. Missing Malaysia Airlines Jet [Internet]. 2015. Available from: https://www.disasterscharter.org/web/guest/-/missing-malaysia-airlines-jet [Accessed: 2015-11-24]

[56] Tomnod. Search for Flight MH370 [Internet]. 2015. Available from: http:// www.tomnod.com/campaign/malaysiaairsar2014/map/15qx1ry59 2015-11-24]

[57] iRevolutions. Results of the Crowdsourced Search for Malaysia Flight 370 [Internet]. 2015. Available from: http://irevolution.net/2015/04/27/digital-jedis-nepal-earthquake http://irevolution.net/2014/03/15/results-of-the-crowdsourced-flight-370-search/ [Accessed: 2015-11-24] 


\section{Section 5}

Remote Sensing Image Processing 

Chapter 12

\title{
Topological Characterization and Advanced Noise- Filtering Techniques for Phase Unwrapping of Interferometric Data Stacks
}

\author{
Pasquale Imperatore and Antonio Pepe \\ Additional information is available at the end of the chapter
}

http://dx.doi.org/10.5772/61847

\begin{abstract}
This chapter addresses the problem of phase unwrapping interferometric data stacks, obtained by multiple SAR acquisitions over the same area on the ground, with a twofold objective. First, a rigorous gradient-based formulation for the multichannel phase unwrapping $(\mathrm{MCh}-\mathrm{PhU})$ problem is systematically established, thus capturing the intrinsic topological character of the problem. The presented mathematical formulation is consistent with the theoretical foundation of the discrete calculus. Then within the considered theoretical framework, we formally describe an innovative procedure for the noise filtering of time-redundant multichannel multilook interferograms. The strategy underlying the adopted multichannel noise filtering (MCh-NF) procedure arises from the key observation that multilook interferograms are not fully time consistent due to multilook operations independently applied on each single interferogram. Accordingly, the presented MCh-NF procedure suitably exploits the temporal mutual relationships of the interferograms. Finally, we present some experimental results on real data and show the effectiveness of our approach applied within the well-known small baseline subset (SBAS) processing chain, thus finally retrieving the relevant Earth's surface deformation time series for geospatial phenomena analysis and understanding.
\end{abstract}

Keywords: SAR interferometry, phase unwrapping, discrete calculus

\section{Introduction}

Multichannel (or multitemporal) InSAR techniques address the processing of interferometric data stacks obtained by combining multiple SAR acquisitions over the same area. These approaches can be essentially categorized in two main classes: persistent scatterers (PS) and 
small baseline (SB)-based techniques. The solution of the multichannel phase unwrapping (MCh-PhU) problem is generally required in multichannel InSAR techniques, whenever multidimensional SAR data set, conveying information about complex Earth's crust events, have to be systematically investigated on suitable space-time scales for geospatial phenomena understanding [1-29]. In this chapter, we focus on two different related main issues.

Primarily, we present a rigorous gradient-based formulation of the MCh-PhU problem that is consistent with the theoretical foundation of the discrete calculus [30-34]. Emphasis is placed on the topological characterization of the underlying discrete setting provided by the differential operators of the discrete calculus, which are formally associated with matrix operators and represent the discrete counterparts of the classical differential operators of the vector calculus. Accordingly, $\mathrm{MCh}$-PhU problem formulation is systematically established in terms of discrete differential operators, which are defined by the topology of the intrinsically discrete spaces upon which they act, thus capturing the essential topological character of the problem within a systematic matrix formalism [35]. It is worth highlighting that our approach provides an unambiguous and theoretical-consistent formalism for the MCh-PhU problem, overcoming the conceptual inconsistencies of the existing gradient-based formulations [1, 17, 29]. Indeed, the existing approaches pose some conceptual limitations from a mathematical viewpoint since they rely on an intrinsically discrete setting based description and, at the same time, resort to the concepts of gradient and curl of the conventional vectorial calculus, which inherently imply a reference to an underlying continuum space and the notion of the infinitesimal [30]. In addition, the proposed formal framework enables meaningful analytical investigations on a mathematical consistent playground, also providing interesting implications and permitting to express previous obtained results in a more general way.

Then we present an innovative procedure to filter out the noise affecting the phase components of a redundant set of (multitemporal) multilook small-baseline interferograms. This is achieved by independently solving, for each pixel of the scene, a nonlinear optimization problem based on computing the wrapped phase vector that minimizes the (weighted) circular variance of the difference between the original and noise-filtered interferograms [43]. This noisefiltering procedure arises from the key observation that multilook interferograms are not fully time consistent because they are generated through multilook operations that are independently carried out on each single interferogram. Indeed, the wrapped discrete curl of the interferometric phases defined on a graph whose nodes and edges describe SAR acquisitions (in the time/perpendicular baseline domain) and inherent interferograms, respectively, is different from zero. This modulo- $2 \pi$ cyclic inconsistency of multichannel interferometric phases is properly handled by the presented multichannel noise-filtering (MCh-NF) procedure. The presented technique is very easy to implement because it does not imply a preliminary time-consuming selection of statistically homogenous pixels (SHP), as for instance required by the SqueeSAR technique [44], and it has no need of any a priori information on the statistics of complex-valued SAR images. The effectiveness of the presented noise-filtering approach as well as its impact on the quality of multichannel phase unwrapping procedures are also fully investigated. 


\section{Multichannel phase unwrapping problem}

In this Section, we review the mathematical formulation of the multichannel phase unwrapping (MCh-PhU) problem within the purview of the discrete calculus. As a matter of fact, a graph-based description naturally arises in formulating the $\mathrm{MCh}-\mathrm{PhU}$ problem due to the underlying discrete irregular data structure. Indeed, as far as discrete settings (e.g., graphs) are concerned, resorting to the conventional vectorial calculus might not be adequate since it inherently implies a reference to an underlying continuum space. On the contrary, discrete calculus offers a rigorous methodological framework since it treats a discrete domain as entirely its own entity. In particular, discrete calculus provides proper differential operators that make it possible to purely operate onto a finite, discrete structure without referring to the continuous space and notion of the infinitesimal [30]. More specifically, the introduction of some wellknown algebraic structures [30-33] capturing the essential topological character of the underlying graphs permits to phrase pertinent differential operators as matrices. Therefore, one of the most important consequences of this approach is that the purely topological nature of the discrete differential operators is made more apparent and concrete. Accordingly, by systematically adopting the relevant key concepts and tools available within this theoretical framework, we here provide a description of the MCh-PhU problem on a suitable mathematical playground. For such a purpose, we first establish the notation and terminology used throughout the subsequent Sections 2.1, and then the problem at hand is reviewed within this formalism (Sections 2.2 and 2.3). We remark that the focus here is on presenting key concepts that are useful for the following analyses; however, a comprehensive treatment of the discrete calculus and related huge fields of mathematics (e.g., algebraic topology, exterior calculus, and differential forms) is clearly beyond the scope of this work but can be found in refs. [30-33].

\subsection{The theoretical framework of discrete calculus}

A graph $\mathcal{G}(\mathcal{V} ; \mathcal{E})$ is defined by two sets: $\mathcal{V}$ and $\mathcal{E}$. The former is the set of nodes (or vertices) of the graph, and the latter represents the corresponding set of edges. Let $Q$ and $M$ be the cardinality of $\mathcal{V}$ and $\mathcal{E}$, respectively. The vector space $\mathbb{R}^{M}$ is referred to as the edge space, and the vector space $\mathbb{R}^{l}$ is referred to as the vertex space, with $\mathbb{R}$ denoting the field of real numbers. Without loss of generality, we here assume that the graph $\mathcal{G}$ is connected (i.e., every pair of vertices in the graph is connected [33]). Moreover, an orientation establishes a default direction on an edge that is considered positive or negative, thus yielding an oriented graph. The $M \times$ $Q$ incidence matrix $\Pi=\left[\Pi_{m q}\right]$ of an oriented graph $\mathcal{G}$ specifies its edge-node connectivity relations, whose entries are defined as follows [30-33]:

$$
\Pi_{m q} \equiv\left\{\begin{aligned}
-1, & \text { if } m \text { th edge starts at } q \text { th node } \\
+1, & \text { if } m \text { th edge ends at } q \text { th node } \\
0, & \text { otherwise }
\end{aligned}\right.
$$

with $m=1,2, \ldots, M$ and $q=1,2, \ldots, Q$. It is important to note that the column rank of $\Pi$ is $Q-1$. The incidence matrix $\Pi$ generates an orthogonal decomposition $\mathbb{R}(\Pi) \oplus \mathcal{N}\left(\Pi^{\mathrm{T}}\right)=\mathbb{R}^{M}$, where $\mathbb{R}(\boldsymbol{\Pi})$ is the column space of the incidence matrix $\Pi$, and $\mathcal{N}\left(\Pi^{\mathrm{T}}\right)$ denotes the kernel (or null- 
space) of the matrix $\Pi^{\mathrm{T}}$. The notion of cycle space is also fundamental in graph theory. The cycle space of the graph $\mathcal{G}$, namely, $\mathcal{C}=\mathcal{C}(\mathcal{G})$, is the subspace of edge space $\mathbb{R}^{M}$ spanned by all the cycles in $\mathcal{G}$. The dimension of $\mathcal{C}(\mathcal{G})$ is also referred to as the cyclomatic number of $\mathcal{G}$ [33]. It is also well known that, for every connected graph $\mathcal{G}$ with $Q$ nodes and $M$ edges, the dimension of the cycle space is given by $R=\operatorname{dim}(\mathcal{C}(\mathcal{G}))=M-Q+1$ [30]. Each basis for $\mathcal{C}(\mathcal{G})$ (i.e., the cycle basis) is therefore uniquely specified by an $M \times R$ matrix $\Omega$, called cycle matrix. Thus, the column vectors of $\Omega=\left[\omega^{1}, \ldots, \omega^{R}\right]$ form a basis for an $R$-dimensional vector subspace (the cycle space of $\mathcal{C}(\mathcal{G})$ of $\mathbb{R}^{M} \cdot \mathcal{C}(\mathcal{G})$ is indeed the null-space of $\Pi^{\mathrm{T}}$ so that a cycle basis provides a basis for $\mathcal{N}\left(\Pi^{\mathrm{T}}\right)$ [30]. Accordingly, a fundamental property of a linear graph is expressed by the remarkable relations:

$$
\begin{array}{r}
\boldsymbol{\Pi}^{\mathrm{T}} \boldsymbol{\Omega}=\mathbf{0} \\
\boldsymbol{\Omega}^{\mathrm{T}} \boldsymbol{\Pi}=\boldsymbol{0}
\end{array}
$$

Indeed, several methods for defining a cycle set have been studied, and they can be used to define incidence relations between edges and cycles. Specifically, the definition of a cycle set from the edge set can be obtained algebraically and geometrically (i.e., from an embedding). Algebraic methods find a suitable $M \times R$ matrix $\Omega$ whose columns provide a basis for the nullspace of $\Pi^{\mathrm{T}}$, with $R=\operatorname{dim}\left(\mathcal{N}\left(\boldsymbol{\Pi}^{\mathrm{T}}\right)\right)$. Geometric methods for defining a cycle set (i.e., from an embedding) permit to identify algorithmically a cycle set (representing the faces) in this embedding and may be used to produce the edge-face incidence matrix $\Omega$ (as illustrated in Figure 1). In particular, it is possible to consider a normalized irreducible cycle basis forming elementary (or irreducible) cycles [30-33], i.e., cycles that contain no other cycles, so that we can associate to each elementary cycle an elementary cycle vector $\omega^{r}=\left[\omega_{1}, \ldots, \omega_{M}\right]^{\mathrm{T}}$, whose entries are defined as follows:

$$
\omega_{i} \equiv\left\{\begin{array}{cc}
+1 & \text { if } r \text { th cycle traverses } i \text { th edge forward } \\
-1 & \text { if } r \text { th cycle traverses } i \text { th edge backward } \\
0 & \text { otherwise }
\end{array}\right.
$$

Accordingly, the so defined $\Omega=\left[\boldsymbol{\omega}^{1}, \ldots, \boldsymbol{\omega}^{R}\right]$ provides a particularly attractive basis for $\mathcal{N}\left(\boldsymbol{\Pi}^{\mathrm{T}}\right)$, i.e., the cycle basis formed by all the elementary cycle vectors associated with the elementary cycles in $\mathcal{G}$. We also note that $\Omega$ defines the incidence connectivity relations between edges and cycles (see Figure 1).

It is instructive to highlight that the topological operators $\Pi, \Pi^{\mathrm{T}}$, and $\Omega$ provide the discrete counterparts of the classical gradient $(\nabla)$, divergence $(\nabla \cdot)$, and $\operatorname{curl}(\nabla \times)$ operators of the vector calculus for continuous space, respectively. Accordingly, they can be regarded as differential 
operators on the discrete setting [30]. In addition, it is worth emphasizing that identities (2) and (3) mimic the properties of their classical vector calculus counterparts $\nabla \cdot \nabla \times=0$ (div curl $=0)$ and $\nabla \times \nabla=0$ (curl grad $=0)$, respectively. It should be pointed out that $\Pi$ yields differences along edges of nodal "potentials" represented by $\Pi \mathbf{x}$. Conversely, given an arbitrary $\mathbf{f} \in \mathbb{R}^{M}$, a solution of the equation $\Pi \mathbf{x}=\mathbf{f}$ (if it exists) is called the potential of $\mathbf{f}$. Note also that $\mathbf{x}$ (if it exists) is not unique since the constant column $\mathbb{1}=[1, \ldots, 1]^{\mathrm{T}} \in \mathbb{R}^{Q}$ is an element of the kernel of $\Pi$. Of course, not every $\mathbf{f} \in \mathbb{R}^{M}$ is the discrete gradient of some $\mathbf{x}$ since $\mathbf{f}$ may contain a curl component. Indeed, a prescribed $\mathbf{f} \in \mathbb{R}^{M}$ can be written as a nodal difference $(\mathbf{f}=\Pi \mathbf{x})$ if it is cyclically consistent, i.e., if it satisfies $\Omega^{\mathrm{T}} \mathbf{f}=\mathbf{0}$ (i.e., there is no component of the flow in the cycle space). Note also that $\Omega$ is the (cross) differential operator of the graph whose expression can be given in terms of a normalized cycle basis; $\mathcal{N}\left(\Omega^{\mathrm{T}}\right)$ denotes the subspace of $\mathbb{R}^{M}$ with zero flow circulation (curl-free) around cycles. Moreover, $\Pi^{\mathrm{T}} \mathbf{f}$ yields nodal accumulations from flows along edges. As a result, the differential operators, as basic tools of the discrete calculus, have been established and properly phrased on the discrete space. This mathematical abstraction meaningfully captures the topological structure of the underlying discrete setting. Note that the topological characterization of the graph is essentially embodied in the algebraic structure of the associated discrete (matrix) operators and their interrelations. We also stress the significant distinction between the discrete operators and the commonly adopted discretized versions of the continuous differential operations obtained via the method of finite differences in numerical analysis; the latter generally lack the desirable topological behaviour [42].

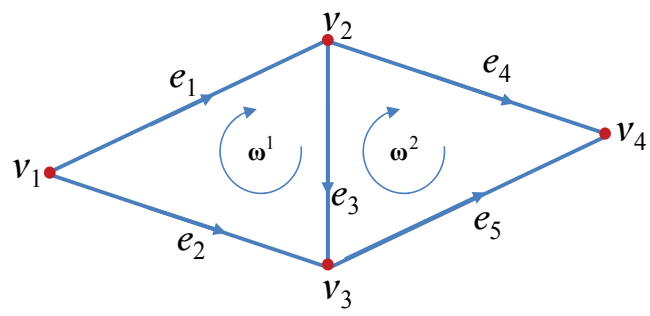

$$
\boldsymbol{\Pi}=\left[\begin{array}{cccc}
-1 & 1 & 0 & 0 \\
-1 & 0 & 1 & 0 \\
0 & -1 & 1 & 0 \\
0 & -1 & 0 & 1 \\
0 & 0 & -1 & 1
\end{array}\right] \quad \boldsymbol{\Omega}=\left[\begin{array}{cc}
1 & 0 \\
-1 & 0 \\
1 & -1 \\
0 & 1 \\
0 & -1
\end{array}\right]
$$

Figure 1. An example graph shown along with its edge-node incidence matrix, $\Pi$, and cycle (edge-face incidence) matrix, $\Omega$. Note that $M=5, Q=4$ and $R=2$.

As a final remark, some considerations on the total unimodularity (TU) property inherent to the matrix operators, which is extremely important in integer linear programming, are in order. We recall that a matrix is TU if the determinant of every submatrix is either zero or \pm 1 . For any graph, the edge-node incidence matrix is TU. On the contrary, the face-edge incidence matrix, in general, is not TU [30-34]. However, the edge-face incidence matrix is TU when each edge 
is included in exactly two faces that traverse the edge in opposite directions (e.g., a planar graph with a minimum cycle basis [30]). In this circumstance, total unimodularity of the edgeface incidence matrix stems from the fact that the face-edge incidence matrix is the edge-node incidence matrix of the dual graph [30]. Indeed, a TU constraint matrix (and integer constraints) guarantees that the solution of the related optimization problem (see also optimization problems (21) and (22) in the following) will be integer. Nonetheless, TU property has a further practical significance since the relaxed problem, obtained by neglecting the integer constraints, can also be solved using generic linear (not integer) programming solvers.

\subsection{Rigorous gradient-based formulation of the $\mathrm{MCh}-\mathrm{PhU}$ problem}

Once the basic concepts of the discrete calculus and graph theory are presented, we are in the position to frame the formulation of the $\mathrm{MCh}-\mathrm{PhU}$ problem on an appropriate mathematical playground. Let us consider a set of $Q$ single-look-complex (SLC) SAR data acquired over a certain area of interest. One of them is assumed as the reference (master) image, with respect to which the images are properly coregistered. This set is characterized by the corresponding acquisition times $\left\{t_{1}, \ldots, t_{Q}\right\}$ and perpendicular baselines $\left\{b_{\perp 1}, \ldots, b_{\perp Q}\right\}$. Accordingly, for each coregistered SLC pair, a multilook phase interferogram (suitably depurated by the flat-Earth and topography contributions, by using a priori information about the topography and acquisition geometry) can be produced [37]; however, a common practice (within the multitemporal SB InSAR class) is first to identify a suitable small-baseline subset of the relevant multibaseline (temporal and spatial-perpendicular baselines) interferometric-pair set [6]. This is done to confine the effect of decorrelation phenomena associated with inherent angular and temporal electromagnetic backscattering variations [38]. Furthermore, a subset of common pixels of the $M$ interferograms are then usually identified via the estimated coherence $[37,38]$, so that only $P$ pixels characterized by relatively high coherence values are singled out. In other words, the coherence index, providing a quantitative estimation of the decorrelation effects, permits to discriminate in favor of the "reliable" pixels.

The final aim is to reconstruct the absolute (i.e., not restricted in the principal $[-\pi, \pi)$ interval) interferometric phases values from the wrapped (i.e., observed only in the principal $[-\pi, \pi)$ interval) interferometric phase pertinent to $M$ multichannel interferograms.

The problem we are interested in can be naturally framed on a discrete setting. Indeed, one possibility is to regard the discrete set of $P$ selected (typically sparsely distributed) coherent pixels as a set of nodes, $\nu_{\mathrm{B}}$, in the Euclidean (azimuth, range) plane, and the set of $Q$ SAR acquisitions representing a set of nodes, $\mathcal{V}_{\mathrm{A}}$, in the Euclidean (temporal-baseline, perpendicularbaseline) plane [26]. Accordingly, a formal description of the problem at hand can be given in terms of a couple of abstract graphs: $\mathcal{G}_{\mathrm{A}}=\left(\mathcal{V}_{\mathrm{A}} ; \mathcal{E}_{\mathrm{A}}\right)$ and $\mathcal{G}_{\mathrm{B}}=\left(\mathcal{\nu}_{\mathrm{B}} ; \mathcal{E}_{\mathrm{B}}\right)$ where the corresponding edge sets $\varepsilon_{\mathrm{A}}$ and $\varepsilon_{\mathrm{B}}$ have to be properly defined. Accordingly, with $Q$ and $M$, we denote the cardinality of $\mathcal{V}_{\mathrm{A}}$ and $\mathcal{E}_{\mathrm{A}}$, and with $P$ and $N$ the cardinality of $\mathcal{V}_{\mathrm{B}}$ and $\mathcal{E}_{\mathrm{B}}$, respectively. Note also that defining $\mathcal{E}_{\mathrm{A}}$ pertains to the $M$ interferometric pairs selection. Defining a meaningful edge set for a collection of nodes is now concerned since different criteria can be adopted to achieve it. The dimensionality of the ambient space in which the graph is embedded deserves some considerations. In this regard, we recall that a graph is called planar if it can be embedded in the plane [30-33]. Note also that a graph is not generally guaranteed to be planar, even if the 
nodes are embedded in two dimensions. Since planarity is important for the workability of the implicated optimization procedure with powerful numerical solvers, a typical option to preserve graph planarity is resorting to the Delaunay triangulation in the Euclidean plane for establishing the edge set from nodes embedded in two dimensions [26]. Note that such an option specifically pertains to the solution strategy [26, 35]; nonetheless, our general formulation applies as well when different edge structures are adopted. Accordingly, once $\mathcal{G}_{\mathrm{A}}$ and $\mathcal{G}_{\mathrm{B}}$ have been somehow defined, the topological properties inherent to each graph are algebraically captured by the related differential operators, which are summarized in Table 1.

\begin{tabular}{ccc}
\hline Symbol & Quantity & Related meaning \\
\hline$Q$ & Nodes number of $\mathcal{G}_{\mathrm{A}}$ & Number of SAR acquisitions \\
\hline$R$ & Edges Number of $\mathcal{G}_{\mathrm{A}}$ & Number of interferometric pairs \\
\hline$\Pi_{A}$ & Dimension of the cycle space of $\mathcal{G}_{\mathrm{A}}$ & Discrete-gradient operator \\
\hline$\Pi_{A}^{T}$ & $M \times Q$ incidence matrix of $\mathcal{G}_{\mathrm{A}}$ & Discrete-divergence operator \\
\hline$\Omega_{\mathrm{A}}$ & $M \times R$ cycle matrix of $\mathcal{G}_{\mathrm{A}}$ & Discrete-curl operator \\
\hline$P$ & Nodes number of $\mathcal{G}_{\mathrm{B}}$ & Number of selected pixels \\
\hline$N$ & Edges number of $\mathcal{G}_{\mathrm{B}}$ & \\
\hline$L$ & Dimension of the cycle space of $\mathcal{G}_{\mathrm{B}}$ & Discrete-gradient operator \\
\hline$\Pi_{B}$ & $N \times P$ incidence matrix of $\mathcal{G}_{\mathrm{B}}$ & Discrete-divergence operator \\
\hline$\Pi_{B}^{T}$ & $N \times L$ cycle matrix of $\mathcal{G}_{\mathrm{B}}$ & Discrete-curl operator \\
\hline$\Omega_{\mathrm{B}}$ & & \\
\hline
\end{tabular}

Table 1. Adopted notation

First of all, we consider the absolute phase relevant to the multichannel SAR acquisition as a node variable pertinent to both the graphs $\mathcal{G}_{\mathrm{A}}$ and $\mathcal{G}_{\mathrm{B}}$; by using a matrix representation, this information can be conveniently arranged in a $Q \times P$ matrix $\Phi$ as follows:

$$
\boldsymbol{\Phi}=\left[\varphi^{1}, \ldots, \varphi^{P}\right]=\left[\begin{array}{c}
\varphi_{1} \\
\vdots \\
\varphi_{Q}
\end{array}\right]
$$

where $\forall p \in\{1,2, \ldots, P\} \varphi^{p} \in \mathbb{R}^{Q}$ encodes in a vectorial manner the $p$ th node variable relevant to the graphs $\mathcal{G}_{\mathrm{A}}$; similarly, $\forall q \in\{1,2, \ldots, Q\} \varphi_{q} \in \mathbb{R}^{P}$ encodes the $q$ th node variable relevant to $\mathcal{G}_{\mathrm{B}}$. 
Widely adopted global gradient-based PhU approaches, which have historically been developed for the single-channel case, generally consist in three processing steps [1, 29]. First, an estimation of the (wrapped) phase gradient is obtained; the estimated phase gradient is then suitably corrected (in terms of $2 \pi$ multiples), and subsequently integrated to attain the unwrapped (absolute) phase.

Within the formulation of the MCh-PhU problem we concern [26], a twofold estimation of the discrete gradient field is carried out onto the considered two graphs $\mathcal{G}_{\mathrm{A}}$ and $\mathcal{G}_{\mathrm{B}}$, as discussed in the following. The stack of the absolute interferometric phases relevant to the $M$ (vectorized) interferograms can be formally represented through a $P \times M$ matrix denoted by

$$
\Psi=\left[\psi^{1}, \ldots, \psi^{M}\right]=\left[\begin{array}{c}
\psi_{1} \\
\vdots \\
\psi_{P}
\end{array}\right]
$$

wherein the $P$-dimensional vector $\psi^{m}$ refers to the absolute phase field pertinent to the $m$ th interferogram. Accordingly, $\Psi$ is formally related to the absolute (unwrapped) phase matrix $\Phi$ via the discrete gradient operator $\Pi_{\mathrm{A}}$ :

$$
\Psi^{\mathrm{T}}=\boldsymbol{\Pi}_{\mathrm{A}} \boldsymbol{\Phi}
$$

Note also that

$$
\Psi^{\mathrm{T}}=\left[\psi_{1}^{\mathrm{T}}, \ldots, \psi_{P}^{\mathrm{T}}\right]=\left[\boldsymbol{\Pi}_{\mathrm{A}} \varphi^{1}, \ldots, \boldsymbol{\Pi}_{\mathrm{A}} \varphi^{P}\right]
$$

By applying the discrete gradient operator $\Pi_{\mathrm{B}}$ to the absolute phase of each interferometric pair, we obtain

$$
\Pi_{\mathrm{B}} \Psi=\left[\Pi_{\mathrm{B}} \psi^{1}, \ldots, \Pi_{\mathrm{B}} \psi^{M}\right]
$$

As a result, by using Eq. (7), we get

$$
\boldsymbol{\Pi}_{\mathrm{B}} \Psi=\boldsymbol{\Pi}_{\mathrm{B}} \Phi^{\mathrm{T}} \boldsymbol{\Pi}_{\mathrm{A}}^{\mathrm{T}}
$$

Second, we consider the (wrapped) interferometric phase that is uniquely defined only in the principal value range since it is obtained as the phase of a complex function. Hence, it is 
convenient to formally introduce the non-injective (modulo- $2 \pi$ ) wrapping operator $W: \varphi \in \mathbb{R} \rightarrow \bmod (\varphi+\pi, 2 \pi)-\pi \in[-\pi, \pi)$. It should be noted that the following trivial identities hold:

$$
\begin{array}{ll}
W(W(\boldsymbol{A}) \pm W(\boldsymbol{B}))=W(\boldsymbol{A} \pm \boldsymbol{B})=W(W(\boldsymbol{A}) \pm \boldsymbol{B})=W(\boldsymbol{A} \pm W(\boldsymbol{B})) & \mathrm{a} \\
W(\boldsymbol{A})=\boldsymbol{A}+2 \pi \boldsymbol{Z} & \mathrm{b}
\end{array}
$$

where $A$ and $B$ represent two generic matrices and $Z$ is a suitable integer matrix. Given the stack of the unknown absolute (unwrapped) interferometric-phases $\Psi$, the corresponding stack of the wrapped phases $\widetilde{\boldsymbol{\Psi}}$ can be conveniently expressed in terms of the wrapped discrete gradient of (wrapped) observed phase as follows:

$$
\tilde{\boldsymbol{\Psi}}^{\mathrm{T}}=\left[W\left(\boldsymbol{\Pi}_{\mathrm{A}} W\left(\boldsymbol{\varphi}^{1}\right)\right), \ldots, W\left(\boldsymbol{\Pi}_{\mathrm{A}} W\left(\boldsymbol{\varphi}^{P}\right)\right)\right]=W\left(\boldsymbol{\Pi}_{\mathrm{A}} W(\boldsymbol{\Phi})\right)=W\left(\boldsymbol{\Pi}_{\mathrm{A}} \boldsymbol{\Phi}\right)
$$

where we have exploited Eq. (11b). Note also that the $p$ th column of $\widetilde{\boldsymbol{\Psi}}^{\mathrm{T}}$, i.e., $\widetilde{\psi}_{p}^{\mathrm{T}}=W\left(\Pi_{\mathrm{A}} W\left(\varphi^{p}\right)\right)$, can be regarded as an estimate of the absolute-phase discrete gradient on the graph $\mathcal{G}_{\mathrm{A}}$. It is worth remarking that the observed (multilook) interferometric phase can however be corrupted by noise [39-41], which is taken into account by considering an additive phase noise term $\boldsymbol{D}$. Accordingly, by using Eq. (11a), we get

$$
\tilde{\boldsymbol{\Psi}}^{\mathrm{T}}=W\left(W\left(\boldsymbol{\Pi}_{\mathrm{A}} \boldsymbol{\Phi}\right)+\boldsymbol{D}\right)=W\left(\boldsymbol{\Pi}_{\mathrm{A}} \boldsymbol{\Phi}+\boldsymbol{D}\right)
$$

More specifically, whenever a possible spatial filtering (e.g., conventional multilooking followed by a noise-filtering step [42]) is independently applied to each SAR interferometric data pair, the resulting term $D$ in Eq. (13) implies that the phase interferograms $\widetilde{\psi}^{m}$, with $m \in\{1,2, \ldots, M\}$, are no more fully time consistent (in the sense of $[26,43,44])$. To clarify this point, we observe that by using Eq. (13), it turns out that

$$
W\left(\boldsymbol{\Omega}_{A}^{T} \boldsymbol{\Psi}^{T}\right)=W\left(\boldsymbol{\Omega}_{A}^{T}\left(\boldsymbol{\Pi}_{A}+\boldsymbol{D}+2 \pi \mathbf{Z}\right)\right)=W\left(\boldsymbol{\Omega}_{A}^{T} \boldsymbol{\Pi}_{A} \boldsymbol{\Phi}+\boldsymbol{\Omega}_{A}^{T} \boldsymbol{D}\right)=W\left(\boldsymbol{\Omega}_{A}^{T} \boldsymbol{D}\right) \neq \mathbf{0}
$$

where we have used Eq. (11b) with $A=\Pi_{\mathrm{A}} \Phi+D$ and noted that $\Omega_{\mathrm{A}}^{\mathrm{T}} Z$ is an integer matrix and $\boldsymbol{\Omega}_{\mathrm{A}}^{\mathrm{T}} \boldsymbol{\Pi}_{\mathrm{A}}=\mathbf{0}$ (according to Eq. (3)). Eq. (14) reads as "the wrapped discrete curl of the interferometric phase on $\mathcal{G}_{\mathrm{A}}$ (i.e., pertinent to the 'temporal' domain) is generally different from zero"; it formally expresses the (modulo- $2 \pi$ ) cyclic inconsistency of the multichannel interferometric phase inherent to independently filtered SAR interferograms. Note also that Eq. (14) represents, within our framework, the generalization (to a wider class of discrete settings) of the "phase triangularity" condition in ref. [44], capturing the underlying structure of the problem within a suitable matrix formalism. With reference to the $m$ th interferometric pair, the 
estimated absolute interferometric-phase gradient on the graph $\mathcal{G}_{\mathrm{B}}$ is then obtained by wrapping the discrete gradient of (wrapped) interferometric-phase field: $\mathbf{g}^{m}=W\left(\Pi_{\mathrm{B}} \widetilde{\Psi}^{m}\right)$. Thus, by stacking the so-obtained absolute phase gradient estimations, we get the $N \times M$ matrix $G=\left[\mathbf{g}^{1}, \mathbf{g}^{2}, \ldots, \mathbf{g}^{M}\right]$, where

$$
\boldsymbol{G}=W\left(\Pi_{\mathrm{B}} \tilde{\Psi}\right)
$$

Finally, by substituting Eq. (13) in Eq. (15), we obtain

$$
\boldsymbol{G}=W\left(\Pi_{\mathrm{B}} \tilde{\boldsymbol{\Psi}}\right)=W\left(\Pi_{\mathrm{B}} W\left(\left[\Pi_{\mathrm{A}} \boldsymbol{\Phi}\right]^{\mathrm{T}}+\boldsymbol{D}^{\mathrm{T}}\right)\right)
$$

From Eq. (16), by using Eq. (11b), we get

$$
\boldsymbol{G}=W\left(\Pi_{\mathrm{B}} \boldsymbol{\Phi}^{\mathrm{T}} \boldsymbol{\Pi}_{\mathrm{A}}^{\mathrm{T}}+\Pi_{\mathrm{B}} \boldsymbol{D}^{\mathrm{T}}+2 \pi \Pi_{\mathrm{B}} \boldsymbol{Z}\right)=W\left(\Pi_{\mathrm{B}} \boldsymbol{\Phi}^{\mathrm{T}} \boldsymbol{\Pi}_{\mathrm{A}}^{\mathrm{T}}+\Pi_{\mathrm{B}} \boldsymbol{D}^{\mathrm{T}}\right)
$$

where in the last equality we have noted that $\Pi_{\mathrm{B}} Z$ is also an integer matrix. It should be emphasized that, under the assumption $\boldsymbol{D}=\boldsymbol{o}$, the equality between Eqs. (10) and (17) holds only up to an integer matrix multiplied by $2 \pi$.

\subsection{The MCh-PhU problem as constrained optimization}

In this Section, the nonlinear inversion $\mathrm{MCh}-\mathrm{PhU}$ problem is reformulated as a (nonlinear) constrained optimization problem. According to the presented general formulation, we introduce in the following the MCh-PhU problem as the solution of the following matrix equation:

$$
\boldsymbol{\Pi}_{\mathrm{B}} \boldsymbol{\Phi}^{\mathrm{T}} \boldsymbol{\Pi}_{\mathrm{A}}^{\mathrm{T}}+\boldsymbol{\Pi}_{\mathrm{B}} \boldsymbol{D}^{\mathrm{T}}+2 \pi \boldsymbol{K}=\boldsymbol{G}
$$

where the columns of $G$ represent the interferometric-phase pseudo-gradients estimated from the observed phase, and $K$ is an (unknown) $N \times M$ integer matrix, whose columns represent the corresponding ( $2 \pi$-normalized) corrections to be added to the (wrapped) interferometricphase pseudo-gradients in order to recover the absolute interferometric-phase discrete gradients. It is worth noting that the term pseudo-gradient is used here to emphasize that the integration of the estimated gradient is path-dependent (non-conservative behavior); the term residues [1] is also typically used to connote the inconsistency of the estimated phase gradient. As a matter of fact, matrix equation (Eq. (18)) describes an ill-posed problem, in which the data 
$G$ generally do not constrain sufficiently the problem to get a unique solution. Additional suitable constraints and a priori assumption have, thus, to be introduced to solve the problem. First, for restoring the cyclic consistency (see Section 2.1) of the estimated pseudo-gradients pertinent to the graphs $\mathcal{G}_{\mathrm{B}}$ and $\mathcal{G}_{\mathrm{A}}$, two corresponding sets of (equality) constraints have to be enforced, respectively. More specifically, pre-multiplying both sides of Eq. (18) by $\Omega_{\mathrm{B}}^{\mathrm{T}}$ and taking into account Eq. (3), we obtain

$$
\boldsymbol{\Omega}_{\mathrm{B}}^{\mathrm{T}}(\boldsymbol{G}-2 \pi \boldsymbol{K})=\mathbf{0}
$$

Similarly, by premultiplying both sides of the transposed version of Eq. (18) by $\Omega_{\mathrm{A}}^{\mathrm{T}}$ and taking also into account Eq. (3), we obtain

$$
\boldsymbol{\Omega}_{\mathrm{A}}^{\mathrm{T}}\left(\boldsymbol{G}-\boldsymbol{\Pi}_{\mathrm{B}} \boldsymbol{D}^{\mathrm{T}}-2 \pi \boldsymbol{K}\right)^{\mathrm{T}}=\mathbf{0}
$$

Constraints stated by Eq. (19) imply that the columns of $G-2 \pi K$ must lie in the null-space of $\Omega_{\mathrm{B}}^{\mathrm{T}}$. Since the matrix $\Pi_{\mathrm{B}}$ represents a basis to span the null-space of $\Omega_{\mathrm{B}}^{\mathrm{T}}$ (see Eq. (3)), we may then write $G-2 \pi K=\Pi_{\mathrm{B}} X$, where $X$ is a new variable. Accordingly, the corrected pseudogradients stack $G-2 \pi K$ is enforced to be a stack of discrete gradients, which can thus be unambiguously integrated. Similarly, Eq. (20) implies $\left[G-\Pi_{\mathrm{B}} D^{\mathrm{T}}-2 \pi K\right]^{\mathrm{T}}=\Pi_{\mathrm{A}}$ Y. As a result, the two sets of constraints, stated by Eqs. (19) and (20), guarantee that the solution of the problem is effective in preserving the cyclic consistency (curl-free) property of the corrected gradients pertaining to the graphs $\mathcal{G}_{\mathrm{B}}$ and $\mathcal{G}_{\mathrm{A}}$, respectively. As a matter of fact, the solution of Eq. (18) cannot be determined by using the two sets of constraints (Eqs. (19) and (20)) only; thus, the inverse problem must be first regularized [45]. The minimum-norm methods search for a global solution that minimizes a generalized error-norm associated with an optimality criterion, so incorporating prior information about the behavior of the solution [1]. Accordingly, we resort to a regularization approach using $l_{1}$-norm minimization in weighted version, as a specific case of $l_{\mathrm{p}}$-norm general formulation. Formally, the $\mathrm{MCh}-\mathrm{PhU}$ problem may be then formulated as a constrained optimization problem for the field of integer corrections:

$$
\hat{\boldsymbol{K}}=\underset{\boldsymbol{K} \in \mathbf{Z}^{\mathrm{N} \times M}}{\arg \min }\|\boldsymbol{K}\|_{1, C}
$$

subject to

$$
\left\{\begin{array}{c}
\boldsymbol{\Omega}_{\mathrm{A}}^{\mathrm{T}} \boldsymbol{K}^{\mathrm{T}}=\boldsymbol{\Omega}_{\mathrm{A}}^{\mathrm{T}}\left[\boldsymbol{G}-\boldsymbol{\Pi}_{\mathrm{B}} \boldsymbol{D}^{\mathrm{T}}\right]^{\mathrm{T}}(2 \pi)^{-1} \\
\boldsymbol{\Omega}_{\mathrm{B}}^{\mathrm{T}} \boldsymbol{K}=\boldsymbol{\Omega}_{\mathrm{B}}^{\mathrm{T}} \boldsymbol{G}(2 \pi)^{-1}
\end{array}\right.
$$


wherein

$$
\|\boldsymbol{K}\|_{1, \boldsymbol{C}}=\sum_{m=1}^{M} \sum_{n=1}^{N} c_{n m}\left|k_{n m}\right|
$$

represents the weighted $l_{1}$-norm [46] of the matrix $K, C=\left[c_{n m}\right]_{N \times M}$ denotes a suitable weighting matrix, and $\mathbb{Z}$ indicates the field of integer numbers. As far as the existence of an integer solution for Eqs. (21) and (22) is concerned, it should be noted that the considerations at the end of Section 2.1 apply. Since the first matrix equation in Eq. (22) includes a generally not null (unwanted) term $\Omega_{\mathrm{A}}^{\mathrm{T}} \boldsymbol{D}$, its fulfillment deserves further discussion. Although the evaluation of $W\left(\Omega_{\mathrm{A}}^{\mathrm{T}} \boldsymbol{D}\right)$ can be obtained according to Eq. (14), however, a full estimation for $\boldsymbol{\Omega}_{\mathrm{A}}^{\mathrm{T}} \boldsymbol{D}$ is generally not a simple task. Further discussion is provided in Section 3. The solution of the optimization problem (Eqs. (21) and (22)) is also referred to as the minimum weighted discontinuity solution (in a weighted $l_{1}$-norm sense) $[1,23]$. As a matter of fact, finding the global minimum point of the problem stated by Eqs. (21) and (22) for an arbitrary pair of graphs is, in general, a difficult task. A suboptimal strategy aimed at solving Eqs. (21) and (22) consists in adopting a two-stage approach. This is, in particular, the solution strategy implemented through the extended minimum cost flow (EMCF) technique [26], in which the edge structure of each considered graph is usually defined via a Delaunay triangulation in the Euclidean plane, to take advantage from efficient solvers for minimum cost flow (MCF) problems [47, 49, 50]. We remark that the distinctive characteristic of the EMCF approach is the extensive use of the computationally efficient MCF method. Moreover, a dual-level parallel model for EMCF has also been proposed in refs. [35] and [36]. Moreover, different approaches toward full 3D phase unwrapping have recently been proposed in refs. [63] and [64].

\section{Noise-filtering of multichannel SAR interferograms}

In this Section, we review the basic concepts concerning the filtering of noise that corrupts a stack of multitemporal SAR interferograms. First, the noise-filtering operation for singlechannel multilook interferograms is discussed; subsequently, the general framework of the multichannel noise-filtering (MC-NF) approach, which is intimately connected with the problem of multichannel phase unwrapping, is described.

\subsection{Decorrelation noise in SAR interferograms}

In order to introduce the problem at hand, let us first consider one single-channel SAR interferogram obtained starting from two SAR (synthetic aperture radar) images, namely, $i_{1}$ and $i_{2}$, acquired (over the same scene on Earth) at two different times, namely, $t_{1}$ and $t_{2}$, respectively. The two SAR images can be represented via two complex-valued signals, say $i(x, r)$ and $i_{2}(x, r)$, with $x$ and $r$ denoting the two independent spatial variables (with respect 
to azimuth and range direction, respectively) in the radar geometry. The two complex signals can be expressed as follows $[29,51]$ :

$$
\begin{aligned}
& i_{1}(x, r)=\gamma_{1}(x, r) e^{-j \frac{4 \pi}{\lambda} r}+n_{1}(x, r) \\
& i_{2}(x, r)=\gamma_{2}(x, r) e^{-j \frac{4 \pi}{\lambda}(r+\delta r)}+n_{2}(x, r)
\end{aligned}
$$

where $\delta r$ is the sensor-to-target slant range difference at time $t_{2}$ with respect to time $t_{1}$, and $\gamma_{1}(x, r)$ and $\gamma_{2}(x, r)$ are the corresponding (complex-valued) reflectivity functions of the illuminated scene at time $t_{1}$ and $t_{2}$, respectively. Furthermore, the two additive (noise) contributions $n_{1}(x, r)$ and $n_{2}(x, r)$ describe random quantities that are included in Eq. (24). As a result of these noise terms and of the intrinsic random nature of the two images reflectivity functions, when the two SAR images are interfered to form a so-called interferogram, i.e., when their phase difference $\psi$ is extracted, the interferometric phase will be noisy. An important parameter influencing the quality of the retrieved interferometric phase is the (complex) crosscorrelation factor between the two involved SAR images, which is typically defined as

$$
\chi=\frac{E\left[i_{1} \cdot i_{2}^{*}\right]}{\sqrt{E\left[\left|i_{1}\right|^{2}\right] \cdot E\left[\left|i_{2}\right|^{2}\right]}}=\rho \mathrm{e}^{j \psi}
$$

where $\rho \in[0,1], \psi \in[-\pi, \pi)$, and the asterisk denotes the conjugate complex value. Noteworthy, the cross-correlation factor (Eq. (25)) is a complex-valued term that can be decomposed in terms of amplitude $\rho$ (i.e., $\rho=|\chi|$ ) and phase $\psi$. For interferometric SAR images, $\chi$ can be evaluated by performing spatial averaging (known as multilooking) operations on a statistically homogeneous area. Indeed, the symbol $E[]$ in Eq. (25), which is representative of the statistical expectation operation [52], can then be replaced by the spatial averaging operation. The amplitude factor $\rho$, which is known to as coherence, accounts for the similarity between the two SAR images, whereas $\psi$ is the multilook interferometric phase. A value for the coherence that approaches zero is representative of an uncorrelated scene, whereas coherence value that is close to unity corresponds to a noise-free interferogram.

There are several causes that are responsible for coherence decrease. As matter of fact, the cross-correlation factor in Eq. (25) depends on different noise sources, and it can be conveniently factorized as follows [51]:

$$
\chi=\chi_{\text {the }} \cdot \chi_{\text {tem }} \cdot \chi_{\text {spa }} \cdot \chi_{\text {dop }} \cdot \chi_{\text {mis }} \cdot \chi_{\mathrm{vol}} \cdot e^{j \psi}
$$


where

- $\chi_{\text {the }}$ is the contribution of the thermal noise.

- $\chi_{\text {temp }}$ accounts for the effects due to (temporal) changes in the complex-valued reflectivity function between the two passages of the radar sensor over the illuminated area. The socalled temporal decorrelation is very difficult to be statistically modeled being associated to complex modifications of the electromagnetic response of the scene: They can be induced by human activities and/or natural causes.

- $\chi_{\text {spa }}$ is the term that takes into account the fact that from one SAR image to another the same ground resolution cell is imaged from two slightly different looking angles. The change change of the looking angle, in turn, leads to a shift between the range spectra of the two SAR images, and accordingly, it causes decorrelation since the range spectra of the two interfering SAR images are only partly overlapped. It can be shown that range spectra shift depend on the perpendicular baseline of the considered SAR data pair, and there is a limit value for the perpendicular baseline (known to as critical baseline) for which the two range spectra are completely non overlapped (i.e., the images are definitely uncorrelated one another) $[29,51]$.

- The term $\chi_{\text {dop }}$ takes into account of the so-called Doppler decorrelation effects due to the fact that SAR azimuth spectra are centered on a specific frequency (Doppler Centroid). When two SAR images with considerably different Doppler Centroid values interfere, a decorrelation noise contribution arises from the imperfect overlapping of the two related azimuth spectra. Hence, in the case that the two azimuth spectra are not overlapped at all, we have $\chi_{\text {dop }}=0$.

- $\chi_{\text {mis }}$ accounts for possible misregistration between two SAR images.

- $\chi_{\mathrm{vol}}$ accounts for volumetric decorrelation effects [53].

The multilook operation, leading to the multilook phase $\psi$ in Eq. (25), reduces the level of noise corrupting interferograms, although this is paid in terms of a reduction of spatial resolution of interferograms. Multilook interferometric phase can be described by using a random quantity and, accordingly, it can be characterized via the knowledge of its probability density function. It has been shown in literature $[40,41,54]$ that the probability density function (pdf) of an $L$-multilook interferometric phase (with $L$ being the number of averaging samples in the averaging window used for the estimation of the statistical average operation involved in the calculation of Eq. (25)) can be given in terms of a Gauss hypergeometric function:

$$
p_{L}(\psi)=\frac{\Gamma\left(L+\frac{1}{2}\right)\left(1-\rho^{2}\right)^{L} \beta}{2 \sqrt{\pi} \Gamma(L)\left(1-\beta^{2}\right)^{L+\frac{1}{2}}}+\frac{\left(1-\rho^{2}\right)^{L}}{2 \pi}{ }_{2} F_{1}\left[L, 1 ; \frac{1}{2} ; \beta^{2}\right]
$$


where $\psi \in[-\pi, \pi), \beta=\rho \cos \left(\psi-\psi_{0}\right), \rho$ represents the coherence, ${ }_{2} F_{1}$ denotes the Gauss hypergeometric function, $\Gamma(\cdot)$ is the gamma function, and $\psi_{0}$ represents the expected "true" value of the interferometric phase. The peak of the distribution is located at $\psi=\psi_{0}$.

The pdf in Eq. (27) is sketched in Figure 2a for different values of $L$ and in Figure $2 b$ for different values of the $\rho$, with $\psi_{0}=0$. By observing Figure $2 \mathrm{a}$, it is clear that pdfs become narrower as the number of looks $L$ increases (as expected). This finding is extremely important because it demonstrates that the interferometric phase may be thought to be corrupted by an additive noise random signal, namely, $v$, that has the same pdf as in Eq. (27) but with a zero-mean expected value, i.e., we may assume as valid the following additive model for the interferometric noise [54]: $\psi=\psi_{0}+v$. To further investigate about the statistics of multilook interferograms, we can observe that the validity of Eq. (27) is only restricted to the $[-\pi, \pi)$ interval. However, this restriction does not apply when the phase signal is directly derived in the complex plane instead of the real plane. In the works of Lopez (2003) [55] and Lopez and Pottier (2007) [40], a comprehensive analytical derivation of the noise statistics in the complex plane is derived. Nonetheless, the Cramér-Rao bound for the standard deviation of multilook phase is given by [59]

$$
\sigma_{v}=\frac{1}{\sqrt{2 L}} \frac{\sqrt{1-\rho^{2}}}{\rho}
$$

that shows that standard deviation depends on the coherence $\rho$ and multilook factor $L$. Note that the phase standard deviation approaches the limit (Eq. (28)) asymptotically as the number of looks increases.

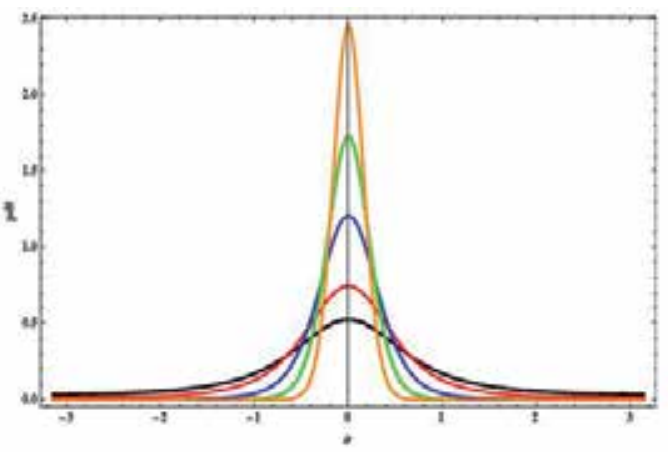

(a)

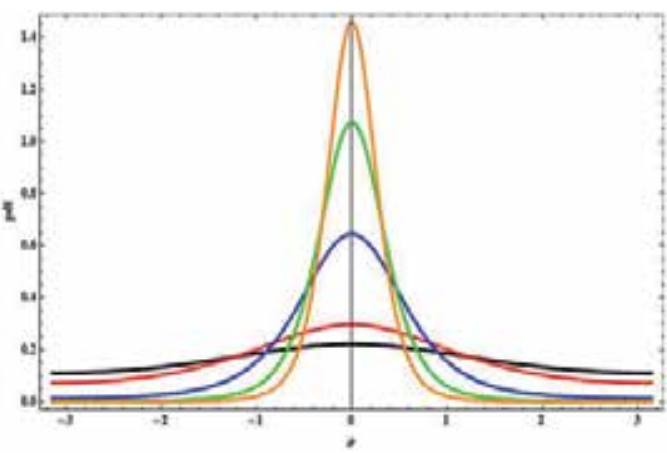

(b)

Figure 2. Probability density function of the interferometric phase $\psi$ [rad]: (a) for different values of the number of looks $L$ (1-black line, 2 -red line, 5 -blue line, 10-green line, 20-orange line), with $\rho=0.7$; (b) for different values of the correlation coefficient $\rho(0.1$-black line, 0.2 -red line, 0.5 -blue line, 0.7 -green line, 0.8 -orange line $)$ with $L=$ 4. 


\subsection{Single-channel noise-filtering approaches for multilook interferograms}

In order to mitigate the effects of decorrelation noise artifacts affecting SAR interferograms, several noise-filtering techniques, mostly working on single-channel data, have been proposed in literature over the years $[42,54,56,57]$. As shown in previous Section 3.1, the statistics of multilook interferograms can be characterized via a probability density function expressible in closed form (Eq. (27)), and the noise standard deviation generally depends upon the coherence $\rho$ and the number of looks $L$ [see also Eq. (28)]. Three different multilook interferograms, which are characterized by the same perpendicular baseline (of about $100 \mathrm{~m}$ ), have been obtained by using three SAR sensors working at the different $(C, X$, and $L)$ bands of the microwave region and are depicted in Figure 3. As it is evident from Figure 3, L-band interferograms are less affected by noise than the ones pertinent to $\mathrm{C}$ and/or $\mathrm{X}$-band.
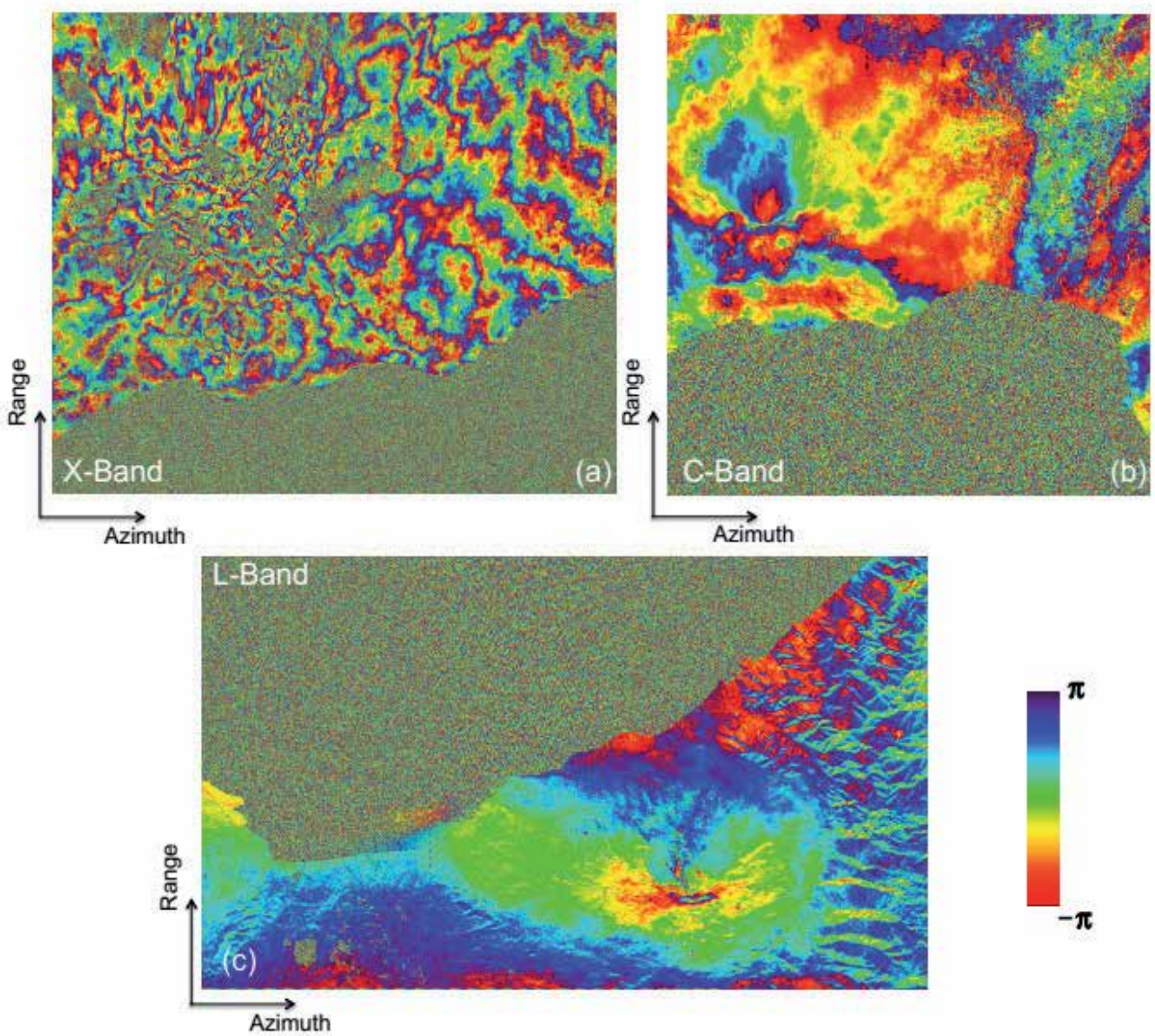

Figure 3. Multilook interferogram computed by using different SAR data pairs: (a) July 11, 2011-August 16, 2011, Xband Cosmo-SkyMed (CSK); (b) September 15, 2004-October 29, 2004, C-band ASAR/ENVISAT; (c) July 30, 2007-September 14, 2007, L-band ALOS/PALSAR-1. 
It should be emphasized that coherence and noise levels can also significantly change from one SAR system to another depending on the operational wavelength.Multilook processing has been proved to be effective for noise reduction, but this is paid in terms of a decrease of the image spatial resolution. Noise filtering constitutes a preliminary step before phase unwrapping. Indeed, the multilook operation usually involves an averaging on neighboring SAR pixels, hence reducing the spatial resolution of the interferograms. Several algorithms have been proposed in literature. The most commonly used noise filter is the boxcar filter applied in the complex plane. Another frequently used option is provided by the Golstein's frequency-domain algorithm [42], which is an empirical approach proposed for geophysical applications. In this case, a complex interferogram (amplitude and phase) is segmented into overlapping rectangular patches and for each patch the relevant power spectrum $Z$ is computed.

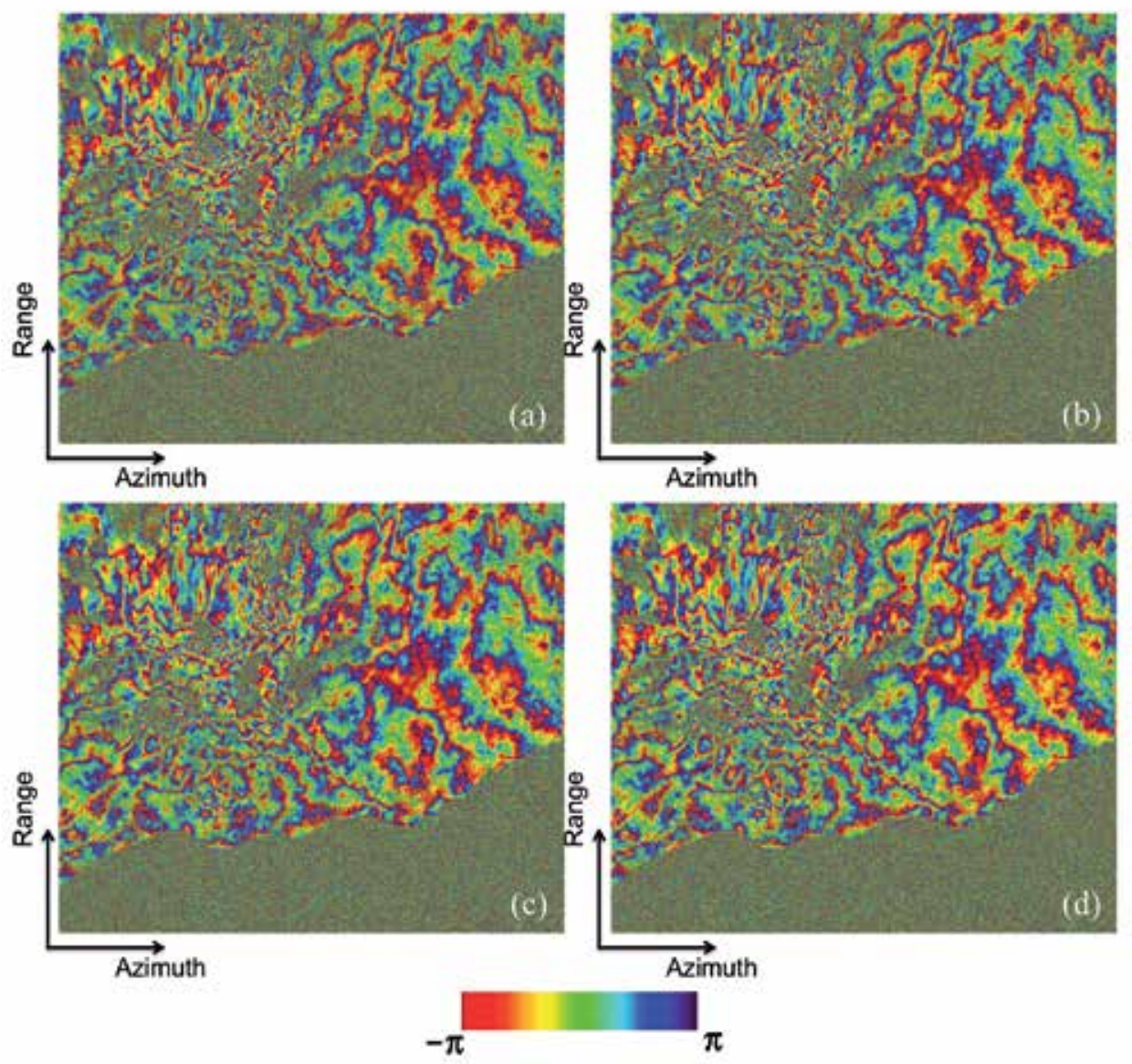

Figure 4. Multilook interferogram relevant to the SAR data pair July 11, 2011-August 16, 2011, X-band Cosmo-SkyMed (CSK): (a) Original, (b-d) Goldstein filtering, with (b) $\alpha=0.25$, (c) $\alpha=0.5$, and (d) $\alpha=1.0$. 
The response of the Golstein's filter is then computed from the power spectrum as follows:

$$
H(\xi, \eta)=|Z(\xi, \eta)|^{\alpha}
$$

where $\xi$ and $\eta$ denote the relevant spectral variables, respectively. Notice that the filtering effect vanishes when $\alpha=0$; conversely, the filtering effect is more pronounced as the parameter $\alpha$ approaches unity. We show in Figure 4 the result of the application of the Goldstein's filter to a multilook interferogram, relevant to the Mt. Etna (Italy) volcano, obtained by using the Cosmo-Skymed sensor of the Italian Space Agency (ASI). Specifically, different values of the filtering parameter $\alpha$ have been considered in Figure 4. The limited effectiveness of the filtering capabilities of Goldstein approach is evident from the result depicted in Figure 4. A modification of the Goldstein filter that relies on an adaptive choice of the filtering factor $\alpha$ (which depends on the spatial coherence $\rho$ ) has also (more recently) been proposed by Baran in 2003 [58]. Other filters, such as the median filter [59] and the two-dimensional Gaussian filter, are also used to reduce noise while performing multilooking operations. It is worth noting that boxcar and Goldstein filters do not adapt to the direction of the fringes because these filters are operated in a square window. In order to overcome such a limitation, Lee et al. 1998 [54] then proposed a self-adaptive filter based on local gradient slope estimation that is able to improve noise-filtering performance by exploiting directional characteristics of an InSAR interferogram. Several adaptations and relevant improvements of the Lee filter have subsequently proposed in literature over the recent years [56, 57], most of them based on the exploitation of the intrinsic directional behavior of InSAR interferograms. In fact, compared with the fringe phase and gradient, the fringe direction variation is gently, thus making it possible to use fringe direction to guide interferogram filtering.

\subsection{The multichannel noise-filtering (MCh-NF) algorithm}

The noise-filtering methods discussed in the previous Section have historically been developed to analyse and filter out the noise affecting single interferograms, separately, thus without taking into account their mutual temporal relationships. A multichannel noise-filtering problem arises when a stack of SAR interferograms need to be jointly exploited. In this case, it is profitable to develop/use noise-filtering approaches that not only exploit spatial/frequency information but can also take into account temporal relationships among available multichannel interferograms, in order to identify and filter out the noise affecting the whole interferometric data stack in the more reliable way as possible. A specific multichannel noise-filtering (MCh-NF) method [43], which is based on using a stack of time-redundant multilook interferograms, is described in this Section. The MCh-NF method is here described by adopting the same rigorous formalism and terminology used for the topological description of multichannel phase unwrapping problem presented in Section 2. According to the adopted symbolism, let us consider $Q$ SAR images and let $M$ be the number of multilook interferograms characterized by small perpendicular and temporal baselines. 
The resulting interferometric data stack of the $M$ (wrapped) small-baseline multilook inter-

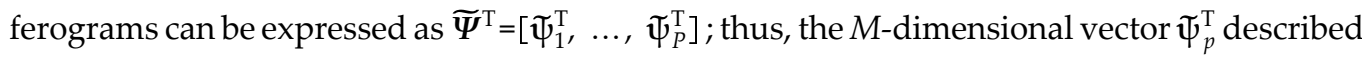
the (vectorized) multichannel interferometic-phase pertinent to the $p$ th pixel, with $p \in\{1, \ldots, P\}$ and $P$ denoting the number of coherent pixels common to all interferograms. In particular, $\widetilde{\Psi}$ can be expressed in terms of discrete gradient $\Pi_{\mathrm{A}^{\prime}}$ according to Eq. (13), as:

$$
\tilde{\Psi}^{\mathrm{T}}=W\left(\boldsymbol{\Pi}_{\mathrm{A}} \boldsymbol{\Phi}+\boldsymbol{D}\right)
$$

wherein $\Phi$ represents the (unknown) phases associated with the available SAR images, and the matrix $D$ describes the additive noise-term that corrupts the stack of interferograms. The noise term should be estimated and properly filter out from the generated interferograms. As discussed in Section 3.2, the term $\boldsymbol{D}$ arises since both a multilook operation and a noise-filtering procedure are typically applied to each single interferogram, separately. Both these operations are independently carried out on each single interferogram; hence, they are not necessarily time consistent. The fact that the interferograms are not fully time consistent can be formally expressed, according to Eq. (14), in terms of discrete curl $\Omega_{\mathrm{A}}^{\mathrm{T}}$, in the form:

$$
\mathrm{W}\left(\boldsymbol{\Omega}_{A}^{T} \tilde{\boldsymbol{\Psi}}^{T}\right)=W\left(\boldsymbol{\Omega}_{A}^{T} \boldsymbol{D}\right) \neq \mathbf{0}
$$

which represents the topological generalization of the phase-triangularity condition exploited by the SqueeSAR technique [44]. Therefore, the multichannel noise-filtering (MCh-NF) approach suitably addresses the temporal inconsistencies inherent in the time-redundant multilook interferograms, which can be mathematically described in terms of the (modulo- $2 \pi$ ) cyclic inconsistency of the multichannel interferometric phases [see Eq. (31)]. More specifically, MChNF is based on the solution of the a nonlinear optimization problem, as detailed in the following. First, $\forall p \in\{1, \ldots, P\}$, the $Q$-dimensional vector ( $Q$ is the number of SAR acquisitions) representing the (unknown) wrapped phases $\widetilde{\boldsymbol{\Phi}}^{p}=W\left(\boldsymbol{\Phi}^{p}\right)$ is estimated as follows:

$$
\hat{\tilde{\boldsymbol{\Phi}}}^{p}=\underset{\tilde{\boldsymbol{\Phi}}^{p} \in \mathrm{R}^{Q}}{\arg \max }\left|\bar{\zeta}_{p} \circ e^{j\left(\tilde{\boldsymbol{\Psi}}_{p}^{T}-W\left(\boldsymbol{I}_{\mathrm{A}} \tilde{\boldsymbol{\Phi}}^{p}\right)\right)}\right|
$$

where $j=\sqrt{-1}$ denotes the imaginary unit, $P$ denotes the number of coherent pixels to which the noise-filtering procedure is applied, the symbol represents the Hadamard product, and $\bar{\zeta}_{\mathrm{p}}=\left[\bar{\zeta}_{p}^{1}, \ldots, \bar{\zeta}_{p}^{M}\right]^{T}$ is an $M$-dimensional normalized weighting vector representing our confidence on the quality of the exploited $M$ (small-baseline) interferometric phases pertinent to the $p$ th pixel, with 


$$
\bar{\zeta}_{p}^{m}=\frac{\zeta_{p}^{m}}{\sum_{h=1}^{M} \zeta_{p}^{h}}
$$

wherein the generic elements $\zeta_{p}^{m}$ can be related to the spatial coherence as detailed after. Subsequently, these estimated vectors $\hat{\widetilde{\Phi}}_{\wedge}^{p}$ are used to reconstruct a new (noise-filtered) stack of time-consistent interferograms $\hat{\widetilde{\Psi}}^{\mathrm{T}}=\left[\hat{\boldsymbol{\Psi}}_{1}^{\mathrm{T}}, \ldots, \hat{\boldsymbol{\Psi}}_{P}^{\mathrm{T}}\right]$, where $\hat{\widetilde{\Psi}}_{p}^{\mathrm{T}}=W\left(\Pi_{\mathrm{A}} \hat{\widetilde{\Phi}}^{p}\right)$ and $p \in\{1, \ldots, P\}$. We emphasize that, according to Eq. (32), the MCh-NF technique is based on searching for the (unknown) wrapped-phase vector $\widetilde{\boldsymbol{\Phi}}^{p} \in \mathbb{R}^{Q}$ that minimizes the (weighted) circular variance of the random (phase) vector representative of the phase difference, $\widetilde{\boldsymbol{\Psi}}_{p}^{T}-W\left(\boldsymbol{\Pi}_{\mathrm{A}} \widetilde{\mathbf{\Phi}}^{p}\right)$, between the "original" and the "reconstructed" interferograms.

The evaluation of the weights for the optimization problem in Eq. (32) is now addressed. Let $\breve{\Theta}=\left[\breve{\Theta}_{i, j}\right]$ be a matrix description for a generic 2-D phase map, whose corresponding vectorized representation is provided by the $P$-dimensional vector $\Theta$. Each pixel of the phase map is identified by discrete range and azimuth coordinates, denoted by $i$ and $j$, respectively. Accordingly, each pair $(i, j)$ is uniquely associated with a monodimension index $p \in\{1, \ldots, P\}$ identifying an element of the vector $\boldsymbol{\Theta}$. The spatial coherence relevant to $\Theta$ (i.e., $\widetilde{\Theta}$ ) evaluated around the pixel $(i, j)$ (associated with the index $p$ ) is defined as

$$
\zeta_{p}(\Theta)=\frac{1}{\left(2 L_{R}+1\right)\left(2 L_{A}+1\right)}\left|\sum_{l=-L_{R}}^{L_{R}} \sum_{h=-L_{A}}^{L_{A}} \exp \left[j \breve{\Theta}_{i+l, j+h}\right]\right|
$$

where $2 L_{R}+1$ and $2 L_{A}+1$ are the number of azimuth and range pixels within the used boxcar averaging window, which is centred around the generic pixel identified by the discrete range and azimuth coordinates, $i$ and $j$, respectively. In particular, the $m$ th weight $\zeta_{p}^{m}$ is expressed, according to Eq. (34), in terms of spatial coherence relevant to the (vectorized) interferograms $\widetilde{\psi}^{m}$ and evaluated around the pixel associated with the index $p$, in the functional form $\zeta_{p}^{m}=\zeta_{p}\left(\Psi^{m}\right), \forall m \in\{1, \ldots, M\}$. Therefore, $\zeta_{p}=\left[\zeta_{p}^{1}, \ldots, \zeta_{p}^{M}\right]^{\mathrm{T}}$ can be evaluated in terms of the spatial coherence directly from the stack of $M$ multilook interferograms $\widetilde{\boldsymbol{\Psi}}=\left[\widetilde{\psi}^{1}, \ldots, \widetilde{\Psi}^{M}\right]$. As experimentally demonstrated in ref. [43], the "reconstructed" interferograms with MCh-NF are significantly less affected by noise than the original ones. However, a group of the reconstructed interferograms, although limited, can exhibit spatial coherence values smaller than the ones relevant to the corresponding original interferograms, thus implying that a partial corruption of the spatial coherence occurs during the minimization procedure. In particular, it happens in correspondence to interferograms that were originally significantly coherent, and this is due to the fact that the strategy in Eq. (32) tends to "inject" coherence from very coherent to incoherent interferograms, by exploiting the time redundancy of the small 
baseline data pairs. Accordingly, in order to also preserve the spatial coherence of the very coherent interferograms, a simple nonlinear combination between the original and the reconstructed interferograms is carried out, thus further increasing the phase quality of the whole set of $M$ reconstructed interferograms. In particular, the two sets of interferograms are combined through the following (wrapped) weighted averaging operation:

$$
\bar{\psi}^{m}=\arctan \left(\frac{\zeta^{m} \circ \sin \left(\tilde{\boldsymbol{\psi}}^{m}\right)+\hat{\zeta}^{m} \circ \sin \left(\hat{\tilde{\boldsymbol{\psi}}}^{m}\right)}{\zeta^{m} \circ \cos \left(\tilde{\boldsymbol{\psi}}^{m}\right)+\hat{\zeta}^{m} \circ \cos \left(\hat{\tilde{\boldsymbol{\psi}}}^{m}\right)}\right) \forall m \in\{1, \ldots, M\}
$$

where the symbol represents the Hadamard product, and $\zeta^{m}$ and $\hat{\zeta}^{m}$ are two $P$-dimensional vectors. In particular, $\zeta^{m}=\left[\zeta_{1}^{m}, \cdots, \zeta_{P}^{m}\right]^{\mathrm{T}}=\left[\zeta_{1}\left(\widetilde{\Psi}^{m}\right), \cdots, \zeta_{P}\left(\widetilde{\Psi}^{m}\right)\right]^{\mathrm{T}}$ is expressed in terms of the spatial coherence relevant ${ }_{n}$ to the original multilook interferogram $\tilde{\psi}^{m}$. Similarly, $\hat{\zeta}^{m}=\left[\hat{\zeta}_{1}^{m}, \cdots, \hat{\zeta}_{P}^{m}\right]^{\mathrm{T}}=\left[\zeta_{1}\left(\hat{\Psi}^{m}\right), \cdots, \zeta_{P}\left(\hat{\Psi}^{m}\right)\right]^{\mathrm{T}}$ is expressed in terms of the spatial coherence relevant to the reconstructed multilook interferogram $\widetilde{\psi}^{m}$. The block diagram of the MCh-NF algorithm is depicted in Figure 5. A pertinent pseudo-code for computing the filtered interferometric data stack is also presented (Figure 6).

Note that the exploitation of "conventional" small baseline multilook interferograms is the distinctive characteristic of MCh-NF approach with respect to other previous solutions, such as the SqueeSAR [44] and Phase Linking [62] methods and other recently proposed multitemporal-filtering techniques $[60,61]$ based on constraining the analysis to distributed scatterers [29], which are identified through a pixel-by-pixel selection procedure performed at the full resolution complex SAR image spatial grid. Such a selection permits to rely on the distributed scattering hypothesis, under which the probability density function (pdf) of the complex-valued SAR image may be regarded as being a zero-mean multivariate circular normal distribution, and an appropriate maximum likelihood (ML) estimation step of the filtered phase values associated to each SAR acquisition is implemented. On the contrary, the presented MCh-NF approach focuses on conventional multilook interferograms generated without any a priori pixel selection step. Accordingly, in this case, it is not possible to rely on the validity of the above-mentioned distributed scattering hypothesis. Therefore, both the phase linking [62] and the phase triangulation of the SqueeSAR [44] algorithms require a preliminary identification of the statistically homogeneous pixels (SHPs) on the full-resolution range-azimuth grid. In particular, in ref. [44], the selection strategy of these pixels is based on the application of the Kolmogorov-Smirnov test to carefully select a homogeneous statistical population. Clearly, this requires working at the full resolution spatial scale and implies the analysis of the amplitude values of the complex SAR image pixels. A more detailed comparison among the presented MCh-NF method and the ones provided in ref. [44] can be found in ref. [43]. 


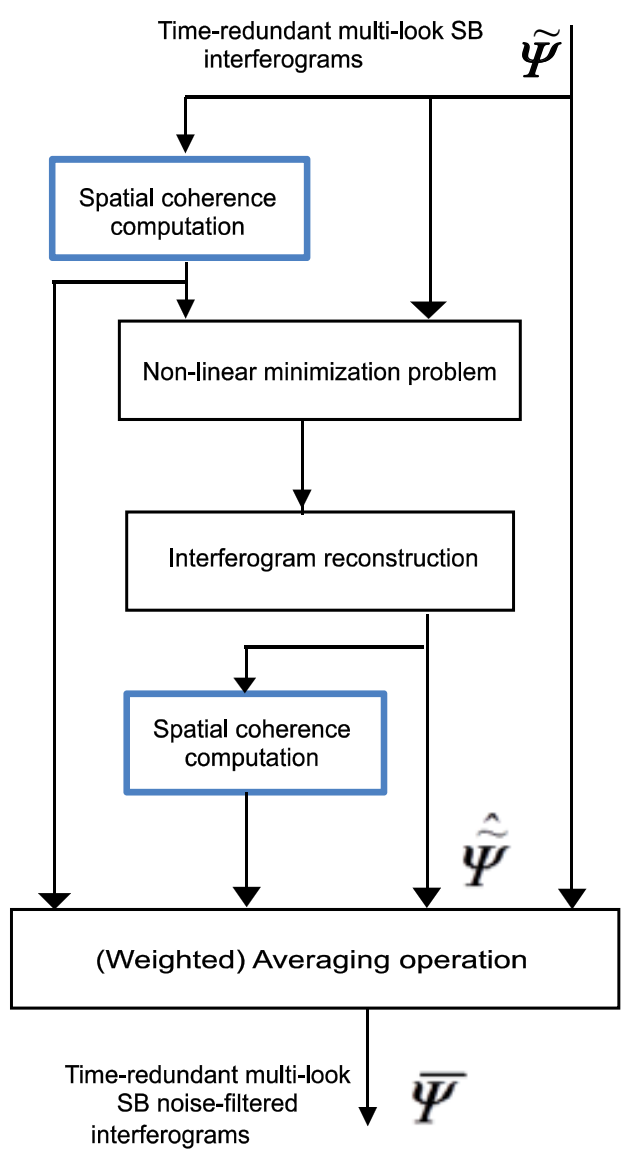

Figure 5. MCh-NF block diagram

\section{Experimental results}

We present in this section some results we obtained by processing a data set consisting of 39 SAR images (Track 308, Frame 2754), collected by the ENVISAT sensor between December 2002 and August 2010 over the Abruzzi region (Italy). The test-site area includes the city of L'Aquila and its surroundings, which were struck on 6 April 2009, by an Mw 6.3 earthquake that caused more than three hundred fatalities, thousands of evacuees, as well as severe industrial and residential building damages. Starting from the available SAR images, we retrieved a stack of 338 small baseline differential SAR interferograms with a maximum perpendicular baseline of $400 \mathrm{~m}$ and a maximum time span of 2000 days [43]. The interferograms have been computed by performing a complex multilook operation with 4 and 20 looks in the range and azimuth directions, respectively. For the interferogram generation, we used precise satellite orbit information and a three-arcsecond shuttle radar topography mission 
(SRTM) digital elevation model (DEM) of the region to remove the topographic phase contributions. Finally, the multilook interferograms have been prefiltered by applying the Goldstein's filter [42].

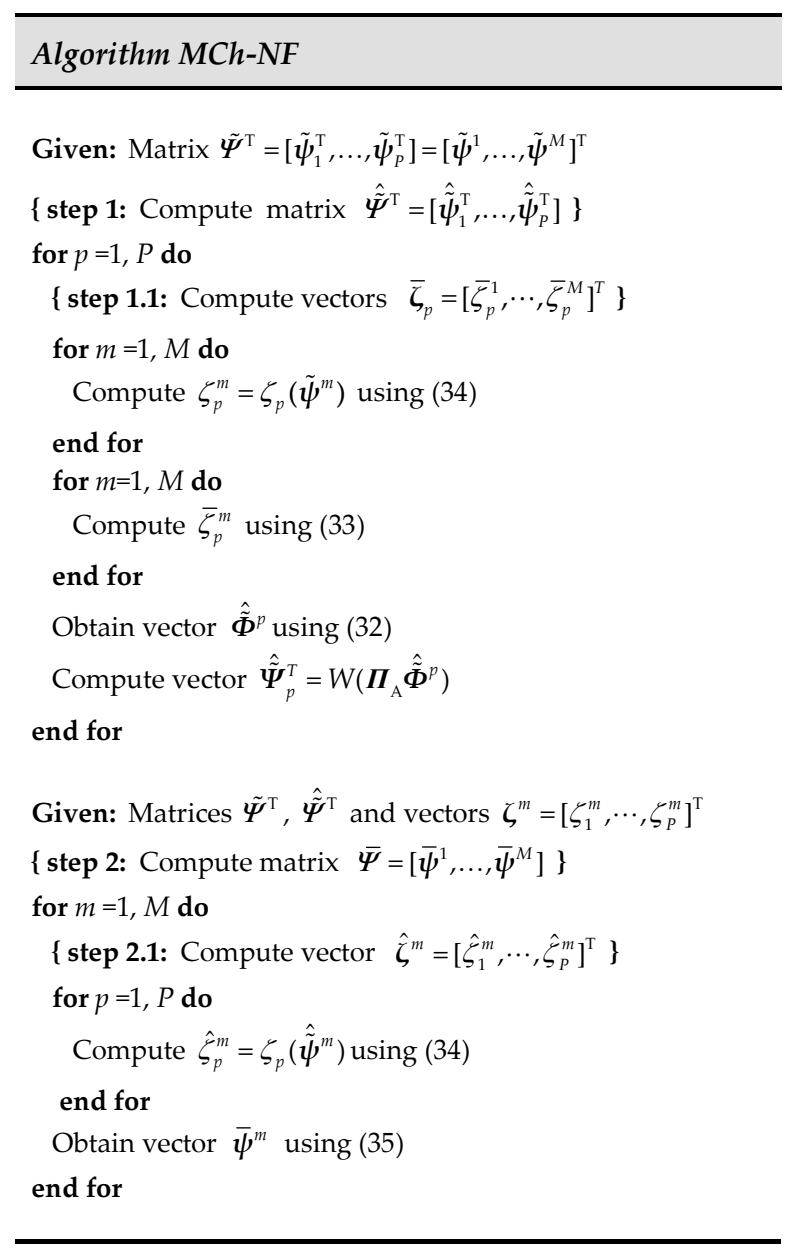

Figure 6. Pseudo code of the MCh-NF algorithm.

To investigate the performance of the presented noise-filtering approach, we applied the nonlinear minimization procedure in Eq. (32) to the stack of the generated (original) multilook small baseline interferograms. As a result, we retrieved a new set of noise-filtered interferograms that are characterized by generally improved coherence values. This is clearly visible in Figure 7a-f, where we compare three unfiltered (left side) interferograms with the corresponding (right side) noise-filtered interferograms. It is evident how the fringes due to the earthquake are well recovered. Such interferometric data stacks can then be used for the generation of surface deformation time series using the small baseline subset (SBAS) [6] 

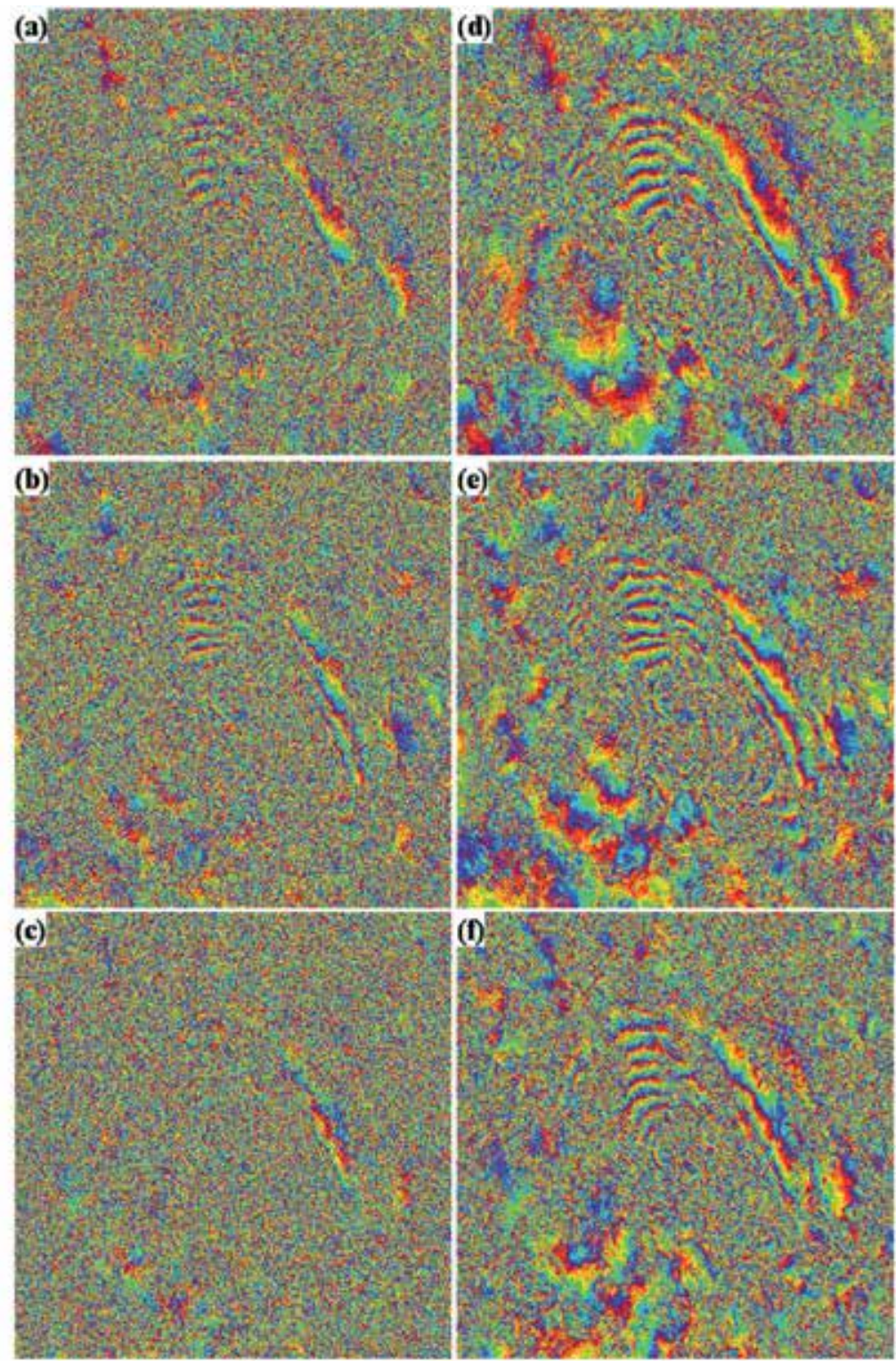

$-\pi$

$\pi$

Figure 7. Comparison between the original (left column) and noise-filtered (right column) multilook interferograms relevant to the area of the Abruzzi region (Italy). (a-c) October 30, 2005, to November 8, 2009, August 21, 2005, to June 6, 2010, and August 1, 2004, to April 12, 2009, interferograms, characterized by perpendicular baseline values of 192, 145 , and $395 \mathrm{~m}$, respectively. (d-f) Noise-filtered multilook interferograms corresponding to the ones in panels a-c, respectively.

processing chain, whose parallel version (P-SBAS) has been proposed in refs. [13, 14, 35, 36]. This is matter for the analysis presented in the next subsection. 


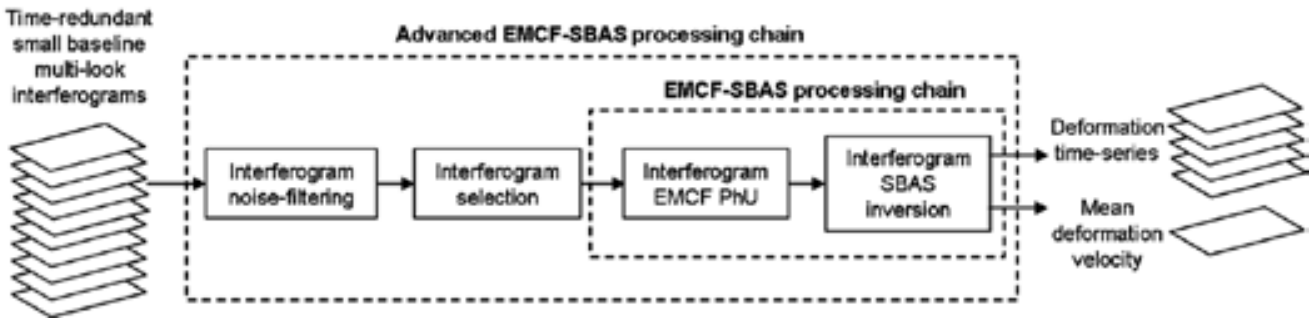

Figure 8. Block diagram of the advanced EMCF-SBAS processing chain.

\subsection{The use of MCh-NF algorithm within MCh-PhU framework}

We present in this subsection how the MCh-NF algorithm can be efficiently used within the SBAS processing chain, where phase unwrapping procedures are implemented through the $\mathrm{MCh}-\mathrm{PhU}$ technique known as extended minimum cost flow (EMCF), also discussed in the first part of the chapter. Figure 8 shows the diagram block of the advanced EMCF-based SBAS processing chain $[26,35,43]$, which integrates the conventional SBAS codes, exploiting the EMCF MCh-PhU procedure to perform phase unwrapping operations, with the presented MCh-NF noise-filtering technique. In addition, an effective procedure for the selection of timeredundant interferograms is also included; interested readers can find additional details in ref. [43]. To provide an example of the potential of the advanced processing chain incorporating both the discussed MCh-PhU and MC-NF techniques, we here focus on the area of Yellowstone caldera, representing one of the largest and most active volcanic systems in the world. We analyze the temporal evolution of the surface deformation occurring in this area by applying the implemented EMCF-SBAS processing chain to a set of 22 ENVISAT images (Track 41, Frame 2709), acquired from May 2005 to September 2010, from which we have retrieved a corresponding set of 122 small baseline interferograms [43]. As in the previous case study (relevant to Abruzzi area), the prescribed maximum values of $400 \mathrm{~m}$ and 2000 days for perpendicular and temporal baseline, respectively, have also been considered. The retrieved mean deformation velocity map depicted in Figure 9, which has been obtained by applying the processing chain (MCh-NF + EMCF-SBAS) of Figure 8, allows us to recognize the complex deformation scenario affecting the Yellowstone Caldera region and its surroundings, where uplift effects and broad subsidence patterns characterize the detected deformation field. In addition, the deformation time series relevant to four pixels, whose locations are identified by the black stars labeled as P1, P2, P3, and P4, are also illustrated in Figure 9.

\section{Conclusion}

Within the context of SAR interferometry, two main issues related to the multichannel phase unwrapping and noise filtering for interferometric data stacks processing have been addressed. First, a rigorous gradient-based formulation for the multichannel phase unwrapping (MCh-PhU) problem has been systematically established, thus providing a topological 


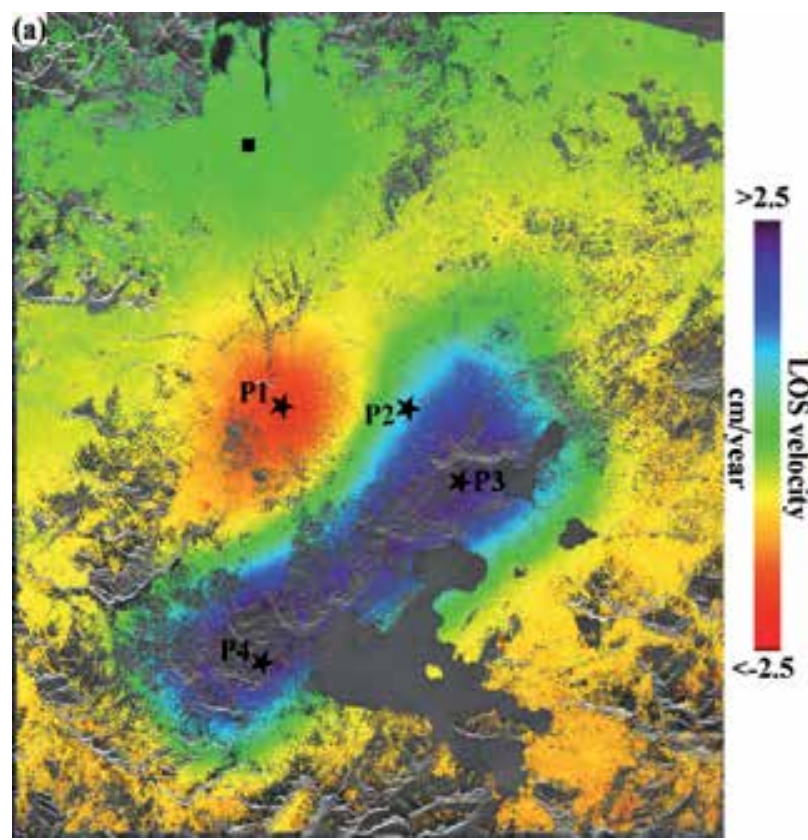

(b)

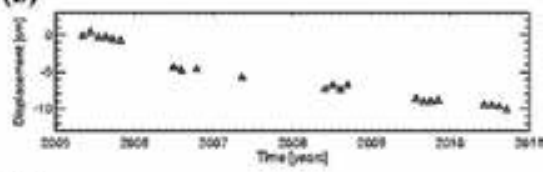

(c)

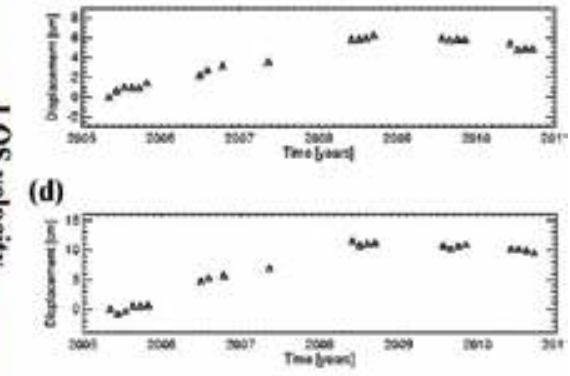

(e)

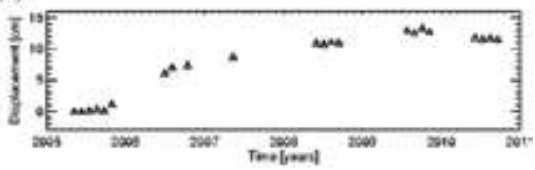

Figure 9. (a) Mean deformation velocity map (in color) of Yellowstone Caldera, computed in coherent pixels only and superimposed on the SAR amplitude image (gray-scale representation) of the zone, retrieved by applying the advanced EMCF-SBAS processing chain. The black square marks the location of the reference SAR pixel. (b-e) Deformation time series relevant to the four pixels identified via black stars in Fig. 8(a).

characterization of the problem within the purview of the theoretical foundation of the discrete calculus. Then the innovative MCh-NF procedure for the noise filtering of time-redundant multichannel multilook interferograms has been properly presented within the considered topological framework, by adopting a consistent formalism. Finally, some experimental results obtained with real data have been shown, thus demonstrating the effectiveness of our approaches and their relevance for geospatial phenomena analysis and understanding.

\section{Acknowledgements}

This work was supported by the Italian Ministry of University and Research (MIUR) under the project "Progetto Bandiera RITMARE." We would like to thank the European Space Agency for providing the ENVISAT ASAR data and the University of Delft, Delft, The Netherlands, for the related precise orbits. We would also like to thank Italian Space Agency (ASI), which has provided us the Cosmo-SkyMed SAR images under the framework of the European Union's Seventh Program for research, technological development, and demonstration MED-SUV project (grant no. 308665). Finally, the authors thank the Japanese Space Agency (JAXA), which has provided the used ALOS-1 data through the project entitled "Advanced Interferometric SAR Techniques for Earth Observation at L-band" (ID project 1149) in the framework of "The 4-th ALOS Research Announcement for ALOS-2" call. 


\section{Author details}

Pasquale Imperatore* and Antonio Pepe

*Address all correspondence to: imperatore.p@irea.cnr.it

Istituto per il Rilevamento Elettromagnetico dell'Ambiente (IREA), National Research Council (CNR) of Italy, Napoli, Italy

\section{References}

[1] D. C. Ghiglia, M. D. Pritt, Two-dimensional phase unwrapping: theory, algorithms and software, New York, John Wiley, 1998.

[2] Goldstein, and H.A. Zebker, "Mappings mall elevation changes over large areas: Differentia radar interferometry," J. Geophys. Res., vol.94, no.B7, pp. 9183-9191, 1989.

[3] D. Massonnet and K. L. Feigl, "Radar interferometry and its application to changes in the Earth's surface," Rev. Geophys., vol. 36, pp. 441-500, 1998.

[4] Bürgmann, P. A. Rosen, and E. J. Fielding, "Synthetic aperture radar interferometry to measure Earth's surface topography and its deformation," Annu. Rev. Earth Planet. Sci., vol. 28, pp. 169-209, May 2000.

[5] A. Ferretti, C. Prati, and F. Rocca, "Permanent scatterers in SAR interferometry," IEEE Trans. Geosci. Remote Sens., vol. 39, no. 1, pp. 8-20, Jan. 2001.

[6] P. Berardino, G. Fornaro, R. Lanari, and E. Sansosti, "A new algorithm for surface deformation monitoring based on small baseline differential SAR interferograms," IEEE Trans. Geosci. Remote Sens., vol.40, no.11, pp. 2375-2383, Nov.2002.

[7] A. Hooper, H. Zebker, P. Segall, and B. M. Kampes, “A new method for measuring deformation on volcanoes and other natural terrains using InSAR persistent scatterers," Geophys. Res. Lett., vol. 31, no. 23, p. L23 611, Dec. 2004, DOI: 10.1029/2004GL021737.

[8] M. Crosetto, B. Crippa, and E. Biescas, "Early detection and in-depth analysis of deformation phenomena by radar interferometry," Eng. Geol., vol. 79, no. 1/2, pp. 8191, Jun. 2005.

[9] B. M. Kampes, “Radar Interferometry: Persistent Scatterer Technique," Springer, 2006.

[10] A. Hooper and H. Zebker, "Phase unwrapping in three dimensions with applications to InSAR time series," J. Opt. Soc. Am. A, vol. 24, no. 9, pp. 2737-3747, Aug. 2007. 
[11] J. Hunstad, A. Pepe, S. Atzori, C. Tolomei, S. Salvi, and R. Lanari, "Surface deformation in the Abruzzi region, Central Italy, from multi-temporal DInSAR analysis," Geophys. J. Int., vol. 178, no. 3, pp. 1193-1197, Sep. 2009.

[12] S. Elefante, P. Imperatore, I. Zinno, M. Manunta, E. Mathot, F. Brito, J. Farres, W. Lengert, R. Lanari, F. Casu, "SBAS-DINSAR time series generation on cloud computing platforms," Proc. IEEE IGARSS 2013, pp. 274-277, Melbourne (AU), July 2013.

[13] P. Imperatore, et al., "Scalable performance analysis of the parallel SBAS-DINSAR algorithm," Proc. IEEE IGARSS 2014, pp. 350-353, Québec City, Canada, July 2014.

[14] F. Casu, S. Elefante, P. Imperatore, I. Zinno, M. Manunta, C. De Luca, R. Lanari, "SBAS-DInSAR parallel processing for deformation time series computation," IEEE J. Select. Topics Applied Earth Observ. Remote Sens., vol.7, no.8, pp. 3285-3296, Aug. 2014.

[15] R. Gens, "Two-dimensional phase unwrapping for radar interferometry: Developments and new challenges," Int. J. Remote Sens., vol.24, N.4, pp. 703-710, 2003.

[16] C. W. Chen and H. A. Zebker, "Phase unwrapping for large SAR interferograms: statistical segmentation and generalized network models," IEEE Trans. Geosci. Remote Sens., vol. 40, No. 8, pp-1709- 1719, Aug. 2002.

[17] M. Costantini, "A novel phase unwrapping method based on network programming," IEEE Trans. Geosci. Remote Sens., vol. 36, pp. 813-821, May 1998.

[18] C. W. Chen and H. A. Zebker, "Network approaches to two-dimensional phase unwrapping: intractability and two new algorithms," J. Opt. Soc. Am., vol.17, no. 3, pp. 401-414, Mar. 2000.

[19] K. Zhang, L. Ge, Z. Hu, A. Hay-Man Ng, X. Li, and C. Rizos, "Phase unwrapping for very large interferometric data sets," IEEE Trans. Geosci. Remote Sens., vol. 49, No. 10, pp. 4048-4061, Oct. 2011.

[20] W. Xu and I. Cumming, "A region-growing algorithm for InSAR phase unwrapping," IEEE Trans. Geosci. Remote Sens., 37, pp. 124-134. 1999.

[21] G. F. Carballo and P. W. Fieguth, "Hierarchical network flow phase unwrapping," IEEE Trans. Geosci. Remote Sens., vol. 40, No. 8, pp. 1695-1708, Aug. 2002.

[22] G. Fornaro, A. Pauciullo,D. Reale, "A null-space method for the phase unwrapping of multitemporal SAR interferometric stacks," IEEE Trans. Geosci. Remote Sens., vol. 49, no.6, pp. 2323-2334, June 2011.

[23] T. J. Flynn, "Two-dimensional phase unwrapping with minimum weighted discontinuity," J. Opt. Soc. Am. A, 14(10), pp. 2692-2701. 1997.

[24] O. Mora, J. J. Mallorquí, and A. Broquetas, "Linear and nonlinear terrain deformation maps from a reduced set of interferometric SAR images," IEEE Trans. Geosci. Remote Sens., vol. 41, no. 10, pp. 2243-2253, Oct. 2003. 
[25] S. Usai, "A least squares database approach for SAR interferometric data," IEEE Trans. Geosci. Remote Sens., vol. 41, no 4, pp. 753-760, April 2003.

[26] A. Pepe, and R. Lanari, "On the extension of the minimum cost flow algorithm for phase unwrapping of multitemporal differential SAR interferograms," IEEE Trans. Geosci. Remote Sens., vol. 44, no. 9, pp. 2374-2383, Sept. 2006.

[27] A. P. Shanker and H. Zebker, "Edgelist phase unwrapping algorithm for time series InSAR analysis," J. Opt. Soc. Am. A, vol. 27, no. 3, pp. 605-612, Mar. 2010.

[28] M. Costantini, S. Falco, F. Malvarosa, F. Minati, F. Trillo, and F. Vecchioli, “A general formulation for robust integration of finite differences and phase unwrapping on sparse multidimensional domains," in Proc. Fringe, Frascati, Italy, Dec. 2009.

[29] R. Bamler, P.Hartl, "Synthetic aperture radar interferometry," Inverse Problems, vol. 14, no.4, R1, 1998.

[30] L. J. Grady, J. Polimeni, Discrete Calculus: Applied Analysis on Graphs for Computational Science, Springer, 2010.

[31] N. Biggs, Algebraic Graph Theory. Cambridge University Press, Cambridge, UK, 1994.

[32] C. Berge, Graphs and Hypergraphs. North-Holland Publishing Co., Amsterdam, 1973.

[33] R. Diestel, Graph Theory, Springer-Verlag, New-York, 2000.

[34] L. Grady, "Minimal surfaces extend shortest path segmentation methods to 3D," IEEE Trans Pattern Anal. Mach. Intell., vol. 2, no. 32, pp. 321-334, 2010.

[35] P. Imperatore, A. Pepe, R. Lanari, "Multichannel phase unwrapping: problem topology and dual-level parallel computational model," IEEE Trans. Geosci. Remote Sens., vol. 53, no.10, pp. 5774-5793, October 2015.

[36] P. Imperatore, A. Pepe, R. Lanari, "High-performance parallel computation of the multichannel phase unwrapping problem," Proceedings of the IEEE International Geoscience and Remote Sensing Symposium, IGARSS 2015, Milan, Italy, July 2015.

[37] P. A. Rosen, S. Hensley, I. R. Joughin, F. K. Li, S. R. Madsen, E. Rodriguez, and R. M. Goldstein, "Aperture radar interferometry," Proc. IEEE, vol. 88, 3,pp. 333-381, 2000.

[38] H. A. Zebker and J. Villasenor, "Decorrelation in interferometric radar echoes," IEEE Trans. Geosci. Remote Sens., vol. 30, pp. 950-959, Sept. 1992.

[39] C. H. Gierull, "Statistical analysis of multilook SAR interferograms for CFAR detection of ground moving targets," IEEE Trans. Geosci. Remote Sens., vol. 42, n. 4, April 2004. 
[40] C. Lopez-Martinez and E. Pottier, "On the extension of multidimensional speckle noise model from single-look to multilook SAR image, "IEEE Trans. Geosci. Remote Sens., vol. 45, n. 2, February 2007.

[41] Lee, J. S. K. W. Hopple, S. A. Mango and R. Miller: "Intensity and phase statistics of multilook polarimetric interferometric SAR imagery," IEEE Trans. Geosci. Remote Sens., 32(5), 1017-1028, 1994.

[42] R. M. Goldstein, and C. L. Werner, "Radar interferogram filtering for geophysical applications," Geophys. Res. Lett., vol. 25, pp. 4035-4038, 1998.

[43] A. Pepe, Y. Yang, M. Manzo, R. Lanari, "Improved EMCF-SBAS processing chain based on advanced techniques for the noise-filtering and selection of small baseline multi-look DInSAR interferograms," IEEE Trans. Geosci. Remote Sens., vol. 53, no. 8, pp. 4394-4417, Aug. 2015.

[44] A. Ferretti, A. Fumagalli, F. Novali, C. Prati, F. Rocca, and A. Rucci, "A new algorithm for processing interferometric data-stacks: SqueeSAR," IEEE Trans. Geosci. Remote Sens., vol. 49, pp. 3460-3470, Sept. 2011.

[45] S. S. Rao, Engineering Optimization: Theory and Practice, Fourth Edition, John Wiley \& Sons, Inc, 2009.

[46] K. Yosida, Functional Analysis, Berlin, Germany: Springer-Verlag, 1980.

[47] D. Bertsekas, P. Tseng, "The relax codes for linear minimum cost network flow problems," Ann. Oper. Res., V. 13, 1988.

[48] M. Costantini, P.A. Rosen, "A generalized phase unwrapping approach for sparse data," Proc. IGARSS99, pp. 267-269, Hamburg (Germany), 1999.

[49] R.K. Ahuja, T.J. Magnanti, J.B. Orlin, Network Flows: Theory, Algorithms, and Applications, Prentice Hall, Ney Jersey, 1993.

[50] D. Bertsekas and P. Tseng. RELAX-IV: a faster version of the RELAX code for solving minimum cost flow problems. Technical report. Department of Electrical Engineering and Computer Science, MIT, Cambridge, MA, 1994.

[51] G. Franceschetti and R. Lanari, Synthetic Aperture Radar Processing Boca Raton, FL: CRC, Mar. 1999.

[52] H. Stark and J. W. Woods, Probability and Random Processes with Applications to Signal Processing, 3rd edition, Pearson, 2012.

[53] C. Elachi, "Spaceborne radar remote sensing: applications and techniques. Institute of Electrical and Electronics Engineers, 1998.

[54] Jong-Sen Lee, Konstantinos P. Papathanassiou, Thomas L. Ainsworth, Mitchell R. Grunes, and Andreas Reigber, "A new technique for noise filtering of SAR interfero- 
metric phase images," IEEE Trans. Geosci. Remote Sens., vol. 36, no. 5, pp. 14561465, Sep. 1998.

[55] C. López-Martínez and X. Fàbregas, "Polarimetric SAR speckle noise model," IEEE Trans. Geosci. Remote Sens., vol. 41, no. 10, pp. 2232-2242, Oct. 2003.

[56] Sihua Fu, Xuejun Long, Xia Yang, and Qifeng Yu, "Directionally adaptive filter for synthetic aperture radar interferometric phase images," IEEE Trans. Geosci. Remote Sens., vol. 51, no. 1,Jan 2013.

[57] Qingsong Wang, Haifeng Huang, Anxi Yu, and Zhen Dong, "An efficient and adaptive approach for noise filtering of SAR interferometric phase images," IEEE Trans. Geosci. Remote Sens. Lett., vol. 8, no. 6, Nov 2011.

[58] I. Baran, M. P. Stewart, B. M. Kampes, Z. Perski, and P. Lilly, "A modification to the Goldstein radar interferogram filter," IEEE Trans. Geosci. Remote Sens., vol. 41, no. 9, Sept. 2003.

[59] E. Rodriguez, J. M. Martin, “Theory and design of interferometric synthetic aperture radars," IEE Proceedings F Radar and Signal Processing, vol.139, no.2, pp. 147-159, Apr 1992.

[60] A. Parizzi, and R. Brcic, "Adaptive InSAR stack multilooking exploiting amplitude statistics: a comparison between different techniques and practical results," IEEE Trans. Geosci. Remote Sens. Lett., 8, pp. 441-445, May 2011.

[61] G. Fornaro, D. Reale and S. Verde, "Adaptive spatial multilooking and temporal multilinking in SBAS interferometry," Proceedings of the IEEE International Geoscience and Remote Sensing Symposium (IGARSS), Munich (Germany), July 2012.

[62] A. Parizzi and R. Brcic, "Adaptive InSAR stack multi-looking exploiting amplitude statistics: a comparison between different techniques and practical results," IEEE Trans. Geosci. Remote Sens. Lett., vol. 8, no. 3, pp. 441-445, May 2011.

[63] A. P. Shanker and H. Zebker, "Edgelist phase unwrapping algorithm for time series InSAR analysis," J. Opt. Soc. Am. A, Opt. Image Sci. Vis., vol. 27, no. 3, pp. 605-612, Mar. 2010.

[64] M. Costantini, S. Falco, F. Malvarosa, F. Minati, F. Trillo, and F. Vecchioli, “A general formulation for robust integration of finite differences and phase unwrapping on sparse multidimensional domains," in Proc. Fringe, Frascati, Italy, Dec. 2009. 

Chapter 13

\title{
Processing of Multichannel Remote-Sensing Images with Prediction of Performance Parameters
}

\author{
Benoit Vozel, Oleksiy Rubel, Alexander Zemliachenko, Sergey Abramov, \\ Sergey Krivenko, Ruslan Kozhemiakin, Vladimir Lukin and Kacem Chehdi \\ Additional information is available at the end of the chapter
}

http://dx.doi.org/10.5772/61853

\begin{abstract}
In processing of multichannel remote sensing data, there is a need in automation of basic operations as filtering and compression. Automation presumes undertaking a decision on expedience of image filtering. Automation also deals with obtaining of information based on which certain decisions can be undertaken or parameters of processing algorithms can be chosen. For the considered operations of denoising and lossy compression, it is shown that their basic performance characteristics can be quite easily predicted based on easily calculated local statistics in discrete cosine transform (DCT) domain. The described methodology of prediction is shown to be general and applicable to different types of noise under condition that its basic characteristics are known in advance or pre-estimated accurately.
\end{abstract}

Keywords: Multichannel remote sensing data, automatic processing, denoising, lossy compression, performance prediction, DCT

\section{Introduction}

Remote-sensing (RS) data are widely used for numerous applications [1], [2]. Primary RS images acquired onboard of airborne or spaceborne carriers and intended for Earth surface monitoring are usually not ready for direct use and, thus, are subject to a certain preprocessing. This preprocessing can be carried out in several stages and includes the following operations: geo-referencing and calibration, blind estimation of noise/distortion characteristics, prefiltering, lossless or lossy compression, [1], [2], etc. These operations can be distributed between onboard and on-land computer means (processors) in different ways depending upon many factors [3-5]. 
Regardless of the distribution of functions, the operations onboard are usually performed in a fully automatic manner (although there can be some changes in algorithm parameters by command passed from Earth). In turn, the operations carried out on land can be, in general, performed in an interactive manner and labor of highly qualified experts is exploited for this purpose. However, a certain degree of automation of on-land data processing is required as well. The need in processing automation is especially high if one deals with multichannel (e.g., hyperspectral) RS data [6], where the number of channels (components, sub-bands) can reach hundreds. Such RS images have become popular and widespread (available) currently due to their (potential) ability to provide rich information for various applications [6], [7].

Meanwhile, the multichannel nature of RS data results in new problems in their processing [3], [8]. The main problems and actual questions are the following:

- How to manage large volumes of acquired data with maximal or appropriate efficiency (here, different criteria of efficiency can be used)?

- Is it possible to skip some operations of data processing if their efficiency is not high and, consequently, if it is not worth performing them?

The latter question can be mainly addressed as mentioned below. It is strictly connected with other questions as follows:

- Is it possible to predict the performance of some standard operations of RS data (image) processing?

- What is the accuracy of such a prediction and is this accuracy high enough to undertake a decision to skip carrying out an operation or to set a certain value of some parameter used in the image-processing chain [9]?

This chapter will focus on two typical operations of multichannel RS data processing, namely, filtering and lossy compression. While considering them, the fact that the acquired images are noisy is taken into account. One can argue that noise is not seen in many RS images (or components of these images). This is true, and noise cannot be observed in approximately $80 \%$ of the visualized sub-band images of hyperspectral data. This is explained by the peculiarities of human vision, which does not see noise if peak signal-to-noise ratio (PSNR) in a given singlechannel (component) image exceeds 32-38 dB. However, recent studies [7], [10-12] have demonstrated that noise is present in all sub-band images and this is due to the principle of operation of hyperspectral imagers.

Moreover, it has been shown in [10], [11] that noise is (can be) of quite a complex nature and the noise acquired in multichannel RS images has specific properties. First, it is signaldependent [10], [11], [13]. Second, it is of essentially a different intensity (see Abramov et al., 2015 in [14]). More precisely, the wide variation of dynamic range and noise intensity in subband images jointly leads to wide limits of signal-to-noise ratio (SNR) in components of multichannel images. This has led to the use of the term "junk bands" [15] and different strategies of coping with noisy channels in multichannel data. Some researchers prefer to use these sub-bands in further processing while others propose to remove them; it is also discussed whether they can be filtered or not [15]. It has been shown that if filtering of these junk bands 
is efficient, this can improve the classification of hyperspectral data [16]. However, the aforementioned questions concern the efficiency of image preprocessing and its prediction.

The questions raised can be partly answered with the results obtained in recent research. The objective is to show that important performance parameters of image denoising and/or lossy compression can be quickly and quite accurately predicted using simple input parameter(s) and dependences obtained in advance. The obtained results are divided into two parts. The first part deals with the prediction of filtering efficiency. This research has started in 2013 [17] and has its history in a study conducted in [18]. The second part relates to the compression of noisy images [19], [20]. In fact, the results obtained for predicting the parameters of lossy compression can be treated as based on the same principle as that for image filtering and for further research.

Before taking the image performance criteria and preprocessing techniques into consideration, it is important to note the following: first, there are two hypotheses. It is supposed that noise type is known or determined in advance. It is also assumed that its parameters are either known or accurately pre-estimated. It is to be noted that, currently, there are quite a few efficient methods for estimating the parameters of pure additive noise [8], [21-25], speckle noise [26], and different types of signal-dependent noise [10-12], [27], [28]. The noise parameters are taken into account by the most modern filtering techniques that belong to the families of orthogonaltransform-based filters [29-33] and nonlocal filters, for example, block-matching and threedimensional filtering (BM3D) [34]. The same relates to modern methods of lossy compression of noisy images [19], [35].

Second, we restrict ourselves to consider the image- filtering and compression techniques based on discrete cosine transform (DCT). This is explained using several reasons. DCT is a powerful orthogonal transform widely exploited in image processing. Filters and compression techniques based on DCT are currently among the best [34]. They can be quite easily adapted to the signal-dependent noise directly [32], [36] or equipped with proper variance-stabilizing transformations (VST) [19], [32], [37]. This restriction does not mean that the approach to prediction cannot be applied to other filtering and lossy compression techniques. This approach should be applicable (with certain modifications) but is yet to be thoroughly checked.

Third, in the analysis of the prediction approach, traditional quality metrics are employed such as mean square error (MSE) and peak signal-to-noise ratio (PSNR), as well as some visual quality metrics such as PSNR human visual system masking metric (PSNR-HVS-M) [38]. Behavior and properties of traditional metrics are understood well by those dealing with image processing. Although PSNR-HVS-M is less popular, this is one of the best metrics that takes into account the peculiarities of human visual system (HVS) and that can be calculated for either one component of a multichannel image or a group of components of a multichannel image. It is expressed in $\mathrm{dB}$, and it is usually either slightly smaller than PSNR (for annoying types of distortions like spatially correlated noise) or larger than PSNR (if distortions are masked by texture). This is important since we assume that the processing of multichannel images is carried out either component-wise or in groups of channel images, where a group includes the entire image in marginal case. 
Fourth, other criteria of image-processing efficiency, such as classification accuracy, object detectability, etc., are important for the preprocessed RS data. We are unable to predict them, but recent research shows [39] that these criteria are connected with the traditional criteria of image processing. Thus, it is expected that if good values of conventional and HVS metrics are provided due to preprocessing, appropriate classification accuracy and other criteria will be attained.

\section{The considered image-performance criteria and preprocessing techniques}

This chapter considers the following model of an observed multichannel image:

$$
I_{k i j}^{\text {noisy }}=I_{k i j}^{\text {true }}+n_{k i j}\left(I_{k i j}^{\text {true }}\right), i=1, \ldots, I, j=1, \ldots, J, k=1, \ldots, K
$$

where $I_{k i j}^{\text {noisy }}$ is $i j$-th sample of noisy (original) $k$-th component of a multichannel image, $n_{k} i j$ denotes the $i j$-th value of the noise in $k$-th component statistic, which is, in general, supposed to be dependent on the true image value $I_{k i j}^{\text {true }}$ in this voxel (3D pixel), $I$ and $J$ define the image size, and $K$ denotes the number of channels. It is also assumed that the images $\left\{I_{k i j}^{\text {true }}\right\}$ and $\left\{I_{k+1}^{\text {true }}{ }_{i j}\right\}$ are strongly correlated and they have similar dynamic ranges $D_{k}$ and $D_{k+1}$ determined as $D_{k}=I_{k}^{\max }-I_{k}^{\min }$, where $I_{k}^{\max }$ and $I_{k}^{\min }$ are maximal and minimal values in $k$-th channel image, respectively. It is also possible to assume that noise is of the same type and neighbor channels have quite close values of input MSEs (equal to noise variance $\sigma_{k}^{2}$ if the noise is pure additive) as follows:

$$
M S E_{k}^{\mathrm{inp}}=\sum_{i=1}^{I} \sum_{j=1}^{J}\left(I_{k i j}^{\mathrm{noise}}-I_{k i j}^{\mathrm{true}}\right)^{2} /(I J), k=1, \ldots, K
$$

and input PSNR

$$
\operatorname{PSNR}_{k}^{\mathrm{inp}}=10 \log _{10}\left(D_{k}^{2} / M S E_{k}^{\mathrm{inp}}\right), k=1, \ldots, K
$$

The same assumptions are valid for input $P S N R-H V S-M_{k}^{\text {inp }}$ determined similarly to expression (3) with the difference that $M S E_{k}^{\text {inp }}$ is replaced by $M S E_{H V S ~}^{\text {inp }}$, which is a special kind of weighted MSE calculated in spectral (DCT) domain considering the masking effects [38]. The aforementioned assumptions are valid for color red, green, blue (RGB) images [27], multispectral and hyperspectral RS images [14], [40], dual polarization, and multifrequency radar 
images [2]. These properties can be effectively exploited in multichannel image preprocessing [39].

After applying a considered filter, one obtains a filtered image $\left\{I_{k i j}^{f}\right\}, \quad i=1, \ldots, I, j=1, \ldots, J, k=1, \ldots, K \quad$ that is supposed to be closer to $\left\{I_{k i j}^{\text {true }}\right\}, i=1, \ldots, I, j=1, \ldots, J, k=1, \ldots, K$ according to a chosen metric (a quantitative criterion). These output metrics are calculated as

$$
\begin{aligned}
& M S E_{k}^{\text {out }}=\sum_{i=1}^{I} \sum_{j=1}^{J}\left(I_{k i j}^{f}-I_{k i j}^{\text {true }}\right)^{2} /(I J), k=1, \ldots, K, \\
& P S N R_{k}^{\text {inp }}=10 \log _{10}\left(D_{k}^{2} / M S E_{k}^{\text {out }}\right), k=1, \ldots, K .
\end{aligned}
$$

Output PSNR - HVS $-M_{k}^{\text {out }}$ is determined similarly to (5).

Then, one has to characterize the efficiency of filtering. One way to do this is to use

$$
\begin{gathered}
\kappa=M S E_{k}^{\text {out }} / M S E_{k}^{\text {inp }}, \\
I P S N R_{k}=P S N R_{k}^{\text {out }}-P S N R_{k}^{\text {inp }}, \\
I P H V S M_{k}=P S N R-H V S-M_{k}^{\text {out }}-P S N R-H V S-M_{k}^{\text {inp }} .
\end{gathered}
$$

Small values of the ratio in expression (6) and large values of expressions (7) and (8), both expressed in $\mathrm{dB}$, are evidence in favor of efficient filtering.

Similarly, after lossy compression, one obtains $\left\{I_{k i j}^{c}\right\}, i=1, \ldots, I, j=1, \ldots, J, k=1, \ldots, K$. It is usually supposed that for a larger compression ratio (CR), the quality of compressed image is worse. This is true for lossy compression of noise-free images where more distortions are introduced for a larger CR. However, in lossy compression of noisy images, the situation is specific [41]. Lossy compression results in certain filtering (noise removal) effect under certain conditions. Due to this filtering effect, it is possible that

$$
M S E_{k}^{c}=\sum_{i=1}^{I} \sum_{j=1}^{J}\left(I_{k i j}^{c}-I_{k i j}^{\mathrm{true}}\right)^{2} /(I J), k=1, \ldots, K
$$


occurs to be less than $M S E_{k}^{\text {inp }}$. Then, the compression method parameter (quantization step (QS), scaling factor (SF) or bits per pixel (bpp) depending upon a coder used) for which $M S E_{k}^{c}$ falls into global minimum is called optimal operation point (OOP). This parameter is important and needs additional explanation. Fig. 1(a) presents the dependences of

$$
\operatorname{PSNR}_{k}^{c}=10 \log _{10}\left(D_{k}^{2} / M S E_{k}^{c}\right), k=1, \ldots, K
$$

on QS for the lossy DCT-based coder AGU [42] for two known gray-scale test images Airfield (Fig. 1(b)) and Frisco (Fig. 1(c)) corrupted by additive white Gaussian noise (AWGN) with variance $\sigma^{2}=100$. The test image Frisco has a simpler structure - it contains more homogeneous image regions that correspond to sea surface. Due to this, the filtering effect of lossy compression is larger and the dependence has an obvious global maximum (i.e., the OOP), according to $P S N R^{c}$, since maximum of $P S N R^{c}$ corresponds to minimum of $M S E^{c}$. Formally, there is no OOP for the other test image Airfield, but the dependence $P S N R^{c}(Q S)$ has local maximum. Both aforementioned maxima take place for $Q S_{\mathrm{OOP}} \approx 4 \sigma$, which is a recommended choice for the coder AGU [43].

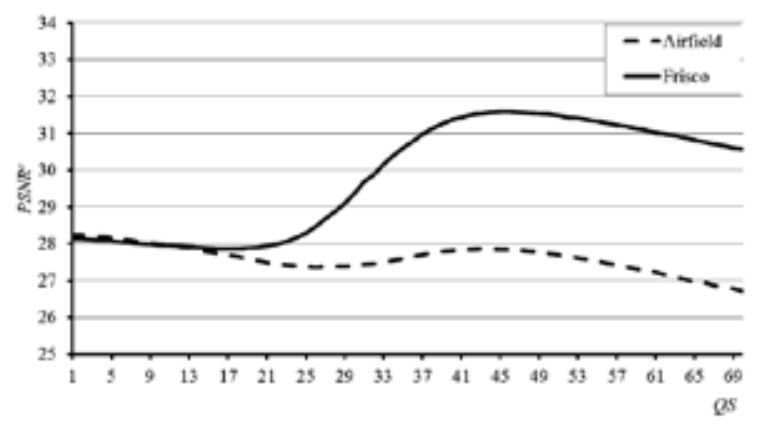

(a)

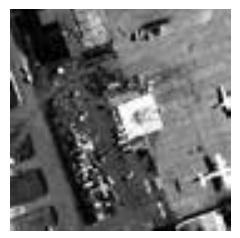

(b)

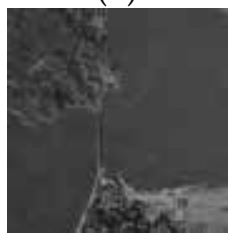

(c)

Figure 1. Dependences $P S N R^{c}(Q S)$ for the coder AGU (a) and test images Airfield (b) and Frisco (c) corrupted by AWGN with noise variance equal to 100

The lossy compression in the neighborhood of OOP has obvious advantages. Compressed images have high quality, and, at the same time, they have CR considerably larger than for lossless compression [9], [44]. Because of these benefits, the lossy compression of noisy images in the OOP neighborhood is considered. If OOP does not exist, nevertheless, the recommended setting $Q S_{\mathrm{OOP}} \approx 4 \sigma$ can be considered. If noise is signal dependent and VST is not used, the setting is $Q S_{\mathrm{OOP}} \approx 4 \sigma_{\text {equiv }}$ where $\sigma_{\text {equiv }}^{2}=M S E^{\mathrm{inp}}$. Then, in OOP, one has parameters 
$M S E_{k}^{\mathrm{OOP}}, P S N R_{k}^{\mathrm{OOP}}, P S N R-H V S-M_{k}^{\mathrm{OOP}}$ and it is possible to determine for them the following metrics (parameters characterizing compression performance):

$$
\begin{gathered}
\kappa=M S E_{k}^{\mathrm{OOP}} / M S E_{k}^{\mathrm{inp}}, \\
I P S N R_{k}=P S N R_{k}^{\mathrm{OOP}}-P S N R_{k}^{\mathrm{inp}}, \\
I P H V S M_{k}=P S N R-H V S-M_{k}^{\mathrm{OOP}}-P S N R-H V S-M_{k}^{\mathrm{inp}},
\end{gathered}
$$

where $M S E_{k}^{\mathrm{OOP}} / M S E_{k}^{\mathrm{inp}}<1$ and positive $I P S N R_{k}$ or $I P H V S M_{k}$ mean that OOP exists according to the corresponding metric.

Certainly, there are also other valuable performance criteria. For image pre-filtering, it is important to know the computational efficiency of the denoising method and how easily it can be implemented, especially onboard. For image lossy compression, it is important to know CR provided and how easily it can be attained. To partly address these issues, the filtering and compression techniques are briefly described.

DCT-based filtering [18], [30] is performed in a block-wise manner, where $8 \times 8$ pixels are a typically set block size. Filtering can be performed with nonoverlapping, partly overlapping, and fully overlapping blocks. In the latter case, filtering efficiency (expressed in improvement of PSNR (IPSNR) or improvement of PSNR-HVS-M (IPHVSM)) is the highest but more computations are needed. Nevertheless, the filter is very fast since it is possible to use fast algorithms and to parallelize computations.

There are three main steps in processing: direct 2D DCT in each block; thresholding of DCT coefficients; inverse DCT applied to thresholded DCT coefficients; then, the filtered data from overlapping blocks are aggregated. Within this structure, different variants of thresholding are possible but employing hard thresholding is preferred, where DCT coefficient values remain unchanged if their amplitudes exceed a threshold or are assigned zero values otherwise. If one deals with AWGN, the threshold is set fixed as

$$
T=\beta \sigma
$$

For spatially uncorrelated signal-dependent noise with a priori known or accurately preestimated dependence of local standard deviation on local (block) mean $\sigma_{\text {loc }}=f\left(\bar{I}_{\mathrm{bl}}\right)$, one has to set a locally adaptive threshold:

$$
T_{\mathrm{bl}}=\beta f\left(\bar{I}_{\mathrm{bl}}\right) .
$$


Finally, for spatially correlated and signal-dependent noise with a priori known or properly pre-estimated normalized DCT spectrum $W_{q s}^{\text {norm }}, q=0, \ldots, 7, s=0, \ldots, 7$, where $q s$ are indices of DCT coefficients in blocks [33], the thresholds are locally adaptive and frequency dependent:

$$
T_{\mathrm{bl}}(q, s)=\beta f\left(\bar{I}_{\mathrm{bl}}\right) \sqrt{W_{q s}^{\text {norm }}}
$$

In expressions (14-16), $\beta$ is the parameter. Depending upon the image complexity and noise intensity, its optimal value can vary a little [18], but the recommended choices are $\beta=2.6$ to provide good filtering according to IPSNR and $\beta=2.3$ to ensure quasi-optimal denoising according to IPHVSM. In further studies, $\beta=2.6$ will be used. A 3D version of the DCT-based filter [39] performs similarly. The difference is that the blocks are 3D, of size $8 \times 8 \times K_{g r}$, where $K_{g r} \leq K$ denotes a channel group size.

Conventional BM3D [34] is a more sophisticated denoising method. It presumes search for similar patches (blocks), with their joint processing in a 3D manner using DCT and Haar transform, and post-processing stage. This filtering principle, originally designed to cope with AWGN in gray-scale images, has been later adapted to the cases of signal-dependent noise after a proper VST [37], spatially correlated noise [45] and color (three-channel) images corrupted by AWGN [46]. The BM3D and its modifications provide a slightly better performance than the corresponding modifications of the conventional DCT-based denoising by the expense of considerably more extensive computations.

The lossy compression technique called AGU [42] is based on DCT in $32 \times 32$ pixel blocks, a more efficient (compared to JPEG) coding of quantized DCT coefficients and post-processing to remove the blocking artifacts after decompression. This coder is quite simple but slightly more efficient than JPEG 2000) or set partitioning in hierarchical trees (SPIHT) in rate/distortion sense. This coder has 3D version [19] and CR for both 2D and 3D versions is controlled (changed) by QS.

\section{Prediction of filtering efficiency}

The main idea of filtering efficiency prediction is the following [17]. Suppose there is some input parameter(s) able to jointly characterize image complexity and noise intensity and also there is some output parameter(s) capable of adequately describing the image denoising efficiency. Assume that there is a rather strict connection between these input and output parameters that allows predicting output value(s) having input value(s).

An additional assumption (and requirement to prediction) is that input parameter(s) have to be calculated easily and quickly enough, faster than denoising itself (otherwise, the prediction becomes useless). If all these assumptions are valid, it becomes possible to determine a predicted output value before starting image filtering and to decide whether it is worth filtering a given image (component) or not. Another decision can relate to setting parameter(s) of a used 
filter. For example, if a processed image seems to be textural (having high complexity), parameter(s) of a used filter can be adjusted to provide better edge/detail/texture preservation. For example, the parameter $\beta$ for the DCT-based filter can be set equal to 2.3 .

Keeping these general principles in mind, we have to address several tasks:

- What is a good (in the best case, optimal) input parameter (or a set of parameters)?

- What is a good (proper, acceptable) output parameter (or a set of parameters) that allows to characterize the filtering efficiency adequately and to undertake a decision (on using filtering or not, on setting a filter parameter, etc.)?

- How to get dependence between output and input parameters and how accurate it is?

These questions are partly answered below and the outcomes obtained in design and performance analysis of prediction techniques are described. We believe that a partial answer to the second question is the following. The ratio in expression (6) as well as the parameters $I P S N R_{k}$ and IPHVSM $M_{k}$ (especially if analyzed jointly) are able to provide the initial insights (characterization) of filtering efficiency. Note that expressions (6) and (7) are mutually dependent metrics and IPSN $R_{k}=10 \log _{10}\left(M S E_{k}^{\text {inp }} / M S E_{k}^{\text {out }}\right)$. Thus, they can be used as output parameter(s) at the current stage of research.

\subsection{Input and output parameter sets testing and comparison}

Based on the outcomes of the study [18], Abramov et al. in 2013 [17] observed that there is dependence between efficiency of filtering expressed by (6) and simple statistics of DCTcoefficients determined in $8 \times 8$ blocks. Two probability parameters have been considered. The first one denoted as $P_{2 \sigma}$ is the mean probability that the amplitudes of DCT coefficients are not larger than $2 \sigma$, where $\sigma$ denotes the standard deviation of additive white Gaussian noise. This parameter originated from analogies with known sigma filter [47]. The second parameter denoted as $P_{2.7 \sigma}$ is the mean probability that the amplitudes of DCT coefficients are larger than 2.7 $\sigma$. Here, there is an obvious analogy with hard thresholding in DCT-based filter, where the recommended $\beta=2.7$. At the starting point, Abramov et al., 2013 had no idea on the optimality of input parameters. The objective was just to check whether the prediction is possible, in principle, using a restricted set of test gray-scale images (18) and standard deviations of AWGN $(5,10,15)$. The data have been presented as scatterplots, where the $Y$-axis reflects the ratio in expression (6) and $X$-axis corresponds to a considered statistical (input) parameter (either $P_{2 \sigma}$ or $\left.P_{2.7 \sigma}\right)$. These scatterplots are represented in Fig. 2. Obviously, the scatterplots' points are clustered well along the fitted lines (for easy fitting, second-order polynomials were used). Interestingly, small $P_{2 \sigma}$ and large $P_{2.7 \sigma}$ correspond to complex structure images corrupted by low-intensity noise. In this case, efficiency of image filtering is low (the ratio in expression (6) is close to unity, see Fig. 2). Note that this is in agreement with the theory of filtering [48], [49]. It shows that efficient filtering of textural images is problematic for any existing filters including the most sophisticated nonlocal ones [34]. 


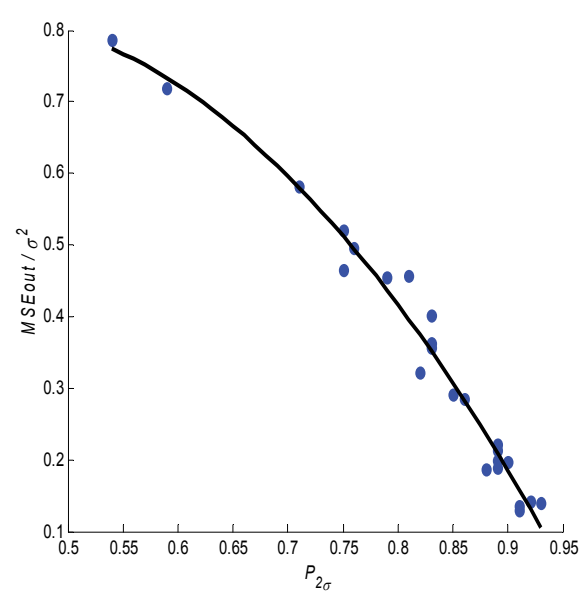

(a)

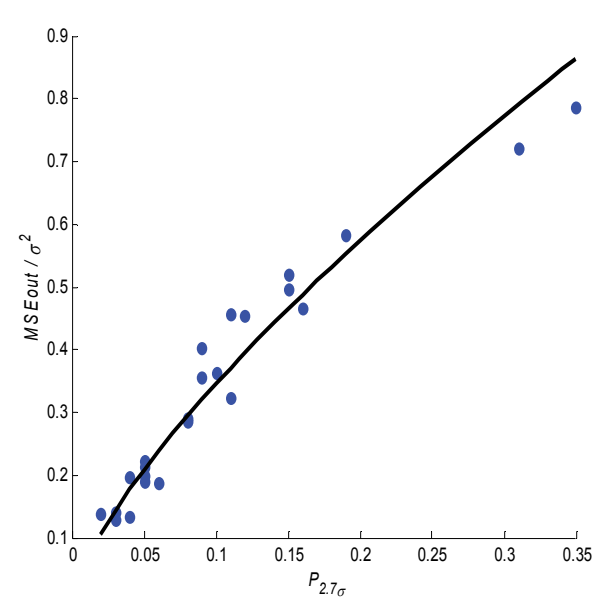

(b)

Figure 2. Examples of scatterplots and curve fitting into them for $P_{2 \sigma}$ (a) and $P_{2.7 \sigma}$ (b)

The results of the study conducted in [17] have also shown the following. First, quality of fitting has to be characterized quantitatively. For this purpose, the approach [50] works well. It provides the parameter (coefficient of determination) $R^{2}$ that tends to unity for perfectly fitted curves and root mean square error (RMSE) of fitting that should be as small as possible. These parameters are strictly connected with prediction accuracy. For perfectly determined $P_{2 \sigma}$ or $P_{2.7 \sigma}$, RMSE of fitting directly describes the accuracy of prediction.

The conclusions drawn in [17] can be recalled here. First, the prediction of filtering efficiency for BM3D is less accurate than for the conventional DCT-based filter. This conclusion has been confirmed in later studies. This is associated with the use of two denoising mechanisms (DCT denoising and similar block search with their joint processing), where the latter mechanism has no connection to DCT statistics. Second, although the prediction accuracy for both $P_{2 \sigma}$ and $P_{2.7 \sigma}$ is quite good $\left(R^{2}>0.9\right.$ and RMSE $\left.<1.0\right)$, the probability $P_{2 \sigma}$ provides sufficiently better prediction (quality of fitting) than $P_{2.7 \sigma}$. This shows that the use of other input parameters is possible. Third, different types of fitting functions (polynomials, power and exponential functions) were able to provide approximately the same quality of fitting (for example, the fitted curve in Fig. 2(a) is $\kappa=-2.63 P_{2 \sigma}^{2}+2.15 P_{2 \sigma}+0.38$; for the BM3D filter, the obtained function of $P_{2.7 \sigma}$ is $\kappa=1.86 P_{2.7 \sigma}^{0.73}$ ). Thus, certain reserves in improving the fitting accuracy "are hidden" in choosing an approximating curve and its parameters. Fourth, it has also been shown that the probabilities $P_{2 \sigma}$ and $P_{2.7 \sigma}$ can be determined with appropriate accuracy from analysis of not all possible overlapping blocks but from partly or even nonoverlapping blocks if their total number is not less than $300 . . .500$. This additionally accelerates the prediction compared even to conventional DCT-based filtering. 
There are also observations understood later (in two recent years). First, there should be some restrictions imposed on the approximating function. For example, it is clear that the ratio in expression (6) cannot be negative. It is also clear that an approximating (fitting) function should be determined for all possible values of its arguments. Since the probabilities serve as arguments, they can vary from zero to unity. Meanwhile, arguments in both scatterplots in Fig. 2 vary in narrower limits. Besides, it could be good for curve fitting to have point arguments with approximately uniform density.

These requirements have been satisfied by using considerably more test images (including highly textural ones) and a wider set of noise standard deviations (including quite small ones). This has allowed obtaining scatterplot points for small $P_{2 \sigma}$ and large $P_{2.7 \sigma}$.

Examples of the obtained scatterplots and fitted curves for the DCT-based denoising are shown in Fig. 3. As it is seen, fitting is rather good and coefficient of determination is approximately 0.95 (see the details below). We believe these are already good results that allow practical recommendations. For example, it is clearly seen that there is no reason to carry out filtering if $P_{2 \sigma}$ is smaller than 0.5 since the benefit obtained due to denoising is negligible (approximately $1 \mathrm{~dB}$ or less). Prediction itself is carried out as follows. Having the fitted curves obtained in advance as described above, it is needed to calculate $P_{2 \sigma}$ or $P_{2,7 \sigma}$ for a given image before filtering and to substitute it as argument into the approximating function to calculate a desired metric that characterizes the predicted denoising efficiency.

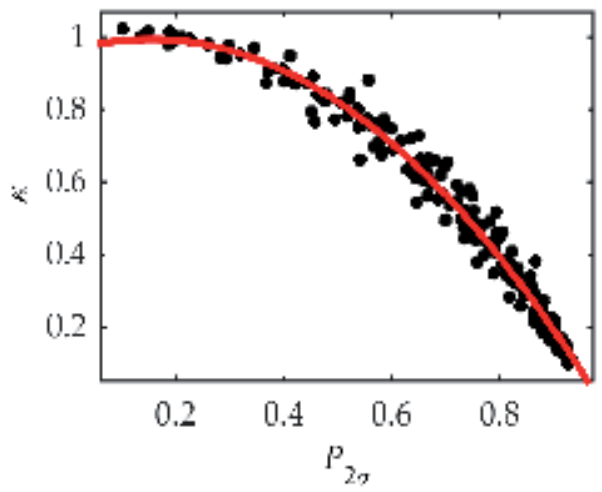

(a)

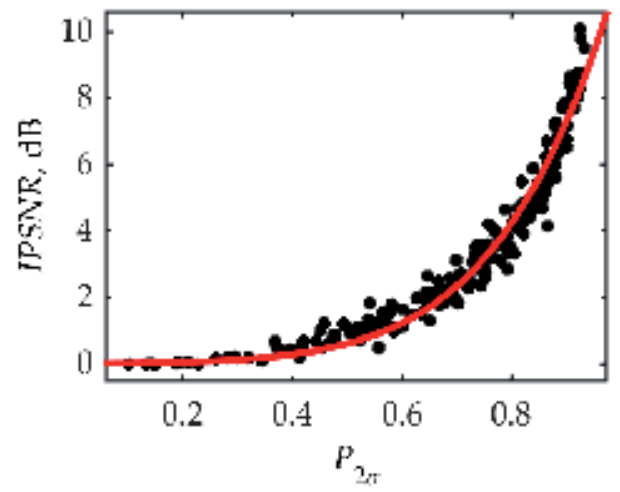

(b)

Figure 3. Scatterplots of $\kappa(a)$ and IPSNR (b) on $P_{2 \sigma}$ and the fitted curves

Expressions for the obtained approximations for the DCT filter are as follows (we give only the functions of $\mathrm{P}_{2 \sigma}$, more details can be found in [51]):

$$
\kappa=-1.45 P_{2 \sigma}^{2}+0.45 P_{2 \sigma}+0.96,
$$




$$
\begin{aligned}
& \mathrm{IPSNR}=100 * \exp \left(-\left(\frac{P_{2 \sigma}-1.92}{0.63}\right)^{2}\right), \\
& \mathrm{IPHVSM}=100^{*} \exp \left(-\left(\frac{P_{2 \sigma}-2.08}{0.67}\right)^{2}\right) .
\end{aligned}
$$

The values of $R^{2}$ are presented in Table 1 . The analysis confirms that it is better to use $P_{2 \sigma}$ than $P_{2.7 \sigma}$. Prediction of $\kappa$ is slightly more accurate than the prediction of IPSNR. However, the prediction of IPHVSM is worth improving.

\begin{tabular}{ccc}
\hline Metric & $\boldsymbol{P}_{2 \sigma}$ & $\boldsymbol{P}_{2.7 \sigma}$ \\
\hline$K$ & 0.978 & 0.955 \\
\hline$I P S N R$ & 0.963 & 0.935 \\
\hline$I P H V S M$ & 0.82 & 0.78 \\
\hline
\end{tabular}

Table 1. Goodness of fit $\left(R^{2}\right)$ of the obtained approximations

It has been discovered that not only the mean of local (block) estimates of probability $P_{2 \sigma}$ is connected with predicted metrics [51], but the other statistical parameters of the distribution of local estimates can also be exploited to improve prediction. The general framework to obtain an estimate of a predicted metric by multiparameter fitting is described by the following formula:

$$
\text { Metric }_{\text {est }}=\mathrm{a}^{*} \exp \left(\sum_{i=1}^{n} b_{i} O_{i}(P)\right),
$$

where $a$ and $b_{i}$ are approximation factors, $O_{i} . i=1, \ldots, n$, is some parameter of distribution, $n$ defines the number of such parameters. As $O_{i}$, it is possible to use the distribution mean, median, mode, variance, skewness, and kurtosis. The factors $a$ and $b_{i}, i=1, \ldots, n$ have to be obtained in advance by multidimensional ( $n$-dimensional) regression.

The results of using multidimensional regression are presented in Table 2 . The abbreviations used are the following: $M$ - mean; Var - variance; Med - median, Mod-mode; $K$ - kurtosis; $S$ - skewness; all calculated for a set of local estimates of probability $P_{2 \sigma}$. The results are given for both considered filters for the metrics IPSNR and IPHVSM. Only the best sets for $n$ from 1 
to 5 are presented since the joint use of all considered parameters is less efficient than five input parameters employed together.

\begin{tabular}{|c|c|c|c|}
\hline Filter & Metric & Statistical Parameters & $R^{2}$ \\
\hline \multirow{10}{*}{ DCT filter } & \multirow{5}{*}{ IPSNR } & $M$ & 0.963 \\
\hline & & M, Var & 0.971 \\
\hline & & M, Var, Mod & 0.974 \\
\hline & & M, Var, Mod, K & 0.976 \\
\hline & & M, Var, Med, Mod, S & 0.977 \\
\hline & \multirow{5}{*}{ IPHVSM } & Med & 0.848 \\
\hline & & M, Var & 0.923 \\
\hline & & M, Var, Med & 0.926 \\
\hline & & M, Var, Med, S & 0.927 \\
\hline & & M, Var, Med, Mod, S & 0.928 \\
\hline \multirow{10}{*}{ BM3D } & \multirow{5}{*}{ IPSNR } & $M$ & 0.95 \\
\hline & & M, Var & 0.955 \\
\hline & & M, Var, Mod & 0.959 \\
\hline & & M, Var, Mod, S & 0.961 \\
\hline & & M, Var, Med, Mod, S & 0.961 \\
\hline & \multirow{5}{*}{ IPHVSM } & Med & 0.845 \\
\hline & & M, Var & 0.905 \\
\hline & & $M$, Var, S & 0.905 \\
\hline & & $M$, Var, S, K & 0.909 \\
\hline & & M, Var, Med, S, K & 0.917 \\
\hline
\end{tabular}

Table 2. Goodness of the best multiparameter fit for $P_{2 \sigma}$

The conclusions are the following. The use of more input parameters leads to larger (better) $R^{2}$ for both filters and both metrics. The benefit of using several input parameters instead of one is quite small for IPSNR, where $R^{2}$ for one-parameter prediction is already quite high. Meanwhile, for the visual quality metric IPHVSM, the improvement is quite large. Interestingly, the use of median of local estimates instead of the mean considerably improves prediction (compare the data in Tables 2 and 1) for IPHVSM for the DCT-based filter and $P_{2 \sigma}$. 


\begin{tabular}{ccccc}
\hline \multirow{2}{*}{ Filter } & Metric & $\boldsymbol{a}$ & $\boldsymbol{b}_{1}$ & $\boldsymbol{b}_{2}$ \\
\hline \multirow{2}{*}{ DCT filter } & IPSNR & 0.023 & 6.338 & 7.459 \\
\cline { 2 - 5 } & IPHVSM & $2.225^{*} 10^{-4}$ & 10.81 & 37.14 \\
\hline \multirow{2}{*}{ BM3D } & $I P S N R$ & 0.019 & 6.591 & 6.849 \\
\cline { 2 - 5 } & $I P H V S M$ & $5.324^{*} 10^{-5}$ & 12.42 & 41.36 \\
\hline
\end{tabular}

Table 3. Coefficient values of the obtained approximations for $P_{2 \sigma}$

More input parameters provide better prediction. At the same time, more time is needed for calculation of input parameters (although their calculation is not difficult). Then, a compromise solution could be the use of the dependence of the type

$$
\operatorname{Metric}_{\text {est }}=\mathrm{a}^{*} \exp \left(b_{1} \operatorname{mean}\left(\hat{P}_{2 \sigma \text { loc }}\right)+b_{2} \operatorname{var}\left(\hat{P}_{2 \sigma \text { loc }}\right)\right)
$$

where $\hat{P}_{2 \sigma \text { loc }}$ denotes the local estimates of probabilities obtained in blocks. The approximation coefficients for all cases are presented in Table 3.

The expression (20) is not the only way to combine several input parameters into a joint output. Neural networks (NN) are known to perform this task rather well and to be good approximators [52]. This property has been used by us in [53] to make the neural network predict the considered metrics based on multiple input parameters. The obtained results are practically the same as in Table 3. Therefore, there is no need to use a more complex NN approximator instead of expression (20).

A more reasonable solution is to look for better input parameters. Such a study has been conducted in [51]. It has been shown that the probability $P_{0.5 \sigma}$ is more informative than $P_{2 \sigma}$, that $P_{0.5 \sigma}$ is the mean probability where the magnitudes of DCT coefficients in blocks are smaller than $0.5 \sigma$. Theoretically, for Gaussian distribution, this probability does not exceed 0.38 . Gaussian distribution takes place for DCT coefficients of AWGN. Thus, the mean $P_{0.50}$ approaches to 0.38 only if a considered image is "very homogeneous" and noise is intensive. This is postulated in further studies.

The obtained results for multiparameter fitting are presented in Table 4. The abbreviations are the same as in Table 2. The first observation is that even for one parameter (mean of local probabilities), the values $R^{2}$ are sufficiently better than the corresponding values for $P_{2 \sigma}$. Again the results for the BM3D filter are slightly worse than for the DCT-based filter and the results of predicting IPHVSM are worse than for predicting IPSNR. Again the use of only two input parameters, mean and variance of local estimates, seems to be a good practical choice. Thus, the best parameters of the function (21) are presented for this case in Table 5. Besides, we give an example of scatterplot fitting by 2D surface (function) for two-parameter case of using mean and variance of local estimates of the considered probability for predicting IPHVSM (see Fig. 4). 


\begin{tabular}{|c|c|c|c|}
\hline Filter & Metric & Statistical Parameters & $R^{2}$ \\
\hline \multirow{10}{*}{ DCT filter } & \multirow{5}{*}{ IPSNR } & $M$ & 0.986 \\
\hline & & M, Var & 0.989 \\
\hline & & $M, S, K$ & 0.989 \\
\hline & & $M$, Med, S, K & 0.989 \\
\hline & & M, Var, Med, Mod, S & 0.99 \\
\hline & \multirow{5}{*}{ IPHVSM } & Mod & 0.844 \\
\hline & & M, Var & 0.944 \\
\hline & & M, Var, Mod & 0.949 \\
\hline & & M, Var, Mod, S & 0.951 \\
\hline & & M, Var, Med, Mod, S & 0.952 \\
\hline \multirow{10}{*}{ BM3D } & \multirow{5}{*}{ IPSNR } & $M$ & 0.975 \\
\hline & & M, Var & 0.977 \\
\hline & & $M$, Var, S & 0.978 \\
\hline & & M, Var, Med, S & 0.978 \\
\hline & & M, Var, Med, Mod, S & 0.978 \\
\hline & \multirow{5}{*}{ IPHVSM } & Mod & 0.852 \\
\hline & & $M$, Var & 0.935 \\
\hline & & M, Var, Mod & 0.939 \\
\hline & & M, Var, Mod, S & 0.941 \\
\hline & & M, Var, Med, Mod, S & 0.941 \\
\hline
\end{tabular}

Table 4. Goodness of the best multiparameter fit for $P_{0.5 \mathrm{\sigma}}$

\begin{tabular}{ccccc}
\hline Filter & Metric & $\boldsymbol{a}$ & $\boldsymbol{b}_{1}$ & $\boldsymbol{b}_{2}$ \\
\hline \multirow{2}{*}{ DCT filter } & $I P S N R$ & 0.168 & 10.8 & 19.28 \\
\cline { 2 - 4 } & $I P H V S M$ & 0.01 & 15.66 & 144.3 \\
\hline \multirow{2}{*}{ BM3D } & $I P S N R$ & 0.148 & 11.33 & 17.7 \\
\cline { 2 - 4 } & $I P H V S M$ & 0.004 & 18.25 & 161.7 \\
\hline
\end{tabular}

Table 5. Approximation coefficients values of obtained approximations for $P_{0.5 \sigma}$ 


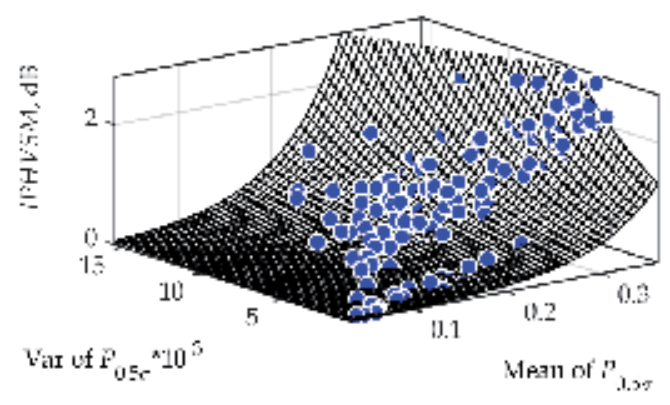

Figure 4. Scatterplot of IPHVSM for the DCT-based filter efficiency on statistics of $P_{0.5 \sigma}$ and the fitted surface

\subsection{Analysis for signal-dependent and spatially correlated types of noise}

Let us define the models of signal-dependent noise used. According to a first model [7], [11], the expression (1) transforms to

$$
I_{k i j}^{\mathrm{noise}}=I_{k i j}^{\mathrm{true}}+N_{k i j}^{S I}+N_{k i j}^{S D}
$$

where $N_{k i j}^{S I}, N_{k i j}^{S D}$ denote signal-independent(SI) and signal-dependent (SD) noise components. Both the noise components in expression (22) are assumed zero mean, spatially uncorrelated and Gaussian. Then, the model for the noise variance is $\sigma_{k i j}^{2}=\sigma_{k}^{2}+\gamma I_{k i j}^{\text {true }}$, where $\sigma_{k}^{2}$ is the SI noise variance and $\gamma$ is the SD noise parameter (which is usually between zero and unity). A second model [2] presumes purely multiplicative noise with $I_{k i j}^{\text {noise }}=I_{k i j}^{\text {true }} \mu_{k i j}$, where $\mu_{k i j}$ denotes unity mean random factor with variance $\sigma_{\mu k}^{2}$ that is within the limits from 0 to 1 . It is supposed for both the models that the noise is spatially uncorrelated.

As mentioned in Section 2 (expression no. 15), the local threshold is set as $T_{\mathrm{bl}}=\beta \sqrt{\sigma_{0}^{2}+\gamma \bar{I}_{\mathrm{bl}}}$ for signal-dependent noise (expression no. 22) and as $T_{\mathrm{bl}}=\beta \sigma_{\mu} \bar{I}_{\mathrm{bl}}$ for pure multiplicative noise. In addition to modifying the filtering algorithm, we need to modify the algorithm of input parameter calculation. Then, the local probability estimate has to consider the local variation of noise standard deviation. For instance, the local estimate of probability $P_{2 \sigma}$ is obtained as

$$
\hat{P}_{2 \sigma}^{\mathrm{bl}}=\sum_{q=0}^{7} \sum_{s=0}^{7} \delta_{q s} / 63,
$$

where $\delta_{q s}=1$, if $\left|D_{q s}\right| \leq 2 \sigma_{\mathrm{bl}}$ and 0 otherwise $\left(\sigma_{b l}\right.$ is equal to $\sqrt{\sigma_{0}^{2}+\gamma \bar{I}_{\mathrm{bl}}}$ or to $\sigma_{\mu} \bar{I}_{\mathrm{bl}}$ depending upon a model used). DC component of DCT coefficients in blocks is not taken into account as it always exceeds the local threshold. 
Some of the results of studies in our papers [54], [55] are presented next. One aspect that was specially addressed in these studies was to check the influence of an image set used in forming a scatterplot. In fact, two scatterplots have been formed separately: for the set of standard images used in optical image processing as Baboon, Barbara, Lena, etc., and for the set of images called "Remote Sensing" as Frisco, Diego, etc. The reason for such study was the following fact. Some people from RS community are categorically against using standard grayscale test images in their studies although there are no commonly accepted sets of test RS images.

The methodology of obtaining scatterplot was modified a little. For the noise expression model (22), three different cases were modeled: prevailing influence of SI noise, dominant influence of SD noise, and comparable contribution of both components. As a result, a wide range of mean $P_{2 \sigma}$ has been provided. Scatterplot points that belong to different image sets are indicated by different signs (and different colors). There are also two fitted curves. We believe there is no essential difference between the scatterplots and fitted curves. Thus, it can be concluded that the prediction is quite universal and suitable for conventional gray-scale optical images and component-wise (single-channel) RS images. Moreover, it has been shown in a study [55] that prediction is valid for single-look SAR images corrupted by fully developed spatially uncorrelated speckle. It is also possible to compare the results in Fig. 5 with the data in Fig. 3(b). They are very similar. Fig. 4 shows that IPSNR is approximately $1 \mathrm{~dB}$ or less for $P_{2 \sigma}$ approximately 0.5 and then denoising is practically useless. Meanwhile, if IPSNR is approximately $4 \mathrm{~dB}$ for $P_{2 \sigma}$ approximately 0.8 , then the use of filtering is expedient. The parameter $R^{2}$ for both fitting curves in Fig. 5 is approximately 0.96, that is, the prediction is approximately as good as for AWGN case. Again, the results for $P_{2 \sigma}$ are better than for $P_{2.7 \sigma}$; fitting for IPSNR is more accurate than for IPHVSM. Improved fitting by means of using multiple input parameters has not been investigated yet.

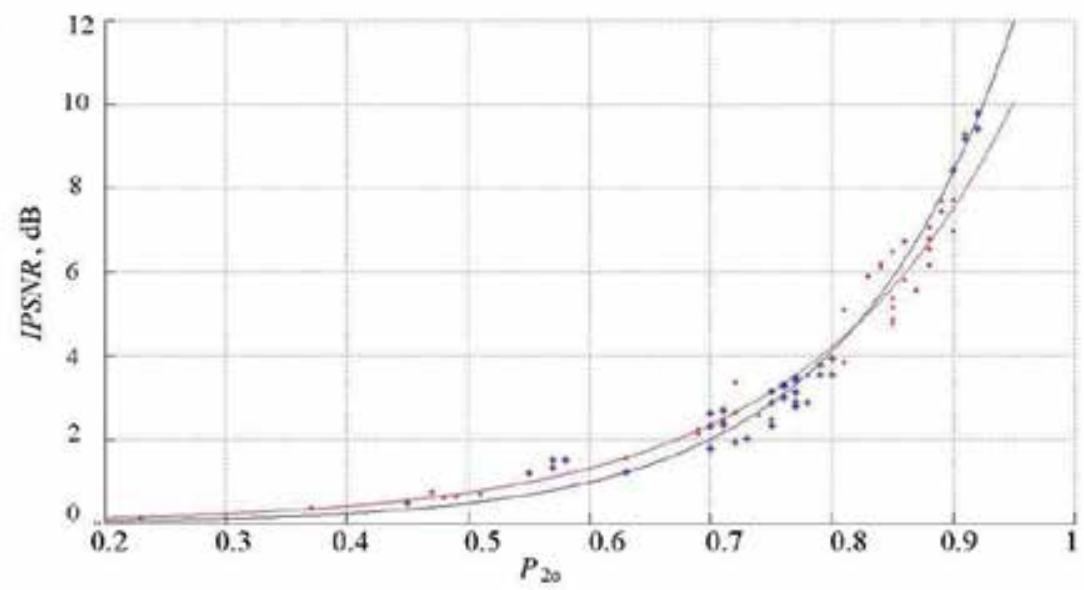

Figure 5. Scatterplots of IPSNR for the DCT-based filter efficiency on statistics of $P_{2 \sigma}$ 
Two examples of image processing are presented here. Fig. 6(a) represents the noisy image Frisco, where noise parameters are $\sigma_{0}{ }^{2}=100 ; \sigma^{2}=100$, and $\gamma=0.2$. The output image for the DCTbased filter is presented in Fig. 6(b). The effect of denoising is obvious. Actual provided improvement of PSNR is equal to $9.77 \mathrm{~dB}$. The predicted value for mean $\mathrm{P}_{2 \sigma}=0.92$ is approximately $9.5 \mathrm{~dB}$ (see the blue fitted curve in Fig. 5), that is, there is good agreement of attained and predicted values. Prediction shows that it is worth applying denoising in this case.

For a real-life data, it is impossible to determine true values of the considered metrics characterizing filtering efficiency. However, it is possible to analyze the predicted values and denoising results visually. For fragments of sub-band images of hyperspectral sensor, Hyperion, such analysis was done. For example, noise parameters of the expression model (22) have been blindly estimated [11]. The noisy image for the 13th sub-band of the set EO1H1800252002116110KZ is depicted in Fig. 7(a). Noise is clearly seen. The prediction of IPSNR is approximately $8.5 \mathrm{~dB}$ and IPHVSM is approximately $5.7 \mathrm{~dB}$. Thus, it is expedient to perform denoising. The denoised image is presented in Fig. 7(b). As can be seen, its quality has very much improved due to filtering.

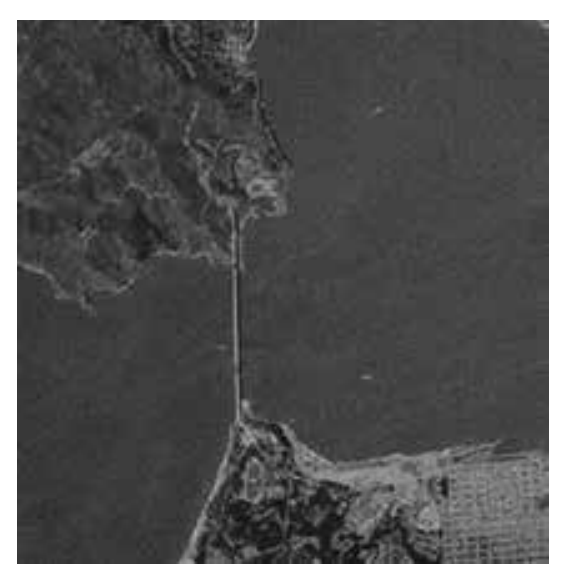

(a)

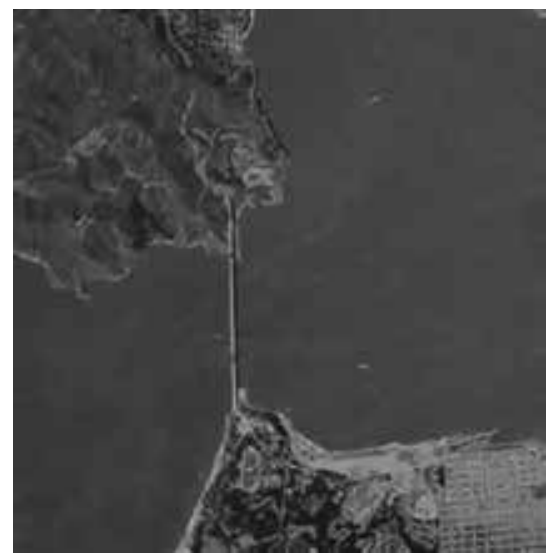

(b)

Figure 6. Noisy (a) and output (b) images Frisco

The sub-bands 13...22 are considered for two sets of Hyperion data. The values IPSNR are always larger than IPHVSM. This means that it is harder to provide an improvement of image visual quality than to gain improvement according to standard metrics (MSE, PSNR). For the sub-bands with indices $k=13 \ldots 16, I P S N R$ is always larger than $1.6 \mathrm{~dB}$ and IPHVSM exceeds $0.6 \mathrm{~dB}$, that is, filtering is desirable. For other sub-bands, as the predicted improvements are small, it is doubtful whether it is worth carrying out filtering. Visual inspection of images in sub-bands with $k=17 \ldots 22$ has shown that noise is either hardly noticeable or practically invisible. Positive effect of its removal is partly or fully compensated by edge/detail/texture smearing performed by any filter, even the most sophisticated one [56]. The texture filtering is always problematic and the prediction approach is able to reliably predict this [56]. 


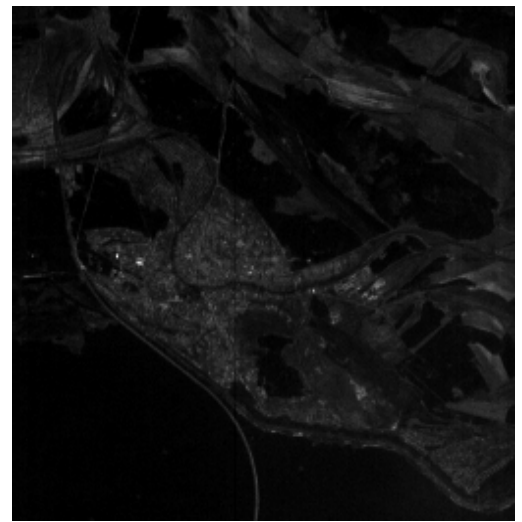

(a)

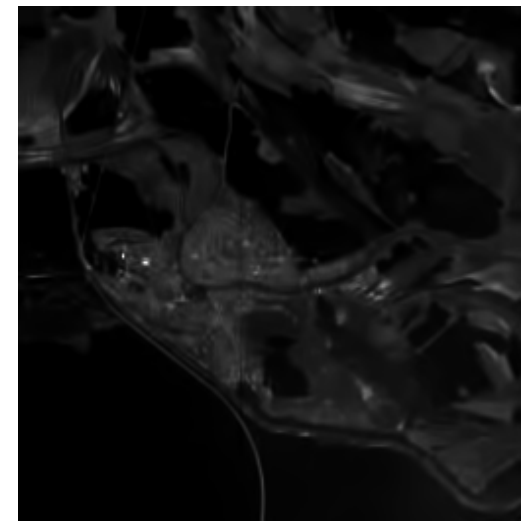

(b)

Figure 7. Noisy (a) and output (b) images of 13th sub-band images of Hyperion sensor

Considering certain benefits achieved due to using $P_{0.5 \sigma}$ as input parameter, the analysis similar to the one presented in Fig. 5 has been performed. The results are presented in Fig. 8. The noise is signal-dependent and most scatterplot points correspond to the expression model (22). The curve is fitted employing all points (although they relate to optical and RS subsets). Obviously, fitting is very good and, according to quantitative criteria, it is better than for the parameter $P_{2 \sigma}$ (Fig. 5). Four black points at the scatterplot in Fig. 8 correspond to one-look SAR images. They fit the curve well and have the arguments close to the maximal potential limit $(0.38)$, where IPSNR attains very large values (approximately $10 \mathrm{~dB}$ and more).

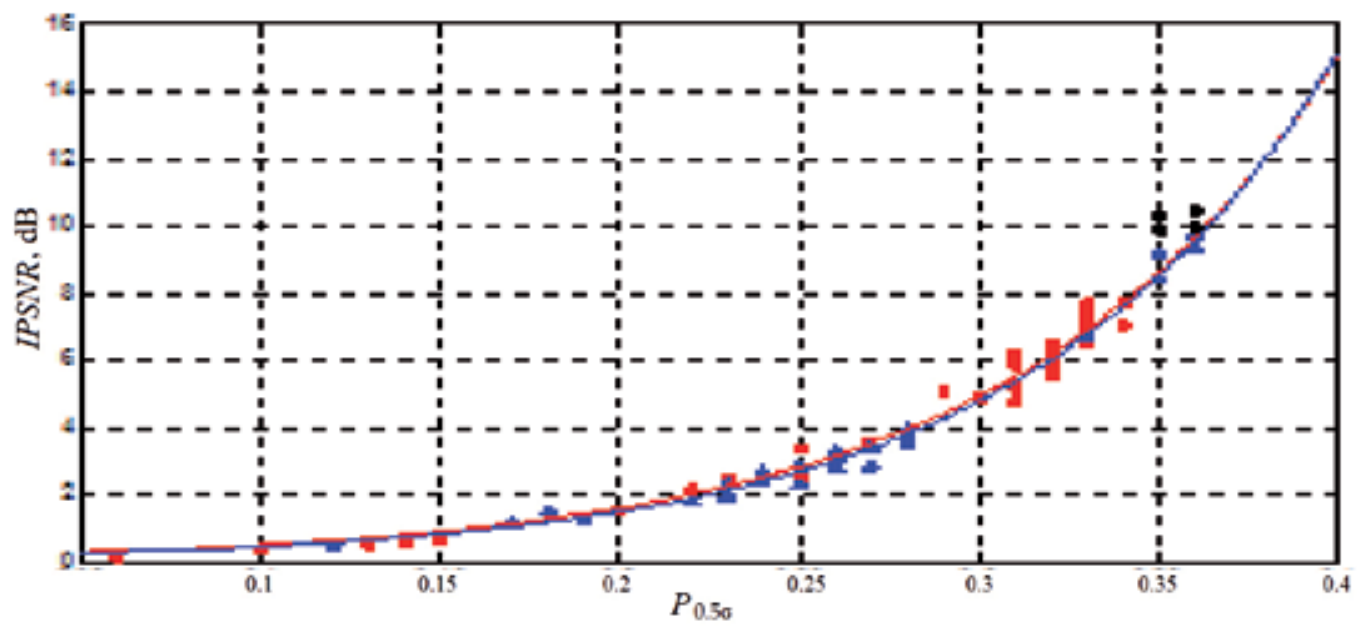

Figure 8. Scatterplots of IPSNR for the DCT-based filter efficiency on the statistics of $P_{0.50}$ (two sets of images and two fitted curves) 
Additional studies concentrated on the multi-look SAR images that were corrupted by pure multiplicative noise [57]. Analysis has been done for speckle variance $\sigma_{\mu}^{2}=0.273 / L$, where $L$ denotes the number of looks. Scatterplot points are presented in Fig. 9 for different number of looks. An obvious tendency is that mean $P_{0.5 \sigma}$ becomes larger and IPSNR increases for smaller number of looks. Other conclusions that can be drawn from analysis in a study in [57] are the following. Prediction is possible for filtering techniques with and without VST, where the prediction quality is better in the latter case. Prediction using different types of functions (polynomial, power, exponential) produce fitting of approximately equal accuracy. Meanwhile, accuracy of prediction is worth improving (RMSE is approximately $1 \mathrm{~dB}$ ) since it is sufficiently worse than for the case of AWGN.

Understanding that, in practice, noise can be spatially correlated [33], the case of spatially correlated noise - additive in [45] and multiplicative in [57] - are also studied. A difficulty of dealing with spatially correlated noise is that there are numerous shapes (and parameter sets) of 2D auto-correlation function or spatial spectrum of such a noise. Thus, studying a particular case of spatially correlated noise gives only limited information on general dependences. Hence, two models of spatially correlated noise (called middle correlation and strong correlation) have been considered [45]. A peculiarity of prediction is that the local estimate of probability $P_{2 \sigma}$ is obtained according to expression (23), where, in the general case, $\delta_{q s}=1$, if $\left|D_{q s}\right| \leq 2 \sigma_{\mathrm{bl}}(W(q, s))^{1 / 2}$ and 0 otherwise $\left(\sigma_{b l}\right.$ is the local standard deviation in a considered block; expressions for its derivation depending upon noise model are given above). If the probability $P_{0.5 \sigma}$ is used, the condition is $\delta_{q s}=1$, if $\left|D_{q s}\right| \leq 0.5 \sigma_{\mathrm{bl}}(W(q, s))^{1 / 2}$ and 0 otherwise.

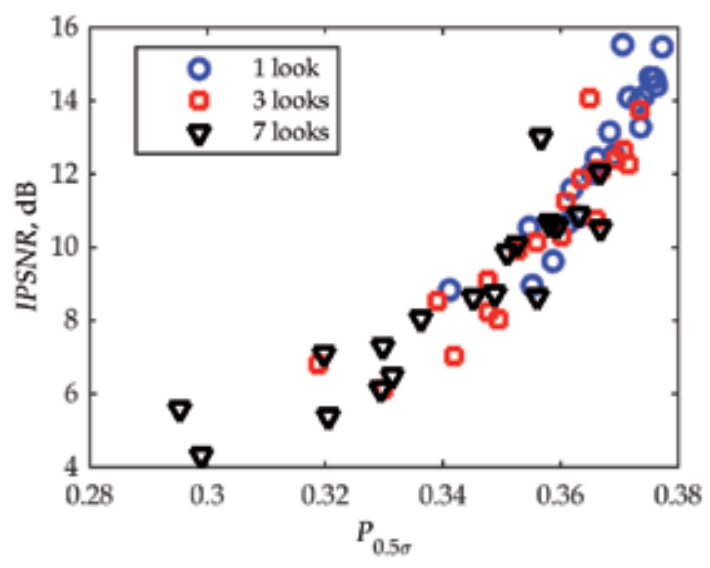

Figure 9. Scatterplot for IPSNR vs. mean $P_{0.5 \sigma}$ for a part of test images corrupted by spatially uncorrelated speckle

The scatterplots and fitted curves are presented in Fig. 10. The fitted curves are similar and they clearly show that there is no reason to filter images if $P_{0.5 \sigma}$ is smaller than 0.15 . The difference in the scatterplots for IPHVSM and IPSNR is that the latter one is more compact and, thus, IPSNR can be predicted more accurately. An additional distinctive feature of the plot for 


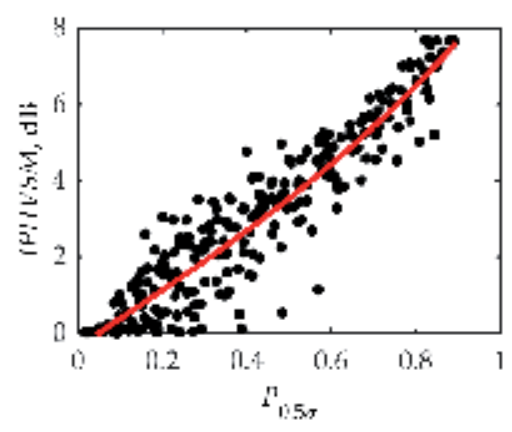

(a)

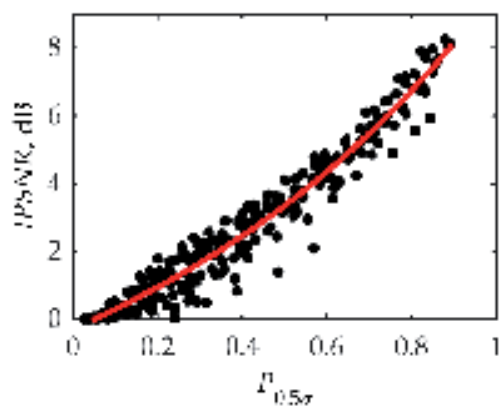

(b)

Figure 10. The scatterplots for middle-correlation noise and the fitted curves for IPHVSM (a) and IPSNR (b)

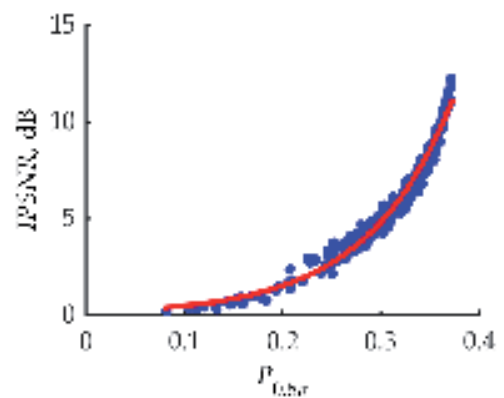

(a)

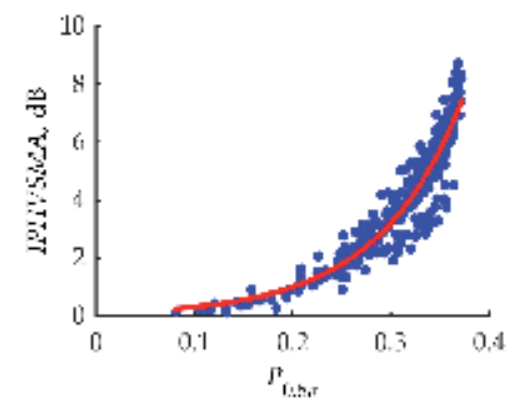

(b)

Figure 11. The scatterplots and the fitted curves for IPSNR (a) and IPHVSMA (b)

IPSNR is that its maximal values are smaller than for AWGN case (data in Fig. 3(b)). The scatterplots for a strong correlation of the noise and the conclusions derived from them are similar.

We have also studied the case of spatially correlated speckle [57]. It has been shown that the prediction seems possible for a spatially correlated noise. However, more research is needed to understand how to select a parameter or several parameters to characterize spatial correlation and how it can be involved in prediction.

Finally, a preliminary research has been carried out for denoising color images corrupted by AWGN with equal variance values in channels [58]. There are two differences in prediction. First, all DCT coefficients in 3D block are subject to analysis for estimating the local probabilities. Second, the metric PSNR-HMA [59], which is a color extension of PSNR-HVS-M, and improvement of this metric due to filtering similar to expression (8) have been used. In addition, instead of BM3D, its color version called C-BM3D has been analyzed [46].

The scatterplots have been obtained and curves were fitted to them (see examples in Fig. 11). As mentioned earlier, filtering is useless for $P_{0.5 \sigma}<0.15$. However, this happens rarely (only for highly textured images when noise standard deviation is small). Another observation is the 
same as earlier - visual quality can be predicted worse than IPSNR. The prediction accuracy for C-BM3D is worse than for 3D DCT filter.

Taking into account our previous experience, the multiparameter input was analyzed with exponential function expressed in (20). Considerable improvement has been reached, especially for IPHVSMA, for the 3D DCT filter. For the C-BM3D filter, the positive effect is less. One has $\mathrm{R}^{2}$ equal to 0.8481 for one input parameter and 0.8555 for four parameters. Again, a reasonable practical solution is to use the mean and variance of local estimates of probability. One more important observation for color image filtering is that $P_{0.5 \sigma}$ for $3 \mathrm{D}$ filter is larger than for DCT filter applied to components of a processed color image. This again proves that $3 \mathrm{D}$ processing of color and multichannel images iiis are potentially more efficient compared to their component-wise denoising.

\section{Prediction in lossy compression of noisy images}

In this section, the compression of images corrupted by AWGN is considered. Lossy compression is carried out by the aforementioned coder AGU with $Q S=4 \sigma$. In this case, OOP may exist or be absent. The task is to predict IPSNR and IPHVSM and to decide whether OOP exists as well as to predict what CR is.

\subsection{Prediction of OOP existence and metrics' values in it}

This section shortly describes how the scatterplots were obtained. As in the filtering case, a set of gray-scale test images of different content and complexity was used. AWGN of different intensity has been added and then the obtained images have been compressed by AGU. After this, the parameters (12) and (13) have been calculated as well as $P_{2 \sigma}$ for each compressed image. Clearly, all these actions are done off-line before applying the prediction approach in practice.

The obtained scatterplot is presented in Fig. 12. A specific feature of this scatterplot is that it has negative values and they seem to be approximately $-3.5 \mathrm{~dB}$ for $P_{2 \sigma}$ approaching to zero. Therefore, not all fitting functions can be used. The study carried out by Zemliachenko et al. in [44] has shown that the polynomials of the fourth and fifth order usually allow approximating the dependence very well (with $R^{2}$ almost equal to unity and RMSE approximately 0.25 for IPSNR). As can be seen from the analysis of the scatterplot in Fig. 12, there are quite many images and/or noise variances when OOP does not exist (IPSNR is negative). OOP exists with high probability if $P_{2 \sigma}$ exceeds 0.82 . This can be used as a basis for predicting OOP existence.

The scatterplot for the metric IPHVSM is presented in Fig. 13. In some sense, behavior of the fitted polynomial is similar to the one in Fig. 12. There are many values about $-4 \mathrm{~dB}$ showing that due to lossy compression the visual quality becomes worse. However, this mainly happens for small $P_{2 \sigma}$ that corresponds to high-complexity images and/or low level of the noise. The visual quality improves for $P_{2 \sigma}$ exceeding 0.9 and this takes place for low-complexity images and rather intensive noise. 


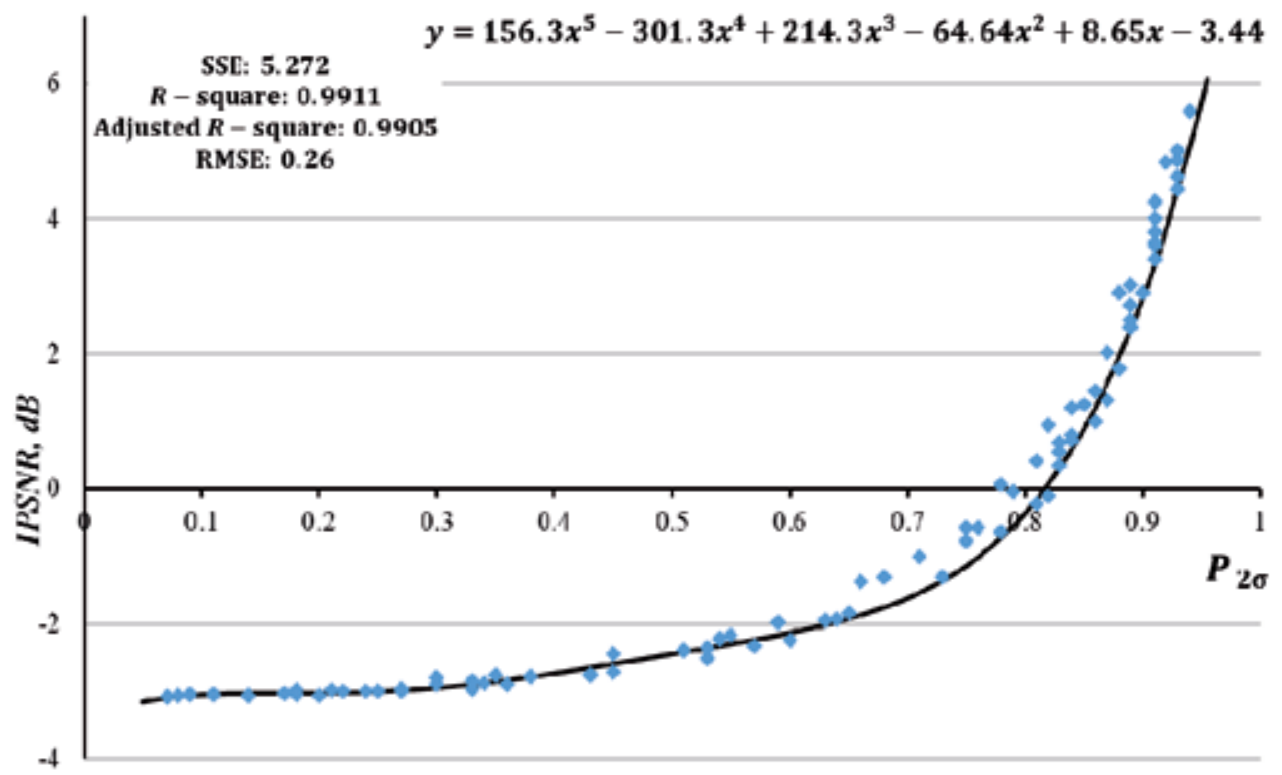

Figure 12. The scatterplot and the fitted curves for IPSNR and the coder AGU

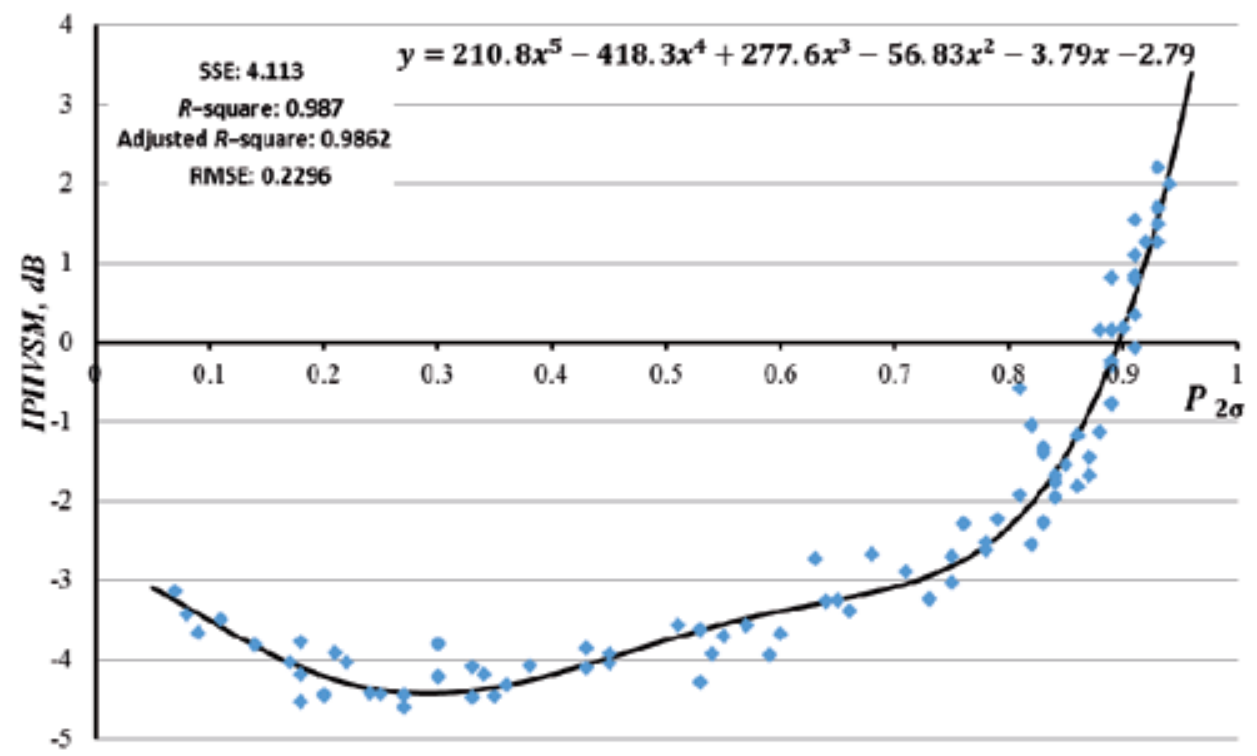

Figure 13. The scatterplot and the fitted curves for IPHVSM and the coder AGU 
Although prediction has been studied by simulations only for images corrupted by AWGN, it can also be applied to images corrupted by a signal-dependent spatially uncorrelated noise under condition that a proper VST is applied to them before compressing. Such VST (a generalized Anscombe transform in this case) provides approximately constant noise variance that usually equals to unity. Thus, $\mathrm{QS}=4$ is used. This approach has been used for Hyperion data and the results are presented in Fig. 14. There are two groups of sub-bands that are usually not analyzed in Hyperion data since they are too noisy. Thus, the prediction values are not given for all sub-bands. Analysis of the presented values shows that there are only a few subbands where it is worth expecting OOP. For most other sub-bands, IPSNR is about $-3 \mathrm{~dB}$ and the ways of dealing with them are considered in a study [44]. One proposition is to set less QS but this leads to smaller CR.

Fig. 15 shows the original and the decompressed images in 110-th sub-band, where decrease of visual quality according to quantitative criteria is predicted. Noise is not seen in the original image and the compression practically does not influence the image quality (in our opinion, both images look the same).

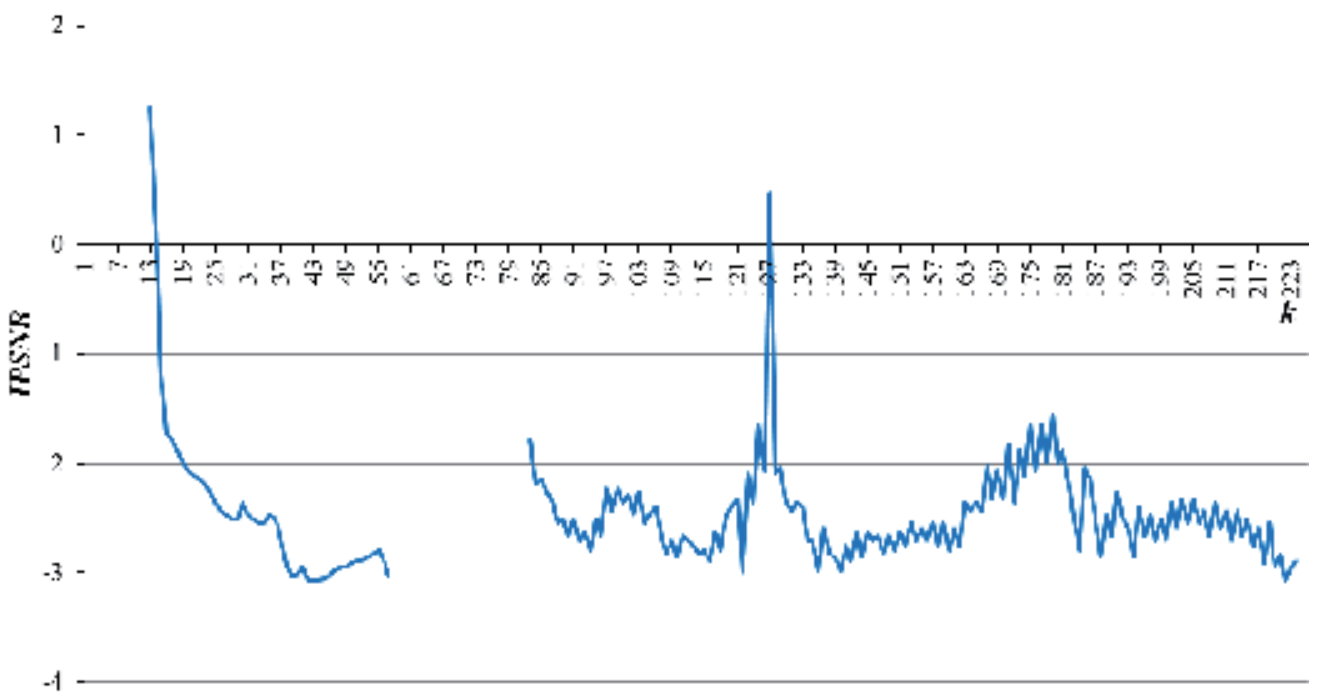

Figure 14. Predicted IPSNR for Hyperion hyperspectral image compressed by the coder AGU

A study [44] also presents data for three other DCT-based coders, where two of them are specially suited for providing better visual quality. It is demonstrated that the coder adaptive DCT (ADCT), which exploits the optimized partition schemes [60], provides certain improvements compared to AGU. Meanwhile, DCT coders oriented on improving the visual quality being applied to noisy images do not offer substantial benefits and, moreover, are even less efficient in many practical situations. 


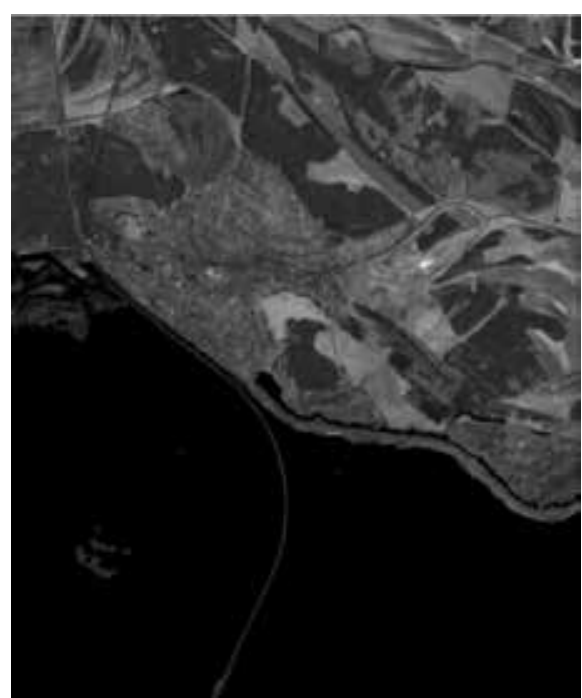

(a)

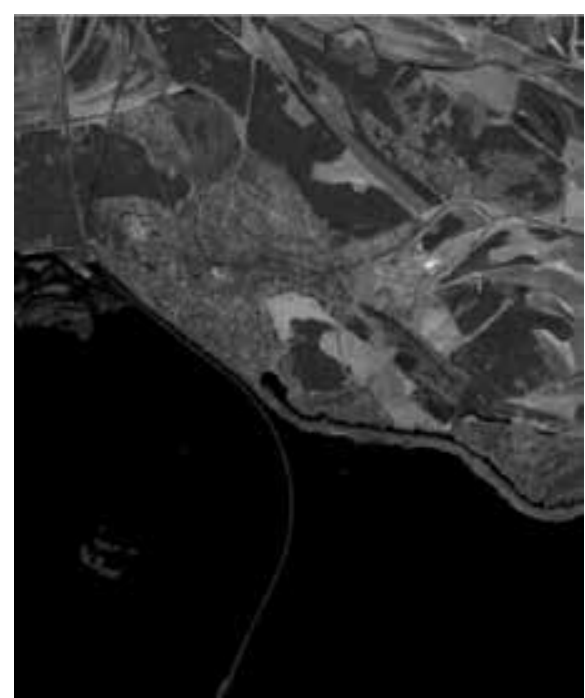

(b)

Figure 15. The 110-th sub-band images before (a) and after (b) compression

\subsection{Prediction of compression ratio in OOP}

The methodology of predicting CR in OOP is the same as that for filtering. It is based on the scatterplot obtaining and curve fitting. The only difference is that the vertical axis relates to $\mathrm{CR}$, while the horizontal axis, as earlier, corresponds to mean probability. Two mean probabilities $P_{2 \sigma}$ and $P_{2.7 \sigma}$ have been considered where the latter occurred to be worse again. Therefore, the obtained results for the mean probability $P_{2 \sigma}$ only are presented below.

Two lossy compression methods, namely, the coders AGU and ADCT, have been studied. Their scatterplots are presented in Fig. 16. Contrary to other cases considered above, fitting is performed using a sum of two weighted exponential functions. As can be seen, fitting in both cases is very good with $R^{2}$ exceeding 0.99 . Slightly larger values of CR are provided by the more sophisticated coder ADCT [60]. Very large (over 20) values of CR are provided for $P_{2 \sigma}>$ 0.93, that is, for simple structure images corrupted by intensive noise.

We did not have real-life multichannel images corrupted by AWGN. But the hyperspectral data for the sensors Hyperion and airborne visible/infrared imaging spectrometer (AVIRIS) were available. Noise in them is signal dependent [14] with prevailing SD component for the model (22). The parameters of this noise were estimated in an automatic manner [11] and, thus, it became possible to apply VST (a generalized Anscombe transform with properly adjusted parameters) with converting noise into pure additive with unity variance.

Lossy compression in OOP neighborhood has been applied after VST. After decompression, inverse transform has to be applied, respectively. The obtained and predicted values of CR for Hyperion data are depicted in Fig. 17(a). As can be seen, the curves are in good agreement. There are some channels where predicted CRs are slightly larger than attained ones. This is 


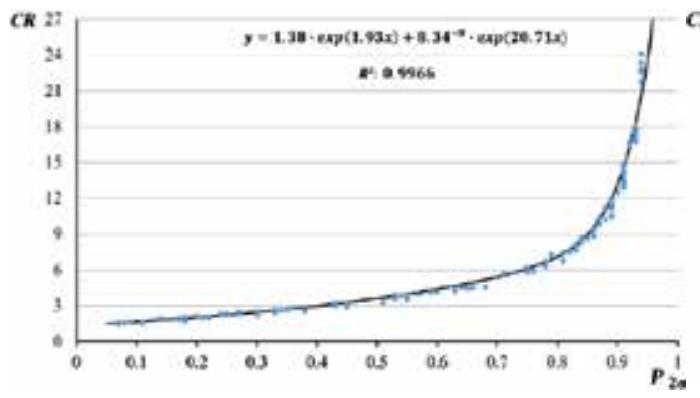

(a)

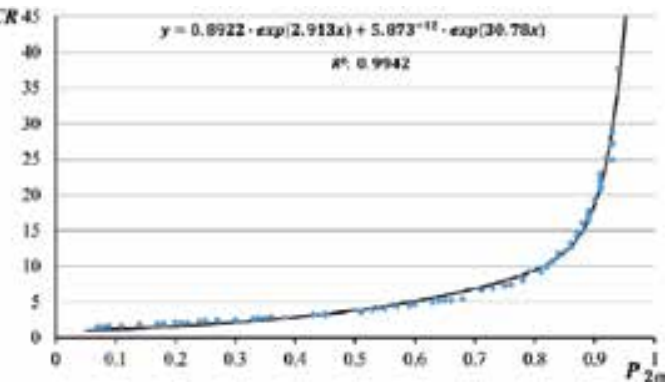

(b)

Figure 16. Scatterplots and fitted curves of dependences of CR vs. $P_{2 \sigma}$ for the coders AGU (a) and ADCT (b)

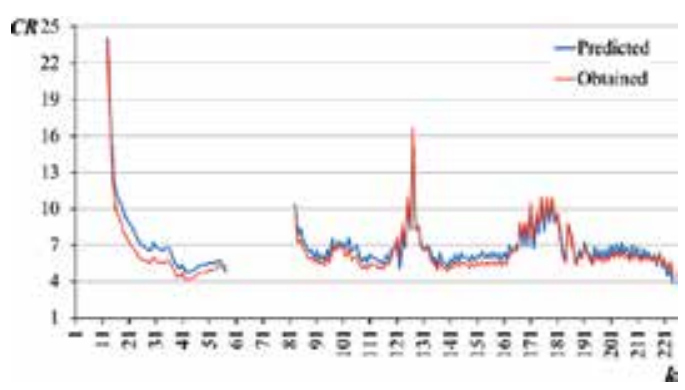

(a)

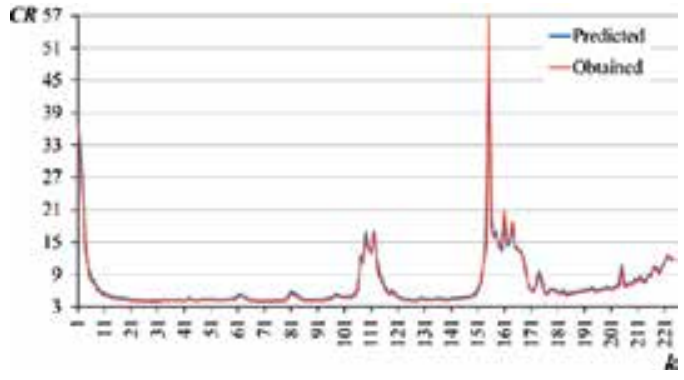

(b)

Figure 17. Results of a component-wise compression of Hyperion data (the analyzed set is EO1H1800252002116110KZ) (a) and AVIRIS Lunar Lake image (b) by the coder AGU after the generalized Anscombe transform

explained by the imperfectness of VST and blind estimation of noise parameters for channels with high signal-to-noise ratio. The largest CRs take place for sub-bands with low SNR (these are the sub-bands with indices 13-20, 125-130, and 175-180).

The results for the AVIRIS test image Lunar Lake are given in Fig. 17(b). Here, the agreement between the predicted and the attained values is even better than for the Hyperion data. Again, the largest CR is observed for sub-bands with low SNR. There are considerable differences in maximal and minimal values of CR. The main reason is the different SNR and different dynamic range in sub-band images. Certainly, CR also depends upon the image content.

\section{Conclusions and future work}

It is demonstrated that it is possible to predict the efficiency of image filtering as well as the parameters of lossy compression of a noisy image in OOP neighborhood. As opposed to the earlier known approaches that allow predicting potential efficiency of filtering, the present approach predicts practically a reachable performance and makes this very rapidly, by one or more orders faster than filtering or compression itself. 
Certainly, a limited number of quality metrics, filtering, and compression techniques have been considered. However, it is important that a general methodology of prediction is proposed, and it is shown there are somewhat strict connections between simple input parameters (that can be easily and quickly calculated) and output parameters that are able to adequately characterize the efficiency of filtering or lossy compression techniques. In favor of this methodology, there are certain facts. First, there are many modern filters that have filtering efficiency of the same order as the DCT-based filter and BM3D. Thus, predicting denoising efficiency for the filters mentioned above, it is possible to approximately predict performance for other modern filters (although such prediction would be less accurate). Second, the same holds for lossy compression methods. For example, AGU and JPEG2000 provide similar performance characteristics. Then, by predicting compression parameters for AGU, they are, in fact, estimated for JPEG2000 as well.

Concerning the decision making, whether to perform filtering or not, strict recommendations have been given for probabilities $P_{2 \sigma}$ and $P_{0.5 \sigma}$. Filtering can be expedient if $P_{2 \sigma}$ exceeds 0.5 or $P_{0.5 \sigma}$ exceeds 0.15 . Similarly, OOP is quite possible if $P_{2 \sigma}$ is approximately 0.85 or larger. A very important fact is that these rules for filtering are valid for different types of noise (pure additive and signal-dependent, additive white Gaussian and spatially correlated). This generalization can be considered as one of the main contributions of this chapter. Meanwhile, the case of spatially correlated noise requires more attention in future. In prediction of filtering efficiency, general prediction approximations for spatially correlated noise with a priori known or preestimated properties (e.g., 2D spectrum) have not been obtained yet. It can only be expected that the scatterplots for spatially correlated noise with other (not analyzed yet) shapes and parameters of spatial power spectrum behave similarly. The studies for lossy compression of images corrupted by spatially correlated noise are yet to be started. This opens a very wide field for future research.

The results of this research show that although sometimes the prediction of performance characteristics based on one input parameter is appropriately accurate, there are several means to improve the prediction accuracy. One way that deals with multiparameter input has been already used for particular cases. The use of mean $P_{0.5 \sigma}$ has shown itself a good solution, although it has not yet been tried for all possible applications. In particular, mean $P_{0.5 \sigma}$ has not been tested for lossy compression. It is hoped that performance can be improved due to this reason. Neural networks or other approximators of multidimensional functions (surfaces) can be useful.

There are also other possible directions for future research. 3D filtering warrants a more thorough study, at least, for the case of more than three channels. The same relates to 3D lossy compression performance, which has not been tried to predict yet. Compression parameters for QS other than the one recommended for OOP is also of sufficient interest in DCT-based lossy compression. Influence of errors in a priori information on noise parameters or their blind estimates on prediction accuracy has to be studied as well. 


\section{Author details}

Benoit Vozel ${ }^{2 *}$, Oleksiy Rubel ${ }^{1}$, Alexander Zemliachenko ${ }^{1}$, Sergey Abramov ${ }^{1}$,

Sergey Krivenko ${ }^{1}$, Ruslan Kozhemiakin ${ }^{1}$, Vladimir Lukin ${ }^{1}$ and Kacem Chehdi ${ }^{2}$

*Address all correspondence to: benoit.vozel@univ-rennes1.fr

1 National Aerospace University, Ukraine

2 University of Rennes 1, France

\section{References}

[1] Schowengerdt R. (2006). Remote Sensing, Third Edition. Models and Methods for Image Processing, Academic Press, Orlando, FL.

[2] Oliver C. \& Quegan S. (2004). Understanding Synthetic Aperture Radar Images. SciTech Publishing, Herndon, VA.

[3] Christophe, E. (2011). Hyperspectral Data Compression Tradeoff. In: Optical Remote Sensing in Advances, Signal Processing and Exploitation Techniques, Eds. Prasad S., Bruce L. M., and Chanussot J., pp. 9-29. Springer.

[4] Lukin V., Abramov S., Ponomarenko N., Uss M., Zriakhov M., Vozel B., Chehdi K., \& Astola J.(2011). Methods and automatic procedures for processing images based on blind evaluation of noise type and characteristics. SPIE Journal on Advances in Remote Sensing, Vol. 5, No. 1, 053502. Doi: 10.1117/1.3539768.

[5] Lukin V., Abramov S., Ponomarenko N., Krivenko S., Uss M., Vozel B., Chehdi K., Egiazarian K., \& Astola J. (2014). Approaches to Automatic Data Processing in Hyperspectral Remote Sensing. Telecommunications and Radio Engineering, Vol. 73, No. 13, pp. 1125-1139.

[6] Chang C. I. (Ed.). (2007). Hyperspectral Data Exploitation: Theory and Applications. Wiley-Interscience, Hoboken, NJ.

[7] Aiazzi B., Alparone L., Barducci A., Baronti S., Marcoinni P., Pippi I., \& Selva M. (2006). Noise modelling and estimation of hyperspectral data from airborne imaging spectrometers. Annals of Geophysics, Vol. 49, No. 1, pp. 1-9.

[8] Vozel B., Abramov S., Chehdi K., Lukin V., Ponomarenko N., Uss M., \& Astola J. (2009). Blind methods for noise evaluation in multi-component images, In: Multivariate Image Processing, pp. 263-295. France.

[9] Ponomarenko N., Lukin V., Egiazarian K., \& Lepisto L. (2013). Adaptive Visually Lossless JPEG-Based Color Image Compression. Signal, Image and Video Processing, Doi: 10.1007/s11760-013-0446-1, 16 p. 
[10] Meola J., Eismann M. T., Moses R. L., \& Ash J. N. (2011). Modeling and estimation of signal-dependent noise in hyperspectral imagery. Applied Optics, Vol. 50, No. 21, pp. 3829-3846.

[11] Uss M., Vozel B., Lukin V., \& Chehdi K. (2011). Local signal-dependent noise variance estimation from hyperspectral textural images. IEEE Journal of Selected Topics in Signal Processing, Vol. 5, No. 2, pp. 469-486. Doi: 10.1109/JSTSP.2010.2104312.

[12] Uss M., Vozel B., Lukin V., \& Chehdi K. (2012). Maximum likelihood estimation of spatially correlated signal-dependent noise in hyperspectral images. Optical Engineering, Vol. 51, No. 11. Doi: 10.1117/1.OE.51.11.111712.

[13] Abramov S., Zabrodina V., Lukin V., Vozel B., Chehdi K., \& Astola J. (2011). Methods for Blind Estimation of the Variance of Mixed Noise and Their Performance Analysis. In: Numerical Analysis - Theory and Applications, Ed. J. Awrejcewicz, pp. 49-70. InTech, Austria, ISBN 978-953-307-389-7.

[14] Abramov S., Uss M., Abramova V., Lukin V., Vozel B., \& Chehdi K. (2015). On Noise Properties in Hyperspectral Images. IGARSS, Milan, Italy, pp. 3501-3504.

[15] Zhong, P., Wang, R. (2013). Multiple-Spectral-Band CRFs for Denoising Junk Bands of Hyperspectral Imagery in IEEE Transactions on Geoscience and Remote Sensing, Vol. 51(4), pp. 2269-2275.

[16] Blanes I., Zabala A., Moré G., Pons X., \& Serra-Sagristà J. (2009). Classification of hyperspectral images compressed through 3DJPEG2000. KES '08 Proceedings of the 12th International Conference on Knowledge-Based Intelligent Information and Engineering Systems, Part III, LNAI, Springer, Berlin, Heidelberg, Vol. 5179, pp. 416423.

[17] Abramov S., Krivenko S., Roenko A., Lukin V., Djurovic I., \& Chobanu M. (2013). Prediction of Filtering Efficiency for DCT-based Image Denoising. Proceedings of MECO, Budva, Montenegro, pp. 97-100.

[18] Pogrebnyak O. \& Lukin V. (2012). Wiener DCT Based Image Filtering. Journal of Electronic Imaging, Vol. 4, No. 14, pp. 043020-043020.

[19] Zemliachenko A. N., Kozhemiakin R. A., Uss M. L., Abramov S. K., Ponomarenko N. N., Lukin V. V., Vozel B., \& Chehdi K. (2014). Lossy compression of hyperspectral images based on noise parameters estimation and variance stabilizing transform. Journal of Applied Remote Sensing, Vol. 8, No. 1, 25 p. Doi: 10.1117/1.JRS.8.083571.

[20] Zemliachenko A., Abramov S., Lukin V., Vozel B., \& Chehdi K. (2015). Compression Ratio Prediction in Lossy Compression of Noisy Images, Proceedings of IGARSS, Milan, Italy, pp. 3497-3500.

[21] Pyatykh S., Hesser J., \& Zheng L. (2013). Image noise level estimation by principal component analysis. IEEE Transactions on Image Processing, Vol. 22, No. 2, pp. 687-699. 
[22] Sendur L. \& Selesnick I. W. (2002). Bivariate shrinkage with local variance estimation. IEEE Signal Processing Letters, Vol. 9, No. 12, pp. 438-441.

[23] Ponomarenko N. N., Lukin V. V., Egiazarian K. O., \& Astola J. T. (2010). A method for blind estimation of spatially correlated noise characteristics. Proceedings of SPIE 7532 of Image Processing: Algorithms and Systems VIII, 753208, San Jose, USA, January 2010. Doi: $10.1117 / 12.847986$.

[24] Lebrun M., Colom M., Buades A., \& Morel J. M. (2012). Secrets of image denoising cuisine. Acta Numerica, Vol. 21, pp. 475-576.

[25] Van Zyl Marais I., Steyn W.H., \& du Preez J.A. (2009). On-Board Image Quality Assessment for a Small Low Earth Orbit Satellite. Proceedings of the 7th IAA Symp. on Small Satellites for Earth Observation, Berlin, Germany.

[26] Anfinsen S. N., Doulgeris A. P., \& Eltoft T. (2009). Estimation of the equivalent number of looks in polarimetric synthetic aperture radar imagery. IEEE Transactions on Geoscience and Remote Sensing, Vol. 47, No. 11, pp. 3795-3809.

[27] Liu C., Szeliski R., Kang S. B., Zitnick C. L., \& Freeman W. T. (2008). Automatic estimation and removal of noise from a single image. IEEE Transactions on Pattern Analysis and Machine Intelligence, Vol. 30, No. 2, pp. 299-314.

[28] Colom M., Lebrun M., Buades A., \& Morel J. M. (2014). A Non-Parametric Approach for the Estimation of Intensity-Frequency Dependent Noise. IEEE International Conference on Image Processing (ICIP). Doi: 10.1109/ICIP.2014.7025865.

[29] Mallat S. (1998). A Wavelet Tour of Signal Processing. Academic Press, San Diego.

[30] Öktem R., Yaroslavsky L., Egiazarian K., \& Astola J. (2002). Transform domain approaches for image denoising. Journal of Electronic Imaging, Vol. 11, No. 2, pp. 149 156.

[31] Solbo S. \& Eltoft T. (2004). Homomorphic wavelet-based statistical despeckling of SAR images. IEEE Transactions on Geoscience and Remote Sensing, Vol. GRS-42, No. 4, pp. 711-721.

[32] Öktem R., Egiazarian K., Lukin V.V., Ponomarenko N.N., \& Tsymbal O.V. (2007). Locally adaptive DCT filtering for signal-dependent noise removal. EURASIP Journal on Advances in Signal Processing, Vol. 2007, 10 p.

[33] Lukin V., Ponomarenko N., Egiazarian K., \& Astola J. (2008). Adaptive DCT-based filtering of images corrupted by spatially correlated noise. Proceedings of SPIE 6812 of Image Processing: Algorithms and Systems VI, 68120W, San Jose, USA. Doi: 10.1117/12.764893.

[34] Dabov K., Foi A., Katkovnik V., \& Egiazarian K. (2007). Image denoising by sparse 3$\mathrm{D}$ transform-domain collaborative filtering. IEEE Transactions on Image Processing, Vol. 16, No. 8, pp. 2080-2095. 
[35] Bekhtin Yu. S. (2011). Adaptive Wavelet Codec for Noisy Image Compression. Proceedings of the 9-th East-West Design and Test Symposium, Sevastopol, Ukraine, Sept. 2011, pp. 184-188.

[36] Bazhyna A., Ponomarenko N., Egiazarian K., \& Lukin V. (2007). Compression of noisy Bayer pattern color filter array images. Proceedings of SPIE Photonics West Symposium, San Jose, USA, Jan. 2007, Vol. 6498, 9 p.

[37] Makitalo M., Foi A., Fevralev D., \& Lukin V. (2010). Denoising of single-look SAR images based on variance stabilization and non-local filters. CD-ROM Proceedings of MMET, Kiev, Ukraine, 4 p.

[38] Ponomarenko N., Silvestri F., Egiazarian K., Carli M., Astola J., \& Lukin V. (2007). On Between-Coefficient Contrast Masking of DCT Basis Functions. CD-ROM Proceedings of VPQM, USA, $4 \mathrm{p}$.

[39] Lukin V., Abramov S., Krivenko S., Kurekin A., \& Pogrebnyak O. (2013). Analysis of classification accuracy for pre-filtered multichannel remote sensing data. Journal of Expert Systems with Applications, Vol. 40, No. 16, pp. 6400-6411.

[40] Lukin V. \& Bataeva E. (2012). Challenges in Pre-processing Multichannel Remote Sensing Terrain Images, Importance of GEO initiatives and Montenegrin capacities in this area. The Montenegrin Academy of Sciences and Arts, Book No. 119, The Section for Natural Sciences, Book No. 16, pp. 63-76.

[41] Al-Shaykh O. K. \& Mersereau R. M. (1998). Lossy compression of noisy images. IEEE Transactions on Image Processing, Vol. 7, No. 12, pp. 1641-1652.

[42] Ponomarenko N. N., Lukin V. V., Egiazarian K., \& Astola J. (2005). DCT Based High Quality Image Compression. Proceedings of 14th Scandinavian Conference on Image Analysis, Joensuu, Finland, Vol. 14, pp. 1177-1185.

[43] Zemliachenko A. N., Abramov S. K., Lukin V. V., Vozel B., \& Chehdi K. (2014). Prediction of Optimal Operation Point Existence and Parameters in Lossy Compression of Noisy Images, Proceedings of SPIE, Vol. 9244, Image and Signal Processing for Remote Sensing XX, 92440H. Doi: 10.1117/12.2065947.

[44] Zemliachenko A., Abramov S., Lukin V., Vozel B., \& Chehdi K. (2015). Lossy compression of noisy remote sensing images with prediction of optimal operation point existence and parameters. SPIE Journal on Applied Remote Sensing, Vol. 9, No. 1, pp. 095066-1-095066-26.

[45] Rubel A., Lukin V., \& Egiazarian K. (2015). A method for predicting DCT-based denoising efficiency for grayscale images corrupted by AWGN and additive spatially correlated noise. Proceedings of SPIE Symposium on Electronic Imaging, SPIE, Vol. 9399, USA. Doi:10.1117/12.2082533.

[46] Dabov K., Foi A., Katkovnik V., \& Egiazarian K. (2007). Color Image Denoising via Sparse 3D Collaborative Filtering with Grouping Constraint in Luminance-Chromi- 
nance Space. IEEE International Conference on Image Processing, ICIP, Vol. 1, pp. 313-316.

[47] Lee J.S. (1983). Digital image smoothing and the sigma filter. Computer Vision, Graphics, and Image Processing, Vol. 24, No. 2, pp. 255-269.

[48] Chatterjee P. \& Milanfar P. (2010). Is denoising dead? IEEE Transactions on Image Processing, Vol. 19, No. 4, pp. 895-911.

[49] Levin A. and Nadler B. (2011). Natural image denoising: Optimality and inherent bounds. IEEE Conference on Computer Vision and Pattern Recognition (CVPR), pp. 2833-2840.

[50] [50 Cameron C., Windmeijer A., Frank A.G., Gramajo H., Cane D.E., \& Khosla C. (1997). An R-squared measure of goodness of fit for some common nonlinear regression models. Journal of Econometrics, Vol. 77, No. 2, pp. 1790-1792.

[51] Rubel O. \& Lukin V. (2014) An Improved Prediction of DCT-Based Filters Efficiency Using Regression Analysis. Information and Telecommunication Sciences, Kiev, Ukraine, Vol. 5, No. 1, pp. 30-41.

[52] Badiru A. \& Cheung J. (2002). Fuzzy Engineering Expert Systems with Neural Network Applications. Wiley-Interscience, New York.

[53] Rubel A., Naumenko A., \& Lukin V. (2014). A Neural Network Based Predictor of Filtering. Proceedings of MRRS, Kiev, Ukraine, pp. 14-17.

[54] Krivenko S., Lukin V., Vozel B., \& Chehdi K. (2014). Prediction of DCT-based Denoising Eficiency for Images Corrupted by Signal-Dependent Noise. Proceedings of IEEE $34^{\text {th }}$ International Scientific Conference Electronics and Nanotechnology, Kiev, Ukraine, pp. 254-258.

[55] Lukin V., Abramov S., Rubel A., Naumenko A., Krivenko S., Vozel B., Chehdi K., Egiazarian K., \& Astola J. (2014). An approach to prediction of signal-dependent noise removal efficiency by DCT-based filter. Telecommunications and Radio Engineering, Vol. 73, No. 18, pp. 1645-1659.

[56] Rubel A., Lukin V., \& Pogrebnyak O. (2014). Efficiency of DCT-based denoising techniques applied to texture images, Proceedings of Mexican Conference of Pattern Recognition, Cancun, Mexico, pp. 261-270.

[57] Rubel O., Lukin V., \& de Medeiros F.S. (2015). Prediction of Despeckling Efficiency of DCT-based Filters Applied to SAR Images, Proceedings of 2015 International Conference on Distributed Computing in Sensor Systems, Fortaleza, Brazil, pp. 159-168.

[58] Rubel O. S., Kozhemiakin R. O., Krivenko S. S., \& Lukin V. V. (2015). A Method for Predicting Denoising Efficiency for Color Images. Proceedings of 2015 IEEE 35th International Conference on Electronics and Nanotechnology (ELNANO), Kiev, Ukraine, pp. 304-309. 
[59] Ponomarenko N., Ieremeiev O., Lukin V., Egiazarian K., \& Carli M. (2011). Modified Image Visual Quality Metrics for Contrast Change and Mean Shift Accounting. Proceedings of CADSM, Ukraine, pp. 305 - 311.

[60] Ponomarenko N., Lukin V., Egiazarian K., \& Astola J. (2008). ADCT: A New High Quality DCT Based Coder for Lossy Image Compression. CD-ROM Proceedings of LNLA, Switzerland, 6 p. 




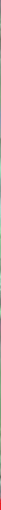

\section{Edited by Maged Marghany}

Nowadays, the innovation in space technologies creates a new trend for the Earth

observation and monitoring from space. This book contains high quality and compressive work on both microwave and optical remote sensing applications. This book is divided into five sections: (i) remote sensing for biomass estimation, (ii) remote sensing-based glacier studies, (iii) remote sensing for coastal and ocean applications, (iv) sewage leaks and environment disasters, and (v) remote sensing image processing.

Each chapter offers an opportunity to expand the knowledge about various remote sensing techniques and persuade researchers to deliver new research novelty for environment studies.

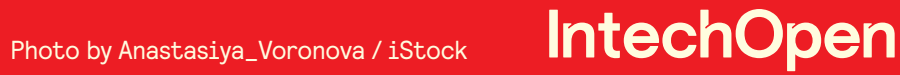
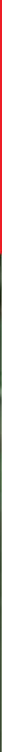